Julia Devlin, Tanja Evers, Simon Goebel ( $H_{g .}$.)

\title{
Praktiken der \\ (Im-)Mobilisierung
}

Lager, Sammelunterkünfte und Ankerzentren im Kontext von Asylregimen

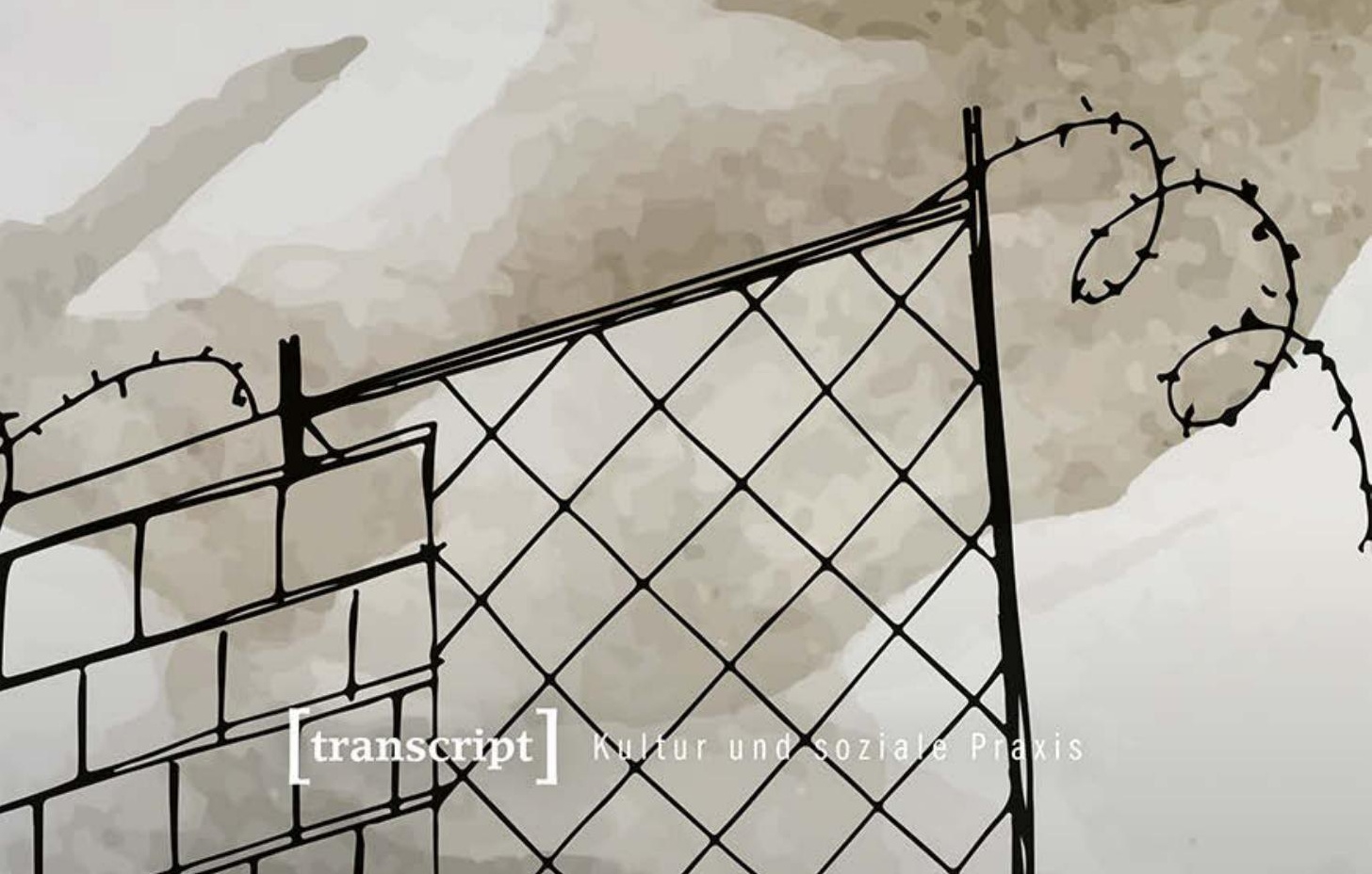


Julia Devlin, Tanja Evers, Simon Goebel (Hg.)

Praktiken der (Im-)Mobilisierung 
Julia Devlin (Dr. phil.), geb. 1967, ist Geschäftsführerin des Zentrums Flucht und Migration Eichstätt-Ingolstadt. Als Historikerin mit Schwerpunkt Migrationsgeschichte forscht sie zu Gewaltmigration, Erinnerungskultur und Identitätskonstruktion.

Tanja Evers (Dr. phil.), geb. 1983, ist Kommunikationswissenschaftlerin und Mitarbeiterin am Zentrum Flucht und Migration Eichstätt-Ingolstadt. Aus dem Blickwinkel der politischen Kommunikation beschäftigt sich ihre Forschung unter anderem mit Beteiligungschancen in digitalen Öffentlichkeiten, Populismus und den medialen Narrativen zu Flucht und Migration.

Simon Goebel (Dr. phil.), geb. 1984, ist wissenschaftlicher Mitarbeiter am Zentrum Flucht und Migration Eichstätt-Ingolstadt und forscht u.a. zur Repräsentation von Flucht und Migration in Medien, zu Kulturkonstruktionen und zu einem Dispositiv der Lager. Er ist Mitglied im Rat für Migration. 
Julia Devlin, Tanja Evers, Simon Goebel (Hg.)

\section{Praktiken der (Im-)Mobilisierung}

Lager, Sammelunterkünfte und Ankerzentren im Kontext von Asylregimen 
Die Publikation wurde finanziert vom Zentrum Flucht und Migration, Katholische Universität Eichstätt-Ingolstadt

\section{Bibliografische Information der Deutschen Nationalbibliothek}

Die Deutsche Nationalbibliothek verzeichnet diese Publikation in der Deutschen Nationalbibliografie; detaillierte bibliografische Daten sind im Internet über http://dnb.d-nb.de abrufbar.

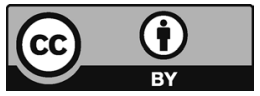

Dieses Werk ist lizenziert unter der Creative Commons Attribution 4.० Lizenz (BY). Diese Lizenz erlaubt unter Voraussetzung der Namensnennung des Urhebers die Bearbeitung, Vervielfältigung und Verbreitung des Materials in jedem Format oder Medium für beliebige Zwecke, auch kommerziell. (Lizenztext:

https://creativecommons.org/licenses/by/4.o/deed.de)

Die Bedingungen der Creative-Commons-Lizenz gelten nur für Originalmaterial. Die Wiederverwendung von Material aus anderen Quellen (gekennzeichnet mit Quellenangabe) wie z.B. Schaubilder, Abbildungen, Fotos und Textauszüge erfordert ggf. weitere Nutzungsgenehmigungen durch den jeweiligen Rechteinhaber.

\section{Erschienen 2021 im transcript Verlag, Bielefeld (c) Julia Devlin, Tanja Evers, Simon Goebel (Hg.)}

Umschlaggestaltung: Maria Trump und Janina Greif, Augsburg

Lektorat \& Korrektorat: Julia Devlin, Tanja Evers, Simon Goebel, Lena Heller, Simone Leneis und Alina Löffler, Eichstätt

Übersetzung der meisten deutschen Abstracts: Sylvia Schmager, Eichstätt

Satz: Lena Heller und Alina Löffler, Eichstätt

Druck: Majuskel Medienproduktion GmbH, Wetzlar

Print-ISBN 978-3-8376-5202-4

PDF-ISBN 978-3-8394-5202-8

https://doi.org/10.14361/9783839452028

Gedruckt auf alterungsbeständigem Papier mit chlorfrei gebleichtem Zellstoff. Besuchen Sie uns im Internet: https://www.transcript-verlag.de Unsere aktuelle Vorschau finden Sie unter www.transcript-verlag.de/vorschau-download 


\section{Inhalt}

\section{Einleitung}

Julia Devlin, Tanja Evers und Simon Goebel

9

\section{Theoretische Konzeptualisierungen}

Flüchtlingslager jenseits der Ausnahme vom Recht denken

Theoretische Schlaglichter und aktuelle Debatten

Anne-Marlen Engler

Mobilität als Wasserkocher

Entwurf einer migrationsinspirierten Theorie der sozialen Ungleichheit und erste Anwendungsbeispiele

Ria Prilutski....

Physische Barrieren als Elemente der Ordnung und Regierung von Geflüchteten

Ansätze einer geogouvernementalistischen Mobilitätsforschung am

Beispiel Lesvos

Tobias Breuckmann

\section{Grenzen}

Symbolische Ordnungen

Materialitäten

Transitzentrum oder: Über die (Un-)Durchlässigkeit von (Lager-)Grenzen

Lea Gelardi. 


\section{Formen der Einschließung und Ausschließung}

Unterbringungspraxen von Geflüchteten in Ungarn

Janka Böhm

\section{ANKER : KASERNE : FABRIK}

Zur Architektur sozialer Kontrolle

Julia Devlin

\section{Lebensrealitäten}

\section{Praktiken}

Agency

Psyche

Demobilisierungslager der Guerilla in Kolumbien zwischen Ausnahme und Normalität

Anna-Lena Dießelmann und Andreas Hetzer

\section{Klimawandel und Fluchtmigration}

(Im-)Mobilitäten ehemaliger Nomad*innen in (in-)formellen Lagern Somalias

\section{„Doing Family« auf der Flucht und in Unterkünften}

Caterina Rohde-Abuba

Stuck in limbo

Psychosoziale Dynamiken von Immobilisierung

Simon Arnold, Andreas Jensen, Magdalena Kuhn, Rana Zokai und Jan Lohl. 219

Perspektiven von Refugees auf Alltag und Widerständigkeit in Aufnahmeeinrichtungen

Annäherungen an ein Dispositiv der Lager II

Simon Goebel

\section{Politische, soziale und rechtliche Aushandlungen}

Lager - Prognosen - Labels

Zur Rolle der "Bleibeperspektive« im bayerischen Unterbringungssystem

Simon Sperling und Sebastian Muy .... 


\section{Das Lager als Nicht-Ort}

Anmerkungen zum Bamberger Ankerzentrum

Daniel Göler

Die Flüchtlings- und Integrationsberatung in den Ankerzentren im Spannungsfeld von politischer Beeinflussung und sozialarbeiterischer Einflussnahme

Mathias Schmitt.

Bildung unter den Bedingungen von (Im-)Mobilität

Elisabeth Beck und Christine Heimerer.

Zwischen räumlicher Mobilität und struktureller Immobilität

Venezolanische Geflüchtete in Kolumbien

Alina Löffler. 345

\section{Medien und Öffentlichkeit}

\section{Komplizen des Asylregimes?}

Historische Medieninfrastrukturen in Flüchtlingslagern und Asylunterkünften Philipp Seuferling 369

Sichtweisen der bayerischen Bevölkerung auf das Unterbringungskonzept Ankerzentrum

Ramona Kay und Nadine Segadlo 391

\section{Medial verAnkERt}

Die Darstellung bayerischer Erstaufnahmeeinrichtungen für Geflüchtete in der regionalen Berichterstattung

Tanja Evers

\section{Ausblick}

\section{Nach dem Lager}

Begegnung, Inklusions- und Exklusionsmechanismen an ländlichen

Wohnstandorten in Deutschland

Birgit Glorius 



\section{Einleitung}

Julia Devlin, Tanja Evers und Simon Goebel

\section{Luftlinie von Lesbos nach Eichstätt: 1.617 km}

Während wir im September 2020 diese Einleitung schreiben, brennt auf der griechischen Insel Lesbos das Flüchtlingslager Moria. Nahezu 13.000 Menschen befanden sich zu diesem Zeitpunkt in dem seit Jahren überfüllten Lager, das für bis zu 3.000 Personen ausgelegt war. ${ }^{1}$ Die unmenschlichen Zustände werden seit Bestehen des Hotspots von zivilgesellschaftlichen Organisationen und sozialen Bewegungen kritisiert. Nur zwei Tage vor dem Brand stellten Aktivist"innen verschiedener Initiativen wie der Seebrücke und Sea Watch 13.000 Stühle vor dem Reichstagsgebäude in Berlin auf. Damit sollte ein Zeichen gesetzt werden: Deutschland hat die Kapazitäten zur Aufnahme der Geflüchteten. Wiederum wenige Tage zuvor wurde bekannt, dass es in Moria 35 bestätigte Corona-Fälle gibt. Die Antwort der griechischen Regierung war nicht etwa die Evakuierung des Lagers, sondern die Beauftragung einer Firma zur Errichtung eines weiteren Zauns. Die Menschen im Lager sollten eingeschlossen werden, um die Ausbreitung des Virus außerhalb des Lagers zu verhindern. Die Einschließung der Geflüchteten hatte die griechische Regierung bereits vor der Ausbreitung des Corona-Virus im November 2019 beschlossen. Als erstes wurde ein entsprechendes Inhaftierungslager (für Schutzsuchende wohlgemerkt, nicht für Straftäter*innen) auf der Insel Kos eingesetzt. Hunderte Menschen, unabhängig von Geschlecht und Alter, sind dort untergebracht (vgl. Hänsel/Kasparek 2020: 25). ${ }^{2}$

Die griechischen Hot-Spot-Lager wurden durch den EU-Migrationspakt 2015 beschlossen und durch das EU-Türkei-Abkommen vom März 2016 maßgeblich ausgestaltet (vgl. Hänsel/Kasparek 2020).

2 Die Idee, die aufgrund der Insellage ohnehin eingeschränkte Bewegungsfreiheit gänzlich zu unterbinden, teilt die griechische mit der deutschen Regierung. In einem Konzeptpapier der Bundesregierung, das im Vorfeld der deutschen EU-Ratspräsidentschaft im zweiten Halbjahr 2020 öffentlich wurde, heißt es, dass durch »geeignete, notfalls freiheitsbeschränkende Maßnahmen « (Bundesregierung 2020) sichergestellt werden müsse, dass sich Asylsuchende nicht den Vorprüfungen entziehen können, die den regulären Asylverfahren dort vorgelagert sind. Dies ist eine Legitimation von Inhaftierungslagern. 
Lager sind Werkzeuge migrationspolitischer Regierungspraktiken. Sie sollen Kontrolle, Ordnung, Regulation herstellen. Weltweit existieren Lager, in denen Menschen freiwillig oder unfreiwillig untergebracht sind, die von einem anderen Ort geflohen sind. Lager sind dabei immer auch ein Ort der Prekarisierung, eines Lebens am Rande der Gesellschaft, eines Lebens mit eingeschränkter Handlungsmacht und Selbstbestimmung.

Die Lagerforschung beschäftigt sich mit diversen Facetten der Unterbringung von Geflüchteten in Lagern. Im deutschsprachigen Raum gibt es dazu bislang noch relativ wenig Literatur. ${ }^{3}$ Gleichwohl haben uns die vielen Einreichungen auf unseren Call for Articles im September 2019 gezeigt, dass viele Wissenschaftler*innen hierzulande derzeit über Lager forschen. In den nächsten Jahren sind also einige deutschsprachige Studien zu erwarten. Ursächlich ist sicherlich der Lange Sommer der Migration 2015, der zu einer erheblichen Ausweitung der gesamten Fluchtforschung geführt hat (vgl. Kleist et al. 2019).

Unsere Motivation, einen Sammelband zu Lagern herauszugeben, ist demnach nicht nur dem Wunsch geschuldet, den Forschungsstand um eine aktuelle und interdisziplinäre Zusammenschau zu erweitern, sondern folgt außerdem unserem forschungspolitischen Anliegen, Expertisen zu einem Thema zusammenzustellen, das quasi »vor unseren Haus- und Bürotüren« liegt. Schließlich liegt das Zentrum Flucht und Migration (ZFM) als interdisziplinäre Einrichtung für Forschung und Bildung der Katholischen Universität Eichstätt-Ingolstadt im beschaulichen Altmühltal. Bereits 2014, noch vor dem Sommer der Migration, war die Aufnahme von geflüchteten Menschen Ausgangspunkt zahlreicher Initiativen in unserer Kleinstadt. Der Bischof von Eichstätt, Gregor Maria Hanke, stellte die leerstehende Maria-Ward-Schule im Herzen der Stadt als Unterkunft zur Verfügung, und rasch etablierte sich ein System professionellen und ehrenamtlichen Engagements, getragen von den Einwohner*innen Eichstätts, Ärzt*innen, kirchlichen und universitären Kreisen. Dieses Engagement wurde über die Region hinaus als mustergültig bekannt, so dass sogar vom »Eichstätter Modell« gesprochen wurde (vgl. Bayerischer Rundfunk 2015).

Nach 1.033 Tagen wurde die Erstaufnahmedependance geschlossen. Zeitgleich, im Sommer 2017, eröffnete im örtlichen Landgerichtsgefängnis eine Abschiebehaftanstalt. Ebenfalls 2017 wurde die in Manching bei Ingolstadt 2015 in einer ehemaligen Kaserne eingerichtete Ankunfts- und Rückführungseinrichtung (ARE) zu einem Transitzentrum und 2018 zum Ankerzentrum umgewidmet.

Um den Anschluss an Entwicklungen auch in der schwierig zu erreichenden Max-Immelmann-Kaserne nicht $\mathrm{zu}$ verlieren und weiterhin Engagement $\mathrm{zu}$ er-

3 Einschlägig im deutschsprachigen Raum Pieper 2013, Inhetveen 2010 und Täubig 2009; außerdem u.a. Bauer 2017; Christ/Meininghaus/Röing 2017; Greiner/Kramer 2013; Kapraun 2002; Hennig/Wießner 1982. 
möglichen, hat das Zentrum Flucht und Migration in Kooperation mit der Caritas Pfaffenhofen dort eine Projektstelle zum Brückenbau in die Stadtgesellschaft eingerichtet.

Vor unseren Haus- und Bürotüren konnten wir also mitverfolgen, wie sich die asylpolitische Praxis entwickelt hat: von ad hoc eingerichteten, stark zivilgesellschaftlich mitorganisierten, dezentralen Orten hin zu stärker politisch kontrollierbaren, zentralisierten Einrichtungen, die den Zugang zivilgesellschaftlichen Engagements erschweren. Bayern ist dasjenige Bundesland, das die Weiterentwicklung von Lagern in der Bundesrepublik am stärksten forciert hat. Mit der erwähnten Ankunfts- und Rückführungseinrichtung bzw. dem Transitzentrum wurden bereits Prototypen der Ankerzentren ${ }^{4}$ getestet, die die Bundesregierung in ihrem Koalitionsvertrag 2018 beschlossen hat (und die unter diesem Titel bislang nur von Bayern, Sachsen und dem Saarland umgesetzt wurden).

Das Konzept soll laut des bayerischen Asylplans »schnellere und effektivere Verfahren « (StMI 2018: 4) ermöglichen, indem die behördliche Präsenz vor Ort gebündelt wird. Untergeordnet ist diese Maßnahme der Unterbringung jedoch unter das Ziel, Migration nach Deutschland und Bayern zukünftig klarer zu steuern, zu begrenzen und zu ordnen. Der bayerische Innenminister und sein Staatssekretär betonen in vier von sieben Punkten die Aspekte Abschiebung, Rückführung, innere Sicherheit und Grenzkontrollen (vgl. ebd.: 4f.) - keine Rede ist dagegen von Teilhabemöglichkeiten für Geflüchtete. Die Einführung der Ankereinrichtungen bzw. die Umwandlung der drei bereits bestehenden Transitzentren und anderer Aufnahmeeinrichtungen wurde dementsprechend von der politischen Opposition, Nichtregierungsorganisationen und der Flucht- und Migrationsforschung kritisch begleitet. Die Institutionen wurden als »menschenrechtlich problematisch « bewertet. Ankerzentren führten $\mathrm{zu} »$ soziale[r] Spaltung mit enormer Sprengkraft« (Hess et al. 2018: 9f.; auch Mouzourakis/Pollet/Ott 2019).

Erst 2013 hat die Bayerische Staatsregierung nach langem - auch innerparteilichem Streit - den Passus in der bayerischen Asyldurchführungsverordnung gestrichen, wonach die Unterbringung von Geflüchteten ihre »Bereitschaft zur Rückkehr in das Heimatland fördern« (GVBl. 2013: 505) soll (vgl. Migazin 2009). Der Satz führt die Kontinuität der politischen Motivation, Geflüchtete in Lagern unterzubringen, vor Augen. 1982, zu Beginn der Einrichtung der Lager in Deutschland, hieß es aus der CSU beispielsweise, dass »durch bewußt karge, lagermäßige Un- 
terbringung [die unerwünschte Integration Asylsuchender in die deutschen Lebensverhältnisse] zu verhindern « sei (Schneider 1985: 24). ${ }^{5}$

In ganz Deutschland arbeiten Landesregierungen und die Bundesregierung an der »2015-darf-sich-nicht-wiederholen-Ideologie«, die die Bundesregierung im Koalitionsvertrag 2018 dargelegt hat. Anstatt eine Diskursverschiebung anzustreben, wie sie 2015 in greifbarer Nähe schien (Stichwort »Willkommenskultur«), werden weiterhin Bedrohungsszenarien reproduziert und in Teilen rechtspopulistische Agenden antizipiert.

Als Zentrum Flucht und Migration befinden wir uns nicht nur mitten in Bayern, sondern auch mitten in diesem Aushandlungsprozess. Als Zentrum und als Einzelpersonen verfolgen wir das Ziel, eine nachhaltige, gerechte, verantwortungsvolle und solidarische Gesellschaft mitzugestalten. So sind wir gleichzeitig Forschende mit unterschiedlichen sozial- und geisteswissenschaftlichen Expertisen zu Flucht und Migration und wir sind vielleicht gerade wegen dieser Expertisen auch Menschen, die sich politisch positionieren - und zwar selbstverständlich gegen die Unterbringung von Menschen in Lagern, weil diese Unterbringung all das nicht ist: Sie ist unseres Erachtens nicht nachhaltig, nicht gerecht, nicht verantwortungsvoll und nicht solidarisch. Die Lagerunterbringung verhindert Anerkennung, Respekt, menschenwürdige Behandlung, faire Verfahren und Teilhabechancen und steht damit in krassem Gegensatz zu unserem ethischen und politischen Selbstverständnis.

\section{Theoretische Vorüberlegungen}

Vor diesem Hintergrund wollen wir Lager, Sammelunterkünfte und Ankerzentren mobilitätstheoretisch analysieren. Eine solche analytische Herangehensweise haben wir mit unserem Call for Articles vorgeschlagen. Damit widmen wir uns einem im deutschsprachigen Raum bislang wenig diskutierten Konzept. Mobilitätstheorien orientieren sich u.a. an dem zentralen Text »The new mobilities paradigm« von Mimi Sheller und John Urry (2006). Darin wird die Bedeutung der Mobilität von Menschen und Dingen für die Analyse von Gesellschaft hervorgehoben, die die Sozialwissenschaften zu lange ausblendeten:

5 Ebenfalls deutlich wird die Abschreckungsintention in dem offen rassistischen Zitat des damaligen Ministerpräsidenten von Baden-Württemberg Lothar Späth: »Die Buschtrommeln werden in Afrika signalisieren - kommt nicht nach Baden-Württemberg, da müsst ihr ins Lager.« (Schwäbisches Tagblatt vom 5.5.1982, zitiert nach Pieper 2013) Freilich führt die Kontinuitätslinie noch viel weiter zurück. Bereits in der Weimarer Republik wurden (deutsche) Geflüchtete in Lagern untergebracht - auch mit dem Ziel, weitere Fluchtwillige abzuschrecken (vgl. Oltmer 2005: 122f.). 
»The paradigm challenges the ways in which much social science research has been sa-mobiles. Even while it has increasingly introduced spatial analysis the social sciences have still failed to examine how the spatialities of social life presuppose (and frequently involve conflict over) both the actual and the imagined movement of people from place to place, person to person, event to event.«(Sheller/Urry 2006: 208)

Damit regten Sheller und Urry einen "mobility turn « (Hannam/Sheller/Urry 2006: 1) an, der die Sozialwissenschaften des 20. Jahrhunderts in besonderer Weise herausfordert. Mobilität - verstanden als Schlüsselelement postmoderner Gesellschaft - etabliert eine neue forschungsleitende Perspektive, die dazu auffordert, nicht nur disziplinäre Grenzen zu überwinden, sondern auch traditionelle, statische und teils binäre Kategorien wie Nation, Sesshaftigkeit, Heimat und Gemeinschaft grundlegend zu irritieren und aufzulösen (vgl. Sheller/Urry 2006: 211f; auch Kaufmann 2002; Brah 1996).

Neu am proklamierten Paradigma ist dabei weniger die wissenschaftliche Beschäftigung mit Bewegung als vielmehr die Ganzheitlichkeit der Perspektive. Die ehemals auf Raum beschränkte Definition von Mobilität im Sinne von »Bewegungen einzelner Personen oder Personengruppen zwischen verschiedenen Positionen im Raum« (Wilde 2014: 34) wird ergänzt um die Grundannahme der Konstruiertheit sozialer Wirklichkeit, was die Beziehung zwischen Sozialität und Raum in den Fokus rückt (vgl. Weichhart 2008: 9). Indem Mobilität nun in den Orientierungshorizont verschiedener sozialwissenschaftlicher Disziplinen gelangt, wird sie immer häufiger als zentraler Faktor des sozialen, kulturellen, materiellen, politischen und ökonomischen Geschehens auf der Welt bestimmt (vgl. Adey 2009: 31). So betont der Humangeograph Tim Cresswell die verbindende Kraft, welche das Mobilitätsparadigma zwischen Natur-, Sozial- und Humanwissenschaften stiftet. Zudem bezieht es alle Formen der Mobilität mit ein - von der Betrachtung individueller Mobilität auf der Mikroebene bis zu den abstrakten globalen Strömen von Finanzen, Gütern, Menschen, Informationen und Ideen auf der Makroebene (vgl. Cresswell 2010: 551f.).

Im Rahmen der disziplinären Weiterentwicklungen des Mobilitätskonzepts haben sich auch die Definitionen und Variationen von Mobilität immer weiter ausdifferenziert. Oftmals ist daher von Mobilitäten im Plural die Rede, die sodann nach einer Systematisierung verlangen. Exemplarisch sei hier John Urrys Strukturierungsvorschlag genannt, der zwischen "corporeal travel of people«, "physical movement of objects«, »imaginative travel«, »virtual travel« und »communicative travel« unterscheidet (Urry 2007: 47). Die letzten beiden Kategorien verweisen auf die Wirkmacht von (digitaler) (Medien-)Kommunikation. In »Mobilitätsgesellschaften « (Tully/Baier 2006: 15ff.) spielt zunehmend auch die informationelle Mobilität eine bedeutende Rolle (vgl. ebd.: 33f.). Die Beobachtung, mit welcher 
Leichtigkeit heute Bedeutungen und Diskurse in vielfach verschränkten analogen und digitalen öffentlichen Sphären zirkulieren, bildet den Ausgangspunkt für die Forschungsperspektive der »kommunikativen Mobilität«, die den engen Zusammenhang zwischen mobilen Medien wie Smartphones und der lokalen Mobilität ihrer Nutzer in den Blick nimmt (vgl. Hepp 2006: 19f.). Die damit einhergehende soziale Mobilität, verstanden als die »Beweglichkeit, Bewegungsvorgänge von Einzelpersonen, Gruppen und Kollektiven innerhalb einer Gesellschaft in sozialer und regionaler Hinsicht« (Hillmann 1994: 565), zeigt, dass räumliche und soziale Mobilität untrennbar miteinander verknüpft sind. Der Übergang von Personen »aus einer sozialen Position (Lage) in eine andere« (Hartfiel 1981: 36) - kurz der soziale Auf- und Abstieg - korrespondiert mit räumlicher Mobilität und umgekehrt.

Wendet man dies auf Migration als Form der Mobilität an, dann treten die komplexen Interdependenzen deutlich zu Tage. Schließlich ist Migration immer mit sozialer Mobilität verknüpft, die aber eben nicht nur Folge, sondern genauso Ursache einer Migrationsentscheidung sein kann. So ist die Entscheidung zu migrieren beispielsweise häufig eng mit dem Wunsch nach sozialer Mobilität, also der Hoffnung auf einen besseren Zugang zu sozialen, kulturellen und ökonomischen Ressourcen wie Bildung oder Arbeit, verbunden. Gleichzeitig erfordert es häufig erst ein ausreichendes Maß der genannten Ressourcen - also einen ausreichenden sozioökonomischen Status -, um Migrationspläne - möglicherweise gar gegen Widerstände - umzusetzen (vgl. de Haas 2003).

Der Sammelband beleuchtet die vielfältigen mobilitätstheoretischen Facetten aus interdisziplinären Perspektiven am Beispiel der Unterbringung von Geflüchteten in Lagern. Die Zusammenschau der Perspektiven ist getragen von der Idee, dass Migration Mobilität ist und damit ein selbstverständliches Moment menschlichen Handelns in globalisierten (post-)migrantischen Gesellschaften. De Haas beschreibt Migration als Teil eines sozialen Wandels. Er konzipiert Migration auf einer Mikroebene als »capability to choose where to live« (ebd.: 4) und unterstreicht so die Handlungsfähigkeit bzw. Handlungsmacht (agency) mobiler Individuen. Gleichzeitig seien die individuellen Hoffnungen von materiellen und sozialen Ressourcen abhängig, die die Migrationsentscheidungen beeinflussen. Sein aspirations-capabilities-framework betont neben den persönlichen Motivationen und Limitationen für Mobilität auch die (im-)mobilisierenden Wirkungen struktureller Rahmenbedingungen auf der Metaebene. Menschen on the move sind also weder lediglich passive Akteur*innen, die aufgrund komplexer Kräfte des globalen Kapitalismus migrieren, noch sind sie frei in der Gestaltung ihrer individuellen und kollektiven geografischen, sozialen und alläglichen Mobilität.

Ein positiv gerahmtes Verständnis von Mobilität findet seinen Ursprung in der Beobachtung technologischer Transformationen, die Menschen, Dinge und Ideen im doppelten Wortsinne bewegen. Aus der Wahrnehmung von Gesellschaft als modern, fluide und prozessual gehe ein normatives Mobilitätsverständnis hervor, das 
wiederum Migration von diesem als negativ konnotierte, unerwünschte Form der Mobilität abgrenzt (vgl. Göttsch-Elten 2011: 16). Das gilt in besonderer Weise für Menschen auf der Flucht, deren Mobilität ausgelöst wurde von Konflikten, Kriegen, Verfolgung oder einer anderen Art der existenziellen Bedrohung.

Mobilität ist demnach zutiefst in Machtverhältnisse eingebunden und von Diskursen und Praktiken abhängig (Norm der Sesshaftigkeit, nationale, sprachliche und sonstige Zugehörigkeiten), die mobilisierend oder immobilisierend wirken (vgl. Sheller/Urry 2006: 210f.). Mobilität geht dabei immer mit Immobilität einher, beides findet gleichzeitig statt (vgl. Schewel 2019: 334). So sind Bewegungen stets mit immobilen Infrastrukturen verknüpft - man denke beispielsweise an Kabel für Datenübertragungen oder Flughäfen als fixe Knotenpunkte des Transports. Der Prozess menschlicher Mobilität verläuft zudem nicht linear, sondern vielmehr fragmentiert und weist nicht selten auch Phasen einer »involuntary immobility« (Carling 2002) auf. Neuere Ansätze plädieren jedoch dafür, Immobilität »as a lens to challenge the grand narrative of hypermobility, flux, and fluidity associated with modernity« zu nutzen und dabei neben den Triebfedern für Mobilitätsentscheidungen auch die (Un-)Freiwilligkeit von Immobilität in der Forschung miteinzubeziehen (vgl. Schewel 2019: 332). Um die Mobilitäten geflüchteter Menschen zu verstehen, gilt es nicht allein die Faktoren zu fokussieren, die Migrationsbewegungen auslösen bzw. aufrechterhalten, sondern gerade auch die persönlichen und strukturellen Kräfte in den Blick zu nehmen, die Mobilität einschränken oder ihr entgegenwirken (vgl. ebd.:346). Die Erfahrungen mit und Entscheidungen zu (Im)Mobilität enden zudem nicht mit der "Ankunft « in einer Aufnahmegesellschaft; vielmehr treffen sie sodann auf die Restriktionen eines Asylregimes. Im europäischen Kontext sind Asylregime geprägt von einem Steuerungs- und Regulierungsideologem, das in einer ambivalenten Dialektik aus humanitärem Ansinnen und menschenrechtsverletzenden Regierungspraktiken changiert. Mithilfe eines analytischen (Im-)Mobilitätsverständnisses lassen sich diese Praktiken der Migrationsregime sichtbar machen, in denen Subjekte (im-)mobilisieren und (im-)mobilisiert werden (vgl. Holert/Terkessidis 2005: 101f.). »Das dialektische Verhältnis von Mobilität und Immobilität « (Etzold 2019: 17; vgl. auch Göttsch-Elten 2011: 21) erklärt die gängige Klammer-Schreibweise: (Im-)Mobilität und (Im-)Mobilisierung.

Im Titel unseres Sammelbandes verweisen wir daher nicht auf den Zustand der (Im-)Mobilität, sondern auf Praktiken der (Im-)Mobilisierung und stellen dadurch den prozessualen Charakter der Perspektive ins Zentrum. (Im-)Mobilisierung rekurriert dabei unter anderem auf die (politische) Strategie, die den Zugang zu den nötigen Ressourcen für räumliche und soziale Mobilität ermöglicht oder verhindert (vgl. Etzold 2019: 8). Die Unterbringung geflüchteter Menschen in Lagern ist für uns kein Endpunkt, kein finaler Zustand, der erreicht wurde. Vielmehr stellt dieser Zeitraum nur eine einzelne weitere Station in der Mobilitätsbiographie geflüchteter Menschen dar, viele weitere sind ihr vor- und nachgelagert. Zudem ist die Phase 
des Aufenthalts in den Aufnahmeeinrichtungen selbst von Aushandlungen, Kämpfen und Regulationsversuchen, von rechtlichen Beschränkungen und Öffnungen, von Warten, Frustration, Angst, Hoffnung und Widerstand geprägt - Projektionsfläche für vielfältige (Im-)Mobilisierungen auf unterschiedlichen Ebenen.

\section{Struktur und Inhalte des Sammelbandes}

Wir möchten an dieser Stelle unseren großen Dank an Lena Heller, Simone Leneis und Alina Löffler aussprechen, die uns bei der Erstellung des Sammelbandes durch ihr hervorragendes Lektorat und Korrektorat sowie bei der Manuskripterstellung unterstützt und viel Arbeit abgenommen haben. Herzlich bedanken möchten wir uns auch bei Maria Trump und Janina Greif, die uns den passenden und großartig gelungenen Einband gestaltet haben.

Im Folgenden stellen wir die Artikel des Sammelbandes in aller Kürze vor. Für den Aufbau der Kapitel des Sammelbandes haben wir uns bewusst dazu entschieden, die verschiedenen Beiträge quer zu ihren disziplinären Anbindungen zu strukturieren. Ebenso erfolgte die Zuordnung nicht entlang der Dualität nationale versus internationale Perspektive. Vielmehr stand der Versuch im Vordergrund, die verschiedenen Zugänge induktiv über einen gemeinsamen Orientierungshorizont in passende inhaltliche Sinneinheiten zu ordnen. So widmet sich der Sammelband zunächst Texten, die eine konkrete theoretische Konzeptualisierung von (Im-)Mobilisierung vorschlagen, gefolgt von einem Abschnitt, der sich mit den Wirkungen materieller, sozialer und symbolischer Grenzen und Grenzziehungspraktiken beschäftigt. Die folgenden drei Kapitel folgen der Logik eines Zoom Outs: Zunächst liefern die Beiträge im dritten Kapitel Innenansichten und bilden die Lebensrealität in Lagern $a b$, mit besonderem Fokus auf psychische Implikationen, soziale Praktiken und die Handlungsmacht geflüchteter Menschen. Auf der Mesoebene zeigt das vierte Kapitel die vielschichtigen politischen, sozialen und rechtlichen Aushandlungen zwischen den verschiedenen Akteur*innen, die das Asylregime im und rund um die Lager in Auseinandersetzung mit den Bewohner*innen gestalten. Abschließend wechselt die Perspektive zu den Außenansichten auf die Lagerunterbringung. Das Kapitel zu Medien und Öffentlichkeit beleuchtet historisch und mit aktuellen Bezügen, wie Medientechnologie und öffentliche Diskurse in Journalismus und Bevölkerung die (Im-)Mobilisierung der Lager begleiten und katalysieren.

\section{Theoretische Konzeptualisierungen von (Im-)Mobilisierung}

Aus einer rechtssoziologischen Perspektive heraus betrachtet Anne-Marlen Engler Lager für Geflüchtete als Räume, in denen gegenwärtige gesellschaftliche Herrschaftsverhältnisse aufgrund nationalstaatlicher Souveränitätspolitik in der Mi- 
grationssteuerung gleichsam verdichtet werden. In kritischer Distanz zu Agambens Theorie des permanenten Ausnahmezustands hinterfragt sie die Vorstellung von Flüchtlingslagern als rechtslose Räume und plädiert für eine differenzierte rechtstheoretische Analyse.

Die herkömmliche systemperspektivische Trennung von räumlicher und sozialer Mobilität wird der komplexen Wirklichkeit nicht gerecht, argumentiert Ria Prilutski. Sie entwirft eine migrationsinspirierte Theorie der sozialen Ungleichheit, in der sie Migration als soziale Mobilität mit räumlichen Mitteln definiert. Dabei unterscheidet sie drei Dimensionen sozialer Mobilität - etwas bewegen, sich bewegen und nicht bewegt werden - und entwickelt aus der migrantischen Realität heraus ein multidimensionales Mobilitätsmodell.

Von der geographischen Mobilitätsforschung kommend untersucht Tobias Breuckmann mit einer geogouvernementalistischen Herangehensweise, wie physische Barrieren als Instrument der Regierung von Asylsuchenden eingesetzt werden, um Mobilität zu steuern. Foucaults Konzept der Gouvernementalität bezieht er beispielhaft auf das "Reception and Identification Center Lesvos", bekannt als »Moria«.

\section{Grenzen, symbolische Ordnungen und Materialitäten}

Lea Gelardi widmet sich den Lagergrenzen mit der Frage nach deren (Un-)Durchlässigkeit in einem bayerischen Transitzentrum, einer Vorläufereinrichtung der Ankerzentren. Sie argumentiert, dass die Durchlässigkeit von Grenzen auch das Resultat fortwährender komplexer Aushandlungsprozesse zwischen vielen beteiligten Akteur*innen ist.

In Ungarn bewirkte der Sommer der Migration 2015 eine drastische Veränderung in der Grenz- und Asylpolitik. Janka Böhm nimmt über den Zeitraum 2012 bis 2020 zwei verschiedene Unterbringungsformen für Geflüchtete in den Blick, die Aufnahmeeinrichtung der Stadt Bicske und die nach 2015 eingerichteten Transitzonen. Dabei zeigt sich, dass unter dem Druck einer anti-pluralistischen, europakritischen Politik eine Praxis offener Ausgrenzung durchgesetzt wurde.

Die meisten der bayerischen Ankerzentren sind in Kasernen untergebracht, nach Foucault ein typischer Disziplinarraum, in dem die Kontrolle (Immobilisierung) und Abrufbarkeit (Mobilisierung) der darin wohnenden Menschen im Vordergrund steht. Julia Devlin untersucht, inwiefern der ursprünglich intendierte soziale Raum in den gegenwärtigen Ankerzentren weiterwirkt.

\section{Lebensrealitäten, Praktiken, Agency, Psyche}

Anna-Lena Dießelmann und Andreas Hetzer erforschen den Demobilisierungs- und Reintegrationsprozess in Lagern für ehemalige FARC-Guerillakämpfer*innen im 
Rahmen der kolumbianischen Friedensbemühungen. Sie legen dar, dass die Demobilisierungslager Orte des Übergangs von einer illegalen, militärischen in eine zivile Existenz sind. Als temporäre Einrichtungen geplant, verstetigen sich jedoch viele dieser Lager zu dauerhaften Siedlungen und verlängern dadurch die liminale Konfliktphase.

Der Klimawandel bedroht im globalen Süden die Existenzgrundlagen der ländlichen Bevölkerung. Durch die häufiger werdenden Dürreperioden haben somalische Nomad"innen ihre Tiere verloren. Samia Aden und Samira Aden untersuchen, wie traditionell mobile Nomad*innen in eine immobile Existenz in Lagern gezwungen werden und mit welchen Bewältigungsstrategien sie darauf reagieren.

Caterina Rohde-Abuba geht der Frage nach, wie sich familiäre care Praktiken in unterschiedlichen Phasen geographischer und individueller (Im-)Mobilität gestalten. Sie unterscheidet dabei die mobile Phase der Flucht(entscheidung), die persönliche Immobilisierung während des Asylverfahrens und die der sozialen Aufwärtsmobilität, die nach einer Aufenthaltsgenehmigung eintritt, und beobachtet jeweils spezifische Veränderungen im doing family.

Die psychosozialen Dynamiken, die durch die Praktiken der Immobilisierung im Asylverfahren ausgelöst werden, bezeichnen Simon Arnold, Andreas Jensen, Magdalena Kuhn, Rana Zokai und Jan Lohl als stuck in limbo. In den Psychosozialen Zentren in Hessen erforschten sie, wie geflüchtete Menschen die Erfahrung von Gewalt, Verlust und Trennung verarbeiten. Wenn sich mit der Ankunft im Zielland Hoffnungen nicht erfüllen, kann dies zu schwerwiegenden psychischen Belastungen führen.

Der institutionalisierten Immobilisierung im Lager setzen Geflüchtete die Selbstmobilisierung entgegen, konstatiert Simon Goebel. In Interviews mit Geflüchteten erwies sich, dass Lagerbewohner*innen ihren häufig als menschenunwürdig empfundenen Lageralltag nicht einfach akzeptieren, sondern in vielfältige widerständige Praktiken involviert sind, um ihre Lebensbedingungen zu verbessern.

\section{Politische, soziale und rechtliche Aushandlungen}

Die sogenannte Bleibeperspektive spielte bereits in den Vorläuferinstitutionen der Ankerzentren, den Transitzentren und Ankunfts- und Rückführungseinrichtungen (ARE) eine große Rolle. Asylsuchende werden in den Unterbringungskonzepten nach den ihnen zugemessenen Aufenthaltschancen kategorisiert. Simon Sperling und Sebastian Muy untersuchen, wie prognostische Überlegungen Einfluss auf den Aushandlungsprozess um das Bleiben nehmen.

Ausgehend von Marc Augés Denkfigur der »Nicht-Orte«, bei der die Funktionalität des Ortes, nicht das Individuum im Vordergrund steht, und Foucaults Heterotopie-Begriff analysiert Daniel Göler das Ankerzentrum Bamberg. Er plädiert für die multidimensionale Herangehensweise der Geographizität, die den komple- 
xen Wirkungszusammenhang aller relevanten Phänomene in und um das Lager in den Blick nimmt und die Logik des Ortes durch mehrere empirische Untersuchungen - so eine Befragung der Bewohner*innen zu ihrer Vorstellung ihrer räumlichen Umwelt - erschließt.

Die Flüchtlings- und Integrationsberatung in den Ankerzentren fokussiert Mathias Schmitt in einer doppelten Fragestellung. Er arbeitet heraus, welche Formen die politische Einflussnahme auf die Soziale Arbeit annimmt, und mit welchen Methoden andererseits auch Asylberater*innen Einfluss auf die Politik nehmen. Ein deutlicheres Bewusstsein über methodische Handlungsmacht in der Sozialen Arbeit, so folgert er, würde eine größere Unabhängigkeit der Beratung garantieren und das Vertrauen der Geflüchteten stärken.

Wie Bildung unter den herausfordernden Bedingungen von (Im-)Mobilität stattfindet, erforschen Elisabeth Beck und Christine Heimerer am Beispiel des Ankerzentrums Manching-Ingolstadt. Dabei nehmen sie sowohl schulische als auch nicht-schulische Bildungsangebote an diesem besonderen, d.h. durch eine temporäre Konstellation charakterisierten Lernort in den Blick und zeigen Verbesserungspotential in der Gestaltung von Bildungs- und Freizeitangeboten für geflüchtete Menschen auf.

Mehr als 1,8 Millionen Venezolaner*innen sind in den vergangenen Jahren nach Kolumbien geflüchtet. Alina Löffler beleuchtet ihre Situation vor dem Hintergrund, das Kolumbien durch den internen bewaffneten Konflikt bereits Erfahrungen mit (Binnen-)Migration gemacht hat. Da Kolumbien eine Politik der offenen Grenzen betreibt, werden venezolanische Geflüchtete in ihrer räumlichen Mobilität nicht durch restriktive Gesetze gehindert, doch sind sie extremer Armut und Marginalisierung ausgesetzt und daher in ihrer Selbstbestimmung stark eingeschränkt.

\section{Medien \& Öffentlichkeit}

Philipp Seuferling untersucht, wie Medientechnologien auf die Kommunikation in Asylunterkünften wirken. Seine Analyse historischen Archivmaterials im Zeitraum von 1945 bis in die 1990er Jahre zeigt, wie Medieninfrastrukturen Migrationsinfrastrukturen ermöglichen und dadurch einer Immobilisierung Vorschub leisten.

Die Sichtweise der bayerischen Bevölkerung auf das Unterbringungskonzept Ankerzentrum nehmen Ramona Kay und Nadine Segadlo in den Fokus. Ihre Studie basiert auf einer repräsentativen Online-Befragung und weist darauf hin, dass Kontaktmöglichkeiten essentiell sind, um eine größere Akzeptanz geflüchteter Menschen $\mathrm{zu}$ erreichen. Diese Kontaktmöglichkeiten werden jedoch durch zentralisierte, separierende Unterkünfte erschwert.

Tanja Evers analysiert die Darstellung von Ankerzentren in bayerischen Regionalzeitungen und der Bildzeitung und stellt fest, dass tendenziell das tradierte Narrativ von Lagern als »Problemorte« fortgeschrieben wird. Die kritische, aber pola- 
risierte Debatte zum Konzept der Ankereinrichtungen ist thematisch verengt und lässt kaum Raum für die Perspektive der Geflüchteten selbst, was zu deren medialen Ghettoisierung beiträgt. Journalistische Berichterstattung fungiert demnach selbst als (im-)mobilisierender Faktor gesellschaftlicher Teilhabe.

\section{Ausblick}

Birgit Glorius thematisiert, wie Geflüchtete nach der Immobilisierungsphase im Lager in eine ländliche Gesellschaft integriert werden können. Diese Gesellschaften sind potentiell durch integrative Ressourcen charakterisiert, die aber nur dann für Geflüchtete mobilisiert werden können, wenn diese die herrschenden sozialen Normen übernehmen.

\section{Literaturverzeichnis}

Adey, Peter (2009): Mobility, London \& New York: Routledge.

Bauer, Isabella (2017): Unterbringung von Flüchtlingen in deutschen Kommunen: Konfliktmediation und lokale Beteiligung. State-of-Research Papier 10, Osnabrück.

Bayerischer Rundfunk (2015): Unter unserem Himmel. Eichstätt und seine Flüchtlinge, vom 20.01.2015, R: Martin Weinhart, https://www.br.de/brfernsehen/sendungen/unter-unserem-himmel/eichstaett-seine-fluechtlingedokumentation-100.html, Abrufdatum 12.10.2020.

Brah, Avtar (1996): Cartographies of Diaspora: Contesting Identitie, London: Routledge.

Bundesregierung (2020): Neuausrichtung des Gemeinsamen Europäischen Asylsystems. Konzeptpapier der Bundesregierung, vom 04.02.2020, https:// www.frsh.de/fileadmin/pdf/stellungnahmen/19-4-441_BMI-Konzeptpapier_ Neuausrichtung.GEAS_20200204_.pdf, Abrufdatum: 15.10.2020.

Carling, Jørgen (2002): »Migration in the Age of Involuntary Immobility: Theoretical Reflections and Cape Verdean Experiences«, in: Journal of Ethnic and Migration Studies 28, S. 5-42.

Christ, Simone/Meininghaus, Esther/Röing, Tim (2017): »All Day Waiting«: Konflikte in Unterkünften für Geflüchtete in NRW (BICC Working Paper No. 3/2017), Bonn, https:/www.bicc.de/uploads/tx_bicctools/BICC_WP_3_2017_w eb_01.pdf, Abrufdatum: 17.05.2020.

Cresswell, Tim (2010): »Mobilities I: Catching up«, in: Progress in Human Geography 35(4), S. 550-558.

Etzold, Benjamin (2019): Auf der Flucht - (Im)Mobilisierung und (Im)Mobilität von Schutzsuchenden. State-of-Research Papier 04, Verbundprojekt >Flucht: For- 
schung und Transfer<, Osnabrück: Institut für Migrationsforschung und Interkulturelle Studien (IMIS) der Universität Osnabrück/Bonn: Internationales Konversionszentrum Bonn (BICC), Juni 2019.

Göttsch-Elten, Silke (2011): »Mobilitäten - Alltagspraktiken, Deutungshorizonte und Forschungsperspektiven «, in: Reinhard Johler/Max Matter/Sabine ZinnThomas (Hg.), Mobilitäten. Europa in Bewegung als Herausforderung kulturanalytischer Forschung, Münster u.a.: Waxmann, S. 15-29.

Greiner, Bettina/Kramer, Alan (Hg.) (2013): Die Welt der Lager. Zur »Erfolgsgeschichte« einer Institution, Hamburg: Hamburger Edition.

GVBl. [Bayerisches Gesetz- und Verordnungsblatt] Vierte Verordnung zur Änderung der Asyldurchführungsverordnung, vom 30. Juli 2013, 26-5-1-A, Nr. 15/2013, S. 505, https://www.verkuendung-bayern.de/gvbl/2013-505/, Abrufdatum: 09.09.2020.

De Haas, Hein (2003): Migration and Development in Southern Morocco: The Disparate Socio-Economic Impacts of Out-Migration on the Todgha Oasis Valley, Nijmegen: Radboud University.

Hannam, Kevin/Sheller, Mimi/Urry, John (2006): »Mobilities, Immobilities and Moorings«, in: Mobilities 1, S. 1-22.

Hänsel, Valeria/Kasparek, Bernd (2020): Hotspot-Lager als Blaupause für die Reform des Gemeinsamen Europäischen Asylsystems? Politikfolgenabschätzung des Hotspot-Ansatzes in Griechenland, erstellt im Auftrag des Rat für Migration e.V., Mai 2020, https://ratfuermigration.files.wordpress.com/2020/06/rfmexpertise-hotspots.pdf, Abrufdatum: 15.10.2020.

Hartfiel, Günter (1981): Soziale Schichtung. München.

Hennig, Claudius/Wießner, Siegfried (Hg.) (1982): Lager und menschliche Würde. Die psychische und rechtliche Situation der Asylsuchenden im Sammellager Tübingen, Tübingen: AS-Verlag.

Hepp, Andreas (2006): »Kommunikative Mobilität als Forschungsperspektive: Anmerkungen zur Aneignung mobiler Medien-und Kommunikationstechnologie«, in: Ästhetik \& Kommunikation 37(135), S. 15-22.

Hess, Sabine/Pott, Andreas/Schammann, Hannes/Scherr, Albert/Schiffauer, Werner (2018): Welche Auswirkungen haben »Anker-Zentren«? Eine Kurzstudie für den Mediendienst Integration, Berlin.

Hillmann, Karl-Heinz (1994): Wörterbuch der Soziologie, Stuttgart: Alfred Kröner Verlag.

Holert, Tom/Terkessidis, Mark (2005): Was bedeutet Migration?«, in: Aytaç Eryllmaz/Frank Frangenberg (Hg.), Projekt Migration, Köln: DuMont, S. 98-107.

Inhetveen, Katharina (2010): Die politische Ordnung des Flüchtlingslagers. Akteure - Macht - Organisation. Eine Ethnographie im Südlichen Afrika, Bielefeld: transcript. 
Kapraun, Inge (2002): Flüchtlingsunterbringung und der Schutz der Menschenwürde: Dimensionen eines politischen Konflikts. Hintergründe und Einflußfaktoren kommunaler Policy-Prozesse am Beispiel der Münchner Flüchtlingsunterbringungspolitik in den Jahren 1986-1944, Diss., München: Akademischer Verlag.

Kaufmann, Vincent (2002): Re-thinking Mobility: Contemporary Sociology, Aldershot: Ashgate.

Kleist, J. Olaf/Engler, Marcus/Etzold, Benjamin/Mielke, Katja/Oltmer, Jochen/Pott, Andreas/Schetter, Conrad/Wirkus, Lars (2019): Flucht- und Flüchtlingsforschung in Deutschland - Eine Bestandsaufnahme. Abschlussbericht, Verbundprojekt >Flucht: Forschung und Transfer«, Osnabrück: Institut für Migrationsforschung und Interkulturelle Studien (IMIS) der Universität Osnabrück/Bonn: Internationales Konversionszentrum Bonn (BICC), Juni 2019.

Migazin (2009): Unterbringung von Flüchtlingen soll ihre Bereitschaft zur Rückkehr in das Heimatland fördern, vom 29.07.2009, https://www.migazi n.de/2009/07/29/unterbringung-von-fluchtlingen-soll-ihre-bereitschaft-zurruckkehr-in-das-heimatland-fordern/2/, Abrufdatum: 09.09.2020.

Mouzourakis, Minos/Pollet, Kris/Ott, Jean-David (2019): The AnkER centres. Implications for asylum procedures, reception and return. European Council on Refugees and Exiles, Brüssel.

Oltmer, Jochen (2005): Migration und Politik in der Weimarer Republik, Göttingen: Vandenhoeck \& Rupprecht.

Pieper, Tobias (2013): Die Gegenwart der Lager. Zur Mikrophysik der Herrschaft in der deutschen Flüchtlingspolitik, 2. Aufl., Münster: Westfälisches Dampfboot.

Schewel, Kerilyn (2019): »Understanding Immobility: Moving Beyond the Mobility Bias in Migration Studies", in: International Migration Review 1(1), S. 328-335. Schneider, Christian (1985): „Grüne wollen Verschärfungen des Asylrechts nicht hinnehmen. Absicht der Staatsregierung als verfassungswidrig bezeichnet «, in: Süddeutsche Zeitung vom 14.03.1985, S. 24.

Sheller, Mimi/Urry, John (2006): »The new mobilities paradigm«, in: Environment and Planning A 38, S. 207-226.

[StMI] Bayerisches Staatsministerium des Innern und für Integration (2018): Der Bayerische Asylplan. Maßnahmen im Überblick, München, https://www.lfar. bayern.de/mam/header/lfar_im_ueberblick/ueber_das_lfar/der_bayerische_ asylplan_stand_juli_2018.pdf, Abrufdatum: 14.10.2020.

Täubig, Vicki (2009): Totale Institution Asyl. Empirische Befunde zu alltäglichen Lebensführungen in der organisierten Desintegration, Weinheim/München: Juventa.

Tully, Claus/Baier, Dirk (2006): Mobiler Alltag: Mobilität zwischen Option und Zwang - Vom Zusammenspiel biographischer Motive und sozialer Vorgaben, Wiesbaden: VS Verlag für Sozialwissenschaften. 
Urry, John (2007): Mobilities, Cambridge: Polity Press.

Weichhart, Peter (2008): Entwicklungslinien der Sozialgeographie: Von Hans Bobek bis Benno Werlen, Stuttgart: Franz Steiner Verlag.

Wilde, Mathias (2014): Mobilität und Alltag, Studien zur Mobilitäts- und Verkehrsforschung, Wiesbaden: Springer Fachmedien Wiesbaden. 

Theoretische Konzeptualisierungen 



\section{Flüchtlingslager jenseits der Ausnahme vom Recht denken

\author{
Theoretische Schlaglichter und aktuelle Debatten
}

Anne-Marlen Engler

\section{Zusammenfassung ${ }^{1}$}

Während Flüchtlingslager in den Ceschichts- und Rechtswissenschaften bisher wenig im Blickfeld standen (vgl. Engler 2019; Bispinck/Hochmuth 2014: 13) entwickelte der Philosoph Giorgio Agamben in der Reihe homo sacer eine ganze Theorie des modernen Rechtsstaats aus der Analyse des Lagers. Agamben markiert das Lager dabei als einen Raum, »der sich öffnet, wenn der Ausnahmezustand zur Regel zu werden beginnt « (Agamben 2002: 177) und fasst unter dem Begriff des Lagers auch Flüchtlingslager (vgl. ebd.: 179). Auch Erving Goffmans Theorie der totalen Institution findet im Kontext der Lagerforschung nach wie vor Anwendung. Lager als totale Institutionen beschreibt Coffman dabei zwar nicht als Orte der permanenten rechtlichen Ausnahme, wohl aber als Orte gesellschaftlicher Isolation (vgl. Goffman 1973: 24). Beide Theorien haben die deutsche Lagerforschung geprägt (vgl. Pieper 2013; Täubig 2009). Wie können sie jedoch vor dem Hintergrund aktueller Entwicklungen in den Migrationswissenschaften wie etwa der Grenzregime-Forschung (vgl. Hess/Kasparek 2012) oder dem Konzept der Crimmigration (vgl. Garcia Hernandez 2013) verstanden werden? Lässt sich die Idee der Autonomie der Migration mit dem Konzept des ohnmächtigen homo sacer verbinden? Können deutsche Flüchtlingsunterkünfte als totale Institutionen im Rahmen einer Crimmigration beschrieben werden? Unter Berücksichtigung dieser Fragen wirft der Artikel zunächst einen Blick auf Agambens Theorie des permanenten Ausnahmezustands. Daran anknüpfend geht die Autorin auf aktuelle Debatten in den Migrationswissenschaften ein, um den Versuch einer zeitgemäßen theoretischen Rahmung der Flüchtlingsunterbringung in Deutschland zu wagen. denken? Rechtstheoretische Überlegungen « in der Ausgabe 1/2020 der Zeitschrift Juridikum, https://doi.org/10.33196/juridikum202001008901. Ich danke dem Verlag Österreich für die Genehmigung einer Zweitveröffentlichung. 


\begin{abstract}
Summary
While refugee camps have so far received little attention in the historical and legal sciences (cf. Engler 2019; Bispinck/Hochmuth 2014: 13), the philosopher Giorgio Agamben developed an entire theory of the modern constitutional state from an analysis of the camp in his series homo sacer. Agamben highlights the camp as a space »that opens up when the state of emergency begins to become the rule« (Agamben 2002: 177) and also includes refugee camps in the term camp (ibid: 179). Erving Coffman's theory of the total institution also continues to be applied in the context of camp research. Although Goffman does not describe camps (as stotal institutions`) as places of permanent legal exception, he does describe them as places of social isolation (cf. Coffman 1973, 24). Both theories have shaped Cerman camp research (cf. Pieper 2013; Täubig 2009). How can they be understood against the background of current developments in migration studies, such as border regime research (cf. Hess/Kasparek 2012) or the concept of >crimmigration< (cf. Garcia Hernandez 2013)? Can the idea of the autonomy of migration be combined with the concept of the powerless homo sacer? Can German refugee accommodations be described as total institutions in the context of crimmigration? Taking these questions into account, this article first takes a look at Agamben's theory of the permanent state of emergency. Following this, the author discusses current debates in migration studies in order to attempt a contemporary theoretical framing of refugee accommodation in Germany.
\end{abstract}

\title{
Flüchtlingslager² als Kampfmittel gegen die "verlorene Souveränität»
}

Das jüngst erschienene Buch Die Zauberlehrlinge von Maximilian Steinbeis und Stephan Detjen behandelt eine »der wirkmächtigsten politischen Mythen unserer Zeit« (Detjen/Steinbeis 2019: Klappentext): In dieser Neuerscheinung widmen sich die Autoren der These, dass die deutsche Bundeskanzlerin Angela Merkel mit der Öffnung der deutschen Grenzen im Herbst 2015 einen Verstoß gegen Recht, Gesetz und Verfassung begangen haben könnte (vgl. ebd.: 12). Eine These, die nicht nur Staatsrechtler*innen beschäftigte (vgl. Di Fabio 2016; Thym 2016), sondern auch Philosoph*innen auf die Bühne rief, die mit aller Welt ihre Sorge um den souveränen Staat teilten (vgl. Cicero 2016) - und zusammen mit den besorgten Verfassungsrechtler*innen einen Argumentationsboden pflügten, auf dem

2 Der Begriff des »Lagers « wird hier zu Beginn funktional als »Unterkunftsmöglichkeit für größere Menschenmassen « und damit als Sammelbegriff für Massenunterkünfte verstanden (Doßmann/Wenzel/Wenzel 2007: 220). Weitere Merkmale ergeben sich aus dem Text. 
die Neue Rechte prächtig gedeihen konnte. ${ }^{3}$ Kern der sogenannten RechtsbruchThese ist dabei ein staatszentriertes Souveränitätsverständnis, das durch eine unkontrollierte Migration in seinen Grundfesten erschüttert werden kann (vgl. Depenheuer/Grabenwarter 2016: 7).

Flüchtlingslager wurden ${ }^{4}$ und werden in diesem Kontext zum Symbol des Kampfes gegen diese »verlorene Souveränität« (Pichl 2018). Sie sollen die abhanden gekommene Migrationssteuerung wiederherstellen, indem sie Geflüchtete lokalisierbar machen und den Zugriff auf sie vereinfachen - zumindest lässt es sich so in zahlreichen Gesetzesbegründungen nachlesen. So wurde 2019 erneut die gesetzliche Wohnpflicht in Erstaufnahmeeinrichtungen mit der Begründung verlängert, dass das »zur Durchsetzung der vollziehbaren Ausreisepflicht zur Verfügung stehende rechtliche Instrumentarium [...] sich als noch nicht effektiv genug erwiesen [hat], um eine ausreichende Durchsetzung der Ausreisepflicht zu gewährleisten « (Gesetzentwurf der Fraktionen der CDU/CSU und SPD 2019: 1). Es verwundert nicht, dass in diesem Zusammenhang das Gelingen einer effizienten Flüchtlingsunterbringung stellvertretend für das Gelingen einer effizienten Migrationssteuerung steht. So lösten die Ereignisse in der baden-württembergischen Erstaufnahmeeinrichtung Ellwangen und die misslungene Abschiebung eines Bewohners der Unterkunft eine nationale Debatte über die "Asylindustrie« und Rechtsstaatlichkeit aus, bei der das Funktionieren des Rechtsstaats an den effektiven Zugriff auf die Bewohner*innen der Flüchtlingsunterkünfte geknüpft wurde (vgl. Beitzer 2019). Der Ruf nach einem starken Staat schallte durch die Medien, die darauffolgenden Polizei-Razzien in der Erstaufnahmeeinrichtung wurden medial bejubelt, ohne $\mathrm{zu}$ beachten, dass diese selbst gegen Grundrechte verstießen speziell die Unverletzlichkeit der Wohnung aus Art. 13 Grundgesetz (GG) ${ }^{5}$ (vgl. Engler 2019b). Hier wurde ein Verständnis von Flüchtlingslagern sichtbar, das durch die Reduzierung auf ihre Funktion für die souveräne Migrationssteuerung geprägt ist. ${ }^{6}$

Für die Bewegung der Neuen Rechten lässt sich dies exemplarisch am Frauenmarsch der AfD und der darauffolgenden Erklärung 2018 nachverfolgen, die sich gegen die »illegale Masseneinwanderung« unter Merkel richteten (Erklärung 2018). des deutschen Flüchtlingslagersystems vgl. Pieper 2013: 32.

6 Dieses Verständnis ist nicht neu. Benz und Schwenken kritisieren etwa das politikwissenschaftliche Verständnis von Migration Ende der 1990er Jahre, weil bei diesem ein Konzept der Migration als »bedrohlich empfundener staatlicher Souveränitätsverlust im Mittelpunkt« stünde (Benz/Schwenken 2005: 364). 


\section{Lager als Raum der souveränen Exklusion: Giorgo Agambens homo sacer Projekt}

Eine ähnliche Rolle schreibt ihnen auch der Philosoph Giorgio Agamben zu. Um seine Theorie des Lagers als Ort des permanenten Ausnahmezustands kommt man in diesem Themenfeld aufgrund ihrer breiten Rezeption nicht herum (vgl. exemplarisch für die Migrationsforschung: Schwarte 2015; Turner 2015; Schulze Wessel 2014; Pieper 2013; Buckel/Wissel 2010). Um zu verstehen, wie Agamben das Lager theoretisch fasst, muss zunächst ein Blick auf seine Souveränitätstheorie geworfen werden. Ausgangspunkt seines Souveränitätskonzepts ist Carl Schmitts berühmte These: "Souverän ist, wer über den Ausnahmezustand entscheidet.« (Schmitt 2015: 13) Diese nimmt Agamben zum Anlass einer Neubestimmung westlicher Souveränität, in deren Mittelpunkt seit den Anfängen moderner Nationalstaaten die Ausnahme vom Recht stehe. Nur mithilfe des permanenten Ausnahmezustands könne der Souverän die juridisch-politische Ordnung schaffen und aufrechterhalten (Agamben 2002: 29). Agamben möchte sich dabei von Schmitts klarer Unterscheidung von Ausnahme und Norm abgrenzen. Er betont gerade die "Schaffung einer Ununterschiedenheit zwischen Innen und Außen, Chaos und normaler Situation, das heißt des Ausnahmezustands« (ebd.) als souveräne Regierungstechnik. Deshalb wird nicht Schmitts Ordnung, sondern das Anomische zum Fundament der Souveränität:

»Der Ausnahmezustand definiert einen Zustand des Cesetzes, in dem die Norm zwar gilt, aber nicht angewandt wird (weil sie keine Kraft hat) und auf der anderen Seite Handlungen, die nicht den Stellenwert von Gesetzen haben, deren `Kraft gewinnen.«(Agamben 2004: 49)

Agamben zäumt das Schmitt'sche Pferd von hinten auf: Die Abhängigkeit der Rechtsordnung von der Ordnung bei Schmitt wird bei Agamben zu einer Abhängigkeit der Ordnung von der Anwendung der Rechtsordnung. Die Verwobenheit von Ausnahme und Souveränität geht in Agambens Theorie insbesondere an den Individuen nicht spurlos vorbei - im Gegenteil. Es ist gerade »die fundamentale Leistung der souveränen Macht« (Agamben 2002: 190) etwas zu produzieren, das ebenfalls auf der Schwelle zum Recht steht: das nackte Leben. So entdeckt Agamben im Traktat über die Bedeutung der Wörter von Sextus Pompeius Festus ${ }^{7}$ die Figur des homo sacer: „Sacer aber ist derjenige, den das Volk wegen eines Delikts angeklagt hat; und es ist nicht erlaubt, ihn $\mathrm{zu}$ opfern; wer ihn jedoch

$7 \quad$ Kritik an Agambens Quellengenauigkeit in Bezug auf den homo sacer übt Gratton. Er weist auf die verschiedenen Interpretationsmöglichkeiten des Begriffs homo sacer im Römischen Recht sowie auf den beschränkten Quellenzugang von Festus selbst hin (vgl. Gratton 2011). 
umbringt, wird nicht wegen Mordes verurteilt." (Ebd.: 81) Wie auch die Souveränität befindet sich der homo sacer an der Grenze der Rechtsordnung. Er ist einer »doppelten Entziehung« (ebd.: 95) des Rechts und des Opfers ausgeliefert und »extremsten Wechselfällen« (ebd.: 168) überlassen. Die Figur des homo sacer steht dabei paradigmatisch für die Ohnmacht und Sprachlosigkeit, denen der Mensch in modernen westlichen Gesellschaften ausgeliefert ist. Sie ist geprägt durch den absoluten Verlust von Handlungsmacht gegenüber einem Souverän, der die Menschen durch die permanente Ausnahme vom Recht in seinem Bann hält. Empirische Beispiele für den homo sacer findet Agamben deshalb in äußerst verschiedenen Menschengruppen: In den Versuchspersonen der nationalsozialistischen KZ, aber auch in zum Tode verurteilten US-Amerikaner*innen, denen bei Teilnahme an medizinischen Versuchen Straferlasse versprochen wurden (vgl. ebd.: 168) ${ }^{8}$. Zweifelsohne übernimmt Agamben hier Arendts Bild der »abstrakten Nacktheit « der Staatenlosen und Überlebenden der Vernichtungslager, die in das zurückgefallen seien "was die politische Theorie den Naturzustand und die zivilisierte Welt die Barbarei nannte« (Arendt 2003: 620).

Die Ohnmacht des homo sacer offenbart Agambens Rechtsbegriff, bei dem Recht als rein repressives Instrument der Souveränität gedacht wird und der die gesellschaftlichen Kämpfe um und mit Hilfe des Rechts unsichtbar macht (vgl. Gündoğdu 2012: 14). Fast nebensächlich beinhaltet die Analyse des zur Passivität verdammten homo sacer eine allgemeine Absage an die Möglichkeit zur Subjektivität als Möglichkeit zum Entscheiden ${ }^{9}$ und erst recht eine Absage an Rechtssubjektivität. Die fehlende Handlungsmacht lässt den homo sacer mehr noch als Antonym zur Idee der Rechtssubjektivität erscheinen. Der homo sacer kann sich nicht auf seine Rechte berufen, denn sie sind es gerade, die ihn in den Bann zum Souverän setzen. Dies gilt auch für »Flüchtlinge« (ebd.: 140). Zum Teil werden sie sogar als »prototypische Figur eines neuen homo sacer « hervorgehoben (Schulze Wessel 2017: 61). Für westliche Nationalstaaten müssen Geflüchtete laut Agamben als besondere Bedrohung gelesen werden. So könnten Staatenlose, indem sie keine Nationalität besäßen, die Anknüpfung der Bürgerrechte an das Leben offenbaren. Der Bezug des Souveräns auf das nackte Leben seiner Staatsbürger"innen wird in dem Moment sichtbar, in dem er mit Menschen konfrontiert wird, deren Rechtlosigkeit nicht durch die Staatsbürgerschaft verschleiert wird, sondern offensichtlich ist: Geflüchtete bringen »auf der politischen Bühne für einen Augenblick jenes nackte Leben zum Vorschein« (ebd.: 140), das durch die »Maske des Bürgers« (ebd.: 141) verdeckt werde.

Wenn der Kern der Souveränität die Ausnahme ist und Gegenstand souveräner Maßnahmen das Leben, dann scheint es logisch, dass Orte, die diese Beziehung gezweifelt (historisch von Gratton 2011: 606; empirisch von Vasilache 2007). 
offenbaren, paradigmatisch für tiefer liegende rechtsstaatliche Strukturen stehen. Diesen Ort sieht Agamben im Lager: Das Lager wird zum »Raum, der sich öffnet, wenn der Ausnahmezustand zur Regel zu werden beginnt « (ebd.: 177). Als räumliche Einrichtung des permanenten Ausnahmezustands bleibt er dauerhaft außerhalb der Rechtsordnung.

Schon die rechtliche Entstehung der Lager zeige, dass die Ausnahme wichtiger Bestandteil deren Fundaments sei. So sei die Einführung der ersten so bezeichneten - und von Agamben als Ausgangspunkt genommenen - Konzentrationslager sowohl in Kuba als auch den englischen Kolonien mit Hilfe des Kriegsrechts bzw. dem rechtlichen Ausnahmezustand durchgesetzt worden (vgl. ebd.: 175). Insofern als das Lager sein eigenes ausnahmerechtliches Fundament als »dauerhaft räumliche Einrichtung« (ebd.: 178) normalisiert, wird es zu dem Ort, in dem die Norm und ihre Anwendung auseinanderfallen und zugleich ununterscheidbar werden: Das Lager wird "zum Hybrid von Recht und Faktum, in dem beide Glieder ununterscheidbar geworden sind « (ebd.: 179). Anders als in der einschlägigen historischen Literatur definiert Agamben das Lager nicht über eine Typisierung, wie etwa die Einteilung in Internierungs-, Konzentrations- und Vernichtungslager (vgl. Greiner/Kramer 2013: 11). Für ihn gilt das Kriterium der Ununterscheidbarkeit von Recht und Faktizität. ${ }^{10}$ So seien Lager $»$ sowohl das Stadion von Bari, in dem 1991 die italienische Polizei illegale albanische Einwanderer provisorisch zusammenpferchte, bevor sie sie in ihr Land zurückbeförderte, als auch das Wintervelodrom, das den Behörden von Vichy als Sammelstelle für Juden diente, bevor sie diese an die Deutschen auslieferten, wie auch das Flüchtlingslager an der Grenze zu Spanien, in dessen Umgebung 1939 Antonio Machado zu Tode kam und die zones d'attente auf den internationalen Flughäfen Frankreichs, in denen Ausländer zurückgehalten werden, die die Anerkennung des Flüchtlingsstatus beantragen« (Agamben 2004: 41). Indem das Lager »den politischen Raum der Moderne als solchen in entscheidender Weise prägt« (Agamben 2002: 184), wird es zu dem Ort, der die Krise der modernen Rechtsstaaten offenbart. In ihm wird der Zugriff des Souveräns auf das Leben sichtbar. Das Lager bei Agamben ist also paradigmatisch für westliche Rechtsstaaten: Es offenbart die souveräne Exklusion, das Anomische innerhalb des Rechtsstaats und ein zutiefst ohnmächtiges Individuum, den homo sacer.

10 Turner entwickelt von Agamben ausgehend eine Definition des Lagers als Ort des Ausnahmezustands anhand der zwei Dimensionen des Raums und der Zeitlichkeit (vgl. Turner 2015). In Bezug auf die Frage nach Flüchtlingslagern als (nicht-)rechtlichen Räumen bleibt Turners Definition jedoch zu unbestimmt. 


\section{Flüchtlingslager: Raum, Sonderstatus und subjektive Rechte}

Agambens Thesen scheinen verlockend: Denn, dass das Konzept der territorialen Souveränität sich auch räumlich manifestiert, ist plausibel. Insbesondere die Legal Geography beschäftigt sich mit den räumlichen Aspekten territorialer Grenzen, die sich auch innerhalb der Staatsgrenzen reproduzieren, etwa in Lagern wie Guantanamo Bay, und extraterritoriale Räume innerhalb des nationalstaatlichen Territoriums schaffen (vgl. Elden 2007). Tatsächlich sprechen einige empirische und rechtsdogmatische Befunde dafür, einen rechtlich und räumlich extraterritorialen Status auch auf Flüchtlingslager zu übertragen: Insofern als Flüchtlingsunterkünfte als »ordnungspolitische Maßnahmen« gedacht werden, verknüpft das deutsche Asylrecht eine spezifische rechtliche Stellung mit dem Aufenthalt in Flüchtlingsunterkünften. Bewohner*innen erhalten gekürzte Sozialleistungen, unterliegen einem Arbeitszwang ${ }^{11}$ und müssen mit Verweis auf die ordnungspolitische Funktion der Unterkünfte zahlreiche grund- und menschenrechtliche Einschränkungen erdulden (vgl. Engler 2019b). Es erstaunt demnach nicht, wenn empirische Studien zeigen, dass die Bewohner*innen der Unterkünfte diese als Gefängnisse erleben (vgl. Dilger/Dohrn 2016). ${ }^{12}$ Die Einordnung in ein besonders geartetes Rechtsverhältnis ${ }^{13}$ lässt sich auch in der Flüchtlingsunterbringung finden.

Gleichzeitig ist der Raum der Unterkunft, ähnlich wie Heime oder Gefängnisse, von einer Fülle rechtlicher Regulierungen durchdrungen. Ihn wie Agamben als »Leerstelle des Rechts« (Agamben/Raulff 2004: 609) zu bezeichnen, ginge fehl. Empirisch ist es eher die Masse der rechtlichen Regelungen statt ihr Fehlen, die die Handlungsmacht der Bewohner*innen einschränkt (vgl. bzgl. Deutschland Pieper 2013). ${ }^{14}$ Aus diesem Grund wird der Idee des Flüchtlingslagers als rechtslosem Raum zum Teil das Konzept der totalen Institution entgegengestellt (vgl. Pieper 2013; Täubig 2009). Der von Erving Goffman entwickelte Begriff (vgl. Goffman 1973) stellt gerade die Durchregulierung der Räume und die bürokratische Verwaltung aller Lebensbereiche in den Vordergrund, die das Leben in der Institution allumfassend bestimmen. Das Konzept der totalen Institution mag in seiner Schematik überholt sein. Es macht jedoch sichtbar, worum es (auch) in der Kritik an Flüchtlingslagern geht: Im Mittelpunkt steht die fehlende Handlungsmacht der Insass*innen. Diese

Vgl. § 5 Abs. 4 AsylbLG, nach dem die Asylbewerberleistungen unter das Existenzminimum gekürzt werden können, sofern die Bewohner*innen eine zur Verfügung gestellte Arbeitsgelegenheit »unbegründet«ablehnen.

12 Siehe dazu auch den Beitrag von Simon Goebel in diesem Band.

13 Den Vergleich mit der rechtsdogmatisch veralteten Figur des besonderen Cewaltverhältnisses zieht bspw. die Antidiskriminierungsberatung Brandenburg in ihrem Gutachten zu Grundrechten in Cemeinschaftsunterkünften (vgl. Lederer 2018).

14 Für andere EU-Länder lässt sich dies jedoch pauschal so nicht sagen (vgl. Commissioner for Human Rights of the Council of Europe 2018; EGMR 2011). 
fehlende Handlungsmacht könnte nun aus rechtlicher Sicht in die Beschränkung subjektiver Rechte gegenüber dem Staat übersetzt werden (vgl. Kopetzki 2008). Inwiefern es deshalb jedoch sinnvoll ist, spezifische Räume als absolute Ausnahmeräume zu markieren, in denen subjektive Rechte keinerlei Anwendung finden, ist allein schon fraglich, weil die Mobilisierung subjektiver Rechte auch außerhalb totaler Institutionen Barrieren begegnet. So hat die feministische Rechtswissenschaft gezeigt, dass die Herrschaft des Rechts unterschiedlich erlebt wird, und die Handlungsmöglichkeiten, die den Einzelnen Recht verschaffen, auch außerhalb totaler Institutionen oder Flüchtlingslager von sozialen Verhältnissen wie class, race und gender abhängen (vgl. Crenshaw 1989). Statt absoluter Ausnahmeräume im Gegensatz zur Außenwelt wäre es im Zusammenhang mit Flüchtlingslagern also sinnvoller von einer Verdichtung bereits bestehender Herrschaftsverhältnisse zu sprechen, die die Rechtsmobilisierung erschweren.

\section{Die Ausnahme aus rechtstheoretischer Perspektive}

Dafür spricht auch ein Blick auf das Rechtsstaatsverständnis, das Agambens Theorie des permanenten Ausnahmezustands im Lager impliziert. Denn es leidet an einer Kinderkrankheit: Agambens $»$ Denken vom Ausnahmezustand her ${ }^{15}$ verharrt in einer empiristischen Negativität, ${ }^{16}$ bei der er die Ausnahme als analytischen Kern seiner Theorie in der Wirklichkeit vorfindet, ohne normativ $\mathrm{zu}$ begründen, was denn eigentlich unter einer Ausnahme zu verstehen sei (für das Verfassungsrecht siehe Kaiser 2017: 36). Aus rechtswissenschaftlicher Perspektive entwickelt Agamben in vielerlei Hinsicht provokante Thesen: Nicht nur belebt er den Ausnahmezustand als Grundlage einer Souveränitätsbestimmung in Anlehnung an Schmitt wieder. Vielmehr verwirft er im selben Zuge die Emanzipationsmöglichkeiten der Menschenrechte überhaupt und führt die Krise des Rechtsstaats auf das Auseinanderfallen von Faktizität und Normativität im permanenten Ausnahmezustand zurück. Hier zeigt sich ein Rechtsstaatsbegriff, der rechtssoziologisch überholt ist: Gerade weil das Recht zugleich Gebote vorgeben (Normativität) und wirksam werden muss (Faktizität), ist die Möglichkeit der Transformation der Rechts (etwa weil es unwirksam ist) eines seiner wesentlichen Bestandteile. Agamben kann

15 Augsberg bemerkt hierzu: »Zusammenfassend kann man daher der echten Ausnahme zwar einen erkenntnistheoretischen, nicht aber eine normative Funktion zuerkennen. (Augsberg 2009: 33) Finke entwickelt einen Begriff der Ausnahme, der auf der Annahme basiert, »dass der Begriff der Ausnahme für sich genommen inhaltsleer ist « (Finke 2015: 517).

16 Siehe hierzu auch Marchart, der Agambens Theorie von Adornos negativer Dialektik abgrenzt (Marchart 2013: 225). Ceulen spricht in diesem Zusammenhang auch von einer »Apodiktik der bloßen Setzung«(Geulen 2009: 76). 
diese Transformationsmöglichkeit bzw. -notwendigkeit aufgrund seines Ausnahmebegriffs nicht denken. ${ }^{17}$ Stattdessen affirmiert er einen »reaktionären « (Menke 2015: 163) Begriff von Ausnahme und Recht, bei dem Normativität und Faktizität im Recht unvermittelt bleiben: Im Ausnahmezustand steht auf der einen Seite das geltende normative Recht und auf der anderen Seite das gewaltvolle faktische Chaos. Paradoxerweise findet er sich damit doch erneut in der Gesellschaft der liberalen Tradition der Trennung von Recht und Gewalt wieder, die er angetreten war, auf das Schärfste zu bekämpfen.

Demgegenüber betonen marxistische Theorien gerade die Reflexivität des modernen Rechts auf das Nicht-Recht und die Doppelfunktion der Rechtsform der subjektiven Rechte. Menke macht beispielsweise sichtbar, dass sich das moderne Recht notwendigerweise selbstreflexiv zu seinem faktischen Umfeld verhalten muss. Was bedeutet das? Selbstreflexiv ist das moderne Recht nach Menke deshalb, weil es sich selbst zugleich durch die Unterscheidung zum Nicht-Recht hervorbringt und es zu seinem Gegenstand macht (vgl. Menke 2015: 126). Moderne Rechte berechtigen die Rechtsträger*innen, zunächst außerrechtliche Gegenstände, wie etwa das Bedürfnis, seine Meinung zu äußern, gegen andere geltend zu machen. Dabei müssen sie sich notwendiger Weise auf ihren eigenen Gegenstand reflektieren, was wiederum zu einer Veränderung der (normativen) Rechte führe: Die Selbstreflexion des Rechts »verändere die Form seiner Normativität« (ebd.: 129). Während die Selbstreflexion des Rechts sowohl den Begriff der Norm als auch des Faktums verändert, indem sie sie miteinander verschränkt, lasse Agamben jedoch beides in der permanenten Ausnahme getrennt. Die Ausnahme »definiert das Recht weiterhin so wie immer, als normative Ordnung gegenüber dem Leben« (ebd.: 163). Für die Möglichkeit einer Transformation des Rechts ist dies fatal: Nur wenn das Recht sich auf außerrechtliche Gegenstände reflektieren kann, kann es durch diese verändert werden. Das Recht (der Flüchtlingslager) kann nicht auf eine abstrakte losgelöste Ansammlung normativer Bestimmung darüber, wie die Migrationssteuerung laufen soll reduziert werden, sondern kann sich auf außerrechtliche Debatten dazu, wie das Leben in den Flüchtlingslagern ist, reflektieren. Es reflektiert sich aber nicht nur auf außerrechtliche Gegenstände, es ist selbst ein Produkt gesellschaftlicher Kämpfe. Sofern die Ausnahme vom Recht als primäres Problem moderner Gesellschaften proklamiert wird, wird die Bedeutung gesellschaftlicher Herrschaftsverhältnisse für das Recht verkannt. Ausnahmen vom Recht zu problematisieren ist insofern legitim, als das Recht tatsächlich eine »relative Autonomie« gegenüber der Gesellschaft besitzt und einen Schutzmechanismus gegen gesellschaftliche Missstände darstellen kann - der durch die Ausnahme vom Recht un- 
terlaufen wird. Es verbleibt jedoch in einem dialektischen Verhältnis mit den ihm zugrundeliegenden sozialen Praxen: »Die Verselbständigung sozialer Verhältnisse ist zugleich die Bedingung ihrer >relativen Autonomieく. Die spezifische kapitalistische Vergesellschaftung kreiert soziale Formen, >ökonomischeく nicht weniger als rechtliche oder politische. Es ist die Autonomisierung und Fetischisierung jener Verhältnisse, die eine eigene Materialität dieser Formen ermöglicht.« (Ebd.: 242f.) Die Ausnahme zum Gegenstand der Rechtskritik zu machen, naturalisiert den Begriff der Ausnahme genauso wie den des Rechts und blendet aus, dass das, was als Ausnahme vom Recht verstanden oder gesetzt wird, durch gesellschaftliche Kämpfe bestimmt ist. Die bloße Skandalisierung der Ausnahme vom Recht bleibt deshalb zu oberflächlich.

Buckel betont zudem, dass die Form des subjektiven Rechts sowohl zur Anerkennung als Freie und Gleiche als auch zur Subjektivierung als Vereinzelte führe und nicht in eine Richtung hin theoretisch aufgehoben werden könne (vgl. Buckel 2007: 314). Moderne Rechtssubjektivität bedeute in diesem Sinne Rechte gegen andere geltend zu machen und sich damit isoliert gegen andere zu positionieren (mein Recht auf Meinungsfreiheit mache ich gegen andere geltend) und zugleich Teil einer Anerkennungsgemeinschaft von Freien und Gleichen zu werden (indem ich mein Recht auf Meinungsfreiheit gegen andere geltend mache, werde ich Teil der freien und gleichen Rechtsträger*innen). Recht hat demnach eine ambivalente Wirkung: Es ermöglicht und verhindert zugleich emanzipatorische Prozesse. Feministische Rechtswissenschaftler"innen haben in diesem Zusammenhang auch auf die "Dilemmata im Recht« (Baer 1996: 242) oder die »Paradoxie der Rechte« (Brown 2017: 454) hingewiesen.

Für die Frage nach dem Recht in Flüchtlingslagern sind diese rechtstheoretischen Analysen äußerst relevant: Die rechtliche Einschränkung subjektiver Rechte der Bewohner*innen kann nur vor dem Hintergrund gesellschaftlicher, migrationsfeindlicher Diskurse verstanden werden. Zudem darf nicht übersehen werden, dass die Form der subjektiven Rechte zum Teil selbst zu Ausschlüssen und der Reproduktion von Herrschaft führt; beispielsweise weil sie voraussetzt, dass einzelne Rechtssubjekte ihre Rechte einklagen - die Bewohner*innen der Unterkünfte verfügen jedoch oftmals nicht über die notwendigen Ressourcen hierfür. Weil das Recht aber selbstreflexiv und gesellschaftlich verankert ist, kann es (im Sinne der Bewohner*innen) transformiert werden. Flüchtlingslager als Orte der Trennung des Rechts vom anomischen Nichtrecht zu skandalisieren, versperrt den Blick für diese wichtigen rechtstheoretischen Debatten und Analysen. 


\section{Geflüchtete: Bloße Opfer souveräner Politiken?}

Die Ambivalenz subjektiver Rechte bedeutet, dass gerade aufgrund der relativen $\mathrm{Au}$ tonomie des Rechts, das geltende angewendete Recht und die Handlungsmacht der Individuen nicht zwingender Weise ein kongruentes Verhältnis zueinander haben. So stilisiert Agamben mit der Figur des homo sacer Migrant*innen zu vereinzelten Opfern souveräner Politiken, weil ihnen der Zugang zum Recht versperrt bleibt. Inwiefern ist es jedoch passend, Migrant*innen als bloße Opfer souveräner Politiken darzustellen? In der kritischen Migrationsforschung wurden in diesem $\mathrm{Zu}$ sammenhang Debatten geführt, die vielschichtige Handlungsmöglichkeiten von Migrant*innen sichtbar und die gängige Dichotomie zu Migrant*innen als »Schurken« oder »Opfer« (Bojadžijev 2011: 140) dekonstruieren möchten: Unter dem Begriff der Autonomie der Migration ${ }^{18}$ wurde ein Migrationsverständnis entwickelt, bei dem »die Perspektive der Migration« eingenommen und ein transnationales Migrationsverständnis etabliert werden sollte. Migration im Sinne der Autonomie der Migration sei »kein Projekt Einzelner, sondern ein Prozess, der auf translokalen Netzwerken und einer globalen Bewegung aufruht « (ebd.: 140f.). Diese Perspektive kann demnach die Vielschichtigkeit an Handlungspraktiken von Migrant*innen sichtbar machen. Statt eine Viktimisierung der Migrierten zu wiederholen, kann mit Fokus auf die Autonomie der Migration deutlich gemacht werden, »dass Handlungsspielräume auch unter Bedingungen der Entrechtung existieren, wenngleich diese immer erkämpft werden müssen« (ebd. 141; ähnlich Hess/Kasparek/Schwertl 2018: 275). Dem Konzept der Autonomie der Migration liegt demnach ein Politik- und Staatsverständnis zugrunde, das sich von Agambens Zentrierung auf die Souveränität unterscheidet und stattdessen die Frage in den Vordergrund stellt, »wie sich Politik durch Kämpfe formiert, wie sich gesellschaftliche Aushandlungen, gerade auch im Sinne einer imperceptible politics in Gesellschaft und Staat einschreiben« (Hess/Kasparek/Schwertl 2018: 271).

Vor diesem Hintergrund scheint es sinnvoll, von Flüchtlingslagern als Räumen der »Immobilisierung « zu sprechen. Immobilisierung meint dabei »die materiellen Bedingungen und politischen Strategien [...], die sowohl eine Mobilisierung als auch die Mobilität von Menschen aktiv verhindern« (Etzold 2019: 8). Die Immobilisierung der Migrant*innen ist nach diesem Verständnis Teil eines europäischen Grenzregimes, das Mobilität kontrolliert, indem es territoriale Grenzen als »materielle, medientechnologisch vermittelte und räumlich ausgreifende Praxis« (Opitz 2011: 259) herstellt. Dabei ist das europäische Grenzregime kein »einseitiger Prozess starrer Exklusion« (Cuttitta 2010: 28), sondern dient der Selektion der Migrant*innen, insbesondere als potenzielle Erwerbsarbeiter*innen. Flüchtlingsla-

18 Zur Begriffsherkunft siehe Binder, Ege und Färber, die sie »beiläufig, im Diskussionszusammenhang des Postoperaismus« verorten (Binder/Ege/Färber 2007: 136). 
ger wirken in diesem Prozess »entschleunigend «(Panagiotidis/Tsianos zitiert nach ebd.:32), indem sie die Mobilität der Migrant*innen einschränken. Ausgangspunkt bleibt hier ein Migrationsverständnis, bei dem nicht der*die Einzelne passiviert der souveränen Herrschaft entgegentritt, sondern Teil eines sozialen Migrationsnetzwerks ist. Dieses begibt sich durchaus in Kämpfe um subjektive Rechte, ist jedoch nicht von einer Idee eines für sich selbst verantwortlichen Rechtssubjekts abhängig. Andersherum werden Migrant*innen nicht automatisch zu handlungsunfähigen Opfern, weil ihnen subjektive Rechte entzogen werden. Inwiefern sie deshalb als autonom beschrieben werden können, kann jedoch hinterfragt werden. So begegnet der Begriff der Autonomie der Migration und die Idee einer Immobilisierung der Migrant*innen der Kritik, dass diese eine »Romantisierung widerständiger Subjekte« reproduziere, die annulliere, dass »auch migrantische Netzwerke hierarchische Machtstrukturen und damit Abhängigkeitsverhältnisse ausweisen, die auf Ungleichheit basieren und sie reproduzieren« (Benz/Schwenken 2005: 374). Die Idee eines autonomen Subjekts reproduziere dabei einerseits die dichotome Gegenüberstellung von souveränem Staat auf der einen und autonomem Subjekt auf der anderen Seite. Zugleich blende es die Reproduktionsarbeiten, die Migration ermöglichen (beispielsweise durch die Entstehung globaler Pflegeketten), aus und verstärke so eine »normative Maskulinität « (ebd.) der Migration. ${ }^{19}$

\section{Lager als Orte der Crimmigration}

Die Perspektive der Autonomie der Migration klingt verlockend, betont sie doch die Handlungsfähigkeit der Lagerbewohner*innen. Aber kann sie den Alltag der Bewohner*innen mit dem Lager als Ort der Immobilisierung tatsächlich greifen? Ihr könnte über die Kritik am Begriff der Autonomie hinaus in Bezug auf Flüchtlingslager entgegengehalten werden, dass sie die faktische Ohnmacht, die in der strukturellen Gewalt ${ }^{20}$ gegen die Bewohner*innen steckt, nicht sichtbar genug macht. Denn die Frage, inwiefern subjektive Rechte wie etwa auf die Unverletzlichkeit der Wohnung, die Privatsphäre oder Rechtsschutz in den Flüchtlingsunterkünften gewährt werden, ist eben nicht nur eine freiheitsrechtliche Frage, sondern auch eine Frage des rechtsstaatlichen Schutzes vor Gewalt und der Ausübung von struktureller Gewalt durch den Rechtsstaat selbst: Orte, die dazu führen, dass regelmäßig

19 Benz und Schwenken schlagen aus diesem Grund vor, statt von der »Autonomie der Migration« von der »Eigensinnigkeit der Migration«zu sprechen (Benz/Schwenken 2005: 374).

20 »Strukturelle Gewalt ist nicht die dem Individuum zurechenbare, intendierte Handlung, vielmehr ist strukturelle Gewalt die vermeidbare Beeinträchtigung des Individuums, seine Bedürfnisse und seine Möglichkeiten in voller Form zu entfalten [...].« (Elsuni 2011: 42f.) 
körperliche und psychische Gewalt gegen Bewohner*innen ausgeübt wird, als Orte der Immobilisierung zu bezeichnen, scheint vor diesem Hintergrund vielleicht $\mathrm{zu}$ verharmlosend. So lassen sich Lager auch als Orte bezeichnen, in denen die Bewohner*innen aufgrund der Crimmigration ${ }^{21}$, d.h. die Kriminalisierung der Migration, zunehmend wie potenzielle Straftäter*innen behandelt werden - etwa wenn diese der Passbeschaffungspflicht nicht rechtzeitig nachkommen. Die Crimmigration schlägt dabei in eine mangelnde Strafverfolgung von Gewaltdelikten gegen die Bewohner*innen um, etwa durch die Sicherheitsdienste, und schafft Strukturen, die den Gewaltschutz strukturell erschweren bis verunmöglichen. So können ganz praktisch schon die Kosten anwaltlicher Beratung nicht durch die Leistungen des Asylbewerberleistungsgesetzes gestemmt werden und die Besuchsverbote für Nichtregierungsorganisationen in den Unterkünften unterbinden eine Gegenöffentlichkeit in den Unterkünften, die zu einem Schutz vor Gewalt durch deren öffentliche Skandalisierung führen könnte (vgl. Engler 2018; Deutsches Institut für Menschenrechte 2017: 46ff.). Nichtregierungsorganisationen haben auf die mangelnde Öffentlichkeit und die sich daraus ergebenden Gefahren für die Bewohner*innen immer wieder hingewiesen (vgl. Aktion Bleiberecht 2020; Anker Watch 2020; Culture of Deportation 2018). Die Bewohner*innen unterliegen einerseits nach $\$ 47$ AsylG der gesetzlichen Wohnpflicht für Erstaufnahmeeinrichtungen und müssen dort mindestens sechs Monate ohne Rückzugorte und die Möglichkeit auf Privatsphäre leben. Zugleich gewähren viele Hausordnungen der Aufnahmeeinrichtungen den privaten Akteur*innen in der Flüchtlingsunterbringung Befugnisse, wie Taschenkontrollen oder Zimmerdurchsuchungen, ohne diese rechtlich (etwa in den Landesaufnahmegesetzen) festzulegen und einen umfassenden Rechtsschutz gegen deren Missbrauch für die Bewohner*innen zu gewährleisten (vgl. Engler 2019a). Die Beschränkung subjektiver Rechte hat so unmittelbare kriminologische Folgen. Der mangelnde Rechtsschutz wird im Zusammenhang mit der Kriminalisierung der Migration als »ein typisches Merkmal von CrimmigrationRecht « (Graebsch 2019: 85) gesehen. Den Bewohner*innen der Unterkünfte, die gerade aufgrund ihrer Fluchterfahrungen eine spezifische Vulnerabilität besitzen, werden so struktureller Gewalt ausgesetzt. ${ }^{22}$

Was sagt dieser Befund über die Idee der Flüchtlingsunterkünfte als Ausnahmeräume aus? Dass bestimmte Straftaten bzw. bestimmte Gruppen von Straftäter*innen stärker oder weniger als andere staatlich sanktioniert werden, liegt in

21 Der Begriff stammt aus dem Amerikanischen (Crimmigration) und wurde durch USamerikanische Rechtswissenschaftlerin Juliet P. Stumpf geprägt (vgl. Graebsch 2019; Stumpf 2006).

22 Diese trifft Personen, die von unterschiedlichen Diskriminierungsachsen betroffen sind, besonders hart. So müsste bspw. LGBTIQ-Bewohner*innen in den Unterkünften ein besonderer Gewaltschutz gewährt werden (vgl. Sußner 2019). 
der Natur der staatlichen oder gesellschaftlichen Kriminalisierung von Handlungen. Sie ist wie alles Recht das Ergebnis sozialer Praktiken (vgl. Kunz/Singelnstein 2016: 179). Dass bestimmte Straftaten weniger verfolgt werden, ist also kein Phänomen, das sich auf bestimmte Orte oder bestimmte Ausnahmezustände beschränken ließe. Aus der Kriminalisierung der Migration oder einem strukturellen Mangel an Rechtsschutz lässt sich ebenfalls kein Auseinanderfallen von Norm und Normanwendung schließen, rühren diese doch gerade aus der rechtlichen Regelung der Flüchtlingsunterbringung. Diese bleibt der relativen Autonomie des Rechts gesellschaftlich und damit in politischen und kulturellen Prämissen verortet. Der Begriff der Crimmigration kann dennoch darauf aufmerksam machen, wie Handlungsmacht in den Flüchtlingslagern durch Kriminalisierung bzw. mangelnde Strafverfolgung eingeschränkt und die strukturelle Gewalt gegen die Bewohner*innen produziert und aufrechterhalten wird.

\section{Ausblick: Lager, Prekarität und die Potenzialität von Menschenrechten}

Flüchtlingslager sind demnach Räume, die gesellschaftliche, im Recht kodifizierte Herrschaftsverhältnisse verdichten. Die Gleichzeitigkeit von souveräner Herrschaft, individueller Handlungsmacht und der Möglichkeit einer Transformation des Rechts lässt sich in der Hannah Arendt-Rezeption der Politikwissenschaftlerin Ayten Gündoğdu wiederfinden. Gündoğdu sieht Flüchtlingslager dabei einerseits vom souveränen Recht der Nationalstaaten auf Migrationssteuerung geprägt. Die Rechtsprechung des Europäischen Gerichtshof für Menschenrechte im Fall Saadi/UK (EGMR 2008) zur Inhaftnahme illegal Eingereister zeige, wie unter dem Primat der territorialen Souveränität willkürlich Menschenrechte, wie das Recht auf Freiheit der Person, eingeschränkt werden könnten. Der Fall gelangte 2008 vor den EGMR, als der irakische Arzt Shayan Baram Saadi nach seiner Asylantragsstellung am Heathrow Airport aufgrund seiner illegalen Einreise für 12 Tage inhaftiert wurde. Der EGMR bestärkte das souveräne Recht der Nationalstaaten auf Migrationssteuerung und sah in der Inhaftierung keine Menschenrechtsverletzung nach Art. 5 EMRK. Darüber hinaus könne jedoch auch anhand der Kontroversen um das Urteil gezeigt werden, wie die Rechtspersönlichkeit von Migrant*innen $\mathrm{zu}$ einer "geschichteten Kategorie« (Gündoğdu 2014: 124; Übersetzung A.E.) wurde: Während die Inhaftierung Asylantragsstellender moralisch stark skandalisiert wurde, blieb der Großteil der Migrant*innen der territorialen Souveränität schutzlos ausgeliefert (vgl. ebd.: 124). Dies führe jedoch nicht zur absoluten Ohnmacht der Betroffenen. Denn Rechtspersönlichkeit ist bei Gündoğdu keine trennscharfe Kategorie, sondern in Anlehnung an Hannah Arendt ein sozial hergestelltes Instrument. Aus diesem Grund fasst Gündoğdu die rechtliche Stellung von Migrant*innen nicht als absolut rechtlos, sondern bezeichnet sie als "prekär«. Der Begriff der 
Prekarität ist primär aus dem Kontext der prekären Lohnarbeit bekannt. Rechtliche Prekarität »weist auf zeitgenössische Praktiken und Prozesse hin, die im Rahmen des Konzepts der universellen Persönlichkeit zu Spaltungen, Schichtung und Grenzziehungen führen und die Rechte verschiedener Kategorien von Migranten von völlig unberechenbaren Meinungen und höchst willkürlichen Entscheidungen abhängig machen « (ebd.: 107). Gleichzeitig ermögliche die Neuinterpretation von Arendts Konzept des »Rechts auf Rechte« als revolutionärer Beginn, den Blick auf Menschenrechte als ein umkämpftes und widersprüchliches Feld zu verschieben (vgl. ebd.: 209). Das hat einerseits zur Folge, dass (Menschen-)Rechte nicht per se als problematisch verworfen werden müssen. Darüber hinaus wird so ein Perspektivwechsel vollzogen, bei dem nicht danach gefragt wird, ob Recht wirksam wird, sondern wie es zur Anwendung kommt.

Kehrt man nun zu Agamben und dem Lager als Ort des permanenten Ausnahmezustands zurück, lässt sich vor diesem Hintergrund sagen, dass Flüchtlingslager nicht adäquat als Ausnahmeräume analysierbar sind. Die verlockende Trennschärfe vom Außen und Innen des Rechts verkennt bei einem genaueren Blick dessen grundlegende Ambivalenzen. Diese treten auch außerhalb der Flüchtlingslager auf und sollten beachtet werden: Nur eine differenzierte rechtstheoretische Analyse kann die Unterdrückungsmechanismen sowie die emanzipatorischen Potenziale des Rechts in den Flüchtlingslagern sichtbar machen. Deshalb lässt sich auch erst recht keine Rechtsstaatstheorie aus Flüchtlingslagern als Ausnahmeräumen ableiten, ohne schmerzhafte rechtstheoretische Vereinfachungen vorzunehmen. Der Begriff der Prekarität ist hingegen auch für die Rechtswissenschaft und die rechtstheoretische Einordnung von Flüchtlingslagern hilfreich, um deren Spezifika nicht zu ignorieren: Die Verdichtung von Herrschaftsverhältnissen in den Flüchtlingslagern aufgrund souveräner Politiken der Migrationssteuerung prekarisiert den rechtlichen Status der Bewohner*innen erheblich und reproduziert strukturelle Gewalt gegen sie. In diesem Zusammenhang ist die rechtliche Prekarisierung Symptom und Ursache einer gesellschaftlichen Immobilisierung der Migrant*innen. Sie ist einerseits das Produkt gesellschaftlicher migrationsfeindlicher Diskurse. Zugleich erschwert sie den Zugang zum Recht und damit die Möglichkeit, rechtliche Kämpfe um Mobilität, etwa durch das Recht auf Asyl, zu führen.

Flüchtlingslager sind demnach nicht durch die Abwesenheit des Rechts, sondern durch die verstärkte Prekarität der rechtlichen Stellung ihrer Bewohner*innen geprägt. Diese ist im Sinne einer intersektionalen Betroffenheit von rechtlichen Herrschaftspraktiken als eine Vielzahl von »Spaltungen, Schichtungen und Grenzziehungen« (ebd.: 107) der Rechtssubjekte in den Unterkünften zu verstehen. Unterschiedliche Bewohner*innen werden demnach unterschiedlich stark prekarisiert. Die rechtliche Prekarität macht sie jedoch nicht zu reinen Opfern. Das Konzept der sozial hergestellten Rechtspersönlichkeit und der Idee der Autonomie der Migration verdeutlicht, dass Handlungsmacht und Rechtspersönlichkeit nicht auf 
den guten Willen des Souveräns beschränkt sind. Dieses Verständnis der Flüchtlingslager löst sich sowohl von dem Blick ihrer Funktion für die souveräne Migrationssteuerung als auch von der Verwirklichung subjektiver Rechte als Garant für Handlungsmacht in den Unterkünften - ohne ersteres oder letzteres zu verleugnen:

»Die prekäre Existenz kreist nicht um das Individuum, sondern um eine Vielzahl von Verbindungen, von Kooperationen und Interdependenzen. Das schließt Unterdrückung und Leid ebenso ein wie Perspektiven der Befreiung, der freien Assoziation.« (Atzert, zitiert nach Panagiotidis/Sener 2004: 34)

\section{Literaturverzeichnis}

Agamben, Giorgio (2002): Homo sacer: Die souveräne Macht und das nackte Leben, Frankfurt a.M: Suhrkamp Verlag.

Agamben, Giorgio (2004): Ausnahmezustand: Homo sacer II.1, Frankfurt a.M.: Suhrkamp Verlag.

Agamben, Giorgio/Raulff, Ulrich (2004): »Interview with Giorgio Agamben - Life, A work of art without an author: The state of exception, the administration of disorder and private life«, in: German Law Journal 5, S. 609-614.

Aktion Bleiberecht (2020): Stellungnahme zur Verhandlung wegen Zimmerkontrolle in Landeserstaufnahmeeinrichtung Freiburg, vom 21.01.2020, https://www. aktionbleiberecht.de/?p=16858, Abrufdatum: 03.05.2020.

Anker Watch (2020): Gewalttätiger >Sicherheitsdienst< bleibt im ANKER-Zentrum Bamberg, in: Anker Watch vom 07.01.2020, https://www.anker-watch.de/gewa lttaetiger-sicherheitsdienst-bleibt-im-anker-zentrum-bamberg/, Abrufdatum: 03.05.2020.

Arendt, Hannah (2003): Elemente und Ursprünge totaler Herrschaft: Antisemitismus. Imperialismus. Totale Herrschaft, München: Piper Taschenbuch.

Asylbewerberleistungsgesetz in der Fassung vom 05.08.1997 (BGB1. I S. 2022), zuletzt geändert durch Art. 18 G vom 12.06.2020 (BGB1. I S. 1248).

Asylgesetz in der Fassung der Bekanntmachung vom 02.09.2008 (BGB1. I S. 1798), zuletzt geändert durch das Gesetz vom 20.11.2019 (BGB1. I S. 1626) m.W.v. 26.11.2019.

Augsberg, Steffen (2009): »Denken vom Ausnahmezustand her. Über die Unzulässigkeit der anormalen Konstruktion und Destruktion des Normativen «, in: Felix Arndt/Nicole Betz/Anuscheh Farahat/Matthias Goldmann/Matthias Huber/Rainer Keil/Petra L. Láncos/Jan Schaefer/Maja Smrkolj/Franziska Sucker/Stefanie Valta (Hg.), Freiheit - Sicherheit - Öffentlichkeit 48. Assistententagung Öffentliches Recht, Baden-Baden: Nomos, S. 17-39. 
Baer, Susanne (1996): »Dilemmata im Recht und Gleichheit als Hierarchisierungsverbot - Der Abschied von Thelma und Louise«, in: Kriminologisches Journal 4, S. 242-260.

Baer, Susanne (2006): »Der Bürger« im Verwaltungsrecht: Subjektkonstruktion durch Leitbilder vom Staat, Tübingen: Mohr Siebeck.

Beitzer, Hannah (2019): „Die Illusion, dass wir unsere Grenzen schützen können, bröckelt«, in: Süddeutsche Zeitung vom 20.05.2018, www.sueddeutsche.de/politik/ellwangen-die-illusion-dass-wir-unsere-grenzen-schuetzen-koennenbroeckelt-1.3981958, Abrufdatum: 06.12.2019.

Benz, Martina/Schwenken, Helen (2005): »Jenseits von Autonomie und Kontrolle: Migration als eigensinnige Praxis«, in: PROKLA. Zeitschrift für kritische Sozialwissenschaft 35, S. 363-377.

Binder, Beate/Ege, Moritz/Färber, Alexa (2007): »Debatte: Autonomie der Migration«, in: Zeitschrift für Kulturwissenschaften 5, S. 135-138.

Bispinck, Henrik/Hochmuth, Katharina (2014): Flüchtlingslager im Nachkriegsdeutschland. Migration, Politik, Erinnerung, Berlin: Christoph Links Verlag.

Bojadžijev, Manuela (2011): »Das Spiel der Autonomie der Migration«, in: Zeitschrift für Kulturwissenschaft 5, S. 139-146.

Brown, Wendy (2017): »Die Paradoxie der Rechte ertragen«, in: Christoph Menke/Francesca Raimondi (Hg.), Die Revolution der Menschenrechte, Berlin: Suhrkamp, S. 454-473.

Buckel, Sonja (2007): Subjektivierung und Kohäsion: Zur Rekonstruktion einer materialistischen Theorie des Rechts, Weilerswist: Velbrück.

Buckel, Sonja/Wissel, Jens (2010): „State Project Europe: The Transformation of the European Border Regime and the Production of Bare Life«, in: International Political Sociology 4, S. 33-49.

Cicero Redaktion (2016): Peter Sloterdijk über Merkel und die Flüchtlingskrise: »Wir haben das Lob der Grenze nicht gelernt«, in: Cicero vom 26.01.2016, www.cicero.de/innenpolitik/peter-sloterdijk-ueber-merkel-unddie-fluechtlingskrise-es-gibt-keine-moralische, Abrufdatum: 08.12.2019.

Commissioner for Human Rights of the Council of Europe (2018): Report of the Commissioner for Human Rights of the Council of Europe Dunja Mijatovic following her visit to Greece from 25 to 29 June 2018, vom 06.11.2018, https://reliefweb.int/sites/reliefweb.int/files/resources /CommDH \%282018 \%2924 \%20- \%20Greece \%20report_EN.docx.pdf, Abrufdatum: 03.01.2020.

Crenshaw, Kimberle (1989): »Demarginalizing the Intersection of Race and Sex: A Black Feminist Critique of Antidiscrimination Doctrine, Feminist Theory and Antiracist Politics«, in: University of Chicago Legal Forum, S. 139-167.

Culture of Deportation (2018): Stop security guard and police violence! Stop criminalizing refugees!, in: Culture of Deportation vom 18.12.2018, http://cu 
ltureofdeportation.org/2018/12/18/justizwatch-on-the-bamberg-police-raid/, Abrufdatum: 03.05.2020.

Cuttitta, Paolo (2010): »Das europäische Grenzregime: Dynamiken und Wechselwirkungen«, in: Sabine Hess/Bernd Kasparek (Hg.), Grenzregime: Diskurse, Praktiken, Institutionen in Europa, Berlin: Assoziation A, S. 23-43.

Depenheuer, Otto/Grabenwarter, Christoph (2016): Der Staat in der Flüchtlingskrise: zwischen gutem Willen und geltendem Recht, Paderborn: Ferdinand Schöningh.

Detjen, Stephan/Steinbeis, Maximilian (2019): Die Zauberlehrlinge: Der Streit um die Flüchtlingspolitik und der Mythos vom Rechtsbruch, Stuttgart: Klett-Cotta.

Deutsches Institut für Menschenrechte (2017): Entwicklung der Menschenrechtssituation in Deutschland Juli 2016-Juni 2017, https://www.institutfuer-menschenrechte.de/fileadmin/user_upload/Publikationen/Menschenrechtsbericht_2017/Menschenrechtsbericht_2017.pdf, Abrufdatum: 03.05.2020.

Di Fabio, Udo (2016): Migrationskrise als föderales Verfassungsproblem, Gutachten im Auftrag des Freistaates Bayern, www.bayern.de/wp-content/uploads/2016/01/Gutachten_Bay_DiFabio_formatiert.pdf, Abrufdatum: 08.12.2019.

Dilger, Hansjörg/Dohrn, Kristina (Hg.) (2016): Living in Refugee Camps in Berlin: Women's Perspectives and Experiences, Berlin: Weißensee Verlag.

Doßmann, Axel/Wenzel, Jan/Wenzel, Kai (2007): »Barackenlager. Zur Nutzung einer Architektur der Moderne«, in: Ludger Schwarte (Hg.), Auszug aus dem Lager. Zur Überwindung des modernen Raumparadigmas, Bielefeld: transcript, S. 220-245.

EGMR (2008): Urteil vom 29.1.2008, 13229/03, Saadi/United Kingdom.

EGMR (2011): Urteil vom 21.1.2011, 30696/09, MSS/Griechenland und Belgien.

Elden, Stuart (2007): »Terror and Territory«, in: Antipode 39, S. 821-845.

Elsuni, Sarah (2011): Geschlechtsbezogene Gewalt und Menschenrechte, BadenBaden: Nomos.

Engler, Anne-Marlen (2018): »Hausverbote in Flüchtlingsunterkünften«, in: Asylmagazin, S. 154-161.

Engler, Anne-Marlen (2019a): »Private Sicherheitsfirmen in Flüchtlingsunterkünften. Probleme, Befugnisse, Grenzen des Handelns privater Akteure im öffentlichen Auftrag«, in: Asylmagazin, S. 94-100.

Engler, Anne-Marlen (2019b): »Wohnen als ordnungspolitische Funktion: Deutsche Flüchtlingsunterbringung zwischen dem Recht auf die Unverletzlichkeit der Wohnung und der Abgrenzung zum Freiheitsentzug«, in: Zeitschrift für Ausländerrecht und Ausländerpolitik, S. 323-327.

Erklärung 2018 (2018): Gemeinsame Erklärung vom 15.03.2018, www.erklaerung2018.de, Abrufdatum: 02.01.2020. 
Etzold, Benjamin (2019): »Auf der Flucht - (Im)Mobilisierung und (Im)Mobilität von Schutzsuchenden«, in: Flucht: Forschung und Transfer. IMIS Osnabrück, https://flucht-forschung-transfer.de/neue-publikation-zur-immobilisi erung-und-immobilitaet-von-schutzsuchenden/, Abrufdatum: 05.05.2020.

Finke, Jasper (2015): »Funktion und Wirkung der Ausnahme im Recht«, in: Archiv des öffentlichen Rechts, S. 514-541.

Gesetzentwurf der Fraktionen der CDU/CSU und SPD (2015): Entwurf eines Zweiten Gesetzes zur besseren Durchsetzung der Ausreisepflicht, BT-Drucks. 19/10047.

Geulen, Eva (2009): Giorgio Agamben zur Einführung, Hamburg: Junius Verlag.

Goffman, Erving (1973): Asyle: über die soziale Situation psychiatrischer Patienten und anderer Insassen, Frankfurt a.M.: Suhrkamp.

Graebsch, Christine M. (2019): »Krimmigration: Die Verwobenheit strafrechtlicher mit migrationsrechtlicher Kontrolle unter besonderer Berücksichtigung des Pre-Crime-Rechts für `Gefährder««, in: Kriminologie - Das Online-Journal, S. $75-103$.

Gratton, Peter (2011): »What More Is There to Say? Revisiting Agamben's Depiction of Homo Sacer«, in: The European Legacy 16, S. 599-613.

Greiner, Bettina/Kramer, Alan (Hg.) (2013): Welt der Lager: Zur »Erfolgsgeschichte« einer Institution, Hamburg: Hamburger Edition.

Grundgesetz für die Bundesrepublik Deutschland vom 23.05.1949 (BGBl. S. 1), zuletzt geändert durch Gesetz vom 29.09.2020 (BGB1. I S. 2048).

Gündoğdu, Ayten (2012): »Potentialities of Human Rights: Agamben and the Narrative of Fated Necessity«, in: Contemporary Political Theory 11, S. 2-22.

Gündoğdu, Ayten (2014): Rightlessness in an Age of Rights: Hannah Arendt and the Contemporary Struggles of Migrants, New York: Oxford University Press.

Hess, Sabine/Kasparek, Bernd/Schwertl, Maria (2018): »Regime ist nicht Regime ist nicht Regime. Zum theoriepolitischen Einsatz der ethnografischen (Grenz-)Regimeanalyse«, in: Andreas Pott/Christoph Rass/Frank Wolff (Hg.), Was ist ein Migrationsregime? What Is a Migration Regime?, Wiesbaden: Springer Fachmedien, S. 257-283.

Kaiser, Anna-Bettina (2017): Ausnahmeverfassungsrecht - Manuskript.

Kopetzki, Christian (2008): »Erving Goffmans >Totale Institutionen und das besondere Gewaltverhältnis«, in: Wiener Zeitschrift zur Geschichte der Neuzeit, Totale Institutionen, S. 143-150.

Kunz, Karl-Ludwig/Singelnstein, Tobias (2016): Kriminologie, Bern: Haupt Verlag. Lederer, Anja (2018): Grundrechte für Geflüchtete in Gemeinschaftsunterkünften. Eingriffe begrenzen, Einschränkungen verhindern, Gutachten für die Antidiskriminierungsberatung Brandenburg vom Dezember 2018, https://www. antidiskriminierungsberatung-brandenburg.de/wp-content/uploads/2019/03/ Grundrechtsverletzung_Heime_Online.pdf, Abrufdatum: 11.12.2019. 
Loevy, Karin (2016): Emergencies in Public Law: The Legal Politics of Containment, New York: Cambridge University Press.

Marchart, Oliver (2013): Die politische Differenz: Zum Denken des Politischen bei Nancy, Lefort, Badiou, Laclau und Agamben, Berlin: Suhrkamp Verlag.

Menke, Christoph (2015): Kritik der Rechte, Berlin: Suhrkamp Verlag.

Opitz, Sven (2011): »Grenzregime«, in: Werner Fuchs-Heinritz/Daniela Klimke/Rüdiger Lautmann/Otthein Rammstedt/Hanns Wienold/Urs Stäheli/Christoph Weischer (Hg.), Lexikon zur Soziologie, Wiebaden: VS Verlag für Sozialwissenschaften, S. 259.

Panagiotidis, Efthimia/Sener, Ulas (2004): »Marx' Gespenster in der Debatte um die >Autonomie der Migration«", in: Analyse und Kritik 487, S. 34.

Pichl, Max (2018): Die Fiktion der Souveränität in Transitzentren - Was ist eigentlich mit der Orbánisierung Europas gemeint?, in: Verfassungsblog vom 04.07.2018, https://verfassungsblog.de/die-fiktion-der-souveraenitaet-intransitzentren-was-ist-eigentlich-mit-der-orbanisierung-europas-gemeint/, Abrufdatum: 04.05.2020.

Pieper, Tobias (2013): Die Gegenwart der Lager: zur Mikrophysik der Herrschaft in der deutschen Flüchtlingspolitik, Münster: Westfälisches Dampfboot.

Schmitt, Carl (2015): Der Begriff des Politischen: Text von 1932 mit einem Vorwort und drei Corollarien, Berlin: Duncker \& Humblot.

Schülein, Johann August (2007): »Asyle< - Über Goffmans Analyse und Kritik sozialer Ausgrenzung und Kontrolle«, in: Österreichische Zeitschrift für Soziologie 32 , S. 32-52.

Schulze Wessel, Julia (2014): „Vom Lager zur Grenze: Giorgio Agamben über Ausnahmeräume und Flüchtlinge«, in: Miriam Aced/Tamer Düzyol/Arif Rüzgar/Christian Schaft (Hg.), Migration, Asyl und (Post-)Migrantische Lebenswelten in Deutschland, Berlin: LIT Verlag, S. 11-28.

Schulze Wessel, Julia (2017): Grenzfiguren - zur politischen Theorie des Flüchtlings, Bielefeld: transcript.

Schwarte, Ludger (2015): Auszug aus dem Lager. Zur Überwindung des modernen Raumparadigmas in der politischen Philosophie, Berlin/Boston: transcript Verlag.

Stumpf, Juliet (2006): »The Crimmigration Crisis: Immigrants, Crime, and Sovereign Power«, in: American University Law Review 56, S. 367-419.

Sußner, Petra (2019): »Wer geht, ist selber schuld? Unionsrechtliche Perspektiven auf Gewaltschutzansprüche von LGBTIQ-Asylsuchenden in Unterkünften - unter Berücksichtigung der Rechtsprechung des EGMR«, in: Europäische Grundrechte Zeitschrift 46, S. 437-453.

Täubig, Vicki (2009): Totale Institution Asyl: Empirische Befunde zu alltäglichen Lebensführungen in der organisierten Desintegration, Weinheim: Beltz Juventa. 
Thym, Daniel (2016): Der Rechtsbruch-Mythos und wie man ihn widerlegt, in: Verfassungsblog vom 02.05.2018, https://verfassungsblog.de/der-rechtsbruch-my thos-und-wie-man-ihn-widerlegt/, Abrufdatum: 08.12.2019.

Turner, Simon (2015): »What Is a Refugee Camp? Explorations of the Limits and Effects of the Camp«, in: Journal of Refugee Studies 29, S. 139-148.

Vasilache, Andreas (2007): »Gibt es überhaupt >Homines sacri<? Das nackte Leben zwischen Theorie und Empirie«, in: Janine Böckelmann/Frank Meier (Hg.), Die gouvernementale Maschine: zur politischen Philosophie Giorgio Agambens, Münster: Unrast, S. 58-75. 



\section{Mobilität als Wasserkocher \\ Entwurf einer migrationsinspirierten Theorie der sozialen Ungleichheit - und erste Anwendungsbeispiele}

Ria Prilutski

\section{Zusammenfassung ${ }^{1}$}

Die in den Sozialwissenschaften übliche Trennung zwischen sozialer und räumlicher Mobilität muss in der Migrationsforschung scheitern, denn Migration ist beides: Sie ist eine Form von sozialer Mobilität mit räumlichen Mitteln. Wer sich im Raum bewegen möchte, geht auf Reisen. Wer migriert, sucht immer nach einem besseren Leben, oder überhaupt nach einem Leben, das diesen Namen verdient. Der Beitrag schließt sich zunächst den Ansätzen der mobility studies an, die Migration als eine Form von Mobilität neben anderen begreifen, geht jedoch weiter mit dem Vorschlag einer alternativen Definition von sozialer Mobilität, die transnationale Migration umfasst, ohne auf sie beschränkt zu sein. Soziale Mobilität ist einerseits ein Vermögen und andererseits ein Prozess: das Vermögen eines Individuums oder eine Cruppe, seine bzw. ihre Lebensumstände und gesellschaftliche Position zu verändern, und der Prozess dieser Veränderung. Anschließend werden drei Dimensionen der sozialen Mobilität herausgearbeitet: etwas bewegen (Handlungsmacht), sich bewegen (Autonomie) und nicht bewegt werden (gleichwertiger Menschenstatus). Die soziale Ungleichheitsstruktur in modernen Gesellschaften wie Deutschland lässt sich mit Hilfe dieser Konzepte als ein Kontinuum sozialer Mobilitäten begreifen. Im letzten Abschnitt werden zwei Fallbeispiele aus von mir durchgeführten qualitativen Interviews untersucht: Einerseits geht es um den Zusammenhang zwischen den Strukturen von Herrschaft und Diskriminierung, der sozialen Mobilität als Vermögen und den konkreten Lebensverhältnissen, andererseits um die relative Zusammensetzung der sozialen Mobilität anhand ihrer drei Ausprägungen. Im ersten Beispiel wird der Zusammenhang zwischen der rassistischen, klassistischen und sexistischen Unterdrügeförderten) Promotion dar und ist dementsprechend als »work in progress « zu betrachten. Mein Dank gilt den beiden Interviewpartnerinnen, die ihre Zeit und Arbeit für mein Projekt zur Verfügung gestellt haben. 
ckung und der sozialen Mobilität einer aus dem Iran geflohenen Frau betrachtet. Im zweiten Fall werden die Auswirkungen einer Institution auf die soziale Mobilität einer Personengruppe betrachtet: Die bayerischen Ankerzentren erscheinen hier als eine Institution sozialer Immobilisierung.

\section{Summary}

Distinguishing between social and spatial mobility as it is common in the social sciences is bound to fail in the field of migration research. Migration is both - it is a form of social mobility by spatial means. People who want to move in space just travel. If you migrate, you are always searching for a better life - even when it means a life worth living. This article agrees with approaches of mobility studies in conceptualizing migration as a form of mobility among others, but goes further and proposes an alternative definition of social mobility that comprises transnational migration without being limited to it. Social mobility constitutes both a capability/property and a process: the capability of an individual or a group of people to change their conditions of life or their position in society and the process of these changes. Subsequently, three dimensions of social mobility are differentiated: to move something (capacity to act), to move oneself (autonomy) and not to be moved (equal status as a human being). By utilizing these concepts, the structure of social inequality in modern societies like Germany can be understood as a continuum of social mobilities. In the last section, two cases based on qualitative interviews conducted by the author are presented. On the one hand, this concerns the relationship between structures of power and discrimination, social mobility as capability or property and concrete conditions of living, on the other hand the relative composition of social mobility based on its three dimensions. In the first example the interrelation of racist, classist and sexist oppression and the social mobility of a woman who has fled from Iran is analyzed. The second case, however, is not concerned with a person, but with an institution and presents the Bavarian special refugee camps for »arrival, decision and repatriation « (Ankerzentren) as institutions of social immobilization.

\section{Einleitung}

»Aufgrund seiner Komplexität entzieht sich das Phänomen >Migration< [...] einer alle Bedürfnisse auf gleiche Weise befriedigenden Definition. Es erscheint daher sinnvoll, zunächst im allgemeinsten Sinn vom Begriff der >Mobilität<auszugehen, definiert als Wechsel von Personen (oder Personengruppen) von einem System in ein anderes (bzw. von einem Teilsystem eines größeren Systems in ein anderes seiner Teilsysteme). Wird das >System<sozial bestimmt, so handelt es sich bei einem Systemwechsel um soziale Mobilität, d.h. Auf-oder Abstiegsbewegungen (Karrie- 
ren). Wird das System räumlich bestimmt, so handelt es sich bei einem Systemwechsel um räumliche Mobilität, d.h. Migration. Soziale und räumliche Mobilität sind häufig eng miteinander verbunden.«(Hoffmann-Nowotny 1994: 388)

Gegenüber diesem in den Sozialwissenschaften vorherrschenden Verständnis, das ich einem Nachschlagewerk für spezielle Soziologien entnommen habe, gibt es freilich auch das im Alltag und in den medialen Schlagzeilen vorherrschende Denken über Migration und Migrant*innen. Pointiert lässt sich dessen Problematik mit den Worten der antirassistischen Autorin Noah Sow zusammenfassen:

»In den letzten Jahren hat der Subtext des Wortes >Migrant_in che Bedeutung fast vollständig abgelöst. Er basiert auf folgenden, philosophisch gehaltvollen Leitgedanken (nachstehend abgekürzt als LC):

LG (1): $\rightarrow$ Weiße Nord- und Mitteleuropäer sind keine Migranten, $\rightarrow$ People of Color $(\mathrm{PoC})$ und Russen sind Migranten.

LC (2): Je dunkler desto Migrant.

LG (3): Westlich und weiß ₹ fremd." (Sow 2011: 444, Kursiv und Sonderzeichen im Original)

Während die erste Definition von Migration eine >neutrale und abstrakte Ebene einnimmt, betont die zweite Beschreibung den Aspekt des rassistischen Otherings, das dem Migrationsbegriff in seinem alltäglichen Gebrauch innewohnt. Die Dekonstruktion eines solchen Verständnisses von transnationaler Migration ist eine politisch und moralisch notwendige Aufgabe, zu der auch wir Sozialwissenschaftler*innen beitragen können - jedoch mit unseren eigenen Mitteln und nach unseren eigenen Standards. Während sich Noah Sow gekonnt des Mittels der Ironie bedient, schlage ich in meiner Arbeit den Weg der praxisorientierten soziologischen Theoriebildung ein. Meine Frage lautet daher: Wie hängt das erste Zitat mit dem zweiten zusammen?

Aus dem Zitat des Migrationssoziologen Hoffmann-Nowotny können wir lernen, dass es eine räumliche und eine soziale Mobilität geben kann, dass es bei der sozialen Mobilität um Karrieren geht und bei der räumlichen um Migration, und dass es dabei um einen Systemwechsel geht. Was für die Bestimmung und Untersuchung von Migration also relevant ist, ist der Charakter des Systems, der in diesem Fall räumlich ist. Häufig besteht jedoch eine Verbindung zwischen der sozialen und der räumlichen Mobilität.

Was diese Kategorisierung allerdings nicht zu erklären vermag, ist, warum ein Umzug von Berlin nach Großschwabhausen so gut wie nie als Migration begriffen wird, ein Umzug einer Person etwa aus Słubice nach Frankfurt an der Oder hingegen schon, obwohl die Entfernung nur wenige Hundert Meter beträgt. Sie kann uns auch keine Antwort auf die Frage geben, wie es dazu kommt, dass People of Colour und Russ*innen als Migrant*innen gesehen werden, weiße Nordeuropä- 
er*innen aber nicht. Und auch die Frage, wie wir bei einem räumlichen Systemwechsel Migration von längeren touristischen Reisen unterscheiden sollen, bleibt dadurch unbeantwortet.

Meine erste Antwort ist: Wir müssen dafür die System-Perspektive verlassen und uns den Motiven der Individuen zuwenden. Shirin Foumani ${ }^{2}$ floh aus dem Iran, um sexistischer Verfolgung zu entkommen. Während des Interviews hat sie sich immer wieder vergewissert, dass sie bei mir Verständnis findet, da ich schließlich eine andere Gesellschaft verlassen habe. In allen informellen Gesprächen mit Menschen, die ihre Staaten, Städte, Dörfer oder sogar Stadtteile und Wohnungen verlassen haben, um andere Staaten, Städte, Dörfer, Stadtteile oder Wohnungen $\mathrm{zu}$ bewohnen, wurden mir verschiedenste Motivationen dargelegt: Eine Flucht vor Krieg, Armut oder Gewalt, Suche nach Arbeits- oder Bildungsmöglichkeiten, zwischenmenschliche Beziehungen, bis hin zu besseren Verkehrsanbindungen oder größerem Wohnraum. Eines kam aber nie vor: Ein reiner Raumwechsel als Motiv. Wer einen räumlichen Wechsel vollziehen wollte, ging auf Reisen. Wer migrierte, wollte immer ein besseres Leben, und sei es auch ein Leben, das nicht täglich in Gefahr ist. Wenn wir all diese vielfältigen Wünsche ernst nehmen, müssen wir erstens Migration als soziale Mobilität begreifen, zweitens, soziale Mobilität nicht allein als Karriereweg definieren, und drittens, erklären, warum und wie diese soziale Mobilität beschränkt wird, wenn sie von bestimmten Menschen in Anspruch genommen oder erstrebt wird. Genau das werde ich in und mit diesem Artikel versuchen. ${ }^{3}$

\section{Transnationale Migration als soziale Mobilität mit räumlichen Mitteln}

In sozialwissenschaftliche Sprache übersetzt, können die Worte Noah Sows eine wichtige Korrektur zum sneutralen< Verständnis von Migration leisten: Was mit Migration in der Regel gemeint ist, ist nicht Migration als solche, sondern die transnationale Migration rassifizierter Personen. ${ }^{4}$ Diese Form von Migration ist es, die in den sogenannten Aufnahmegesellschaften immer wieder als Problem und

2 Hier und in allen weiteren Zitaten aus Interviews wurden Personen- und Städtenamen entfernt oder geändert.

3 Ich verorte meine Arbeit, also auch diesen Artikel, in der (noch jungen) Tradition der kritischen Migrationsforschung. Dies umfasst eine explizit diskriminierungskritische, hier insbesondere rassismuskritische, Perspektive. Mehrere Begriffe werden vor diesem Hintergrund ausschließlich in einfachen Anführungszeichen verwendet, die im Gegensatz zu doppelten Anführungszeichen oder kursiven Hervorhebungen als Mittel zur Distanzierung von potenziell rassismusfördernden Begriffen und als Hinweis auf ihren sozialen Konstruktionscharakter dienen. 
Normabweichung behandelt wird. Die Kritik am Othering der transnationalen Migration und ihrer Subjekte ist nicht mehr ganz neu. Der (sozial-)wissenschaftliche Beitrag zu diesem Othering der migrantischen Realitäten wurde vor einigen Jahren im Vorwort zum Sammelband Migrationsforschung als Kritik (Mecheril et al. 2013) ausführlich erläutert: Auch wenn das gesellschaftliche Interesse an und auch die wissenschaftliche Beschäftigung mit Migrationsphänomenen seit einigen Jahren sichtbar zunimmt, bleiben migrierte Menschen darin etwas Besonderes, eine Abweichung. Mit Migration beschäftigt sich eine spezielle Soziologie oder eine interkulturelle Pädagogik, womit der Eindruck erzeugt wird, es gäbe »ein von (migrationsgesellschaftlicher) Differenz bereinigtes Allgemeines (ebd.: 14), das von der allgemeinen Soziologie erforscht wird.

Die Frage jedoch, wie man dieses Othering (gesellschaftspolitisch und wissenschaftlich) überwinden kann, ist nach wie vor aktuell. Ein Lösungsansatz, der bereits im oben angeführten Zitat von Hoffmann-Nowotny anklingt, besteht im alternativen Begriff Mobilität. ${ }^{5}$ Seit den 1990er Jahren entwickelt sich insbesondere in der englischsprachigen Wissenschaftslandschaft ein eigenständiger Bereich der Mobilitätsforschung, der sich nicht, wie zuvor, auf Transport- und Tourismusforschung beschränkt. Die Aktivitäten in diesem Forschungsbereich nahmen in den $2000 e r$ Jahren soweit $\mathrm{zu}$, dass seine zentralen Autor*innen einen mobility turn bzw. ein neues Mobilitätsparadigma in den Sozialwissenschaften ausgerufen haben $^{6}$ : Moderne, komplexe und globalisierte Gesellschaften sollen unter dem Gesichtspunkt der verschiedenen (Im-)Mobilitäten untersucht werden, da traditionelle sozialwissenschaftliche Kategorien und Methoden zu statisch sind und hierfür nicht mehr ausreichen (Büscher/Urry 2009; Urry 2007; Sheller/Urry 2006). In der Tat bietet der Begriff der Mobilität in der Migrationsforschung einen wesentlichen Vorteil: Er ermöglicht eine sachlich >neutrale< Auseinandersetzung mit Migrationsbewegungen, da diese als eine Form von Mobilität neben anderen betrachtet werden können. Zwei weitere Aspekte erscheinen für eine Auseinandersetzung mit transnationaler Migration (insbesondere im Hinblick auf ihre vielfältigen Formen) ebenfalls bedeutsam: die relationale Perspektive auf Mobilität und Immobilität bzw. Sesshaftigkeit als sich gegenseitig bedingende Phänomene (für die englischsprachige Mobilitätsforschung vgl. Adey $(2017,2006)$, für die deutschsprachige Geschichtswissenschaft vgl. Friedrichs (2018)) sowie die Relevanz der potenziellen

5 Siehe dazu auch Amelina/Vasilache (2014): Die Autor*innen kritisieren einen Sesshaftigkeits-Bias in der Migrationsforschung (Migration wird als Abweichung vom >Normalfall< Sesshaftigkeit behandelt) und schlagen den Mobilitätsansatz als eine bessere Alternative vor.

6 Zur Geschichte des mobility turns, aber auch den Zweifeln an seiner Neuheit vgl. Adey (2017: $23 \mathrm{ff} ., 34)$. 
Mobilität bzw. der Fähigkeit, mobil zu sein, für die soziale Ungleichheit. ${ }^{7}$ Zwei Aspekte des Mobilitätsparadigmas können sich jedoch für eine kritische Migrationsforschung als problematisch erweisen.

An erster Stelle kann man aus wissenschaftsethischer Perspektive fragen, ob die vorteilhafte Sachlichkeit und Neutralität, die Migration neben anderen Formen der Mobilität untersucht, nicht wieder zum Nachteil wird, wenn man die Unterschiede aus den Augen verliert: Auch wenn es sich etwa bei Fluchtmigration oder Abschiebungen genauso um räumliche Bewegungen von Personen handelt wie zum Beispiel bei Tourismus oder bei der beruflichen Mobilität von Hochqualifizierten, sind die qualitativen Unterschiede doch erheblich. Diese Arten von Mobilität lassen sich nicht ohne Weiteres zusammen analysieren und erforschen, da sie meiner Ansicht nach viel mehr Unterschiede aufweisen als durch das Dach der mobility studies suggerierte Gemeinsamkeiten. Friedrichs geht mit ihrer Kritik in eine ähnliche Richtung, als sie dem Zugang der mobility studies in Bezug auf Migration das Problem attestiert, dass hierbei die jeweils auf die menschliche Mobilität wirkenden Machtverhältnisse vernachlässigt werden (vgl. Friedrichs 2018: 174). Zugleich trifft die Kritik an der Machtvergessenheit der mobility studies jedoch nicht ausnahmslos $\mathrm{zu}$, denn erstens wird in dieser Forschungsrichtung auch viel Selbstkritik ${ }^{8}$ praktiziert und zweitens beschäftigen sich einige der neueren Arbeiten gerade mit der Verbindung von Mobilität und Macht. ${ }^{9}$ Was bisher hingegen noch nicht geleistet wurde, ist es, das Verhältnis von Mobilität und Diskriminierung systematisch zu theoretisieren.

Der zweite - und gravierendere - Kritikpunkt bezieht sich auf die vorherrschende Trennung zwischen räumlicher und sozialer Mobilität, die bei der Erforschung von Migrationsprozessen und -folgen im Weg steht und durch die vorhandenen Ansätze der mobility studies nicht aufgehoben werden kann. So kritisiert Mimi Sheller (2014: 46) in ihrem Übersichtsartikel zu soziologischer Mobilitätsforschung, dass der soziologische Mainstream dem Raum und dem Räumlichen nicht genügend Aufmerksamkeit widmet und unter Mobilität im Allgemeinen eine soziale Mobilität im Sinne eines Auf- und Abstiegs versteht: »This positional understanding of mobility still predominates in sociology, and studies of geographical mobility are limited to specific sub-fields such as migration studies or labor studies

Potenzielle Mobilität wird auch als Motilität (motility) bezeichnet, siehe Kaufmann/Bergmann/Joye (2004) sowie Kaufmann (2002, 2014). Aber auch John Urry (2007: 185ff.) berücksichtigt den Zusammenhang zwischen Mobilitäten und bestimmten sozialen Ungleichheiten.

$8 \quad$ Z.B. am Eurozentrismus der Mobilitätsforschung und der Vernachlässigung der Mobilität im Clobalen Süden und der vielfältigen Unterdrückungsverhältnisse, die Mobilitäten mitbeeinflussen (vgl. dazu Adey 2017: 45ff.) sowie zu den kolonialen und rassistischen Aspekten der Idealisierung von Mobilität (vgl. Cresswell 2006: 53f.). 
[...].« (Ebd.) Diese Kritik trifft einen wichtigen Punkt: Das traditionelle soziologische Verständnis von Mobilität greift zu kurz. Ansätze und Modelle, die zwischen räumlicher und sozialer Mobilität trennen und letztere lediglich als Auf- und Abstiegsprozesse in einer bestehenden hierarchischen Ordnung begreifen, sind weit verbreitet und gehören zum klassischen soziologischen Wissenskanon. ${ }^{10}$ Diese Definition von sozialer Mobilität bringt aus meiner Sicht mehrere Probleme mit sich.

Erstens verfestigt die in Auf- und Abstiegskategorien erfasste soziale Mobilität das nationalistische »Container-Denken «, ${ }^{11}$ da Auf- und Abstiegsprozesse einen nationalen Referenzrahmen benötigen, um Vergleiche durchzuführen. Zweitens setzt dieser Referenzrahmen Kategorisierungen und Messungen voraus, ${ }^{12}$ die sich auf viele in Deutschland lebende Personen nicht anwenden lassen, etwa diejenigen, die teilweise in einer anderen Statushierarchie und Ungleichheitsstruktur als der deutschen/westlichen sozialisiert wurden (z.B. ist der Status- und Einkommensunterschied zwischen Akademiker*innen und Nicht-Akademiker*innen in einigen Gesellschaften von geringerer Relevanz). ${ }^{13}$ Und drittens vermag das lineare Verständnis sozialer Mobilität auch soziale Stratifizierungen und Ausschlüsse nicht zu erfassen, die nicht unmittelbar mit Migrationsprozessen zu tun haben, aber dennoch Teil vieler Lebenserfahrungen in (spät-)modernen Gesellschaften sind. Dazu zählen sowohl Erfahrungen mit Prekarität und Deklassierung als auch Phänomene des bewussten Verzichts, die nur in unzureichender Weise als >freiwilliger Abstieg beschrieben werden können, da sie für ihre Subjekte oft überhaupt keinen Abstieg darstellen. Auch für die Ungleichheitsforschung sind es nicht gerade feine Unterschiede, ob jemand freiwillig halbtags arbeitet oder keinen angemessenen Arbeitsplatz findet, aus freien Stücken Diät macht oder an Mangelernährung leidet, aus ökologischen Gründen aufs Autofahren verzichtet oder sich schlicht keinen Führerschein leisten kann.

Die in den mobility studies favorisierte Hinwendung zum Räumlichen kann meines Erachtens jedoch keine Lösung für die Migrations- oder allgemein Mobilitätsforschung sein. Im Falle der transnationalen Migration werden hier die Ziele und

Sheller zufolge geht dieses Denken auf die Arbeit des Soziologen Pitigrim Sorokin zurück, der insbesondere mit seinem Buch Social Mobility (1927) in der Mitte des 20. Jahrhunderts einen großen Einfluss auf die US-amerikanische Soziologie hatte. Ein Beispiel der Systematisierung des Mobilitätsbegriffs, bei dem Migration unter das Räumliche subsumiert wird und unter sozialer Mobilität Auf- und Abstiegsprozesse verstanden werden, findet sich bei Tully/Baier (2006: 30ff.) Zur gesellschaftstheoretischen Bedeutung des Mobilitätsbegriffs und dem ungeklärten Verhältnis zwischen der physikalischen und der sozialen Mobilität vgl. Bonß/Kesselring 1999. Auch der Begründer des mobility turns John Urry greift in seinem Werk Mobilities (2007: 8) zu dieser Typologie. In der Regel wird mit Variationen der sogenannten meritokratischen Triade (Bildung, Beruf und Einkommen) gearbeitet. Dieses Problem stellt sich auch partiell für Akademiker*innen aus der ehemaligen DDR. 
die Mittel durcheinandergebracht, denn auch wenn die räumliche Dimension etwa in der Forschung zu Fluchtrouten, Grenzregimen oder transnationalen Räumen nicht wegzudenken ist, birgt die einseitige Fokussierung auf das Räumliche die Gefahr, durch die Verräumlichung des Sozialen ${ }^{14}$ seiner Ethnisierung Vorschub zu leisten. Die Ziele, aber auch die Effekte transnationaler Mobilität haben in erster Linie einen sozialen Charakter: Die Protagonist*innen suchen nach einem besseren Leben, stoßen auf soziale und politische Barrieren und verändern die Gesellschaftsstruktur. Die Faktoren, die Migration von anderen Mobilitäten unterscheiden, sind ebenfalls sozialer Natur. Die Unterscheidung zwischen der räumlichen und der sozialen Mobilität muss in der Migrationsforschung scheitern, denn Migration ist beides: Sie ist soziale Mobilität mit räumlichen Mitteln. Auf diese Einsicht folgt allerdings auch die Notwendigkeit, unser Verständnis der sozialen Mobilität zu überdenken.

\title{
Von der Ungleichheit der Lebensverhältnisse zur Ungleichheit der Mobilitäten - und umgekehrt
}

\begin{abstract}
»What appears as globalization for some means localization for others; signalling a new freedom for some, upon many others it descends as an uninvited and cruel fate. Mobility climbs to the rank of the uppermost among the coveted values - and the freedom to move, perpetually a scarce and unequally distributed commodity, fast becomes the main stratifying factor of our late-modern or postmodern times.«(Bauman 1998: 1f.)
\end{abstract}

Die Definition der sozialen Mobilität, die ich vorschlagen möchte, hat den Vorteil, dass sie transnationale Migration berücksichtigt, ohne auf sie beschränkt zu sein, und den Unterschieden zwischen verschiedenen Formen von Mobilität genügend Raum lässt. Zudem macht sie die Bedeutung der Potenzialität und der Ungleichheit für Untersuchungen zugänglich. Als soziale Mobilität verstehe ich einerseits das Vermögen eines Individuums oder einer Gruppe von Individuen, seine bzw. ihre Lebensumstände in einer Gesellschaft zu verändern und andererseits den Prozess dieser Veränderung. Durch den doppelten Charakter (Vermögen/Prozess) der sozialen Mobilität, wie ich sie verstehe, kann auch die klassische strukturalistische Definition darin enthalten bleiben, weil sie in der Prozesshaftigkeit der sozialen Mobilität aufgeht. Der Vermögenscharakter der sozialen Mobilität macht die Arbeit damit anschlussfähig gegenüber anderen Theorien sozialer Ungleichheiten, da Vermögen gleichzeitig als Eigenschaft und als Kapital verstanden werden kann und

14 Eine kurze Übersicht der Diskussion um die Verräumlichung des Sozialen findet sich bei Belina/Wehrheim (2011: 208f.). 
sollte. ${ }^{15}$ Eine so verstandene soziale Mobilität lässt sich, genauso wie etwa Bourdieus Kapitalsorten, nur als Kontinuum begreifen, denn niemand ist vollständig mobil oder absolut immobil.

Die Beschäftigung mit den Ungleichheiten zwischen verschiedenen Positionen in diesem Kontinuum und den vielfältigen, oft widersprüchlichen Verhältnissen zwischen den räumlichen und den sozialen Ausprägungen dieser Positionen kann helfen, einen genaueren Blick auf die Phänomene der erzwungenen oder sogar erfundenen räumlichen Mobilität zu werfen und diese als soziale Immobilisierung zu begreifen. Denn, wie Huub van Baar (2015) am Beispiel der RomaMinderheiten in Europa eindrucksvoll gezeigt hat, muss die geographische Mobilität gar nicht erst faktisch vorhanden sein, um zur Grundlage für rassistische Diskriminierung gemacht zu werden: Die traditionsreiche Unterstellung der >Wurzellosigkeit « der Roma führt über die diskursive Darstellung als >übermäßige`, >irreguläre und sillegale`Mobilität zu zahlreichen strukturellen, rechtlichen und symbolischen Ausschlüssen. Je nach Gruppenzugehörigkeit wird auch im Rahmen der EUFreizügigkeit eine, faktische oder imaginierte, Mobilität zum Problem gemacht. Gerade am Beispiel der Roma ließe sich einerseits das komplexe Verhältnis zwischen der sozialen und der räumlichen Mobilität, andererseits aber auch das Verhältnis zwischen Mobilität und Rassismus untersuchen. Wenn sich soziale Mobilität und darunter auch (die Fähigkeit zu) Migration als Kontinuum von Positionen im Gefüge der sozialen Ungleichheit verstehen lässt, muss auch das Verhältnis zwischen Rassismus und anderen Diskriminierungs- und Herrschaftsstrukturen zu diesem Kontinuum berücksichtigt werden.

Auf diesen Vorüberlegungen aufbauend, arbeite ich im Folgenden mit zwei Thesen. Erstens: Es ist anzunehmen, dass sich transnationale Migration durch ihre (partielle) Unerwünschtheit von anderen Formen der Mobilität unterscheidet: Je unerwünschter bestimmte Formen von Migration oder vor allem bestimmte Personen in der Einwanderungsgesellschaft sind, umso eher werden sie als Migrant*innen und ihre Bewegung als Migration (und nicht als Mobilität) wahrgenommen. Gerade im Ergebnis dieser Unerwünschtheit und Geringschätzung werden die sozialen Bedürfnisse der Protagonist*innen nicht ernst genommen oder auf die räumlichen Mittel ihrer Umsetzung reduziert. Die zweite These besagt, dass sich traditionelle Diskriminierungen nach $>$ Rasse $</$ Ethnie, Klassenposition und anderen Merkmalen auf das subjektive Vermögen der sozialen Mobilität auswirken

15 Dieser Gedanke ist im Ansatz bereits im Konzept der Motilität von Vincent Kaufmann enthalten, der damit auf das Potenzial und die Möglichkeit, sich zu bewegen, als relevante Ungleichheitskategorie und gesellschaftlich relevantes Kapital aufmerksam macht. Zugleich bleibt der Ansatz in meinen Augen auf halben Weg stehen, da es die Fixierung auf das Räumliche nicht überwindet (mit Motilität wird die Fähigkeit, sich räumlich zu bewegen, verstanden, vgl. Kaufmann 2014: 7f.), obwohl Kaufmann diese Fixierung explizit kritisiert (ebd.: 4f.). 
und durch diesen Einfluss weiterhin mit dem Gefüge sozialer Ungleichheiten verbunden bleiben. Die Struktur der sozialen Ungleichheit moderner Einwanderungsgesellschaften wie Deutschland lässt sich dementsprechend als eine Struktur ungleich verteilter sozialer Mobilitätspositionen begreifen, wobei die Ebene der sozialen Mobilität eine vermittelnde Position zwischen den Herrschafts- und Diskriminierungsstrukturen und den konkreten Lebensbedingungen von Personen einnimmt. Umgekehrt wirken sich jedoch auch die subjektiven Lebensbedingungen auf die Möglichkeiten und Prozesse der sozialen Mobilität aus und verändern über diese vermittelt auch die Diskriminierungsstrukturen.

Abbildung 1: Diskriminierungs- und Herrschaftsstrukturen, soziale Mobilität und Lebensverhältnisse im Zusammenhang

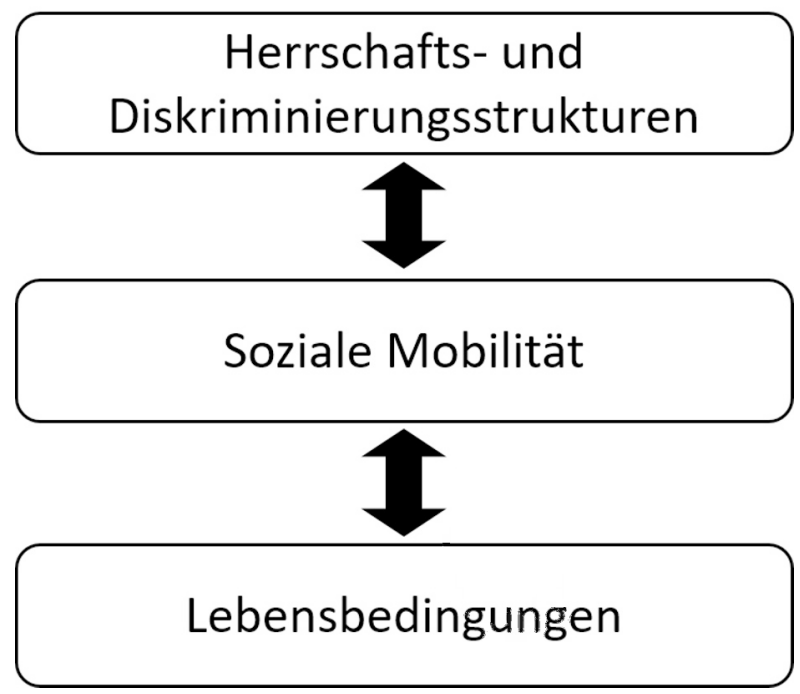

Quelle: Eigene Abbildung.

Wenn sich, wie in meinen Vorüberlegungen dargestellt, moderne soziale Ungleichheiten als ein Kontinuum der sozialen Mobilität begreifen lassen, in dem Personen aufgrund ihres subjektiven Vermögens zur Mobilität unterschiedlich positioniert sein können, muss es möglich sein, dieses subjektive Vermögen anhand quantitativ messbarer oder qualitativ beschreibbarer Kriterien zu bestimmen. Hier schlage ich eine qualitative Beschreibung anhand von drei aufeinander aufbauenden Dimensionen vor. Erstens, die Fähigkeit, etwas zu bewegen, das heißt, auf sein eigenes Leben und das Leben der Anderen Einfluss zu nehmen, politische und soziale Verhältnisse verändern zu können. Zweitens, die Fähigkeit, sich zu bewegen, 
die in etwa dem entspricht, was Anja Weiß (2017) unter der sozial-räumlichen Autonomie ${ }^{16}$ versteht: also die Fähigkeit, auf Wunsch den Kontext $\mathrm{zu}$ wechseln und sich in ein anderes soziales Setting zu begeben. Und drittens, die Fähigkeit, nicht bewegt $\mathrm{zu}$ werden. Hier handelt es sich, mit Anne Friedrichs Worten, um »Grenzverwischungen zwischen Mensch und >Ding « (2018: 185), die in bestimmten extremen Situationen ein selbstbestimmtes Handeln unmöglich machen. Grenzverschiebungen zwischen Mensch und Ding müssen sich in meinem Verständnis jedoch nicht auf die extremen Phänomene wie Sklaverei, Folter oder Deportation beschränken: Im jeweils unterschiedlichen Maße beeinflusst jede Situation, in der Menschen nicht wie ein Selbstzweck (im kantischen Sinne) behandelt werden, ihre soziale Mobilität. Die Fähigkeit oder das Vermögen, nicht wie ein Objekt bewegt und geschoben zu werden, ist die basale Dimension und ihr (zumindest minimales) Vorhandensein die Voraussetzung für jede andere soziale Mobilität. Die Zusammensetzung der sozialen Mobilität wird in der folgenden Abbildung deutlich.

Abbildung 2: Drei Dimensionen der sozialen Mobilität

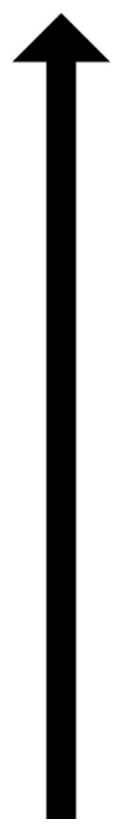

\section{etwas bewegen}

\section{sich bewegen}

\section{nicht bewegt werden}

Quelle: Eigene Abbildung.

16 Weiß verwendet anhand ähnlicher wie der von mir dargestellten Kritikpunkte den Begriff der sozial-räumlichen Autonomie, den ich hier nicht übernehme, um die beschriebenen Vorteile des Mobilitätszugangs für meine Arbeit produktiv nutzen zu können. 
Mit dem Verständnis der Migration als einer Form sozialer Mobilität verschiebt sich auch das Verständnis ihrer Ablehnung oder Kontrolle, denn entsprechend sind auch Praktiken der Migrationskontrolle auf die Kontrolle des Sozialen ausgerichtet: Nicht die räumliche Mobilität wird hier in erster Linie kontrolliert, reglementiert, sgemanagt oder verhindert, sondern die soziale. Dies geschieht auch und gerade dadurch, dass unerwünschte (oder nur ungern tolerierte) Mobilität als Migration bezeichnet ${ }^{17}$ und auf ihre räumliche Dimension reduziert wird. Es hat noch nie eine unmittelbare Rolle gespielt, wie viele Kilometer genau eine geflüchtete Person zurückgelegt hat; entscheidend war und ist, ob diese Person zu einer hier erwünschten Gruppe gehört, legitime >Beweggründe`vorzeigen kann und wertvolle Ressourcen zur Verfügung hat. Entscheidend ist, wer sich wie bewegen kann. Dies soll im folgenden Abschnitt verdeutlicht werden.

\section{Soziale Immobilisierung (mit räumlichen Mitteln) von Geflüchteten ${ }^{18}$}

Im Folgenden werde ich meinen theoretischen Ansatz auf Erkenntnisse aus zwei qualitativen Interviews anwenden, die ich im Februar und März 2020 durchgeführt habe. Das erste Interview mit einer ehemaligen Asylsuchenden war überwiegend biographisch. Das zweite Interview war ein Expert"inneninterview mit einer Mitarbeiterin einer Unterstützungsorganisation für Geflüchtete in Bayern und hatte seinen inhaltlichen Schwerpunkt in der Funktionsweise der sogenannten Ankerzentren. Für beide Interviews benutzte ich einen flexiblen Leitfaden, von dem ich immer wieder abgewichen bin, um freie Erzählpassagen zuzulassen und neben Fakten und Erlebnissen auch die gesellschaftspolitischen Einstellungen meiner Interviewpartnerinnen zu erfassen. Beide Interviews wurden aufgezeichnet und anschließend transkribiert. Nach der Transkription und Anonymisierung der Interviews wurden die Aufnahmen zum Schutz der Interviewpartnerinnen gelöscht.

In der Auswertung verwende ich die oben beschriebene Heuristik der sozialen Mobilität als Interpretationsrahmen: Aus den Erzählungen und Ansichten meiner Interviewpartnerinnen versuche ich, die Wechselwirkungen von Diskriminierungs- und Herrschaftsverhältnissen, der sozialen Mobilität von Asylsuchenden (also ihr Vermögen, etwas zu bewegen, sich selbst zu bewegen und

17 Dazu Rübner Hansen/Zechner: »Whilst >mobility< is discursively associated with ascent, improvement, progress and development, as operating on a high level of a social, cultural and material capital today, >migration< is associated with downward social mobility, coercion and victimhood.«(2017:115)

18 Der folgende Abschnitt basiert auf der vorläufigen Auswertung der ersten zwei Interviews im Rahmen meines Dissertationsvorhabens. Die Ergebnisse sind entsprechend unvollständig, da eine ausführliche Auswertung sowie weitere Erhebungen noch ausstehen. 
letztendlich nicht bewegt zu werden) und ihren Lebensumständen herauszuarbeiten.

\section{"Ich will dich nicht im Gefängnis besuchen«}

Shirin Foumani wuchs im Iran als das jüngste von fünf Kindern einer gebildeten Familie auf. Ihre Erziehung im Elternhaus erlebte sie als offen und unterstützend. Im Widerspruch dazu stand jedoch das öffentliche Leben, das nach der Islamischen Revolution insbesondere für Frauen voller Beschränkungen war. Bereits in der Grundschule hatte sie "zwei Leben«, ein privates, wo »alles erlaubt« war, und ein öffentliches, in dem "alles verboten [war] außer atmen" (Interview B1). Die Ungleichbehandlung und Verfolgung, die sie in ihrer Kindheit und Jugend erfuhr, bestimmte ihr ganzes Leben, und auch heute, mit Mitte vierzig, kann sie ihre Angst vor Islamisten nicht verbergen und fürchtet sich vor dem iranischen Geheimdienst in Deutschland. Über ihre Erfahrungen mit iranischen Gefängnissen redet sie nur in der Pause, als ich das Gespräch nicht aufzeichne. Auch 15 Jahre nach ihrer Flucht hat sie immer noch Angst um ihr Leben.

Mit Anfang 20 kommt sie zum ersten Mal nach Deutschland, um in einer westdeutschen Großstadt zu studieren. Drei Monate später möchte sie kurz ihre Familie besuchen und bekommt im Iran ein Ausreiseverbot für zehn Jahre - sie kann nicht einmal ihre in Deutschland zurückgebliebenen Sachen holen. Die gesellschaftspolitische Lage bedeutet für sie in den Jahren danach nicht nur Unterdrückung, sondern zunehmende Lebensgefahr. Ihre Bekannten, die sich dem Regime auch nur in einem bescheidenen Maß widersetzten, wurden zu Gefängnisstrafen verurteilt, vergewaltigt und/oder ermordet. Diejenigen, die die Möglichkeit dazu haben, fliehen ins Ausland. Auch Frau Foumanis Mutter rät ihr dazu, das Land bei erster Gelegenheit zu verlassen: Sie möchte sie nicht im Gefängnis besuchen müssen.

Nach Ablauf des Ausreiseverbots, mit Anfang 30, gelingt ihr die Flucht: Sie bekommt eine Zulassung an einer ostdeutschen Universität in einem angewandtnaturwissenschaftlichen Fach. Doch in Deutschland, das sie zunächst als Land der Freiheit und Menschenrechte wahrnimmt, bekommt sie zwei weitere Probleme: Erstens muss sie sich dieses Mal selbst versorgen und findet über ein Jahrzehnt lang keine gut bezahlten Arbeitsgelegenheiten, worunter ihr Studium leidet und woran später auch ihre Promotion scheitert - und zweitens wird ihr wiederholt zu verstehen gegeben, dass sie hier als `Ausländerin nicht willkommen ist.

Nach Abschluss ihres Studiums und mangels anderer Optionen stellt Frau Foumani einen Asylantrag. Etwa drei Jahre später wird dieser positiv entschieden, doch in dieser Zeit verschlechtert sich ihr psychischer Zustand extrem wegen der täglichen Angst, ins Land ihrer Verfolger zurückkehren zu müssen, und der hier erlittenen Erniedrigungen. Nach immer wechselnden Jobs in verschiedenen Berei- 
chen findet sie endlich eine Anstellung als Lehrerin an einer Berufsschule in einer ostdeutschen Kleinstadt.

Ich traf Frau Foumani in ihrer alten Wohnung in der ostdeutschen Großstadt, in der sie mittlerweile nur am Wochenende und in den Schulferien wohnt, da sie endlich eine kleine Wohnung an ihrem Arbeitsort gefunden hat, in der sie an Arbeitstagen schlafen kann. Nun hat sie weniger Schmerzen und kann mehr schlafen. Das Thema Freiheit dominiert alle ihre Erzählungen - die Freiheit, sich zu kleiden, wie sie will, Menschen treffen, die sie treffen will, arbeiten und wohnen, wo sie will, die Freiheit, das zu essen, zu kaufen, zu lesen, zu sagen, zu denken und zu glauben, was sie möchte, vor allem als Frau.

Anhand Frau Foumanis Erzählungen über ihre Biographie lassen sich im Sinne der sozialen Mobilität als Prozess zwei zentrale Ereignisse bzw. Prozesse unterscheiden: der Umzug nach Deutschland und die Suche nach einem passenden Arbeitsplatz. Die zentrale Stellung dieser Themen bedingt sich durch Frau Foumanis Prioritäten: Neben persönlicher Freiheit ist auch die finanzielle Unabhängigkeit ein immer wiederkehrendes Thema in ihren Darstellungen. So war der Asylantrag ihre letzte Option, zu der sie gegriffen hat, als alle anderen Möglichkeiten, in Deutschland zu bleiben, erschöpft waren. Sie weigerte sich, Leistungen nach dem Asylbewerberleistungsgesetz anzunehmen, auf die sie während der Bearbeitungszeit einen Anspruch hatte, und betont, dass sie keinen einzigen Euro von diesem Staat bekommen hat.

Zur sozialen Mobilität als Vermögen lassen sich je nach Zeitpunkt große Unterschiede anhand der einzelnen Dimensionen herausarbeiten, so dass es oft sinnvoll erscheint, zwischen dem Vermögen der sozialen Mobilität vor und nach der Flucht bzw. vor und nach der Einstellung als Lehrerin zu unterscheiden.

\section{a) Nicht bewegt werden}

Dieses Vermögen ist im Fall von Frau Foumani vor der Flucht ernsthaft eingeschränkt und gefährdet. Die wichtigsten Faktoren, die dies verursachen, sind Sexismus und politisch-religiöse Verfolgung. Bereits das Lesen verbotener Bücher kann zu einer Haftstrafe führen, und in Gefängnissen wird gefoltert. Witze über den Propheten können mit einem Todesurteil enden. Die basale Fähigkeit, nicht bewegt zu werden, wird auch durch das Ausreiseverbot eingeschränkt, das als soziopolitisches Festhalten verstanden werden kann. Das Erlebte nimmt sie als Trauma mit nach Deutschland, was auch ihre späteren Lebenschancen beeinflusst. Ihr Vermögen, nicht bewegt zu werden, bleibt zudem auch in Deutschland eingeschränkt durch ihre Rassismuserfahrungen und ihren zeitweiligen Status als >Asylbewerberin`, steigt jedoch im Laufe der Jahre langsam. 


\section{b) Sich bewegen}

Die Fähigkeit, sich zu bewegen, ist in Frau Foumanis Jugend in einem erheblichen Maße vorhanden, und zwar dank ihrem Klassenvorteil. Ihr Elternhaus vermittelt ihr eine weltoffene politische Einstellung und >bildungsnahe` Freizeitaktivitäten (das verbotene Schachspielen, Tanzunterricht) und der Übergang zwischen verschiedenen Bildungseinrichtungen scheint selbstverständlich: „Und ich bin in diese Zeit, ich sollte das noch in die Schule gehen und Gymnasium, und dann weiter studieren.« (Interview B1) Auf die Frage, wie sie nach Deutschland gekommen ist, heißt es, sie habe sich an der Uni in [Stadt A] beworben, dann die Zulassung bekommen und sei hierhergekommen. Im Iran hatte sie eine eigene Wohnung, ein Auto und einen gut bezahlten Job, die sie alle zurückgelassen hat, um frei leben zu können. Jedoch ermöglichten ihr genau diese Dinge andere Freiheiten, wie eine problemlose Zulassung an einer deutschen Universität, ein Studienvisum, für das man (gerade als Nicht-EU-Bürgerin) erhebliche finanzielle Mittel vorweisen muss, sowie ein Mindestmaß an Vertrauen in die eigenen Fähigkeiten. Zugleich ist Frau Foumanis Fähigkeit, sich zu bewegen, durch die Begrenzung der Fähigkeit, nicht bewegt zu werden, in einem extremen Maße bedroht: Alle Vorteile, die sie als Angehörige der gebildeten Mittelklassen genießt, können durch eine Inhaftierung oder Ermordung vernichtet werden.

Klassismus spielt jedoch nach der Flucht eine völlig andere Rolle und steht hier in einer Wechselwirkung mit Rassismus. Frau Foumani wird nicht mehr von ihren Eltern finanziert und muss sich während ihres Studiums selbst versorgen. Zugleich macht sie die Erfahrung, dass >Ausländer*innen hier nur in unqualifizierten, schlecht bezahlten Tätigkeiten willkommen sind. Auf ihre Bewerbungen bekommt sie keinerlei Rückmeldungen, während Bewerber*innen mit einem >westlich klingenden Namen und ähnlichen Qualifikationen zu Bewerbungsgesprächen eingeladen werden. Die Auflistung ihrer Arbeitserfahrungen ist von einer enormen Länge. Bereits in ihrem Studium hat sie mit starken Einschränkungen zu kämpfen, da sie sich nach einer Fabrikschicht nicht mehr auf die Vorlesungen konzentrieren kann und Prüfungen nachschreiben muss. Ihre Kommiliton*innen wollen nichts mit ihr zu tun haben, bis auf drei Personen, die ebenfalls migriert sind. Von Dozierenden bekommt sie mitgeteilt, dass in Deutschland kein Platz für sie sei. Nach dem Studium versucht sie, zu promovieren. Die rassistische und klassistische Ausgrenzung, die Frau Foumani erlebt, trägt jedoch in einem entscheidenden Maße dazu bei, dass sie trotz großer Bemühungen dabei scheitert. Ihr eigener Chef und Doktorvater sorgt dafür, dass sie keine gut entlohnte Projektstelle bekommt, also muss sie ihre Promotion durch Sieben-Stunden-Schichten in einem McDonalds-Restaurant finanzieren, nach denen sie jedoch zu erschöpft ist, um an ihrer Dissertation $\mathrm{zu}$ arbeiten. Im Labor, in dem sie promoviert, wird sie immer 
als erste beschuldigt, wenn etwas kaputt geht oder unordentlich ist, selbst wenn sie gar nicht vor Ort war.

Als Frau Foumani nach Jahren vergeblicher Arbeitssuche endlich eine Stelle als Lehrerin in ihrem Fach findet, steigt ihr ökonomisches Kapital - und damit auch ihr Vermögen der sozialen Mobilität - wieder. Damit tritt jedoch ein anderes Problem in den Vordergrund: die Wohnungssuche. Die Schule, in der Frau Foumani unterrichtet, befindet sich in einer ostdeutschen Kleinstadt, in der sie nicht leben möchte und auch nicht sicher leben kann. Um dennoch dort arbeiten zu können, braucht Frau Foumani ein Zimmer oder eine kleine Wohnung, in der sie unter der Woche übernachten kann. Trotz des hohen Leerstands wird sie von Vermietern jedoch aufgrund ihres Namens und ihrer Aussprache diskriminiert: Die Wohnungen, die gerade eben noch frei waren, als ihre weißen deutschen Kolleginnen angerufen haben, sind plötzlich vergeben, als sie selbst anruft. In der Folge muss sie monatelang neben ihrem Vollzeitjob fünf bis sechs Stunden täglich Zug fahren, was bei ihr gesundheitliche Beschwerden verursacht. Die Fähigkeit, sich zu bewegen, wird gerade durch diese Zwangsbewegung (unfreiwilliges Pendeln) eingeschränkt.

\section{c) Etwas bewegen}

Dennoch nimmt ihre Fähigkeit, sich zu bewegen, im Laufe der Jahre tendenziell zu, und Frau Foumani entwickelt ein (wenn auch sehr begrenztes) Vermögen, etwas zu bewegen. So leistet sie einige Jahre lang Unterstützung für mehrere nach Deutschland geflohene Frauen. In der Schule, in der sie aktuell arbeitet, hatte sie anfangs große Probleme mit ihren Schüler*innen, die »keine Ausländerin als Lehrerin« (Interview B1) wollten. Mittlerweile kann sie ihre Klassen jedoch nach eigener Darstellung "gut beherrschen« (ebd.) und setzt sich für höhere Unterrichtsstandards ein. Am Beispiel der Unterstützung für ihre (mittlerweile verarmte) Mutter lässt sich jedoch auch beobachten, dass Frau Foumani ihre Fähigkeit, etwas zu bewegen (Versorgung von Angehörigen) durch Anteile ihrer Fähigkeit, sich zu bewegen, eintauschen muss: Sie kann ihren Traum von Urlaubsreisen in Europa nicht verwirklichen, da alles Geld, dass sie nicht unmittelbar zum Leben braucht, zurück in den Iran fließt.

Der Zusammenhang zwischen der räumlichen und der sozialen Mobilität ließ sich in meiner Untersuchung bisher nicht ausführlich analysieren, bleibt jedoch als eine brisante Frage stets im Hintergrund. In der Tendenz lässt sich beobachten, dass es bei Personen, die über ein hohes Maß an sozialer Mobilität verfügen, diese positiv mit der räumlichen Mobilität zusammenhängt (was jedoch nicht heißt, dass diese Personen in jedem Fall davon Gebrauch machen). In Positionen starker Benachteiligung ist der Zusammenhang oft widersprüchlich: Je nach Situation kann räumliche Mobilität nahezu nahtlos in die soziale übergehen (Ausreiseerlaubnis), während in anderen (Frau Foumanis gesundheitsgefährdendes Pendeln) die Tatsa- 
che, dass Personen sich räumlich bewegen (müssen), von einer Einschränkung der sozialen Mobilität zeugt oder aus dieser hervorgeht. Einen partiellen Erklärungsansatz bietet die in meiner oben beschriebenen Heuristik entwickelte Dimension des Nicht-Bewegt-Werdens: Bei Personen, deren Fähigkeit, nicht bewegt zu werden, eingeschränkt oder in Frage gestellt wird, korreliert die soziale Mobilität oft negativ mit der räumlichen. Am deutlichsten wird das am Beispiel der Abschiebungen oder Inhaftierungen: Wer wie ein Gegenstand räumlich bewegt und/oder festgehalten wird, kann sich weder räumlich noch sozial selbst bewegen.

\section{Von Polizeirazzien, brutal aufgeladenen Wasserkochern und dem Zwang zur Pflege-Ausbildung}

Die Praxis der Inhaftierung oder De-facto-Inhaftierung von Migrant "innen hat eine lange Geschichte. Tim Cresswells Kapitel zur sozialer Konstruktion migrantischer Mobilitäten beginnt mit dem Beispiel von Angel Island, wo sich in den 19101940er Jahren eine Haftanstalt für Eingewanderte aus China befand (vgl. Cresswell 2006: 175f.). Eine räumliche Infrastruktur kann dem zufolge zur Produktion unerwünschter, sillegitimer Mobilitäten beitragen. Im Expert"inneninterview mit Frau Werner, Mitarbeiterin einer Unterstützungsorganisation für Geflüchtete, lag der inhaltliche Schwerpunkt auf ihrem Spezialgebiet, den bayerischen Ankerzentren, die seit 2018 das weiterentwickelte Konzept der Erstaufnahmeeinrichtung für Asylsuchende und abgelehnte Asylsuchende darstellen. Die folgenden Ausführungen und Analysen haben daher zwar eine eingeschränkte Gültigkeit, da sie Frau Werners (berufliche wie aktivistische) Perspektive darstellen. Dennoch können aus ihrem Arbeitsalltag und ihren Einschätzungen erste Erkenntnisse über die Auswirkungen der Institution Ankerzentrum auf die soziale Mobilität von Geflüchteten abgeleitet werden.

Anhand der Darstellungen meiner Interviewpartnerin lassen sich vier zentrale Faktoren unterscheiden, die aus ihrer Erfahrung die Lebensmöglichkeiten von Asylsuchenden in Ankerzentren bestimmen:

- Isolation: Ankerzentren sind umzäunte Gebäude, zu denen es in der Regel keinen öffentlichen Zugang gibt. Besuche seitens der Presse oder der Unterstützungsorganisationen erfolgen nur mit einem Termin, und auch private Besuchsmöglichkeiten sind beschränkt. Viele der Ankerzentren befinden sich in ländlichen Gegenden oder am Stadtrand, so dass es für ihre Bewohner"innen oft schwierig ist, Beratungsstellen, Ärzt"innen oder ihre privaten Kontaktpersonen zu erreichen. Zudem unterliegen sie der Residenzpflicht und dürfen ihren Landkreis ohne Genehmigung nicht verlassen. 
- Kontrolle: Ankerzentren werden durch Sicherheitspersonal überwacht, das auch die Zimmer der Bewohner*innen kontrolliert. Es gibt Eingangs- und Ausgangskontrollen, bei denen man häufig auch seinen*ihren Ausweis abgeben muss. Die Taschen werden oft durchsucht und verbotene Lebensmittel oder Gegenstände konfisziert. Die Bewohner*innen haben keine Rückzugsmöglichkeiten und eine extrem eingeschränkte Privatsphäre: Zwei bis acht Personen leben in einem Zimmer, an manchen Standorten gibt es keine abschließbaren Duschkabinen. Wenn man sieben Tage lang nicht in seinem Zimmer ist, wird der ganze persönliche Besitz entsorgt. ${ }^{19}$ Hinzu kommen "präventive« Polizeieinsätze, bei denen die Einrichtungen von »teilweise bis $\mathrm{zu}$ [...] 270 Polizist/innen plus Hunden« (Interview E1) durchsucht werden.

- Willkür und Intransparenz: Es gibt einerseits erhebliche Unterschiede zwischen den einzelnen Ankerzentren, weil die Zustände (Freizeitgestaltung, Wohnraumqualität, Kinderbetreuung, Schulbesuch, Sprach- und Beratungsangebote durch Ehrenamtliche) in einem hohen Maße vom Engagement des oder der Unterkunftsleiter*in und der lokalen Politiker*innen abhängen, und andererseits besteht eine hohe Verantwortungsdiffusion durch informelle Kommunikationswege. Durch die informelle Zusammenarbeit von Behörden, Ärzt*innen und Sozialarbeiter*innen, die oft ihre Arbeitsstellen im selben Gebäude haben, ergeben sich unklare Zuständigkeiten und Beschlüsse (etwa Ablehnungen von Überweisungen zu Fachärzt*innen oder Arbeitsgenehmigungen) ohne einen anfechtbaren schriftlichen Bescheid.

- Entrechtung: »Auch wenn ihnen das nahegelegt wird vom ersten Tag an, also du kriegst quasi, wenn du da rein kommst und gleichzeitig mit Asyl beantragen kriegst du 'ne Broschüre, welche Möglichkeiten du hast zur freiwilligen Ausreise«. (Ebd.) Die Beratungsangebote sind an manchen Standorten derart mangelhaft, dass Personen selbst bei der Anhörung über ihre Asylanträge nicht wissen, was mit ihnen geschieht. Vielen Bewohner*innen fehlt das Wissen über ihre Rechte oder die Möglichkeit, sie in Anspruch zu nehmen (häufig fehlt das Geld für die Fahrkarte in die größeren Städte, um Beratungsstellen aufzusuchen oder das Geld für eine*n Anwalt*Anwältin). ${ }^{20}$

Ankerzentren sind nach ihrer Wirkungsweise als komplexe Institutionen der sozialen Immobilisierung zu begreifen, und die Mittel dieser Immobilisierung sind in

19 In einem Fall verließ eine Frau mit ihren Kindern die Einrichtung über Weihnachten und verlor ihren gesamten Besitz, weil die Cenehmigung für ihre Reise nicht an die Unterkunftsleitung weitergegeben wurde.

20 So mussten nach Angaben von Frau Werner einige schwangere Frauen im Winter zu Fuß in die nächste Stadt laufen, um einen Gynäkologen aufzusuchen. 
erster Linie räumlich. Durch die räumliche und juristische Segregation der unerwünschten >Anderen v vom Rest der Bevölkerung wird ihr Anderssein erst erschaffen. Rassismus fungiert hier als diejenige Herrschafts- und Diskriminierungsform, die Ankerzentren verursacht und legitimiert, aber gleichzeitig in den Augen meiner Interviewpartnerin durch diese noch verstärkt wird:

»Das heißt, ich hab so 'nen Bild von, die Polizei ist ständig vor Ort, ja, die Leute, die sind da irgendwie abgeschottet, vielleicht eventuell auch eher am Stadtrand und dann eben auch mit diesem Stacheldrahtzaun, ja, das ist, die Leute verschwinden ja irgendwie als Persönlichkeiten, als Individuen in solchen, hinter diesen Bildern, ja? Also insofern wird da ja schon viel damit auch wiederum erzeugt. (Ebd.)

Die Einschränkungen, die Asylsuchende erfahren, sind demnach maßgeblich durch (strukturellen) Rassismus verursacht, wirken aber zugleich auf die Herrschaftsebene zurück (siehe Abbildung 1) und verstärken die rassistischen Bilder in der Bevölkerung. Die Konsequenzen für die Bewohner*innen lassen sich auch hier anhand der drei Dimensionen der sozialen Mobilität analysieren. In diesem Fall scheint es jedoch angebracht, mit der höchsten Ebene der sozialen Mobilität (etwas bewegen) anzufangen.

\section{a) Etwas bewegen}

Die Fähigkeit der Ankerzentrenbewohner*innen, etwas zu bewegen, ihre Lebensumstände zu beeinflussen, - oder viel eher das Ausmaß ihrer Begrenzung - wird durch das Beispiel des Wasserkochers deutlich zum Ausdruck gebracht. In den meisten Einrichtungen ist es nicht nur verboten, selbst zu kochen oder »verderbliche Lebensmittel« mitzubringen, sondern auch, Kochplatten und Wasserkocher $\mathrm{zu}$ besitzen. Gerade der Wasserkocher ist »wirklich seit Jahren irgendwie so ein, ja, so ein zentraler Gegenstand, um den sich extrem viel dreht« (Interview E1). Das generelle Verbot wurde gelockert, nachdem kritisiert wurde, dass Mütter von Säuglingen ihre Flaschen nicht auskochen und keine Säuglingsnahrung zubereitet konnten. Nachdem der Besitz von Wasserkochern für diese Gruppe von Asylsuchenden erlaubt wurde, kamen »in Gesprächen mit der Regierung « ${ }^{21}$ Beschwerden über die fehlende Dankbarkeit hierfür zur Sprache. Der Besitz von Wasserkochern ist ein "großes Privileg innerhalb dieser [...] Einrichtungen«, »dieser Gegenstand ist irgendwie echt so was von aufgeladen, es ist irgendwie brutal« (ebd.). Eine basale und überlebensnotwendige Fähigkeit wie die, Wasser zu erhitzen, wird in der Institution Ankerzentrum zum Privileg und zum Politikum.

Ein Wasserkocher steht hier jedoch nicht nur für eine extrem eingeschränkte Fähigkeit, etwas zu bewegen, sondern wird zugleich zum Mittel des alltäglichen 
Widerstands. Es werden trotz Kontrollen verbotenes Essen und Gegenstände hineingeschmuggelt, und »das Hühnchen wird halt dann im Wasserkocher gekocht, das Hühnchen kann man aber auch irgendwie quasi garen über lange Zeit in 'nem Waschbecken mit heißem Wasser« (ebd.).

\section{b) Sich bewegen}

Die Fähigkeit, sich seinen Lebenskontext selbst auszusuchen und sowohl räumliche als auch institutionelle Wege zu gehen, wird durch die De-facto-Inhaftierung der Asylsuchenden stark eingeschränkt. Als ein herausstechendes Merkmal betont meine Interviewpartnerin die lange Verweildauer von Asylsuchenden in diesen Einrichtungen, die in Kombination mit der Isolation und der Entrechtung ihre Bleibeperspektiven oft vernichtet: Personen, die für 18 bis 24 Monate kaum Kontakte nach außen knüpfen konnten, bis vor Kurzem überhaupt nicht arbeiten durften außer für 80 Cent in der Stunde in der Einrichtung selbst, ${ }^{22}$ nur minimale Deutschkenntnisse erwerben konnten und danach einen Ablehnungsbescheid bekommen, finden erstens keine anderen Wege, ihren Aufenthalt in Deutschland zu sichern (Erwerbstätigkeit, Ausbildung, >Integrationsleistungen`) und zweitens nur schwer eine rechtliche Unterstützung, um eben diesen Ablehnungsbescheid anzufechten. Die Fähigkeit, sich zu bewegen, die durch Ankerzentren radikal beschränkt wird, heißt in diesem Fall: die Fähigkeit, zu bleiben.

Einen weiteren Aspekt stellen die Verhinderung von weiterführender Bildung sowie die Einschränkung der freien Berufswahl dar. In vielen Ankerzentren werden Kinder und Jugendliche im Gebäude unterrichtet und dürfen keine regulären Schulen besuchen. An Berufsschulen innerhalb der Einrichtungen kann man jedoch keinen Abschluss machen und der Unterrichtsstoff unterscheidet sich stark von dem der öffentlichen Schulen. ${ }^{23}$ Ein Bestandteil ihrer Arbeit, den meine Interviewpartnerin als besonders belastend empfindet, ist der Zwang, abgelehnte Asylsuchende gegen ihre Wünsche in eine Ausbildung, am besten »im Pflegebereich « (Interview E1), zu vermitteln: Da eine sogenannte Ausbildungsduldung, besonders in einem Beruf, der gerade gefragt wird, eine Bleibeperspektive darstellt, ein Studium, das sich viele Betroffene wünschen, aber nicht zum Aufenthalt berechtigt, stehen sie vor der Wahl, Pfleger*in oder Bäcker*in zu werden oder das Land zu verlassen.

22 Mittlerweile ist Erwerbstätigkeit nach neun Monaten erlaubt, allerdings nicht für alle Gruppen von Asylsuchenden. 


\section{c) Nicht bewegt werden}

Die Fähigkeit, nicht bewegt zu werden, wird im Fall von Asylsuchenden bereits durch den Prozess ihrer Verteilung begrenzt: Verteilung bedeutet, dass Geflüchtete nach Kriterien, die nicht ihren Wünschen und Vorteilen entsprechen, an verschiedene Standorte geschickt werden, die sie in der Zeit darauf nicht dauerhaft verlassen dürfen. Allerdings gibt es bei der Praxis der Verteilung auch Unterschiede und Steigerungen. In einem Beispiel aus einer bayerischen Großstadt, von dem meine Interviewpartnerin berichtete, störten die Gruppen Schwarzer Personen mit Handys im Stadtbild ${ }^{24}$ die lokale Bevölkerung dermaßen, dass eine Übereinkunft mit der Stadt erreicht wurde, nicht mehr als 500 Schwarze Personen an das dortige Ankerzentrum zu verteilen. Geflüchtete erscheinen in solchen Situationen wie eine bedrohliche, störende Masse, die man jedoch auch problemlos begrenzen und entfernen, also bewegen kann.

Das Infragestellen der (Gleich-)Menschlichkeit von Ankerzentren-Bewohner* innen wird zudem durch die häufigen verdachtsunabhängigen Polizeirazzien offensichtlich, die als Präventionsmaßnahmen legitimiert werden, da Geflüchtetenunterkünfte im bayerischen Polizeiaufgabengesetz zu Orten erklärt werden, die jederzeit >zur Gefahrenabwehr d durchsucht werden dürfen. ${ }^{25}$ Aus der Sicht meiner Interviewpartnerin hat diese Praxis gravierende Konsequenzen, da sie bei den Bewohner*innen kontinuierlich psychische Traumata auslöst oder verstärkt. Die Fähigkeit der Asylsuchenden, nicht bewegt zu werden, wird jedoch noch grundsätzlicher bedroht aufgrund ihrer durch die Institution Ankerzentrum gezielt hergestellte Abschiebbarkeit, ${ }^{26}$ denn die Polizeieinsätze sind für die Betroffenen nicht nur an sich traumatisch, sondern auch, weil dabei immer wieder Menschen abgeholt werden und verschwinden.

Insgesamt zeigt sich, dass sich mein aus der migrantischen Realität entwickeltes Verständnis von sozialer Mobilität gut in (zumindest qualitativen) empirischen Untersuchungen anwenden lässt. Dass Diskriminierungen konkrete Lebensbedingungen beeinflussen, ist zwar keine Neuigkeit, doch wird mit der vermittelnden Ebene der sozialen Mobilität zunehmend deutlich, wie das geschieht. Zudem lohnt sich die Anwendung eines multidimensionalen Mobilitätsmodells gerade in komplexen Fällen, in denen sich verschiedene miteinander verbundene Diskriminierungsstrukturen in verschiedenen Lebensbereichen manifestieren.

24 Die Personen suchten in der Innenstadt nach WLAN-Hotspots, da sie im Ankerzentrum keinen Internetzugang hatten.

25 Das Gesetz selbst und diese Maßnahmen sind rechtlich umstritten, das hindert die Polizei jedoch nicht an der Fortsetzung dieser Praxis. 
Als abschließende Bemerkung möchte ich auf einen Punkt hinweisen, der mir erst bei der Auswertung der Interviews aufgefallen ist: Beide Interviewpartnerinnen sprechen wiederholt von der Abhängigkeit Asylsuchender von freiwilliger Unterstützung durch länger in Deutschland lebende Menschen. Frau Foumani weist mit Nachdruck darauf hin, dass Menschen für sie da sind, ohne deren Hilfe sie keine Bleibeperspektive, keine Wohnung und Probleme in ihrem derzeitigen Beruf hätte. Frau Werner spricht von enormen Unterschieden zwischen den einzelnen Ankerzentren und einzelnen Fällen hinsichtlich des Zugangs zu ehrenamtlichen Beratungsangeboten, die letztendlich zu besseren Erfolgschancen auf eine Anerkennung oder eine anderweitige Bleibemöglichkeit führen. In den von mir entwickelten Kategorien der sozialen Mobilität lässt sich dazu sagen, dass die Fähigkeit der Einen, etwas zu bewegen, die Fähigkeit der Anderen, sich überhaupt zu bewegen, enorm begünstigen oder auch behindern kann. Für die weiteren Untersuchungen empfiehlt es sich deshalb, den Einfluss von Solidarität auf die soziale Mobilität zu berücksichtigen.

\section{Literaturverzeichnis}

Adey, Peter (2006): »If Mobility is Everything Then it is Nothing: Towards a Relational Politics of (Im)Mobility«, in: Mobilities 1(1), S. 75-94.

Adey, Peter (2017): Mobility. London/New York: Routledge.

Amelina, Anna/Vasilache, Andreas (2014): »The Shadows of Enlargement: Theorising Mobility and Inequality in a Changing Europe«, in: Migration Letters 11(2), S. 109-124.

Baar, Huub van (2015): »The Perpetual Mobile Machine of Forced Mobility: Europe's Roma and the Institutionalization of Rootlessnesss«, in: Yolande Jansen/Joost de Bloois/Robin Celikates (Hg.), The Irregularization of Migration in Contemporary Europe: Deportation, Detention, Drowning, London/New York: Rowman \& Littlefield, S. 71-86.

Bauman, Zygmunt (1998): Globalization: The Human Consequences, Cambridge: Polity Press.

Belina, Bernd/Wehrheim, Jan (2011): »Gefahrengebiete Sozialen zur Reproduktion gesellschaftlicher Strukturen«, in: Soziale Probleme 23(2), S. 207-229.

Bonß, Wolfgang/Kesselring, Sven (1999): Mobilität und Moderne. Zur gesellschaftstheoretischen Verortung des Mobilitätsbegriffs«, in: Claus J. Tully (Hg.), Erziehung zur Mobilität. Jugendliche in der automobilen Gesellschaft, Frankfurt/New York: Campus, S. 99-116.

Büscher, Monika/Urry, John (2009): »Mobile Methods and the Empirical«, in: European Journal of Social Theory 12(1), S. 99-116. 
Cresswell, Tim (2006): On the Move. Mobility in the Modern Western World. New York: Routledge.

De Genova, Nicholas P. (2002): »Migrant >Illegality and Deportability in Everyday Life«, in: Annual Review of Anthropology 31, S. 419-447.

Friedrichs, Anne (2018): »Placing Migration in Perspective. Neue Wege einer relationalen Geschichtsschreibung «, in: Geschichte und Gesellschaft 44, S. 167-195.

Hess, Sabine (2011): »Welcome to the Container. Zur wissenschaftlichen Konstruktion der Einwanderung als Problem«, in: Sebastian Friedrich (Hg.), Rassismus in der Leistungsgesellschaft. Analysen und Perspektiven zu den rassistischen Normalisierungsprozessen der `Sarrazindebatte`, Münster: edition assemblage, S. 40-59.

Hoffmann-Nowotny, Hans-Joachim (1994): »Migrationssoziologie«, in: Harald Kerber/Arnold Schmieder (Hg.), Spezielle Soziologien. Problemfelder, Forschungsbereiche \& Anwendungsorientierungen, Hamburg: Rowohlt, S. 388-406.

Kaufmann, Vincent (2002): Re-thinking Mobility: Contemporary Sociology, Aldershot: Ashgate.

Kaufmann, Vincent (2014): »Mobility as a Tool for Sociology«, in: Sociologica 8(1), S. 1-17.

Kaufmann, Vincent/Bergman, Manfred Max/Joye, Dominique (2004): »Motility: Mobility as Capital«, in: International Journal of Urban and Regional Research 28(4), S. 745-756.

Mecheril, Paul/Thomas-Olalde, Oskar/Melter, Claus/Arens, Susanne/Romaner, Elisabeth (2013): "Migrationsforschung als Kritik? Erkundung eines epistemischen Anliegens in 57 Schritten«, in: Paul Mecheril/Oskar Thomas-Olalde/Claus Melter/Susanne Ahrens/Elisabeth Romaner (Hg.), Migrationsforschung als Kritik? Konturen einer Forschungsperspektive, Wiesbaden: Springer, S. 7-55.

Rübner Hansen, Bue/Zechner, Manuela (2017): »Intesecting Mobilities. Declassing and Migration from the Viewpoint of Organising within and against Precarity«, in: movements. Journal für kritische Migrations- und Grenzregimeforschung 3(1), S. 109-126.

Sheller, Mimi (2014): »Sociology after the Mobilities Turn«, in: Peter Adey/David Bissell/Kevin Hannam/Peter Merriman/Mimi Sheller (Hg.), The Routledge Handbook of Mobilities, Abingdon/New York: Routledge, S. 45-54.

Sheller, Mimi/Urry, John (2006): »The new mobilities paradigm«, in: Environment and Planning A 38, S. 207-226.

Söderström, Ola/Randeria, Shalini/Ruedin, Didier/D’Amato, Gianni/Panese, Francesco (Hg.) (2013): Critical Mobilities. Lausanne: EPFL Press.

Sorokin, Pitigrim (1927): Social Mobility, New York: Harper and Brothers.

Sow, Noah (2011): »Migrant«, in: Susan Arndt/Nadja Ofuatey-Alazard (Hg.), Wie Rassismus aus Wörtern spricht. (K)Erben des Kolonialismus im Wissensarchiv 
deutsche Sprache. Ein kritisches Nachschlagewerk, Münster: Unrast, S. 444445 .

Tully, Claus J./Baier, Dirk (2006): Mobiler Alltag. Mobilität zwischen Option und Zwang - Vom Zusammenspiel biographischer Motive und sozialer Vorgaben, Wiesbaden: VS Verlag für Sozialwissenschaften.

Urry, John (2007): Mobilities, Cambridge: Polity Press.

Weiß, Anja (2017): Soziologie Globaler Ungleichheiten, Berlin: Suhrkamp.

\section{Interviews}

Interview B1, mit einer ehemaligen Asylsuchenden vom 10.02.2020.

Interview E1, mit einer Mitarbeiterin einer Geflüchteten-Unterstützungsorganisation vom 12.03.2020. 


\section{Physische Barrieren als Elemente der Ordnung und Regierung von Geflüchteten Ansätze einer geogouvernementalistischen Mobilitätsforschung am Beispiel Lesvos}

Tobias Breuckmann

\section{Zusammenfassung}

Der vorliegende Beitrag setzt sich mit der Rolle materieller Barrieren für die Regierung von Asylsuchenden in Lagern auseinander. Mit Rückbezug auf den Regierungsmodus der Gouvernementalität wird Zirkulation und dessen Rahmung als Technologie verstanden, Mobilität zu steuern. In Abgrenzung dazu und mit Verweis auf geographische Wendungen der Couvernementalitätsforschung wird auf lokaler Ebene der Modus der Mobilisierung eingeführt, also die Regierung durch die kleinräumige Bewegung und das Bewegt-Werden. In diesem Konzept spielen materielle Barrieren in den sozialräumlichen Gefügen der regierten Raumeinheiten eine entscheidende Rolle. Diese Position wird entlang einer empirischen Erhebung im Reception and Identification Centre Lesvos mit dem Schluss untermauert, dass Barrieren unterschiedlich zur Mobilisierung und Immobilisierung eingesetzt und mit anderen Formen der Kontrolle und Regierung vernetzt werden. Dabei werden die begrenzenden Faktoren beispielsweise dazu genutzt, zum Zweck der Kontrolle zu immobilisieren, Zugänge zu Informationen und Institutionen zu beschränken sowie Positionen zuzuweisen. Dafür dienen nicht nur die Zäune, über die Abstand hergestellt werden kann, sondern ebenfalls kleinere Barrieren, die der Flussregulation und der Lokalisierung Einzelner dienen und so Verwaltungshandlungen im Sinne der Regierenden erleichtern.

\section{Summary}

The present article approaches the role of material barriers for governing asylum seekers in camps. With reference to the mode of governmentality, circulation and its framing is understood as a technology for controlling mobility. In contrast to this, and with reference to geographical turns in governmentality studies, the mode of mobilisation is introduced on a local level, i.e., governing through smallscale movement and being moved. In this concept, material barriers in the socio- 
spatial structures of the governed spatial units play a decisive role. This position is substantiated by an empirical survey conducted at the Reception and Identification Centre Lesvos, which concludes that barriers are used differently for mobilisation and immobilisation and are linked to other forms of control and governance. In this context, the limiting factors are used, for example, to immobilise for control purposes, to restrict access to information and institutions, and to assign positions. Not only the fences that create distance serve this purpose, but also smaller barriers that serve to regulate the flow and localise individuals, thus facilitating administrative action in the interest of those in power.

\section{Einleitung}

Sprechen wir über Praktiken der Mobilisierung und Immobilisierung, muss auch die Mobilität als inhärent räumliches Konzept thematisiert werden, welches in der geographischen Mobilitätsforschung reichlich bearbeitet wurde und immer noch wird (vgl. z.B. Davidson 2020). Eines der Interessenfelder bilden Praktiken der Mobilisierung, also die Regierung von und durch Mobilität (vgl. Bærenholdt 2013). In dieses Feld lässt sich ebenfalls das Lager einbinden, welches als Mechanismus der Regierung bestimmter mobiler Bevölkerungsteile theoretisiert werden kann (vgl. Pallister-Wilkins 2018: 3). Aktuelle Strömungen der Grenz-, Lager- und Mobilitätsforschung beschäftigen sich mit Mobilität zum einen oft auf einer übergeordneten sozialräumlichen Ebene, indem sie Grenzen und Lager als Filter- und Mobilisierungsmechanismen (vgl. Salter 2013: 8) konzeptualisieren, ohne sonderlich ins Detail zu gehen. Zum anderen nehmen weitere Untersuchungen auf kleinräumiger Ebene Praktiken in den Blick (besonders ausführlich bei Inhetveen 2010), die jedoch selten deren materielle Ausgestaltungen und Rückkopplungen berücksichtigen. Dabei wird im gemeinsamen Feld von Regierungstechnologien und Mobilität meist lediglich auf die Zirkulation von Personen und die Ausgestaltung von Zirkulation eingegangen (vgl. Aradau 2016: 567), ohne jedoch zu berücksichtigen, dass sich die vielfältigen Facetten menschlicher Mobilität vor allem in lokalen Settings identifizieren lassen.

Diesem Desiderat, sozialräumliche Praktiken der Regierung mobiler Bevölkerungsteile auf der Mikroebene näher zu beleuchten, möchte ich begegnen, indem ich zuerst auf die unterschiedlichen Konzeptualisierungen und Strukturierungselemente von Mobilität auf unterschiedlichen räumlichen Ebenen eingehe. Während der Begriff der Zirkulation die vornehmliche Perspektive auf das Spannungsfeld von Mobilität und Immobilität als soziales Verhältnis darstellt, haben vereinzelte Theoretiker*innen Zäune, Wände und generell Barrieren als im konkreten Austausch mit Subjekten stehende Elemente der (Im-)Mobilisierung als weiteren strukturierenden Faktor von Mobilität identifiziert (vgl. Pallister-Wilkins 2016: 2). 
Zur analytischen Beleuchtung der Mobilisierungspraktiken in Geflüchtetenlagern stütze ich mich, neben den Konzeptualisierungen von Mobilität und Barrieren, auf das Konzept der Gouvernementalität sowohl als bestimmte Regierungform als auch als ein Forschungsprogramm der Untersuchung von Rationalitäten der Regierung. Foucault, auf den die ersten Analysen und das Forschungsprogramm zurückgehen, identifizierte die Zirkulation als vorherrschenden Modus der im 17. Jahrhundert aufkommenden gouvernementalen Regierungstechniken auf übergeordneter sozialräumlicher Ebene (vgl. Foucault 2017: 100). Für die kleinräumige Perspektive auf Barrieren und deren Rolle für die Mobilität von Subjekten lassen sich die geographischen Fortentwicklungen der Theorie von Foucault nutzen, die sich mit sozialräumlichen Praktiken des Regierens von Bevölkerungsteilen auseinandersetzen. Vor allem letzterer Perspektive widme ich mich anhand meines Untersuchungsfeldes, dem Reception and Identification Centre Lesvos, besser bekannt als Moria. Dabei gehe ich im vorliegenden Beitrag der Frage nach, wie Barrieren genutzt werden, um die Regierungsrationalitäten des Geflüchtetenlagers lokal umzusetzen und wie diese im Austausch mit den Praktiken der dort untergebrachten Geflüchteten stehen. Zu Beginn des empirischen Teils gebe ich eine kurze Einführung in das Untersuchungsfeld und dessen Kontext, um mich im Anschluss daran den bisherigen Ergebnissen meiner Forschung zu widmen und sie in den Kontext sozialräumlicher Praktiken der (Im-)Mobilisierung zu setzen.

\section{Von Zirkulation und Mobilisierung: Geographisch- gouvernementalistische Mobilitätsforschung}

Im Jahr 2006 proklamieren Sheller und Urry durch die zunehmende Globalisierung und damit einhergehende gesteigerte Mobilität ein neues Mobilitätsparadigma in den Sozialwissenschaften, mit dem sie sich von statischen Paradigmen der Forschung abwenden und den Einbezug systematischer Bewegung fordern (Sheller/Urry 2006: 208). Mobilität kann in ihrem Verständnis als das Ausmaß der Möglichkeit betrachtet werden, sich möglichst ungehindert durch und innerhalb von Raumeinheiten zu bewegen. Sie ist demnach sowohl Grundlage als auch Resultat sozialräumlicher Beziehungen, die von Machtbeziehungen durchzogen sind (vgl. Bærenholdt 2013: 21). Da Machtverhältnisse ebenso wie sozialräumliche Beziehungen relational sind (vgl. Füller/Michel 2012: 12), drücken sie sich ebenfalls in den räumlichen Beziehungen der Akteur*innen zueinander aus. Diese Beziehungen entfalten sich in einem Spannungsverhältnis zwischen der Möglichkeit, sich selbst in eine bestimmte Position zu bewegen, und bewegt zu werden, also in sozialer Interaktion einen bestimmten Grad an Mobilität innezuhaben (vgl. Bærenholdt 2013: 27). Somit kann Mobilität nicht als Ausmaß an (erzwungener) Bewegung gesehen 
werden, sondern vielmehr als die Fähigkeit, möglichst frei über die eigenen Bewegungen und Positionierungen zu verfügen (vgl. Sheller/Urry 2006: 213).

Mit Fokus auf das Ausmaß ungehinderter Mobilität wird sowohl in den Security Studies als auch in der geographischen Mobilitätsforschung der Begriff der Zirkulation eingeführt. Dieser beschreibt ein im zirkulären Austausch mit anderen Systemen stehender Fluss ${ }^{1}$ von Personen, Gütern und Kapital innerhalb globaler bis lokaler Systeme (vgl. Forman 2018: 232). Die Zirkulation unterliegt allerdings dem Bestreben verschiedener - und im transnationalen Kontext oft staatlicher Akteur"innen, sie möglichst in ihrem Sinne auszugestalten. Hierbei kann von der Regierung der Zirkulation gesprochen werden, wobei Regierung auf intersubjektiver Ebene Handlungen in Bezug auf die Handlungen Anderer innerhalb eines Machtverhältnisses beschreibt. Auf gesellschaftlicher Ebene meint sie die Anordnung von Dingen, Ressourcen und Subjekten zur Beeinflussung übergeordneter gesellschaftlicher Dynamiken (vgl. Foucault 2017: 146). Es geht bei der Regierung der Zirkulation also um eine Relationierung mobiler und immobiler Güter, Informationen und Personen und damit nicht nur um die Erzeugung von Mobilität, sondern ebenfalls gezielter Immobilität (vgl. Salter 2013: 8). Aus den unterschiedlich gelagerten Interessen und den Machtverhältnissen zwischen den Akteur*innen sowie dem Interessensgegenstand der Regierung konzipieren sich Systeme der Zirkulation.

Im Anschluss daran sollte der wissenschaftliche Fokus vom systemischen Blickwinkel der Zirkulation auf sozialräumliche Beziehungen zwischen mehreren Subjekten und räumlichen Elementen wie z.B. Infrastrukturen erweitert werden. Diese formen gegenüber den Systemen der Zirkulation die Mobilität im Konkreten, stehen aber mit jenen im reziproken Verhältnis (vgl. ebd.: 9). Deshalb macht es Sinn, die Ebene der konkreten sozialräumlichen Beziehungen von jener der Systeme der Zirkulation analytisch abzugrenzen, allerdings auf sie zu beziehen (vgl. Tazzioli 2019: 4). Dafür halte ich den Begriff der Mobilisierung für angebracht, der sich als die konkrete Platzierung von Körpern durch das Subjekt selbst oder Andere in sozialräumlichen Praktiken fassen lässt (vgl. Kreichauf 2017: 419). Dabei geht es also nicht nur um die Regierung von Mobilität, wie er im Modus der Zirkulation

$1 \quad$ In Assoziation mit der Rhetorik der Flüchtlingswelle und anderen dehumanisierenden Diskurselementen kann dieser Begriff als problematisch erachtet werden, spiegelt jedoch die theoretische Diskussion um flows als systematische, möglichst ungehinderte und übergeordnet regulierte Bewegung in Abgrenzung zur gezielten Bewegung einzelner Subjekte wider (siehe weiter unten). 
vorherrschend ist, sondern um die Regierung durch Mobilität auf lokaler Ebene ${ }^{2}$ (vgl. Bærenholdt 2013: 20).

An dieser Schnittstelle der Regierung von und durch Mobilität lässt sich durch die Synthese der geographischen Mobilitätsforschung und der geographischen Gouvernementalitätsforschung der analytische Blick schärfen. In seiner Vorlesung Sicherheit, Territorium, Bevölkerung. Geschichte der Gouvernementalität I zeichnet Michel Foucault die Entwicklung des Regierungsmodus der Gouvernementalität als Folge des westfälischen Friedens und der Konstitution einer Bevölkerung mit Bezug zum Souverän nach (vgl. Foucault 2017: 428). Dieser Modus richtete sich auf ein Gleichgewicht der Zusammensetzung der Bevölkerung in Bezug auf Merkmale wie Produktivität, Alter, Gesundheit etc., das vor allem durch die möglichst ungehinderte Zirkulation von Gütern, Kapital und Personen bewerkstelligt werden sollte (vgl. Aradau 2016: 567). Dabei werden konkrete Strukturen benötigt, die gewünschte Zirkulation befördern und unerwünschte Zirkulation verhindern (vgl. Amicelle et al. 2017: 172; Salter 2013: 9). Foucault spricht hierbei selbst von einer Normierung der Zirkulation (Foucault 2017: 100). Die aus diesem Spannungsfeld von erwünschter und unerwünschter Zirkulation entstehenden Sicherheitspraktiken produzieren durch die Normierung der Zirkulation ungleiche Mobilität: »The contemporary production of suneven mobilities < [...] continues to be mediated through security practices, which make possible distinction between dangerous and non-dangerous, risky and non-risky bodies. (Aradau 2016: 565) Mit Verweis auf die weiter oben ausgeführten, jedoch von Foucault etwas vernachlässigten Zusammenhänge von übergeordneten Systemen der Zirkulation und intersubjektiven Praktiken der Mobilisierung (vgl. ebd.: 567), erscheint es auf der konkret mikrophysischen (vgl. Foucault 1976: 32f.) Handlungsebene sinnvoll, raumtheoretische Überlegungen zur Konzeption der Mobilisierung anzustellen. Geht man davon aus, dass die Herstellung von Beziehung durch die Relationierung - durch bewegen und bewegt werden - sichergestellt werden kann, lässt diese sich nur über soziale Handlungen innerhalb spezifisch räumlicher Kontexte gewährleisten (vgl. Füller/Michel 2012: 12). Obwohl Foucault eine gewisse theoretische Unterbelichtung der Kategorie Raum bei Regierungstechniken nachgesagt wird (vgl. Thrift 2007: 55), lassen sich doch seine impliziten Ausführungen heranziehen, um ein stringentes Konzept von Raum zu zeichnen: So können Raumproduktionen als relationale Gefüge betrachtet werden, die im reziproken Verhältnis zu Machtbeziehungen und -strategien stehen (vgl. Kreichauf 2017: 414). Besonders prägnant

2 An dieser Stelle sei nochmal explizit darauf hingewiesen, dass sich die beiden Techniken nicht voneinander trennen lassen, da die Regierung durch Mobilität auch eine Beeinflussung von Mobilität der betreffenden Subjekte darstellt bzw. auf der Mobilität der beteiligten Subjekte basiert. 
wird die Disziplinierung von Subjekten (vgl. Foucault 2016) über die Hierarchisierung und Relationierung von Körpern im und mit dem Raum sichergestellt (vgl. Kreichauf 2017: 419). Auch in Bezug auf die Regierung der Zirkulation lassen sich räumliche Bezüge feststellen (vgl. Foucault 2017: 27).

Mit diesem Zusammenhang zwischen eben jenen Regierungstechniken und Raumproduktionen haben sich zahlreiche Geograph*innen beschäftigt. So machen Füller und Michel mit ihrer Beschreibung vom »Raum als Machttechnik« noch einmal grundlegend deutlich, dass der Raum nicht als Hintergrund von Handlungen konzeptualisiert werden kann, sondern selbst als fundamentaler Teil von sozialen Handlungen und gesellschaftlichen Strukturierungen anzuerkennen ist (Füller/Michel 2012: 12). Hier lassen sich drei grundlegende Elemente des Raums als Machttechnik mit dem Modus der Gouvernementalität verknüpfen: Erstens ermöglichen und behindern bzw. erleichtern und erschweren Materialitäten bestimmte aufeinander bezogene Handlungen und damit auch Machtverhältnisse und -mechanismen. Das Hauptaugenmerk der Kontrolle von Abläufen und Bevölkerung und damit der reziproken Produktion von Wissen über die Bevölkerung liegt beispielsweise auf deren Lokalisierung - ein inhärent räumlicher Begriff - sowie auf der räumlichen Relationierung zur besseren Lokalisierung, also zum Zweck der Sicht- und Beobachtbarkeit (vgl. Huxley 2008: 1646). Dies können konkret überwachte Durchgänge, Wachtürme oder Ähnliches sein. Sozialräumliche Verhältnisse und Materialitäten rahmen dementsprechend die Techniken und Praktiken, mit denen Überwachung und Kontrolle von Räumen und Durchgängen sichergestellt werden (vgl. Klauser 2017: 27). Ebenfalls lassen sich Raumstrategien und -produktionen dazu nutzen, diese Techniken der Kontrolle zu unterlaufen und zu transformieren, sodass das Wechselverhältnis zwischen Kontrolle und Umgang mit der Kontrolle in der Beforschung dieser Raumproduktionen sichtbar bleibt (vgl. Gilliom 2005). Zweitens lässt sich die Zirkulation als grundlegendes Motiv des Sicherheitsdispositivs ebenfalls nur durch räumlich-materielle Techniken und Strukturen sicherstellen. Über die Veränderung der räumlichen Komponenten oder im Foucaultschen Duktus - durch die Stellschrauben der Zirkulation lassen sich Begebenheiten und Handlungen wahrscheinlicher oder unwahrscheinlicher machen (vgl. Marquardt/Schreiber 2012: 41). Mit Rückgriff auf die vorausgegangenen Ausführungen muss dieser Punkt zusätzlich um die Techniken der Mobilisierung ergänzt werden, also die Regierung durch Mobilität, die mit Blick auf die geographische Forschung zu Modi der gouvernementalen Regierung bislang weitgehend unbeachtet bleibt. Diese auf Mobilität gerichteten Regierungsmodi betreffen also nicht nur die Möglichkeit, durch räumliche Arrangements bessere Kontrolle über Durchgangsräume wie z.B. Grenzposten, aber auch Tore oder Ähnliches zu erlangen, sondern gezielt sozial-räumliche Beziehungen den Regierungsrationalitäten folgend zu beeinflussen. Als drittes Element des Raumes als Machttechnik, das sich in der geographischen Forschung zu gouvernementalen Regierungstech- 
niken produktiv machen lässt, ist die Einbindung von Raumproduktionen in die Reziprozität von Macht und Wissen zu nennen. Dabei stehen Räumlichkeiten im Wechselverhältnis zwischen materiellen und symbolischen Ordnungen, die einen bestimmten Ausschnitt an Handlungs- und Subjektivierungsweisen eröffnen (vgl. Marquardt/Schreiber 2012 43).

Vor dem Hintergrund der theoretischen Vorüberlegungen lässt sich nun nach konkreten Formen des Bestrebens, durch den Raum zu regieren, Ausschau halten. Um Modi der Zirkulation und Mobilisierung im Speziellen zu analysieren, bieten sich physisch-räumliche Elemente an, konkret die im Weiteren thematisierte Barriere. Das Spektrum Lexikon der Geographie beschreibt eine Barriere allgemein »als materielles begrenzendes Objekt oder begrenzender Faktor« (Spektrum 2020: o.S.). Da diese Definition in Bezug auf Barrieren als Regierungstechnologie nur bedingt hilfreich ist und Belina zufolge die »tatsächliche jeweilige Relevanz des Räumlichen der sozialen Praxis [...] nur aus konkreten sozialen Praxen und Prozessen abstrahiert werden « kann (Belina 2017: 24), macht es Sinn, die Eigenschaften von Barrieren im konkreten Interessengebiet näher zu betrachten. Analog zur Grenze können Barrieren zuerst einmal als Mittel identifiziert werden, um Populationen voneinander zu trennen (vgl. Rijke 2020: 4). Für Rosière und Jones dienen undurchlässige Barrieren hingegen nicht nur der Trennung, sondern der substantiellen Einschränkung der Bewegungsfreiheit bestimmter Bevölkerungsteile (Rosière/Jones 2012: 219). Pallister-Wilkins konstatiert hingegen, dass Barrieren nicht nur der Blockade dienen und plädiert dafür, Barrieren und deren Funktionsweisen in den jeweiligen politischen und sozialräumlichen Kontext einzubetten (vgl. Pallister-Wilkins 2016: 2f.). So fungieren Barrieren ihrer Meinung nach als Regierungselemente im biopolitischen Sinne und erlauben die Regierung von Population durch die Normierung von Zirkulation (vgl. ebd.: 4). Durch Barrieren wie offengelassene Durchgänge kann Bewegung kontrolliert und so trotzdem Zirkulation sichergestellt werden (vgl. ebd.: 7). Geht man jedoch davon aus, dass es eben nicht nur um die freie Zirkulation geht, sondern auch um die Überwachung und teilweise Unterbrechung und Verlangsamung von Zirkulation durch konkrete Platzierung und Relationierung von Körpern und räumlichen Elementen, so scheint der Begriff der Mobilisierung als Mittel der Ermöglichung von erwünschter Zirkulation angebrachter. So haben Zäune laut Aradau in der Grenzpolitik die Aufgabe, die frei bewegliche und nicht in die Rationalitäten der normierten Zirkulation einzubindende Masse zu regieren (Aradau 2016: 569). Durch die Abschottung der Kanäle möglichst ungehinderter Zirkulation und deren Verbindung mit weiteren Kontrolltechniken werden besagte Kanäle mehr oder weniger adäquat vor nicht erwünschter Zirkulation geschützt.

Doch wie wirken diese Techniken der Mobilisierung durch und mit Barrieren in Geflüchtetenlagern, also einem ganz bestimmten sozialräumlichen Ensemble, das dazu dient, die unerwünschte Zirkulation derer, denen kein Anspruch auf Asyl 
zugesprochen wird, zu unterbinden? Wie werden hingegen diejenigen, denen Asyl gewährt wird, auf eine bestimmte Weise in die allgemeine Zirkulation bei vorheriger Prüfung eingebunden? Wie dieser Ordnungsmechanismus auf konkreter räumlicher Ebene zusammengesetzt ist, möchte ich im Folgenden auf Grundlage empirischer Untersuchungen näher beleuchten. Mein Hauptaugenmerk gilt dabei der Rolle von Barrieren innerhalb des Lagers und wie diese in Beziehung zur Gesamtheit des Lagers und zu den damit verbundenen Regierungsrationalitäten stehen. Mein Ziel ist es, einen konzeptionellen Beitrag zu Barrieren als Element der Mobilisierung zu leisten und den Forschungsstand um diese bislang eher vernachlässigten Zusammenhänge zu erweitern.

\section{Barrieren als Mittel der Mobilisierung? Empirische Zugänge am Beispiel Lesvos}

Im europäischen Kontext kulminieren Praktiken der Migrationskontrolle und der humanitären Versorgung in den Hot Spot-Centres an den EU-Außengrenzen (vgl. Soykan 2017: 57), welche im Zuge und im Nachgang des Sommers der Migration (vgl. Hess et al. 2017) im Jahr 2015 und des EU-Türkei-Deals im März 2016 errichtet wurden. Dabei dienen diese Einrichtungen als europäischer Mechanismus zur Unterstützung nationaler asyl- und migrationsbezogener Institutionen und sind in die grenzübergreifende europäische Migrationspolitik eingebunden (vgl. Kasparek 2017: 47). Das Lager Moria war - vor dem sich dort zutragenden umfassenden Brand und daraus resultierender fundamentaler Transformationen des lokalen Feldes - Teil dieser europapolitischen Dynamiken und bildete das Untersuchungsfeld für den vorliegenden Beitrag. Es lag im Süden der Ägäis-Insel Lesvos (dt.: Lesbos) und fasste offiziell ca. 2.500 Personen (vgl. Hänsel 2019: 32). Seit Beginn meiner Promotionsforschung auf der Insel im September 2018 ist das Lager jedoch immer um mindestens das Doppelte ${ }^{3}$ überbelegt gewesen. Die Ergebnisse des Beitrags basieren auf Daten aus vier Feldphasen zwischen September 2018 und April 2020. Diese umfassen sowohl Interviews mit Mitarbeiter*innen der Lagerverwaltung, NGOs und Geflüchteten als auch teilnehmende Beobachtungen innerhalb des Lagers. Diese konnte ich zum einen im Rahmen eines administrativ genehmigten Forschungsaufenthalts und zum anderen durch die Mitarbeit bei der christlichen NGO Eurorelief erheben, die mit der Unterbringung und teilweisen Versorgung der Geflüchteten beauftragt sind. ${ }^{4}$

4 Daraus resultieren methodologische Ambivalenzen und forschungsethischen Bedenken, die bspw. auf die allgemeinen Aufgaben der Unterbringung von Asylsuchenden in einem Lager, 
Abbildung 1: Überblick Moria

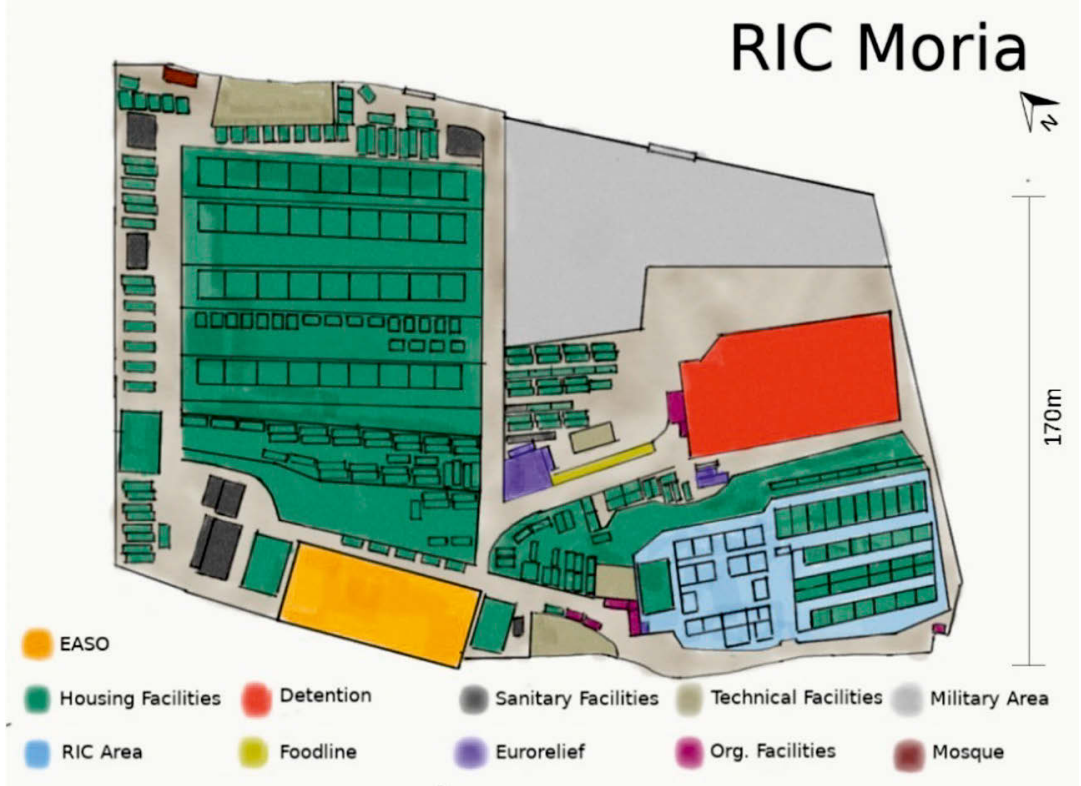

Quelle: Eigene Abbildung.

Ein erster Blick auf die Architektur des Camps offenbart bereits die Relevanz von Barrieren in der materiellen Ausgestaltung des europäischen Asylregimes: Moria war ringsum von Zäunen umgeben. Der einzige offizielle Zugang befand sich an der Südseite. Kontrolliert wurden vor allem nicht als Migrant*innen gelesene Personen (aufgrund von zugeschriebener Ethnizität, Hautfarbe, Arbeitskleidung von NGOs) mit Verweis auf das Militärgebiet, in dem sich das Camp befand. Auch die jeweiligen Ebenen, die sich der Hanglage des Camps anpassten (s. grüner Bereich links), auf denen die Geflüchteten größtenteils innerhalb des Camps untergebracht waren, sind als Rückstand des Militärgebiets mit Zäunen von mehreren Metern Höhe umgeben gewesen, deren Zugänge jedoch stets geöffnet waren. Einzelne Zonen, vor allem jene, in denen sich für die Versorgung und Registrierung der Asylsuchenden elementare Institutionen befanden (s. Abbildung I und spezifischer die folgenden Abbildungen), waren umzäunt und wurden entweder ununterbrochen bewacht oder gänzlich geschlossen gehalten. Zusätzlich gab es vereinzelt

jedoch auch auf Berichte von früheren Missionarstätigkeiten innerhalb von Moria zurückgehen. 
kleinere und weniger abschließende Barrieren und Wegeleitsysteme, auf die ich im Folgenden näher eingehen werde. Das Hauptaugenmerk liegt auf der Frage, wie die Barrieren in die sozialen Handlungen mit einbezogen wurden und damit zur Konstituierung des Geflüchtetenlagers beitrugen.

\section{Barrieren als Mittel der Zugangsregulation zu Institutionen und Informationen}

Zutritt zu innerhalb des Lagers umzäunten Bereichen erhielten lediglich Personen, die eine Zugangsberechtigung besaßen oder die sich - wie im Fall des New ArrivalAreals - zur Erstregistrierung dort aufhalten mussten (s. Abbildung 2).

Abbildung 2: Überblick New Arrival

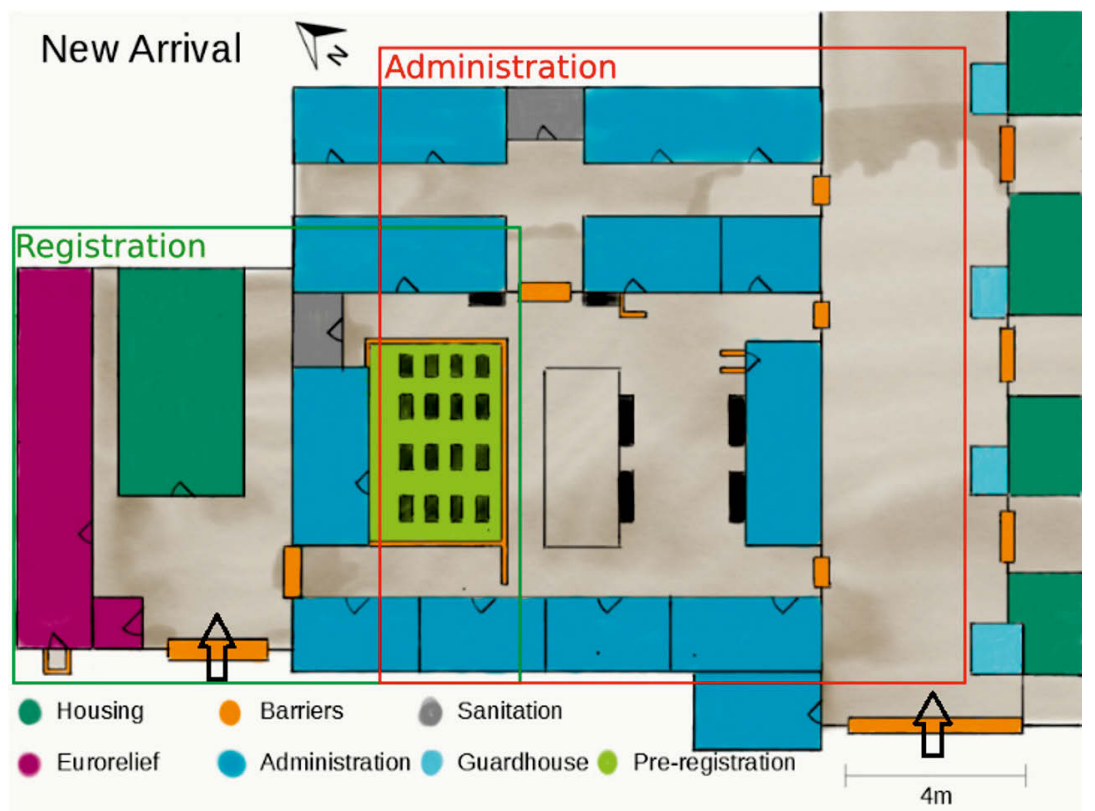

Quelle: Eigene Abbildung.

Da sich die Bewegungs- und Informationsflüsse an den Fenstern und Durchgängen konzentrierten, war es möglich, die Zugänge zu kontrollieren und teils schon Verwaltungsakte und Interaktionen vor Eintritt abzuwickeln. So wurden dort schon die Zugänge gefiltert, wie bei der medizinischen NGO Kitrinos, die sich ebenfalls im New Arrival-Areal befand: 
»Mir fällt auf, dass die Leute bei der Anmeldung bei Kitrinos erst durch den sonst sichtgeschützten Maschendrahtzaun mit den Angestellten reden und erst nachher in den Bereich gelassen werden, wo der richtige Behandlungsraum ist.« (Beobachtungsprotokoll vom 29.03.2019)

Dabei ist die Erteilung der Zugangsberechtigungen teilweise durch Willkür, Zufall oder strukturelle Unzulänglichkeiten (z.B. überlastete Terminausgabe) sowie Kommunikationsfehler gekennzeichnet gewesen:

»Die meisten NCO-Mitarbeiter"innen werden ohne Probleme reingelassen, die Geflüchteten müssen jedoch vor der Tür warten, teilweise sind sie schlecht informiert, haben den falschen Termin oder ihnen wird gesagt, sie sollen später oder morgen wiederkommen.«(Beobachtungsprotokoll vom 13.03.2019)

Allerdings existierten kaum Möglichkeiten, sich ohne zugewiesenen Termin $\mathrm{Zu}$ gang zum New Arrival-Areal zu verschaffen bzw. selbst einen Termin zu beantragen. Das fällt besonders ins Gewicht, da das Areal nicht nur zur Erstregistrierung, sondern auch zur Abwicklung von Verwaltungsakten und medizinischen Untersuchungen aufgesucht werden musste.

Analog zur materiellen Einzäunung zentraler Institutionen wurden so elementare Informations- und Versorgungsleistungen bzgl. des Asylverfahrens stark eingeschränkt: So lag beispielweise auch Kelpno, die Stelle des griechischen Gesundheitsamts, welche für die medizinische Erstuntersuchung zuständig ist, innerhalb des New Arrival-Bereichs. Sie ist mit ihren Begutachtungen zentral für die Anerkennung der Asylsuchenden als vulnerabel, ein Status, der das Asylverfahren verkürzt und die geographische Restriktion auf die Insel Lesvos aufhebt. Es kam jedoch nicht selten vor, dass Kelpno die Arbeit (bspw. als Reaktion auf Ausschreitungen) unterbrochen hat oder Termine auf für die Asylsuchenden nicht wahrnehmbare Zeitpunkte festlegte.

\section{Barrieren als Mittel des Rückzugs}

Zusätzlich zur Zugangskontrolle durch Einbezug der Barrieren kann der Rückzug der Verwaltungshandelnden von den Barrieren, durch oder über die hinweg interagiert wurde, als Regulation von Versorgung mit Gütern und Informationen gesehen werden. Da die Asylsuchenden keinen Zugang zu den Bereichen hinter den Barrieren hatten, konnten sich die Verwaltungshandelnden der Interaktion entziehen. Es entstand ein extremes Ungleichgewicht an Handlungsressourcen, ausgelöst durch den Einbezug der Barriere und die dadurch erfolgte Positionierung der am Feld Beteiligten zueinander. Dies wurde zum Beispiel explizit von einzelnen Mitarbeitenden von Eurorelief empfohlen, um sich der Konfrontation mit Anfragenden zu entziehen: 
»Während er [eine Person, die in einer Unterkunft registriert werden will] wieder seine Papiere herausgibt und ziemlich lang wartet, soll ich nochmal los [...]. Danach fragt er mich nochmal, wie lange es dauert, ich sage, ich schau nach. Jenny legt mir nahe, einfach so lange drin zu bleiben, bis der Vorgang abgeschlossen ist, damit er mich nicht weiter konfrontiert.«(Beobachtungsprotokoll vom 21.03.2019)

\section{Barrieren als Abgrenzung zur Regulierung von Menschen(-ansammlungen)}

Zusätzlich zur Abgrenzung wurden Barrieren bzw. der fehlende Zugang zu den dahinterliegenden Bereichen dazu genutzt, Personen zu mobilisieren. So waren beispielsweise die Fenster bzw. Durchreichen innerhalb des doppelten, mit Stacheldraht bewehrten Maschendrahtzaunes bei EASO (European Asylum Support Organisation) - dem Bereich für das Asylverfahren - elementar für die Interaktion zwischen Behördenangehörigen und Asylsuchenden:

»Kurz darauf erreichen wir den Bereich der Asylprozedur, betrieben von EASO und IOM [...]. Dort sind zwei hohe Zäune hintereinander aufgestellt, wobei sowohl auf den Zäunen als auch zwischen den beiden Stacheldraht gespannt ist [...]. In den Zaunsegmenten selber befinden sich Durchreichen, wodurch die meisten Geflüchteten und Angestellten miteinander kommunizieren und Papiere austauschen.«(Protokoll vom 13.03.2019)

Die partielle und fragmentierte Durchlässigkeit an den einzelnen Fenstern und der stark bewachten Tür entfaltete seine regulierende Wirkung erst durch die Interaktion. Die Asylsuchenden wurden stets mit ihren Anliegen an die unterschiedlichen, mit einzelnen Themen betrauten Durchreichen verwiesen. Viel wichtiger dabei ist jedoch, wie die Asylsuchenden zum einen dazu gebracht wurden, den vor der Tür abgegrenzten Eingang zum eigentlichen Bereich freizuhalten und sich an die jeweiligen Fenster zu wenden:

»Während meiner einstündigen Beobachtungsphase [...] kommt es öfter vor, dass Asylsuchende kommen und innerhalb des Türbereiches Kontakt aufnehmen oder Einlass bekommen wollen, jedoch von dem Sicherheitsmitarbeiter hinter der äußeren Tür meist durch Rufe oder Handbewegungen dazu aufgefordert werden, den Bereich wieder zu räumen. Prinzipiell wird auch vor der Tür der Großteil der Kommunikation schlicht und ergreifend verweigert [...]. Der Beamte steht sogar meist angelehnt mit dem Rücken zum Außen des Bereichs, um mit den Kollegen zu kommunizieren.«(Beobachtungsprotokoll vom 13.03.2019)

Die Mobilisierung - im Sinne einer Zuweisung von Plätzen - wurde hier also nicht nur durch die Leitfunktionen von Barrieren sichergestellt, sondern auch durch die fehlende Kooperation seitens der Verwaltungshandelnden, die den Asylsuchenden den Zugang zu wichtigen Institutionen verweigerten. Es findet eine Disziplinie- 
rung durch die starke Beschränkung des eigentlichen Zugangs und die Kanalisierung der Belange durch die unterschiedlichen Fenster statt.

Die Strategie der Mobilisierung durch den Aufbau von Distanz bzw. Verweigerung der Kooperation wurde jedoch nicht nur in formellen Kontexten wie der Abwicklung des Asylsystems angewandt, sondern ebenfalls bei Nichtregierungsorganisationen. Dies kann besonders eindrücklich am Beispiel der Terminausgabe für Windeln illustriert werden, die über die Theke bei Eurorelief (s. Abbildung 3) stattfand:

»Als die eine Person, die die Zettelchen ausgibt, auf eine andere Seite wechselt, bildet sich eine Traube. Die Anstehenden werden dazu aufgefordert, eine Schlange zu bilden, damit es weitergeht. [...] Eine richtige Schlange bildet sich nicht mehr, trotzdem werden die letzten Zettelchen rausgegeben [...].«(Beobachtungsprotokoll vom 19.03.2019)

Abbildung 3: Überblick Eurorelief und Essensausgabe

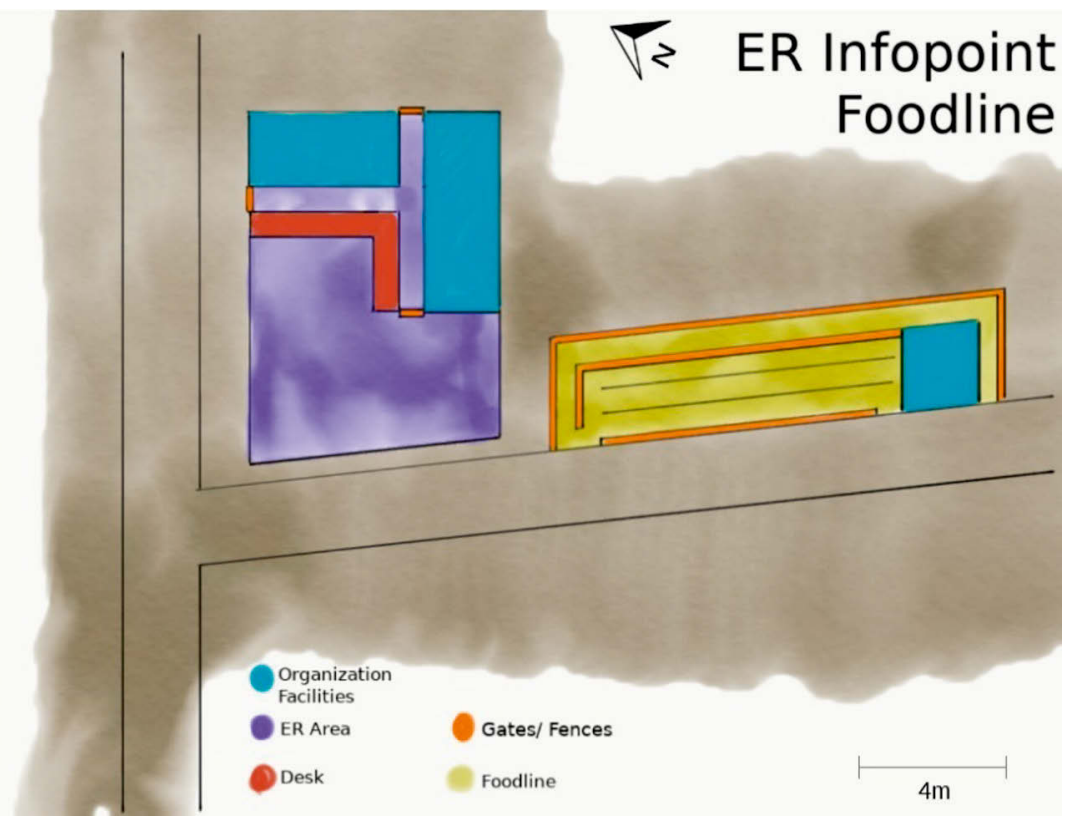

Quelle: Eigene Abbildung.

Hier hingegen werden auch Variationen bei der Durchsetzung und der Rolle der unterschiedlichen Anlaufstellen deutlich. Während bei EASO die Zuweisungen deutlich konsequenter durch das Sicherheitspersonal durchgesetzt wurden, waren 
die meist jungen Freiwilligen der Nichtregierungsorganisation weniger strikt in ihren Anweisungen, sodass zusätzlich Spielräume entstanden.

\section{Barrieren als Flussregulatoren bei Zugängen}

Wie sich schon im Verweis auf die Freihaltung des Eingangsbereichs vor EASO angedeutet hat, wurden die Anweisungen und Verweigerungen zuweilen mit explizitem Verweis auf Barrieren gemacht. So standen vor allem in der New Arrival-Zone und vor dem Eingang zu EASO hüfthohe Barrieren. Sammelten sich Personen vor der Tür, stellten sie Anfragen oder wurden sie aufgerufen, ist ihnen stetig zuerst der Platz außerhalb der Barriere oder mit genug Abstand zum Verwaltungspersonal zugewiesen worden. In vielen beobachteten Fällen ging das Verfahren erst weiter, sobald die Asylsuchenden den ihnen zugewiesenen Platz eingenommen hatten. Die Zuweisung auf die Plätze an den Eingängen scheint dabei vor allem dem Umstand geschuldet, dass die Zugänge zu den Institutionen zum Zweck der Zugangskontrolle eben stark verengt waren und sich aus diesem Grund häufig Menschenansammlungen bildeten.

Zusätzlich existierten in begrenzter Zahl auch Barrieren, welche klassische Modi der Regulation von Flüssen unterstützten, so wie Barrieren als Wegleitsysteme. Die Essensausgabe bildet das offensichtlichste Beispiel (s. Abbildung 3). Dort waren vier Reihen durch die Barrieren angelegt, die zu der ebenfalls durch Durchreichen gewährleisteten Essensausgabe führten. Allerdings waren meist nur vereinzelte Durchreichen geöffnet und die Barrieren zudem nicht durchgehend, sodass die Anstehenden sich vordrängeln oder über Barrieren klettern konnten. Zusätzlich dazu bestanden vor einzelnen Institutionen außerhalb der eingezäunten Zonen ebenfalls kurze Wegeleitsysteme. So sorgten beispielsweise der UNHCR oder einzelne Infostellen, die für den Transfer oder die Aktualisierung von Papieren und Bankkarten zuständig waren, dafür, dass Geflüchtete entlang von Barrieren zu bestimmten Fenstern oder einer Tür geführt wurden.

\section{Barrieren als Mittel der zeitweiligen Immobilisierung}

Während bis jetzt vor allem Praktiken beleuchtet wurden, die aus dem Ausschluss von und der Zugangsregulierung zu strukturell wichtigen Bereichen bestanden, lassen sich ebenfalls Praktiken der zeitweisen Immobilisierung identifizieren, die auf Einschluss durch Barrieren basierten. Dies gilt vor allem bei der Registrierung, die eine lückenlose Erfassung der Neuangekommenen anstrebte. So wurden Geflüchtete nach ihrer Ankunft in die New Arrival-Zone gebracht, in der die Erstregistrierung durch die Polizei und Frontex stattfand. Dafür wurden sie in einen separaten, jedoch nur mit mobilen Barrieren abgegrenzten Bereich gebracht (s. Abbildung 2 Mitte), um von dort für die einzelne Erfassung aufgerufen zu werden: 
»In der Registration Area selbst befindet sich mitten in dem Bereich das Areal, um das herum alle für die Registrierung und den Weitertransfer wichtigen Büros untergebracht waren. In der Mitte befindet sich ein freier Raum, der durch einen mobilen Zaun abgetrennt ist. Dort sitzen die Neuankömmlinge von morgens und warten auf ihre Erstregistrierung bei Frontex, deren Büro ebenfalls in dem Bereich ist. (Beobachungsprotokoll vom 15.03.2019)

Abhängig von der Anzahl der Neuangekommenen und der Auslastung der Behörden kam es jedoch vor, dass die lückenlose Registrierung nicht an einem Tag durchgeführt werden konnte. In diesem Fall wurden die Asylsuchenden im angrenzenden Gemeinschaftszelt, das für schon Registrierte, aber noch nicht regulär Untergebrachte vorgesehen war, untergebracht. Dieses Zelt war ebenfalls durch ein Tor von dem Areal der Registrierung abgegrenzt. Kam es zum Rückstau bei der Registrierung, konnte der Bereich des Zeltes abgetrennt werden, um den Unregistrierten die Möglichkeit zu nehmen, sich undokumentiert inner- und außerhalb des Camps zu bewegen. Zusätzlich sollten die Neuankommenden von den Campbewohner*innen getrennt werden, jegliche Interaktion wurde unterbunden, wie Osai mir in Bezug auf seine Ankunft in Moria schilderte: "Yeah, they drop us off and then, straight away, we were not allowed to talk to anyone, someone to come and see you. We were not allowed, nobody was. Nobody was, no one was allowed to come close to us. " (Interview mit Osai) Zusätzlich dazu bestand eine besonders restriktive Form der Mobilisierung innerhalb des Lagers: Die Haft/Detention folgte vor allem der Logik der niedrigen Anerkennungsquote, sodass vor allem Asylsuchende aus Westafrika mit dem Verweis auf Verdunkelungs- und Verzögerungsgefahr für maximal drei Monate unmittelbar nach der Registrierung inhaftiert wurden. Dort hatten sie im Vergleich zu den schon beschränkten Zugängen zu Informationen und Institutionen kaum die Möglichkeit, ärztlichen oder juristischen Beistand zu konsultieren. Aufgrund des fehlenden Zugangs zu Beratung mussten sie meist unvorbereitet und mit sehr eingeschränktem Kontakt zu Außenstehenden das Asylinterview, das während der Haftzeit angesetzt wurde, absolvieren. Dies mündete laut Aussage einzelner Interviewpartner*innen meist in einer ersten Ablehnung des Asylantrags. Man könnte hier von einem innengelagerten Sortiermechanismus durch Einschluss sprechen.

Die politischen Entwicklungen des letzten Jahres legen dazu noch einen weiteren Mechanismus des Einschlusses auf übergeordneter Ebene offen: Als die griechische Regierung zum 1. März 2020 das Asylverfahren für einen Monat aussetzte (vgl. Infomigrants 2020: o.S.), sollten neu an der Küste Angekommene nicht nach Moria gebracht, sondern in Detention-Centres auf dem griechischen Festland interniert und von dort aus abgeschoben werden (vgl. Humanrightswatch 2020: o.S.). $\mathrm{Zu}$ diesem Zweck wurden etwa 500 Asylsuchende in der Nähe eines Militärschiffes am Hafen von Mytilini, der Hauptstadt von Lesvos, festgehalten. Zwar konnten sich 
die Asylsuchenden innerhalb der Einzäunungen des Hafens bewegen, als Außenstehende Kontakt aufnahmen, wurde jedoch jeglicher Kontakt durch das Aufstellen von Barrieren innerhalb des Hafens unterbunden. Ein besonders drastisches Veranschaulichungsbeispiel bot sich nach dem Brand in Moria im September 2020: Nachdem die griechische Regierung seit März 2020 einen Lockdown verhängte und als Reaktion auf erste dokumentierte Corona-Fälle das komplette Lager durch den Bau eines Zaunes abzuriegeln gedachte (BalkanInsight 2020), musste es infolge des verheerenden Brandes komplett evakuiert werden. Als die Asylsuchenden den Weg in die Hauptstadt Mytilini antraten, wurden sie auf der Küstenstraße in Richtung der Hauptstadt gestoppt und dort für mehrere Tage auf besagter Straße durch Straßenblockaden festgehalten. Diese komplette Blockade diente der griechischen Regierung dazu, das Feld der Migrationskontrolle ad hoc zu reorganisieren und ein provisorisches Lager direkt an der Küste zu errichten. Den Einzug in das neue Camp setzten die Behörden durch den Einsatz physischer Gewalt und Tränengas, die zeitweilige Unterbindung der Versorgung von Betroffenen und Drohungen bezüglich der Aussetzung des Asylverfahrens bei Nichtbefolgung durch (mare liberum 2020).

\section{Umgangsstrategien/Selbstorganisation}

Während bis jetzt die Strategien der Verwaltungshandelnden betrachtet wurden, sind noch vereinzelte, in ihrer Breite subtilere Umgangsstrategien mit Barrieren seitens der Geflüchteten zu verzeichnen gewesen. Beispielsweise schnitten Asylsuchende Löcher in den Zaun des Lagers, um sich erleichterten Zugang abseits des offiziellen Tores zu schaffen. Diese wurden allerdings geduldet, weil das Management den Nutzen gegen den Schaden dieser informellen Zirkulation abwog:

»Als ich meine Begleitung auf die zahlreichen Löcher im Zaun anspreche, sagt er mir lediglich, dass sich der Zugang aufgrund der Überbelegung und der großen Zahl der Menschen nicht kontrollieren lässt und dass die Leute vom Olive Grove ${ }^{5}$ so ebenfalls einen direkten Zugang zum Camp und damit ebenfalls zur Essensausgabe haben.«(Beobachtungsprotokoll vom 13.03.2019)

Zusätzlich dazu ließen sich die geschaffenen Strukturen unter bestimmten Bedingungen vorteilhaft nutzen, so wie es mir Hamid beschrieb, der sein Asylverfahren nach Versäumnis eines Termins wiederaufnehmen und dafür einen neuen Termin an den Fenstern von EASO bekommen wollte: 
»After one hour, he bring for me an appointment for three months [...]. And I come from this window to another one and I told another one. [...] I told her sir, I have this problem, my case is closed, and, he said, ok wait here, he go exactly on that time, and he go and he bring for me another appointment for one week, after one week.«(Interview mit Hamid)

Durch die Parzellierung der Zugänge und Zuständigkeiten gestaltete sich auch der Informationsfluss zwischen den unterschiedlichen Stellen innerhalb der Zone als unzureichend. Diese Fragmentierung nutzten Asylsuchende in ihrem Sinne.

Neben den Praktiken, die die Strukturen zum Teil unterlaufen, ließen sich auch solche ausfindig machen, die jene eher stützten und auf der Selbstorganisation und -regulation der Lagerbewohnenden basierten. So organisierte sich bspw. die afghanische Community im Lager in Bezug zur Essensausgabe selbst: Einzelne Personen, ausgestattet mit gelben Warnwesten, regelten den ordnungsgemäßen Verlauf an der Ausgabe. Zusätzlich dazu entstanden Praktiken, die weniger im Sinne der Positionierung zu und Umgang mit Barrieren gezählt werden können, sondern auf gegenseitiger Hilfe beruhten und den beschränkten Zugang zu Informations- und Versorgungsleistungen, zum Beispiel durch gemeinsames Einkaufen oder die Weitergabe von Informationen über Netzwerke, teilweise substituierten. Das Angewiesen-Sein vor allem auf Institutionen des Asylverfahrens konnten sie hingegen nicht verringern.

\section{Schlussbetrachtung}

Bei abschließender Betrachtung der Empirie und mit Rückbezug auf die Theorie der geographisch-gouvernementalistischen Mobilitätsforschung wurden Barrieren vor allem als Mittel genutzt, um den adäquaten Ablauf von Verwaltungshandlungen in Bezug auf Asylsuchende sicherzustellen. Die stark differierende Mobilität, ausgedrückt als Möglichkeit, sich und andere in der Interaktion zu positionieren, hat sowohl der Theorie als auch der Empirie zufolge große Auswirkungen auf den Handlungsspielraum der Akteur*innen und auf die Konstitution des Feldes Geflüchtetenlager.

So führt schon die Barriere des Meeres dazu, dass Asylsuchende kaum undokumentiert weiterreisen können und in das Regime des Hot Spot-Centres eintreten und sich zu großen Teilen zur Steigerung ihrer Mobilität den Registrierungs- und Verwaltungsprozeduren fügen mussten. Auf kleinräumigerer Ebene drückte sich die Mobilität als Handlungsmöglichkeit vor allem im Zugang zu institutionell und strategisch wichtigen Arealen wie EASO oder dem New Arrival-Areal aus. Dadurch, dass sich die Verwaltungshandelnden (mit Abstufungen) frei bewegen konnten und somit eine höhere Mobilität besaßen, konnten sie sich und andere zu Gunsten der 
Verwaltung positionieren und erhielten mehr Handlungsressourcen. Dies drückt sich in der Möglichkeit aus, sich und andere zu mobilisieren, also der Theorie nach durch Mobilität bzw. Bewegung zu regieren. Die Verwaltungshandelnden konnten sich aus der Interaktion zurückziehen, bestimmte Personengruppen aus einem bestimmten Bereich heraushalten oder innerhalb von Bereichen immobilisieren, sodass die Handlungsmöglichkeiten geflüchteter Personen in hohem Ausmaß eingeschränkt worden sind. Dies bezieht sich nicht nur auf die Mobilisierung von Personen. Auch die Mobilisierung von Gütern und Informationen besaßen Einfluss auf die Handlungsressourcen der Asylsuchenden. Zwischen beidem besteht jedoch ein Zusammenhang: Erhöht sich die Mobilität der Geflüchteten, steigt auch ihr Zugang zu Informationen und Versorgungsleistungen und umgekehrt, was auf die komplexen Wechselverhältnisse verweist.

Wie sich in der Empirie zeigt, sind die Praktiken der Mobilisierung mit den übergeordneten Systemen der Zirkulation verschränkt, sei es auf der übergeordneten Ebene des europäischen und griechischen Asylsystems, aber auch innerhalb des Lagers. So waren die Mobilisierungstechniken darauf ausgelegt, einen möglichst flüssigen Ablauf von Verwaltung des Lagers und Abwicklung des Asylsystems im Sinne der Verwaltenden zu gewährleisten. Das bedeutet freilich nicht, dass die Asylgesuche möglichst schnell abgewickelt wurden, denn in der übergeordneten Politik und der konkreten lokalen Ausformung lässt sich eine Tendenz zur Verlangsamung der Zirkulation von Asylsuchenden bis hin zur direkten Inhaftierung und Abschiebung erkennen.

Mit speziellem Fokus auf die Barrieren wurden diese und damit in Verbindung stehende Durchgänge auf unterschiedliche Weise in soziale Praktiken mit einbezogen, um Asylsuchende entweder zu mobilisieren, zu immobilisieren sowie sie $\mathrm{zu}$ lokalisieren. Dabei wurde durch und über Barrieren hinweg kommuniziert, sie beeinflussten damit die Interaktion bzw. wurden aktiv in diese einbezogen. Fenster und Türen konnten hingegen genutzt werden, um Verwaltungshandeln entweder direkt abzuwickeln oder die Flüsse eben auf jene $\mathrm{Zu}$ - und Durchgänge zu konzentrieren. Zusätzlich dazu konnte über die Barrieren Abstand zwischen den Verwaltungshandelnden und den Asylsuchenden hergestellt werden: Entweder, um Konfrontationen zu vermeiden oder um Asylsuchende, meist mit Verweis auf Abgrenzungen oder ihnen zugeschriebene Positionen, zu mobilisieren. Die an der Interaktion Beteiligten wurden also mit Rückbezug auf die Raum- und Mobilisierungstheorie durch Bewegung, aber vor allem unter Einbezug der Zäune und Theken, unterschiedlich in Beziehung gesetzt und erhielten dadurch unterschiedliche Handlungsressourcen zueinander. Dabei lassen sich zwei Hauptfunktion der Barrieren identifizieren: Zum einen der Ein- und Ausschluss von Personen, zum anderen die partielle und kontrollierte Durchlässigkeit als Mittel der Kontrolle von Zirkulation als auch der Mobilisierung einzelner Personen. Während durch restriktive Zugänge Positionen zugewiesen wurden, nützt die eingeschränkte Bewegungsfrei- 
heit der klaren Lokalisierung und Registrierung, im Falle der Detention auch der Isolierung von Zugängen zu Institutionen und Informationen.

Der ersten Analyse folgend können einige Stellen identifiziert werden, die durch weitere Forschung und kleinteiligere Analyse gefüllt werden sollten: In Bezug auf das Feld selbst erscheint es notwendig, Transformationen und neue Erscheinungsformen der Praktiken der (Im-)Mobilisierung zu identifizieren, die aus dem Brand und der damit einhergehenden grundlegenden Reorganisierung des Feldes der Migration in Form eines neuen und potentiell zukünftigen Lagers hervorgehen, und sie darauf zu untersuchen, wie Barrieren und andere Materialitäten mit einbezogen werden. Die Ankündigung der griechischen Regierung, ein geschlossenes Lager errichten zu wollen, gibt einen ersten Vorgeschmack. Zusätzlich müssten etwa die in der Theorie aufgeworfenen Subjektivierungsund Selbstregulationsweisen infolge der Verknüpfung von Raum und Wissen sowie symbolischer Ordnungen näher beleuchtet werden. Durch die weitere Durchführung und Auswertung von Interviews können nicht nur diese, sondern auch subtilere Gegenstrategien identifiziert werden, die das Feld grundlegend mit konstituieren und einen nuancierteren Blick auf eben jenes zulassen. Es erscheint ebenfalls als gewinnbringend, das Feld dahingehend zu durchleuchten, welche weiteren Materialitäten und Technologien ${ }^{6}$ in Verbindung mit der Regierungshandlung durch Barrieren stehen, um breitere Funktionsweisen und auch Brüche, die unter anderem durch zunehmende Komplexität auftreten, offenzulegen. Zusätzlich dazu schien immer wieder eine Analyseachse durch, die vor allem in der Geographie wieder mehr Beachtung findet und schon implizit in der Theorie mitgeschwungen ist: die der räumlichen Skala. Im Beispiel der Aussetzung des Asylverfahrens und der sich daraus ergebenden veränderten Verwaltungshandlungen kann argumentiert werden, wie die unterschiedlichen räumlichen Ebenen ineinandergreifen und sich gegenseitig stützen bzw. konstituieren. Das Zusammenbringen der Regierung von Flüssen auf übergeordneter Ebene mit der Mobilisierung auf lokaler Ebene sollte demnach ebenfalls im Zentrum weiterer Analyseschritte stehen, um die Funktionsweisen des Lagers als Teil des Grenzregimes adäquat beschreiben und in Beziehung setzen zu können.

\section{Literaturverzeichnis}

Amicelle, Anthony/Côté-Boucher, Karine/Dupont, Benoît/Mulone, Massimiliano/Shearing, Clifford/Tanner, Samuel (2017): „Criminology in the face of 
flows: reflections on contemporary policing and security« in: Global Crime 18, S. 165-175.

Aradau, Claudia (2016): »Political grammars of mobility, security and subjectivity«, in: Mobilities 11, S. 564-574.

BalkanInsight (2020): Greece Presses Case for Closed Refugee Centres after Moria COVID-19 Case, vom 09.09.2020, https://balkaninsight.com/2020/09/09/gr eece-presses-case-for-closed-refugee-centres-after-moria-covid-case/, Abrufdatum: 01.10.2020.

Bærenholdt, Jørgen Ole (2013): „Governmobility: The Powers of Mobility«, in: Mobilities 8, S. 20-34.

Belina, Bernd (2017): Raum. $\mathrm{Zu}$ den Grundlagen eines historisch-geographischen Materialismus, Münster: Westfälisches Dampfboot.

Davidson, Anna (2020): »Radical Mobilities«, in: Progress in Human Geography [submitted paper].

Forman, Peter J. (2018): „Circulations beyond nodes: (in)securities along the pipeline«, in: Mobilities 13, S. 231-245.

Foucault, Michel (1976): Mikrophysik der Macht. Über Strafustiz, Psychiatrie und Medizin, Berlin: Merve.

Foucault, Michel (2016): »Überwachen und Strafen. Die Geburt des Gefängnisses«, in: Michel Foucault, Hauptwerke, Frankfurt a.M.: Suhrkamp, S. 701-1020.

Foucault, Michel (2017): Sicherheit, Territorium, Bevölkerung. Geschichte der Gouvernementalität I, Frankfurt a.M.: Suhrkamp.

Füller, Henning/Michel, Boris (2012): »Einleitung: Raum als Heuristik für die sozialwissenschaftliche Machtanalyse«, in: Henning Füller/Boris Michel (Hg.), Die Ordnung der Räume. Geographische Forschung im Anschluss an Michel Foucault, Münster: Westfälisches Dampfboot, S. 7-22.

Gilliom, John (2005): »Resisting Surveillance«, in: Social Text 83, S. 71-83.

Hänsel, Valeria (2019): Gefangene des Deals. Die Erosion des europäischen Asylsystems auf der griechischen Hotspot-Insel Lesbos, München: bordermonitoring.eu e.V.

Hess, Sabine/Kasparek, Bernd/Kron, Stefanie/Rodatz, Mathias/Schwertl, Maria/Sontowski, Simon (2017): "Der lange Sommer der Migration. Krise, Rekonstitution und ungewisse Zukunft des europäischen Grenzregimes«, in: Sabine Hess/Bernd Kasparek/Stefanie Kron/Mathias Rodatz/Maria Schwertl/Simon Sontowski (Hg.), Der lange Sommer der Migration. Grenzregime III, Berlin/Hamburg: Assoziation A, S. 6-24.

Humanrightswatch (2020): Greece: Nearly 2,000 New Arrivals Detained in Overcrowded, Mainland Camps, vom 31.03.2020, https://www.hrw.org/news/ 2020/03/31/greece-nearly-2000-new-arrivals-detained-overcrowded-m_ainland-camps, Abrufdatum: 12.08.2020. 
Huxley, Margo (2008): »Space and Government: Governmentality and Geography«, in: Geography Compass 2(5), S. 1635-1658.

Infomigrants (2020): Greece has >no right 03.03.2020, https://www.infomigrants.net/en/post/23142/greece-has-no-right -to-suspend-asylum-applications-un, Abrufdatum: 12.08.2020.

Inhetveen, Katharina (2010): Die politische Ordnung des Flüchtlingslagers. Akteure - Macht - Organisation. Eine Ethnographie im Südlichen Afrika, Bielefeld: transcript.

Kasparek, Bernd (2017): »Routen, Korridore und Räume der Ausnahme«, in: Sabine Hess/Bernd Kasparek/Stefanie Kron/Mathias Rodatz/Maria Schwertl/Simon Sontowski (Hg.), Der lange Sommer der Migration. Grenzregime III. Berlin/Hamburg: Assoziation A, S. 38-51.

Klauser, Francisco (2017): Surveillance and Space, London: SAGE.

Kreichauf, René (2017): »Michel Foucault: Raum als relationales Mittel zum Verständnis und zur Produktion von Macht«, in: Frank Eckardt (Hg.), Schlüsselwerke der Stadtforschung, Wiesbaden: Springer VS, S. 411-433.

mare liberum (2020): Moria 2.0 - The reproduction of inhumanity, vom 25.09.2020, https://mare-liberum.org/en/news/moria-2-o-the-reproductionof-inhumanity/, Abrufdatum: 01.10.2020.

Marquardt, Nadine/Schreiber, Verena (2012): »Die Neue Kulturgeographie und Foucault. Arbeit mit und in gemischten Zuständen«, in: Henning Füller/Boris Michel (Hg.), Die Ordnung der Räume. Geographische Forschung im Anschluss an Michel Foucault, Münster: Westfälisches Dampfboot, S. 23-53.

Pallister-Wilkins, Polly (2016): »How walls do work: Security barriers as devices of interruption and data capture«, in: Security Dialogue 47, S. 1-14.

Pallister-Wilkins, Polly (2018): »Hotspots and the geographies of humanitarianism«, in: Environment and Planning D: Society and Space o(0), S. 1-18.

Rijke, Alexandra (2020): »Checkpoint Knowledge: Navigating the Tunnels and Al Waja Checkpoints in the Occupied Palestinian Territories«, in: Geopolitics, S. 122.

Rosière, Stéphane/Jones, Reece (2012): »Teichopolitics: Re-considering Globalisation Through the Role of Walls and Fences«, in: Geopolitics 17, S. 217-234.

Salter, Mark (2013): »To Make Move and Let Stop: Mobility and the Assemblage of Circulation«, in: Mobilities 2013, S. 7-19.

Sheller, Mimi/Urry, John (2006): The new mobilities paradigm, in: Environment and Planning A 38, S. 207-226.

Soykan, Cadivan (2017): »Turkey as Europe's Gatekeeper. Recent Developments in the Field of Migration and Asylum and the EU-Turkey-Deal of 2016«, in: Sabine Hess/Bernd Kasparek/Stefanie Kron/Mathias Rodatz/Maria Schwertl/Simon Sontowski (Hg.), Der lange Sommer der Migration. Grenzregime III. Berlin/Hamburg: Assoziation A, S. 52-60. 
Spektrum (2020): Lexikon der Geographie: Barriere, https://www.spektrum.de/lex ikon/geographie/barriere/733, Abrufdatum: 12.08.2020.

Tazzioli, Martina (2019): »Governing migrant mobility through mobility: Containment and dispersal at the internal frontiers of Europe«, in: EPC: Politics and Space 38(1), S. 3-19.

The Guardian (2020): Lesbos coronavirus case sparks fears for refugee camp, vom 11.03.2020, https://www.theguardian.com/global-development/2020/ma $\mathrm{r} / 11 /$ lesbos-coronavirus-case-sparks-fears-for-refugee-camp-moria, Abrufdatum: 12.08.2020.

Thrift, Nigel (2007): »Overcome by Space: Reworking Foucault«, in: Jeremy Crampton/Stuart Elden (Hg.), Space, Knowledge and Power. Foucault and Geography, Hampshire: Routledge, S. 53-56.

\section{Interviews und Beobachtungsprotokolle}

Interview mit Hamid vom 23.03.2019

Interview mit Osei vom 03.04.2019

Beobachtungsprotokoll vom 13.03.2019

Beobachtungsprotokoll vom 15.03.2019

Beobachtungsprotokoll vom 19.03.2019

Beobachtungsprotokoll vom 21.03.2019

Beobachtungsprotokoll vom 29.03.2019 
Grenzen

Symbolische Ordnungen

Materialitäten 



\section{Transitzentrum oder: Über die (Un-)Durchlässigkeit von (Lager-)Grenzen}

Lea Gelardi

\section{Zusammenfassung}

Der Beitrag stützt sich auf Erkenntnisse einer empirischen Forschungsarbeit und fokussiert restriktive Zugangspraktiken eines bayerischen Transitzentrums (jetzt: Ankerzentrum). Transitzentren wurden 2017 als Unterbringungsform für sog. Asylbewerber*innen mit geringer Bleibeperspektive eröffnet und 2018 in Ankerzentren umgewandelt. Offizielle Ziele sind die Beschleunigung der Verfahren sowie die Ermöglichung zeitnaher Rückführungen. Die Ergebnisse der Forschung zeigen Mechanismen von Exklusion, Isolation, Regulierung und Kontrolle, die mit theoretischen Ansätzen der traditionellen Lagerforschung in Beziehung gesetzt werden. Es wird ersichtlich, wie besondere Raumspezifika, Zutrittsbeschränkungen und -verbote für Unterstützer*innengruppen und (andere) bürgerschaftlich Engagierte sowie diverse (Kommunikations-)Kontrollpraktiken charakteristisch für das Transitzentrum sind. Diese tragen zur Abschottung und Distanzierung der Bewohner*innen bei, welche sich durch das `Festsetzen<, der Immobilisierung der Bewohner*innen in der Unterkunft, verstärkt. Der Zugang zur Außenwelt ist zudem aufgrund rechtlicher und organisationaler Hürden eingeschränkt. Trotz einiger Cemeinsamkeiten zeigen sich im bayerischen Transitzentrum auch Abweichungen von stotalen< Formen der Kasernierung bzw. des Lagers. Vor allem aufgrund der vielen beteiligten Akteur*innen und deren fortlaufenden (politischen) Kämpfe und Aushandlungen ist die Durchlässigkeit der (Lager-)Grenzen zu betonen. Das >Lager und damit verbundene Grenzen bzw. Grenzziehungen sind nicht total, sondern durchlässig und veränderbar, was sich insbesondere anhand der divergierenden Interessen und unterschiedlich genutzten Handlungsspielräume der Akteur*innen in Kommunen, Wohlfahrtsverbänden und der Zivilgesellschaft zeigt. Es handelt sich bei den beschriebenen exklusiven und restriktiven Praktiken somit nicht um >totale< Ausschlusspraktiken, sondern um dynamische und veränderbare Grenzziehungsprozesse, die unterschiedliche (Aus-)Handlungsfelder des täglichen Lebens betreffen, fortlaufend hervorgebracht werden und immer umkämpft sind. 


\section{Summary}

This article is based on findings of empirical research and focuses on restrictive access practices in a Bavarian transit centre (now: Anker centre). Transit centres were opened in 2017 as a form of accommodation for so-called asylum seekers with few prospects of staying in Germany and were converted into Anker centres in 2018. The official goals are to speed up procedures and to enable prompt deportations. Results of the research project show mechanisms of exclusion, isolation, regulation and control that are put in relation to theoretical approaches of traditional camp research. It becomes apparent how particular spatial conditions, access restrictions and prohibitions for supporter groups and (other) civic engagement as well as diverse (communication) control practices are characteristic of the transit centre. These contribute to the isolation and distancing of the residents, an effect that is intensified by the sfixation', the immobilisation of the residents in the accommodation. Access to the outside world is also restricted due to legal and organisational barriers. Despite some common features, the characteristics of the Bavarian transit centre also deviate from stotal forms of barracking or camps. The permeability of (camp) borders should in particular be emphasised in view of the many actors involved and their ongoing (political) battles and negotiations. The camp and the borders and demarcations associated with it are not total, but permeable and changeable, which is particularly evident in the diverging interests and scope for action of the actors in municipalities, welfare associations and civil society that is used in different ways. Thus, the exclusive and restrictive practices described are not stotal exclusionary practices, but dynamic and changeable processes of bordering that affect different fields of action (and negotiation) in daily life, and that are produced on a continuous basis and are always contested.

\section{Einleitung}

Immer wieder rückt die Unterbringung von Geflüchteten in Lagern in den öffentlichen Diskurs. Zuletzt im Frühjahr 2020 hat sich deutlich gezeigt, dass Sammelunterkünfte die dort untergebrachten Menschen einem hohen Gesundheitsrisiko durch das Corona-Virus SARS-CoV-2 aussetzen. Im Jahr 2018 wurde die Einrichtung von Ankerzentren als zentralisierte Sammelunterkünfte öffentlich diskutiert. Dabei geraten regelmäßig die Kontinuitäten und Brüche der Unterbringung von Geflüchteten aus dem Blick. In diesem Beitrag werden daher die bayerischen Transitzentren diskutiert, die nur wenig öffentliche sowie wissenschaftliche Aufmerksamkeit erhielten. Das Konzept der Transitzentren hatte nur kurz Bestand; es wirft gleichwohl einen erkenntnisreichen Blick auf Begründungszusammenhänge der 2018 eingeführten Ankerzentren: »[W]ir knüpfen an bestehende Einrichtun- 
gen und die erfolgreichen Konzepte unserer bayerischen Transitzentren an « (Bayerische Staatskanzlei 2018: 3), verkündete die bayerische Staatsregierung und ließ damit implizit wissen, dass die Verkündung der Einführung von Ankerzentren im Koalitionsvertrag der Bundesregierung 2018 eine bayerische Handschrift trägt.

Es gab drei Transitzentren, je eines in Manching/Ingolstadt, Regensburg und Deggendorf. Diese wurden 2018 (mit den weiteren bayerischen Aufnahmeeinrichtungen Bamberg, Zirndorf, Schweinfurt und Donauwörth) in Ankerzentren umgewandelt (vgl. BStMI 2018). Statt einer bayernweiten Verteilung der Asylbewerber*innen auf die Kommunen sollten jene mit vermeintlich "geringer Bleibeperspektive« nun zentralisiert untergebracht werden. Damit sollten Verfahren beschleunigt und zeitnahe Rückführungen erreicht werden (vgl. Bayerische Staatskanzlei 2017: 7). Bei Transitzentren handelte es sich um besondere Aufnahmeeinrichtungen im Sinne des Asylgesetzes. Dort sollten Asylbewerber*innen untergebracht werden, um sie einem beschleunigten Asylverfahren zu unterziehen. Das Bundesamt für Migration und Flüchtlinge (BAMF) unterhielt dafür Außenstellen in den Transitzentren. Die Pflicht zum Aufenthalt in Aufnahmeeinrichtungen betrug in der Regel maximal sechs Monate. Diese Beschränkung galt jedoch nicht für Personen aus »sicheren Herkunftsstaaten «, welche überwiegend in Transitzentren untergebracht wurden. ${ }^{1}$

Der vorliegende Beitrag basiert auf einem 2018 von mir durchgeführten ethnografischen Forschungsprojekt, in dem ich Regulierungs- und Kontrollpraktiken in einem Transitzentrum untersucht habe. ${ }^{2}$ Anhand des empirischen Materials werden die Zugänge im Kontext des Transitzentrums analysiert. Die leitenden Forschungsfragen lauteten: Auf welche Weise wird der Zutritt zur Einrichtung für bestimmte Personen (insbesondere bürgerschaftlich Engagierte) reguliert? Welche Rolle spielen hierbei auch materielle und symbolische Dinge und Artefakte? Inwiefern wird den Bewohner*innen räumliche und soziale Mobilität in Form von gesellschaftlicher Teilhabe ermöglicht oder verwehrt? Welche Rolle spielt der (Nicht-)Zugang zu Informationen v.a. für Mitarbeitende der dort tätigen Wohlfahrtsverbände und bürgerschaftlich Engagierte, verknüpft mit einer Kommunikationskontrolle bei Mitarbeitenden der Kommune, Regierung und Betreiberfirma?

Anhand der Beobachtungen und vor dem Hintergrund einer kritischen Grenzund Migrationsforschung zeigen sich nicht allein exkludierende Praktiken, sondern ebenso Praktiken, die auf eine Durchlässigkeit der Lagergrenzen schließen

Personen aus sicheren Herkunftsstaaten wurden für die gesamte Dauer des Asylverfahrens dort untergebracht, alle anderen höchstens zwei Jahre (vgl. § 47 Abs. 1a und 1b AsylC). Seit dem 21.08.2019 gilt die Sechsmonatsregelung in Aufnahmeeinrichtungen nur noch für Kinder, deren Eltern bzw. Sorgeberechtigte und Geschwister.

2 Aus Anonymisierungsstrategien wird weder der Name des Transitzentrums noch der Dependancen genannt. 
lassen. Mit der Sichtbarmachung der Permeabilität der Lagergrenzen werden Lagertheorien infrage gestellt, die auf die Totalität von Lagergrenzen verweisen. $\mathrm{Zu}$ dem wird gezeigt, inwiefern die Aushandlungen der Zugänge als Grenzziehungsprozesse zu konzeptualisieren sind.

\section{Das Transitzentrum als Lager}

In diesem Abschnitt werden Mechanismen der Exklusion, Isolation, Restriktion, Regulierung und Kontrolle im Transitzentrum anhand der Analyse empirischen Materials aufgezeigt und mit Blick auf die Lagertheorien von Goffman (1972) und Foucault $(2005,1979)$ diskutiert. ${ }^{3}$ Hierbei soll kein umfassender Forschungsstand dargestellt, sondern nützliche theoretische »Sehhilfen « (Scheffer 2002: 370) direkt mit der Empirie in einer integrierenden Darstellung zusammengebracht werden. Ziel ist nicht, theorieprüfend vorzugehen, sondern sozialwissenschaftliche Theorien weiterzuentwickeln und bestehende Ansätze $\mathrm{zu}$ »irritieren « (Breidenstein et al. 2015: 166). Die empirischen Daten stammen aus einer ethnografischen Feldforschung, die 2018 durchgeführt wurde und umfassen Gesprächs- und Beobachtungsprotokolle sowie Feldnotizen, die im Rahmen »informelle[r] Gespräche« (ebd.: 80, Herv. i.O.) am Telefon und auf diversen Treffen und Veranstaltungen ${ }^{4}$ sowie $^{-}$ »explizite[r] Interviews« (ebd., Herv. i.O.) erhoben wurden. Die Interviews wurden mit zehn Personen geführt, darunter hauptamtliche Mitarbeiter*innen der Kommune sowie der örtlichen Wohlfahrtsverbände und mit bürgerschaftlich Engagierten, die im Transitzentrum tätig waren. Weiterhin erfolgten einige teilnehmende Beobachtungen im Rahmen eines sogenannten Infobusses, in dem Flüchtlingsräte und Amnesty International Beratungsgespräche anboten.

\section{Zutrittsverbote und -kontrollen: Praktiken des Öffnens und Schließens}

Das Transitzentrum kann als Heterotopie im Sinne Foucaults, als »anderer Ort im Verhältnis zu den gewöhnlichen kulturellen Orten « (Foucault 1992: 41) gefasst werden. Es stellt einen Gegenraum dar, der u.a. durch eine spezielle Öffnungs- bzw. Schließungslogik charakterisiert wird. Foucault führt aus, dass

3 Auch Agamben und Arendt werden in der gegenwärtigen und v.a. rechtstheoretischen und rechtsphilosophischen Lagertheorie häufig herangezogen, scheinen aber für die Diskussion in vorliegendem Beitrag aus soziologischem und empirischem Blickwinkel weniger gewinnbringend (vgl. hierzu auch: Bochmann 2017: 2). Für eine kritisch-rechtstheoretische Auseinandersetzung mit Agamben siehe den Beitrag von Anne-Marlen Engler in diesem Band.

4 Bspw. Vernetzungstreffen von Wohlfahrtsverbänden und öffentliche Veranstaltungen der Kommune zum Transitzentrum sowie Treffen einer Beratungsgruppe von Amnesty International. 
»Heterotopien stets ein System der Öffnung und Abschließung besitzen, welches sie von der Umgebung isoliert. Einen heterotopen Ort betritt man nicht wie eine Mühle. Entweder wird man dazu gezwungen [...] oder man muss Eingangs- und Reinigungsrituale absolvieren« (Foucault 2005: 18).

Im Transitzentrum wird die Abschließung durch die Eingangskontrollen besonders hervorgehoben. Die Bewohner*innen sind rechtlich-administrativ dazu gezwungen in der Einrichtung zu wohnen. Bewohner*innen und Nicht-Bewohner*innen erleben am Eingangsbereich verschiedene »Eingangsrituale« wie die allgemeinen Ausweiskontrollen. Bei Bewohner*innen werden zudem häufig Taschen auf eine Vielzahl von Lebensmitteln oder weitere verbotene Gegenstände kontrolliert. Für Besucher*innen muss vor dem Besuch eine von der zuständigen Regierung bestätigte Anmeldung vorliegen.

Es gibt auch einige Personen und Gruppen, die prinzipiell keinen Zugang zur Einrichtung erhalten. Diese Zutrittsbeschränkungen erfuhr ich selbst in meiner Rolle als Forscherin. Schriftliche Anfragen an die zuständige Bezirksregierung, um zu Forschungszwecken Zugang zu erhalten, wurden nie offiziell beantwortet. Die Einrichtungsleitung erklärte mir am Telefon, dass für mich ein freies Bewegen innerhalb des Transitzentrums und beliebige Gespräche mit den Bewohner*innen nicht erlaubt seien. Ein Besuch bei den Wohlfahrtsverbänden sei prinzipiell möglich, dieser wäre dann aber auf deren Wirkungsbereich beschränkt. Neben den Wohlfahrtsverbänden gibt es weitere zivilgesellschaftliche Organisationen, die den Bewohner*innen Verfahrens- bzw. Rechtsberatung anbieten, jedoch keinen Zutritt erhalten. Mitglieder von zwei Flüchtlingsräten sowie einer Ortsgruppe von Amnesty International organisierten daher ihr Beratungsangebot in Infobussen, die sich - nachdem sie keine Zugangsberechtigung erhielten - in der Nähe der Ein- und Ausgänge des Transitzentrums und seiner Dependancen postierten. Auch Angehörige der Presse erhalten in der Regel keinen ungehinderten Zutritt. Stattdessen werden Besuchstermine organisiert, für die im Vorfeld einige Vorkehrungsmaßnahmen getroffen werden. Wie Gesprächspartner*innen berichteten, werden in diesem Zuge die Anlagen besonders hergerichtet und diejenigen Zimmer exemplarisch gezeigt, die nicht bewohnt werden. Mitarbeitende der Wohlfahrtsverbände wurden bei offiziellen Terminen meist nicht einbezogen, beispielsweise um Stellung zu beziehen oder über ihre Arbeit zu berichten oder sie wurden erst gar nicht über die Pressebesuche informiert. Die Vermutung liegt nahe, dass diese Einschränkungen gegenüber Presse, Forscher*innen und Unterstützer*innengruppen dazu dienen, den Bilder- und Informationsfluss an die Öffentlichkeit zu kontrollieren.

Es gibt Akteur*innen, die prinzipiell Zutritt zur Einrichtung erhalten, der aber mit Komplikationen verbunden ist. Mitarbeiter*innen der Wohlfahrtsverbände und bürgerschaftlich Engagierte berichten, dass es bei den Eingangskontrollen 
regelmäßig zu Situationen kommt, bei denen der Zutritt nicht oder nur nach einigen Aushandlungen gewährt wird. Diese Probleme treten hauptsächlich bei den bürgerschaftlich Engagierten auf, die Bewohner*innen während ihres Asylverfahrens unterstützen, z.B. wenn sie diese zu Behörden begleiten.

»Und da kam dann eben dieser Vorfall, dass ich zuerst reingelassen wurde. Und dann rannte mir quasi der Security Mann nach, nachdem er dann [...] bei der Regierung Bescheid gesagt hatte und hat gesagt: [Name], es tut mir leid, Sie müssen wieder gehen. Dann habe ich gesagt: Wieso? Ja, Anweisung von der Regierung. Dann habe ich gesagt: ]a, jetzt geben Sie mir fünf Minuten. [...] Wir regeln das jetzt hier schnell [...]. Jetzt haben Sie mir ja eh schon gesagt, dass man nicht aufs Zimmer darf. [...] Und wir haben uns ja eh da vorne in diesem [Name der Betreiberfirma] Gebäude getroffen. Und dann hat er gesagt: Ja, also er drückt jetzt beide Augen zu und kommt dann in fünf Minuten wieder und dann kam er nach einer Minute wieder und hat gesagt: Tut mir leid, Sie müssen jetzt gehen. Und dann haben sie mich tatsächlich rausgeschmissen. «(Interview mit Ehrenamt B) ${ }^{5}$

Einige der bürgerschaftlich Engagierten stehen normalerweise auf einer Liste, die in der Regel einen Zugang ohne weitere Bestätigungen erlaubt und der Betreiberfirma vorliegt. Allerdings erfährt diese Form des vermeintlich »erleichterten« Zugangs auch immer wieder Abweichungen, wie das obige Beispiel einer bürgerschaftlich engagierten Person zeigt.

\section{Praktiken der Immobilisierung}

Ähnlich wie es für »totale« (Goffman 1972) Unterbringungsformen charakteristisch ist, werden die Bewohner*innen im Transitzentrum vorschriftsmäßig untergebracht sowie bürokratisch verwaltet und kontrolliert. Räumliche und damit soziale Isolation wird durch die spezielle Öffnungs- und Schließungslogik in der Unterkunft begünstigt. Im Folgenden werden materielle und symbolische Restriktionen

Um die Anonymität zu wahren und keine Rückschlüsse aufdie Personen zuzulassen, erhalten die Gesprächspartner*innen Pseudonyme. Diese ergeben sich aus deren Tätigkeit ( $>$ Kommunals, >Wohlfahrtı, , Ehrenamt`) und der Reihenfolge der stattgefundenen Cespräche (A, B, C etc.). Es werden keine Hinweise gegeben, die auf die genaue Berufsbezeichnung der Person oder ihr Geschlecht schließen lassen könnten. Namen von Personen, die in den Cesprächen genannt werden, werden unkenntlich gemacht. Die Geschlechter der Personen werden zufallsbasiert verändert oder bleiben gleich. Andere Bezeichnungen, die auf den genauen Ort schließen könnten, werden herausgenommen bzw. geändert. Zum Schutz der Cesprächspartner*innen wird somit an einigen Stellen auf detaillierte Beschreibungen konkreter Situationen verzichtet, um auch hier Rückschlüsse zu vermeiden. Diese Angst der Gesprächspartnerinnen wurde auch immer wieder im Rahmen der Cespräche deutlich, wie im Folgenden noch ausgeführt wird. 
wie die Architektur des Transitzentrums ${ }^{6}$ und der begrenzte Ressourcenzugang als Praktiken der Immobilisierung diskutiert. Foucault beschreibt im Zusammenhang mit Disziplinaranstalten das Charakteristikum der »Klausur, die bauliche Abschließung eines Orts von allen anderen Orten« (Foucault 1979: 181, Herv. i.O.). Diese Eigenschaft zeigt sich neben den Eingangskontrollen an der unmittelbaren Umgebung des Transitzentrums und seiner Dependancen. Bei einigen Dependancen grenzen keine anderen Gebäude an die Einrichtungen. Bis auf eine Dependance liegen alle in peripherer Lage. Das Gelände aller Unterbringungseinrichtungen ist durch Tore und Zäune, einzelne durch hohe Bäume abgegrenzt, sodass die Unterkünfte überwiegend außerhalb der Sichtweite der ansässigen Bevölkerung liegen. Die Unterbringung erfolgt in ehemals militärisch genutzten Gebäuden, Containern oder Barracken, die nicht als gewöhnlicher Wohnraum ausgelegt sind.

»Ihr allumfassender oder totaler Charakter wird symbolisiert durch Beschränkungen des sozialen Verkehrs mit der Außenwelt sowie der Freizügigkeit, die häufig direkt in die dingliche Anlage eingebaut sind, wie verschlossene Tore, hohe Mauern, Stacheldraht, Felsen, Wasser, Wälder oder Moore.«(Goffman 1972: 15)

Auch das Transitzentrum distanziert Bewohner*innen und Bevölkerung räumlich durch die architektonische Gestaltung. In den Gesprächen mit den Mitarbeiter*innen sowie bürgerschaftlich Engagierten werden die Anlagen meist als wenig attraktiv und abschreckend beschrieben. Die Mitarbeiter"innen erklären, dass mehr bürgerschaftliche Aktivitäten in zentral gelegenen Einrichtungen stattfinden. So erzählt eine Person, dass sie den Zaun abschreckend empfindet: »Und, es sieht natürlich auch erst mal aus, als würde ich einen Gefängnisbesuch machen. [...] Aber, klar wirkt das abschreckend.« (Interview mit Kommunal A). Ähnlich beschreibt eine andere befragte Person, dass wenn »man da, ja, in einem abgezäunten Gelände ist und die Sicherheitsleute ständig zu sehen sind, das [...] schon sicherlich auf Dauer nicht so einfach [...] wegzustecken [ist].«(Interview mit Ehrenamt A). Daher erinnere sie das Lager an ein »Untersuchungsgefängnis« (ebd.).

Durch Gitter, Zäune, Stacheldraht und die periphere Lage wird im Transitzentrum ehrenamtliches Engagement räumlich-architektonisch entmutigt. Diese Entmutigung kommt ebenfalls durch Situationen der Zugangsgewährung zum Tragen. Bürgerschaftlich Engagierte und teilweise auch Mitarbeitende der Wohlfahrtsverbände müssen sich immer wieder neugierigen Fragen aussetzen, warum sie Einlass gewährt bekommen möchten, mit welchen Bewohner*innen sie sich treffen möchten und aus welchen Gründen.

»Weil, die [Ehrenamtlichen] haben einfach sehr viel Negatives erlebt. [U]nd es ist tatsächlich so, dass sehr restriktiv die Zugänge gehandhabt werden. Also man 
muss genau sagen, für was der Ehrenamtliche da ist, [...] mit wem er sich trifft, für welche Aufgaben er da ist. Und das empfinden natürlich die Ehrenamtlichen sehr einschränkend.«(Interview mit Wohlfahrt A)

Durch die Erschwernisse bei den Eingangskontrollen und die »exkludierende Raumstruktur (Pieper 2013: 267) wird die Entstehung sozialer Kontakte zwischen Bewohner*innen und Bevölkerung erschwert. Die spezifische Raumstruktur spielt auch hinsichtlich der Markierung und Abwertung der Bewohner*innen eine Rolle. Verallgemeinerungen und Stigmatisierungen werden durch die Distanzierung erhöht. »Die bewusste Degradierung des Wohnraumes schreibt sich in den sozialen Raum ein und führt $\mathrm{zu}$ einer öffentlichen Stigmatisierung« (ebd.: 316), die aufgrund des fehlenden Kontakts nicht oder nur geringfügig relativiert bzw. revidiert werden kann. ${ }^{7}$ Die Art des Aufbaus und der Nutzung des Transitzentrums gibt Hinweise auf den Aspekt der Vorläufigkeit und des Provisoriums. Die Unterbringung soll nicht von Dauer sein. Den Bewohner*innen wird eine "geringe Bleibewahrscheinlichkeit « bescheinigt. Darauf verweist schon der Wortbestandteil »Transit« als Bezeichnung für einen Ort des Durchgangs - nicht des Bleibens. Auch die Insassen in Goffmans totaler Institution »[weisen] häufig eine hohe Fluktuation auf « (Goffman 1972: 114). Übersehen wird dadurch jedoch leicht der Aspekt der Dauerhaftigkeit, der permanenten Vorläufigkeit eines Provisoriums, den das Transitzentrum aufweisen kann. Der Aufenthalt erstreckt sich entgegen der durchschnittlichen Verweildauer (vgl. Bayerischer Landtag 2017: 3) für einige Bewohner*innen über einen sehr viel längeren Zeitraum.

Foucault (1979: 280) beschreibt als Zweck von Disziplinareinrichtungen auch das »Festsetzen« sowie die Kontrolle und Verwaltung großer Menschenmengen. Durch die Festsetzung könnten die Insassen kontrolliert, diszipliniert und erzogen werden. Dies entspricht den Funktionsweisen des Transitzentrums, wo die Kontrollen dem Zweck dienen, »zu wissen, wo und wie man die Individuen finden kann« (ebd.). Dies dient dem von der Bayerischen Staatsregierung intendierten Zweck, Abschiebungen durchzusetzen und zu »verhindern, dass sich der Aufenthalt [der Betroffenen, Anm. d.Verf.] verfestigt « (Bayerische Staatskanzlei 2017: 7). Das Verlassen des Transitzentrums ist für die meisten Angelegenheiten im Rahmen des Asylverfahrens - und auch des Aufenthalts generell - nicht vorgesehen. Durch die Zentralisierung befinden sich alle relevanten Behörden und Anlaufstellen vor Ort. Die Einrichtung muss nicht einmal für das Einkaufen verlassen werden, da die Bewohner*innen Catering erhalten und die meisten Lebensmittel nicht mit in die Einrichtung hineingenommen werden dürfen. Für die meisten findet die Beschulung (wenn überhaupt) in der Einrichtung oder einer der Dependan- 
cen statt. ${ }^{8}$ Weiterhin kann die » Residenzpflicht « größere Einschränkungen für die Bewohner*innen mit sich bringen. Muss für einen Termin die Kommune bzw. der Landkreis verlassen werden, ist ein Antrag auf Verlassenserlaubnis notwendig. Die Wahrnehmung eines Termins in einer der größeren Städte in der Nähe ist daher mit organisatorischem und bürokratischem Aufwand verbunden. Charakteristisch für das Transitzentrum ist auch die Umstellung auf ein erhöhtes Sachleistungsprinzip, d.h. dass die Leistungen zum Lebensunterhalt nach dem Asylbewerberleistungsgesetz (AsylbLG) überwiegend in Sachleistungen ausgegeben werden und sich dadurch der Geldbetrag, der den Bewohner*innen zur Verfügung steht, verringert (vgl. Interview mit Kommunal B). Auch damit war das Transitzentrum ein Prototyp des 2018 beschlossenen »Bayerischen Asylplans «, der u.a. darauf abzielte, »das Sachleistungsprinzip [insbesondere in Ankereinrichtungen] maximal umzusetzen« (Bayerische Staatskanzlei 2018: 7). Dadurch wird die Teilhabe am gesellschaftlichen Leben und die selbstbestimmte Gestaltung des eigenen Lebens stark eingeschränkt. ${ }^{9}$ Dies knüpft erneut an das Lagerkonzept nach Goffman an, der von eingeschränkten Möglichkeiten der sozialen Interaktion und Selbstbestimmung zwischen einem Innen und einem Außen des Lagers ausgeht (vgl. Goffman 1972: 15).

Auch wenn vieles darauf hindeutet, dass Techniken der Überwachung im Transitzentrum angewendet werden, betrifft dies nicht alle Lebensbereiche der Bewohner*innen (vgl. ebd.: 18). Es handelt sich nicht wie in »totalen Institutionen « um eine Überregulierung des Alltags bzw. darum, dass »der ganze Tagesablauf [...] vorgeplant wird « (ebd.: 21). Tätigkeiten werden nicht rund um die Uhr reguliert oder kontrolliert, meist betrifft dies nur einzelne Aspekte. Der Tagesablauf ist nicht exakt geplant, es handelt sich hier vielmehr um eine Unter- statt Überregulierung des Alltags, da den Bewohner*innen Möglichkeiten zur freien und selbstständigen Tagesstrukturierung fehlen. Die Bewohner*innen werden immobilisiert und sitzen dadurch überwiegend fest. Dies führt zur Herstellung räumlicher und sozialer Distanz und begünstigt gesellschaftlichen Ausschluss. Es handelt sich weniger um eine zwangsweise Festsetzung (wie z.B. im Gefängnis), da die Einrichtung prinzipiell verlassen werden kann. Das Festsetzen funktioniert über symbolische und bürokratische bzw. organisatorische Barrieren und materiellen Ausschluss aus der Gesellschaft.

Neben der Klausur, der räumlichen Einschließung, spricht Foucault von Verteilungstechniken, die nach dem Prinzip der »Lokalisierung« und »Parzellierung« (Foucault 1979: 183) funktionieren. Am Beispiel der Transitzentren beschreibt dies 
die Zuweisungen, Verteilungen bzw. Verlegungen der Bewohner*innen. Insbesondere sollen Personen mit "geringer Bleibewahrscheinlichkeit « von jenen mit "guter Bleibewahrscheinlichkeit « getrennt untergebracht werden. Dieser Aspekt verstärkt Stigmatisierungen gegenüber der im Transitzentrum untergebrachten Personen. Durch die Kategorien "sichere Herkunftsstaaten « und "geringe Bleibeperspektive« und die damit zusammenhängende Unterbringung im Transitzentrum werden die Bewohner*innen illegalisiert, d.h. sie werden pauschal verdächtigt, keine Schutzgründe zu haben. Ergänzt durch die politisch intendierte Vorannahme, Personen aus »sicheren Herkunftsstaaten« würden im Herkunftsstaat nicht bedroht (vgl. BAMF 2019), wird eine Einteilung in »richtige« und »falsche« (»illegale«) Asylbewerber*innen vorgenommen, die sich räumlich in der Unterbringung in einer je spezifischen Unterkunft manifestiert. Dadurch werden Bewohner*innen des Transitzentrums als nicht-schutzbedürftig und nicht-asylberechtigt kategorisiert, womit wiederum Stigmatisierung und soziale Exklusion als Folgeerscheinungen $\mathrm{zu}$ erwarten sind. Das Bild der »Illegalität« spiegelt sich auch in der Bereitschaft zum bürgerschaftlichen Engagement wider. Mitarbeiter*innen der Wohlfahrtsverbände berichten, dass potenziell Engagierte weniger Interesse daran haben, sich in Transitzentren einzubringen, aufgrund der Annahme, die dort Untergebrachten kämen hauptsächlich aus wirtschaftlichen Gründen und »nur des Geldes wegen« (Interview mit Wohlfahrt B) nach Deutschland.

Die Kategorisierung und Sortierung der Asylbewerber*innen hat Einfluss auf deren Lebensumstände, Rechte und auf die öffentliche (Fremd-)Wahrnehmung. Die Kategorie "geringe Bleibeperspektive« und der damit angenommene kurze Aufenthalt aufgrund vermeintlicher Nicht-Schutzbedürftigkeit soll bestimmte administrative Vorgehensweisen der Anders- bzw. Ungleichbehandlung legitimieren. ${ }^{10}$

\section{Praktiken der Informations- und Kommunikationskontrolle}

Durch die bereits beschriebenen Kontrollen und die restriktiven Zugangsbeschränkungen für Zivilbevölkerung, Presse und Forschung sowie durch die Immobilisierung der Bewohner*innen gelangen nur wenige Informationen über den Betrieb des Transitzentrums in die Öffentlichkeit. Während der Feldforschung konnten Einschränkungen in der Informationsvermittlung auch anhand kommunikativer Praktiken der Mitarbeiter*innen der Wohlfahrtsverbände und der Kommune beobachtet werden. Im Folgenden werden einige Beispiele, an denen sich eine Art

10 Hierzu zählen im Besonderen - und im Unterschied zu Gemeinschaftsunterkünften - erhöhte Kontrollen, erweiterter Sicherheitsdienst, Catering statt Selbstversorgung sowie erhöhtes Sachleistungsprinzip. Siehe zum Thema Bleibeperspektive auch den Beitrag von Simon Sperling und Sebastian Muy in diesem Band. 
Kommunikationskontrolle erkennen lässt, expliziert. Bei den Mitarbeiter*innen der Wohlfahrtsverbände und darüber organisierten bürgerschaftlich Engagierten zeigt sich dies vornehmlich an Aspekten wie Nicht-Information, Verzögerungen und Intransparenz über Zuständigkeiten von Seiten der Betreiberfirma und der zuständigen Bezirksregierung (vgl. Interview mit Wohlfahrt D). Diese sowie die Mitarbeiter*innen der Kommune äußern sich oft nur vorsichtig oder gar nicht.

Während meiner Feldarbeit zeigten sich immer wieder kommunikative Vorsichtsmaßnahmen - insbesondere von Seiten der kommunalen Mitarbeiter*innen:

»Weil, das ist auch wieder [...] eine städtische Stelle. Und, wie formuliert man Missstände so, dass es, also als städtischer Mitarbeiter kannst du es nicht so formulieren wie wenn du halt ein freier Wohlfahrtsträger oder Person XY als Ehrenamtliche bist. [...] Das geht halt einfach nicht. Ja? Und darum sind wir so vorsichtig. « (Interview mit Kommunal A)

Aussagen zur Unsicherheit und Vorsicht der Interviewpartner*innen wurden zum einen explizit geäußert, zum anderen auch durch stumme, implizite Praktiken deutlich. Während des Gesprächs mit einem kommunalen Mitarbeiter zeigte sich, dass er auf manche meiner Fragen nicht antworten wollte oder konnte. Dies äuBerte sich in ausweichenden Aussagen oder durch den Verweis auf eine andere Zuständigkeitsebene: »Ich denke, da muss Ihnen die Regierung [...] Auskunft geben.« (Interview mit Kommunal C)

Alle Gesprächspartner*innen von kommunaler Seite bestätigten, dass es eine Dienstanweisung gibt, dass sie sich öffentlich nicht zum Thema Asyl äußern dürfen. Anfragen zu dieser Thematik müssten immer über die Pressestelle laufen. Während die kommunalen Mitarbeiter*innen dem*der Bürgermeister*in unterstehen und aus dienstrechtlicher Sicht seine*ihre Interessen mitvertreten (müssen), ist dies bei den Wohlfahrtsmitarbeiter*innen (bzw. freiwillig Engagierten) nicht der Fall (Interview mit Kommunal A und Wohlfahrt C). Hiermit ergeben sich auch unterschiedliche Handlungsspielräume. Die Wohlfahrtsmitarbeiter*innen können unabhängiger agieren als die kommunalen Angestellten bzw. Beamt*innen. Dennoch sind auch erstere nicht komplett frei in der Art und Weise, wie sie sich äußern. Ihnen wird von Seiten der Regierung oder der Einrichtungsleitung durchaus signalisiert, wenn sie sich in einem bestimmten Kontext unerwünscht oder »zu politisch« geäußert haben (Interview mit Wohlfahrt C). Daher sei ein Balanceakt in der öffentlichen Kommunikation wichtig, um sich nicht "politisch angreifbar [zu] machen « (ebd.) und bisher Erreichtes wie der erarbeitete Status in der Einrichtung und die Etablierung von Beratungs- und Unterstützungsangeboten sowie Spielräume nicht wieder zu verlieren (vgl. ebd).

Bei E-Mail-Anfragen an die zuständige Betreiberfirma, ob Gespräche mit deren Mitarbeiter*innen möglich seien, wurde ich an die eigene Pressestelle sowie an die Pressestelle und Leitung der zuständigen Bezirksregierung verwiesen, die 
immer in Kopie gesetzt wurden. Bei erneuten Nachfragen wurde mitgeteilt, dass ich eine Anfrage bei der Regierung mit den konkreten Inhalten der Interviews stellen könne und diese dann eventuell an mich herantrete. In einem Telefonat mit der Einrichtungsleitung wurde mir erklärt, es sei nicht so, dass die Mitarbeitenden der Betreiberfirma »Maulkörbe« (Gesprächsprotokoll) tragen würden, allerdings kennten diese teilweise die Gesetze nicht genau. Es solle verhindert werden, dass es $\mathrm{zu} »$ massiven Missverständnissen « (ebd.) komme und Informationen »falsch nach draußen« (ebd.) gelangten. Hierbei seien Formulierungen oft sehr wichtig. Ich solle demnach Fragen für die Betreiberfirma direkt an die Regierung schicken. Damit nichts »Verfängliches nach draußen« (ebd.) gelange, gebe es bei der Pressestelle »Spezialisten, die das erledigen« (ebd.). Auch ein offizielles Gespräch bzw. Interview mit der Einrichtungsleitung konnte nicht geführt werden.

Die genannten Beispiele verdeutlichen, wie restriktive und exkludierende $\mathrm{Zu}$ gangspraktiken, Kontrolle und Regulierung auch kommunikativ hervorgebracht werden. Es lässt sich zusammenfassen, dass sich Mitarbeiter*innen der Wohlfahrtsverbände und bürgerschaftlich Engagierte vermehrt mit Problemen unklarer Zuständigkeiten und Absprachen konfrontiert sehen und oft nicht in Planungen miteinbezogen oder über Neuerungen informiert werden. Kommunale Mitarbeiter*innen äußern sich nicht oder oftmals nur sehr vorsichtig. Gründe dafür werden v.a. in den sehr divergierenden Handlungsspielräumen der Akteur*innen gesehen. Gespräche mit Mitarbeiter*innen der Betreibenden sind gar nicht möglich. Die Strategie der beschränkten Informationsweitergabe wird auch von Goffman aufgegriffen: »[I]n jedem Fall gibt dieses Vorenthalten von Informationen dem Stab besondere Voraussetzungen für die Distanz von den und die Kontrolle über die Insassen.«(Goffman 1972: 20). Diese beschränkte Weitergabe findet nicht nur hinsichtlich der Bewohner*innen, sondern auch einiger Mitarbeiter*innen statt. Die Informationskontrolle dient auch einer in sich stimmigen Außendarstellung, die das Transitzentrum gegenüber der Öffentlichkeit legitimieren soll.

\section{Von totalen zu permeablen Grenz(ziehung)en. Das Transitzentrum aus regimetheoretischer Sicht}

Trotz einiger Gemeinsamkeiten unterscheidet sich das Transitzentrum von totalen Formen der Kasernierung, was in diesem Abschnitt verdeutlicht werden soll.

Für das Transitzentrum konnten Merkmale totaler Institutionen und Disziplinarinstitutionen aufgezeigt werden. Zutreffender erscheinen jedoch biopolitische Aspekte zu sein, da die Regulierungspraktiken vielmehr auf den Kollektivkörper, die Bevölkerung, und nicht auf Individuen ausgerichtet sind. Die Biomacht wirkt - entgegen der Disziplinarmacht - »nicht individualisierend, sondern massenkonstituierend « (Foucault 1993: 30). Als »Regulationstechnologie des Lebens« (ebd.: 
36) stehen bei der Biomacht Maßnahmen zur Optimierung des Lebens im Fokus. Disziplinar- und Biomacht stehen nicht im Gegensatz zueinander, sondern ergänzen sich. Neben Disziplinierungsmechanismen werden so Kontrolle, Produktivität und Optimierung des Kollektivkörpers miteinbezogen. Im Kontext Migration lassen sich Disziplinar- und Biomacht eher als koordinierende und lenkende Aspekte von Regieren verstehen und weniger als Bekämpfung und exklusiv repressive Machtverteilung (vgl. Schulze Wessel 2017: 188).

Mit Blick auf das Transitzentrum können die Praktiken von Regulierung, Kontrolle und Überwachung von Seiten der zuständigen Bezirksregierung und Einrichtungsleitung als Ausführung politisch intendierter Migrationskontrolle bzw. -steuerung verstanden werden. ${ }^{11}$ Aus der Perspektive der Durchführungsinstanzen erhöht sich die »deportability« (De Genova 2002), die tatsächliche Durchführung von Abschiebbarkeit der Bewohner*innen des Transitzentrums, da die Isolation Unterstützungsmöglichkeiten wie Beratungstätigkeiten durch die Bevölkerung bzw. bürgerschaftlich Engagierten erschwert.

Obwohl aber restriktive staatliche Praktiken wie diese zum Zwecke der besseren Abschiebbarkeit zu beobachten sind, funktionieren sie nicht einfach reibungslos. Es ist beispielsweise zweifelhaft, ob die Maßnahmen der Isolation und Hinderung von Unterstützungsangeboten tatsächlich zu höheren Abschiebezahlen führten. Im Sinne der Regimeanalyse sollten daher auch jene Praktiken in den Blick genommen werden, die den Regierungspraktiken entgegenstehen, sie konterkarieren oder sie auf sonstige Weise betreffen.

»Wo vorher von als überwiegend durch staatliche Politik bestimmten Migrationssystemen die Rede war, ermöglicht der Regime-Begriff eine Vielzahl von Akteuren in die Analyse einzubeziehen, deren Praktiken zwar aufeinander bezogen sind, nicht aber in Gestalt einer zentralen (systemischen) Logik. Was den Regimebegriff so bedeutsam macht, ist, dass er es erlaubt, Regulationen als Effekte, als Verdichtungen von sozialen Handlungen zu verstehen und sie nicht funktionalistisch vorauszusetzen.«(Hess/Karakayali 2007: 48)

Der Regimebegriff soll nicht nur auf institutionalisierte, formalisierte und ausschließende Machtformen (bzw. Herrschaft) Bezug nehmen. Vielmehr gilt es die »Untersuchungen von Aushandlungen« (Oltmer 2018: 4) mit ihren Beziehungen, Konflikten und Kooperationen zu fokussieren. Daher soll nun herausgearbeitet werden, inwiefern Regime als Gestaltungs- und Handlungsfelder zu verstehen

11 Hinweise für eine verstärkte politische Steuerung und Regulierung lassen sich auch im Bayerischen Asylplan finden. Dort heißt es: „Zustände wie im Herbst 2015 dürfen sich nicht wiederholen. Unser Weg ist: Steuerung, Begrenzung und Ordnung der Migration« (Bayerische Staatskanzlei 2018: 3). Dies solle u.a. durch Ankerzentren gelingen, die an die Transitzentren anknüpfen. 
sind, an denen heterogene Akteur*innen mit unterschiedlichen Beziehungen, Interessen, Betrachtungsweisen, Normen und Praktiken beteiligt sind. In diesem Zuge wird ebenfalls problematisiert, inwiefern der Begriff der restriktiven oder exkludierenden Praktiken zu statisch und undurchlässig erscheint. Dies soll insbesondere anhand durchlässiger bzw. permeabler Grenzpraktiken (vgl. Schiffauer et al. 2018: 17) verdeutlicht werden. Hierbei werden Aushandlungen bzw. (politische) Kämpfe der Wohlfahrtsmitarbeiter*innen und der bürgerschaftlich Engagierten in den Fokus gesetzt.

Die bisher beschriebenen exkludierenden Praktiken wurden in einschlägigen Arbeiten zu Lagern im Sinne Goffmans und Foucaults konzipiert und damit einseitig auf Dualismen wie Innen und Außen oder Macht und Ohnmacht abgestellt. Dies greift meines Erachtens zu kurz. Der Exklusionsbegriff ist im Zusammenhang mit der Analyse von Migrationsregimen immer wieder kritisiert worden (vgl. Schulze Wessel 2017: 187f.), wird er doch oftmals $\mathrm{zu}$ eindimensional betrachtet: »Exklusion fokussiert somit nicht nur auf die absolute, in dualistischen Kategorien zu erfassende Trennung zwischen Exkludierenden und Exkludierten, benennt nicht allgemein das Andere oder das Außen « (ebd.: 191), sondern sollte vielmehr als Relations- und Prozessbegriff gesehen werden (vgl. ebd.: 190f.; Gerst et al. 2018: 6f.). Schulze Wessel schlägt daher eine »begriffliche Verschiebung [vom Lagerbegriff] hin zur Grenze« (Schulze Wessel 2017: 201) vor. Dies »eröffnet die Möglichkeit, Auseinandersetzungen, Überschneidungen, Transformationen oder Irritationen von Grenzziehungen in den Blick zu bekommen, auch wenn das Machtgefälle und die Ungleichheit zwischen den Akteuren immer mitgedacht werden muss« (ebd.).

So sollte auch nicht Gefahr gelaufen werden, einem »radikal inklusionistischen Forschungsparadigma« (Krasmann/Opitz 2007: 130) folgend, besonders restriktive und exklusive Praktiken aus dem Blick zu verlieren und "gegenüber Ereignissen der Exklusion blind zu werden« (ebd.). Bei totalitären Lagerkonzepten werden die Handlungsfähigkeiten der beteiligten Akteur*innen vernachlässigt und »bleiben bei diesen totalitären Strukturen und Machttypen unterworfene Individuen « (Bochmann 2017: 6). Aus einer grenztheoretischen Perspektive könnten die restriktiven Praktiken als durabel (vgl. Schiffauer et al. 2018: 16f.), aber auch als nicht vollkommen exkludierend oder ausschließend beschrieben werden. Genau hier ist das Potential dieses Konzepts der Grenze zu erkennen. Es bietet die Möglichkeit den Fokus auf Durchlässigkeit statt auf eine Exklusions-Inklusions-Dichotomie zu legen.

Vor allem durch die vielen Akteur*innen und deren fortlaufenden (politischen) Kämpfe und Aushandlungen ist die Durchlässigkeit der (Lager-)Grenzen auch im Falle des Transitzentrums zu betonen. Unterschiedliche Akteur*innen mit teils stark divergierenden Interessen sind mit der Thematik des Transitzentrums bzw. direkt vor Ort beschäftigt. Insbesondere durch die Wohlfahrtsverbände ergeben 
sich immer wieder Aushandlungen, die zu Veränderungen in der Einrichtung führen. Im konkreten Fall des Transitzentrums zeigt sich die Permeabilität der Lagergrenzen in den bereits beschriebenen Praktiken der Mitarbeiter*innen der Wohlfahrtsverbände. Sie wirken durch ihr ständiges Nachfragen und Anprangern, Hinweisen auf Missstände und Berichterstatten auf das Geschehen im Transitzentrum stark ein. Sie betreiben Öffentlichkeitsarbeit, laden in die Einrichtung ein, geben Interviews, knüpfen Kontakte, informieren und akquirieren weitere Unterstützer"innen. Aus dieser intensiven Netzwerkarbeit entstehen neue Zugänge und Verbindungen in das Lager auch für politische und aktivistische Gruppen, wodurch wiederum Aufmerksamkeit für Zustände innerhalb der Einrichtung erlangt wurde. So konnten beispielsweise neue Gerätschaften für Schwangere und Mütter und weitere Unterstützungsleistungen wie zusätzliche Beratungsstellen für spezifische Themen und Freizeitangebote für Bewohner*innen verhandelt und erzielt werden. Auch bürgerschaftlich Engagierte, die immer wieder mit Hindernissen konfrontiert sind, entwickeln stetig sich verändernde Strategien der Unterstützung. Sie konnten beispielsweise dazu beitragen, dass Mitarbeiter"innen der Betreiberfirma an der Einlasskontrolle künftig bei ihren Vorgesetzten anrufen können, wenn eine Person an den Eingangskontrollen nicht auf der Ehrenamts-Liste steht und sie sich unsicher sind, ob Zugang gewährt werden darf oder nicht. Weitere Strategien lassen sich auch am Beispiel der engagierten Gruppen zeigen, die mittels der Infobusse zusätzliche Beratungsangebote für die Bewohner*innen bereitstellen und mit einem Netzwerk von Anwält"innen kooperieren. Nachdem das Einfahren in das Gelände nicht (mehr) gestattet wurde, platzierten sie die Busse in der Nähe der Einrichtungen, damit Bewohner*innen weiterhin die Beratungen in Anspruch nehmen können. Der Infobus fährt in der Regel einmal wöchentlich Dependancen an. Die Akzeptanz, wo genau sich die Busse platzieren dürfen, ist jeweils abhängig von den diensthabenden Mitarbeiter*innen des Sicherheitsdienstes und regelmäßigen Aushandlungen mit diesen. In einem gesonderten Büro außerhalb der Einrichtung können sich Anwält"innen und Bewohner*innen des Transitzentrums regelmäßig treffen. Vorteilhaft ist, dass die Bewohner*innen dafür keinen Antrag auf Verlassenserlaubnis mehr stellen müssen.

Bessere Bedingungen konnten auch für Personen erreicht werden, die nach Beendigung ihres Asylverfahrens einen anerkannten Status erhalten. Diese wurden nach einigen Aushandlungen in Gemeinschaftsunterkünften (GU) untergebracht, obwohl dies eigentlich nicht vorgesehen ist. ${ }^{12}$ Laut den Mitarbeiter"innen stellt dies eine Chance für verbesserte Unterbringungs- und Lebensbedingungen der

12 Asylbewerber*innen können nur in andere Einrichtungen verlegt werden, solange sie noch im Asylverfahren sind oder nach einem abgelehnten Asylantrag. Nach einer Schutzgewährung durch den positiven Bescheid des BAMF müssten sie eigenverantwortlich in private Wohnungen ziehen, was oft sehr schwierig ist und nicht gelingt. 
Bewohner*innen dar. Es wurde zunächst »nicht daran gedacht, dass tatsächlich Menschen eine Anerkennung bekommen« (Interview mit Wohlfahrt C).

»Deswegen sind wir froh, dass es jetzt die Regierung [...] ermöglicht, dass die in GUs verteilt werden. Auch wenn sie anerkannt sind, das dürfen die normalerweise nicht. Das machen die jetzt trotzdem. Weil sie da einfach sich selber versorgen können.«(Interview mit Wohlfahrt B)

Auch die kommunalen Vertreter*innen tragen dazu bei, die Thematik nicht ganz unter Verschluss zu halten, konträr zu den Vorgaben ihres Arbeitgebers. Obwohl die Aspekte des vorsichtigen Äußerns und Nicht-Äußerns anhand kommunikativer Praktiken kommunaler Mitarbeiter*innen explizit wurden, sind einige von ihnen auch an der Zusammenarbeit mit den vor Ort tätigen Wohlfahrtsverbänden interessiert und übernehmen teilweise die Rolle eines Bindeglieds:

»Und ich bin da gern dabei, weil ich bin halt wahnsinnig gut vernetzt. Und kann da sicher auch [...] so ein bisschen taktisch, diplomatisch und durch das Wissen [...] was beitragen. Ich habe ein gutes Verhältnis zur Regierung. [...] Habe auch ein gutes Verhältnis zum Dienstleister. Und werde einen Teufel tun, mir das zu verderben. [...] Und ich glaube, diese Position so zwischen allen Stühlen zu sitzen und neutral zu wirken, das ist so das, was ich halt einbringen kann. [...] Und man hat dann doch mal die Möglichkeit ein bisschen einzuwirken. Ich glaube, es ist ganz praktisch. (lacht).«(Interview mit Kommunal B)

Und weiter: "[A]lso ich denke, jeder muss sich da irgendwie so verbiegen, dass er auf der einen Seite ins System passt. Und auf der anderen Seite irgendwie schauen muss, dass er noch in den Spiegel gucken kann. (Ebd.) Zudem berichten die Mitarbeiter*innen der Wohlfahrtsverbände und bürgerschaftlich Engagierten immer wieder von Einzelpersonen, die - auch auf Seiten der Betreiberfirma oder der Regierung - in unterschiedlichem Maße von ihren Handlungsspielräumen Gebrauch machen. Auf Seiten der Betreiberfirma gebe es beispielsweise Personen, die bestimmte, nicht vorgesehene, Aufgaben übernehmen, z.B. das Übersetzen von Briefen.

\section{Zusammenfassung}

Die Betrachtung restriktiver und exkludierender Praktiken der Organisation eines Transitzentrums hat gezeigt, dass Bezüge zur traditionellen Lagerforschung nützlich sind, diese allerdings an gewissen Stellen zu kurz greifen. Es wurden Mechanismen von Restriktion, Isolation, Exklusion und Regulierung aufgezeigt, welche sich in folgenden Aspekten manifestieren: Zum einen gibt es generelle Zutrittsverbote für bestimmte Personen(gruppen), wie z.B. viele Unterstützungs-/Beratungs- 
gruppen, Presse und Forscher*innen. Zum anderen haben bürgerschaftlich Engagierte immer wieder mit schwierigen Eingangskontrollen umzugehen. Weiterhin wurde gezeigt, wie neben Zutrittsverboten und -beschränkungen auch Immobilisierungspraktiken Bewohner*innen und Umgebung voneinander distanzieren. Aspekte des Festsetzens sowie spezifische Regularien und Vorschriften tragen zu Beschränkungen mit der Außenwelt und zur Immobilisierung der Bewohner*innen bei. Darüber hinaus führen Verteilungstechniken sowie Kategorisierungen wie die "geringe Bleibeperspektive« und die Unterbringung in der spezifischen Einrichtung zu weiterer sozialer Distanz und Stigmatisierungen. Es konnte allerdings auch gezeigt werden, dass die Bewohner*innen im Transitzentrum nicht vollkommen exkludiert oder ausgeschlossen werden. Es sind heterogene Akteursgruppen an der Alltagsgestaltung der Bewohner*innen beteiligt. Auch die bürgerschaftlich Engagierten werden nicht vollkommen exkludiert oder ausgeschlossen, denn es eröffnen sich die Möglichkeiten des Eintritts und es besteht kein generelles Verbot bürgerschaftlichen Engagements (mehr). Die Abschließung ist nicht »total«. Nichtsdestotrotz sollen restriktive Praktiken und ungleiche Machtverhältnisse dadurch nicht verschleiert werden. Die Konzepte des Regimes und der Grenze haben das Potenzial, relationale und dynamische Prozesse, Aushandlungen und Kämpfe besser $\mathrm{zu}$ fassen und somit einen wertvollen Beitrag zu leisten, um die Unterbringung von Geflüchteten in vermeintlich vollkommen abgeschotteten Lagern zu überdenken.

Die Durchlässigkeiten der Grenzen und die damit unvollständige Abgeschlossenheit der Einrichtung kommen besonders durch die Aushandlungen und politische Kämpfe der vielfältig eingebundenen Akteur*innen zum Tragen, die in »Arenen«(Oltmer 2018: 10) von staatlichen, nicht-staatlichen und zivilgesellschaftlichen Akteur*innen sowie den Bewohner*innen des Transitzentrums ausgetragen werden. Es wurde aufgezeigt, inwiefern sich Mitarbeiter"innen, Gruppen und engagierte Einzelpersonen für die Rechte und Bedürfnisse der Bewohner*innen vor Ort einsetzen und diese unterstützen. Trotz verschiedener Beschäftigungsabhängigkeiten versuchen Einzelpersonen und Organisationen über intensive Netzwerkarbeit Aushandlungsprozesse anzustoßen, Handlungsspielräume zu nutzen und zu erweitern. Nicht zuletzt sind die Bewohner*innen Akteur*innen in dieser Ordnung. ${ }^{13}$ Auch sie stellen keine homogene Einheit dar und haben unterschiedliche Beziehungen und Kontakte innerhalb und außerhalb des Transitzentrums. An dieser Stelle wird ein Forschungsdesiderat deutlich. Bewohner*innen zentralisierter Unterbringungsformen sowie weitere Akteur*innen und ihre Grenzverhandlungen sollten in zukünftige Analysen einbezogen werden. Es wurde deutlich gemacht, wie bestimmte symbolische und materielle Dinge und Artefakte (wie z.B. Zäune,

13 Für den Einbezug der Perspektive von Bewohner*innen siehe den Beitrag von Simon Coebel in diesem Band. 
Architektur) den (Nicht-)Zugang zur Einrichtung mitbestimmen und diese als Mitwirkende an Praktiken verhaltensformativ auftreten. Materielle Grenzen sind nicht einfach vorhanden oder ausschließlich exklusiv. Sie sind ebenfalls Teil dynamischer und veränderbarer Grenzprozesse, welche performativ hervorgebracht werden und stets umkämpft sind. Die den Alltag strukturierenden Regeln und Ordnungen erscheinen starr und durabel, doch auch diese sind ein Stück weit veränderbar. Daher ist es wichtig für weitere Vorhaben »Grenzziehungen von der Grenze her zu analysieren« (Gerst/Krämer 2017: 3). Hier ist nicht unmittelbar die topologische Perspektive gemeint. Das Transitzentrum oder andere Einrichtungen können als eine Art Grenzraum betrachtet werden, dessen Grenzziehung über diese Orte hinausgehen und sich in räumlichen, zeitlichen, sozialen, rechtlichen und anderen Trennungen wiederfinden.

\section{Literaturverzeichnis}

Asyldurchführungsverordnung (DVAsyl) vom 16. August 2016 (GVBl. S. 258, BayRS 26-5-1-I), zuletzt geändert durch \$1 der Verordnung vom 1. Oktober 2019 (GVBl. S. 613), www.gesetze-bayern.de/Content/Document/BayDVAsyl/true, Abrufdatum: 18.05.2020.

Asylgesetz (AsylG), in der Fassung vom 2. September 2008 (BGBl. I S. 1798), zuletzt geändert durch Artikel 48 des Gesetzes vom 20. November 2019 (BGBl. I S. 1626), https://www.gesetze-im-internet.de/asylvfg_1992/AsylG.pdf, Abrufdatum: 18.05.2020.

[BAMF] Bundesamt für Migration und Flüchtlinge (2019): Sichere Herkunftsstaaten, vom 14.11.2019, https:/www.bamf.de/DE/Themen/AsylFluechtlings schutz/Sonderverfahren/SichereHerkunftsstaaten/sichereherkunftsstaatennode.html, Abrufdatum: 18.05.2020.

Bayerische Staatskanzlei (2017): Bericht aus der Kabinettssitzung vom 21. März 2017, www.bayern.de/wp-content/uploads/2017/03/170321-Ministerrat.pdf, Abrufdatum: 18.05.2020.

Bayerische Staatskanzlei (2018): Bericht aus der Kabinettssitzung vom 05. Juni 2018, https:/www.bayern.de/wp-content/uploads/2018/06/180605-minister rat.pdf, Abrufdatum: 18.05.2020.

Bayerischer Landtag (2017): Drucksache 17/17526, vom 18.10.2017, https://www. bayern.landtag.de/www/ElanTextAblage_WP17/Drucksachen/Schriftliche \%2oAnfragen/17_0017526.pdf, Abrufdatum: 18.05.2020.

[BStMI] Bayerisches Staatsministerium des Innern, für Sport und Integration (2018): Startschuss für ANKER-Einrichtungen, vom 01.08.2018, www.stmi.bayern.de/med/aktuell/archiv/2018/180801anker/, Abrufdatum: 02.09.2018. 
Bundesregierung (2018): Koalitionsvertrag zwischen CDU, CSU und SPD, 19. Legislaturperiode, vom 12.03.2018, https://www.bundesregierung.de/reso urce/blob/975224/847984/5b8bc23590d4cb2892b31c987ad672b7/2018-03-14koalitionsvertrag-data.pdf?download=1, Abrufdatum: 02.07.2020.

Bochmann, Annett (2017): »Soziale Institution Lager. Theoretische Grundlagen, Flüchtlingslager und die Macht lokaler Mikrostrukturen«, in: Stephan Lessenich (Hg.), Geschlossene Gesellschaften, Verhandlungen des 38. Kongresses der Deutschen Gesellschaft für Soziologie in Bamberg 2016.

Breidenstein, Georg/Hirschauer, Stefan/Kalthoff, Herbert/Nieswand, Boris (2015): Ethnografie. Die Praxis der Feldforschung, 2. Auflage, Konstanz und München: UVK.

De Genova, Nicholas (2002). Migrant »Illegality« and Deportability in Everyday Life, in: Annual Review of Anthropology 31, S. 419-447.

Foucault, Michel (1979): Überwachen und Strafen. Die Geburt des Gefängnisses, 3. Auflage, Frankfurt a.M.: Suhrkamp.

Foucault, Michel (1992): »Andere Räume«, in: Karlheinz Barck (Hg.), Aisthesis. Wahrnehmung heute oder Perspektiven einer anderen Ästhetik, Leipzig: Reclam, S. 34-46.

Foucault, Michel (1993): »Leben machen und sterben lassen: Die Geburt des Rassismus«, in: Sebastian Reinfeldt/Richard Schwarz/Michel Foucault (Hg.), BioMacht, Duisburg DISS-Texte Nr. 25, S. 27-50.

Foucault, Michel (2005): Die Heterotopien, Baden-Baden: Nomos.

Gerst, Dominik/Krämer, Hannes (2017): »Methodologische Prinzipien einer allgemeinen Grenzsoziologie«, in: Stephan Lessenich (Hg.), Geschlossene Gesellschaften. Verhandlungen des 38. Kongresses der Deutschen Gesellschaft für Soziologie in Bamberg 2016.

Gerst, Dominik/Klessmann, Maria/Krämer, Hannes/Sienknecht, Mitja/Ulrich, Peter (2018): »Komplexe Grenzen. Aktuelle Perspektiven der Grenzforschung«, in: Berliner Debatte Initial 29(1), S. 3-11.

Goffman, Erving (1972): Asyle. Über die soziale Situation psychiatrischer Patienten und anderer Insassen, Frankfurt a.M.: Suhrkamp.

Hess, Sabine/Karakayali, Serhat (2007): New Governance oder die imperiale Kunst des Regierens. Asyldiskurs und Menschenrechtsdispositiv im neuen EUMigrationsmanagements, in: TRANSIT MIGRATION Forschungsgruppe (Hg.), Turbulente Ränder, Bielefeld: transcript, S. 39-55.

Krasmann, Susanne/Opitz, Sven (2007): »Regierung und Exklusion. Zur Konzeption des Politischen im Feld der Gouvernementalität«, in: Susanne Krasmann/Michael Volkmer (Hg.), Michel Foucaults >Geschichte der Gouvernementalität in den Sozialwissenschaften, Bielefeld: transcript, S. 127-155. 
Oltmer, Jochen (2018): »Einführung: Migrationsregime vor Ort und lokales Aushandeln von Migration«, in: Jochen Oltmer (Hg.), Migrationsregime vor Ort und lokales Aushandeln von Migration, Wiesbaden: Springer VS, S. 1-12.

Pieper, Tobias (2013): Die Gegenwart der Lager. Zur Mikrophysik der Herrschaft in der deutschen Flüchtlingspolitik, 2. Auflage, Münster: Westfälisches Dampfboot.

Scheffer, Thomas (2002): „Das Beobachten als sozialwissenschaftliche Methode von den Grenzen der Beobachtbarkeit und ihrer methodischen Bearbeitung", in: Doris Schaeffer/Gabriele Müller-Mundt (Hg.), Qualitative Gesundheits- und Pflegeforschung, Bern: Huber, S. 351-374.

Schiffauer, Werner/Koch, Jochen/Reckwitz, Andreas/Schoor, Kerstin/Krämer, Johannes (2018): Borders in Motion: Durabilität, Permeabilität, Liminalität, Working Paper Series B/ORDERS IN MOTION Nr. 1, Frankfurt (Oder): Viadrina, doi:10.11584/B-ORDERS. 1.

Schulze Wessel, Julia (2017): Grenzfiguren - Zur politischen Theorie des Flüchtlings, Bielefeld: transcript.

\section{Interviews und Gesprächsprotokolle}

Ehrenamt A, geführt am 07.05.2018.

Ehrenamt B, geführt am 18.05.2018.

Gesprächsprotokoll, geführt am 25.05.2018.

Kommunal A, geführt am 27.04.2018.

Kommunal B, geführt am 07.05.2018.

Kommunal C, geführt am 18.05.2018.

Wohlfahrt A, geführt am 07.05.2018.

Wohlfahrt B, geführt am 08.05.2018.

Wohlfahrt C, geführt am 23.05.2018.

Wohlfahrt D, geführt am 29.05.2018. 


\section{Formen der Einschließung und Ausschließung Unterbringungspraxen von Geflüchteten in Ungarn}

Janka Böhm

\section{Zusammenfassung}

Der Sommer der Migration in 2015 bedeutete in Ungarn eine Zäsur für das Grenz- und Fluchtregime, die zum Abbau eines zwar fehlerhaften, aber legalen Unterbringungssystems und zur Etablierung einer klar immobilisierenden und rechtswidrigen Asylpraxis führte. Dieser Beitrag stellt zwei unterschiedliche Unterbringungsformen von Geflüchteten als Ergebnisse politisch-gesellschaftlicher Aushandlungsprozesse vor. Vor 2015 erfolgte die Unterbringung ausschließlich in großen, offenen Sammellagern, als implizit fremdenfeindliche Praxis der Einschließung und Marginalisierung. Hier wird die Aufnahmeeinrichtung in der Stadt Bicske als ein hybrides System der Integration und Segregation dargelegt. Im zweiten Teil wird erläutert, wie nach 2015 als Folge radikaler Asylrechtsänderungen und des hegemonialen Diskurses der Versicherheitlichung und Fremdenfeindlichkeit die Asylsuchenden aus dem ganzen Land ausgeschlossen und in den Transitzonen de facto inhaftiert wurden.

\section{Summary}

The Summer of Migration in 2015 was a turning point for the Hungarian Border and Asylum Policy, which resulted in the complete deconstruction of a defective, but lawful reception practice of asylum seeker. This essay introduces two different types of accommodation as a result of a social and political negotiation. Refugees were hosted before 2015 exclusively in centralized reception centres, which symbolize the implicit xenophobe act of confinement and marginalisation. The reception centre in Bicske is presented as a hybrid system of integration and segregation. The second part describes how after 2015 through radical asylum law changes and the hegemonial discourse of securitization and xenophobia the asylum seekers were excluded from the whole country and de facto detained in the transit zones. 


\section{Einleitung}

Der Sommer der Migration 2015 erschütterte die ungarische Gesellschaft. Ungarn ist ein Staat mit rund zehn Millionen Einwohner*innen. Der Anteil an Ausländer*innen lag in den letzten Jahrzehnten konstant bei ca. zwei Prozent. Im Jahr 2015 wurden 424.055 Personen im Land illegal aufgefunden und 177.135 Asylanträge gestellt (vgl. Eurostat 2020a, b). Für viele Ungar*innen war es das erste Mal, dass sie mit dem Thema Flucht und geflohenen Menschen von außerhalb Europas konfrontiert wurden. In der ungarischen Asyl- und Grenzpolitik ist dieses Ereignis eine Zäsur. Die rechts-populistische Regierung unter Viktor Orbán nutzte es, um daraus politisches Kapital für ihre Partei zu schlagen und Fluchtmigration wurde durch die politische Inszenierung zu einer der wichtigsten Aushandlungsorte politischer Macht.

Ungarn ist 1989 der Genfer Flüchtlingskonvention beigetreten, und die Grundlagen des ungarischen Asylrechts und des Asylsystems wurden damals geschaffen. Drei große Sammellager mit insgesamt ca. 1.400 Plätzen wurden eröffnet, die lange Zeit vor allem Kriegsgeflüchtete aus dem ehemaligen Jugoslawien beherbergten. Infolge des Beitritts zur Europäischen Union 2004 wurden die Richtlinien und Normen des Europäischen Asylrechts implementiert. Ungarn ist seit 2007 Teil des Schengen-Raumes und kontrolliert dessen Außengrenze. Das Land liegt auf der sogenannten Balkanroute und ist bis heute ein Transitland der Fluchtmigration. Die Mehrheit der Geflüchteten verlassen Ungarn Richtung Westeuropa noch während des Asylprozesses oder sogar nach ihrem positiven Asylbescheid aufgrund häufiger Diskriminierungserfahrungen sowie geringen Chancen auf dem Arbeitsmarkt und auf soziale und kulturelle Inklusion (vgl. Klennert 2019b: 171f).

Die bis 2015 existierende Unterbringungspraxis in isolierten Sammellagern begünstigte die Integrationschancen wenig. Die politische Absicht der Immobilisierung, Kontrolle und sozialen Ausgrenzung wurde als administrative Notwendigkeit inszeniert, denn die diversen Phasen des Asylverfahrens waren jeweils mit einer Überführung in eine neue Sammelunterkunft verbunden. Die Geflüchteten mit guten Aussichten auf eine positive Entscheidung wurden in einer offenen Sammelunterkunft untergebracht und blieben zwischen zwei Monaten und zwei Jahren. Nach dem Auszug aus einer Aufnahmeeinrichtung waren die Menschen stark auf die Hilfe von zivilen Organisationen angewiesen, weil die gesetzlich zugesicherten Leistungen für ein menschenwürdiges Leben nicht ausreichten, was die Mehrheit der Geflüchteten zur Weiterreise veranlasste oder in Kriminalität, Arbeits- und Obdachlosigkeit drängte (ebd.). Der komplette Abbau dieses im Grunde sehr fehlerhaften, aber gesetzmäßigen Systems begann 2015 als Folge der Ausrufung des »Krisenzustands aufgrund der Massenmigration« (HHC 2019: 11).

Dieser Beitrag gibt einen Überblick über die letzten acht Jahre der ungarischen Asylpolitik unter besonderer Berücksichtigung zweier unterschiedlicher Formen 
der Unterbringung von Geflüchteten. Im ersten Teil wird die offene Aufnahmeeinrichtung in der Stadt Bicske als ein hybrides System der Integration und Segregation vorgestellt. Nach 2015 wurden die offenen Aufnahmeeinrichtungen geräumt oder geschlossen und die Asylsuchenden wurden in zwei Transitzonen außerhalb der Landesgrenze de-facto-inhaftiert. Der zweite Teil des Beitrags erläutert, wie die radikalen Asylrechtsänderungen und der hegemoniale Diskurs der Versicherheitlichung und Fremdenfeindlichkeit zur totalen Ausschließung der Asylsuchenden aus dem ganzen Land führten.

\section{Praxis der "Einschließung - Die Aufnahmeeinrichtung von Bicske (Teil 1)}

Im Jahr 2012 erforschte ich die Aufnahmeeinrichtung für schutzberechtigte Personen in Bicske im Rahmen meiner Masterarbeit. Das dort praktizierte hybride System zeigte eine Spannung zwischen europäischen Richtlinien und nationalen Interessen auf und kombinierte diskursive und performative Elemente der Integration und Segregation. Der offizielle Zweck der Einrichtung war die (Vor-)Integration von schutzberechtigten Personen, der aber aufgrund des »totalen« (Goffman 1971) Charakters der Einrichtung und der latenten Repressionspraktiken unerreicht blieb. Die gegensätzlichen Wirkungen führten zur Institutionalisierung von Konflikten, zu Hospitalisierung und »Desintegration« (Täubig 2009).

Die durchgeführte ethnographische Feldforschung umfasste eine Kombination aus teilnehmender Beobachtung und Interviews. Diese explorative Methode verfolgt das Ziel, die Strukturen der Einrichtung, die Alltagspraxis der Beteiligten, die sozialen Interaktionen und individuelle Sinnstiftung als Ganzes kennenzulernen und zu deuten (vgl. Beer 2018: 12). Mein Fokus lag während der Forschung auf dem Vorintegrationsprogramm, insbesondere auf der Funktion und den Folgen dieses widersprüchlichen Konzeptes. Die Datenerhebung erfolgte in der Unterkunft: 24 halbstrukturierte Interviews mit Bewohner*innen und Mitarbeiter*innen und mehr als 40 Stunden teilnehmender Beobachtung und Hospitation in den täglich stattfindenden Ungarischkursen bilden die Datengrundlage meiner Analyse. ${ }^{1}$

Die halbstrukturierten Interviews führte ich mit den Mitarbeiter*innen auf Ungarisch und mit den Bewohner*innen auf Deutsch, Englisch oder Ungarisch durch und sie wurden von mir ins Deutsche übersetzt. Weitere spontane Gespräche fanden oft mit Hilfe freiwilliger Übersetzer*innen statt. Einige Bewohner*innen lebten teilweise schon mehrere Jahre in WestEuropa, vor allem in Deutschland und lernten dort die Sprache. Sie hielten sich in Ungarn entweder wegen des Dublin-Verfahrens oder weil ihr Asylantrag abgelehnt wurde auf und wollten meist zurück nach West-Europa. 


\section{Theoretischer Kontext}

Den theoretischen Rahmen der kritischen Analyse der Unterkunft leistet vor allem das Konzept der »totalen Institutionen« von Erving Goffman (1971). Als »totale Institutionen« versteht er soziale Einrichtungen, die alle Handlungen und Lebensbereiche des normalen Lebens auf einen Ort verdichten. »Total« wird eine Einrichtung durch die Beschränkung der sozialen Kontakte nach außen und oft durch physische Barrieren wie geschlossene Türen und Mauern. Weder die privaten Räume noch die sozialen Kontakte können hier frei gewählt werden (vgl. ebd.). Vicki Täubig begreift die Unterbringungspraxis von Geflüchteten in ähnlicher Weise als totale Institution und bezeichnet die gesetzliche und bürokratische Organisation der Bedürfnisse von Asylbewerber*innen als »organisierte Desintegration« (vgl. Täubig 2009). Sie zeigt auf, dass die Praxis der Unterbringung von Asylbewerber*innen in isolierten Gemeinschaftsunterkünften zur Segregation und zur sowohl strukturellen als auch kulturellen Desintegration führen (vgl. ebd.: 56). In diesem Kontext werden die Geflüchteten nicht als Akteur*innen wahrgenommen, ihre Wünsche und Aspirationen werden weitestgehend ignoriert.

Der totale Charakter der Einrichtung, der Mangel an sinnvollen Tätigkeiten, Arbeitslosigkeit, wenige Kontakte mit der Außenwelt und die Gewöhnung an die allumfassenden Leistungen führen zur Hospitalisierung, die laut aktuellen Erkenntnissen bereits in einem Zeitraum von wenigen Monaten entstehen kann. In diesem Zustand der erlernten Hilfslosigkeit festigen sich falsche Handlungsmuster, Einstellungen und Erwartungen gegenüber dem Versorgungssystem. Dies hemmt sowohl die Handlungsfähigkeit als auch das Kontroll- und Autonomiegefühl der Betroffenen (vgl. Krolify 2007: 75f.).

Aufnahmeeinrichtungen sind durch asymmetrische Machtverteilung und Praktiken der Abschreckung mitbestimmt, wie Festsetzung, Kontrolle und Verwaltung der Geflüchteten, beziehungsweise deren räumliche und soziale Segregation von der Aufnahmegesellschaft (vgl. Muy 2016: 230). "Aus den Frustrationen über die Distributionsverhältnisse, also aus dem Wunsch nach Verbesserung der eigenen benachteiligten Lage«, so Lewis A. Coser, entstehen »echte Konflikte« (Coser, zitiert nach Bonacker 1996: 69) zwischen dem Personal und den Bewohner*innen der Einrichtung. Diese Umstände führen zur Konstitution und Stabilisierung der sozialen Ordnung der Einrichtung, in der die konträr konstruierten Gruppen ständig (re-)produziert und die Konflikte institutionalisiert werden.

\section{Das "Vorintegrationsprogramm " von Bicske als Verwaltung und Aufbewahrung der Geflüchteten}

Bicske ist eine Stadt mit ca. 12.000 Einwohner*innen, rund 40 Kilometer westlich von Budapest. Das Sammellager für Geflüchtete wurde 1992 gegründet und 
war für 464 Personen zugelassen. Der Gebäudekomplex liegt am Rande der Stadt, umgeben von einer hohen Mauer mit Stacheldraht. Besucher*innen durften die Einrichtung nur mit einer Erlaubnis des Amtes für Migration und Flucht (Bevándorlási és Állampolgársági Hivatal) betreten. Die Bewohner*innen konnten sich frei bewegen. Im Jahr 2012 lebten dort ungefähr 200 Personen, davon ca. 50 Kinder. Die Einrichtung wurde 2016 als Folge der Umstrukturierung des gesamten Asylsystems geschlossen.

Zwischen 2008 und 2013 erfüllte das Zentrum »Vorintegrationsaufgaben«, weshalb dort nur Menschen mit Bleibeberechtigung sechs bis zwölf Monate lang untergebracht wurden. ${ }^{2}$ Die »Vorintegration « von anerkannten Geflüchteten in einem zentralisierten Sammellager war ein hybrides Produkt eines Asylsystems, dessen vorgeschriebenes Ziel der Integration ${ }^{3}$ und die implizite politische Absicht der Kontrolle und Abschreckung zu sichtbaren Spannungen führten. Die gesetzlich gesicherten Leistungen in der Aufnahmeeinrichtung beinhalteten täglich eine Stunde Sprachunterricht, die Beantragung der notwendigen Dokumente, Integrationskurse und die Hilfe bei der Suche nach Wohnung, Arbeit und ggf. Schule. Die Bewohner*innen verfügten über eine Arbeitserlaubnis und laut dem Leiter waren acht bis zehn Prozent von ihnen berufstätig - vorwiegend in Budapest (vgl. Interview mit dem Leiter).

Die »Vorintegration« beschrieb der Leiter der Einrichtung, ein Polizist, als »die Vorbereitung der Schutzberechtigten für die Integration in die Gesellschaft. Also wenn sie von hier ausziehen, können sie die Sprache und finden eine Wohnung und Arbeit.« (Interview mit dem Leiter) Die Leiterin der Sozialberatung gab weitere Aspekte an:

»Das Ziel ist das Komfortgefühl, die Zufriedenheit der Menschen. Sie sollen sich wohl fühlen, damit sie keinen Mangel haben, keinen Ärger machen, dann ist hier Ruhe und Frieden. [...] Unsere Methode ist, [die Ceflüchteten] im Stillen zur Kooperation zu bringen. Nur im Notfall greifen wir zu drastischen Maßnahmen, wie zum Beispiel das Ausquartieren. Es ist wichtig, den Sprachunterricht zu besuchen, da sonst das Sozialgeld gekürzt wird.«(Interview mit M1)

Nach der Anerkennung entfiel die Residenzpflicht. Unterstützungsangebote und gesetzlich vorgesehene Leistungen für die Geflüchteten wurden bis 2014 aber nur in Bicske bereitgestellt, deswegen und aus Mangel an Informationen mussten die meisten Ceflüchteten dort einziehen. Zwischen 2008 und 2014 gab es vereinzelte Pilotprojekte zur dezentralen Unterbringung.

3 Die Förderung der Integration von geflüchteten Menschen war die Folge der Implementierung internationaler Abkommen (Genfer Flüchtlingskonvention, Europäisches Asylsystem) (vgl. Klennert 2019: 60f.), wurde aber von der ungarischen Cesellschaft und Regierung nicht unterstützt. Daher ergaben sich Widersprüche zwischen den offiziellen Zielen der Institutionen und deren Verwirklichung durch administrative Prozesse. 
Die Bewohner*innen der Unterkunft hatten wenig Kontakt mit der Außenwelt. Die bessere Vernetzung mit der Stadt oder mit zivilgesellschaftlichen Organisationen wurde vom Personal der Einrichtung nicht angestrebt. Nur wenige etablierte Organisationen aus Budapest besuchten die Einrichtung regelmäßig und boten Freizeitaktivitäten, psychologische Therapie und juristische Beratung an. Für die schulpflichtigen Kinder und Jugendlichen wurde eine Schulklasse im Gebiet der Unterkunft eingerichtet, weil die städtischen Schulen die meisten von ihnen aufgrund des hohen Integrationsaufwandes nicht aufnehmen wollten (vgl. Interview mit M6). Die Integrationsbeauftragten organisierten regelmäßig diverse Freizeitprogramme wie Ausflüge und thematische Abende.

Die befragten Mitarbeiter*innen machten deutlich, dass die Nachteile einer Sammelunterkunft ihnen durchaus bewusst sind. Die praktische Nutzung des Integrationskurses wurde auch von dessen Dozent*innen in Frage gestellt, denn solange die Bewohner*innen keine Erfahrung mit dem Alltag haben, helfe dieser wenig (vgl. Interview mit M2). Die Sprachlehrer*innen wussten, dass die Sprachkurse wegen der geringen Stundenzahl und weil die meisten Teilnehmer*innen das Land verlassen wollten und ihr Interesse gänzlich fehlte, zu wenig Erfolg führen würden (vgl. Interview mit M4 und M5). Aus Effizienzgründen erledigten die Sozialarbeiter*innen alles für die Bewohner*innen, wie Dokumente beantragen, Kontakt halten mit Behörden, Ärzte, Arbeits- und Wohnungssuche und vieles mehr. Diese Arbeitsweise statt individualisierter Beratung und Begleitung verstärkte nur die Hospitalisierung der Bewohner*innen. Die Gründe für den Misserfolg sahen beide Seiten unterschiedlich. Der Leiter meinte über die erfolgreiche Integration, dass

»es auch darauf ankommt, wie sehr sie [die Geflüchteten] es wollen. [...] Weil die Möglichkeiten, die Chancen sind gegeben, sie müssen bloß damit leben, sie müssen es wollen. Sie müssen den Sprachunterricht besuchen, sie müssen rechtzeitig wach werden, was vielen oft schwerfällt.« (Interview mit dem Leiter)

Die beobachteten Umstände und die Äußerungen des Personals weisen eine starke Managementperspektive auf. Durch Ausschließung der Außenwelt, strenge Vorgaben, Erwartungen gegenüber den Bewohner*innen und durch Drohungen werden die Geflüchteten unter Kontrolle gebracht. Die Diskrepanz zwischen dem offiziellen Ziel der Integration und dem tatsächlich verfolgten Zweck der Einrichtung Immobilisierung und Repression - wird in den Aussagen der Interviewten deutlich. Die Anmerkung von Täubig trifft zu: »Die offiziellen Ziele werden von der Öffentlichkeit anerkannt, wobei offenkundig ist, dass sie nicht erreicht werden und viele totale Institutionen als bloße Aufbewahrungsorte für die Insassen dienen.« (Täubig 2009: 47) Ein gerechtes und erfolgreiches Handeln aus Sicht des Personals und die Vorbereitung der Geflüchteten für ein selbstbestimmtes Leben ist in die- 
ser hybriden Form der Integration und Segregation nicht möglich und führt nur $\mathrm{zu}$ weiteren Spannungen.

\section{Die Erfahrungen der Geflüchteten: das Verlangen nach "wahren Chancen«}

Im November 2012 veranstalteten die Bewohner*innen der Aufnahmeeinrichtung von Bicske eine Demonstration in Budapest. In ihrer Petition an das Innenministerium bemängelten sie die Integrationsleistungen von Bicske und forderten eine »wahre Chance, um nützliche Mitglieder der ungarischen Gesellschaft werden zu können. [...] Denn sobald wir die Unterkunft von Bicske verlassen, werden wir der realen Gefahr der Arbeitslosigkeit, und was noch schlimmer ist, der Obdachlosigkeit gegenübertreten« (MigSzol 2012).

Die Wünsche und Bedürfnisse der Geflüchteten erwiesen sich als nicht kompatibel mit dem hybriden Unterbringungssystem. Die Mehrheit wollte trotz ihres Status als Schutzberechtigte nach Westeuropa weiterreisen, weil sie dort schon gelebt hatten, aber abgeschoben wurden oder dort Familie und Freunde hatten. Außerdem erhofften sie sich von Westeuropa bessere Arbeitsaussichten und einen höheren Lebensstandard. Von den 18 befragten Erwachsenen wollten neun Personen Ungarn verlassen, drei Personen wussten nicht, was sie wollten, und nur sechs Personen - vor allem mit Familie - hatten vor zu bleiben.

Weitere Motive für die Weiterreise waren die negativen Erfahrungen und die fehlende Zukunftsperspektive in Ungarn. Viele Geflüchtete verbrachten oft Jahre ausschließlich in Sammelunterkünften und hatten kaum Kontakt mit der Umgebungsgesellschaft. Die Interviews zeigten, dass sie allgemein über sehr wenige, selektive und oft falsche Informationen über das Land und über seine Möglichkeiten verfügten. Die kulturelle und soziale Distanzierung von der Aufnahmegesellschaft führte zur Annäherung zur eigenen Diaspora in Ungarn oder zu einer transnationalen Gemeinschaft (vgl. Interview mit B1/B3/B6/B7).

Aus den Interviews wurde ersichtlich, dass die Untätigkeit, Isolation und das Leben unter Kontrolle zur Hospitalisierung und zum Verlust der Zukunftsperspektive führten. Eine Frau aus Georgien äußerte: »Ich kann hier nichts machen, es gibt nichts zu tun.« (Interview mit B1) Die Frau versuchte, ihre Zeit trotzdem aktiv zu verbringen: Sie unterrichtete Deutsch und versuchte anderen Geflüchteten zu helfen. Ein Mann aus Afghanistan berichtete:

»Wir besuchen die Sprachkurse, es gibt die, die nach Budapest fahren oder den ganzen Tag nur schlafen. Sie [die Männer] würden im Gymnastikraum trainieren, er ist aber klein und kaputt. Sie haben nichts zu tun. [...] Es wäre gut, wenn es irgendeine Ausbildung gäbe, das würde viel helfen. Wenn praktische Sachen, mechanische Sachen unterrichtet werden würden. [...] Ich habe alles versucht, was ich konnte, aber trotzdem muss ich bei null anfangen. In ein paar Tagen muss ich 
dieses Lager verlassen. Wo soll ich hin, was soll ich machen? Ich habe ein paar Bekannte, sie haben keine Arbeit, sie leben unter sehr schlechten Umständen, sie sind sehr arm. Ich habe mit dem schwedischen, deutschen, norwegischen und britischen Konsulat telefoniert.«(Interview mit B3)

Drei Männer aus Somalia erzählten, dass sie vorwiegend schlafen und fernsehen. Sie besuchten nicht den Sprachkurs. Ihr Ziel war, in Bicske zu bleiben bis ihre Dokumente fertig waren, dann wollten sie - illegal - nach Deutschland oder Norwegen weiterziehen, wo Bekannte von ihnen lebten (vgl. Interview mit B6 und B7). Eine positive Geschichte kam von einem Mann aus Afghanistan. Er arbeitete in einer Nähwerkstatt in Budapest und hatte schon eine Unterkunft mithilfe des zivilen Vereins Menedék (Zuflucht) in Aussicht. Sie betrieben eine Gemeinschaftswohnung, er bekam dort zudem Geld und Sprachunterricht und war mit seiner Situation insgesamt zufrieden (vgl. Interview mit B4).

Aufgrund des Mangels an Geld und Kontakten war es schwer, Freizeitaktivitäten außerhalb der Unterkunft zu realisieren. Dies »erschwert eine Teilhabe am >bürgerlichen Leben` der Konsum- bzw. Freizeitgesellschaft « (Täubig 2009: 56). Die Bewohner*innen fuhren häufig nach Budapest, um einen kostenlosen Sprachkurs $\mathrm{zu}$ besuchen oder in die Moschee $\mathrm{zu}$ gehen.

Wiederkehrende Elemente der Erzählungen waren die Sorge um die Zukunft, Mangel an Perspektiven und realistischen Plänen. Die Bewohner*innen äußerten ihren Wunsch nach sinnvollen Tätigkeiten, Selbständigkeit, sozialer und ökonomischer Teilhabe deutlich - der aber in der Einrichtung nicht erfüllt werden konnte. Als Resultat der asymmetrischen Machtstruktur einer totalen Institution wurden die Bewohner*innen nicht in die Entscheidungsprozesse einbezogen und die Interessen des Staates standen über ihren Bedürfnissen. In diesem »Strukturgeflecht« der »organisierten Desintegration« sind die Asylbewerber*innen nur »Angehörige einer bürokratischen Kategorie« (ebd.: 58).

\section{Institutionalisierte Konflikte als Folge der divergierenden Ziele}

Die Machtstrukturen der Einrichtung werden durch diverse - implizite und explizite - diskursive und performative Praktiken reproduziert. Der »totale« (vgl. Täubig 2009; Goffmann 1971) Charakter der Institution und die Repression der Bewohner*innen entsteht in der bürokratischen Organisation des Alltags, der Art und Weise der Kommunikation, der Verteilung von materiellen Ressourcen oder im Umgang mit Informationen. Konflikte in Aufnahmeeinrichtungen sind ein häufiges Phänomen, deren (Fehl-)Funktion asymmetrische Machtverhältnisse und die 
eigentlichen Ziele enthüllen. Im Folgenden werden einige Beispiele vorgestellt und als Aushandlungsprozess der sozialen Ordnung gedeutet ${ }^{4}$.

- Ein Mann suchte das Sozialbüro wiederholt außerhalb der Öffnungszeiten auf, um nach seinen Dokumenten zu fragen. Er wurde abgewiesen, weil sie noch nicht da waren. Daraufhin schnitt er sich vor der Tür des Büros sein Ohr ab.

- Ein Familienvater wollte sich - außerhalb der Öffnungszeiten - bei den Mitarbeiter*innen beschweren, weil seine Frau vom Arzt nicht abgeholt wurde, wie ausgemacht. Weil nach vielem Klopfen und Schreien keiner kam, schlug er die Glastür ein und verletzte sich schwer. Erst nach dem Schlag kam eine Mitarbeiterin und behauptete, dass das Auto wie vereinbart beim Arzt gewartet hatte.

- Eine Frau aus dem Kosovo bat mich darum, einen ungarischen Brief, den sie von der Heimleitung bekommen hatte, zu übersetzen. Im Brief stand, dass ihr Sozialgeld gestrichen wird, wenn sie und ihr Mann noch zweimal beim Sprachkurs fehlen. Die Frau war überrascht, weil sie nicht wussten, dass der Kurs Pflicht ist, obwohl sie schon seit sieben Monaten in der Unterkunft wohnten.

- Ein Mann beschwerte sich bei mir, weil er nicht genügend Geld bekomme. Er verdächtigte die Leitung, dass sie die Einwohner*innen bestehle. Dieses Gerücht glaubten offensichtlich mehrere Bewohner*innen.

Zwischen dem Personal und den Bewohner*innen entstanden Konflikte, vor allem aufgrund von "Störungen in der Organisation«: wegen einem Mangel an Informationen oder gar Desinformationen, Sprachbarrieren, fehlender Kommunikation und fehlender Kooperation (vgl. Jávor/Rozgonyi 2005: 97). Die administrativen Vorgänge, die Sprache und die Informationen nutzte das Personal oft als Mittel zur Kontrolle, Ausschließung oder Repression der Geflüchteten. Die Einschränkung des Handlungsraums von Geflüchteten führte dazu, dass sie nur noch damit argumentieren konnten, was ihnen übriggeblieben war: ihre physische Existenz, Körper und Stimme. Infolge des Misstrauens wurde dem Personal teilweise die Verantwortung für Missstände zugeschrieben, die sie nicht verschuldet hatten, wie zum Beispiel die lange Dauer der Dokumentenanfertigung und Auszahlungen oder Wartezeiten bei den Ärzten. Sebastian Muy stellt fest, dass »unter den allgemeinen Bedingungen der Entrechtung [...] ein >gerechtes` Handeln für die Mitarbeiter*innen überhaupt nicht möglich [sei]« (Muy 2016: 231). Die festen, hierarchisierten Positionen der Geflüchteten und des Personals und ihre unterschiedlichen Ziele - autonomes Leben versus totale Kontrolle - führt zur Institutionalisierung der Konfliktsituation, die nie gelöst werden kann. men der Interviews und weiterer persönlicher Cespräche oder aber auf Basis eigener Beobachtungen vor Ort dokumentiert. 


\section{Zwischenfazit}

Die Aufnahmeeinrichtung von Bicske verweist auf sichtbare und unsichtbare Akte sowohl der Einschließung, Kontrolle und Repression als auch der Hilfeleistung und Integration. Die Bewohner*innen sind aus organisatorischen Gründen, wie kostenloser Unterbringung, Dokumentenanfertigung, Sprachkurs usw. gezwungen, die ungerechten Umstände zu akzeptieren und sich der politischen Absicht der Aufbewahrung und Abschreckung zu unterwerfen. Die geleisteten administrativen Vorgänge werden von den Verantwortlichen der Einrichtung als Hilfe dargestellt, aber im Licht der Forschungsergebnisse sind sie eher als versteckte Form der Repression und Immobilisierung zu deuten. Diese Darstellung und Analyse zeigen auf, wie die asymmetrischen Machtverhältnisse der totalen Institution bzw. die divergierenden Ziele und Aspirationen der beteiligten Seiten zu einer permanenten Konfliktsituation führen. Die darin (re-)produzierte soziale Ordnung der Entrechtung und Ausschließung von Menschen mit Fluchterfahrung bleibt über die Grenzen der Einrichtung hinaus geltend.

\section{Asylpolitik nach 2015 - Die totale Ausschließung der Asylsuchenden in den Transitzonen ${ }^{5}$ (Teil 2)}

Die Entwicklung gegenwärtiger Migrationsregime fassen Tsianos und Karakayali wie folgt zusammen: »Today we see the emergence of new forms of mobility control that operate in the liminal spaces between the public, the state and supranational organizations. "(Tsianos/Karakayali 2010: 374) In Ungarn ist währenddessen eine Rückkehr zu einer nationalistischen Politik zu sehen, die die Zurückeroberung der Kontrolle über das gesamte Feld der Fluchtmigration anstrebt.

Im Herbst 2015 richtete die ungarische Regierung zwei Transitzonen am neu errichteten serbisch-ungarischen Grenzzaun ein und bald darauf wurden diese die Hauptunterbringungsorte für Asylsuchende in ganz Ungarn. Der folgende Abschnitt des Beitrags zeigt den Prozess, der zur radikalen Änderung der

Nach der Einreichung dieses Beitrages fiel das Urteil des Europäischen Gerichtshofs, dass die Transitzonen als »Haft« im Sinne »eines völligen Entzugs der Bewegungsfreiheit« einzustufen sind (vgl. Cerichtshof 2020). Die Praxis der Transitzonen und die Inhaftierung der Asylsuchenden (darunter viele Kinder) von mehr als vier Wochen ohne gültigen Grund widerspricht dem EU-Recht. Als Folge des Urteils wurden die Transitzonen bereits am 21. Mai 2020 geräumt und geschlossen und die Bewohner*innen wurden in offene Sammellager gebracht. Diese positive Entwicklung hat zugleich negative Folgen: Ungarn hat das Asylverfahren komplett ins Ausland verlagert. Einer Cesetzänderung zufolge ist es nur noch in bestimmten ungarischen Konsulaten möglich, einen Asylantrag zu stellen und weitere Rechtsverstöße, wie die Häufung der Push-Backs, sind zu erwarten (vgl. Lübbe 2020). 
Fluchtmigrations- und Grenzschutzpolitik und zur totalen Ausschließung der Geflüchteten führte.

Der ungarische Außenminister Péter Szijjártó erklärte im Jahr 2019 die Position der ungarischen Regierung wie folgt:

»Wir dürfen die Zuwanderung nicht länger managen, sondern müssen sie beenden. [...] Sie ist nicht nur ein Sicherheitsrisiko für unsere Länder, sondern auch ein Risiko für die europäische Kultur. [...] Wir werden es niemals erlauben, dass illegale Einwanderer nach Europa kommen. Deswegen werden wir auch weiter mit Brüssel streiten. Was dort vorgeschlagen wird, ist, dass man die Leute erst ins Land lässt und dann überprüft. Wir wollen sie gar nicht erst reinlassen.«(Szijjártó zitiert nach Hufnagel 2019)

Dieses Zitat zeigt die Anti-Migrationseinstellung und politische Vision der Regierung sehr deutlich: Versicherheitlichung der Fluchtmigration, Betonung der nationalen Souveränität und Ablehnung der Kooperation mit der EU sowie das Schüren von Angst und Panikmache sind wichtige Elemente. »Versicherheitlichung als Dispositif« lässt sich nach Rothe "als Zusammenwirken heterogener Sprechakte mit anderen Praktiken und Techniken begreifen « (Rothe 2017: 50). Das Thema Flucht wird instrumentalisiert und die auf diese Weise inszenierte "Migrationskrise« ist nichts anderes als »eine Art politisch korrekter Deckname für den ewigen Kampf der Meinungsmacher um die Eroberung und Kontrolle des Denkens und Fühlens der Menschen« (Bauman 2016: 7). Dieser Teil des Beitrags untersucht die Zusammenhänge zwischen den Asylrechtsänderungen, der Entstehung eines neuen hegemonialen Diskurses und der Unterbringung von Asylsuchenden.

\section{Die Asylrechtsänderungen}

»We have one message for refugees: Don't come!«(HHC 2017:1) Das sagte Ministerpräsident Viktor Orbán in Brüssel am 3. September 2015. Wie der Bericht der Menschenrechtsorganisation Hungarian Helsinki Committee (HHC) 2017 feststellt, »this warning has been put to effect through extremely restrictive legislative and policy changes. These changes resulted in a willingly destroyed asylum system in a European Union member state.« (Ebd.) Die Regierung reagierte schnell und drastisch auf die Ereignisse des Sommers der Migration 2015. Im Herbst rief Orbán den »Krisenzustand aufgrund der Massenmigration« (HHC 2019: 11) aus, womit er die Befugnisse der Regierung erweiterte. Dieser Krisenzustand wird nach Ablauf der Rechtsgültigkeit alle sechs Monate ohne Rechtsgrundlage verlängert (derzeit bis März 2021). Ein 175 Kilometer langer Stacheldrahtzaun wurde an der serbischungarischen Grenze installiert, um die Balkanroute komplett $\mathrm{zu}$ schließen und die Asylsuchenden abzuschrecken. Außerdem wurden bei Röszke und Tompa zwei Transitzonen errichtet. Unter der Berufung auf den Krisenzustand verabschiedete 
die Regierung in schneller Abfolge Gesetze, die der Kriminalisierung der irregulären Grenzübertritte dienen und damit praktisch die Verhaftung von Asylsuchenden legitimieren sollten. Als sich dies als wirkungslos herausstellte, wurden mithilfe einer Verfassungsänderung im Juli 2016 außergerichtliche Push-Backs eingeführt. Darunter versteht man die automatische Zurückführung aller bis acht Kilometer von der Grenze entfernt aufgefundenen illegalen Grenzüberschreiter*innen nach Serbien (vgl. HHC 2017: 4). Serbien wurde zu einem »sicheren Drittstaat« erklärt, wodurch praktisch alle Asylanträge in einem beschleunigten Verfahren abgelehnt werden konnten.

2016 zog die Regierung alle staatlichen Integrationsmaßnahmen für schutzberechtigte Personen zurück und reduzierte ihre maximale Aufenthaltsdauer in einer offenen Aufnahmeeinrichtung auf 30 Tage. Für Asylbewerber*innen wurde jegliche finanzielle Leistung gestrichen. Ihre Unterstützung fiel damit komplett den Nichtregierungsorganisationen $\mathrm{zu}$.

Vor der Parlamentswahl 2018 verschärfte die Regierung die Asylgesetze weiter. Im Januar 2017 wurde ein Gesetzespaket verabschiedet, wonach alle Asylbewerber*innen (bei unbegleiteten Minderjährigen ab 14 Jahre) ausschließlich in den zwei Transitzonen für die komplette Dauer ihres Asylverfahrens von damals höchstens vier Wochen untergebracht werden mussten. Asylanträge dürfen seitdem nur in Transitzonen eingereicht werden. Illegale Grenzüberschreiter*innen werden im ganzen Gebiet des Landes, ohne die Möglichkeit einen Asylantrag zu stellen, nach Serbien abgeschoben.

Im Februar 2018 verabschiedete die Regierung das sogenannte »Stop Soros«Gesetz, durch welches Personen und Organisationen, die Asylsuchende unterstützen, unter Strafe gestellt werden können. Dies sollte der Einschüchterung und Diskreditierung der ohnehin sehr schwachen Zivilgesellschaft dienen. Weiterhin kündigte die Regierung die Verträge mit der EU-Förderung AMIF (Asylum, Migration and Integration Funding) ab 2019, wodurch die wichtigste Förderquelle der Organisationen in der Flüchtlingshilfe wegfiel, was deren Position im Handlungsfeld weiter schwächte.

Gegen die restriktive Ausgestaltung des ungarischen Asylsystems und das Unterlaufen europäischer Asylrichtlinien konnte die Europäische Kommission wenig ausrichten. Im Juli 2018 verklagte sie Ungarn vor dem Europäischen Gerichtshof wegen asylrechtlicher Verstöße ${ }^{6}$ (vgl. EK 2018). Die ungarische Regierung setzt sich dafür ein, dass die EU ihr Asylsystem komplett externalisiert, die Außengrenzen besser überwacht und dass ansonsten die Mitgliedsstaaten autonom über ihre Migrations- und Asylpolitik entscheiden können (vgl. Kováts 2018: 32). 


\section{Fremdenfeindlicher Diskurs}

Die radikalen Rechtsänderungen wurden von einer Anti-Migrationsrhetorik der Regierung begleitet, die zur Verschiebung der sozialen Realität und zur Verbreitung der Xenophobie in der Gesellschaft führte. Der Sommer der Migration, das Camping von Geflüchteten in den öffentlichen Bereichen in Budapest und der Aufbruch nach Österreich, der sogenannte "March of Hope« wurden in den öffentlichen Medien sehr einseitig dargestellt. ${ }^{7}$ Nach Medienanalysen waren Mitglieder der Fidesz-Partei enorm überrepräsentiert in den Berichten über die Ereignisse (vgl. Barlai/Sík 2017: 152). Sie bezeichneten die Flüchtlinge konsequent ausschließlich als »illegale Migranten« oder »Wirtschaftsmigranten«. Wie bestimmte Ereignisse wahrgenommen, bewertet und interpretiert werden, wird öffentlich verhandelt und diskursiv hergestellt. Die Regierung deutete die »Migrationskrise« als Bedrohung und Sicherheitsproblem, das sich mit dem Erbauen eines Grenzzauns lösen ließe. Nachdem die Grenze geschlossen war, wurden die ausgesperrten Asylsuchenden als kriminell und aggressiv dargestellt. Eine objektive Berichterstattung wurde durch die Verweigerung des Eintritts von Journalist*innen und NGOs in die Grenzgebiete und Transitzonen verhindert (vgl. Bernáth/Messing 2016: 57). Dies führte wiederum zur Stärkung des Sicherheitsdiskurses und verdrängte die ohnehin schon wenigen humanitären Stimmen endgültig (vgl. ebd.: 26). »Versicherheitlichung« bezeichnet das Phänomen, wonach bestimmte gesellschaftliche Probleme »aus ihrem jeweiligen politischen Kontext herausgelöst und in einen Sicherheitskontext übertragen werden« (Rothe 2017: 35). Die Deutung der Geflüchteten als Sicherheitsbedrohung verlangt nach immer strengeren Maßnahmen und legitimiert sie - wie beispielsweise die strengen Asylrechtsänderungen und die DeFacto-Inhaftierung der Asylsuchenden in den Transitzonen.

Die Regierung startete gleichzeitig eine massive Hass- und Desinformationskampagne auch über andere Kanäle. 2015 wurde eine »Konsultation« zum Thema »Migration und Terrorismus« veranstaltet. Dafür wurden der gesamten Bevölkerung Fragebögen geschickt mit Fragen wie: "Is there any relationship between immigration and terrorism? « oder "Should it be possible to detain illegal immigrants?« (Barlai/Sík 2017: 10) Im Herbst 2016 wurde eine Volksabstimmung zum Vorschlag der EU über die Umverteilung von Geflüchteten innerhalb Europas durchgeführt. Die Regierung startete dazu im Vorfeld eine »Informationskampagne« unter landesweit plakatierten Überschriften wie »Wussten Sie? Den Angriff in Paris richteten Migranten an«. All dies führte zur Verbreitung einer »moral pa-

$7 \quad$ »In Ungarn kontrolliert die Regierung über loyale Unternehmer den weitaus größten Teil der Nachrichtenmedien. Auch über ihre Werbeetats und den Rundfunkrat marginalisiert sie unabhängige Stimmen.«(Reporter ohne Grenzen 2020) 
nic«, also der Angst, dass eine Gruppe von Menschen die Werte und das Wohl der Gesellschaft bedroht (vgl. ebd.; Bauman 2016: 7).

Die Fremdenfeindlichkeit der ungarischen Gesellschaft erreichte indes ein historisches Hoch, obwohl de facto bis heute keine Geflüchteten und kaum Migrant*innen im Land leben. Im September 2015 waren 82 Prozent der Bevölkerung für strengere Migrationsgesetze (vgl. Barlai/Sík 2017: 151). 2016/17 lehnten 62 Prozent der Ungar*innen Migrant*innen ab, und nur 34 Prozent zeigten eine positive Haltung ihnen gegenüber, wohingegen sich im europäischen Mittel die Verhältnisse umkehren und sich nur 12 Prozent der Befragten ablehnend und 53 Prozent befürwortend äußerten (vgl. Messing/Ságvári 2018: 14). Die Feindbildkonstruktion der manipulativen Kommunikationskampagnen führte dazu, dass sich große Teile der Bevölkerung einer Politik der Abschiebungen, Push-Backs und Inhaftierung von Asylsuchenden gegenüber zustimmend äußerten.

\section{Die Transitzonen als Praxis der expliziten Ausschließung}

Die neue Ära der Asylpolitik nach 2015 ist gekennzeichnet durch eine völlig neue Regelung der Unterbringung von Geflüchteten. Die zwei größten und am längsten bestehenden offenen Unterkünfte von Bicske und Debrecen mit insgesamt 1.200 Plätzen wurden 2015 und 2016 geschlossen. Eine Momentaufnahme der Unterbringungspraxis im August 2017 zeigt, dass 436 Asylsuchende, davon 226 Kinder, in den Transitzonen untergebracht waren. 17 Personen befanden sich in Abschiebehaft und nur 15 Geflüchtete in offenen Einrichtungen. 2019 waren nur noch zwei offene Aufnahmeeinrichtungen in Betrieb. Von insgesamt 350 Plätzen waren Ende des Jahres fünf besetzt. Zwölf unbegleitete Minderjährige wurden in einem Kinderheim in Fót untergebracht. In den zwei offenen Unterkünften werden seit 2017 keine staatlichen Leistungen mehr erbracht außer der Unterbringung und der Versorgung mit drei Mahlzeiten pro Tag. NGOs bieten unregelmäßig Unterricht und Freizeitaktivitäten an und unterstützen die Bewohner*innen mit Sachspenden. Durchschnittlich bleiben die Schutzberechtigten zwei bis drei Wochen in den Einrichtungen, dann ziehen sie ins Ausland weiter (vgl. HHC 2019: 76-78).

Die Transitzonen wurden 2015 in Röszke und Tompa an der serbisch-ungarischen Grenze eröffnet. Sie dienen seit 2017 als designierte Wohnorte für alle Asylbewerber*innen und als einziger Ort im ganzen Land, an dem ein Asylantrag eingereicht werden kann. Dieses geschlossene Containerlager kann nur Richtung Serbien verlassen werden, was jedoch den Rückzug des Asylantrags bedeutet. Nachdem Serbien $2015 \mathrm{zu}$ einem »sicheren Transitland « erklärt wurde, konnten alle Anträge automatisch abgelehnt werden. Durch das fragwürdige Konzept der Transitzone - innerhalb deren Grenzen Ungarn über die staatliche Autorität verfügt, gleichzeitig aber vorgibt, es sei nicht ungarisches Territorium - wird die totale Ausschließung der Asylsuchenden ermöglicht: 
»In theory, people may only be sent back to another state if the relevant authorities of the receiving country indicate that they will accept them. This is precisely the reason why the Hungarian government invented the transit zones. It says the asylum-seekers staying there are not on Hungarian territory, and thus the interpretation of the Orbán cabinet is that people leaving these zones to the south are not being sent back; they are simply not allowed to enter Hungary. In terms of international law this is a grey area, and the individuals told to leave Hungary are essentially pushed back into Serbian forests. « (Juhász/Molnár/Zgut 2017: 23)

Ungarische Menschenrechtsorganisationen streiten seit Jahren dafür, dass diese Praxis vom Gericht als Inhaftierung anerkannt und beendet wird. ${ }^{8}$ Das zynische Argument der ungarischen Regierung lautet, die Asylsuchenden könnten die Zone nach Serbien jederzeit verlassen und seien daher nicht inhaftiert. Die Verhältnisse in den Containerlagern entsprechen aber denen eines Gefängnisses, wie die HHC in 2019 berichtete:

»The transit zones of Röszke and Tompa are in remote locations, made out of containers built into the border fence. There are different sectors: offices, a sector for families, a sector for unaccompanied minors, a sector for single men and a sector for single women. Containers are [...] approximately $4 \times 3$ meters. Asylum seekers stay in containers furnished with 5 beds. Each asylum-seeker has a bed and a closable wardrobe. When five people are staying in a room, there is no moving space left. [...] Besides sleeping containers, there is a dining container, a community container, shower containers and an Ecumenical prayer room. The containers are placed in a square and in the middle, there is a courtyard with a playground for children and a ping-pong table. The entire transit zone is surrounded by a razorwire fence, and is patrolled by police officers and armed security guards. There are cameras in every corner; there is no privacy or silence. [...] Each transit zone has a medical unit capable of accommodating 10 persons. A general practitioner is available for 4 hours on workdays, whereas a children's doctor is available twice a week; in addition, a field surgeon is available in the transit zone every day, 24 hours a day.« (HHC 2019: 95)

Für Kinder und Jugendliche gibt es keine Freizeit- und Spielmöglichkeiten, Unterricht wird erst seit 2017 angeboten. Mitarbeiter"innen fünf festgelegter Organisationen dürfen die Zone besuchen und für einige Stunden in der Woche Programme anbieten. Die Bewohner*innen dürfen weder Besuch empfangen noch die Transitzone verlassen. 
Das neue System der Grenz- und Asylverfahren hat sich teilweise spontan und willkürlich entwickelt. Die Asylsuchenden warten in Serbien und anhand einer nicht transparenten Warteliste wird täglich eine bestimmte Zahl an Personen in die Transitzone hereingelassen, um ihren Antrag zu stellen. Am Anfang wurden 25 Personen am Tag pro Transitzone hereingelassen, 2016 waren es zehn, 2017 fünf und ab 2018 nur noch eine Person am Tag. Seit Dezember 2019 werden praktisch ohne gesetzliche Grundlage - keine Asylsuchenden mehr in den Transitzonen aufgenommen (vgl. HHC 2019). Vor allem Mitglieder vulnerabler Gruppen konnten erfolgreich einen Asylantrag stellen, die meisten Asylsuchenden wurden aufgrund des Prinzips des sicheren Herkunftslandes nach Serbien zurückgeschickt. Die registrierten Asylbewerber*innen, vor allem Familien und als vulnerabel eingestufte Personen, wurden sporadisch in eine offene Unterkunft überführt.

Das Asylverfahren in den Transitzonen läuft wie folgt ab: Das erste Interview mit den Asylsuchenden (Registrierung) führt direkt nach dem Eintritt in die Transitzone ein*e Polizist*in und notiert die wichtigsten Daten. Danach findet die Anhörung zur Begründung des Asylantrags in der »Polizeiwache« der Transitzone statt, meistens via Videokonferenz, weil Sachbearbeiter* in und/oder Übersetzer* in nicht anwesend sind. Die Qualität der Verbindung ist laut Berichten sehr schlecht. Viele Asylsuchende berichteten davon, dass während des Interviews bewaffnete Polizist*innen neben ihnen standen, was einschüchternd wirkt. Anwälte und Anwältinnen der HHC beobachteten mehrere Fälle, wo der*die amtliche Dolmetscher*in aufgrund von fehlenden Sprachkenntnissen nicht richtig übersetzen konnte. Das rückübersetzte Protokoll wird im Anschluss an das Gespräch dem*der Asylsuchenden zum Durchlesen und Bestätigen ausgehändigt. Die Entscheidung über die Anerkennung trifft die Nationale Generaldirektion der Fremdenpolizei (Országos Idegenrendészeti Fóigazgatóság) und es besteht die Möglichkeit innerhalb von acht Tagen vor dem regionalen Verwaltungs- und Arbeitsgericht Einspruch einzulegen. Der Beschluss muss nicht schriftlich ausgehändigt werden, es reicht eine mündliche Mitteilung mit Dolmetscher*in (vgl. HHC 2019: 28-54). Ursprünglich durften Asylsuchende maximal vier Wochen lang in den Transitzonen bleiben, bis dahin musste das Verfahren abgeschlossen werden. In 2019 verzögerten sich die Prozesse so extrem, dass die durchschnittliche Aufenthaltsdauer vier bis fünf Monate betrug (vgl. ebd.: 92).

Die Transitzonen als De-Facto-Inhaftierung setzen die politischen Ziele der Immobilisierung, der sozialen, kulturellen und räumlichen Ausschließung und das Stigmatisieren der Asylsuchenden erfolgreich um. Als Folge der offenen Fremdenfeindlichkeit und Anti-Migrationspolitik gelingt die Abschreckung der Asylsuchenden aus Ungarn: die Zahl der Asylanträge sinkt rasant (vgl. Eurostat 2020b) und die Mehrheit der Geflüchteten und Schutzberechtigten im Land reist innerhalb von wenigen Wochen nach West-Europa weiter (vgl. HHC 2019). 


\section{Zusammenfassung}

Zwei Formen der ungarischen Unterbringungspraxis wurden hier genauer vorgestellt: eine offene Sammelunterkunft und die geschlossenen Transitzonen, die sich zwischen Einschließung und Ausschließung der Geflüchteten bewegen. Beide Systeme realisieren die Immobilisierung der Geflüchteten durch administrative Vorgänge, üben Kontrolle über ihre soziale und ökonomische Situation aus und weisen implizite und explizite Ausschließungspraktiken einer Anti-Migrationspolitik auf. Die Analysen zeigen auf, dass die Unterbringung von Geflüchteten ein gesellschaftliches Aushandlungsfeld der Herrschaftsordnung und Bedeutungsproduktion ist. Die Aufnahmeeinrichtung von Bicske mit ihrem widersprüchlichen Konzept der »Vorintegration « in einer Sammelunterkunft verfolgt das eigentliche Ziel der Verlängerung der Verweilzeiten anerkannter Geflüchteter. Ihre Einschließung dient als die erweiterte Kontrolle über ihren Alltag, als Abschreckung und vor allem als ihre soziale, kulturelle und räumliche Segregation von der Aufnahmegesellschaft. Die Spannung zwischen Ziel und Zweck der Institution spiegelt sich in den Konflikten zwischen dem Personal und den Bewohner*innen wider. Die strukturell bedingten asymmetrischen Machtverhältnisse führen zur Institutionalisierung der Konfliktsituation. Die implizite Diskriminierung der Geflüchteten wurde nach 2015 als Folge der Asylrechtsänderungen und des fremdenfeindlichen Diskurses durch ein System der expliziten Ausgrenzung ersetzt. Mit der monatelangen De-Facto-Inhaftierung der Geflüchteten in den Transitzonen verstößt die Regierung gegen EU-Recht, kriminalisiert die Asylsuchenden und setzt ein Zeichen für die Außenwelt. Innerhalb weniger Jahre konstruierte die populistische Regierung von Ministerpräsident Orbán ein Narrativ, das die Geflüchteten als die größte Bedrohung für die europäische Kultur und den Wohlstand darstellt und die einzige, legitime Lösung ihre totale Exklusion ist. Die euroskeptische, anti-pluralistische Politik schließt alle anderen Akteur*innen des Feldes der Fluchtmigration aus: die Zivilgesellschaft, die Asylsuchenden, die Europäische Union und weitere supranationale Organisationen. Ziel des Monopols über die Steuerung der Fluchtmigration ist neben der alleinigen staatlichen Kontrolle über das nationale Asylregime die Konstruktion des Bildes einer starken, fähigen und souveränen Regierung und die Stärkung ihrer Machtposition. Eine »populistische Spirale« (Barlai/Sík 2017: 164) wurde in Gang gesetzt, deren weiterer Verlauf unvorhersehbar ist.

\section{Literaturverzeichnis}

Bauman, Zygmunt (2016): Die Angst vor den anderen. Ein Essay über Migration und Panikmache, Berlin: Suhrkamp Verlag. 
Barlai, Melani/Sík, Endre (2017): »A Hungarian Trademark (a >Hungarikum $২$ ): the Moral Panic Button«, in: Christina Griessler/Melani Barlai (Hg.), The Migrant Crisis: European Perspectives and National Discourses, Berlin: LIT Verlag, S. 147-169.

Beer, Bettina (2008): „Einleitung: Feldforschungsmethoden«, in: Bettina Beer (Hg.), Methoden ethnologischer Forschung, Berlin: Reimer Verlag, S. 9-37.

Bernáth, Gábor/Vera, Messing (2016): »Infiltration of political meaning-production: security threat or humanitarian crisis?«, vom 07.12.2020, https://cmds. ceu.edu/sites/cmcs.ceu.hu/files/attachment/article/1041/infiltrationofpoliticalmeaning.pdf, Abrufdatum: 07.04.2020.

Bonacker, Thorsten (1996): Konflikttheorien. Eine sozialwissenschaftliche Einführung mit Quellen, Wiesbaden: Springer.

Europäische Kommission (2018): Kommission verklagt Ungarn wegen Asylpolitik vor dem EuGH, vom 19.07.2018, https://ec.europa.eu/germany/news/20180719 -kommission-verklagt-ungarn-wegen-asylpolitik_de, Abrufdatum: 12.05.2019.

Eurostat (2020a): Third country nationals found to be illegally present, Stand 02/2020, https://appsso.eurostat.ec.europa.eu/nui/show.do?dataset=migr_eipre\&lang=en, Abrufdatum: 08.02.2020.

Eurostat (2020b): Asylum and first time asylum applicants by citizenship, age and sex Annual aggregated data, Stand 02/2020, https://appsso.eurosta t.ec.europa.eu/nui/show.do?dataset=migr_asyappctza\&lang=en, Abrufdatum: 08.02.2020.

Gerichtshof der Europäischen Union (2020): Pressemitteilung Nr. 60/20, vom 14.05.2020, https://curia.europa.eu/jcms/upload/docs/application/pdf/2020-0 5/cp200060de.pdf, Abrufdatum: 02.07.2020.

Goffman, Erving (1971): Asylums, Harmondsworth: Penguin Books.

Hungarian Helsinki Committee (2017): Two Years After: What's Left of Refugee Protection in Hungary?, von 09/2017, https:/www.helsinki.hu/wp-content/uploa ds/Two-years-after_2017.pdf, Abrufdatum: 10.04.2020.

Hungarian Helsinki Committee (2019): Asylum Information Database. Country Report: Hungary, von 03/2020, https://www.asylumineurope.org/reports/countr y/hungary, Abrufdatum: 05.03.2020.

Hufnagel, Margit (2019): Wir müssen die Migration nach Europa stoppen, in: Main Post vom 16.07.2019, https://www.mainpost.de/ueberregional/politik/brennpu nkte/Wir-muessen-die-Migration-nach-Europa-stoppen;art112,10277276, Abrufdatum: 14.03.2020.

Jávor, István/Rozgonyi, Tamás (2005): Hatalom, konfliktus, kultúra, Budapest: KJKKerszöv Kiadó.

Juhász, Attila/Molnár, Csaba/Zgut, Edit (2017): Refugees, Asylum and Migration Issues in Hungary, Prag: Heinrich Böll Stiftung, https://www.boell.de/sites/d 
efault/files/refugees_asylum_migration_issues_in_hungury.pdf, Abrufdatum: 16.03.2020.

Klennert, Zoltán (2019a): »Menekültügy Magyarországon«, in: Zoltán Klennert (Hg.), Menekültügyi ismeretek, Budapest: Dialóg Campus Kiadó, S. 53-68.

Klennert, Zoltán (2019b): »Nemzetközi védelmet szerző külföldiek«, in: Zoltán Klennert (Hg.), Menekültügyi ismeretek, Budapest: Dialóg Campus Kiadó, S. 165176.

Kováts, András (2018): "Situation report at the hungarian-serbian border«, in: María José Castaño Reyero/Cecilia Estrada Villaseñor/Angeliki Dimitriadi/András Kováts/Uga Melchionda/Antonio Ricci/Senada Šelo Šabic/The Economics and International Relations Institute (Hg.), On Europe's External Southern Borders. Situation Report on Migration Management, Budapest, Friedrich Ebert Stiftung, S. 30-34.

Krolify Research Institute (2007): A menedékkérők munkavállalásának feltételei az Európai Unióban magyar szemszögből. Jogi és politikai kutatás, o.D., www.needs.hu/doksik/20071101151538.pdf, Abrufdatum: 11.02.2012.

Lübbe, Sascha (2020): Es wird weitere Rechtsverstöße geben, in: Mediendienst Integration vom 28.05.2020, https://mediendienst-integration.de/artikel/es-wir d-weitere-rechtsverstoesse-geben.html, Abrufdatum: 02.07.2020.

Messing, Vera/Ságvári, Bence (2018): Looking behind the culture of fear. Cross-national analysis of attitudes towards migration, Budapest: Friedrich Ebert Stiftung, http://library.fes.de/pdf-files/bueros/budapest/14181-20180815. pdf, Abrufdatum: 04.03.2020.

MigSzol (2012): Bicskei menekültek tüntetése a Parlament előtt, vom 01.12.2012, www.migszol.com/blog1/bicskei-menekultek-tuntetese-a-parlament-elott, Abrufdatum: 05.02.2020.

Muy, Sebastian (2016): »Hilfe zwischen Abschreckung und Profit. Interessenkonflikte Sozialer Arbeit in Flüchtlingssammelunterkünften gewerblicher Träger«, in: PROKLA 46(183), S. 229 - 244.

Reporter ohne Grenzen (2020): Rangliste der Pressefreiheit, Stand 04/2020, https:/ /www.reporter-ohne-grenzen.de/rangliste/rangliste-2020/ueberblick/, Abrufdatum: 21.04.2020.

Rothe, Delf (2017): „Versicherheitlichung «, in: Tobias Ide (Hg.), Friedens- und Konfliktforschung, Stuttgart: UTB, S. 35-68.

Täubig, Vicki (2009): Totale Institution Asyl, Weinheim/München: Juventa.

Tsianos, Vassilis/Karakayali, Serhat (2010): Transnational Migration and the Emergence of the European Border Regime: An Ethnographic Analysis«, in: European Journal of Social Theory 13(3), S. 373-387. 


\section{Interviews}

Leiter der Einrichtung, persönliche Kommunikation auf Ungarisch, Oktober 2012. Mitarbeiter*innen:

M1, persönliche Kommunikation auf Ungarisch, Oktober 2012.

M2, persönliche Kommunikation auf Ungarisch, Oktober 2012.

M4, persönliche Kommunikation auf Ungarisch, Oktober 2012.

M5, persönliche Kommunikation auf Ungarisch, Oktober 2012.

M6, persönliche Kommunikation auf Ungarisch, Oktober 2012.

Bewohner*innen:

B1, persönliche Kommunikation auf Deutsch, Oktober 2012.

B3, persönliche Kommunikation auf Englisch, Oktober 2012.

B4, persönliche Kommunikation auf Ungarisch, Oktober 2012.

B6, persönliche Kommunikation auf Englisch, Oktober 2012.

B7, persönliche Kommunikation auf Englisch, Oktober 2012. 


\title{
ANKER : KASERNE : FABRIK Zur Architektur sozialer Kontrolle
}

Julia Devlin

\begin{abstract}
Jedes Moment schließt andere Momente, Aspekte oder Elemente ein, die seiner Vergangenheit entstammen. (Lefebvre 1971: 8)
\end{abstract}

\section{Zusammenfassung}

ANKER passt gut in KASERNE. Geübte Scrabble-Spieler erkennen das auf einen Blick. Doch nicht nur semiotisch, auch gebäudetechnisch passen Ankerzentren gut in Kasernen: Blickt man auf die bayerischen Ankerzentren, so zeigt sich, dass die meisten in ehemaligen Kasernen angesiedelt sind. In meinem Artikel werde ich zunächst eine Systematisierung der Ankerzentren hinsichtlich ihrer Architektur vornehmen. Aufbauend auf James C. Scotts Konzept von der Lesbarkeit sozialer Dynamiken (1999), Foucaults Konzept des Disziplinarraums, das er in Überwachen und Strafen (1994) darstellt, und Henri Lefebvres La production de l'espace (2000) ergänze ich meine Untersuchung mit einer Dokumentenanalyse der die Ankerzentren betreffenden Abschnitte des Koalitionsvertrages und des BAMF, um herauszustellen, inwiefern die Intention der Bundesregierung, die Verfahren effizienter zu gestalten, sich in der Architektur der Unterbringung wiederfinden lässt und somit den sozialen Raum, für den sie ursprünglich geschaffen wurde, weiter wirken lässt.

\section{Summary}

The building structure of military barracks is in many ways very suitable for accommodating so-called Anker centres, arrival centres for asylum seekers in Cermany. A look at Anker centres in Bavaria shows that most of them are located in former barracks. In my article, I will start by systematically investigating the Anker centres regarding their architecture. Based on James C. Scott's concept of the legibility of social dynamics (1999), Foucault's concept of disciplinary space, which he presents in Discipline and Punish (1994), and Henri Lefebvre's La production de l'espace (2000), I will be supplementing my investigation by a documentary analysis of 
the sections of the coalition agreement and the BAMF concerning Anker centres. This has the aim of highlighting the extent to which the Federal Government's intention to make the procedures more efficient is reflected in the architecture of the accommodation, thus allowing continued functionality of the social space for which it was originally created.

\section{Ankerzentren - Gebäudetypen}

Insgesamt gibt es sieben Ankerzentren in Bayern, eines in jedem der sieben bayerischen Regierungsbezirke. Zusätzlich gibt es 24 Dependancen. ${ }^{1}$ Die Gebäudetypen lassen sich kategorisieren in Kaserne, Fabrik- bzw. Gewerbegebäude (z.B. Lagerhallen), Bürogebäude, Container und Wohnbau zum Zweck der Geflüchtetenunterbringung.

\section{Abbildung 1: Anzahl der Ankerzentren und Dependancen nach Gebäudetypen (Bayern)}

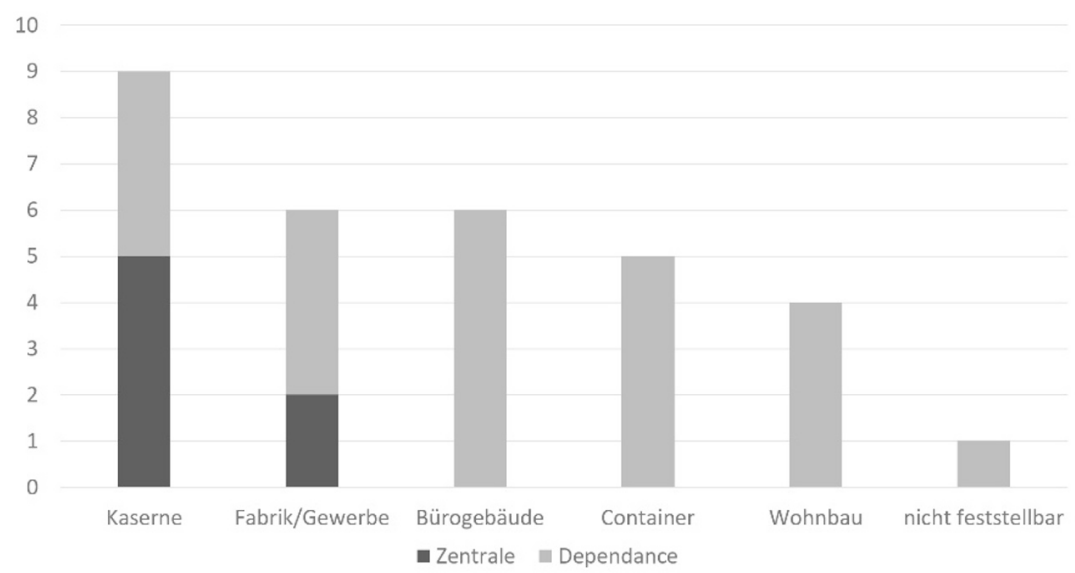

Quelle: Bayerischer Flüchtlingsrat (2020), Stand 15.05.2020.

Die Zentralen der Regierungsbezirke Oberbayern, Oberpfalz, Mittelfranken, Oberfranken und Unterfranken sind in Kasernen untergebracht. Die Zentrale des Ankerzentrums Schwaben befand sich bis 2019 in Donauwörth ebenfalls in einer Kaserne. ${ }^{2}$ Zudem sind mehrere Dependancen in Kasernen.

1 Stand 15. Mai 2020. Die Zahl der Dependancen ist Schwankungen unterworfen.

2 Auch das saarländische Ankerzentrum ist in einer Kaserne untergebracht, das sächsische in einem ehemaligen Bürogebäude. 


\section{Kasernen: Funktion und Lage}

Auf den ersten Blick erscheinen Kasernen als durchaus taugliche Unterkünfte: meist solide gebaut, bieten sie ordentlichen Schutz vor den Elementen, tatsächlichen meteorologischen wie imaginären kriminellen. Sie sind »da« und gehören dem Staat. Grundsätzlich sind sie für die Unterbringung einer großen Anzahl von Menschen gebaut, scheinen also ein hypereffizienter Wohnungsbau zu sein, der nach ihrer Entmilitarisierung als perfekte Wohnmaschine im Sinne von Le Corbusier dienen kann.

Die primäre Funktion einer Kaserne ist zunächst die abrufbereite Unterbringung eines spezifischen Teils des Staatsapparates, des Militärs. Noch im 18. Jahrhundert waren Kasernen als Wohnhäuser für Soldatenfamilien angelegt, quasi als Soldatensiedlungen. Erst ab dem 19. Jahrhundert, mit dem Aufkommen der nationalen Wehrpflicht und des Massenheeres, kennt man die Errichtung von Anlagen, die ausschließlich der Unterbringung von Soldaten dienen (vgl. Tippach 2015: 4952; Gareis/Haltiner/Klein 2006: 15).

Stadtnahe oder gar innerstädtische Lagen sind Ausnahmen. Wenn, sind es entweder Überreste aus einer Belagerungsabwehr früherer Jahrhunderte, gerade im Zusammenhang mit den Stadtbefestigungen, die im Laufe des 19. Jahrhunderts geschliffen wurden, oder vormalige Peripherielagen, die durch das Wachstum der Städte quasi nachträglich eingemeindet wurden.

Doch zumeist liegen Kasernen außerhalb der Stadt (vgl. Köhn 2012: 15). Eine regelmäßige Anbindung an ziviles Leben ist nicht vorgesehen und planerisch häufig nur schwierig einzurichten. Diese mangelnde Erschließung ist durch die Individualmotorisierung des 20. Jahrhunderts zwar für entsprechende Nachnutzungen durch ausreichend wohlhabende Nutzer weniger gravierend geworden, trennt allerdings gerade dadurch die mittellosen Geflüchteten umso stärker ab.

Städtebaulich haben Kasernen eine Wirkung als Riegel. Ähnlich Gefängnissen saugen militärische Anlagen das Leben aus ihrem städtischen Umfeld, da sie nicht zu durchqueren sind und ihre Bewohner*innen nur begrenzte Teilhabe am zivilen Leben führen. Die Bildung eines Identitätsraumes, wie ihn der Sozialgeograph Peter Weichhart in seiner Studie Raumbezogene Identität definiert hat, ist aufgrund der auf Vorläufigkeit angelegten Unterbringung in der Kaserne selber erschwert, in den benachbarten Identitätsräumen wirkt sie als Fremdkörper, dem gegenüber eine Abgrenzung erfolgt (vgl. Weichhart 1990: 52).

Die räumliche Trennung ist zwar in ihrer modernen Ausprägung, jedoch nicht im Grundkonzept eine neue Entwicklung. Der französische Philosoph Henri Lefebvre beschreibt sie im Gegenteil bereits als das Grundkonzept von Stadt und Staat Rom, wo der »espace instrumental« (Lefebvre 2000: 282) des Militärlagers in dialektischem Gegensatz steht zur bürgerlichen Stadt - es ist ein »espace close, retranché, fortifié« (ebd.: 284). 
Dieser Gegensatz besteht nach Lefebvre nicht nur in räumlicher und funktionaler Trennung, sondern auch in einer grundlegend anderen formellen Organisation: der freien, wachsenden, zirkulären, »femininen « Form der Stadt entgegen steht das Lager mit seiner strikten formellen, hierarchischen, "maskulinen « Organisation entlang von Haupt- und Querachse: »Le camp militaire, espace instrumental, obéit à une autre ordonnance (espace rectangulaire, sévèrement symétrique, axé par le cardo et le decumenus).«(Ebd.: 282; vgl. Meyer 2007: 316) Lefebvre definiert drei Aspekte der römischen Stadt mit jeweils dualem Charakter, von denen er zwei spezifisch aus dem Gegensatzpaar zivile Stadt und Militärlager entwickelt: die Repräsentation des Raumes und Repräsentativen Raum; der dritte Aspekt ist die räumliche Praxis durch das Straßennetz, das nicht nur Lager und Stadt verbindet, sondern auch die Beherrschung des Landes ermöglicht (vgl. Lefebvre 2000: 284).

Die aus Sicht ziviler Nutzung ungünstige Lage von Kasernen ist also nicht ein zufälliger Aspekt derselben, sondern im Gegenteil ihre Grundlage. Die abrufbereite Unterbringung von Menschen ist losgelöst von Alltagsverflechtung des normalen Lebensraums und unbehindert angeschlossen an die Infrastruktur des Straßennetzes, um schnelle und effiziente Truppenverlagerungen sicher zu stellen. Es handelt sich um eine Unterbringung nicht nach individuellen Bedürfnissen, sondern nach logistischen Gesichtspunkten, die das Individuum zum Teil einer subjektivierenden Logistik machen. ${ }^{3}$

Je nach Epoche erfüllen Kasernen jenseits der Unterbringung von Soldaten weitere, untergeordnete Zwecke: repräsentative und symbolische. Bis in die 3oer Jahre bedienten sich Architekten gerne eines burgartigen Gestaltungsvokabulars, das Wehrhaftigkeit symbolisiert, ohne dass die Details tatsächliche Aufgaben übernähmen. Selbst im Zeitalter moderner Sprengstoffe und Schusswaffen sahen Kasernen häufig noch so aus, als wären sie auch mit Vorderladern zu verteidigen. Jenseits dieses Funktionsrepräsentatismus gibt es natürlich den grundsätzlich protzig-behäbigen Grundstil, der die Macht des Staates bzw. des Militärs mit mächtigen Mauern betont.

Umgekehrt kann auch eine betont belanglos gestaltete Anlage ein symbolisches Ziel verfolgen, indem jeder militaristische Pomp vermieden und ein pragmatischer Umgang mit der Armee kommuniziert wird - wie es oft in Kasernen sichtbar wird, die nach dem Krieg gebaut wurden. Die Kaserne, in der sich die Zentrale des Ankerzentrums Unterfranken befindet (Schweinfurt-Geldersheim), ist Beispiel für Ersteres, die, in der sich die Zentrale des Ankerzentrum Oberbayern befindet (Manching-Ingolstadt), für Letzteres. zentrum zum Tragen, befinden sich doch in der Nähe zwei Flughäfen (Manching und München). 


\section{Unterfranken - ehemalige NS-Kasernen}

Die Ledward Barracks in Schweinfurt waren von 2015 bis 2018 eine Erstaufnahmeeinrichtung und ab 2018 das Ankerzentrum Unterfranken. Die Anlage wurde 1935 als Adolf-Hitler-Kaserne für Panzereinheiten der Wehrmacht gebaut. Streng geometrisch angelegt wirkt die Anlage funktional, das Hauptquartier zeigt jedoch durch seinen wuchtigen Baukorpus und seinen mittigen Uhrturm einen architektonischen Imponiergestus.

Abbildung 2: Ledward Barracks, ehemals Adolf-Hitler-Kaserne

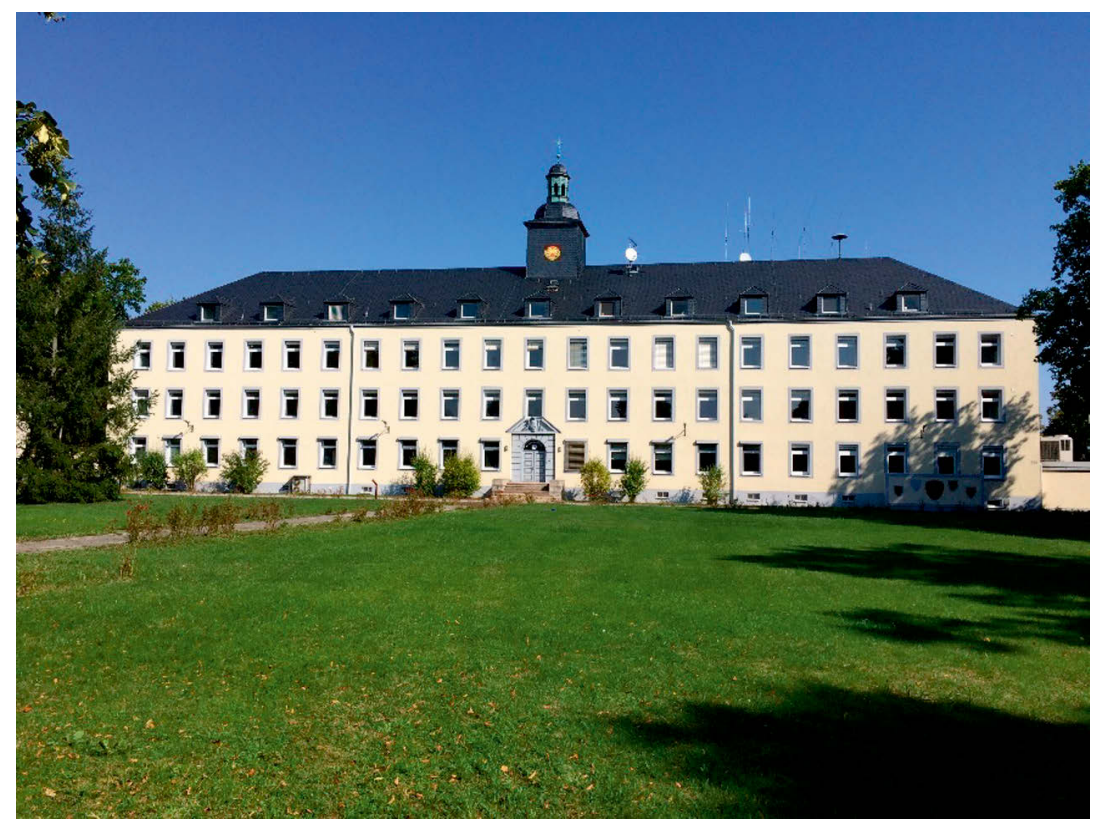

Bildquelle und Bildrechte: Stadt Schweinfurt.

Im Mai 2019 zog das Ankerzentrum in die Conn Barracks um. Der Bau dieser Kaserne wurde 1936 begonnen als Fliegerhorst der Luftwaffe. Die Anlage ist für nationalsozialistische Verhältnisse schlicht und wirkt mehr durch seine Größe und die Anzahl der Gebäude repräsentativ als durch konkrete Architektur. Gerade im Vergleich zur sonst mit ausdrücklicher Symbolik arbeitenden Architektur des NS-Staates erscheinen diese Gebäude stilistisch wenig bemerkenswert. Sie sind konstruktiv einfach und unambitioniert, in niedrigtechnologischer Bauweise errichtet. Sie folgen einer Art Grundschema einfachster Architektur: eine Kiste mit Löchern. Was sie primär auszeichnet, ist die schiere Masse an geschaffener Kapazi- 
tät. Dies lässt den Schluss zu, dass es sich nicht um symbolische Projekte handelte, sondern tatsächliche Schaffung »abrufbereiter Unterbringung« von Soldaten, also um konkrete Kriegsvorbereitungen.

Weitere Kasernen aus der NS-Zeit, in denen sich momentan Dependancen von Ankerzentren befinden, sind der ehemalige Fliegerhorst Fürstenfeldbruck, die Münchner Funkkaserne, die Pionierkaserne in Regensburg und das ehemalige Wehrmachts-Lazarett in Garmisch-Partenkirchen.

\section{Kasernen der Nachkriegszeit: Architektonisch den »Ball flach halten«}

Typische Nachkriegs-Kasernen-Architektur zeigt sich in der Max-ImmelmannKaserne in Manching, die 1959 gebaut wurde und in der sich die Zentrale des Ankerzentrums Oberbayern befindet, und bei der ehemaligen US-Kaserne in Bamberg, dem Ankerzentrum Oberfranken.

\section{Die Kaserne als Disziplinareinrichtung}

Die Entwicklung der Professionalisierung von Armee und ihrer logistikgerechten Unterbringung kann man als Teil dessen sehen, was der französische Philosoph Michel Foucault als die Wandlung moderner Staatsformen hin $\mathrm{zu} »$ Disziplinargesellschaften« definiert (vgl. Deleuze 1992: 40).

In seiner Abhandlung Überwachen und Strafen. Die Geburt des Gefängnisses (1994) beschreibt Foucault die Entstehung von Disziplinareinrichtungen. Disziplin, so Foucault, erfordere die Verteilung von Individuen im Raum, wobei eine der Techniken der Disziplin die Klausur sei, die »bauliche Abschließung eines Ortes von allen anderen Orten « (Foucault 1994: 181). Zu den Disziplinareinrichtungen, die er als Institution der Klausur betrachtet, gehören Kasernen.

»Kasernen: die Armee, diese umherschweifende Masse, muß festgesetzt werden; Plünderungen und Cewalttätigkeiten müssen verhindert werden; die Bevölkerung, die umherziehende Truppen schlecht erträgt, muß beruhigt werden; die Konflikte mit den zivilen Autoritäten müssen unter Kontrolle gebracht werden.« (Ebd.: 182)

\section{Traditionslinien: Displaced Persons-Lager in Kasernen}

Die Unterbringung heimatloser Menschen in Kasernen ist nicht neu. Als im Frühjahr 1945 alliierte Truppen das Deutsche Reich besetzten, fanden sie sich mit schätzungsweise zehn Millionen dislozierter Menschen konfrontiert - Befreite aus Konzentrations- und Zwangsarbeiterlagern, Kriegsflüchtlinge, ehemalige 
Kriegsgefangene der Nationalsozialisten und ihrer Verbündeten. ${ }^{4}$ Der Begriff Displaced Persons (DP) wurde für diese Menschen geprägt (vgl. Jacobmeyer 1985: 26).

Die Alliierten sahen es als wichtige Aufgabe an, diese Opfer von Gewaltmigration zu versorgen und zu repatriieren. In den westlichen Besatzungszonen wurden dafür sogenannte Assembly Centers eingerichtet. Dafür wurden vor allem Kasernen benutzt (vgl. Köhn 2012: 116). Auch Fabrikgebäude, Barackenlager, ehemalige Stätten der Gefangenschaft und requirierte Privathäuser dienten als Unterkünfte. Da die baldige Repatriierung der DPs im Vordergrund stand, sollten die Unterkünfte nicht allzu attraktiv sein (vgl. ebd.: 88, 323).

Kasernenlager für DPs in Bayern befanden sich z.B. in Landsberg am Lech, Augsburg, Dillingen, Würzburg, Eichstätt, Kassel und Wildflecken. ${ }^{5}$ Einige dieser Kasernen dienen heute wieder als Unterkunft für Geflüchtete, so die Funkkaserne in München, in der sich eine der Dependancen des Ankerzentrums Oberbayern befindet. In der bereits erwähnten Panzerkaserne Schweinfurt, der späteren Ledward Barracks, waren bis 1948 ost- und südosteuropäische DPs untergebracht.

Die Alliierten verfolgten im Umgang mit den DPs zwei Ziele: ein humanitäres, indem sie den entwurzelten und verfolgten Menschen halfen, ihre Grundbedürfnisse zu decken, und ein militärisch-logistisches, um sicher zu stellen, dass sie nicht die militärischen Vorgänge behinderten, Krankheiten verbreiteten oder nach Beendigung des Krieges die fragile Nachkriegsordnung störten (vgl. Ziemke 1975). Der Militärhistoriker Earl F. Ziemke schreibt zu den vom Krieg entwurzelten Menschen: »An object of pity as an individual, in the mass he becomes a menace, clogs roads, imposes potentially ruinous burdens on already strained civilian services, and spreads panic." (Ziemke 1975: 52) So lebten die DPs in den Camps in einem Spannungsfeld zwischen Fürsorge und Schutz einerseits und einer administrativen Kontrolle, die bis in kleinste Details wie Kalorienaufnahme und Freizeitgestaltung das Alltagsleben regelte (vgl. Grossmann 2011: 140; Holian 2011: 29f.).

Das DP-Programm fußte klar auf einem militärischen Modell, war es doch schon seit 1944 als Teil der Kriegsführung im Obersten Hauptquartier der Alliierten Expeditionsstreitkräfte (SHAEF) formuliert worden (vgl. Ziemke 1975: 51). Das erklärt auch, warum die Organisation der DPs in Lagern so zentral war: Diese Unterbringungsform erleichterte die Versorgung der Menschen mit Nahrung, Beherbergung, medizinischen Dienstleistungen und Bildung. Sie erleichterte das Sammeln und Organisieren nach nationalen, religiösen oder ethnischen Gruppen ausdrücklich vom DP-Status und damit von der Unterstützung durch die Alliierten bzw. von Hilfsorganisationen der Vereinten Nationen ausgeschlossen (vgl. Holian 2011: 42).

5 Ein ausführliches Verzeichnis aller DP-Camps in den von West-Alliierten besetzten Zonen findet sich im DP-Camp Verzeichnis der Arolsen Archives. 
(vgl. Köhn 2012: 88). Und sie erleichterte die Kontrolle des Flux: Einerseits konnte man die Menschen durch die Unterbringung immobilisieren, andererseits sie abrufbereit wieder mobilisieren, wenn sie repatriiert werden sollten. ${ }^{6}$

Kein Wunder, dass Kasernen (neben Schulen, Krankenhäusern und Klöstern gemäß Foucault weitere klassische Disziplinareinrichtungen) die bevorzugt requirierten Gebäude waren, um DPs unterzubringen, war es doch dem Militär bekanntes Terrain (vgl. Holian 2011: 46f.). Dies kam den deutschen Behörden entgegen. Oft waren sie es, die den Besatzern Kasernen als Sammelunterkünfte vorschlugen (vgl. Köhn 2012: 323).

Die Anthropologin Liisa Malkki konstatiert, dass in dieser Zeit die Form der Unterbringung Gestalt annahm, wie sie heute noch praktiziert wird:

»It was toward the end of World War II that the refugee camp became emplaced as a standardized, generalizable technology of power in the management of mass displacement. The refugee camp was a vital device of power: The spatial concentration and ordering of people that it enabled, as well as the administrative and bureaucratic processes it facilitated within its boundaries, had far-reaching consequences.«(Malkki 1995: 2)

\section{Seeing like a state: Menschen lesbar machen}

Festsetzung und Immobilisierung sind also staatliche Kontroll- und Disziplinierungsmechanismen. Hat der Staat etwas gegen mobile Menschen? Diese Frage stellt der Politologe und Ethnologe James C. Scott in seinem Buch Seeing like a state. Moderne Staaten, so beobachtet er, hätten ein Unbehagen gegenüber nicht sesshaften Menschen: Ob Roma und Sinti, Nomaden, Fahrende Leute oder Obdachlose, sie scheinen ein Dorn im Fleisch des Staates zu sein, und die Versuche, sie dauerhaft sesshaft zu machen, zu immobilisieren, schlagen zuverlässig fehl.

»The more I examined these efforts at sedentarization, the more I came to see them as a state's attempt to make a society legible, to arrange the population in ways that simplified the classic state functions of taxation, conscription, and prevention of rebellion. «(Scott 1999: 2)

James C. Scott prägte den Begriff der Hochmoderne, eine Epoche der Moderne, die ein unkritisches Vertrauen in den durch Naturwissenschaft und Technologie erzeugten Fortschritt setzt und dabei historische, geografische und soziale Entstehungskontexte missachtet. In der Entwicklung zum hochmodernen Staatswesen

6 Kathryn Hulme beschreibt anschaulich die Prozesse von Mobilität und Immobilität tausender polnischer DPs im DP Camp Wildflecken (vgl. Hulme 1953). 
verfeinerten die staatlichen Organe ihren Zugriff, so konstatiert Scott. Sei es die Einführung bleibender Nachnamen, die Normierung von Gewichten und Maßen, die Kodifizierung von Standardsprachen oder die Etablierung von juristischen Regelwerken, dies alles kann interpretiert werden als Maßnahme des Staates, um eine größere Lesbarkeit und Vereinfachung zu erreichen. Die staatlichen Behörden untersagten oder ignorierten komplexe, nur Insider*innen verständliche lokale soziale Praktiken wie traditionelle Namensgebungen oder Gebräuche gemeinsamen Weidebesitzes und schufen stattdessen ein standardisiertes Raster, mit dem sie ihre Bürger*innen zentral verwalten und kontrollieren konnten.

Diese Lesbarkeit und Vereinfachung vergleicht Scott mit einer schematisierten Straßenkarte, die nicht die Realität abbildet, sondern eher ein Muster, dem sich die zu Regierenden einpassen müssen; diese Karten »represented only that slice of it that interested the official observer. They were, moreover, not just maps. Rather, they were maps that, when allied with state power, would enable much of the reality they depicted to be remade." (Ebd.: 3f.) Scott sieht den staatlichen Willen zur Lesbarkeit, die schematische Übertragbarkeit in vielen Bereichen wirksam. Die gewinnorientierte Forstwirtschaft, die moderne Bienenhaltung und die Haussmann'sche städtebauliche Umgestaltung von Paris (1853-1870) haben Lesbarkeit, Vereinfachung, gerade Linien, Zentralverwaltung und einen panoptischen Blick auf das Ganze gemeinsam (vgl. ebd.: 59).

Auch wenn sich die Techniken des Staates ändern, bleibt die Motivation staatlicher Intervention gleich: Es geht vor allen Dingen um Aneignung (z.B. Steuern), Kontrolle und Beeinflussung. Dies klingt negativer, als es gemeint ist: staatliche Interventionen können beispielsweise auch in Hinblick auf Wohlfahrt, Gesundheit oder Bildung geschehen. Doch immer setzen auch die fürsorglichen Aspekte staatlicher Intervention den lesbaren Menschen voraus bzw. haben ihn zum Ziel.

\section{Der Disziplinarraum}

Dies bringt uns zurück zu Michel Foucault. In seinem Werk Überwachen und Strafen. Die Geburt des Gefängnisses (1994) setzt er sich mit der Konzeption des Strafvollzugs im 19. Jahrhundert auseinander. Nach der Aufklärung findet eine Entwicklung statt, die weg von öffentlichen, externalisierten, mitunter spektakulär inszenierten Bestrafungen, hin zu einem diskreten, internalisierten Wissens- und Disziplinarsystem führt:

»[...] an die Stelle des Straf-Theaters, wo dem Cesellschaftskörper eine Dauervorstellung der Züchtigung gegeben werden sollte, ist eine große, geschlossene, komplexe und hierarchisierte Architektur getreten, die sich in den Körper des Staatsapparates integriert.« (Foucault 1994: 149) 
Das Gefängnis, so Foucault, ist damit zum Testgelände geworden: hier hat man Techniken der Kontrolle und der Disziplinierung entwickelt, die dann im Namen des Fortschritts, der Effizienz und Produktivität über andere Bereiche der Gesellschaft ausgebreitet wurden. Weitere Disziplinareinrichtungen entstehen nach ähnlichem Muster. Nicht nur die Kaserne, auch die Manufaktur und später die Fabriken werden zu Räumen der Klausur, entwickeln ein Kontrollwesen (vgl. ebd.: 192). Neben der Abschließung ist auch die Disziplin den Institutionen der Klausur immanent. Foucault bezeichnet sie als Disziplinarraum:

»Es geht gegen die ungewissen Verteilungen, gegen das unkontrollierte Verschwinden von Individuen, gegen ihr diffuses Herumschweifen [...]. Es geht darum, die Anwesenheiten und Abwesenheiten festzusetzen und festzustellen; zu wissen, wo und wie man die Individuen finden kann; die nützlichen Kommunikationskanäle zu installieren und die anderen zu unterbrechen; jeden Augenblick das Verhalten eines jeden überwachen, abschätzen und sanktionieren zu können; die Qualitäten und die Verdienste zu messen. Es handelt sich also um eine Prozedur zur Erkennung, zur Meisterung und zur Nutzbarmachung. Die Disziplin organisiert einen analytischen Raum.«(Ebd.: 183f.)

\section{Disziplinarraum Fabrik}

Betrachtet man die Unterbringungsarten der Ankerzentren, so sind nach Kasernenbauten Fabrikgebäude die zweithäufigste Unterbringungsart - also gemäß Foucault ebenfalls klassische Disziplinarräume. Ihre Aufgabe ist zum einen Kontrolle der darin arbeitenden Menschen und des Produktionsvorganges, aber auch Funktionalität und die dadurch erhoffte Effizienzsteigerung. Auf der Webseite einer Immobiliengesellschaft wird folgende Definition eines Industriegebäudes gegeben:

»Von einem Industriegebäude oder auch einem Industriekomplex ist zu sprechen [sic!] wenn die Funktionalität der Gebäude einen möglichst reibungslosen und kostengünstigen Produktionsprozess ermöglicht. [...] Industriegebäude haben die Aufgabe viele Arbeitsschritte unter einem Dach zu vereinen. Hier wird zwischen zwei Arten von Gebäuden- und Gebäudeabschnitten unterschieden. Das Kerngeschäft befindet sich hierbei in sogenannten Produktions- oder auch Montagehallen statt [sic!], die in den Bereichen der Herstellung oder der Produktveredelung genutzt werden. [...] Die Hauptbüros in denen sich Bereiche wie die Administration oder das Marketing befinden, sitzen zumeist in separaten Gebäuden. Diese Gliederung ermöglicht wiederum einen reibungslosen und störungsfreien Arbeitsablauf beider Bereiche. Die Gesamtheit der Bereiche und deren Wirtschaftlichkeit sind erforder- 
lich um ein Produkt oder auch verschiedene Produktionsketten optimal zu betreiben.«(MASTER 2020, Herv. d.Verf.)

Henri Lefebvre hat in seinen Analysen zur Konstruktion des sozialen Raumes konstatiert, dass dieser ein soziales Produkt ist, das Resultat eines Prozesses sozialer Praxis. Daher reflektiere der gegenwärtige Raum niemals nur den gegenwärtigen Zustand (vgl. Meyer 2007: 313). Die Spuren vorheriger Raumkonstruktion seien niemals vollständig aus dem sozialen Raum zu tilgen, vielmehr übertrügen sich die Eigenschaften früherer Nutzung: "Jedes Moment schließt andere Momente, Aspekte oder Elemente ein, die seiner Vergangenheit entstammen.« (Lefebvre 1971: 87)

Wie schlägt sich der soziale Raum einer Lagerhalle oder eines Fabrikgebäudes auf eine Ankereinrichtung nieder? Im Koalitionsvertrag ist der entsprechende $A b$ satz nicht mit »AnkER-Einrichtung«, sondern mit »Effizientere Verfahren« überschrieben (CDU, CSU, SPD 2018: 107f.). Auf knappen zwei Seiten ist viel die Rede von effizienter Prozessierung, Kategorisierung, Verteilung, Wirksamkeit und Kontrolle. Das Bundesamt für Migration und Flüchtlinge wird in einem sechsseitigen Dokument zu Anker-Einrichtungen expliziter:

»Hinter den neu eingeführten AnkER-Einrichtungen steckt die Idee, alle Schritte des Asylverfahrens und damit auch alle beteiligten Behörden unter einem Dach zu vereinen. Wie im Koalitionsvertrag festgelegt, sollen in den Einrichtungen Ankunft, Entscheidung, kommunale Verteilung bzw. Rückkehr (AnkER), aber auch erste Maßnahmen zur Integration stattfinden. Durch die enge Zusammenarbeit der am Asylverfahren beteiligten Akteure sollen die Verfahren noch effizienter werden. Zentrale Elemente hierbei sind kurze Wege und der direkte Kontakt der Ansprechpartner vor Ort. Dadurch können der gegenseitige Austausch und das Ineinandergreifen der einzelnen Prozessschritte gewährleistet werden. [...] Alle Asylsuchenden werden dabei grundsätzlich bis zum Abschluss des Asylverfahrens vor Ort im AnkER-Zentrum untergebracht.« (BAMF 2018: 1)

Der Grundgedanke der Ankerzentren ist also eine Effizienzsteigerung. Vorbild ist das Prinzip einer Industrieanlage, in der Produktionsketten optimal betrieben werden sollen, in der durch kurze Wege, durch das Vereinen vieler Arbeitsschritte »unter einem Dach« Zeit gespart und dadurch der Output gesteigert werden soll. Das Dokument des BAMF und die Beschreibung der Immobilienfirma zur Funktion von Industriegebäuden klingen verblüffend ähnlich: »Alle am Asylprozess direkt beteiligten Akteure (u.a. Aufnahmeeinrichtungen des Landes, BAMF, Ausländerbehörden, Verwaltungsgerichte, Jugendämter, Bundesagentur für Arbeit) sollen vor Ort vertreten sein.«(BAMF 2018: 1)

»Industriegebäude haben die Aufgabe viele Arbeitsschritte unter einem Dach zu vereinen. [...] Die Gesamtheit der Bereiche und deren Wirtschaftlichkeit sind er- 
forderlich um ein Produkt oder auch verschiedene Produktionsketten optimal zu betreiben.« (MASTER 2020)

Dies nimmt Foucaults Konzept der Klausur auf. Die entscheidenden Akteur*innen begeben sich in Klausur, schließen sich ein: »Denn in dem Maße, in dem sich die Produktionskräfte konzentrieren, gilt es, möglichst viele Vorteile daraus zu ziehen.« (Foucault 1994: 183)

Wie in einer Fabrikanlage werden die verschiedenen Schritte im Voraus geplant. So beinhaltet der Kernprozess »Ankunft und Aufnahme« die Registrierung, Identitätsklärung, den Abgleich mit nationalen und internationalen Datenbanken, Ausstellung des Ankunftsnachweises und eine medizinische Untersuchung, nach der die Unterbringung im Ankerzentrum erfolgt. »Ab diesem Zeitpunkt«, so schreibt das BAMF, "steht der Zugang zu den Beratungsangeboten offen « (BAMF 2018: 3). Weiter geht es mit den im Asylverfahren vorgesehen Verfahrensschritten. Dabei kommt es möglicherweise zur Einleitung des sogenannten Dublin-Verfahrens und Übergabe des Falles an das zuständige Dublin-Zentrum des BAMF. Ist Deutschland hingegen für das Asylverfahren zuständig, wird eine Entscheidung über den Asylantrag getroffen. Bei Ablehnung können die Asylsuchenden bei den in den Ankerzentren eingerichteten Rechtsantragsstellen klagen. »Eine solche Schnittstelle mit den lokalen Verwaltungsgerichten stellt sicher, dass eilbedürftige Verfahren identifiziert und zeitnah gerichtlich entschieden werden können.«(Ebd.: 4)

Noch während das Asylverfahren läuft, findet bereits »eine Vermittlung der in unserer Gesellschaft gelten [sic!] Grundwerte in der Herkunftssprache der Asylsuchenden statt « (ebd.: 4), daran anschließend die Orientierungskurse mit 300 Unterrichtseinheiten. Und weiter geht es mit Sprachtest, Integrationskurs, Terminen mit der Bundesagentur für Arbeit, Ausländerbehörde, Rückkehrberatung etc.

Das Konzept des BAMF vermittelt den Eindruck eines industriellen Förderbandes, einer assembly line ${ }^{7}$, auf dem Menschen zu verschiedenen Stationen, Maschinen und Arbeitenden befördert werden. In dieser »Prozedur zur Erkennung, zur Meisterung und zur Nutzbarmachung (Foucault 1994: 184) wird eine industriell anmutende Vereinfachung und Effizienzsteigerung des Asylprozesses angestrebt, eine Funktionalisierung des Menschen, um der Institution Genüge zu tun. Sämtliche Kriterien, die James C. Scott mit dem staatlichen Willen der Lesbarkeit assoziiert - Vereinfachung, Zentralverwaltung und den panoptischen Blick - sind im sozialen Raum der Ankereinrichtungen und ihrer Dependancen gegeben. Die Qualitäten, die den ursprünglichen Disziplinarräumen innewohnen, lassen sich auf die

7 »Assembly line: an arrangement of machines, equipment, and workers in which work passes from operation to operation in direct line until the product is assembled.«(Merriam-Webster o.J.). 
neuen Bewohner*innen übertragen. Auch bei den geflüchteten Menschen ist »unkontrolliertes Verschwinden« und »diffuses Herumschweifen« (Foucault 1994: 181f.) unerwünscht.

Dies bringt uns zurück zu Scotts ursprünglicher Frage: Warum scheint der Staat etwas gegen mobile Menschen zu haben? Die Antwort lautet: Sie erschweren die staatlichen Bemühungen um Erfassung, Kategorisierung, Kontrolle, kurzum: Lesbarkeit. Im Konzept der Ankerzentren kann man die gesteigerte Anstrengung des Staates sehen, mobile Menschen lesbar zu machen. Dafür eignen sich Kasernengebäude und Fabrikanlagen besonders, stellen sie doch qua Anlage einen Disziplinarraum, einen Raum sozialer Kontrolle dar, in dem die Menschen zunächst immobilisiert werden und dann lesbar und abrufbereit untergebracht werden können.

\section{Die Grenzen des Effizienzdenkens}

Der moderne Staat, so Scott, strebt danach, ein Terrain und eine Bevölkerung zu schaffen, die seinen vereinfachten Vorstellungen entspricht. Dabei soll das Potenzial naturwissenschaftlich-technologischer Gesetze nutzbar gemacht werden. Doch die Behörden hinken zwangsläufig hinter der Gesellschaft, die sie verwalten sollen, hinterher, da die von ihnen geschaffenen Abstraktionen der komplexen Realität nicht entsprechen. Die staatlichen Typisierungen führen zwangsläufig zu einer Simplifizierung und Reduzierung der komplexen Wirklichkeit: »The utopian, immanent, and continually frustrated goal of the modern state is to reduce the chaotic, disorderly, constantly changing social reality beneath it to something more closely resembling the administrative grid of its observations." (Scott 1999: 82) Das Hinterherhinken zeigt sich auch daran, dass die Effizienzsteigerung - die Beschleunigung der Verfahren, die Verkürzung der Verweildauer und die Erhöhung der Abschieberate - nicht in der Eindeutigkeit eingetreten ist, auf die die Initiator*innen gehofft haben. Darauf deuten die stark divergierenden Einschätzungen des »Erfolgsmodells Ankerzentrum « hin (vgl. z.B. Bayerischer Flüchtlingsrat 2019; BMI 2019).

Um zu einem wirklichen Fortschritt zu gelangen, ist es unabdingbar, informelles, lokales Wissen zu nutzen. Auf die Unterbringung geflüchteter Menschen bezogen, bedeutet dies eine Abkehr von zentralisierter Unterbringung und stattdessen das Einbeziehen lokalen Wissens und lokaler Ressourcen. Dass dies erfolgreich ist, zeigten und zeigen die zahlreichen Initiativen bürgerschaftlichen Engagements in der Geflüchtetenhilfe (vgl. Detjen 2020). Das "große Potential lokaler Unterstützungsstrukturen « (Hess et al. 2018: 8), welches 2015 sichtbar wurde und aufgrund von dezentralen Unterbringungsformen entstand, bietet vielfältige Möglichkeiten der Orientierung, des Spracherwerbs, der Integration durch Vereine und lokale In- 
itiativen. Hinger, Schäfer und Pott beschreiben dies als »a particular landscape of asylum«:

»a place-specific process-structure and socio-political order which encompasses much more than local politics. As a socio-spatial construct, this landscape is constantly being reproduced and reshaped, while also feeding back into various urban practices. (Hinger/Schäfer/Pott 2016: 453)

Auf die Gefahr, diese Ressourcen durch die Einrichtung von Ankerzentren zu verlieren, haben Hess et al. bereits 2018 hingewiesen (vgl. Hess et al. 2018: 2). Sie bestätigen auch die negativen psychologischen Auswirkungen der zentralisierten Unterkunft auf die Geflüchteten, die Scott allen rein funktionalen, zweck- und effizienzorientierten Institutionen attestiert:

»Almost all strictly functional, single-purpose institutions have some of the qualities of sensory-deprivation tanks used for experimental purposes. At the limit, they approach the great social control institutions of the eighteenth and nineteenth centuries: asylums, workhouses, prisons, and reformatories. We have learned enough of such settings to know that over time they can produce among their inmates a characteristic institutional neurosis marked by apathy, withdrawal, lack of initiative and spontaneity, uncommunicativeness, and intractability. (Scott 1999: 349; siehe auch Hess et al. 2018: 4f.)

\section{Conclusio}

Ankerzentren befinden sich häufig in ehemaligen Kasernen und Industrieanlagen. Beide sind nach Foucault typische Disziplinarräume. Die Charakteristika des sozialen Raumes, für den diese Architekturen ursprünglich geschaffen wurden - Verfügbarkeit, (Im-)Mobilisierung, Kontrolle, Effizienzsteigerung - sollen sich auch auf die Nutzung als Flüchtlingsunterkunft übertragen. Dies stellt eine Konstante in der Unterbringung geflüchteter und dislozierter Menschen dar. Bereits nach dem Zweiten Weltkrieg wurden ebensolche Gebäude als Displaced Persons-Camps herangezogen.

Hier zeigt sich der Wunsch nach Kontrolle, der - mit der für die Hochmoderne typischen Fortschrittsgläubigkeit - meint, naturwissenschaftlich-technologische Mittel seien auf Menschen nutzbringend anwendbar. Dies wird der komplexen sozialen Realität jedoch nicht gerecht - nicht der des umgebenden sozialen Raumes, und der der geflüchteten Menschen ohnehin nicht. 


\section{Literaturverzeichnis}

Arolsen Archives (o.J.): DP-Camp Verzeichnis, https://dpcampinventory.its-a rolsen.org/uebersicht-zonen/amerikanische-zone/dokumente/, Abrufdatum: 06.07.2020.

[BAMF] Bundesamt für Migration und Flüchtlinge (2018): AnkER-Einrichtung - Ein Überblick, vom 01.08.2018, Nürnberg, https:/www.bamf.de/Shared Docs/Anlagen/DE/Behoerde/Aufbau/anker-einrichtungen-ueberblick.pdf? _ blob=publicationFile\&v=5, Abrufdatum: 06.07.2020.

Bayerischer Flüchtlingsrat (2019): Positionspapier AnkER-Zentren, Stand: Mai 2019, https://www.fluechtlingsratbayern.de/tl_files/2019/Positionspapiere/Pos itionspapier_ANKER.pdf, Abrufdatum: 06.07.2020.

Bayerischer Flüchtlingsrat (2020): Standorte der bayerischen ANKER-Zentren, vom 15.05.2020, https://www.fluechtlingsrat-bayern.de/hintergrund/standorte-de r-bayerischen-anker-zentren/, Abrufdatum: 17.06.2020.

[BMI] Bundesministerium des Innern, für Bau und Heimat (2019): AnkerEinrichtungen sind Erfolgsmodell, vom 01.08.2019, https:/www.bmi. bund.de/SharedDocs/pressemitteilungen/DE/2019/07/20190731-bilanz-1-jahrankerzentren.html, Abrufdatum: 06.07.2020.

CDU, CSU, SPD (2018): Ein neuer Aufbruch für Europa. Eine neue Dynamik für Deutschland. Ein neuer Zusammenhalt für unser Land, Koalitionsvertrag vom 12.03.2018, 19. Legislaturperiode.

Deleuze, Gilles (1992): Foucault, Frankfurt a.M.: Suhrkamp.

Detjen, Marion (2020): ")Wir schaffen das` oder >revolutionäres Bewusstsein«? Überlegungen zur Willkommenskultur 2015«, in: Bundeszentrale für politische Bildung (Hg.), »Wir schaffen das«, S. 20-26.

Foucault, Michel (1994): Überwachen und Strafen. Die Geburt des Gefängnisses, Frankfurt a.M.: Suhrkamp.

Gareis, Sven Bernhard/Haltiner, Karl/Klein, Paul (2006): »Strukturprinzipien und Organisationsmerkmale von Streitkräften«, in: Sven Bernhard Gareis/Paul Klein (Hg.), Handbuch Militär und Sozialwissenschaft, Berlin: Springer, S. 1425, DOI: org/10.1007/978-3-531-90086-5_2.

Grossmann, Atina (2011): »Grams, Calories, and Food: Languages of Victimization, Entitlement, and Human Rights in Occupied Germany, 1945-1949«, in: Central European History 44(1), S. 118-148, DOI: org/10.1017/S0008938910001202.

Hess, Sabine/Pott, Andreas/Schammann, Hannes/Scherr, Albert/Schiffauer, Werner (2018): Welche Auswirkungen haben »Anker-Zentren«? Eine Kurzstudie für den Mediendienst Integration, Berlin.

Hinger, Sophie/Schäfer, Pilipp/Pott, Andreas (2016): »The Local Production of Asylum«, in: Journal of Refugee Studies 29(4), S. 440-463. 
Holian, Anna (2011): Between National Socialism and Soviet Communism: Displaced Persons in Postwar Germany, Ann Arbor: University of Michigan Press. Hulme, Kathryn (1953): The Wild Place, Boston: Little, Brown \& Company. Jacobmeyer, Wolfgang (1985): Vom Zwangsarbeiter zum heimatlosen Ausländer: die Displaced Persons in Westdeutschland 1945-1951, Göttingen: Vandenhoeck \& Ruprecht.

Köhn, Holger (2012): Die Lage der Lager. Displaced Persons-Lager in der amerikanischen Besatzungszone Deutschlands, Essen: Klartext.

Lefebvre, Henri (1971): Der dialektische Materialismus, 5. Aufl., Frankfurt a.M.: Suhrkamp.

Lefebvre, Henri (1974/2000): La Production de l'Espace, 4. Aufl., Paris: Anthropos.

Malkki, Liisa H. (1995): "Refugees and Exile: From >Refugee Studies to the National Order of Things«, in: Annual Review of Anthropology 24, S. 495-523, DOI: 10.1146/annurev.an.24.100195.002431.

MASTER Immobiliengesellschaft mbH (2020): »Was ist ein Industriegebäude?«, h ttps://master.de/was-ist-ein-industriegebaeude/, Abrufdatum: 01.07.2020.

Merriam-Webster's Collegiate Dictionary (o.J.): Assembly line, in: MerriamWebster.com dictionary, https://www.merriam-webster.com/dictionary/asse mbly-line, Abrufdatum: 06.07.2020.

Meyer, Kurt (2007): Von der Stadt zur urbanen Gesellschaft. Jacob Burckhardt und Henri Lefebvre, München: Wilhelm Fink Verlag.

Scott, James C. (1999): Seeing Like a State: How Certain Schemes to Improve the Human Condition Have Failed, New Haven: Yale University Press.

Tippach, Thomas (2015): " '...wodurch das üble Verhältnis entsteht, daß das Militair die Höhe der Steuern bestimmt, welche die Commune zu tragen hat.< Das Servisregulativ von 1810 und seine Folgen«, in: Robert Bohn/Michael Epkenhans (Hg.), Garnisonsstädte im 19. und 20. Jahrhundert, Bielefeld: Verlag für Regionalgeschichte, S. 30-52.

Weichhart, Peter (1990): Raumbezogene Identität. Bausteine zu einer Theorie räumlich-sozialer Kognition und Identifikation, Stuttgart: Franz Steiner Verlag.

Ziemke, Earl Frederick (1975): The U.S. Army in the occupation of Germany, 1944-46, Washington: Center of Military History, U.S. Army. 


\section{Lebensrealitäten}

\section{Praktiken}

Agency

Psyche 



\section{Demobilisierungslager der Guerilla in Kolumbien zwischen Ausnahme und Normalität}

Anna-Lena Dießelmann und Andreas Hetzer

\section{Zusammenfassung}

Die Einrichtung von »Übergangszonen zur Normalisierung« (Zonas veredales transitorias de normalización, ZVTN) war einer der wichtigsten Aspekte des 2016 geschlossenen Friedensabkommens in Kolumbien zwischen der Regierung und der FARC-Guerilla. Die Regierungsziele bestanden darin, den Waffenstillstand mit der FARC zu garantieren, deren Entwaffnung durchzuführen sowie die Reinkorporation der ehemaligen Kämpfer*innen in das Zivilleben und ihren Übergang in die Legalität vorzubereiten. Dazu wurden in verschiedenen Regionen des Landes insgesamt 23 solcher Gebiete und sieben Konzentrationspunkte eingerichtet. Die Kombattant*innen trafen im Februar 2017 in den Lagern ein. Im September 2017 erfolgte die Waffenabgabe und kurz darauf benannte die kolumbianische Regierung die Lager in »Fortbildungs- und Wiedereingliederungszonen« (Espacios Territoriales de Capacitación y Reincorporación, ETCR) um, womit die Etappe der Reintegration ins Zivilleben eingeläutet werden sollte. Die Demobilisierungslager werden als Sonderwelt im Übergang zwischen Kriegszustand und Eingliederung in die Zivilgesellschaft verstanden, also als Nahtstelle gesellschaftlicher Exklusion und Inklusion. Ihre soziale Logik folgt gewissen formalen Kriterien, etwa hinsichtlich Zugangskontrollen, regulierten Besuchszeiten, internen Regeln und einer besonderen Beziehung zu ihrer Umgebung. Im Prozess der Wiedereingliederung in die Zivilgesellschaft ändern sich charakteristische Interaktionsformen, die von der Beschaffenheit des konkreten Ortes beeinflusst werden. In einer Kombination aus fokussierter Datenerhebung audiovisueller und ethnografischer Daten vor Ort mit einer exemplarischen »Datenanalysewerkstatt« werden die Demobilisierten dem Prinzip partizipativer Forschungsmethoden folgend als Akteur*innen miteinbezogen. Mit der Analyse des konkreten Falles in Kolumbien können Erkenntnisse für die internationale Debatte über die Funktion von Lagern für die soziale Integration generalisiert werden. Zudem lassen sich Schlüsse darüber ableiten, welche politischen Konzepte der Reintegration sich durchsetzen lassen - in diesem Fall die Vereinzelung der Demobilisierten seitens der Regierung. 


\section{Summary}

The establishment of »Transitional Zones of Normalisation« (Zonas veredales transitorias de normalización, ZVTN) was one of the most important aspects of the peace agreement concluded between the government and the FARC guerrillas in Colombia in 2016. The government's objectives were to guarantee the ceasefire with the FARC, to carry out its disarmament and to prepare the reincorporation of ex-combatants into civilian life and their transition to legality. To this end, a total of 23 such areas and seven core sites were established in various regions of the country. The combatants arrived in the camps in February 2017. In September 2017, the weapons were handed over and shortly afterwards the Colombian government renamed the camps into »Territorial Training and Reincorporation Spaces« (Espacios Territoriales de Capacitación y Reincorporación, ETCR), which was intended to mark the beginning of the stage of reintegration into civilian life. The demobilisation camps are understood as a special world in the transition between a state of war and integration into civil society, in other words, as the interface between social exclusion and inclusion. Their social logic follows certain formal criteria, such as access controls, regulated visiting hours, internal rules, and a special relationship to their environment. In the process of reintegration into civil society, characteristic forms of interaction, which are influenced by the nature of the specific location, change over time. In a combination of focused data collection of audiovisual and ethnographic data on site with an exemplary »data analysis workshop «, the demobilised persons are included as actors following the principle of participatory research methods. By analysing the specific case in Colombia, insights can be generalised for the international debate as regards the function of camps for social integration. In addition, conclusions can be drawn as to which political concepts of reintegration can be implemented - in this case, the separation of the demobilised persons by the government.

\section{Im Innern des Lagers}

Nach mehr als vier Jahre andauernden Friedensverhandlungen zwischen der kolumbianischen Regierungsdelegation und der sozialrevolutionären Guerillabewegung Fuerzas Armadas Revolucionarias de Colombia - Ejército del Pueblo (FARCEP) wurde am 26. September 2016 feierlich das Friedensablkommen in der Karibikstadt Cartagena unterzeichnet. Damit galt der längste interne bewaffnete Konflikt der westlichen Hemisphäre formal als beendet und die internationale Gemeinschaft applaudierte beim Festakt. Zahlreiche Staatsoberhäupter gratulierten. Dem damaligen Präsidenten Juan Manuel Santos wurde sogar der Friedensnobelpreis verliehen. Über das Abkommen wurde am 2. Oktober desselben Jahres in einer 
Volksabstimmung entschieden. Das Ergebnis überraschte selbst die Gegner*innen der Friedensverhandlungen: 50,21 Prozent lehnten das Friedensabkommen mit der FARC ab. Die Wahlbeteiligung lag bei nur 37,4 Prozent. Daraufhin leitete die Regierung einen Prozess der Nachverhandlung des Abkommens ein, an dem nun auch die führenden Kräfte hinter der Nein-Kampagne beteiligt wurden. Das stark modifizierte »Endgültige Abkommen zur Beendigung des Konflikts und zum Aufbau eines stabilen und dauerhaften Friedens « unterzeichneten schließlich Regierung und FARC-EP in einem weit weniger festlichen Akt am 24. November 2016 in Bogotá (vgl. Charry 2018: 85ff.).

Der bewaffnete und soziale Konflikt in Kolumbien geht indes unvermindert weiter: Im Vergleich zu den Vorjahren des Abkommens sterben weiterhin unzählige Menschen in bewaffneten Auseinandersetzungen. $\mathrm{Zu}$ den Paramilitärs sind zahlreiche neue bewaffnete Gruppen hinzugekommen oder teilweise existierende Strukturen firmieren unter neuen Namen. Im September 2019 kündigte auch ein Teil der FARC-EP die Wiederaufnahme der Waffen an. Hunderte Demobilisierte sind in den Untergrund zurückgekehrt. Die verbleibenden Demobilisierten gründeten eine Partei - auch mit Namen FARC - und nahmen an den letzten Kommunal- und Präsidentschaftswahlen teil, erzielten allerdings kein relevantes Ergebnis. Abgesehen von den Konfrontationen zwischen Regierung und Guerillagruppen existiert ein Krieg um den Drogenhandel, vor allem um Kokain, der von den Anbaugebieten bis zu den Handelsrouten die anliegenden Dörfer terrorisiert. Paramilitärs waren laut den Vereinten Nationen bereits vor dem Abkommen der Hauptverursacher von Menschenrechtsverbrechen und sind es auch weiterhin. Über 300.000 Menschen wurden alleine 2019 von paramilitärischen Gruppen gewaltsam vertrieben. Hinzu kommen politische Morde an Aktivist"innen: Die Staatsanwaltschaft zählt rund 300 ermordete Aktivist*innen seit dem Friedensabkommen, die Defensoría del Pueblo (Ombudsstelle für Menschenrechte) sogar 500 Tote. Das Observatorium Indepaz registriert fast 750 Morde. Mindestens 200 demobilisierte FARC-Kämpfer*innen wurden seither getötet. Diese Morde werden zum Großteil von Paramilitärs oder Auftragsmördern ausgeführt. Zudem warten die Opfer des Konflikts weiterhin auf die Aufarbeitung der Verbrechen - ein Prozess der nur schleppend anläuft. Dies sind nur einige Rahmenbedingungen unter denen sich die FARC-EP freiwillig einem Friedensprozess unterzogen hat - nachdem sie 60 Jahre lang nicht militärisch bezwungen werden konnte. Von den im Juli 2017 gezählten 8.185 FARC-EP-Kämpfer*innen, die an der Demobilisierung teilgenommen haben (vgl. Universidad Nacional 2017: 2), waren im Februar 2020 nur noch 2.893 Personen in den Lagern anwesend (vgl. ARN 2020). 
In der folgenden Analyse ${ }^{1}$ nähern wir uns dem »intimsten« Kapitel dieses Friedensabkommens: den Demobilisierungslagern der Guerilla. Uns interessiert die Frage, auf welche Weise ehemalige Kämpfer*innen den Friedensprozess in ihrer Alltagswelt gestalten und welche Rolle die Einrichtung der Demobilisierungslager dabei spielt. Denn die Schaffung von sogenannten »Übergangszonen zur Normalisierung (Zonas Veredales Transitorias de Normalización, ZVTN) war einer der wichtigsten Aspekte der Verhandlungen. Sie waren Teil der Gespräche zwischen Regierung und FARC-EP unter Beratung seitens der Vereinten Nationen und der Garantenländer. Geplant waren sie zuerst für die Dauer von 180 Tagen (vgl. Presidencia de la República 2016). Die primären Regierungsziele bestanden darin, in diesen Zonen den Waffenstillstand mit der FARC-EP und deren vollständige Entwaffnung zu garantieren sowie die Reinkorporation der ehemaligen Kämpfer*innen in das Zivilleben und ihren Übergang in die Legalität vorzubereiten. Dazu wurden in verschiedenen Regionen des Landes insgesamt 26 solcher Zonen und sieben Konzentrationspunkte eingerichtet. Im August 2017 wurde die Waffenabgabe abgeschlossen. Kurz darauf benannte die kolumbianische Regierung die ZVTN in Fortbildungs- und Wiedereingliederungsgebiete (Espacios Territoriales de Capacitación y Reincorporación, ETCR) um, womit die Etappe der Vorbereitung für das zivile Leben eingeläutet werden sollte. Die Konzentrationspunkte sollten lediglich als kurzfristige Sammelstelle dienen, von denen aus die Demobilisierten in die Lager gebracht werden sollten. Als Demobilisierungslager bezeichnen wir alle von der FARC-EP bewohnten Zonen, zunächst also ZVTN und später auch ETCR, die laut des Abkommens vor allem der Waffenabgabe und Reintegration dienen sollen. Nachdem die ehemaligen Kämpfer*innen in den Lagern ihre Waffen abgegeben hatten, sollten Bildungsangebote geschaffen werden, Gesundheitsversorgung und die Ausstellung von Ausweisen bereitgestellt werden. Diese Angebote liefen allerdings nur sehr schleppend an und wurden in vielen Lagern nicht verwirklicht. Die Teilnahme an der Demobilisierung war gewissermaßen freiwillig, jedoch haben sich rund 2.000 Kämpfer dem Prozess verweigert und haben im Untergrund bewaffnete Folgeorganisationen gegründet. Nach der Waffenabgabe stand es allen Teilnehmer*innen am Friedensprozess frei, die Lager zu verlassen. Der Zugang für Zivilpersonen wurde ebenfalls freigegeben.

Wir hatten das Privileg, seit 2013 kontinuierlich vor Ort in Kolumbien sein $\mathrm{zu}$ können und den Verhandlungsprozess aus verschiedenen Perspektiven zu beleuchten (vgl. Dießelmann/Hetzer 2020, 2018a, 2018b, 2016a, 2016b). Dazu besuchten wir

1 Dieser Artikel präsentiert Ergebnisse des Forschungsprojekts »La paz como laboratorio: Análisis de las ZVTN y su incidencia en los procesos de normalización de excombatientes de las FARC-EP« zwischen der Universidad del Valle in Cali/Kolumbien und der Universität Bayreuth, das gemeinsam mit Prof. Dr. José Fernando Sánchez Salcedo und Prof. Dr. Bernt Schnettler durchgeführt wurde. 
mehrere Demobilisierungslager bis zu zehn Mal in verschiedenen Regionen des Landes, nahmen audiovisuelles Material auf und führten rund 50 Interviews mit FARC-Mitgliedern unterschiedlicher militärischer Ränge. Darüber hinaus stellten uns ehemalige Kämpfer*innen ihre privaten Aufnahmen und Dokumentationen zur Verfügung. Dies ermöglicht es uns, die fotografischen Aufzeichnungen verschiedener Sichtweisen und Momente zu vergleichen, insbesondere aus der Zeit vor der Waffenabgabe, in der wir keinen Zugang zum Lager hatten.

Abbildung 1: Geographische Lage der analysierten ZVTN/ETCR.
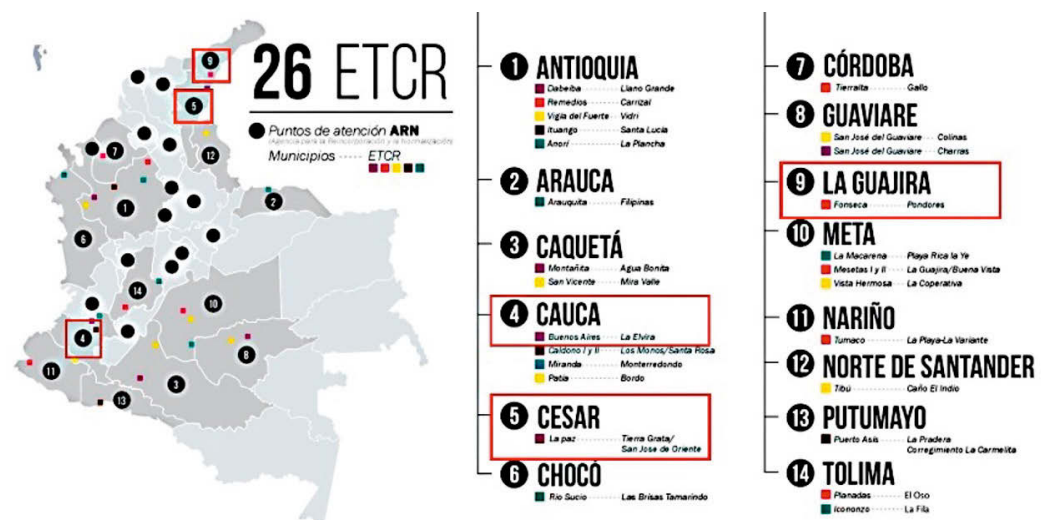

Quelle: Agencia de para la Reincorporación y la Normalización (ARN o.J.). Markierungen wurden von den Autoren des Artikels in der Grafik ergänzt.

Im Folgenden vergleichen wir drei Lager miteinander (siehe Abbildung 1): Zum einen das Lager "Carlos Patiño« in La Elvira im Department Cauca, das wir seit 2016 begleiten. Das zweite Lager »Simón Trinidad« liegt in Tierra Grata im Department César und wurde seit 2019 mehrmals vom Forschungsteam besucht, ebenso das Lager »Amaury Rodríguez« in Pondores im Department La Guajira im Nordwesten des Landes. Die Auswahl der Lager erfolgte nach einem Most-DifferentDesign entlang folgender Kriterien: Erstens aufgrund ihrer unterschiedlichen geographischen Gegebenheiten. Zweitens ist die räumliche Aufteilung der Lager verschieden: La Elvira besteht aus zwei getrennten Zonen, Tierra Grata und Pondores aus jeweils einem kompakten Lagerkomplex. Drittens spielte die Beteiligung der Guerilla-Mitglieder im Moment der Errichtung der Lager und die Konzepte für langfristige Wohnprojekte bei der Auswahl eine entscheidende Rolle. Viertens schließlich unterscheiden sie sich grundlegend bezüglich des Verbleibs ehemaliger Kombattant*innen im Lager. 


\section{Das Demobilisierungslager zwischen Räumlichkeit der Ausnahme und Liminalität}

Giorgio Agamben (2004) beschreibt das Lager als eine Räumlichkeit der Ausnahme. Dabei wird die räumliche Anordnung als ein Mechanismus genutzt, um die strategische Aufteilung des Raums in sogenannte kontrollierbare Mikro-Räume, in Orte des Ausnahmezustands, zu erreichen - darunter das Lager als die am häufigsten auftretende Form. Der italienische Philosoph definiert das Lager als Archetyp des Ausnahmezustands und argumentiert, dass die physischen und räumlichen Bedingungen des Lagers in den alläglichen Praktiken der Insassen ihren Ausdruck finden. Daran anknüpfend lassen sich die FARC-Demobilisierungslager interpretieren: Laut Vorhaben der Regierung sollen in ihnen Personen versammelt und kontrolliert werden, die bis zum Friedensabkommen als Terrorist*innen eingestuft wurden, um diese nun in Bürger*innen mit neuen Verhaltensweisen und Einstellungen zu verwandeln.

»Das Besondere der Situation, die im Ausnahmezustand geschaffen wird, besteht nun darin, dass sie weder als faktische noch als rechtliche Situation bestimmt werden kann, sondern dazwischen eine paradoxe Schwelle der Ununterschiedenheit errichtet.«(Agamben 2004: 26)

Agambens Ausführungen führen uns zu der Idee des Lagers als Ort des Übergangs bzw. als Schwelle zur Normalität. Im Anschluss an Gennep (1909/2013) und Turner (1988) lässt sich die Transformation der Guerillera-Mitglieder im Lager als »Übergangsritus« begreifen. Riten dienen der Markierung einer Veränderung, z.B. dem Übergang von einer Lebensperiode in eine andere oder einer Veränderung des sozialen Status. Sie tragen zur Wahrung der Stabilität der Gesellschaft bei und kodifizieren gleichzeitig die Position des Einzelnen in der sozialen Hierarchie. Ohne hier die Details der Übertragbarkeit von Genneps Vorstellungen auf den Reinkorporationsvorgang der FARC-EP diskutieren zu können, scheint uns insbesondere Turners darauf aufbauendes Konzept der Liminalität als analytische Perspektive auf die Demobilisierungslager geeignet (vgl. Agier 2002: 337).

Der entscheidende Moment des Übergangsritus spielt sich also im Lager ab. Diese Zwischenphase dauert von der Ankunft im Lager bis zur Waffenabgabe und der Umbenennung der ZVTN in Wiedereingliederungsgebiete an. Die militärischen Hierarchien werden aufgebrochen und die Individuen sollen nun fortgebildet werden, um ihre Lebensweise $\mathrm{zu}$ ändern und sich von einem bewaffneten in einen zivilen Akteur zu verwandeln. Offensichtlich wird dieser undefinierte $\mathrm{Zu}$ stand von Widersprüchen und Ungewissheiten begleitet. In dieser Phase besitzen die Personen im Lager keinen klaren Status - noch sind sie keine »Bürger«, so dass sie keiner regulären oder bezahlten Arbeit nachgehen können, aber sie sind auch 
Abbildung 2: Das Drei-Phasen-Modell des Übergangsritus

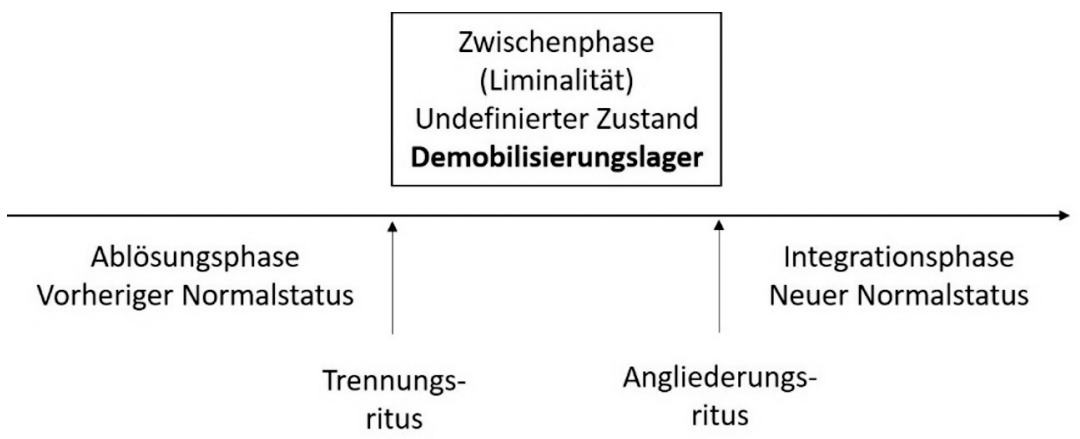

Quelle: Eigene Darstellung.

keine bewaffneten Kämpfer"innen mehr. Das Lager lässt sich demnach als liminale Zone begreifen.

In Übereinstimmung mit Herz definieren wir die Demobilisierungslager also keineswegs als »Nicht-Orte« (Marc Augé), sondern interessieren uns für »the social, legal, and economic interrelations that exist on the ground and the immediate physical context that [...] camps are located within« (Herz 2008: 276). Der ethnographische Zugang nimmt das Alltagshandeln der Bewohner*innen in den Blick, die das Geschehen und die Beschaffenheit des Lagers entscheidend mitprägen. Nach dem französischen Intellektuellen Lefebvre ist der Raum eine Konstruktion seiner Bewohner*innen, der die Grenzen der Möglichkeiten vorgibt und gleichzeitig das Ergebnis von »Vorstellungen, Konstruktionshandlungen und Erfahrungen« (Lefebvre/Roeckl 1972) ist. David Harvey, einer der ersten Soziologen, der sich mit dem Verhältnis von Raum und seiner Konstruktion beschäftigte, definierte »spatial forms [...] not as inanimate objects within which the social process unfolds, but as things which >contain social processes in the same manner that social processes are spatial« (Harvey 2009: 10). In Anlehnung an diese Überlegungen zeigen wir, auf welche Weise die wechselseitige Beziehung zwischen dem Lager als territorial begrenztem Raum und den sozialen Praktiken der demobilisierten Kämpfer*innen den spezifischen Raum erschafft, der sich trotz relativ standardisierter Bauplanungen von Lager zu Lager unterscheidet (vgl. ebd.: 13). 


\section{Über die Aneignung und Veränderung der Lager}

\section{Die geographische Verortung der Lager}

Viele der Lager wurden in Gebieten errichtet, die zuvor Kriegsgebiete waren und häufig von der Guerilla kontrolliert wurden. Strategisch erhoffte sich die FARCEP davon einen gewissen Schutz und die Unterstützung von Sympathisant*innen bei der Wiedereingliederung. La Elvira befindet sich in den westlichen Kordilleren der Anden auf einer Höhe von etwa 2.030 Meter im Departement Cauca. Das Dorf liegt etwa drei Stunden von der letzten asphaltierten Straße entfernt und ist nur über eine Schotterpiste erreichbar. Das Lager ist in zwei Sektoren aufgeteilt: der höher liegende, obere Sektor beherbergt mehrere Baracken aus Gipskarton und Leichtmetall mit 190 Unterkünften, eine improvisierte Bibliothek, eine Erste-HilfeStation und eine Großküche mit Kantine. Dieser obere Wohnbereich ist abgelegen und schwer passierbar. Der untere Sektor verfügt über Gebäude aus Holz für Gäste, zwei Tagungsräume, Speisesaal, Küche und einen überdachten Sportplatz. Hier spielt sich im Allgemeinen das öffentliche Leben ab. Im Laufe der Entwicklung des Lagers entstehen dort später auch »ein Restaurant, der Laden, die Bäckerei, der Raum zur medizinischen Betreuung und der mobile Computerschulungswagen« (Feldtagebuch, AH, 13.10.2017).

Das Lager in Pondores liegt im Departement La Guajira, in der Gemeinde Fonseca, mit hohen Temperaturen um 40 Grad Celsius und extremer Dürre in der Sommersaison. Es ist etwa 17 Kilometer von der Stadt Fonseca und vier Kilometer vom Dorf Conejo entfernt. Von den drei untersuchten Lagern ist es das kompakteste (siehe Foto 1): die Bibliothek, eine Kindertagesstätte, Verwaltungs- und Empfangsbüros, eine Erste-Hilfe-Station, eine Küche, der Speisesaal, Tagungsräume und der Freizeitbereich sind kasernenähnlich angelegt und liegen dementsprechend sehr nahe beieinander. Auch die Unterkünfte befinden sich in unmittelbarer Nähe der Gemeinschaftsräume. Das Besondere an diesem Lager ist, dass ca. 15-20 ExGuerillerxs außerhalb auf einer angemieteten Finca leben, um dort Landwirtschaft $\mathrm{zu}$ betreiben.

Tierra Grata ist von Pondores nur wenige Autostunden entfernt. Es liegt in der Gemeinde Manaure im Departement César, zwischen der Serranía de Perijá und den Bergen der Sierra Nevada. Auch hier herrschen hohe Temperaturen, aber das Lager liegt auf einer Anhöhe (siehe Foto 2), wodurch es gegen Abend abkühlt. Das Lager verfügt über ähnliche Einrichtungen wie die beiden anderen, was auf eine gewisse Standardisierung bei der Planung schließen lässt. Tierra Grata hat den Vorteil in der Nähe des Flughafens von Valledupar und somit sehr gut erreichbar zu sein. Aus diesem Grund wurden sowohl Pondores als auch Tierra Grata, die 


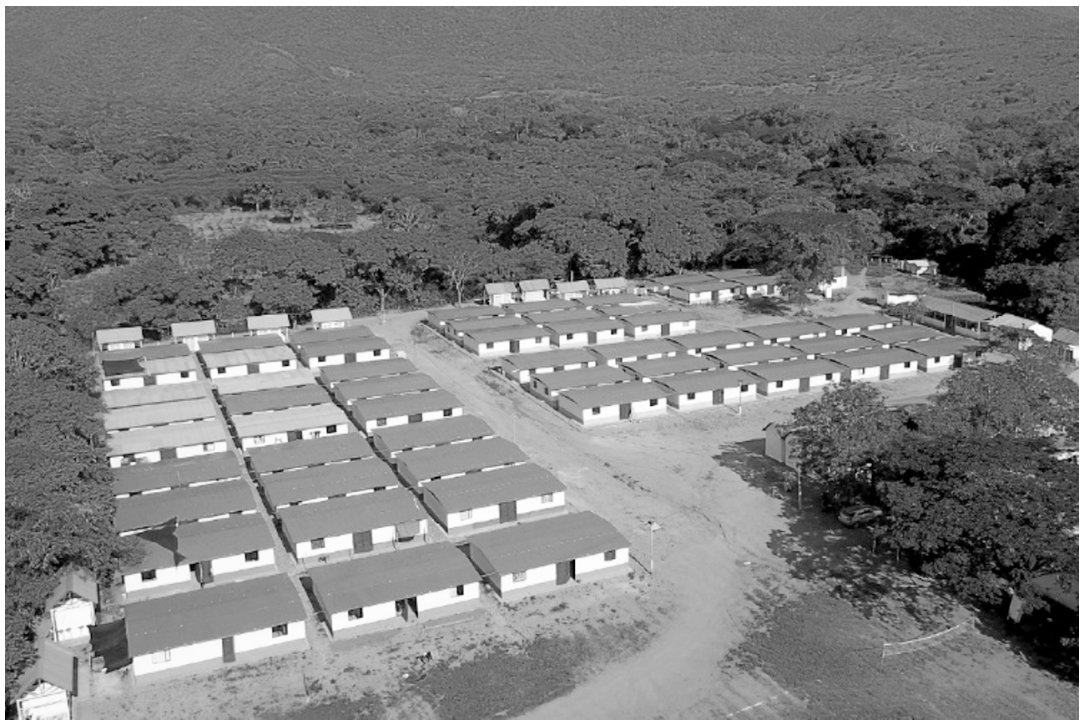

Quelle: Oficina de Alto Comisionado para la Paz.

sich nahe der Grenze zu Venezuela befinden, von hochrangigen nationalen und internationalen Delegationen besucht.

Die jeweilige geographische Lage erklärt bereits zum Teil, warum sich die Anwesenheit nationaler und internationaler Hilfsorganisationen zwischen den Lagern deutlich unterscheidet. Dies wiederum hat Konsequenzen für die Integration und Betreuung der Demobilisierten, wie uns in zahlreichen Interviews mitgeteilt wurde. Die stärkste Präsenz von Institutionen war in Tierra Grata zu beobachten, wo sich permanent Personal der Agentur zur Wiedereingliederung und Normalisierung (ARN) und des Nationalen Ausbildungsinstituts (SENA) sowie der UNDelegation und der FAO im Lager aufhielten. Sie unterhielten sogar Büros und Beratungsstellen. Selbst die Polizei schickt tags und nachts auf Wunsch der Bewohner*innen zum eigenen Schutz vor Mordanschlägen zwei Beamte ins Lager.

\section{Zugang zum Lager und Empfangsbereiche}

Auch die interne Raumaufteilung des Lagers ist entscheidend für die Möglichkeiten des kollektiven Lebens der ehemaligen FARC-Kämpfer*innen. Wir gehen im Folgenden kurz auf die Empfangsbereiche und die Wohnanlagen ein, um die Un- 
Foto 2: Blick auf das Lager Tierra Grata

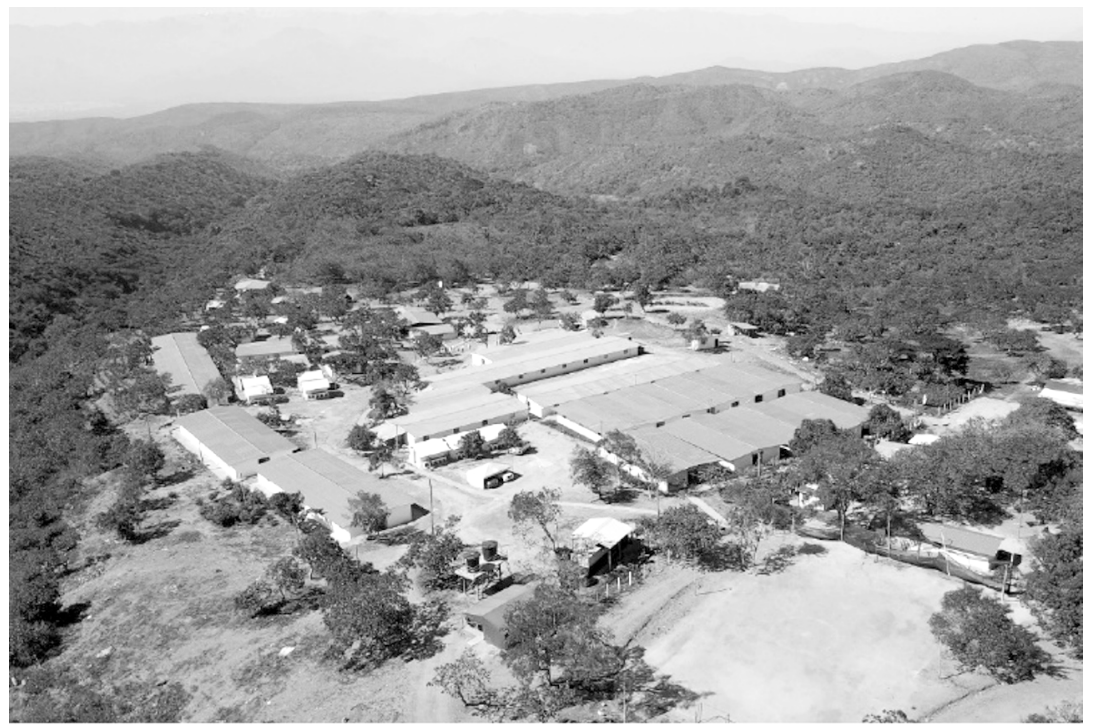

Quelle: Hora724 Noticias, 15.10.2019.

terschiede der Lager und die Aneignung des Raumes durch ihre Bewohner*innen deutlich zu machen.

In Tierra Grata wird die Zufahrt von der Hauptstraße auf den Feldweg zum Lager von den Streitkräften der 10. Brigade des Hochgebirgsbataillons Nr. 7 bewacht, allerdings in Abstimmung mit den Bewohner*innen des Lagers. Der Posten kann seit Ende 2018 ohne Kontrollen passiert werden. Auf dem Weg nach Pondores gibt es neben der Nationalpolizei auch einen Armeeposten, etwa einen Kilometer vom Lager entfernt. Wir stellten noch im Januar 2019 fest, dass die Armee mehrere Kontrollfahrten um das Lager herum unternimmt. In La Elvira hingegen ist die Armee lediglich mit mobilen Einheiten von Gebirgsbrigaden präsent (Foto 3), denn es gibt keinen ständigen Militärposten. Während unseres Aufenthaltes betraten die Soldaten den Empfangsbereich, um ihre Mobiltelefone aufzuladen oder Lebensmittel im Laden zu kaufen, »ohne dabei Unannehmlichkeiten zu verursachen « (Feldtagebuch, AH, 16.11.2018). Auf die Frage nach ihren Beziehungen zu Angehörigen der Armee antworteten die befragten Bewohner*innen in den drei ETCR einstimmig, dass die Autorität zum Schutz der Lager respektiert wird und man zum Teil sogar Arbeitseinsätze mit Polizei und Armee (Tierra Grata) unternommen habe.

Die Beschilderung der Lager hat sich im Laufe der Zeit verändert: Beispielsweise gab es in La Elvira zu Beginn der Lager offizielle Schilder der UN, der Regierung 
Foto 3: Soldat des Gebirgsbataillons des Militärs an der Straße unmittelbar vor dem Empfangsbereich des Lagers La Elvira während einer Patrouille

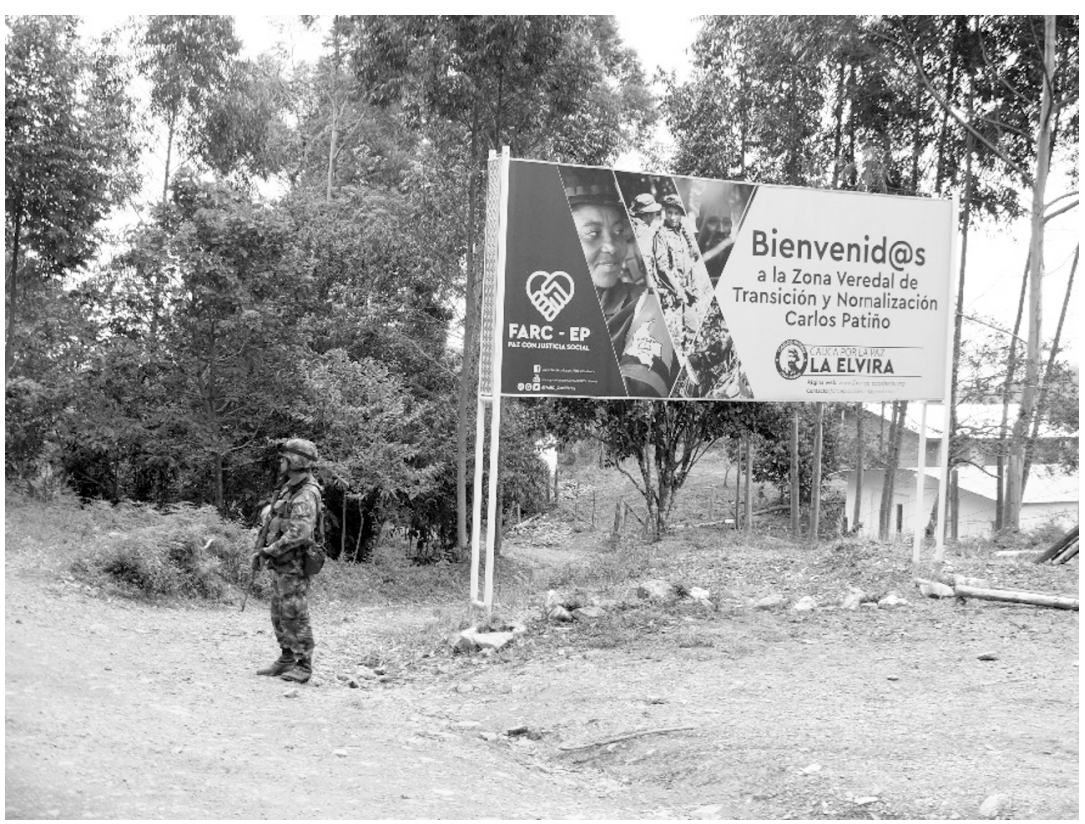

Quelle: Eigenes Material, 16.11.2018.

und der Armee. Diese Schilder wurden mit der Zeit abmontiert oder sind verblichen. Nach rund einem Jahr »begrüßt uns am Eingang des Lagers ein Lageplan der FARC-EP vom Lager zur Orientierung (Feldtagebuch, ALD, 13.10.2017). Auch in den anderen Lagern wurden neue, von den Ex-Kombattant"innen angefertigte Schilder oder Graffitis (Foto 4) angebracht, die an wichtige Persönlichkeiten der bewaffneten Bewegung erinnern. Diese Empfangsbereiche haben darüber hinaus eine hohe Symbolkraft und dienen der Erinnerung und der Identifikation mit ehemaligen ideologischen Führern.

Dies spricht symbolisch für eine neue Funktion dieser Empfangsbereiche. Seit der Waffenabgabe markieren sie gewissermaßen die Trennung zwischen einem öffentlichen und einem privaten Teil des Lagers, wohingegen sie zuvor der $\mathrm{Zu}$ gangskontrolle dienten. Zudem begannen die Bewohner*innen, sie in Räume für die gemeinsame Nutzung und als Treffpunkte umzugestalten, richteten eine Bäckerei und ein Sportzentrum (in La Elvira), Parkplätze, Restaurants und Läden (in allen drei ETCR) ein. In Tierra Grata gibt es darüber hinaus im Eingangsbereich ein offenes Büro in einem Zelt, in dem Treffen mit der FAO und der UN abgehal- 
Foto 4: Empfang mit Restaurant, Tierra Grata

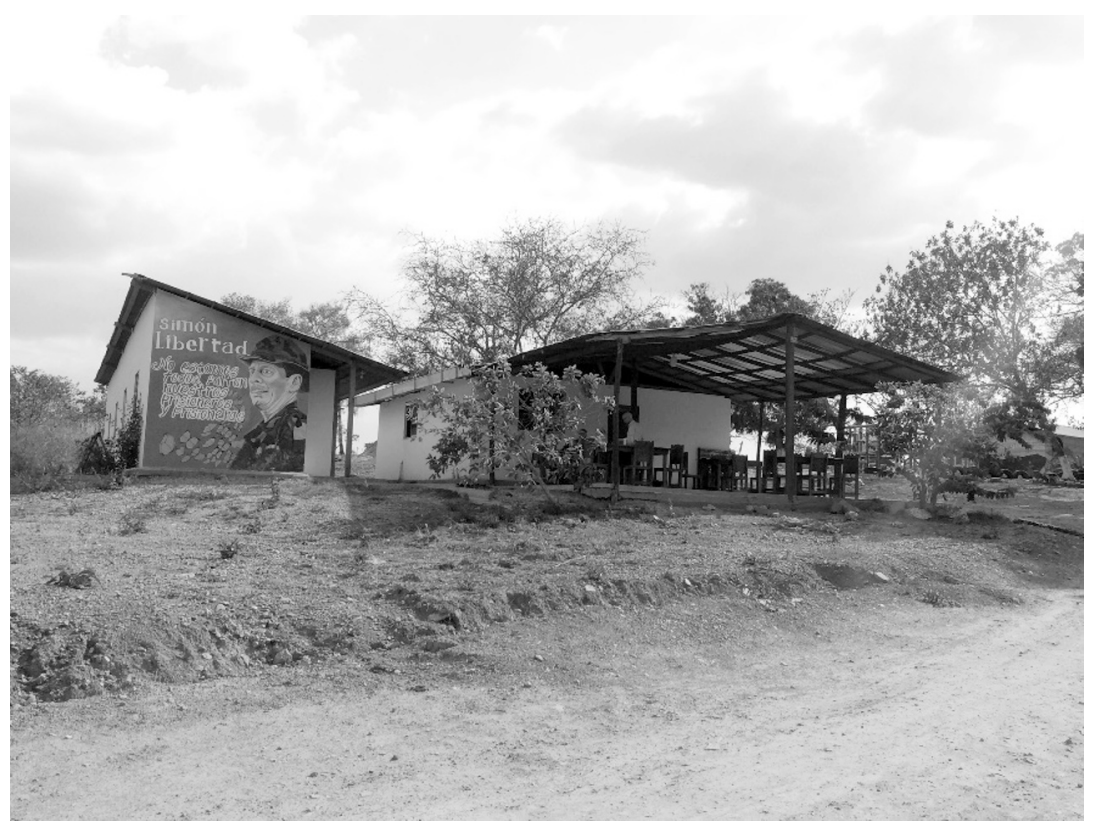

Quelle: Eigenes Material, 04.04.2019.

ten werden und die ARN die Ex-Kombattant*innen betreut (vgl. Feldtagebuch, AH, 05.04.2019). Interessant ist dabei, dass diese Orte auch bis heute dazu dienen, Besucher*innen zu betreuen und in Empfang zu nehmen. Dazu zählen Verwandte, Freund*innen, Forschungsteams, Journalist*innen oder auch Tourist*innen. Alle drei Lager unterhalten Einrichtungen, um Einnahmen aus Dienstleistungen zu erzielen, wie z.B. Restaurants, Läden und Unterkünfte.

\section{Wohnbereiche}

Ein zentraler Aspekt der Entwicklungsmöglichkeit der Lager zu längerfristigen Ansiedlungen ist die Raumaufteilung zwischen den Baracken. In Pondores und Tierra Grata legten die Guerillera-Mitglieder zusammen mit der Baufirma die Aufteilung des Terrains und die Gestaltung der Gebäude fest. MTG berichtet:

»Am Anfang hatten wir einen kleinen Streit mit den Ingenieuren, die den Bauauftrag hatten, weil sie alles nach ihrem Konzept bauen wollten. Wir hatten eine andere Vorstellung. [...] Wir setzten letztendlich eine Raumplanung des La- 
gers durch, dass eher unserer Kultur und unseren Gewohnheiten als Guerilla entsprach.«(Interview mit MTC, 05.04.2019)

Ein Beispiel für ein solches Entgegenkommen beim Bau ist die Anordnung der Wohnräume um einen zentralen Zugang herum, die Integration von Baumbestand in die Lager und das Aufbrechen der strikt geometrischen Anordnung der Bebauung.

In La Elvira hingegen waren die Ex-Guerillera-Mitglieder an diesem Planungsprozess nicht beteiligt, sondern wurden nur als Arbeitskräfte eingesetzt. Zudem liegen die meisten Unterkünfte einen Kilometer vom unteren Teil des Lagers entfernt (Foto 6). Bereits nach einem Jahr wurden wir Zeuge des Verfalls der Baracken, die teilweise nicht einmal fertiggestellt wurden (Foto 5). Als wir einige der verlassenen Häuser betraten - die meisten sind offen - stellten wir fest, dass das Wasser bereits durch die Wände und Dächer gedrungen war (vgl. Feldtagebuch, AH, 16.11.2018). Der Grund, weshalb einige Familien und Personen in den unteren Empfangsbereich des Lagers umsiedelten, wo zudem die Nähe und der Austausch mit der Zivilbevölkerung von Beginn an intensiver war.

Foto 5: Nicht fertiggestellte Baracken, La Elvira

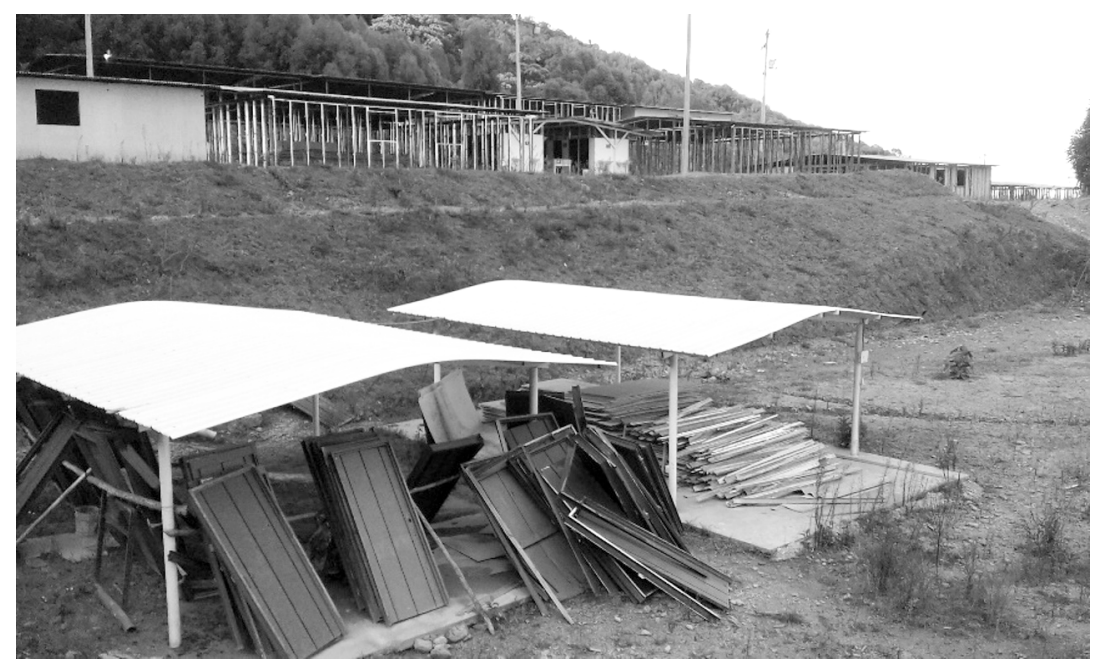

Quelle: Eigenes Material, 16.11.2018.

Im Gegensatz dazu war es in Tierra Grata zum Beispiel möglich, den zugewiesenen Raum nach eigenen individuellen Bedürfnissen zu erweitern. Aufgrund des Wachstums der Familien durch Geburten oder Zuzug von Familienmitgliedern hat sich die Sozialstruktur des Lagers stark verändert. Diese Flexibilität ist nur 
Foto 6: Wohnbaracken und abschüssiges Lagergelände im oberen Teil des Lagers, La Elvira

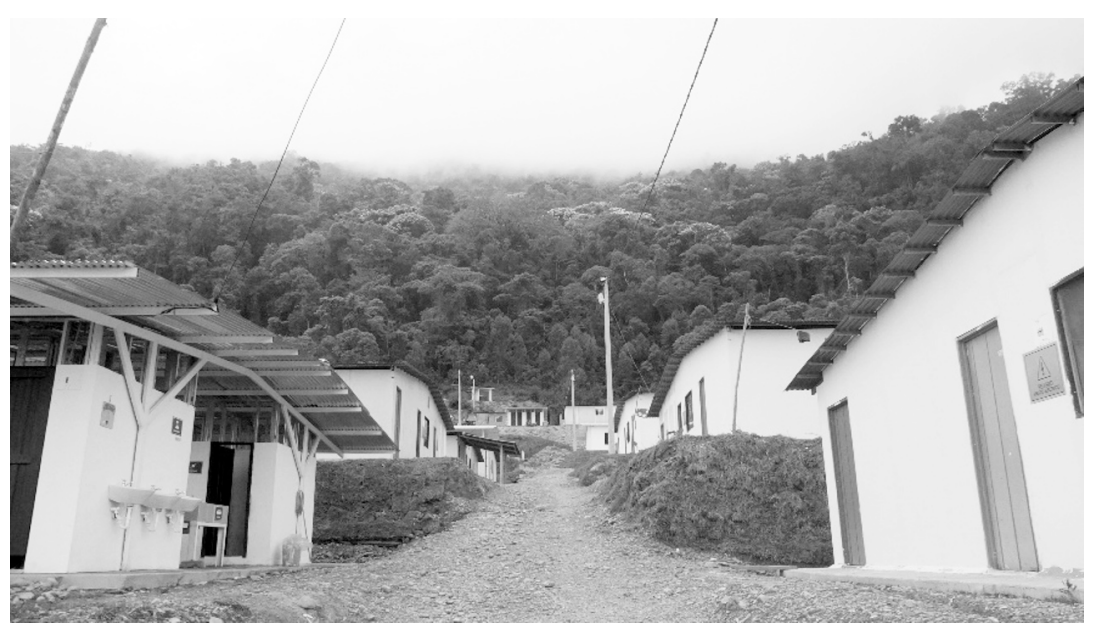

Quelle: Eigenes Material, 13.10.2017.

möglich, weil die ehemaligen Guerillera-Mitglieder bereits während der Errichtung des Lagers entschieden hatten, um die Häuser herum genug Platz zu lassen. Nach Angaben der Ex-Kombattant*innen fällten sie keine Bäume auf dem Gelände, obwohl laut Plan der UN-Mission und der Baufirma alle Häuser linear und geometrisch angelegt werden sollten. Stattdessen bewahrten sie die Pflanzen mit dem Ziel, Schatten zu erhalten und einen weniger geradlinigen Raumplan umzusetzen - mit mehr Möglichkeiten zur Improvisation. Die Ex-Kombattant"innen setzten außerdem durch, die Zugänge zu den Räumen durch Korridore nach innen zu verlegen. Dies hat einen klaren Vorteil: »Einerseits spenden die Korridore mehr Schatten und ermöglichen es den Kindern, drinnen zu spielen, und andererseits erleichtert es die Begegnung der Menschen und die Aufrechterhaltung des Kollektivs pro Baracke.« (Interview mit SP, 06.04.2019) In Pondores wurden 52 Modulhäuser aufgestellt. Jede dieser Baracken hat vier Räume, die teilweise durch Korridore miteinander verbunden sind. Sie waren anfangs nicht überdacht. Um sich jedoch vor der Hitze zu schützen, improvisierten einige Bewohner*innen einen Sonnenschutz (Foto 7). Darüber hinaus ermöglichen auch hier die Häuser die Verbindung zweier Räume durch eine Tür oder das Entfernen einer Wand, so dass Paare ihre Privatzimmer zusammenlegen können. Die räumliche Struktur des Lagers in Pondores weist als Besonderheit einen zentralen Platz mit einem großen Baum in der Mitte und Holzbänken auf. Während der Bauarbeiten wurde beschlossen, einen Freiraum zwischen den Wohnhäusern, der Bibliothek und dem Tagungsraum zu belassen. Dieser Platz dient als hoch frequentierter Treffpunkt. 
Foto 7: Korridore zwischen den Baracken mit Sonnenschutz, Pondores

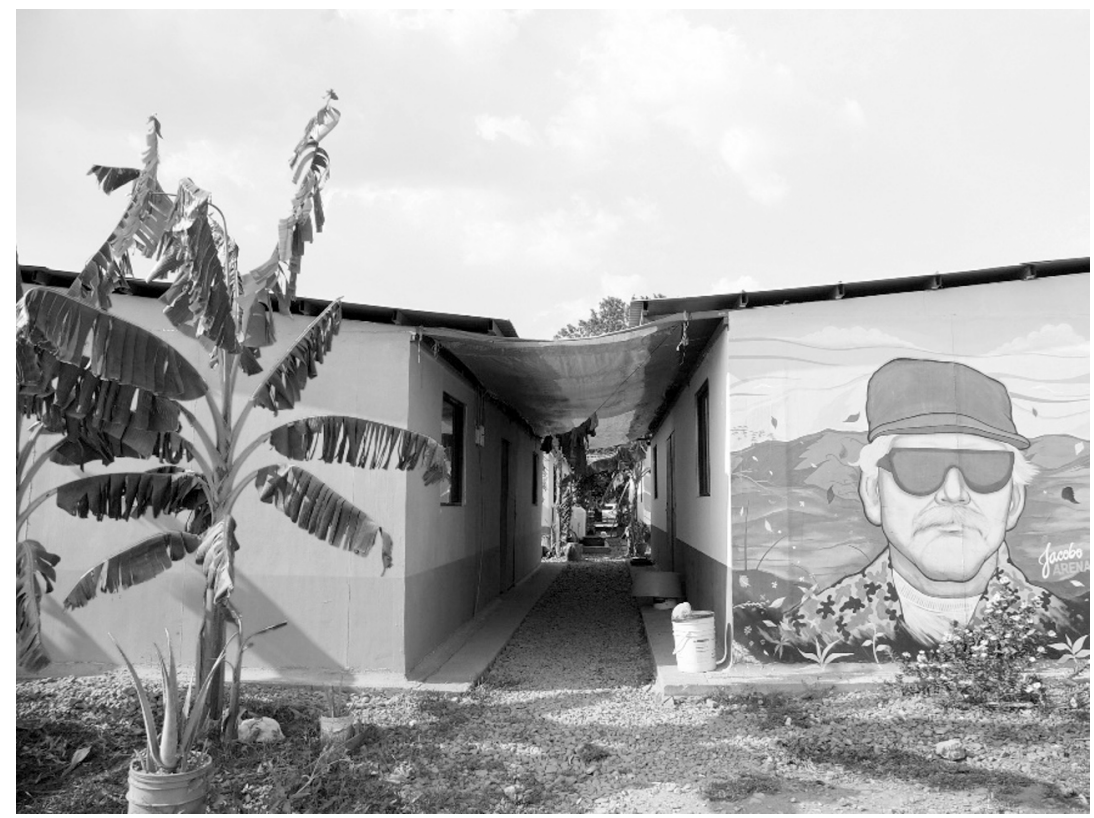

Quelle: Eigenes Material, 08.04.2019.

Vor allem in Pondores und Tierra Grata gestalten die Bewohner*innen der Lager mit kleinen Vorgärten, Pflanzen und anderen Dekorationsformen den Raum und sorgen so für eine grüne Umgebung der Baracken (Foto 8). Dadurch entstehen kleine Obstgärten und Tierhaltung für den Eigenbedarf. Vor allem aus Bauernfamilien stammende Ex-Kombattant*innen haben zügig nach Bezug der Lager begonnen, das Land für Obst- und Gemüseanbau oder Hühnerzucht zu nutzen. In La Elvira sind all diese Phänomene ebenfalls, aber in geringerem Maße zu sehen.

\section{Wechselwirkungen zwischen sozialen Praktiken und Raumstruktur}

\section{Auflösung von Gemeinschaftsräumen}

Die Veränderung der sozialen Kohäsion der FARC-EP in Wechselwirkung mit der Demobilisierung und dem Leben im Lager lässt sich an einigen Beispielen besonders illustrieren. Im Moment der Ankunft der FARC-EP im Lager hatten wir es mit einem militärischen Apparat zu tun, der auf klar geregelten Befehlshierarchi- 
Foto 8: Gärten vor den Baracken, Tierra Grata

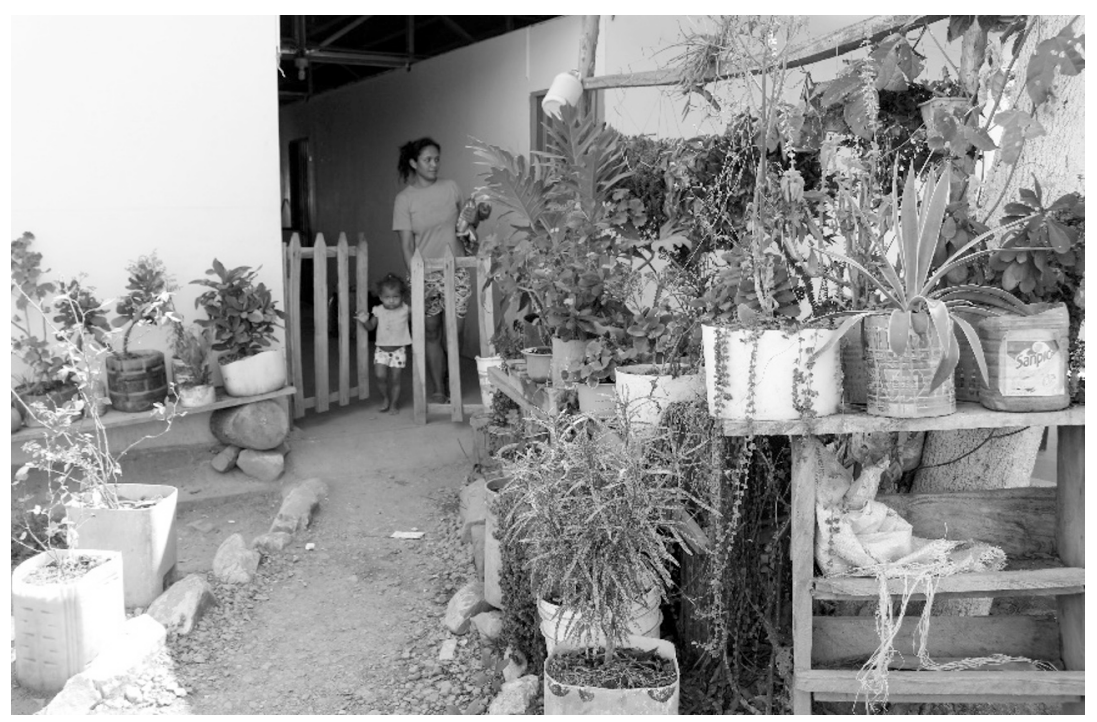

Quelle: Eigenes Material, 05.04.2019.

en, Routinen der Alltagsorganisation und Rollenzuschreibungen beruhte. Das gemeinsame Essen, sich beim Kochen abzuwechseln, die Verteilung der Aufgaben, die zuvor nötig gewesen sind, um das Überleben im Kampf zu organisieren und die ideologische Schulung manifestierten sich einerseits in den Räumen und ihrer Konzeption sowie andererseits in der Aneignung der vorgefundenen Lagerstruktur. Gemeinschaftsküchen und geräumige Speiseräume waren in der Planung der ZVTN vorgesehen. In den ersten Monaten waren die Zubereitung und der Verzehr von Mahlzeiten eine Gemeinschaftsaufgabe. »Wir folgten unserer Tradition, wir bereiteten die Mahlzeit dreimal am Tag gemeinsam zu, Männer und Frauen gemeinsam. (Interview mit RE, 13.10.2017) Mit dem Zuzug von Familienmitgliedern, individuellen Anschaffungen und dem Bau von kleinen Küchen in Privaträumen (Foto 9) verlieren die Gemeinschaftsküchen mehr und mehr ihre Funktion. Die Speise- und Versammlungsräume waren zu Beginn der Demobilisierung Orte der Begegnung und des kollektiven Austauschs. Im Jahr 2019 sind sie meist verlassen. Diese Tatsache kann als eine Folge der Neuordnung der Räumlichkeit nach spezifischen Bedürfnissen von Paaren oder der Kernfamilie interpretiert werden, was eine Herausforderung für den Zusammenhalt des Kollektivs darstellt. Die Familiengründungen können sicherlich als ein Schritt der »Normalisierung« der Demobilisierten interpretiert werden, sie stellen ein Element des Wandels der Lebensform 
dar, also die Loslösung vom Kollektiv in ein privates Leben. Dieser Übergang war von der Regierung möglicherweise sogar gewünscht, aber seitens der Farc-Partei und vieler ehemaliger Kombattant*innen wird er auch im Hinblick darauf kritisiert, dass er die politische Kraft des Kollektivs zu schwächen vermag.

Foto 9: Privatzimmer mit Herd und Kühlschrank, Pondores

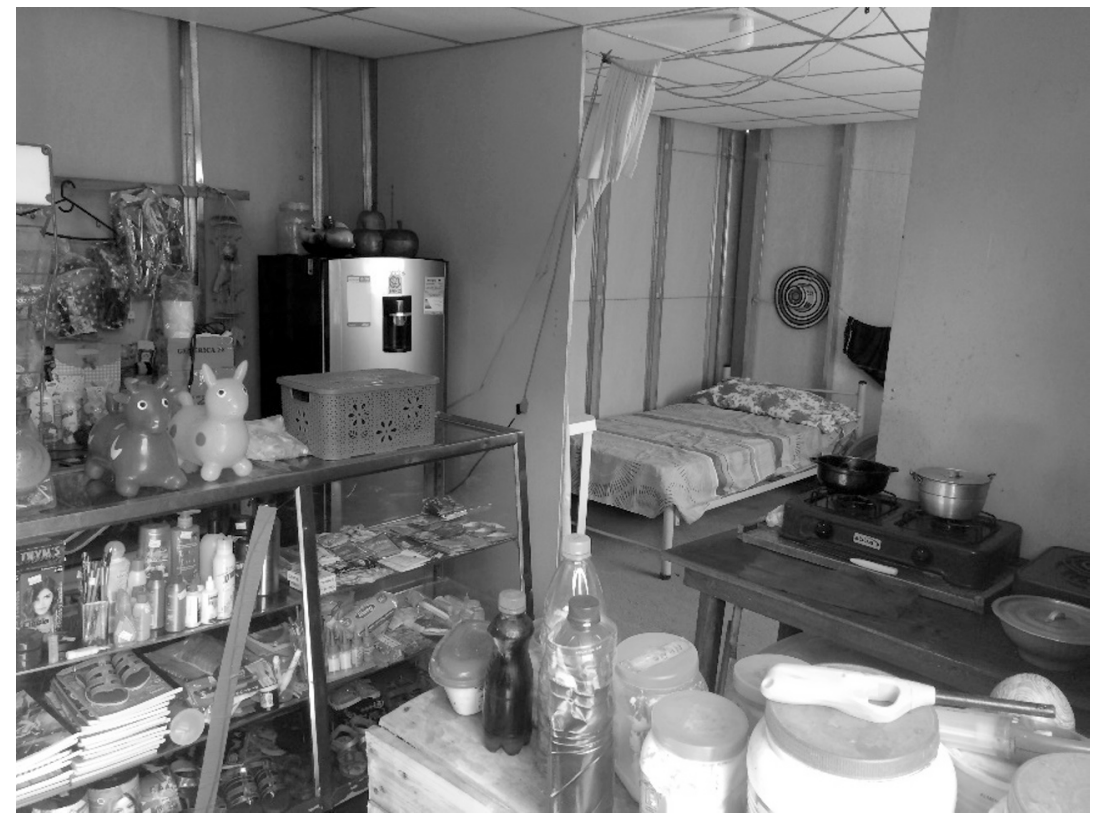

Quelle: Eigenes Material, 08.04.2019.

Wir interpretieren dies als eine Wechselwirkung zwischen dem Verlust des sozialen und politischen Zusammenhalts einerseits und der Vernachlässigung von Gemeinschaftsräumen wie Küche und Kantine andererseits. Besonders erwähnenswert ist zudem, dass sich mit der fortschreitenden Individualisierung der Aufgaben und Räumlichkeiten (Ausbau und stärkere Nutzung von Privaträumen, Abbau und weniger Nutzung der Gemeinschaftsräume) ebenfalls die Beziehungen zwischen den Geschlechtern verändert. »In den Gemeinschaftsküchen waren Männer und Frauen gleichermaßen eingespannt (Interview mit SP, 06.04.2019), mit dem Rückzug in private Räume allerdings wird nicht nur die Zubereitung der Mahlzeiten, sondern auch weitere Reproduktionsarbeit fast ausschließlich von Frauen geleistet. Nur wenige alleinstehende Männer übernehmen diese Aufgaben selbständig. 


\section{Funktionale Differenzierung und Herausbildung von Institutionen}

Ein weiterer Aspekt des Verhältnisses von Raum und Sozialstruktur hängt eng mit der zunehmenden Ausdifferenzierung von Bedürfnissen und Lebensentwürfen der Bewohner*innen zusammen. Beispielsweise ist in Pondores der Kindergarten ein wichtiges Element der kommunalen Integration bei gleichzeitiger Rollendifferenzierung. Kinder aus den umliegenden Dörfern können den Kindergarten besuchen, den ehemalige Kämpfer*innen aufgebaut haben. Für die umliegenden Gemeinden ist dies ein Gewinn, da eine solche Institution in der Region nicht vorhanden war. "Manche Kinder kommen auf Eseln aus ihrem Dorf« (Interview mit JP, 08.04.2019), sie müssen jeden Tag mehrere Kilometer zurücklegen, es gibt keinen öffentlichen Transport. Der Kindergarten ist offiziell zertifiziert, drei ausgebildete Betreuerinnen (Ex-Guerilleras) werden bezahlt und die Lebensmittel für die $\mathrm{Zu}$ bereitung des Mittagessens zur Verfügung gestellt. Der Kindergarten ist aufgrund des Wachstums der Gemeinde und der Zahl der Geburten seit der Ankunft der ExKombattant*innen im Lager von größter Bedeutung. Nach Angaben der Kindergärtnerin ist die Institution morgens geöffnet und bisher kommen von den insgesamt 40 ein- bis sechsjährigen Kindern im Lager täglich etwa zwölf bis 15 (vgl. ebd.). »Der Kindergarten ist für die Gemeinschaft der Ex-Kombattant*innen und den Kontakt mit den Nachbargemeinden von enormer Bedeutung.« (Ebd.) Sie befreit die Frauen für eine bestimmte Tageszeit von ihren Pflichten als Mütter, damit sie in den kommunitären Projekten wie z.B. den landwirtschaftlichen Betrieben mitarbeiten können. In Tierra Grata hingegen gibt es zwar bereits ein Kindergartengebäude, das jedoch aufgrund der fehlenden staatlichen Anerkennung noch nicht genutzt wird. Die komplizierteste Situation für die Familien besteht allerdings in La Elvira, wo es keine solche Errungenschaft gab. Nach Aussage eines Bewohners des Lagers führte dies »zur Abwanderung einiger Ex-Kombattantinnen an andere Orte, wo es günstigere Bedingungen für Kinder gibt « (ebd.). In La Elvira gibt es im Gegensatz zu den ETCR im Nordosten des Landes nur sehr wenige Familien mit Kindern.

Die Gründung eines Kindergartens mit der damit verbundenen Professionalisierung der Arbeit mit Kindern zeigt einen sehr tiefgreifenden Wandel in der inneren Struktur der Gruppe der Ex-Kombattant*innen. Das neue zivile Leben erfordert eine Arbeitsteilung und Spezialisierung in verschiedenen Bereichen des täglichen Lebens. Diese Professionalisierung von Aufgaben im zivilen Leben schafft ein Ungleichgewicht zwischen den ehemaligen Kämpfer*innen, zumal wenn die Einnahmen nicht kollektiviert werden. Von einem Moment auf den anderen werden anerkannte Ausbildungen, frühere Studien, die Anpassungsfähigkeit an zivile Strukturen usw. bedeutsam. Sie verschaffen nicht nur Anerkennung innerhalb der Gruppe selbst, sondern erleichtern es auch, außerhalb des Lagers und fernab des

Kollektivs Arbeit zu finden und ein stabiles Einkommen zu generieren. Ähnliches 
gilt für ehemalige Guerillera-Mitglieder, die nun in der Parteistruktur unterkommen oder als Leibwächter Arbeit gefunden haben und somit eine staatliche Bezahlung erhalten. Doch nicht alle Bewohner*innen sind an wirtschaftlich lukrativen Projekten beteiligt. Die Mehrzahl lebt lediglich von dem staatlich gezahlten Grundeinkommen, das im Friedensabkommen festgelegt und mehrfach verlängert wurde. Dadurch entstehen Fliehkräfte, die die soziale Kohäsion des Kollektivs, in dem zuvor alle denselben »Verdienst « erhielten, vor neue Herausforderungen stellt. Der Kindergarten ist darüber hinaus eines der Elemente, die auf einen Wandel von der Demobilisierungszone zu einer dörflichen Struktur und einer funktionalen Differenzierung von Rollen und Aufgaben hindeuten. Gleiches ist bei den Tätigkeiten in den Werkstätten, der Schneiderei, den Landwirtschaftsprojekten oder im Tourismus zu beobachten.

\section{Sport und Freizeit}

In allen drei Lagern gibt es Einrichtungen für Sport. Besonders die Fußballfelder haben neben der Fitness der Ex-Kombattant*innen noch eine weitere wichtige Funktion: Sie fördern den Kontakt zur Zivilbevölkerung. Das Verhältnis der Guerilla zur Zivilbevölkerung ist regional sehr unterschiedlich und hängt von vielfältigen Faktoren ab. Einzelne Kommandanten waren sehr beliebt und der Kontakt zur Bevölkerung war ihnen wichtig, andere obere Befehlshaber tyrannisierten die Regionen, in denen sie Einfluss hatten. Diese Besonderheiten wirken sich bis heute aus. In vielen Lagern werden Turniere organisiert. Dazu bilden ehemalige Kombattant*innen Teams und laden Mannschaften aus den umliegenden Dörfern ein. In Pondores und Tierra Grata dienen die Bolzplätze vor den Unterkünften als Fußballfelder. In La Elvira gibt es ein überdachtes Spielfeld aus Beton, das auch für Musik- oder Tanzveranstaltungen genutzt wird.

Neben dem Sport gibt es andere Formen der Freizeitgestaltung, die eigene Räume erfordern und die Regeln des Zusammenlebens beeinflussen. In Tierra Grata und Pondores gibt es jeweils eine offene Kneipe oder Bar, in der man Billard oder die landestypischen »tejo « und »sapo« spielen kann, Gesellschaftsspiele ähnlich wie Dart oder Kegeln ${ }^{2}$. Sie sind abendliche Treffpunkte, an denen bis zu einer vorgegebenen Zeit auch laute Musik läuft. Aus Lärmschutzgründen liegen diese in gewisser Entfernung zu den Wohnbaracken. Um Regeln für die Freizeitgestaltung und das Zusammenleben zu definieren, wurde eine eigens gegründete Institution damit beauftragt:

Bei tejo wird mit einem Metallstein auf eine Lehmkiste geworfen, in der kleine Pakete mit Schießpulver stecken und beim Treffer explodieren. Sapo ist ein Holzschrank mit verschieden großen Löchern und Schlitzen, in dessen Mitte ein Frosch aus Metall sitzt. Mit schweren Metallringen wird darauf geworfen und je nach Versenken des Ringes Punkte vergeben. 
»Wir haben einen Kommunalen Aktionsrat (Junta Acción Comunal, Anm. d.Verf.) gegründet, weil wir Regeln für die Cemeinschaft aufstellen mussten. Sie ist wichtig für ein gutes Zusammenleben. Wer sich nicht an diese Regeln und die festgelegten Zeiten hält, muss eine Celdstrafe zahlen.« (Interview mit JTC, 06.04.2019)

Die JAC ist eine Selbstverwaltungsstruktur, in der alle Bewohner*innen der Lager teilnehmen können. Auf diese Weise werden beispielsweise der Verkauf und Konsum von Alkohol im Lager geregelt. Die Regeln und Sanktionen erinnern an die Strafen während der Guerillazeit, jedoch werden diese nun kollektiv diskutiert und nicht von dem*der Kommandant*in festgelegt. Daran zeigt sich der Wandel der Organisation bei gleichzeitiger Aufrechterhaltung kollektiver Regulierungsinstanzen, die sich unmittelbar auf die Raumaufteilung auswirken. Im Wohnbereich wird laute Musik und Alkohol beispielsweise nicht genehmigt.

Mit dem Zerfall der militärischen Hierarchien verändert sich auch die Wahrnehmung und Nutzung von Freizeit und Erholung. Beides sind nicht mehr kollektive Elemente des Alltagslebens, sondern jeder kann sie nach Bedarf und persönlichem Geschmack selbst gestalten. Daraus ergeben sich neue, bisher unbekannte Konflikte um divergierende Bedürfnisse. Andererseits entstehen dadurch auch neue interne Organisationsstrukturen wie die in allen Lagern vorhandenen »Versammlungen des Zusammenlebens«. Die neuen Organisationsformen basieren auf einer breiten Beteiligung und ersetzen so vorherige militärische Hierarchien durch horizontale Strukturen (vgl. Interview mit BP, 09.04.2019). Ehemalige Kämpfer*innen suchen nach neuen Aufgaben und Lebensinhalten, passen sich der sie umgebenden zivilen Gesellschaft an, strukturieren demnach neue Organisationsformen und etablieren demokratischere Formen der Partizipation. Die räumliche Struktur der Lager spielte zu Beginn der Demobilisierung eine zentrale Rolle, stellte gewissermaßen die Startbedingung der Reintegration dar. Nach ihren neuen Bedürfnissen wurden und werden diese Lager umfunktioniert - wo dies möglich ist, bleiben die ehemaligen Guerilla-Mitglieder zusammen, wo dies massiv erschwert wird, ist die Wahrscheinlichkeit höher, dass das Kollektiv zerfällt. Das zivile Leben ermöglicht die Schaffung neuer Räume, in denen Kapazitäten des Kollektivs freigesetzt werden, die nun Verantwortung übernehmen. Dies kann als ein konkretes Beispiel für die Dialektik der Konstruktion von Raum durch soziale Praktiken interpretiert werden.

\section{Divergierende Vorstellungen über die Temporalität des Lagers}

Trotz der Tatsache, dass die ZVTN/ETCR ähnlich wie Flüchtlingslager als temporäre Übergangszonen gedacht waren (vgl. Herz 2008: 276), tendieren sie dazu, als 
»Camps-villes «3 (Agier 2002: 322) zu überdauern. Der französische Anthropologe Agier beschreibt, wie Flüchtlingslager "gradually become the sites of an enduring organization of space, social life and system of power that exist nowhere else. These are paradoxical devices, hybrids« (ebd.) Für die Demobilisierungslager lässt sich Ähnliches feststellen. Besonders stechen in der Analyse die verschiedenen Vorstellungen von Seiten der FARC-EP und der Regierung in Bezug auf die Existenzdauer der Lager hervor: Laut Punkt 3.1.4. des Friedensabkommens sind die Ziele der ZVTN: 1 . »die dauerhafte und vollständige Beilegung der bewaffneten Auseinandersetzungen und die Waffenabgabe zu garantieren «, 2. »die Wiedereingliederung der Mitglieder der FARC-EP in das zivile Leben im wirtschaftlichen, politischen und sozialen Bereich entsprechend ihren Interessen vorzubereiten « und 3. den »Übergang zur Legalität« einzuleiten (Acuerdo Final 2016: 62). Daher sind die ZVTN »territorial begrenzt und temporär als vorübergehend definiert « (ebd.). Dieser Charakter wurde im Abkommen deutlich betont. Die Lager waren nicht als langfristige Aufenthaltsorte, geschweige denn als Dörfer angelegt. In der Phase der Lagerplanung im Jahr 2016 meinte Präsident Santos noch: »Die ZVTN werden für 6 Monate bestehen, genau so lange, bis die FARC ihre Waffen abgeben werden.« (Presidencia de la República 2016)

Der Präsidialerlass 1274 vom 28. Juli 2017 besagte dann, dass »die Dauer der Übergangs- und Normalisierungszonen ZVTN und einiger Normalisierungspunkte PTN bis zum 15. August 2017 verlängert wird, um den Prozess der Waffenabgabe und der Vernichtung der Waffen abzuschließen.« (Präsidialdekret 1274 2017) Um den Wiedereingliederungsprozess weiterzuverfolgen, ordnet derselbe Erlass an, dass »die ZVTN und PTN in Territoriale Räume für Ausbildung und Wiedereingliederung (ETCR) umgewandelt werden« (ebd.). Die ETCR tauchen im Friedensabkommen nicht auf, sondern basieren auf einer nachträglichen Regierungsentscheidung zur Verlängerung des Bleiberechts in den Lagern - nicht zuletzt aufgrund des internationalen Drucks zur Umsetzung des Friedensabkommens. Während der Waffenabgabe wurde damit die Dauer der Ausbildung und Wiedereingliederungsaktivitäten verlängert. Im Dezember 2017 wurde die Laufzeit der ETCR nochmals um zwei Jahre verlängert. Schließlich entschied die neue Regierung von Iván Duque nach Rücksprache mit den Bürgermeistern der Gemeinden, in denen sich die ETCR befinden, den Großteil der Ländereien zu kaufen. Die Landtitel sollen der Agentur für Wiedereingliederung und Normalisierung (ARN) überschrieben und dann den ehemaligen Kämpfer*innen überlassen werden. Das ist bis 2020 nicht passiert. 
Die seitens der Regierung stets als temporäre Lösung gedachten Lager wurden durch den Widerstand der FARC-Mitglieder verstetigt, die entgegen ursprünglicher Vorstellungen auf einen kollektiven Verbleib in den Lagern setzten. Die vorgestellten Praktiken der Raumnutzung und Raumgestaltung durch das neue Gemeinwesen kann als Strategie der Ex-Kombattant*innen interpretiert werden, die Lager in dauerhafte Siedlungen zu verwandeln. Es lässt sich auf der Grundlage der visuellen Daten aus den Feldaufenthalten argumentieren, dass die Aneignung des Raumes in den Lagern eine Schlüsselrolle dabei spielt, die ETCR in kleine Dörfer oder Siedlungen zu verstetigen.

\section{Widerstand gegen die Ausnahme und Wunsch nach Normalisierung}

Die Demobilisierungslager spielen eine zentrale Rolle für den Friedensprozess. Sie stellen gewissermaßen den physischen Dreh- und Angelpunkt der Demobilisierung dar, weil dort die Ankunft bewaffneter Kämpfer*innen aus der Klandestinität, die Konzentration der Guerilla, die Waffenabgabe und legale Verwaltung vormals illegaler Kämpfer*innen stattfindet. In diesem Raum kommen die unterschiedlichen politischen und sozialen Vorstellungen aller beteiligten Akteur*innen über den Frieden zum Ausdruck. Die Bewohner*innen der Lager haben das Bedürfnis nach kollektiven Räumen materialisiert, in denen sie sich langfristig aufhalten können und die ihnen eine Zukunftsperspektive bieten. Der Prozess der Aneignung der provisorischen Lager und der Umbau zu formalisierten Siedlungen ist ein Indikator für den Widerstand gegen das individuelle Reinkorporationskonzept der Ex-Kämpfer*innen, das von der Regierung verfolgt wurde und bis dato zum Standardmodell jedes Demobilisierungsprozesses illegaler bewaffneter Gruppen in Kolumbien zählte.

Obwohl die Lebensbedingungen und die Infrastruktur in Pondores und Tierra Grata weniger günstig sind, beobachten wir dort ein Wachstum der Lager und eine stärkere Kohäsion des Kollektivs als in La Elvira. Die interviewten Personen erklären dies damit, dass die Ex-Kommandant*innen bis heute im Lager geblieben sind und als "neue soziale Aktivist*innen« eine Führungsrolle übernehmen. In diesem Sinne erklärt uns ein ehemaliger Kämpfer: »Ich bleibe hier wegen meines Kommandanten. Sie sagen uns, was wir zu tun haben." (Interview mit EP, 07.04.2019) Die Kommandanten haben weiterhin die Leitung des Lagers inne und regeln Fragen des Zusammenlebens, auch wenn die Mitbestimmung im Vergleich zu Kriegszeiten größer geworden ist. Demnach überdauern militärische Hierarchien und frühere Autoritäten spielen weiterhin eine wichtige Rolle im Übergang zur »Normalität«. Wie wir aber feststellen konnten, hängt die soziale Position im Lager nicht mehr nur von der Stellung innerhalb der vorherigen Hierarchie ab, sondern von der Fähigkeit des Einzelnen, sich an zivile Gewohnheiten anzupassen, 
strategisch wichtige Kontakte nach außen aufzubauen und Ausbildungswege zu beschreiten. Die individuelle Berufswahl und funktionale Differenzierung im Lager wirken auf die Zersetzung des Kollektivs stärker als die allmähliche Auflösung ehemaliger Befehlsketten. Ähnlich wie in Geflüchtetenlagern stellen sich soziale Ungleichheiten in den Lagern über den unterschiedlichen Zugang zu Ressourcen her, die für die Lagerrealität bedeutsam sind (vgl. Agier 2002: 330). Es herrscht also ein Spannungsverhältnis zwischen Aufrechterhaltung von ehemaligen Hierarchien und der sozialen Kohäsion auf der einen Seite und Fliehkräften wie Individualisierung auf der anderen Seite.

Ein weiterer ausschlaggebender Punkt für die Verstetigung des Lagers ist die Organisationskapazität der Gruppe in Bezug auf die legale Interessensdurchsetzung: „Seit dem ersten Moment der Ankunft im Lager haben wir uns zum Bleiben entschieden. Kurz darauf haben wir einen Kommunalen Aktionsrat gegründet, um unseren Interessen in politischen Instanzen Gehör zu verschaffen. (Interview mit JTG, 06.04.2019). Während die Regierung von der Annahme ausging, dass das Leben in den Lagern die individuelle Reinkorporation fördert, und nicht umgekehrt, erklärt eine ehemalige Kämpferin: »Die Regierung möchte, dass jeder von uns das macht, was ihm beliebt, aber hier haben wir eine andere Vorstellung. Wir kämpfen gemeinsam für unsere Zukunft und deshalb sind wir zusammengeblieben." (Interview mit RTG, 05.04.2019) Rückblickend war es zum einen entscheidend, dass sich die Guerillera-Mitglieder in Pondores und Tierra Grata am Bau des Lagers beteiligt und den Raum ihren Vorstellungen und Bedürfnissen gemäß mitgestaltet haben, und zum anderen, dass die FARC-EP zumindest Unterkünfte in Leichtbauweise anstatt Zelte mit der Regierung verhandelt hatte. Die Mitgestaltung des Lagers im Konkreten interpretieren wir als einen Ausdruck des Widerstands gegen die Regierungspolitik. Das Lager ist zum neuen Kampffeld der ehemaligen Kämpfer*innen für eine kollektive Lösung der Transition sowie des politischen und ökonomischen Überlebens der FARC-EP geworden. Die Demobilisierungslager stellen deshalb »den letzten Ort des Krieges und den ersten Ort des Friedens dar« (Marín/Espinosa Menéndez 2017: 442).

Anstatt also das Lager zu verlassen und auf diese Weise ihre Liminalität aufzuheben, verbleiben die ehemaligen Kämpfer*innen in den Lagern und versuchen mittels der Überführung der Lager in eine Dorfgemeinschaft die Temporalität der Ausnahme aufzulösen. Für dieses Argument spricht zudem, dass es in Pondores und Tierra Grata ein neues Bauprojekt mit dem Namen »Friedensdörfer« (Ciudadelas de Paz) mit Unterstützung der EU gibt, um auf dem Gelände des Lagers (in Tierra Grata) bzw. auf einem nahegelegenen Gelände (in Pondores) dauerhafte Unterkünfte für die Lager-Bewohner*innen zu bauen. Aus dieser Perspektive ist der Übergangsritus also nicht mit der Waffenabgabe - also dem militärischen Moment der Normalisierung - abgeschlossen, denn die politische, ökonomische und soziale Reinkorporation bzw. Normalisierung der FARC-EP vermittelt über den Ort 
des Lagers verlangt eine Prolongation des Übergangs, dessen Abschluss vielleicht nie mit einem einzigen Angliederungsritus markiert bzw. vollzogen wird, sondern mehrere zeitversetzte Schlüsselmomente beinhaltet. Auch deswegen befindet sich der Friedensprozess in Kolumbien längst nicht in einer postliminalen, geschweige denn in einer Postkonfliktphase, wie die kolumbianische Regierung und internationale Beobachter*innen gern glauben machen wollen (vgl. Dießelmann/Hetzer 2016a).

Eine weitere Strategie der FARC-EP zur Überwindung der »ausschließenden Einschließung« (Agamben 2002: 117) ist der Kontaktaufbau zu den angrenzenden Dorfgemeinden. Unsere Ergebnisse erlauben es, Agambens Perspektive des Lagers als Elements des Ausnahmezustands zu erweitern, denn die Demobilisierungslager oszillieren zwischen Ausnahme und »Normalität«. Rechtlich bildet der Demobilisierungsprozess diesen Übergang ab: Aus einem völlig entrechteten, illegalen, bewaffneten Akteur wird ein Rechtssubjekt. Der Ausnahmezustand des Lagers $\mathrm{zu}$ Beginn der Demobilisierung wird stückweise von Momenten der Normalität durchsetzt. Das Zusammenleben mit Zivilen im Lager und die Kontakte zu Personen außerhalb des Lagers - sei es durch den Kindergarten oder Sportveranstaltungen - tragen zu einer Normalisierung der Sozialbeziehungen bei. Auf diese Weise verliert der liminale Zustand seinen »anormalen« Charakter und die FARC-EP erreicht einen neuen sozialen Status sowohl als Partei als auch als zivile Dorfgemeinschaft. Gleichwohl versucht sich die FARC-EP diskursiv von der Aufnahmegesellschaft abzugrenzen, um weiterhin eine Existenzberechtigung als »besondere Gemeinschaft« (Interview mit BP, 09.04.2019) mit spezifischen Notwendigkeiten $\mathrm{zu}$ begründen.

Abschließend ist festzuhalten, dass die zunehmende Auflösung vieler ETCR ein wichtiges Indiz für den Zerfall der kollektiven Organisation der FARC-EP und für das Scheitern des Friedensprozesses mit der Guerilla insgesamt ist, was die Zahl der Dissident*innen und die Wiederbewaffnung einiger Einheiten eindrücklich zeigen. Laut dem Zensus der Nationaluniversität vom Juli 2017 befanden sich 8.185 Personen in den ZVTN bzw. PTN (vgl. Universidad Nacional 2017: 2), wohingegen die ARN im Februar 2020 nur noch 2.893 Personen zählt (vgl. ARN 2020), die sich in den ETCR aufhalten. Diese Zahlen verdeutlichen den Mangel an Perspektiven in den Lagern. Zudem wurden mindestens 200 ehemalige Kämpfer*innen ermordet. Falls die positiven Beispiele wie Pondores oder Tierra Grata ebenfalls scheitern sollten, stände eine weitere notwendige Bedingung für einen stabilen und dauerhaften Frieden in Kolumbien auf dem Spiel. 


\section{Literaturverzeichnis}

Acuerdo Final para la Terminación del Conflicto y la Construcción de una Paz Estable y Duradera, ed. por la Oficina del Alto Comisionado para la Paz, Bogotá 2016.

Agamben, Giorgio (2002): Homo sacer. Die Souveränität der Macht und das nackte Leben, Frankfurt a.M.: Suhrkamp.

Agamben, Giorgio (2004): Ausnahmezustand. Homo sacer II.1, Frankfurt a.M.: Suhrkamp.

Agier, Michel (2002): »Between War and City: Towards an Urban Anthropology of Refugee Camps«, in: Ethnography 3(3), S. 317-341.

[ARN] Agencia de Reincorporación y Normalización (2020): „Así avanza la reincorporación«, vom 29.02.2020, www.reincorporacion.gov.co/es/reincorporacion/La Reincorporacion en cifras/Reincorporación en cifras - corte 29022020.pdf, Abrufdatum: 15.05.2020.

[ARN] Agencia de Reincorporación y Normalización (o.J.): »Glosario de reincorporación«, www.reincorporacion.gov.co/es/reincorporacion/Paginas/Glosariode-reincorporacion.aspx, Abrufdatum: 25.03.2020.

Charry Joya, Carlos Andrés (2018): »Rastreando la paz. Medios de comunicación y formación de opinión pública en torno al proceso de paz en Colombia«, in: Charry Joya, Carlos Andrés (Hg.), Ciudadanías conectadas. Sociedades en conflicto. Investigaciones sobre medios de comunicación, redes sociales y opinión pública, Bogotá: Universidad del Rosario, S. 85-140.

Dießelmann, Anna-Lena/Hetzer, Andreas (2016a): "Außenpolitische Darstellung der Regierung Santos und deren Resonanz im medio-politischen Diskurs in Europa und Kolumbien«, in: Papel Político 21(1), S. 197-223.

Dießelmann, Anna-Lena/Hetzer, Andreas (2016b): »Kolumbien: Frieden auf der Kippe«, in: Blätter für deutsche und internationale Politik 61(11), S. 13-16.

Dießelmann, Anna-Lena/Hetzer, Andreas (2018a): »La inferioridad del Otro. Estrategias de deslegitimación de la política latinoamericana en el discurso mediático alemán«, in: Chasqui. Revista Latinoamericana de Comunicación 139, S. 75-94.

Dießelmann, Anna-Lena/Hetzer, Andreas (2018b): »Die Inferiorität des Anderen. Lateinamerika in der Auslandsberichterstattung deutscher Leitmedien«, in: Peripherie 38(149), S. 79-95.

Dießelmann, Anna-Lena/Hetzer, Andreas (i.E.): Encuadres visuales en las fotografías de prensa del proceso de paz en Colombia«, in: Universitas Humanística 88 .

Gennep, Arnold van (1909/2013): Los ritos de paso, Madrid: Alianza editorial. Harvey, David (2009): Social justice and the city (= Geographies of justice and social transformation, Band 1), Athens: University of Georgia Press. 
Herz, Manuel (2008): »Refugee Camps - or - Ideal Cities in Dust and Dirt«, in: I. Ruby \& A. Ruby (Hg.), Urban Transformation, Berlin: Ruby Press, S. 276-289.

Hora724 Noticias (2019): "Comisión de la Verdad, ONU y Pastoral Social, promueven diálogos para fortalecer proceso de paz«, in: Hora724 Noticias vom 15.10.2019, https://hora724.com/comision-de-la-verdad-onu-y-pasto ral-social-promueven-dialogos-para-fortalecer-proceso-de-paz/, Abrufdatum: 10.07.2020.

Informe anual del Alto Comisionado de las Naciones Unidas para los Derechos Humanos sobre la situación de los derechos humanos en Colombia del 2 de marzo de 2018. Consejo de Derechos Humanos, $37^{\circ}$ período de sesiones, No A/HRC/37/3/Add.3, Traducción no oficial.

Lefebvre, Henri/Roeckl, Ulrike (1972): Die Revolution der Städte, München: List.

Marín, Keren X./Espinosa Menéndez, Nicolás (2017): "Normalización sin transición: la dimensión territorial del proceso de paz en la Zona Veredal de Transición y Normalización (ZVTN) de La Macarena«, in: Ágora U.S.B. 17, S. 441-461.

Präsidialdekret 1274 vom 28.07.2017, http://es.presidencia.gov.co/normativa/norm ativa/DECRETO 1274 DEL 28 DE JULIO DE 2017.pdf, Abrufdatum: 03.11.2020.

Presidencia de la República (2016): »Zonas Veredales Transitorias no afectarán en ningún sentido la vida de los colombianos: Presidente Santos«, Sistema Informativo del Gobierno - SIG. Bogotá, http://es.presidencia.gov.co/noticia/ 160818-Zonas-Veredales-Transitorias-no-afectaran-en-ningun-sentido-lavida-de-los-colombianos-Presidente-Santos, Abrufdatum: 09.04.2020.

Turner, Victor Witter (1988): El proceso ritual. Estructura y antiestructura, Madrid: Taurus.

Universidad Nacional (2017): Caracterización FARC-EP. Resultados generales, http://pensamiento.unal.edu.co/fileadmin/recursos/focos/piensa-paz/doc s/presentacion_censo_farc.pdf, Abrufdatum: 15.05.2020.

\section{Interviews}

MTG (Ex-Guerillera und Mitglied des Kommunikationsteams), Tierra Grata, 05.04.2019.

RTG (Ex-Guerillero und Bedienung im Laden), Tierra Grata, 05.04.2019.

JTG (Ex-Guerillera und Mitglied des Kommunalen Aktionsrates), Tierra Grata, 06.04.2019.

SP (Ex-Guerillera), Pondores, 06.04.2019.

EP (ehemaliger politischer Gefangener), Pondores, 07.04.2019.

JP (Ex-Guerillera und Kindergärtnerin), Pondores, 08.04.2019.

BP (Ex-Kommandant), Pondores, 09.04.2019.

YE (ehemalige politische Gefangene), Elvira, 28.03.2017 und 04.12.2018. 
RE (Ex-Guerillero), Elvira, 13.10.2017.

VE (Ex-Guerillero und Bäcker), Elvira, 16.11.2018.

PE (Ex-Kommandant und Führungsspitze der Genossenschaft), Elvira, 17.11.2018.

\section{Feldtagebücher}

ALD - Anna-Lena Dießelmann

$\mathrm{AH}-$ Andreas Hetzer 



\title{
Klimawandel und Fluchtmigration (Im-)Mobilitäten ehemaliger Nomad*innen in (in-)formellen Lagern Somalias
}

Samia Aden und Samira Aden

\begin{abstract}
Zusammenfassung
Der Beitrag diskutiert die Erfahrungen und Perspektiven von Nomad*innen in Ceflüchtetenlagern Somalias, die infolge von klimawandelbedingten Dürreperioden ihre Tiere und damit ihre Lebensgrundlage verloren haben. Sie leben als Binnengeflüchtete im ganzen Land verstreut und sind dauerhaft auf humanitäre Hilfe angewiesen. Fokussiert werden die Auswirkungen des Klimawandels auf die traditionell hoch mobile Lebensweise von Nomad“innen. Einerseits wird die entstehende Immobilität und ihre Abhängigkeit von internationalen Nichtregierungsorganisationen aufgezeigt, andererseits, wie lokale Repressionen zu gewaltvollen Mobilitäten innerhalb von Stadt- und Staatsgrenzen führen können.
\end{abstract}

\section{Summary}

This article discusses the experiences and perspectives of nomad women in refugee camps in Somalia who have lost their animals, and thus their livelihoods, as a result of drought caused by climate change. As internally displaced persons, they live scattered in the entire country and are permanently dependent on humanitarian aid. The focus is on the effects that climate change has on the traditionally highly mobile way of life of nomads. On the one hand, this article illustrates the emerging immobility and their dependence on international nongovernmental organisations; on the other hand, it shows how local repression can lead to violent mobility within city and state borders.

\section{Einleitung}

Durch die 24. UN-Klimakonferenz in Katowice 2018 (COP24) und weltweite Proteste der Schüler*innenbewegung Fridays for Future erhält das Thema Klimawandel erneut nicht nur politisch, sondern auch gesellschaftlich und medial verstärkte 
Aufmerksamkeit. Ziel ist, die globale Erwärmung ab sofort zu begrenzen, damit auch nachfolgende Generationen zukünftig auf der Erde existieren können. Die Ursachen des Klimawandels sind auf anthropogene Einflüsse, insbesondere der Industrienationen des globalen Nordens, zurückzuführen. Währenddessen sind es diese Nationen, die trotz Dürren, Ernteeinbußen, Gletscherschmelze und Waldbränden noch nicht so stark vom Klimawandel betroffen sind wie andere Weltregionen des globalen Südens. Bereits heute sind die Auswirkungen vor allem für diejenigen am folgenreichsten, die den Klimawandel am wenigsten zu verantworten haben, und deren Existenz- und Menschenrechte massiv bedroht sind (vgl. GERICS 2014a; 2014b). In medialen, politischen sowie wissenschaftlichen Debatten sind meist genau diese Regionen und ihre betreffenden Gemeinschaften unterrepräsentiert und werden kaum gehört (vgl. Mihlar 2008).

Im Folgenden werden die Erfahrungen und Perspektiven ehemaliger Nomad*innen in Somalia vorgestellt und sichtbar gemacht. Sie leben als Binnengeflüchtete im ganzen Land verstreut und sind dauerhaft auf humanitäre Hilfe angewiesen. Analysiert werden Gruppendiskussionen mit Frauen* in (in-)formellen Geflüchtetenlagern sowie ethnographische Daten aus dem Umfeld der Camps. Die Daten wurden im Rahmen einer Feldforschung im August und September 2019 in unterschiedlichen Regionen Somalias erhoben. Zunächst erfolgt ein Überblick über den Klimawandel und die aktuellen Klimadebatten und es wird aufgezeigt, welche Regionen auch künftig stark betroffen sein werden. Daran anschließend wird der Zusammenhang von Klimawandel und Fluchtmigration dargestellt, worauf im Folgenden die Erfahrungen der Frauen* in den Geflüchtetenlagern im Mittelpunkt stehen. Insbesondere die subjektiven Sichtweisen auf die Auswirkungen des Klimawandels in Bezug auf ihre traditionell hoch mobile Lebensweise stehen im Fokus des Beitrags. Im Fazit werden die wesentlichen Aspekte ihrer Lebensrealitäten zusammengeführt.

\section{Klimawandel und die aktuelle Klimadebatte}

Der IPCC Intergovernmental Panel on Climate Change bestätigte erstmals 2013 in seinem 5. Sachbericht, dass die fortschreitende globale Erwärmung äußerst wahrscheinlich durch anthropogene Einflüsse herbeigeführt wurde (vgl. IPCC 2013). Die vermehrte Freisetzung von Treibhausgasen in die Atmosphäre unter anderem durch Viehzucht, der Abholzung von Wäldern und fossile Energiegewinnung trägt zu massiven, negativen Auswirkungen auf die Mechanismen des gesamten Erdsystems und deren Lebensräume bei. Die weltweit auftretenden Phänomene wie Unwetter, anhaltende Dürreperioden und die daraus resultierenden Wüstenbildungen sowie der Rückgang der Vereisung in den Nordpolargebieten sind nur einige der Veränderungen, die der IPCC 2007 in der Form schon beschrieben hat 
(vgl. IPCC 2007). Mit der Bestrebung, die Bedrohung durch die globale Erwärmung zu bekämpfen und die anthropogene Störung des Klimas zu verringern, schlossen die Mitgliedstaaten der Vereinten Nationen (UN) 1992 ein Rahmenabkommen über Klimaänderungen (United Nations Framework Convention on Climate Change UNFCCC, vgl. United Nations 1992). Durch das Pariser Klimaabkommen 2015 wurden schließlich Klimaziele präzisiert: Der Anstieg der weltweiten Durchschnittstemperatur soll auf 2 Grad Celsius, besser noch 1,5 Grad Celsius im Vergleich zu den vorindustriellen globalen Durchschnittstemperaturen begrenzt werden (vgl. United Nations 2015).

Die Klimadebatte entwickelt sich zunehmend zu einer Suche nach emissionsfreien Energiequellen, um die Effekte des Klimawandels zu stoppen. Wichtig ist hierbei die Wirtschaftssysteme und die Infrastrukturen dauerhaft zu sichern. Deshalb drängen vor allem wirtschaftliche und politische Bestrebungen im Weltgeschehen in Richtung Energieressourcen. Die sonnenreichen Regionen Afrikas sollen dabei als Produktionsstätten für grüne Energien dienen, um die Energiezufuhr für den globalen Norden zukünftig zu sichern. Dabei sollen mögliche Abhängigkeiten des globalen Nordens zu den Energie-Produktionsstätten des globalen Südens durch politische Maßnahmen und Pakts verhindert werden (vgl. BMBF 2020).

Eine neue Intensität gewann die Debatte durch die 25. UN-Klimakonferenz in Madrid 2019 (COP25), wo sich neben den politischen Entscheidungsträger*innen auch diejenigen zu Wort meldeten, die von den Folgen des Klimawandels am meisten betroffen sind. Sie kritisierten eine einseitige Diskussion und fehlende Perspektiven marginalisierter Personen. Vor diesem Hintergrund organisierten weltweit engagierte Klimaaktivist*innen, wie die Schüler*innenbewegung Fridays for Future und indigene Gemeinschaften, neben der COP25 einen parallel stattfindenden, alternativen Klimagipfel. Ziel war es, ihre Rolle im Kampf gegen den Klimawandel sichtbarer zu machen. Denn es sind vor allem indigene Gemeinschaften in Ländern des globalen Südens, deren Siedlungsräume und Existenzweisen bereits heute derartig eingeschränkt sind, dass sie keine Lebensgrundlage mehr haben. Flucht und Migration ist oft der einzige Ausweg. Gleichzeitig sind es diese Gemeinschaften, die mit ihrer Natur generationsübergreifend im Einklang lebten. Während die aktuelle Klimadebatte von energiepolitischen und wirtschaftlichen Fragen westlicher Industrienationen dominiert wird, finden sich indigene und nomadisierende Gemeinschaften ohne politisch wirksame Stimmen und Positionen wieder. Sie werden in der Klimadebatte zu Nebendarsteller*innen und höchstens als Beisitzer*innen positioniert (vgl. Mihlar 2008).

Insgesamt ist zu beobachten, dass die Diskussion um die Erhaltung der Umwelt vor allem westliche Interessen und post- bzw. neokoloniale Beziehungen festigt (vgl. van Holstein/Head 2018). Über Leistungen und Strukturen der Entwicklungshilfe sowie dominanter Diskurse kann sich der »Westen« erneut als Retter positionieren, während »der Rest« bzw. die betreffenden Gemeinschaften als Op- 
fer konstruiert wird und werden (vgl. Hall 2012). Die postkolonialen Strukturen, ihre diskursive Wirkmächtigkeit sowie die globalen Macht- und Ungleichheitsverhältnisse gilt es in der Klimadebatte zu berücksichtigen.

\section{Der Klimawandel trifft den globalen Süden am härtesten}

Extreme Klimabedingungen zeigen sich beispielsweise im Norden Somalias, Äthiopien, Eritrea und Djibouti, die von starken Regenfällen, Dürreperioden und davon ausgelösten Heuschreckenplagen betroffen waren. Dies traf insbesondere die ländliche Bevölkerung mit einer Intensität und Unvorhersehbarkeit. Sie sind stark vom landwirtschaftlichen Anbau und der Viehzucht abhängig. Auch künftig werden die klimatisch bedingten existenzbedrohenden Situationen Regionen mit ohnehin politisch und ökonomisch geschwächten Strukturen treffen. Klimaszenarien prognostizieren auf Basis von Klimaaufzeichnungen im Zeitraum von 1971 bis 2000, wo sich Klimaveränderungen zunehmend besonders auswirken. Und es sind weiterhin die Regionen des globalen Südens, die besonders stark von den Klimaveränderungen betroffen sein werden (vgl. GERICS 2014a; 2014b). Gleichzeitig wird im internationalen Vergleich anhand von Aufzeichnungen der $\mathrm{CO}_{2}$-Emissionen von 1960-2016 sichtbar, dass sie bislang am geringsten $\mathrm{zu}$ den Klimaeffekten beigetragen haben. Vor allem die Industrienationen des globalen Nordens sind hierfür verantwortlich und bislang am wenigstens von den Folgen betroffen (vgl. The World Bank 2016). Im Jahr 2020 sind allein in Ostafrika aufgrund klimawandelbedingter Folgen über zehn Millionen Menschen von einer schweren Hungersnot betroffen (vgl. Welternährungsorganisation 2020).

\section{Klimawandel und Fluchtmigration}

Mobilität ist für Gesellschaften des globalen Südens Teil ihrer alltäglichen Lebensrealität. Multilokale Mobilitäten sind konstitutiv für diese Regionen. So sind Stadt und Land durch soziale und ökonomische Austauschprozesse und soziale Praktiken schon immer eng miteinander verflochten. Diese freiwillige Form von Mobilität stellt vielerorts keine Abweichung, sondern die Norm dar (vgl. Werthmann/Grätz/Hahn 2004: 325f.). Neben den Fluchtmigrationsbewegungen durch Krieg und Vertreibung werden verstärkt auch klimawandelbedingte unfreiwillige (Im-)Mobilitäten für diese Weltregionen diskutiert und untersucht.

In politischen und wissenschaftlichen Debatten wächst seit Mitte der 8oer Jahre das Bewusstsein über die Bedeutung der Auswirkungen des Klimawandels auf die Lebensformen und Existenzen in sogenannten Entwicklungsländern (vgl. Zetter/Morrissey 2014: 343). Konsens besteht inzwischen darüber, dass Klimawandel die Bewegungen von Menschen, ihre Beziehungen zu Orten und ihre Lebensweisen 
nachhaltig verändert (vgl. de Guttry/Döring/Ratter 2016: 109f.; Oliver-Smith 2011: 160f.). Craig Johnstone, Vertreter des Hohen Flüchtlingskommissars der Vereinten Nationen (UNHCR) formulierte: »Our generation has failed to live up to its obligations to prevent climate change. We need urgently to prepare now for the human consequences of climate change." (Johnstone 2008: 47) Eine dieser Konsequenzen ist Fluchtmigration. In Forschung, Politik und Praxis werden Menschen, die aufgrund von Klima- und Umweltbedingungen fliehen, uneinheitlich definiert und konzeptuell unterschiedlich gefasst. Der 1985 herausgegeben Bericht des UN Environmental Program (UNEP) definiert erstmals den Begriff environmental refugees (Umweltflüchtlinge) als

»[...] those people who have been forced to leave their traditional habitat, temporarily or permanently, because of a marked environmental disruption (natural and/or triggered by people) that jeopardized their existence and/or seriously affected the quality of their life. By senvironmental disruption< in this definition is meant any physical, chemical, and/or biological changes in the ecosystem (or resource base) that render it, temporarily or permanently, unsuitable to support human life.«(El-Hinnawi 1985: 4)

Der UNHCR verwendet in Bezugnahme auf die Flüchtlingsdefinition nach der Genfer Flüchtlingskonvention 1951, welche klimabedingte Fluchtgründe nicht miteinschließt, den Begriff environmentally displaced person (Umweltvertriebene) (vgl. Biermann/Boas 2012; Bates 2002).

Der Zusammenhang von Klimawandel und Fluchtmigration ist unstrittig (vgl. UNHCR 2018), es besteht jedoch Uneinigkeit darüber ob, wie und in welchem Umfang allein klimabedingte Umweltveränderungen zu Fluchtbewegungen führen (vgl. Felgentreff 2018). Eine differenzierte Datenlage $\mathrm{zu} » K$ limaflüchtlingen« liegt in Bezug auf die begriffliche Unschärfe und Herausforderungen in der Erfassung nicht vor, das Internal Displacement Monitoring Center (IDMC) geht für das Jahr 2019 jedoch von über 200 Millionen Menschen aus, die aufgrund von Klima- und Umweltkatastrophen aus ihren Lebensräumen verdrängt worden sind (vgl. IDMC 2019). Fluchtmigrationsgründe und -entscheidungen sind allerdings sehr komplex und mehrdimensional zu betrachten (vgl. Aden et al. 2019: 302). Sowohl langsam eintretende als auch plötzlich auftretende klimawandelbedingte Ereignisse können einen von mehreren Gründen für Fluchtmigration darstellen.

Des Weiteren sind die Auswirkungen des Klimawandels auf (Im-)Mobilitäten nicht für alle Nationen und Lokalitäten gleich stark, sondern abhängig von den Ressourcen und Zugängen zu möglichen Anpassungs- und Bewältigungsstrategien. Die klimawandelbedingten Implikationen für Fluchtmigrationsprozesse werden durch politische, ökonomische und soziale Verhältnisse und Machtstrukturen gerahmt (vgl. Zetter/Morrissey 2014: 343f.). Wie beispielsweise für Somalia angenommen, sind grenzüberschreitende Fluchtmigrationen auf nexus dynamics von 
Krieg, Verfolgung, Hunger, Katastrophen und Klimawandel zurückzuführen (vgl. Weerasinghe 2018: 99). Der UNHCR verweist auf die Tatsache, dass klimabedingte Veränderungen meist zu Fluchtbewegungen innerhalb von Staatsgrenzen (Binnenflucht) führen, bevor sie in grenzüberschreitende Formen übergehen können (vgl. UNHCR 2018). Nicht jede Klima- und Umweltkatastrophe führt zu (grenzüberscheitender) Mobilität, sondern kann hingegen auch bewirken, dass Menschen dauerhaft oder zeitweise immobilisiert werden (vgl. Etzold 2019: 45).

Im Kontext von Klimawandel und Fluchtmigration gelten Personen mit niedrigem sozioökonomischem Status (vgl. Jayawardhan 2017), Frauen* (vgl. Bauriedl 2019) und ländliche Bevölkerungsgruppen (u.a. Nomad*innen) (vgl. Chatty/Sternberg 2015) als besonders vulnerabel.

Der Diskurs um klimawandelbedingte Fluchtmigration wurde vor dem Hintergrund von Massenfluchtszenarien aus dem globalen Süden in den globalen Norden vor allem durch Fragen von Migrationskontrolle, Sicherheit und Anpassungsstrategien sowie Umsiedlungen dominiert (vgl. Schraven 2019; Klepp 2018). Zunehmend kritisiert werden diese einseitigen Wissensproduktionen durch westliche Eliten und die Entpolitisierung von Klimamigrationsdebatten (u.a. Felgentreff 2018; Nash 2018). So sind nicht nur globale Machtverhältnisse, sondern auch individuelle und familiäre Prozesse unterrepräsentiert und marginalisierte Stimmen der bereits heute vom Klimawandel Betroffenen in den Mittelpunkt zu rücken (u.a. Zetter/Morrissey 2014). Der Beitrag setzt an dieser Kritik an und fokussiert die Erfahrungen und Perspektiven von ehemaligen Nomad"innen in Somalia, welche infolge von Dürrekatastrophen zu Geflüchteten geworden sind.

\section{Stimmen, die gehört werden müssen! Ehemalige Nomad*innen erzählen}

\section{Feldforschung in Geflüchtetenlagern Somalias. Empirische Grundlage}

Die empirischen Daten des Beitrags basieren zum einen auf Gruppendiskussionen (1-2,5 Std.) mit jeweils vier bis zehn weiblichen, ehemaligen Nomad"innen ${ }^{1}$ in Somalia, die aufgrund von Dürrekatastrophen innerhalb der vergangenen zehn Jahre ihre gesamte Herde und damit ihre Existenzgrundlage verloren haben. Die Diskussionen wurden in Camps, wie die Frauen* die Zeltlager selbst nennen, geführt. Zum anderen fließen ethnographische Beobachtungen und informelle Gespräche, beispielsweise mit Campleitungen, Begleitpersonen, Dorfbewohner*innen und Nach-

1 Da wir die geschlechtliche und sexuelle Selbstpositionierung der Teilnehmer*innen nicht abgefragt haben, verwenden wir für diese einheitlich das Gendersternchen, um nichtbinäre Ceschlechtsidentitäten nicht auszuklammern. 
bar*innen im Umfeld der Camps, in die Auswertung mit ein. Die Feldforschung ${ }^{2}$ fand zwischen August und September 2019 in urbanen und ländlichen Regionen statt. Aufgrund der kriegs- und konfliktbedingten Gefahren in vielen Teilen Somalias und der instabilen politischen Situation erfolgte die Auswahl der Forschungsorte entlang der möglichen Zugänge und situativen Abwägungen der Sicherheitslage. Aus forschungsethischen Gründen werden die Forschungsorte und Namen der Camps nicht benannt sowie die Namen der Frauen" pseudonymisiert verwendet. Insbesondere werden Gruppendiskussionen aus zwei Camps mit je unterschiedlichen Strukturen fokussiert: Camp A ist ein von den Nomad"innen selbst gegründetes informelles und Camp B ein formales Geflüchtetenlager, welches von internationalen Nichtregierungsorganisationen (NGO) gegründet wurde und unterstützt wird. Der Datenerhebungs- und Analyseprozess erfolgte angelehnt an die Grounded Theory (Glaser/Strauss 2005), die Auswertung mithilfe des Kodierparadigmas nach Strauss und Corbin (1996).

\section{Immobilität durch Klimawandel. Von reer miyi (Nomad*innen) zu qaxoonti (๖Flüchtlingens)}

Der Nomadismus ist konstitutiver Bestandteil der traditionellen Lebens- und Wirtschaftsform Somalias. Das Leben von Nomad"innen (som.: reer miyi) basiert auf Viehzucht (v.a. Kamele, Ziegen und Schafe) und ihren Erträgen bzw. ihrer Produkte. Sie sind im hohen Maße von ihren Tieren und den Weide- und Wetterbedingungen abhängig. Mit ihren Herden ziehen sie in Familien und kleineren (clan-)familiären Gruppen über weite Gebiete. Die fortwährende Suche nach Wasserstellen und Weideflächen bedingt dabei ihre hohe Mobilität. In der Region Ostafrika wandern sie über die im kolonialen Kontext künstlich gezogenen, nationalstaatlichen Grenzen hinweg.

Während unserer Feldforschung ist uns die Omnipräsenz von Nomad*innen aufgefallen, welche wir nicht nur in ländlichen Regionen mit ihren Tieren, sondern vielfach auch in den Städten antrafen. Unübersehbar waren allerdings auch die von ehemaligen Nomad"innen bewohnten unzähligen Zeltlager. Die von uns geführten Gespräche und Diskussionen mit den Frauen* in den Camps zeigen eindeutig und in hoch emotionalen Interviewsettings die Folgen des Klimawandels auf ihre traditionelle Lebensweise. Faduma aus Camp B stößt zu einer der Diskussionen dazu:

2 Die Daten in den Lagern wurden während einer vom Max-Planck-Institut für ethnologische Forschung in Halle (Department Integration and Conflict, Prof. Cünther Schlee) geförderten Feldforschung im Rahmen des Dissertationsprojektes »Transnationale Jugend im Kontext von Flucht und Asyl. Eine multi-sited ethnography in Somalia und Deutschland « (Samia Aden, Universität Kassel) von beiden Autor*innen erhoben und ausgewertet. 
»]etzt erzähle ich! Vorher habt ihr diskutiert, dass eine Dürre (abaar) schlimmer war als die andere und über ihre Geschichte und ihre Entwicklungen. Soviel habe ich mitbekommen. Die, die hier leben, das sind Flüchtlinge (qaxoonti). Die Flüchtlinge, die hier leben sind keine, die umziehen, die irgendwo hingehen oder auf dem Weg sind. Das sind Menschen, die ein Grund hierher getrieben hat. Es sind Menschen, die ihre Tiere, von denen sie gelebt haben, durch die Dürre komplett verloren haben. Diese Leute hier sind nirgendswo hin unterwegs, ziehen nirgendswo hin und flüchten nirgendswo hin weiter, das sind sie nicht. Wir sind richtige Flüchtlinge ${ }^{3}$ « (Gruppendiskussion B, Faduma)

Die Frauen* berichten, wie Dürreperioden und extreme Wetterbedingungen schon immer Teil ihrer nomadisierenden Lebensrealität waren. Sie wissen damit umzugehen, erkennen wann eine Dürre droht, passen ihre Wanderwege an, unterstützen sich in solidarischen Netzwerken mit anderen Nomad"innen oder führen spirituell-religiöse und traditionelle Rituale durch. Immer kürzer werdende Abstände zwischen einzelnen Dürreperioden und weniger Regen führten jedoch dazu, dass sich Böden und Pflanzen nicht mehr selbstständig erholten, Wasserreserven immer knapper wurden und ihre Herden verendeten. Durch die Dürrekatastrophe von 2016 verloren viele der Campbewohner*innen fast ihre ganzen Tiere und besitzen nun keine mehr, oder allenfalls noch einige wenige Kleintiere. Andere haben bereits schon vor 2016 ihre Tiere verloren. Sie verließen ihre Wandergebiete und leben heute mit ihrer Familie als sogenannte Binnenvertriebene (Internally Displaced Persons, IDP) in den aus traditionellen Hütten und/oder Wellblechkonstruktionen bestehenden Camps. Zeynab ergänzt Fadumas Erzählung: »Schwester, keiner setzt sich hin, wenn er Tiere hat. [...] Wir sind Nomaden, die jetzt sesshaft (xeeroney) ${ }^{4}$ geworden sind. [...] Nach der Dürre gibt es keinen Ort, an den jemand zurückkehren kann.« (Gruppendiskussion B, Zeynab) Die eigenen Bewältigungsstrategien reichen nicht mehr aus, um den zunehmenden klimatischen Herausforderungen zu trotzen. Seither fehlen ihnen Möglichkeiten und Ressourcen, ihre gewohnte, hoch mobile Lebensweise fortzuführen. Wie Zeynab und weitere Frauen* erzählen, gibt es für sie aktuell keinen Lebensort, an den sie zurückkehren könnten.

\section{Prekäre Mobilitäten innerhalb von Stadt- und Staatsgrenzen}

Sowohl in formalen als auch in informellen Camps ist die Versorgungslage häufig desolat. Der Zugang zu Wasser, Nahrungsmitteln und ärztlicher Versorgung ist

$4 \quad$ Was wir hier mit Sesshaftigkeit (Xeeroney) übersetzt haben, beschreibt die Praxis von Nomad*innen, ihre Tiere nach der Wanderung in einen Kreis aus Dornenbüschen zu umzäunen. Bis zum nächsten Wanderungsaufbruch sperren sie diese dort ein. 
stark eingeschränkt und es fehlt an Sanitäranlagen (Toiletten, Duschen etc.), Kleidung und Hygieneartikeln. Folgen der prekären Versorgungslage sind unter anderem Hunger, Unterernährung, Krankheiten sowie hohe Mütter- und Kindersterblichkeit. Neben der allgemeinen Knappheit von Ressourcen und den kriegs- und konfliktbedingt erschwerten Zugängen für NGOs in spezifische Regionen spielt Korruption bei der Verteilung von Hilfsmitteln eine wesentliche Rolle für das Verlassen bzw. Wechseln der Camps. Das formale Camp B besteht seit einer Dürrekatastrophe 2016 und liegt in einer ländlichen Region. In Camp B sind ca. 725 Haushalte registriert. Nach den Angaben der Frauen* leben schätzungsweise fünf bis zehn Personen in einer Hütte. Die Familien werden von NGOs finanziell und vereinzelt mit Hilfsmitteln unterstützt, außerdem kommt sporadisch medizinisches Personal in das Camp.

Wie uns die Frauen" in Camp B berichten, erhalten sie 58 Dollar pro Haushalt für drei Monate sowie Wasser über einen gemeinsamen Wassertank, wozu jeder Haushalt registriert wird. Im Kontext der clanbasierten Verwandtschaftsverhältnisse in Somalia kommt es regelmäßig bei der Registrierung der Haushalte vor, dass von Mitarbeiter*innen in den Ministerien, den beauftragten lokalen Organisationen bis hin zu denen vor Ort im Camp, die eigenen, ebenso von Armut betroffenen clanfamiliären Mitglieder bevorteilt werden. Zum Teil würden sie ihre Familien aus den Städten als Binnengeflüchtete registrieren und so würde nur noch ein Bruchteil der Hilfsmittel bei den ehemaligen Nomad"innen ankommen. Insbesondere Angehörige sogenannter Minderheitenclans sind hiervon betroffen. Die clanbasierten Diskriminierungen führen zum erneuten Wechsel bzw. Verlassen der Camps und starker Ungewissheit. Die Frauen" erzählen daher, vielfach schon in anderen Camps innerhalb Somalias gelebt zu haben, bevor sie ins Camp $B$ gekommen sind.

In den informellen Camps schließen sich Gemeinschaften von ehemaligen Nomad"innen, etwa in der Nähe von ausgehobenen und mit Plastikplanen bedeckten Wasserstellen oder Brunnen, zusammen. Die Brunnen wurden im Rahmen von Entwicklungsprogrammen internationaler NGOs erbaut. Das Camp A liegt allerdings an einem Stadtrand ohne Zugang zu derartiger Wasserversorgung oder sonstiger materieller Unterstützung. Lediglich von lokalen muslimischen Organisationen und ihrer Nachbarschaft erhalten sie gelegentlich Hilfen, wie etwa an Ramadan. Neben dem Versorgungsmangel erzählen die Frauen* von (geschlechterspezifischer) Gewalt und Vertreibungen betroffen zu sein. Nadifo beschreibt:

»Ich bin seit 10 Jahren ohne Tiere hier, wie oft wurde gesagt, ich sollte umziehen. [...] Mal bin ich hier oben, dann wieder weiter dort unten. [...] Leute kaufen die Grundstücke und möchten, dass du gehst. Wenn du grade wieder deine drei Stöcker aufgebaut, deine drei Kleider aufgehängt hast, heißt es, mach alles wieder 
ab und du wirst wieder vertrieben. [...]. Aber das schlimmste ist das Feuer, erst letztens hat es hier gebrannt.«(Gruppendiskussion A, Nadifo)

Nadifo thematisiert, wie sie von den Besitzer*innen der von ihr bewohnten Grundstücke immer wieder bedroht und vertrieben wird. Ausführlich wurde über mehrere Brandanschläge berichtet. Sie vermuten, dass Personen von den Eigentümer*innen beauftragt werden, um sie mit allen Mitteln von den Grundstücken zu vertreiben. Erschwerend kommt hinzu, dass die Frauen* mit ihren Kindern meist allein in den Camps sind, da sie geschieden oder ihre Ehemänner* auf der Suche nach Arbeit in den Städten unterwegs sind. Einige erzählen, dass, wenn ihre Männer* Geld verdienen, davon kaum etwas bei ihnen ankommt. So hätten die Männer* teilweise weitere Familien gegründet und/oder litten unter Suchtproblemen. Den Frauen* sei dann die Abwesenheit der Männer* lieber, um nicht potentiellen gewalttätigen Übergriffen durch sie ausgesetzt zu sein.

Im Kontext der politisch instabilen Lage in Somalia, immer wiederkehrender Kriege und Konflikte sowie der gering ausgeprägten staatlichen Strukturen sind vulnerable Gruppen, wie binnengeflüchtete Nomad*innen, besonders von Diskriminierung und Gewalt betroffen. Die Frauen* fühlen sich nicht selten allein und ohne Schutz in den Camps. Es lässt sich beobachten, wie die desolate Sicherheitsund Versorgungslage für sie zu permanenten und prekären Mobilitäten innerhalb Somalias führen.

\section{Verlust von Autonomie}

Für das Leben als Nomad*innen spielte nicht nur das Wandern mit ihren Herden, sondern auch die sozialen und ökonomischen Austauschprozesse zwischen Stadt und Land eine bedeutende Rolle. So sicherte der Verkauf von Produkten wie Fleisch, Tierfelle und Milch, aber auch der Verkauf von Tieren selbst ihre Existenz. Aus den Steppen und den Halbwüsten liefen sie in die teils wenige Stunden bis hin $\mathrm{zu}$ Tagesmärschen entfernten Städte, um Verwandte und Familien zu besuchen, für Arztbesuche oder einfach nur zur Unterhaltung (bashaal). Xalimo erzählt uns, wie sie als Nomadin* einem Fahrer täglich mehrere Kanister Kamelmilch für ihren Sohn, der in der Stadt arbeitete und lebte, mitgab. Ihre Schwiegertochter verkaufte die Milch auf einem lokalen Markt weiter. Der Fahrer erhielt für jeden verkauften Liter anteilig einen Betrag und brachte Xalimo die leeren Kanister sowie die von ihr benötigten Lebensmittel wie Reis, Mehl, Öl usw. zurück. Die Erträge aus der Viehzucht ermöglichten einigen Frauen*, ihre Kinder zu Verwandten in die Städte zu schicken und dort zu beschulen und/oder ein eigenes Geschäft (Teestube, TukTuk o.ä.) zu eröffnen sowie selbst zwischen Stadt und Land hin und her zu pendeln.

Xalimo und weitere Frauen* betonten auch ihre Nähe zur und ihren Respekt vor der Natur und Umwelt sowie ihren von staatlichen Strukturen und Institutionen 
weitestgehend unabhängigen Alltag. Mit dem Verlust ihrer Tiere haben sie nicht nur ihre Mobilität, sondern auch die Ressourcen für ein autonomes Leben verloren. Hamsa aus Camp B sagt hierzu:

»Wir leben von Hilfsorganisationen. [...] Das was wir als erstes sehen, wenn wir morgens aufwachen, wenn Cott uns gesund aufwachen lässt, ist das erste, was wir sehen eine Hilfsorganisation. [...] Unsere Augen suchen und sehen nur nach Hilfsorganisationen. [...] Den Leuten hier ging es besser, als sie weit draußen auf dem Boden Cottes waren und ihre Tiere hatten und jeder seine Tiere zapfte (mahley). [...] [Wir] warten auf Hilfsorganisationen und Menschen die von Gott geschickt werden, die über uns berichten.«(Gruppendiskussion B, Hamsa)

Amina schließt daran an und verleiht ihrem Gefühl von Passivität Ausdruck, indem sie sagt: »Wir sind doch selbst zu Tieren geworden. [...]. Wir wollen nicht mehr dasitzen und auf etwas warten, wir wollen Frauen* sein, die etwas tun.« (Gruppendiskussion B, Amina) Die Frauen* bringen ihren Ärger über das entstandene Abhängigkeitsverhältnis von internationalen NGOs zum Ausdruck. Das Leben in den Camps bedeutet, mit den spärlichen, unzureichenden Hilfsmitteln auszuharren und auf weitere Unterstützung zu hoffen. Dies wird von den Frauen* als furchtbarer und nur schwer auszuhaltender Zustand beschrieben. Sie fühlen sich in ihrer Handlungsfähigkeit stark eingeschränkt und problematisieren die zugewiesene Rolle als passive Hilfeempfänger*innen. Gleichzeitig besitzen sie keine finanziellen Rücklagen oder soziale Netzwerke, um sich selbstständig eine neue Existenz in den Städten aufzubauen. Amina erzählt weiter:

»Die ganze Familie ist von Dürre (abaaro) betroffen, die Schwester ist von der Dürre betroffen, der Onkel ist von der Dürre betroffen, der Sohn ist von der Dürre betroffen, die Tochter ist von der Dürre betroffen. Derjenige, der vielleicht weg ist, kann nicht für seine ganze Familie alleine da sein, das heißt, sie sind einfach zu viele. Es sind einfach zu viele. Sie haben keine Möglichkeit, um jedem ein eigenes Gehalt (biil) zu geben. Weil, wenn sie es könnten, wären die Leute erst gar nicht hier versammelt." (Gruppendiskussion B, Amina)

Abgesehen von den mangelnden staatlichen Strukturen und Hilfesystemen werden fehlende (transnationale) familiäre Netzwerke deutlich. Ihre Familienmitglieder sind selbst $\mathrm{zu}$ »Flüchtlingen« geworden und/oder ihre finanziellen Möglichkeiten reichen nicht aus, um alle betroffenen Angehörigen regelmäßig zu unterstützen.

\section{Solidarität}

Besonders in den informellen Camps ist uns die Solidarität zwischen den Frauen* und die kreativen alltäglichen Bewältigungsstrategien aufgefallen. Sie weisen ein hohes Maß an Empathie, gegenseitiger Unterstützung und Rücksichtnahme auf. 
Sicher trifft dies nicht auf alle Campbewohner*innen $\mathrm{zu}$, dennoch waren unsere Beobachtungen und die Erzählungen der Frauen* zu solidarischen Beziehungen sehr bezeichnend. Sie erziehen ihre Kinder gemeinsam, nehmen Waisen (agon iyo rajo) bei sich auf, unterstützen sich bei der Pflege von älteren und erkrankten Personen und teilen ihre Lebensmittel miteinander.

Beispielhaft hierfür ist die Ankunftssituation in Camp A. Wir versammelten uns mit einer Gruppe von Frauen* unter einem Baum und die alleinstehende Camp-Älteste, welche von allen nur Hooyo (Mutter) genannt wird, begrüßte uns. Sie begann ihre Erzählung damit, wie sie seit zehn Jahren ohne Unterstützung von außen in dieser Gemeinschaft lebt und noch keinen einzigen Tag ohne eine Mahlzeit oder ohne Wasser auskommen musste. Am Tag unseres Besuches erkundigte sich etwa ihre Nachbarin* Muna nach ihr und bot ihr etwas zu essen an. Muna unterbricht sie und sagt:

»]a, ich habe sie gefragt, ob sie heute schon etwas gegessen hat und sie hat gesagt: >) a habe ich, danke [...] ich brauche nix«. Aber ich weiß, dass sie lügt. Sie weiß, ich habe fünf Kinder von nichts zu ernähren und hat deshalb gelogen. [...] Die Leute hier nehmen Rücksicht aufeinander. [...] Wir sind uns das schuldig. [...] Wir sind hier alle wie Familie.« (Gruppendiskussion A, Muna)

Für die Frauen* ist es selbstverständlich, ihre Ressourcen miteinander zu teilen, auch wenn es kaum für sie selbst ausreicht. Nicht nur die Menschen in den Camps, sondern auch ihre Nachbarschaft, die Geschäfte in ihrer Umgebung sowie einzelne engagierte Nachbar*innen spielen eine wesentliche Rolle für die alltägliche Bewältigung ihrer Lebenslage. Geschäfte lassen die Frauen* anschreiben, Nachbar*innen bringen ihnen Lebensmittel vorbei, lokale Ärzt"innen behandeln sie kostenlos und einzelne engagierte Personen geben den Kindern ab und an Koranunterricht. Um die Verteilung der angebotenen Hilfen gebe es keine Konflikte. Jede nehme so viel, wie sie für sich und ihre Familie benötigt. Zudem finden sie kreative Lösungen zur gemeinsamen Überlebenssicherung und teilen notwendige Aufgaben unter sich auf. Während einige aus alten Reissäcken Planen für die Hütten nähen, fertigen andere Teppiche aus Stoffresten an und wiederum andere sammeln Feuerholz ( $x a a b o$ ) in der Umgebung. Als Gemeinschaft zu leben, schützt sie vor extremer Hungersnot. Allerdings scheinen auch die Hoffnung auf ein besseres Leben und der Glaube an Gott sowie Schicksalsergebenheit ihnen Halt zu geben.

\section{Anpassung an die neue Lebenslage und Zukunftsorientierungen}

Vor dem Hintergrund der fehlenden Möglichkeit zur Rückkehr in ein nomadisierendes Leben kritisieren die Frauen* die geringen Chancen auf eine nachhaltige, unabhängige Zukunftsgestaltung. Ihre Wünsche zeigen dennoch, dass sie trotz des 
Verlustes ihrer Herden sehr flexibel sind und neue Zukunftsorientierungen für sich entwickeln. Saida aus Camp B erzählt:

»Und wenn ich über die Mädchen im Camp spreche [...], die brauchen viele Dinge, [...] wir als Frauen brauchen Ausbildungen. Wenn wir zum Beispiel Henna [Bemalungen] lernen, können wir damit arbeiten. Wenn sie Nähen lernen, [...] können sie arbeiten. Mädchen, die nähen können, also die Leute tragen ja Kleidung und sind nicht nackt und manchmal finden wir niemanden der nähen kann und eine Maschine hat. [...] Wir wissen nichts, sind ungebildet (jahiil). Wir brauchen Arbeit und Bildung, Fortschritt (hor mar) brauchen wir, damit wir mit den Mädchen und Frauen aus der Stadt konkurrieren können und Frauen werden, die was rausholen (so saar), die keine Ungebildeten sind und wo wir vorher zurückstanden, müssen wir jetzt aufholen und uns dabei unterstützen, selbst was zu tun. [...] Wenn jetzt zehn, 20 bis 40 Frauen ausgebildet werden [...], dann bringen sie sich später alles gegenseitig bei. [...] Aber wenn du sagst, dieses und jenes habe ich gemacht und gebe mir nur etwas dazu, dann wirst du anerkannt und respektiert. (Gruppendiskussion B, Saida)

Saida formuliert ganz klare Vorstellungen darüber, was die Mädchen* und Frauen* für ein neues, immobiles Leben in den Camps benötigen und welche Voraussetzungen, Fähigkeiten und Ressourcen hierfür notwendig sind. Denn ihre Kenntnisse über Natur und Tiere, traditionelles Handwerk, musisch-künstlerisches und spirituelles Wissen können sie in den Camps und Städten zur Überlebenssicherung kaum verwerten. Wie das Zitat zeigt, müssen mit der neuen Lebenslage auch Bildungsprozesse angepasst und neue Möglichkeiten zur Erwerbstätigkeit in den Camps geschaffen werden. Hierzu sind Bildungsinstitutionen und -orte wie Moscheen, Schulen und Ausbildungsgelegenheiten sowie der Einsatz von kaum verfügbarem qualifiziertem Lehrpersonal und entsprechenden Materialien erforderlich. Ihre hohe Handlungsbereitschaft äußert sich in dem Vorschlag, erworbenes Wissen in einem Schneeballsystem weiterzugeben, anstelle institutionalisierte Bildung der Campbewohner*innen $\mathrm{zu}$ fordern. Bildung verstehen sie zudem als Chance, welche ihnen persönliche Weiterentwicklung und die Aufrechterhaltung ihres Selbstwertgefühls ermöglichen soll.

In beiden Camps wird der Wunsch nach der Entstehung von Infrastrukturen geäußert, jedoch mit unterschiedlicher Gewichtung. Während im informellen Camp A im Hinblick auf die Vertreibung und Gewalterfahrungen der Besitz von Grundstücken und die alltägliche Überlebenssicherung im Fokus stehen, wird im formalen Camp B vor allem die Notwendigkeit der Urbanisierung betont. Ifrah beschreibt: »Dies hier ist ein richtiger Ort. Es ist keiner, von dem man wieder wegzieht. Es ist ein Ort an dem man bleibt, nicht wegzieht. Es ist jetzt ein Ort, der gebaut werden muss«. (Gruppendiskussion B, Ifrah) Hier werden unter anderem der Aufbau von Landwirtschaft, dauerhaften Wohnräumen, Geschäften, Krankenhäu- 
sern, Erwerbsmöglichkeiten sowie Verkehrsmitteln zur Anbindung an die Städte genannt. Diese Prozesse wollen die Campbewohner*innen aktiv in die Hand nehmen und mitgestalten. Sie wünschen sich hierzu erste Programme und Mittel, um ihre Visionen umzusetzen. Regelmäßige Besuche der NGOs und das Dokumentieren ihres »Leidens « sollen beendet und stattdessen ihre Ideen und Perspektiven berücksichtigt werden.

\section{Fazit}

Für den Klimawandel und die vorherrschenden Klimakatastrophen ist hauptsächlich der globale Norden verantwortlich. Es sind dieselben Industrienationen, die im politischen Diskurs dominierend vorangehen und über zukünftige Existenzweisen diskutieren. Gleichzeitig sind sie nicht so stark von den Auswirkungen des Klimawandels betroffen wie der globale Süden. Die Klimadebatte reflektiert kaum die Tatsache, dass indigene und nomadisierende Bevölkerungen, welche eine vergleichsweise geringe Klimabilanz aufweisen, bereits heute von klimabedingten Katastrophen betroffen sind. Die Interessen des globalen Nordens liegen vor allem in den wirtschaftlichen und politischen Möglichkeiten für die zukünftig immer knapper werdende Energieversorgung ihrer Industrie. Die Sicherung von Ressourcen sehen die Industrienationen u.a. in der Energiegewinnung (Sonne) in den Ländern des globalen Südens. Die Energiegewinnung wird zu einem Wettlauf mit anderen Regionen des globalen Nordens. Hierin sind post- bzw. neokoloniale Strukturen $\mathrm{zu}$ verzeichnen, da Klimadebatten des globalen Südens sowie ihre Positionen als Stimm- und Entscheidungsträger übergangen und sie bestenfalls als passive $\mathrm{Ne}$ benfiguren positioniert werden. Die Klimabedingungen werden sich voraussichtlich nicht erholen, vielmehr ist von einer Verschlechterung der Klima- und Erdbeschaffenheiten auszugehen. Gerade den aktuell und zukünftig besonders betroffenen Regionen fehlt es an entsprechenden Ressourcen, um die nötigen Transformationsprozesse für neue Existenz- und Wirtschaftsweisen zu realisieren. Ihre Anpassungs- und Transformationsbereitschaft gilt es in (klima-)politischen und wissenschaftlichen Debatten dringend ernst- und wahrzunehmen.

Die Erfahrungsberichte der ehemaligen Nomad*innen machen die Auswirkungen des Klimawandels auf ihre traditionell hoch mobile Lebensweise sichtbar. Sie haben aufgrund von Dürrekatastrophen ihre Tiere und damit ihre Existenzgrundlage verloren. Im Hinblick auf ihre Vulnerabilität und fehlenden Ressourcen flüchten sie meist in nahe gelegene Orte und Regionen innerhalb Somalias (Binnenflucht). Einerseits führt der Verlust ihrer Existenzgrundlage zur Immobilität und Abhängigkeit von internationalen NGOs. Andererseits sind lokale Repressionen (z.B. Clanstrukturen, Geschlechterverhältnisse) sowie die Verteilungspraxis von Hilfsgütern in einem politisch instabilen Kontext wie in Somalia (Korruption, 
Gewalt, Krieg und Konflikte) Grund für erneute Mobilitäten innerhalb von Stadtund Staatsgrenzen. Den äußeren Umständen sind die ehemaligen Nomad*innen aber nicht nur hilflos ausgesetzt. Im Kontext der neuen, unfreiwilligen Immobilität reagieren sie mit alltäglichen Formen von Solidarität und kreativen Überlebensstrategien. Bezeichnend ist, dass sie trotz des schmerzhaften Verlustes ihrer gewohnten Lebensweise die notwendigen dauerhaften Anpassungsstrategien für ihre immobile Zukunft reflektieren und für sich gestalten möchten. In Bezug auf ihre biographischen Erfahrungen stehen für sie weniger Fragen nach Möglichkeiten für weitere Fluchtmigrationswege im Fokus als Maßnahmen aus der Abhängigkeit von internationalen Nichtregierungsorganisationen und die Wiederherstellung ihrer weitestgehend autonomen Existenz- und Wirtschaftsweise in Somalia selbst.

\section{Literaturverzeichnis}

Aden, Samia/Schmitt, Caroline/Uçan, Yasemin/Wagner, Constantin/Wienforth, Jan (2019): »Partizipative Fluchtmigrationsforschung. Eine Suchbewegung«, in: Z'Flucht. Zeitschrift für Flucht- und Flüchtlingsforschung 3, S. 302-319.

Bates, Diane C. (2002): »Environmental Refugees? Classifying Human Migrations caused by environmental Change«, in: Population and Environment 23, S. 465477.

Bauriedel, Sybille (2019): Klimawandel, Migration und Geschlechterverhältnisse, 21.01.2019, https:/www.bpb.de/gesellschaft/migration/kurzdossiers/ 283411/klimawandel-migration-und-geschlechterverhaeltnisse, Abrufdatum: 01.07.2020.

Biermann, Frank/Boas, Ingrid (2012): „Climate Change and Human Migration: Towards a Global Governance System to Protect Climate Refugees«, in: Jürgen Scheffran/Michael Brzoska/Hans G. Brauch/Peter M. Link/Janpeter Schilling (Hg.), Climate Change, Human Security and Violent Conflict. Challenges for Societal Stability (=Hexagon Series on Human and Environmental Security and Peace, Band 8), Berlin/Heidelberg: Springer Verlag, S. 291-300.

[BMBF] Bundesministerium für Bildung und Forschung (2020): Potenzialatlas Wasserstoff, 10.06.2020, https://www.bmbf.de/de/woher-soll-der-gruene-was serstoff-kommen-11766.html, Abrufdatum: 30.06.2020.

Chatty, Dawn/Sternberg, Troy (2015): »Climate Effects on Nomadic Pastoralist Societies«, in: Forced Migration 49, S. 25-27.

El-Hinnawi, Essam (1985): Environmental Refugees. Nairobi, Kenya: United Nations Environment Programme, https://digitallibrary.un.org/record/121267, Abrufdatum: 01.07.2020. 
Etzold, Benjamin (2019): Auf der Flucht - (Im)Mobilisierung und (Im)Mobilität von Schutzsuchenden. State-of-Research Papier 04, Verbundprojekt Flucht: Forschung und Transfer, Osnabrück: Institut für Migrationsforschung und Interkulturelle Studien (IMIS) der Universität Osnabrück/Bonn: Internationales Konversionszentrum Bonn (BICC).

Felgentreff, Carsten (2018): »Migration durch Klimapolitik. Die globale Produktion von Klimamigrantinnen und Klimamigranten«, in: Andreas Pott/Christoph Rass/Frank Wolff (Hg.), Was ist ein Migrationsregime? What Is a Migration Regime?, Wiesbaden: Springer Verlag, S. 139-165.

Glaser, Barney G./Strauss, Anselm L. (2005): Grounded Theory. Strategien qualitativer Forschung, Bern: Huber Verlag.

Guttry, Corinna de/Döring, Martin/Ratter, Beate (2016): »Challenging the current climate change - migration nexus: exploring migrants' perceptions of climate change in the hosting country«, in: Die Erde 147(2), S. 109-118.

GERICS, Climate Service Center Germany 2.0 (2014a): Climate-Signal-Map: Increase in the occurrence of warm days per year, https://www.climateservice-center.de/imperia/md/content/csc/projekte/klimasignalkarten/csm_ warmdays_dec2014.pdf, Abrufdatum: 30.06.2020.

GERICS, Climate Service Center Germany 2.0 (2014b): Climate-Signal-Map. Increase in the occurrence of very wet days per year, https://www.climateservice-center.de/imperia/md/content/csc/projekte/klimasignalkarten/csm_ verywetdays_dec2014.pdf, Abrufdatum: 30.06.2020.

Hall, Stuart (2012). »Der Westen und der Rest: Diskurs und Macht«, in: Ulrich Mehlem (Hg.) Rassismus und kulturelle Identität. Ausgewählte Schriften 2, Hamburg: Argument-Verlag, S. 137-179.

Holstein, Ellen van/Head, Lesley (2018): »Shifting settler-colonial discourses of environmentalism: Representations of indigeneity and migration in Australian conservation«, in: Geoforum 94, S. 41-52.

[IDMC] Internal displacement monitoring center (2019): Internal Displacement Figures by Country, https://www.internal-displacement.org/database/displac ement-data, Abrufdatum: 30.06.2020.

[IPCC] Intergovernmental Panel on Climate Change (2007): Climate Change 2007. The Physical Science Basis. Contribution of Working Group I to the Fourth Assessment Report of the Intergovernmental Panel on Climate Change, Cambridge: Cambridge University Press, https:/www.ipcc.ch/site/assets/uploads/ 2018/05/ar4_wg1_full_report-1.pdf, Abrufdatum: 01.07.2020.

[IPCC] Intergovernmental Panel on Climate Change (2013): Climate Change 2013: The Physical Science Basis. Contribution of Working Group I to the Fifth Assessment Report of the Intergovernmental Panel on Climate Change, Cambridge: Cambridge University Press, https:/www.ipcc.ch/site/assets/uploads/2018/02/ WGiAR5_all_final.pdf, Abrufdatum: 30.06.2020. 
Jayawardhan, Shweta (2017): „Vulnerability and Climate Change Induced Human Displacement «, in: Consilience: The Journal of Sustainable Development 17, S. 103-142.

Johnstone, Craig L. (2008): »The Future is Now«, in: Forced Migration Review 31, h ttps://www.fmreview.org/climatechange/johnstone, Abrufdatum: 01.07.2020. Klepp, Silja (2018): Klimawandel und Migration. Heterogenes Forschungsfeld und politisierte Debatte, vom 18.05.2018, https://www.bpb.de/apuz/269304/ klimawandel-und-migration-heterogenes-forschungsfeld-und-politisiertedebatte? $\mathrm{p}=$ all\#footnode3-3, Abrufdatum: 01.07.2020.

Mihlar, Farah (2008): Voices that must be Heard: Minorities and Indigenous People Combating Climate Change, London: Minority Rights Group International, https://www.refworld.org/pdfid/492d18da2.pdf, Abrufdatum: 30.06.2020.

Nash, Sarah L. (2018): »Knowing Human Mobility in the Context of Climate Change. The Self-Perpetuating Circle of Research, Policy, and Knowledge Production «, in: Movements. Journal for Critical Migration and Border Regime Studies $4(1)$, S. 67-82.

Oliver-Smith, Anthony (2011): »Sea Level rise, local vulnerability and involuntary migration«, in: Étienne Piguet/Antoine Pécoud/Paul de Guchteneire (Hg.), Migration and Climate Change, New York: Cambridge University Press, S. 160187.

Schraven, Benjamin (2019): Der Zusammenhang zwischen Klimawandel und Migration, 21.01.2019, https://www.bpb.de/gesellschaft/migration/kurzdossiers/ 282320/der-zusammenhang-zwischen-klimawandel-und-migration\#footnode 2-2, Abrufdatum: 01.07.2020.

Strauss, Anselm L./Corbin, Juliet M. (1996): Grounded Theory, Grundlagen Qualitativer Sozialforschung, Weinheim: Belz Psychologie Verl.-Union.

[UNHCR] United Nations High Commissioner for Refugees (2018): Climate change and disaster displacement, https://www.unhcr.org/49e4a5096.html, Abrufdatum: 01.07.2020.

United Nations (1992): United Nations Climate Framework Convention on Climate Change, https://unfccc.int/resource/docs/convkp/conveng.pdf, Abrufdatum: 30.06.2020.

United Nations (2015): Paris Agreement, https://unfccc.int/files/essential_backgr ound/convention/application/pdf/english_paris_agreement.pdf, Abrufdatum: 30.06.2020.

Weerasinghe, Sanjula (2018): In Harm's Way. International protection in the context of nexus dynamics between conflict or violence and disaster or climate change, https://www.unhcr.org/5c1ba88d4.pdf, Abrufdatum: 30.06.2020.

Welternährungsorganisation, FAO (2020): Projektupdate: Heuschreckenplage in Ostafrika, vom 12.05.2020, https://www.welthungerhilfe.de/aktuelles/proje 
ktupdate/2020/heuschreckenplage-in-ostafrika-und-suedasien/, Abrufdatum: 30.06.2020.

Werthmann, Katja/Grätz, Tilo/Hahn, Hans (2004): »Mobilität in Afrika. Multilokale Feldforschungen«, in: Afrika Spectrum 39, S. 325-333.

The World Bank (2016): CO2 emissions (kt), https://data.worldbank.org/indicator/ EN.ATM.CO2E.KT?view=map, Abrufdatum: 02.07.2020.

Zetter, Roger/Morrissey, James (2014): »The Environment-Mobility Nexus: Reconceptualizing the Links between Environmental Stress, (Im)mobility, and Power«, in: Elena Fiddian-Qasmiyeh/Gil Loescher/Katy Long/Nando Sigona (Hg.), The Oxford Handbook of Refugee and Forced Migration Studies. Oxford: Oxford University Press, S. 342-354.

\section{Interviews}

Gruppendiskussion A, August 2019.

Gruppendiskussion B, August 2019. 


\section{„Doing Family» auf der Flucht und in Unterkünften}

Caterina Rohde-Abuba

\section{Zusammenfassung}

Familien stellen einen großen Anteil der Geflüchteten, die in den letzten Jahren nach Deutschland gekommen sind. Basierend auf dem theoretischen Konzept des »doing family« geht dieser Beitrag der Frage nach, wie Bedingungen der Flucht und des deutschen Asylsystems Familienbeziehungen und familiäre care Praktiken beeinflussen. Die Analyse zeigt, dass Familien unterschiedliche Phasen miteinander verbundener geographischer und persönlicher (Im-)Mobilität erleben, die zur Transformation ihrer care Praktiken führen. Die aktive Entscheidung zur Flucht als Mobilisierung der Familie soll das Überleben und Wohl der Kinder sichern. Trotz ihrer hochgradigen geographischen Mobilität erfahren Familien die Flucht, Verteilung und Unterbringung in Deutschland als Phase der »persönlichen Immobilisierung «, da die Fremdbestimmung und Disziplinierung im Asylverfahren die Möglichkeiten von Familien einschränken, ihre Kinder zu beschützen und zu versorgen. Nachdem Familien eine (befristete) Aufenthaltserlaubnis erhalten haben, treten sie in die Phase der sozialen Aufwärtsmobilität mit sich wandelnden Verantwortlichkeiten und care Praktiken ein. Aufgrund ihres schnelleren Spracherwerbs übernehmen Kinder Verantwortung für die Kommunikation nach »außen« mit der Aufnahmegesellschaft und ihren Institutionen. Der Bildungserfolg, den viele geflüchtete Kinder zeigen, stellt für ihre Eltern einen Beleg dar, dass die Entscheidung zur Flucht richtig war.

\section{Summary}

Families make up an important share of the refugee population that has entered Germany during the last years. Based on the theoretical concept of »doing family «, the aim of this article is to investigate how conditions of flight and the German asylum system affect family relations and care practices. The analysis shows that families transform their care practices in the process of flight and asylum seeking, while they go through three different phases of interconnected geographical and personal (im-)mobility. The decision of flight is a mobilising practice of parents aimed at securing the survival and well-being of their children. In contrast to that, many families perceive the actual flight and arrival in Cermany (in spite 
of their geographical mobility) as a phase of »personal immobilisation« due to the regulation and disciplining measures in the asylum system, which threatens parents' ability to care for and protect their children in collective shelters. After families have been granted a (temporary) residence permit, they enter into the phase of social upward mobility with changing family responsibilities. Due to the children's quicker language learning process, they take over responsibilities for communicating with the local population and authorities. For parents, this educational success of their children serves as proof that their decision to flee was right.

\section{Einleitung}

2019 waren 50,1 Prozent aller geflüchteten Menschen, die in Deutschland einen Antrag auf Asyl gestellt haben, minderjährig (vgl. BAMF 2019: 8). Die meisten Kinder und Jugendlichen fliehen »begleitet « durch Familienangehörige, oft mit einem Elternteil oder mit beiden Eltern und Geschwistern. Kinder und Erwachsene erleben die Flucht, das Asylverfahren und ihre Niederlassung in Deutschland durch ihre individuelle Perspektive. Gleichzeitig können Erlebnisse einzelner Familienmitglieder in ihrem Einfluss auf die intergenerationale und interdependente Dynamik der Familie untersucht werden. Sangalang und Vang (2017) zeigen, dass Traumatisierungen geflüchteter Eltern einen Einfluss auf das Wohlbefinden der Kinder haben und die Fürsorgefähigkeit von geflüchteten Eltern ihren Kindern gegenüber einschränken können (vgl. van Ee et al. 2014). Das Wohlergehen der Kinder im neuen Lebenskontext, insbesondere ihr Bildungserfolg, kann aber auch einen entscheidenden Einfluss auf das Wohl ihrer Eltern haben (vgl. Bergnehr 2018). Kallio (2019) weist darauf hin, dass Familienbeziehungen eine wichtige Ressource für die Handlungsfähigkeit Geflüchteter sind, aber auch zusätzliche Belastungen durch Verantwortlichkeiten und Erwartungen hervorrufen können. Hierbei darf der Begriff »Familie« nicht mit dem Verständnis der »westlichen Kleinfamilie« gleichgesetzt werden (Kallio/Häkli 2019), auch wenn viele Kinder tatsächlich mit mindestens einem Elternteil und Geschwistern fliehen. Im Zentrum dieses Beitrags stehen intergenerationale care Praktiken (vgl. Finch/Mason 1993; Finch 1989), durch die erwachsene und minderjährige Verwandte als Familie miteinander verbunden sind. Der Beitrag geht der Frage nach, ob und wie sich care Praktiken und Familienbeziehungen durch Phasen der Mobilisierung und Immobilisierung, die Familien auf der Flucht und in unterschiedlichen Unterbringungsformen erfahren, verändern. Als Datengrundlage dienen zwei qualitative Untersuchungen zur Lebenssituation geflüchteter, begleiteter Kinder in Deutschland, die World Vision Deutschland e.V. 2016 und 2020 veröffentlicht hat. Die in diesen Untersuchungen geführten Interviews mit Kindern und Erwachsenen sind durch die Themen des Verlassens, An- 
kommens und Niederlassens geprägt, die die Struktur der empirischen Analyse zu diesem Beitrag vorgeben.

\section{Theoretische Perspektiven auf Familien im Flucht- und Asylgeschehen}

Familie ist keine gegebene, einheitliche Lebensform, sondern wird durch emotionale und funktionale reziproke Fürsorgeleistungen (vgl. Bengston/Oyama 2007; Bengston et al. 1976) innerhalb bestimmter Lebensbedingungen und Konstellationen alltäglich von Familienmitgliedern hervorgebracht. Diese sozialen Prozesse können als »doing family« bezeichnet werden, die Familienmitglieder als »Praxis der Generationenbeziehungen« (Honig 2017: 8) durch familiäre Routinen und Rituale miteinander verbinden. Mit Bezug auf Butler (1993) argumentiert Dickenson (2010), dass Kind-Sein (hier muss Eltern-Sein komplementär dazu mitgedacht werden) eine soziale Identität ist, die performativ durch Verhaltensweisen, Gesten und Sprache konstituiert wird. Somit sind Kinder und Erwachsene gleichermaßen als soziale Akteur*innen ihrer Familien und Lebenswelten zu verstehen, die Familie in "praktischen alltäglichen >Mühen` fürsorglicher Beziehungen« (Jurczyk 2020: 9) konstituieren. »Doing family« kann somit als »practice of agency« (Abebe 2019: 12) innerhalb gegebener Kontextbedingungen, insbesondere der Institutionalisierung von care in formalisierten Bildungs-, Freizeit- und Kinderbetreuungsangebote (vgl. Honig 2017), verstanden werden.

Care Praktiken und Beziehungen geflüchteter Familien werden aber auch durch "Sonderformen" (Wihstutz 2019: 233) der Institutionalisierung beeinflusst wie die Unterbringung in Gemeinschaftsunterkünften, rechtliche Unsicherheit und ausbleibender Familiennachzug. Mit Foucault (1990) kann hier von einer biopolitischen Regulierung des Status und der Lebensweise von geflüchteten Menschen im Aufnahmekontext gesprochen werden. In einem komplexen Zusammenspiel von staatlicher Regulierung, Nicht-Regulierung und Deregulierung (vgl. Nieswand/Drotbohm 2014) bei der Zuwanderung und gesellschaftlichen Teilhabe geflüchteter Menschen werden jenseits der Staatsbürgerschaft unterschiedliche Kategorien von Zugehörigkeit und Berechtigung geschaffen, die die alltäglichen Praktiken und Routinen geflüchteter Familien disziplinieren, indem diese auf bestimmte Zwänge, Anforderungen und Erwartungen reagieren müssen. Bochmann (2017: 82) kritisiert in ihrem Beitrag zu »Flüchtlingslagern«, dass diese theoretische Rahmung als »Kontroll- bzw. Regulierungsinstitutionen« Mikroformen der agency von Geflüchteten ausblendet. Diese können aber nicht nur im Handeln geflüchteter Menschen in Bezug auf Strukturen des Flucht- und Asylprozesses gefunden werden, sondern auch in der Fürsorge für ihre Bezugspersonen (vgl. Kallio 2019: 7). 


\section{Zur Sekundäranalyse von Interviews mit geflüchteten Kindern und Eltern}

Dieser Aufsatz basiert auf einer Sekundäranalyse von qualitativen Daten, die im Rahmen der World Vision Studien Angekommen in Deutschland von 2016 und Flucht, Religion, Resilienz von 2020 erhoben wurden. Der Begriff Sekundäranalyse bezieht sich auf die Untersuchung empirischen Materials entlang einer Forschungsfrage, die von dem Erkenntnisinteresse des ursprünglichen Forschungsprojektes abweicht (vgl. Ruggiano/Perry 2019; Sherif 2018; Long-Sutehall et al. 2010). Die Sekundäranalyse wurde methodisch als Kombination aus Inhalts- und Sequenzanalyse durchgeführt. Zunächst wurden in beiden Studien vorkommende Themen inhaltsanalytisch induktiv kodiert, z.B. Gewalt durch Schlepper*innen, Erfahrungen in der Sammelunterkunft und Angst vor Abschiebung. Dann wurden die so ausgewählten Narrative in Anlehnung an die Objektive Hermeneutik (vgl. Oevermann 1973) sequenzanalytisch ausgewertet.

Die Studie Angekommen in Deutschland war - vor dem Hintergrund der damals kaum vorhandenen Forschung - darauf ausgerichtet, einen umfassenden Einblick in die Lebenswelten und das Wohl geflüchteter Kinder zu erlangen. Datengrundlage sind zehn Interviews mit Kindern, die in Begleitung von Familienangehörigen - zumeist einem oder beiden Elternteilen - nach Deutschland flohen. Bei dieser Studie wurden keine erwachsenen Familienangehörigen interviewt. Die interviewten Kinder waren zwischen zehn und 13 Jahren alt; drei von ihnen sind Mädchen. Sie stammen aus Serbien, Kosovo, Syrien, Iran, Afghanistan und Eritrea. Einige lebten erst seit ein paar Monaten, andere seit wenigen Jahren in unterschiedlichen Regionen Deutschlands.

Im Jahr 2020 veröffentlichte World Vision Deutschland die Nachfolgestudie Flucht, Religion, Resilienz, die die Bedeutung des individuellen Glaubens und der Einbindung in Religionsgemeinschaften für die Bewältigung von Flucht- und Integrationsbelastungen geflüchteter Kinder und Jugendlicher darstellt. Hier wurden neben geflüchteten Kindern auch erwachsene Familienangehörige, zumeist die Eltern, in zwei Fällen aber auch ein Onkel und ein erwachsener Bruder, interviewt. Das Sample umfasst 20 Familien, aus denen 29 Kinder im Alter von fünf bis 16 Jahren interviewt wurden. Die Familien stammen aus Afghanistan, Irak, Syrien und dem Iran.

Ein Teil der interviewten Familien (insbesondere die aus dem Irak stammenden ezidischen Familien und Familien aus Syrien) verfügen über eine dreijährige Aufenthaltsgenehmigung, andere warteten zum Zeitpunkt der Interviews noch auf eine Entscheidung zu ihrem Asylgesuch, und einige Familien (insbesondere aus Südosteuropa) verfügen über eine Duldung. Alle verwendeten Namen und Orte sind anonymisiert. Interviewpartner*innen aus der 2016er Studie sind als Familien A 110 gekennzeichnet, aus der 2020er Studie als Familien B 1-20. Interviews mit den Kindern wurden auf Deutsch geführt, mit den Erwachsenen in ihrer Herkunfts- 
sprache, so dass ihre Zitate von jeweils zwei professionellen Dolmetscher*innen unabhängig voneinander ins Deutsche übersetzt und geprüft werden mussten.

\section{"Doing family « in den Narrativen von geflüchteten Kindern und Erwachsenen}

Narrative, in denen Eltern und Kinder über die Gründe ihrer Flucht sprechen, zeigen ein komplexes Zusammenspiel von Flucht als erzwungener Mobilität, aber auch aktiver Überlebensstrategie. $\mathrm{Zu}$ fliehen wird als care Praktik der Elternschaft konstituiert, da Eltern nur durch das Verlassen des Lebensortes das Überleben oder die Versorgung ihrer Kinder gewährleisten können.

Nach dem Tod ihres Mannes wurde die alleinerziehende Mutter der syrischen Familie B2 von ihrer Schwiegerfamilie bedroht. Sie möchte die Gründe dafür nicht ausführen. Sie lebte mit ihren zwei Kindern zunächst in einer ehemaligen Schule in Syrien, die als Notunterkunft diente, musste diese dann aber verlassen. Die Entscheidung zur Flucht wird begründet mit der Notwendigkeit, ihre Kinder zu beschützen: "Der Vater meiner Kinder ist tot und ich beschützte sie, weshalb ich mich an eine Schule für Flüchtlinge gewandt habe. Diese Schule sollte geschlossen werden und da gab es keine Alternative mehr.« (Interview mit Mutter der Familie B2)

Die ebenfalls aus Syrien stammende Familie B3 lebte zunächst drei Jahre in der Türkei. Während der Vater Angst hatte, durch eine Flucht nach Europa seine Kinder in Gefahr zu bringen, empfand die Mutter die Lebenssituation ihrer Kinder in der Türkei als nicht länger hinnehmbar. Im Interview erinnert sie sich an das Gespräch mit ihrem Mann: »Denkst du meine Kinder leben? Schule in der Türkei? Konnten sie nicht besuchen. [...] Ich sagte, mach was du willst, lass dich von mir scheiden, aber ich werde meine Kinder hier rausholen.« (Interview mit Mutter der Familie B3)

Mutterschaft konstituiert sich in Zitaten der Frauen über die Verantwortung, einen geeigneten Lebensort für die eigenen Kinder zu finden und ihr Handeln darauf auszurichten. Auch in den Narrativen der Kinder lässt sich das Verständnis finden, dass sich ihre Eltern aktiv zur Flucht entschieden haben, um das Überleben und Wohlergehen der Familie zu sichern. Häufig werden diese Entscheidungen den Müttern zugeordnet, teilweise aber auch dem Elternpaar. Die aus dem Kosovo stammenden zehn- und elfährigen Brüder der Familie Ar erzählen, dass sich ihre Eltern zur Flucht entschieden, als sie aufgrund von Arbeitslosigkeit und Armut die Versorgung ihrer Kinder nicht sicherstellen konnten. Der elfährige Sohn der Familie A1 sagt: »Weil mein Papa ist nicht Arbeit und mein Papa hat kein Geld.« (Interview mit Sohn der Familie A1) Auch die 13-jährige Tochter der Familie A4 aus Eritrea geht davon aus, dass eine konkrete Bedrohungslage im Herkunftsland dazu 
geführt hat, dass sich ihre Mutter zur Flucht entschied: »Wegen Diktatur und- und da habe ich gar keine Ahnung. [...] Und da hat sie [die Mutter] gesagt, >wir fahren<. Und dann sind wir gefahren.« (Interview mit Tochter der Familie A4) Eltern und Kinder nehmen wechselseitig aufeinander Bezug und bestätigen, dass es Eltern bei der Entscheidung zur Flucht vor allem darum geht, das Überleben und die Versorgung ihrer Kinder, die am bisherigen Ort nicht mehr gewährleistet war, zu sichern. So kann die Flucht selbst als Praxis von Elternschaft verstanden werden, denn sie ist dadurch motiviert, dass Eltern ihre Fähigkeit, ihre Kinder zu beschützen und für ihr Wohlergehen zu sorgen, wiederherstellen wollen.

\section{Immobilisierung im deutschen Asylverfahren}

Viele Familien wurden nach ihrer Ankunft in Deutschland zunächst in Erstaufnahmeeinrichtungen gebracht und erhielten dort eine Grundversorgung, die Nahrungsmittel, Kleidung, Hygiene und medizinische Hilfe umfasste. Die Interviews verweisen auf die heterogenen Standards in den Unterkünften in Hinblick auf den Schutz und das Wohlergehen von Kindern. Insbesondere 2015, als viele der hier interviewten Familien nach Deutschland kamen, wurden sie im Asylsystem nach einem »crisis modus of operandi« versorgt, der zu einem temporären Aussetzen bereits existierender Standards geführt hatte, um den erhöhten Bedarf zu decken (vgl. Rosenow-Williams et al. 2019: 264). Dies verdeutlicht die Erzählung einer aus dem Irak stammenden Mutter der Familie B5: "Am Anfang waren wir in einem Heim. Wir wurden in einer großen Halle untergebracht. Die Männer und Frauen waren getrennt. Wir waren 40 Tage dort.« (Interview mit Mutter der Familie B5) Die Geschlechtertrennung in manchen Erstaufnahmestellen und Notunterkünften, die einige interviewte Familien erlebt haben, behindert maßgeblich die Ausübung ihrer familiären Praktiken. Familie B5 wurde anschließend in ein anderes Heim verlegt, indem sie einen Monat lang ein Zimmer mit drei anderen Familien teilten bevor sie ein eigenes bekamen: "Ein Jahr und drei Monate blieben im Heim, ja. Das war sehr schwierig. Wir haben dort kaum Schlaf bekommen. Das war sogar schlimmer als die Flucht.« (Ebd.) Solange sich Familien im Verfahren befinden und in Unterkünften leben, wird ihr Familienleben durch die Disziplinierung des Asylverfahrens reguliert. In der Art der Unterkunft reflektiert sich der eingeschränkte rechtliche Status dieser Familien und wird für sie erfahrbar: ihnen wird kein eigener Raum zur Verfügung gestellt, und sie können ihren Tagesablauf nicht unabhängig gestalten. Viele interviewte Kinder, die überfüllte Unterkünfte erlebt haben, beschreiben diese als »laut «, wie die 14-jährige Tochter der Familie B6: »Als wir im Heim waren, da ging es uns schlecht, und da haben wir immer die ganze Zeit gebetet, dass wir ein schönes Leben wollen und nicht mehr im Heim, an so einem lauten Ort.« (Interview mit Tochter der Familie B6) 
Auch der 19-jährige Sohn der Familie B8 schildert die Zustände ihrer ersten Unterkunft - einem ehemaligen Hotel - ähnlich:

»[...] und die hatten entschieden, das Hotel zu einem Flüchtlingsheim zu machen [...] und so in den ersten paar Wochen ging es ja noch. Aber dann wurde das Heim wirklich überflutet mit den Leuten und war also ein Chaos, ein richtiges Chaos da.« (Interview mit Sohn der Familie B8)

Seine Mutter konkretisiert: "Das war schwer. Und es gab viele andere Leute mit anderen Religionen, mit anderen Gedanken, mit anderer Sprache.« (Interview mit Mutter der Familie B8) Diese Zitate zeigen, dass geflüchtete Kinder und Erwachsene ihre erste Unterbringung in Deutschland als gemeinschaftliche negative Erfahrung der gesamten Familie erinnern, vor der Eltern ihre Kinder nicht beschützen konnten.

Die Unterbringung von Geflüchteten ist ein wichtiger Aspekt der biopolitischen Organisation des Asylsystems, der zum einen die Lebensqualität der Geflüchteten als auch ihre Kontaktmöglichkeiten zur lokalen Bevölkerung als Zusammenspiel von »care and control« (Malkki 1995: 498) maßgeblich bestimmt. Unabhängig davon ob interviewte Familien in Erstaufnahmestellen, Notunterkünften oder Heimen untergebracht wurden, berichten die meisten Familien von einer Überfüllung dieser Unterbringungen. Das oben angesprochene »Chaos« markiert den Zustand der Unordnung innerhalb dieser Unterkünfte als »Räume der Ausnahme« (exceptional space) für Geflüchtete jenseits der »national order of things« (Turner 2016: 139). Durch das permanente Eindringen fremder Menschen in die familiäre Privatsphäre - entweder durch geteilten Wohnraum oder durchdringende Geräusche aus anderen Wohnräumen - fehlt Familien ein Rückzugsort. Erwachsene und Kinder charakterisieren den Zustand in diesen Unterbringungen als »fehlende Ruhe«. Die Unterbringung in "Zwangsgemeinschaften« (World Vision 2016: 49) ohne Privatsphäre und Rückzugsräume kann durch Kinder und Erwachsene als »strukturelle Gewalt« erfahren werden (Tran 2019: 95), die gesellschaftlich verankerte Machtverhältnisse in ihren Lebensbedingungen äußert. Das Nicht-zur-Ruhe-kommen markiert für Familien die Vorläufigkeit dieser oft viele Monate bestehenden Unterbringung, in der ihr wichtigsten Ziel ist, eine eigene Wohnung zu finden. Sehr viele der interviewten Kinder äußerten auf die Frage nach ihren Zukunftswünschen, in einem »eigenen Haus« zu leben. Der zehnjährige Sohn der Familie A2 antwortet auf die Frage der Interviewerin, was zu einem "guten Leben« dazugehöre: »Wichtig finde ich Haus« und ergänzt »Ja. Dass also, und man soll sich, also man soll nicht verhungern. Ja das sind wichtig. « (Interview mit Sohn der Familie A2) Auch die 13-jährige Tochter der Familie A4 antwortet zunächst: »Ich will ein eigenes Haus haben und eine eigene Wohnung « und fügt dann hinzu »Ich will wieder mal nach Eritrea« (Interview mit Tochter der Familie A4), womit sie anzeigt, 
dass sie die Einschränkungen des Asylsystems in Hinblick auf Unterbringung und Bewegungsfreiheit wahrnimmt.

Die Konsequenzen der biopolitischen Regulierung im Asylsystem werden insbesondere im Zusammenhang mit Unterkünften und Lagern darin verstanden, eine Unterscheidung und Distanzierung zwischen der nationalen Bevölkerung und den Geflüchteten herzustellen (vgl. Kreichauf 2018), die unterschiedliche Kategorien der Zugehörigkeit im Alltag erfahrbar machen. Die Narrative der interviewten Kinder und Erwachsene verweisen aber auch darauf, dass das deutsche Asylsystem das Familienleben »nach innen« reguliert, und damit genau das erfüllt, was Foucault als »the administration of bodies and the calculated management of life (Foucault 1978: 149) bezeichnet und sich in den (verhinderten) care Praktiken der Familien wiederfindet.

Die sogenannte Residenzpflicht, die unterbindet, dass Familien, die Asyl ersuchen, ihren Aufenthaltsort frei wählen können, ist neben der Unterbringungsform selbst eine weitere Form der Disziplinierung, die care Praktiken und Beziehungen geflüchteter Familien beeinträchtigen. Die meisten Familien haben nach ihrer Ankunft in Deutschland eine mehrmonatige oder sogar mehrjährige Phase erlebt, während der sie immer wieder in andere Unterkünfte verlegt wurden und dabei kaum die jeweiligen Städte oder Gemeinden kennenlernen konnten. Sowohl die Mobilisierung durch Verlegung als auch die Immobilisierung als Verbleib in einer für die Familien unpassenden Unterkunft zeigen sich in den Narrativen von Erwachsenen und Kindern als Erfahrungen der Fremdbestimmung. Familie B2 lebte nach ihrer Ankunft in Deutschland vier Wochen in einer Großstadt im Norden Deutschlands in der Nähe eines Bruders der Mutter, der bereits die Flucht der Familie finanziell unterstützt und bei der Beantragung des Asyls geholfen hatte. Die Mutter erzählt, dass die Familie im Zuge des Asylverfahrens dann aber gegen ihren Willen in eine andere Großstadt im Osten Deutschlands verlegt wurde: »Ich habe viel Stress gemacht, damit sie mich wieder zurückbringen, aber niemand hat mir geholfen. Ich habe erfahren, dass ich zuerst den Aufenthaltstitel erhalten muss, damit ich an einen anderen Ort umziehen kann.« (Interview mit Mutter der Familie B2) Die Zuweisung einer Unterbringung nimmt Eltern die Autorität und Freiheit, über den Lebensort der Familie zu bestimmen. Oftmals leben an dem Wunschort der Familien bereits andere Angehörige, die die Familien dabei unterstützen, ihre Rechte wahrzunehmen, sie mit Kleidung und Bedarfsgütern versorgen und ihnen ein vertrautes soziales Umfeld bieten. Die Frustration und Angst der Eltern an einen unbekannten Ort ohne Sozialkontakte verlegt zu werden, kann dabei auch ihre Kinder sehr verunsichern, wie sich im Interview mit der 13-jährigen Tochter der Familie A4 zeigt, die sich an die Orientierungslosigkeit und Angst ihrer Mutter erinnert. 
»Wo wir nach in X-Stadt waren, nach drei Monaten, haben die gesagt, wir sollen, äh, wir fahren weg. Und da haben die uns in Y-Dorf [ca. 100 Kilometer entfernt]. Und dann hat meine Mum mein Onkel angerufen und hat gesagt, sich weiß nicht, wo ich bin; ich habe Angst«. (lacht leicht) [...]. Und Y-Dorf ist ja schon richtig (lacht leicht) hart. [...] Und danach haben wir uns dran gewöhnt.« (Interview mit Tochter der Familie A4)

Verteilung und Residenzpflicht konfrontieren Geflüchtete damit, sich an einem Ort, den sie nicht selbst gewählt haben, zurechtfinden müssen. Dass Eltern im Asylverfahren nicht mehr über den Lebensort der Familie entscheiden können, konterkariert ihr Narrativ, sich für die Flucht entschieden zu haben, um für ihre Kinder einen geeigneten Lebensort zu finden. Der aktiven Mobilisierung in der Entscheidung zur Flucht steht so die Erfahrung der persönlichen Immobilisierung in Bezug auf die Handlungsohnmacht gegen die Zuweisung eines Wohnortes im Asylsystem entgegen.

Die Lebensbedingungen in Sammel- und Gemeinschaftsunterkünften ohne eigene, vollausgestattete Wohneinheiten beeinflussen familiäre Praktiken maßgeblich, was insbesondere aus den Erzählungen der Kinder hervorgeht. Der zehnjährige Sohn der Familie A2 aus Afghanistan sagt, dass er die Gemeinschaftsunterkunft, in der die Familie nun wohnt, besser findet als die vorherige Unterkunft:

Sohn der Familie A2: »Weil da kann man selber kochen und so. Aber B-dorf nicht. « Interviewerin: »Mhm. Genau. Da hat dann jemand was gekocht, nä?«

Sohn der Familie A2: »]a. Wenn äh man durfte nicht selber kochen.«

Interviewerin: »Mhm. Und wie war das Essen so?«

Sohn der Familie A2: »Also, da geht. Meine Mutter kocht aber besser.« (Interview mit Sohn der Familie A2)

Auch die 14-jährige Tochter der Familie B6 aus Afghanistan bezieht sich auf die Möglichkeit selbst zu kochen, wenn sie erklärt, warum es ihrer Familie nach dem Umzug in eine Gemeinschaftsunterkunft besser geht: »Also jetzt sind wir Gott sei Dank in einer Unterkunft, hier können wir sehr gut kochen und es ist besser als ein Heim ${ }^{1}$. (Interview mit Tochter der Familie B6) Cover (2014: 10) verweist darauf, dass Biopolitik auch über die Ernährung der Bevölkerung verlaufen kann. Dass Familien in vielen Unterkünften nicht selbst kochen dürfen oder können, ist ein weiterer Aspekt, der ihren rechtlichen Status in der Einschränkung von care Praktiken erfahrbar macht. Das Selbst-Kochen ist für sie eine Form der Selbstbestimmung 
über ihre kulturspezifische und individuelle Ernährung, die das Wohlbefinden steigert und »doing family« über die Zubereitung von Nahrungsmitteln für Familienmitglieder ermöglicht.

Problematisch ist für viele Familien auch, dass Familienbeziehungen und Praktiken durch die Verletzlichkeit des Wohnraums beeinflusst sind. Für die aus dem Kosovo stammenden zehn- und elfjährigen Brüder, deren Familie zum Zeitpunkt des Interviews den Status einer Duldung hat, ist die Unsicherheit über ihren Aufenthalt in Deutschland eine große Belastung. Dazu kommt, dass die Familie sehr beengt in einer Gemeinschaftsunterkunft lebt, in der sie sich ein Zimmer mit einer anderen Familie teilen muss. Bei dem zehnjährigen Jungen zeigen sich die psychologischen Auswirkungen der rechtlichen Unsicherheit und der Unterbringungsform (vgl. zur Traumatisierung von Kinder durch die Angst vor nächtlicher Abschiebung AGJ 2017: 6):

Sohn der Familie A1: »Weil äh die alle sagen, die Kosovo alles gehen zurück. Und mit Stress bleiben. [...] Die nachts nehmen und die Polizei dann gehen in Kosovo.« Interviewerin: »Also man weiß nicht, wann die Polizei kommt?»

Sohn der Familie A1: »Nein, man darf- nein, ich weiß es nicht. Nur nehmen, vielleicht du schlafen ganz gut, schlafen. [...] Und die kommen, der hat Schlüssel.« Interviewerin: »Wer?«

Sohn der Familie A1:»Der kommen. Der, der- und der macht offen.« (Interview mit Sohn der Familie A1)

Der interviewte Junge hat in Zusammenhang mit der Vorstellung, die Familie könnte nachts abgeschoben werden, eine Schlafstörung entwickelt und befindet sich deswegen in therapeutischer Behandlung. Das Interview mit ihm und seinem Bruder macht deutlich, dass ihr Zimmer in der Gemeinschaftsunterkunft für die Familie keinen sicheren und geschützten Raum darstellt, der ein Familienleben mit intergenerationaler Sorgebeziehung ermöglicht. Der Sicherheitsdienst der Unterkunft hat einen weiteren Schlüssel (das vermuten oder wissen viele der interviewten Familien), so dass die Familien durch die fehlende Privatsphäre im Zustand des "Ausgeliefert-seins" (Tran 2017: 4) leben. Einige Familien berichten darüber, dass der Sicherheitsdienst heimlich ihre Zimmer auf Verstöße gegen die Hausordnung (z.B. durch das Aufstellen eigener Möbel oder das Anbringen von Bildern) kontrolliere. Hiermit löst sich für sie die ihnen zugeordnete Privatsphäre in der Öffentlichkeit der Unterkunft auf.

Mit der Erteilung einer befristeten Aufenthaltsgenehmigung über drei Jahre, die viele Familien erhalten haben, wird der von Lewek und Naber beschriebene "Wartezustand « (Lewek/Naber 2017: 6) in asylrechtlicher Hinsicht vorerst beendet. Die Befristung belastet viele Familien zwar, ermöglicht ihnen den rechtlichen und emotionalen Handlungsspielraum sich in Deutschland vorerst niederzulassen. Dies bedeutet für sie vor allem, sich um einen Umzug in eine Wohnung am freien 
Wohnungsmarkt in der Stadt ihrer Wahl zu bemühen. Gerade Mehrkind-Familien in Großstädten mit einem angespannten Wohnungsmarkt leben oft über Jahre hinweg in Unterkünften, da es für sie schwer ist, Zugang zu Wohnraum zu finden. Hiermit verharren diese Familien in einem Zustand der "permanent temporality«, der oft für Camps im Globalen Süden angenommen wird (vgl. Hailey 2009), und sich im familiären Zusammenleben dadurch bemerkbar macht, dass das Thema der Wohnungssuche alle anderen Themen überschattet und eine Verbesserung der familiären Situation daran festgemacht wird. Die zehnjährige Tochter der Familie B3 ist aufgrund einer Traumatisierung in psychotherapeutischer Behandlung. Sie erzählt in ihrem Interview, dass sie in unkontrollierbaren Wutausbrüchen andere Kinder schlägt, obwohl sie dies nicht will. Ihre Mutter nimmt an, dass sich ihre Tochter erst erholen kann, wenn die Familie, die bereits seit vier Jahren in der Unterkunft lebt, in eine eigene Wohnung ziehen kann:

»[...] sie kommt aus der Schule, macht ihre Hausaufgaben und geht spielen, mit den Kindern des Heims. Das ist nicht gut. Dieselben Kinder in der Schule und im Heim. Ständig Schlägereien, Beleidigungen und Ähnliches. Sie hat kein neues Leben hier und in der Schule. Ich sagte zu Ärztin, ändert die Wohnsituation, dann geht es [...] uns besser.« (Interview mit Mutter der Familie B3)

Die interviewten Familien, die bereits in den freien Wohnungsmarkt übersiedeln konnten und eine Wohnung fanden, die eher ihren Bedürfnissen entspricht, haben dies mit der Hilfe ihrer privaten Kontakte und Netzwerke geschafft. Eine aus Syrien stammende Mutter erzählt, dass sie nach anderthalb Jahren in der Gemeinschaftsunterkunft über Bekannte von einem inoffiziellen »Makler« erfahren hat, der ihr eine Dreizimmerwohnung vermittelte: "Ich habe das Haus durch einen Makler bekommen. (lacht) Der Makler hat uns pleite gemacht." (Interview mit Mutter der Familie B2) Insbesondere die ezidischen Familien erzählen auch, dass sie bei der Suche nach einer eigenen Mietwohnung durch Ezid"innen, die schon lange in Deutschland leben, unterstützt wurden.

»Wir waren denke ich drei Monate in einem Heim geblieben, also in X-Stadt. Danach gibt es eine Frau, sie ist auch ezidisch, sie hat uns geholfen, sie hat diese Wohnung für meine Familie gefunden und sie hat auch unsere Papiere alle gemacht. (Interview mit Vater der Familie B7)

Viele Familien versuchen parallel über ihre Kontakte $\mathrm{zu}$ anderen Migrant*innen, über die Flüchtlingshilfe und eigenständige Bewerbungen am freien Wohnungsmarkt, eine Wohnung zu finden. Wenn es um den Kontakt zu deutschsprachigen Personen geht, werden oft auch ältere Kinder in die Wohnungssuche eingebunden. Die hohe Verantwortung, die manche Kinder und Jugendliche in dieser Situation für ihre Familien übernehmen, zeigt sich im Interview der aus dem Iran stammenden Familie B8. Da die Familie dem Christentum angehört, konnte der damals 
19-jährige Bruder, der schon sehr gut Deutsch sprach, mithilfe seiner christlichen Gemeinde eine Wohnung auf dem freien Wohnungsmarkt finden:

»Es gab auch mal einen Cottesdienst, wo ich auf die Bühne ging vor so vielen Leuten, 100, 200 waren da, und habe halt dort gesprochen, die Situation ein bisschen erklärt, und ja, Cott sei Dank, saßen unsere Vermieter da, auch im Gottesdienst, und ja, direkt nach dem Gottesdienst wurde ich darauf angesprochen, dass es halt die Möglichkeit gibt, dass es eine Wohnung gibt.« (Interview mit Sohn der Familie B8)

In fast allen Interviews wird deutlich, dass die Kinder von geflüchteten Familien durch ihren schnelleren Spracherwerb neue Aufgaben und Verantwortungen bei der Niederlassung der Familie übernehmen, insbesondere was die Kommunikation mit der Aufnahmegesellschaft, ihren Behörden und Institutionen betrifft. Die meisten Eltern besuchen zwar einen Sprachkurs in Deutschland, können aber nur selten ausreichende sprachpraktische Kenntnisse erlangen, da ihnen oft Kontakte zu deutschsprachigen Personen und damit Spracherfahrungen fehlen. Auch Kinder sind sich des oftmals schwierigen Spracherwerbs ihrer Eltern bewusst. Die elfährige Tochter der Familie A3 aus dem Iran erzählt, dass ihre Mutter einen Deutschkurs besucht: »Sie ist gut in Schule, aber ist- sie hat, sie hat gewiss so Schiss. Sie schämt sich zu reden.« (Interview mit Tochter der Familie A3)

Durch die hohe Bedeutung der Sprache verändert sich das Verhältnis zwischen Kindern und Eltern. Die Verantwortung für die Kommunikation mit familienfremden Personen verschiebt das Fürsorgeverhältnis in den Familien. Eltern resümieren, dass sie nun auf die Übersetzungen ihrer Kinder angewiesen sind:

»Sie sind diejenigen, die uns gerettet haben. [...] Als sie in die Schule gekommen sind, haben sie die Sprache direkt aufgenommen. Sie lernen viel schneller als die Alten. Wenn wir jetzt zum Beispiel zum Jobcenter gehen, dann geht einer von den Kindern mit.« (Interview mit Mutter der Familie B4)

Für viele Familien folgt auf das Sich-Niederlassen in Deutschland (räumlich und rechtlich) unmittelbar die Frage, ob soziale Aufwärtsmobilität durch einen guten Bildungszugang und -erfolg hergestellt werden kann. Dass ihre Kinder zur Schule gehen und dort gut zurechtkommen, wird von Eltern als Indikator ihres Wohlergehens herangezogen. Eine aus dem Irak stammende Mutter sagt über ihre 13jährigen Zwillinge: »Hier geht es den Kindern sehr gut. Sie haben Deutsch und Englisch gelernt. Hier geht es ihnen viel besser als im Irak.« (Interview mit Mutter der Familie B9) Der Bildungserfolg der meisten interviewten Kinder wird von ihren Eltern als Bestätigung gewertet, dass die Entscheidung zur Flucht richtig war, da sie ihren Kindern im Herkunftsland keine vergleichbaren Lebenschancen bieten konnten. Aufgrund ihres Alters, des schwierigen Spracherwerbs und fehlenden Anerkennungsmöglichkeiten ihrer beruflichen Kenntnisse fokussieren sich 
viele Eltern auf die Bildungs- und Berufsmöglichkeiten ihrer Kinder, damit diese soziale Aufwärtsmobilität in Deutschland erfahren können: »Was unser Zuhause angeht, so ist zuerst der Vater gestorben und dann das Haus zerstört worden. Daher habe ich beschlossen, die Kinder in ein sicheres Land zu bringen, damit ich sie in den besten Jobs sehen kann.« (Interview mit Mutter der Familie B2) Dem eingangs dargestellte Narrativ, dass Mutterschaft unter bestimmten Bedingungen eine Flucht für das Wohl der Kinder erforderlich macht, steht hier das Narrativ gegenüber, dass der soziale Aufstieg der Kinder das mentale und möglicherweise auch materielle Wohlergehen ihrer Mütter sichert.

»Ich bin für die Zukunft meiner Kinder nach Deutschland gekommen, in Syrien gab es keine Zukunft mehr. Und Libyen war es noch schlechter. Es geht mir nur um die Kinder, nicht um mich. Ich bin 35 Jahre alt, was soll ich jetzt machen. Mein Wunsch ist es, dass sie ihre Bildung beenden und ihre Zeugnisse bekommen. Dann bin ich sehr glücklich, als hätte ich selbst ein Zeugnis bekommen.« (Interview mit Mutter der Familie B4)

Diese Narrative zeigen eine starke intergenerationale Interdependenz in den geflüchteten Familien, die daraus hervorgeht, dass das eigene Wohlbefinden an dem der Familienmitglieder festgemacht wird. Die Verschiebung der Verantwortung für den sozialen Aufstieg von Eltern auf Kinder ermöglicht es geflüchteten Familien, sich an die Kontextbedingungen in Deutschland anzupassen, in denen die Eltern kaum Chancen auf eine qualifizierte Berufstätigkeit haben. Es könnte zwar vermutet werden, dass Eltern ihre Kinder durch diese Erwartungen überfordern, aber die hier interviewten Kinder schienen sich eher unterstützt und gefördert zu fühlen.

\section{Schlussfolgerungen}

Die Interviews mit geflüchteten Familien zeigen, dass sie drei unterschiedliche Phasen in Bezug auf Mobilität und Immobilität durchlaufen. In den Narrativen der Kinder und Erwachsenen geht es dabei allerdings weniger um eine konkrete geographische Verortung, sondern eher um die persönliche Handlungs- und Entscheidungsfreiheit, die sie an einem bestimmten Lebensort erfahren. Die Entscheidung zur Flucht stellt die erste Phase der räumlichen und familiären Mobilisierung dar, mit der Erwachsene das Überleben und Wohlergehen ihrer Kinder sicherstellen wollen. Diese Entscheidung wird vor dem Hintergrund getroffen, am aktuellen Lebensort die Sicherheit und Versorgung der Kinder nicht mehr gewährleisten zu können. Hiermit wird die Entscheidung über einen geeigneten Lebensort für die eigenen Kinder zum Wesenskern von Elternschaft und die Kinder an diesen neuen Ort zu bringen zur akuten Aufgabe der Eltern. 
In der zweiten Phase erleben Familien die Flucht und das deutsche Asylverfahren als persönliche Immobilisierung in dem Sinn, dass sie selbst nicht mehr über ihren Aufenthaltsort bestimmten können, an einem Ort festgehalten oder an einen anderen Ort verbracht wurden, und dort in ihrer familiären Handlungsfähigkeit stark eingeschränkt sind. Besonders negativ scheint hierbei die Erfahrung zu sein, der Familie keine sichere und unverletzliche Wohnung bieten zu können.

Mit dem Erhalt einer, wenn auch oft befristeten Aufenthaltsgenehmigung, stabilisiert sich die Situation vieler Familien und sie treten in die dritte Phase, die der sozialen Aufwärtsmobilität, ein. Gerade weil viele Eltern die Erfahrung machen, dass ihnen der Spracherwerb viel schwerer fällt als den Kindern und sie am deutschen Arbeitsmarkt für sich kaum eine Perspektive sehen, übernehmen ihre Kinder neue Verantwortungen in der Familie insbesondere bei der sprachlichen Vermittlung für ihre Eltern. Der Bildungserfolg der Kinder wird von ihren Familien als Indikator für ihr Wohlergehen in Deutschland gesehen und legitimiert die Entscheidung zur Flucht.

\section{Literaturverzeichnis}

Abebe, Tatek (2019): »Reconceptualising Children's Agency as Continuum and Interdependence«, in: Social Sciences 8(81), S. 1-26.

[AGJ] Arbeitsgemeinschaft für Kinder- und Jugendhilfe (2017): Forschungsbedarfe mit Blick auf Geflüchtete im Kontext der Kinder- und Jugendhilfe, Diskussionspapier der Arbeitsgemeinschaft für Kinder- und Jugendhilfe, vom 07./08.12.2017, https://www.agj.de/fileadmin/files/positionen/2017/Forschung sbedarfe_mit_Blick_auf_Gefluechtete.pdf, Abrufdatum: 25.05.2020.

[BAMF] Bundesamt für Migration und Flüchtlinge (2019): Aktuelle Zahlen. Ausgabe 2019, Stand 05/2019, https://www.bamf.de/SharedDocs/Anlagen/DE/Statistik/ AsylinZahlen/aktuelle-zahlen-dezember-2019.pdf?_blob=publicationFile $\& v=4$, Abrufdatum: 27.05.2020.

Bengtson, Vern/Olander, Edward/Haddad, Anees (1976): »The >Generation Gap and Aging Family Members: Toward a Conceptual Model«, in: Jaber Gubrium (Hg.), Time, Roles and Self in Old Age, New York: Human Sciences Press, S. 237-263.

Bengtson, Vern/Oyama, Petrice (2007): Intergenerational Solidarity: Strengthening Economic and Social Ties, Background Paper, Expert Group Meeting, vom 23.-25.10.2007, www.un.org/esa/socdev/unyin/documents/egm_unhq_ oct07_bengtson.pdf, Abrufdatum: 02.03.2012.

Bergnehr, Disa (2018): „Children's influence on wellbeing and acculturative stress in refugee families«, in: International Journal of Qualitative Studies on Health and Well-being, o.S. https://doi.org/10.1080/17482631.2018.1564517. 
Bochmann, Annett (2017): „Soziale Ordnungen, Mobilitäten und situative Grenzregime im Kontext burmesischer Flüchtlingslager in Thailand «, in: PERIPHERIE 45(37), S. 76-97, https://doi.org/10.3224/peripherie.v37i1.04.

Butler, Judith (1993): Bodies that Matter: On the Discursive Limits of `Sex`, New York: Routledge.

Cover, Rob (2014): »Population and Belonging: Performativity, Identity and (National) Relationality«, in: New Scholar: An International Journal of the Humanities, Creative Arts and Social Sciences 3(1), S. 1-12.

Dickenson, Dianne (2010): »Performing Childhood: Media, childhood and identity«, Dissertation thesis, Macquarie University, o.D., http://hdl.handle.net/1 959.14/175366, Abrufdatum: 27.05.2020.

Ee, Elisa van/Mooren, Trudy/Kleber, Rolf (2014): »Broken mirrors: Shattered relationships within refugee families«, in: Ruth Pat-Horenczyk/Danny Brom/Juliet Vogel (Hg.), Helping children cope with trauma: Individual, family and community perspectives, London: Routledge/Taylor \& Francis Group, S. 146-162.

Finch, Janet (1989): Family Obligations and Social Change, Cambridge: Polity Press.

Finch, Janet/Mason, Jennifer (1993): Negotiating Family Responsibilities, London: Tavistock.

Foucault, Michel (1978): The History of Sexuality. Volume I: An Introduction, New York: Pantheon Books.

Foucault, Michel (1990): The use of pleasure. History of sexuality. Vol. 2, New York: Vintage Books.

Hailey, Charlie (2009): Camps-guide to 21st-century space, Cambridge: MIT Press. Honig, Michael-Sebastian (2017): "Institutionalisierte Kindheit. Kindeswohl als kindheitstheoretisches Konstrukt «, in: Marianne Heimbach-Steins/Anna Maria Riedl, Kindeswohl zwischen Anspruch und Wirklichkeit. Theorie und Praxis im Gespräch, Düsseldorf: Ferdinand Schöningh, S. 35-45.

Jurczyk, Karin (2020): »Einführung«, in: Karin Jurczyk (Hg.), Doing und Undoing Family, Weinheim/Basel: Beltz Juventa, S. 7-25.

Kallio, Kirsi Pauliina (2019): »Leading refugee lives together: Familial agency as a political capacity«, in: Emotion, Space, Society 31, o.S.

Kallio, Kirsi Pauliina/Häkli, Jouni (2019): »Care as mundane politics: contested familial refugee lives«, in: Finland, Gender, Place \& Culture 26(6), S. 795-812.

Kreichauf, René (2018): "From forced migration to forced arrival: the campization of refugee accommodation in European cities«, in: Comparative Migration Studies 6(7), o.S., https://doi.org/10.1186/s40878-017-0069-8.

Lewek, Miriam/Naber, Adam (2017): Kindheit im Wartezustand. Studie zur Situation von Kindern und Jugendlichen in Flüchtlingsunterkünften in Deutschland, https://www.unicef.de/blob/137024/ecc6a2cfediabeo41d261b489d2ae6cf/kindheit-im-wartezustand-unicef-fluechtlingskinderstudie-2017-data.pdf, Abrufdatum: 11.06.2020. 
Long-Sutehall, Tracy/Sque, Magi/Addington-Hall, Julia (2010): »Secondary analysis of qualitative data: a valuable method for exploring sensitive issues with an elusive population? «, in: Journal of Research in Nursing 16(4), S. 335-344.

Malkki, Liisa (1995): »Refugees and Exile: From >Refugee Studies< to the National Order of Things «, in: Annual Review of Anthropology 24, S. 495-523.

Nieswand, Boris/Drotbohm, Heike (2014): »Einleitung: Die reflexive Wende in der Migrationsforschung «, in: Boris Nieswand/Heike Drotbohm (Hg.), Kultur, Gesellschaft, Migration, Wiesbaden: Springer Fachmedien, S. 1-37.

Oevermann, Ulrich (1973): »Zur Analyse der Struktur von sozialen Deutungsmustern«, Manuskript, Frankfurt a.M..

Rosenow-Williams, Kerstin/Zimmermann, Inga/Bergedieck, Alina (2019): »Human Security Perspectives on Refugee Children in Germany«, in: Children\&Society 33, S. 253-269.

Ruggiano, Nicole/Perry, Tam (2019): »Conducting secondary analysis of qualitative data: Should we, can we, and how? « in: Qualitative Social Work 18(19), S. 81-97.

Sangalang, Cindy/Vang, Cindy (2017): »Intergenerational Trauma in Refugee Families: A Systematic Review«, in: Journal of Immigrant and Minority Health, 19(3), S. 745-754, doi: 10.1007/s10903-016-0499-7.

Sherif, Victoria (2018): »Evaluating Preexisting Qualitative Research Data for Secondary Analysis«, in: Forum: Qualitative Social Research 19(2), o.S., http://dx. doi.org/10.17169/fqs-19.2.2821.

Tran, Hoa Mai (2017): Herausforderungen im Forschungskontext mit jungen geflüchteten Kindern in Sammelunterkünften - Forschungsethische Spannungsfelder zwischen Anspruch und Wirklichkeit, 38. Kongress der Deutschen Gesellschaft für Soziologie: Geschlossene Gesellschaften.

Tran, Hoa Mai (2019): »Ethisch-reflexive Auseinandersetzungen im Forschungsprozess«, in: Anne Wihstutz (Hg.), Zwischen Sandkasten und Abschiebung. Zum Alltag junger Kinder in Unterkünften für Geflüchtete, Opladen: Verlag Barbara Budrich, S. 75-106.

Turner, Simon (2016): »What Is a Refugee Camp? Explorations of the Limits and Effects of the Camp«, in: Journal of Refugee Studies 29(2), S. 139-148.

Wihstutz, Anne/Fichtner, Sarah/Tran, Hoa Mai/Scott, Penelope/Trang Le, Thi Huyen/Schulz-Algie, Evelyn (2018): "Zum Alltagserleben von jungen Kindern in Unterkünften für Geflüchtete in Berlin«, in: Bundeszentrale für gesundheitliche Aufklärung (Hg.), InfoDienst Migration, Flucht und Gesundheit, BZgA, 02/2018, S. 94-98.

Wihstutz, Anne (2019): »Zentrale Erkenntnisse und Empfehlungen«, in Anne Wihstutz (Hg.), Zwischen Sandkasten und Abschiebung. Zum Alltag junger Kinder in Unterkünften für Geflüchtete, Opladen: Verlag Barbara Budrich, S. 223-238. World Vision Deutschland (2016): Angekommen in Deutschland. Wenn geflüchtete Kinder erzählen, https:/www.worldvision.de/sites/worldvision.de/files/pd 
f/World-Vision-Studie-2016-Angekommen-in-Deutschland.pdf, Abrufdatum: 25.03.2020.

World Vision Deutschland (2020): Flucht, Religion, Resilienz. Glaube als Ressource zur Bewältigung von Flucht- und Integrationsherausforderungen, https://www.worldvision.de/sites/worldvision.de/files/pdf/World-Vision -Kinderstudie-Resilienz-2020.pdf, Abrufdatum: 22.04.2020.

\section{Interviews}

Familie A1: Interview mit zehnjährigem Sohn, Länge 39:05 min; Interview mit elfjährigem Sohn, Länge 43:33 min, November 2015.

Familie A2: Interview mit zehnjährigem Sohn, Länge 40:20 min und zwölfjährigem Sohn, Länge 38:34 min, November 2015.

Familie A3: Interview mit elfähriger Tochter, Länge 51:03 min, November 2015.

Familie A4: Interview mit 13-jähriger Tochter, Länge 1:19:28 min, Januar 2016.

Familie A5: Interview mit zwölffährigem Sohn, Länge 55:15 min, November 2015.

Familie B1: Interviews mit achtjährigem Sohn und elfähriger Tochter, Länge 49:29 min, und Mutter, Länge 1:07:57 min, April 2019.

Familie B2: aufeinanderfolgende Interviews mit 14-jähriger Tochter und Mutter; Gesamtlänge: 1:47 min, Februar 2019.

Familie B3: Interviews mit zehnjähriger Tochter, Länge 1:03:40 min, und beiden Eltern, Länge 56:41 min, Februar 2019.

Familie B4: aufeinanderfolgende Interviews mit 14-jähriger Tochter und Mutter; Gesamtlänge 01:59:40 min, Februar 2019.

Familie B5: Interviews mit zwölfährigem Sohn, Länge 1:04:49 min, und Mutter, Länge 57:55 min, April 2019.

Familie B6: aufeinanderfolgende Interviews mit 14-jähriger Tochter und Mutter, Gesamtlänge 1:06:53 min, Februar 2019.

Familie B7: Interview mit neunjährigem Sohn und 13-jährigem Sohn, Länge 49:33 min, und Interview mit Vater, Länge 37:52 min, April 2019.

Familie B8: aufeinanderfolgende Interviews mit 14-jährigem Sohn, 22-jährigem Sohn und Mutter, Gesamtlänge 1:12:43 min, Februar 2019.

Familie B9: Interview mit 13-jährigen Zwillingen, Länge 1:05:56 min, und Mutter, Länge 28:57 min, April 2019. 



\section{Stuck in limbo \\ Psychosoziale Dynamiken von Immobilisierung}

Simon Arnold, Andreas Jensen, Magdalena Kuhn, Rana Zokai und Jan Lohl

\section{Zusammenfassung}

Ausgehend von der Vorstellung des Limbus als quälendem Raum des ewigen Wartens, beleuchtet der Beitrag die psychodynamischen Dimensionen von Immobilisierung im Kontext der psychosozialen Arbeit mit Geflüchteten. Dafür wird auf Interviewmaterial zurückgegriffen, das im Rahmen eines Forschungsprojekts am Sigmund-Freud-Institut zu den Bedarfen und Belastungen von Ceflüchteten und Mitarbeitenden der Ceflüchtetenhilfe erhoben und ausgewertet wurde. Entsprechend dieser doppelten Perspektive auf die psychosoziale Versorgung von Ceflüchteten, geben die Autor*innen einen Einblick sowohl in die Erfahrungsräume der Helfenden sowie auch derjenigen Ceflüchteten, die an Angeboten der psychosozialen Versorgung partizipieren. Der Beitrag versteht sich dabei als eine psychoanalytische Ergänzung zu Auseinandersetzungen mit sozialen Praxen der Immobilisierung, insofern die Autor"innen das subjektive Erleben der Akteur*innen, deren sozialen Figurationen und biographischen Erfahrungen in den Mittelpunkt der Analyse stellen. Der Beitrag beginnt mit einer kurzen Skizze des besagten Projekts und beschreibt die Felderfahrung des Forschungsteams, in der sich bereits szenisch die immobilisierende Wirkung andeutet, deren Erleben für Geflüchtete und Mitarbeitende der Geflüchtetenhilfe im Anschluss anhand der Analyse eines Interviews und einer Fokusgruppe aufgeschlüsselt werden soll. Zuletzt werden die Ergebnisse in Zusammenhang mit psychoanalytischen Theorien zu Trauma, Hoffnung und dem Zeit- und Raumerleben gebracht, die den Beitrag mit einigen weiterführenden Gedanken abschließen.

\section{Summary}

Taking the idea of limbus as a tormenting space of eternal waiting as an underlying concept, this article sheds light on the psychodynamic dimensions of immobilisation in the context of psychosocial work with refugees. To this end, it draws on interview material that was collected and evaluated in the context of a research project at the Sigmund Freud Institute on the needs and burdens of refugees and employees of the refugee assistance centre. In accordance with this double per- 
spective on the psychosocial care for refugees, the authors provide an insight into the experiences of the helpers as well as those refugees who participate in the psychosocial care services. The article is intended as a psychoanalytical supplement to the discussion of social practices of immobilisation, insofar as the authors focus on the subjective experience of the respective actors, their social figurations and biographical experiences to be the centre of the analysis. The article opens with a short outline of the project and describes the field experience of the research team, in which the immobilising effect is already indicated scenically. The experience of refugees and employees of the refugee assistance centre will be broken down by means of the analysis of an interview and a focus group. Subsequently, the results are connected to psychoanalytical theories on trauma, hope and the experience of time and space, which then conclude the article along with some further thoughts.

\section{Von Toren, Türhütern und Gesetzen: Eine Einleitung}

Franz Kafka erzählt in seiner Parabel Vor dem Gesetz (1915/1976) die Geschichte eines Mannes dem, Einlass zum Gesetz erbittend, von einem Türhüter der Zugang verwehrt wird. Widerwillig, aber letztlich durch die imposante Drohung eingeschüchtert, entschließt sich der Mann, »doch lieber zu warten, bis er die Erlaubnis zum Eintritt bekommt« (ebd.: 120). Auf einem Schemel im Vorraum hadert er mit diesem Schicksal, hatte er doch eine lange Reise auf sich genommen und ist der Überzeugung, dass das Gesetz jedem offenstehe. Doch was er auch versucht und wie viele Verhöre und teilnahmslose Fragen er über sich ergehen lässt, sein Wunsch und auch sein legitimer Anspruch, Einlass zum Gesetz zu finden, bleiben unbefriedigt. Die Erzählung zeichnet ein Bild vergeblichen Wartens, der Langeweile und der Qual des Limbus. Die Vorstellung eines solchen Vorraums - der Vorhölle und der unverschuldet zu ertragenden Leiden - verbindet Kafkas Geschichte mit der Situation vieler Geflüchteter nach der Flucht. Der Limbus beschreibt die Zwischenräume des Ankommens, in denen sich Geflüchtete befinden sowie die immobilisierende Dynamik, die sich in der Auseinandersetzung mit den undurchsichtigen sozialen und rechtlichen Bedingungen vor dem Gesetz der Ankunftsgesellschaft entfaltet.

Im Nachfolgenden sollen die Praktiken der Immobilisierung in ihrer gesellschaftlichen Situierung und ihren psychischen Auswirkungen aus psychoanalytischer Perspektive verfolgt werden. Dabei wird versucht nachzuspüren, wo solche Praktiken potenziell auf soziale Figurationen und biographische Erfahrungen treffen und dadurch eine Eigendynamik entwickeln und nachwirken - oftmals lange nachdem die aufenthaltsrechtlichen Fragen geklärt sind. Die Empfindung von Immobilität, von Steckenbleiben, Nicht-weiter-kommen, der Bewegungsunfähigkeit und das Gefühl des ewigen Wartens werden seit langem mit psychischen Krankhei- 
ten assoziiert, insbesondere mit schwerer Depression oder Traumatisierung (vgl. Schmithüsen 2004). In der Forschung zu Flucht und Migration ist ein sequentielles Konzept formuliert worden, das ein Trauma nicht als einmaliges Ereignis, sondern als längeren psychischen Prozess unterschiedlicher Sequenzen charakterisiert (vgl. Zimmermann 2012; Becker 2006; Keilson 1979). Erst in ihrer Kumulation konstituieren sich vergangene belastende Erlebnisse zu jenem Trauma, das sie von da an immer gewesen sein werden. Die psychischen Dynamiken nach der Flucht - insbesondere die Anfangszeit am Ankunftsort und die Chronifizierung der Vorläufigkeit - werden durch ein Interview mit einem Geflüchteten und einer Fokusgruppe mit Mitarbeiter*innen in der institutionalisierten psychosozialen Geflüchtetenhilfe beschrieben. Dadurch werden ebenjene Praktiken der Immobilisierung beleuchtet, die Geflüchtete vor allem während ihrer Zeit in den Erstaufnahmeeinrichtungen erleiden müssen.

\section{Begleitforschung zur institutionalisierten Geflüchtetenhilfe und szenische Immobilisierung in der Forschungssituation ${ }^{1}$}

Im Rahmen des Forschungsprojekts Verlust, Trauma, Integration wurde unsere Arbeitsgruppe am Sigmund-Freud-Institut in Frankfurt a.M. Ende des Jahres 2018 vom Hessischen Ministerium für Soziales und Integration mit dem Auftrag betraut, die vier Zentren für psychosoziale Versorgung von Geflüchteten in Hessen wissenschaftlich zu begleiten. Auf Landesebene bilden diese vier Psychosozialen Zentren (PSZ) das Kernstück der institutionalisierten Geflüchtetenhilfe und bieten als erste Anlaufstelle u.a. (aufsuchende) Beratungen, Gruppenangebote und therapeutische Kriseninterventionen in den Erstaufnahmeeinrichtungen an (vgl. Witzel 2020; Leuzinger-Bohleber/Hettich 2018; Leuzinger-Bohleber et al. 2017).

Mittels einer Kombination von quantitativ-statistischen und qualitativ-hermeneutischen Methoden wurden sowohl die geflüchteten Klient*innen als auch die Mitarbeiter*innen der psychosozialen Zentren zu ihren persönlichen Geschichten, Belastungsmomenten, psychischen Symptomatiken, Unterstützungsbedarfen und Wirksamkeitstheorien der eigenen Praxis befragt. Das Forschungsdesign trägt damit der Vorstellung Rechnung, die Erstaufnahmeeinrichtungen im Verbund mit den psychosozialen Angeboten als Räume zu begreifen, in denen die Geflüchteten mit den dort tätigen Sozialarbeiter*innen, Psycholog*innen, Psychotherapeut*innen und Dolmetscher*innen das System Geflüchtetenhilfe entstehen lassen. Diese gemeinsame Inszenierung findet aber unter der Maßgabe gesellschaftlicher Verhältnisse, rechtlicher Bestimmungen und Praktiken der Immobilisierung statt, 
welche die psychosoziale Arbeit mit Geflüchteten und die damit verknüpften psychischen Dynamiken bis ins Innerste prägen. So naheliegend diese Doppelperspektive auf diese anderen Orte oder Heterotopien (Foucault 1967/1984) ist, so ungewöhnlich bleibt sie leider in der Forschungslandschaft zu Flucht und Migration.

Das Projekt ermöglichte den Forscher"innen einen unmittelbaren Einblick in die Lebens- und Arbeitssituation von Helfenden und Geflüchteten. So spiegelt sich der Komplex um Flucht und Hilfe, aber auch die Dialektik der Immobilisierung ${ }^{2}$, szenisch in der Begegnung mit den Bewohner"innen, in der Beziehung zwischen den Forscher*innen und den Teilnehmer*innen der Fragebogenerhebung und Interviewten, aber auch in den Strukturen der beteiligten Institutionen und Akteur*innen. Als Forschungsteam stießen wir auf Widerstände und Hinweise, dass der Zugang zu den jeweiligen Einrichtungen nicht möglich sei. Vorbehalte gegenüber den Forschungsaktivitäten äußerten sich auch vordergründig in der Sorge um die Geflüchteten, die - so die Annahme - durch die Befragung zu stark aufgewühlt werden könnten.

Weitere Hindernisse ergaben sich aus der geographischen Lage der Erstaufnahmeeinrichtungen. Auf dem Weg ins »Feld« musste das Forschungsteam mehrstündige Anfahrten mit einem PKW auf sich nehmen, während eine Anreise mit öffentlichen Verkehrsmitteln schlichtweg unmöglich gewesen wäre. Dies spiegelt das Verhältnis von Zentrum und Peripherie, das es für die Forschung, aber auch für viele der psychosozialen Fachkräfte und Ehrenamtlichen zu überwinden gilt. Als Erstaufnahmeeinrichtungen werden häufig im Staatsbesitz befindliche Liegenschaften, z.B. ehemalige Kasernen ${ }^{3}$, revitalisiert. Die so entstandenen Unterkünfte sind meist peripher gelegene Räume und haben diese Stellung historisch vor allem auch mit Psychiatrien gemein. Zudem entstand vor Ort der Eindruck einer hermetischen Institution durch teilweise mehrere Meter hohe Zäune. An den Sicherheitsschleusen angekommen, erwartete die Besucher*innen - trotz Voranmeldung - längeres Warten und funkendes Sicherheitspersonal. Es erfolgten die Aufforderung zum Vorzeigen der Ausweisdokumente sowie das Einsammeln und deren Austausch gegen Besucherausweise.

Nach dem Einlass war es Usus, dass das Forschungsteam begleitet durch Wachpersonal durch die Einrichtungen ging, um für die Teilnahme an der Erhebung

2 In dem vorliegenden Beitrag wird die These vertreten, dass es sich bei der Immobilisierung um ein Phänomen handelt, das sich in einem dialektischen Verhältnis zwischen äußerer und innerer Realität konstituiert. Demnach drängen (äußere) immobilisierende soziale Verhältnisse das Subjekt in eine Passivität hinein, die wiederum auf einen (inneren) psychischen Widerhall im Subjekt stoßen. Zudem beinhaltet die sozialarbeiterische oder therapeutische Beziehung immobilisierende Momente, die Ruhe, Reflexion und ein Zu-sich-selbst-Kommen erst ermöglichen. 
$\mathrm{zu}$ werben und die Menschen »abzuholen«. In manchen Einrichtungen durften Forscherinnen das sogenannte Männerhaus zum »eigenen Schutz«, wie es hieß, nicht betreten. In den Wohnanlagen klopfte das Sicherheitspersonal mit der ganzen Faust an die Zimmertüren und schloss - nur in seltenen Fällen auf eine Antwort wartend - direkt im Anschluss auf, um den Forscher*innen die Räumlichkeit $\mathrm{zu}$ »präsentieren«. Dieser Erstkontakt und das Eindringen in die Privatsphäre der Geflüchteten haben verständlicherweise Misstrauen hervorgerufen oder verstärkt und zumindest im Forschungsteam Assoziationen zu polizeilichen Abschiebe- oder Untersuchungspraktiken evoziert. Eine fotografische Dokumentation dieser Situation war strengstens verboten.

So beginnt sich bereits in der Forschungssituation die Wirkung immobilisierender Strukturen und Praktiken szenisch anzudeuten, deren Konturen und psychischen Niederschläge in den geführten Interviews dann hermeneutisch rekonstruiert werden konnten.

\section{"Weil ich ohne Hoffnung, ohne Sinn vor dem Auge, einfach nur existiere «. Psychische Dynamik der Immobilisierung bei einem Geflüchteten}

Unter den sozialen, politischen und rechtlichen Bedingungen der Ankunftsgesellschaft geraten Menschen, die aufgrund unzumutbarer Lebensumstände aus ihrer Heimat fliehen mussten, in einen Zustand der Passivität und des ewigen Wartens. Die Ankunft ist dementsprechend ambivalent. Dies zeigt sich anhand der Interviews: So berichten Geflüchtete davon, in Deutschland zwar ein Gefühl physischer Sicherheit zu erfahren - die häufig lebensnotwendigen Anstrengungen während der Flucht weichen zunehmend Momenten der Ruhe - doch wird auch deutlich, wie widersprüchlich die aktuelle Lebensrealität und wie kränkend der Wechsel von einem Zustand der Aktivität in die Passivität erlebt wird.

Um das (Er-)Leben von Geflüchteten unter derartigen Bedingungen in seinen psychodynamischen Dimensionen beleuchten zu können, soll im Folgenden die Fallvignette eines geflüchteten Mannes aus Eritrea vorgestellt werden.

Herr F. (Name anonymisiert) ist 29 Jahre alt und lebt seit fünf Jahren in Deutschland. Während des Interviews schildert er den langen, leidvollen Weg seiner Flucht. Obwohl Herr F. dabei einen routinierten Eindruck erweckt - vermutlich musste er von seiner Flucht schon diverse Male berichten - wird deutlich, wie kräftezehrend und einschneidend die Erlebnisse für ihn gewesen sein müssen. So beschreibt Herr F. unter anderem eine versuchte Zwangsrekrutierung durch das eritreische Militär und Foltersituationen, die er in Libyen erleiden musste. In diesen lebensbedrohlichen Situationen habe ihm die Hoffnung auf ein besseres Leben in Europa Kraft gegeben. Ihren Ausdruck findet diese Hoffnung 
in äußerst positiven Bildern von einer zukünftigen Heimat, in der Entwicklung und Frieden möglich erscheinen und in der Herr F. willkommen geheißen und nicht vertrieben wird - in anderen Worten, in denen er ein neues Zuhause findet. Tendenziell wurden diese Hoffnungsszenarien umso bedeutsamer und größer, je stärker sich die Belastungen und Entbehrungen während der Flucht psychisch niederschlugen. Europa und besonders Deutschland avancierten für Herrn F. zu hoffnungsspendenden Objekten, die es ihm während der Flucht nicht nur ermöglichten handlungsfähig zu bleiben, sondern angesichts traumatischer Erfahrungen auch eine strukturierende und haltgebende Funktion erfüllten. Um psychisch zu überleben, mussten die Erfahrungen von Verlust, Trennung und Verlassenheit während der Flucht zunächst aufgeschoben werden. Als innere Objekte halfen die Bilder von einem guten Leben in Europa Herrn F. dabei, die sonst überwältigende fluchtbedingte Angst, Hilflosigkeit und Ohnmacht zu ertragen. So erscheint sein Leiden nicht vergebens, den etlichen Entbehrungen auf der Flucht wird ein Sinn verliehen und seine Anstrengungen und Handlungen folgen einem Telos, der das Versprechen von Harmonie transportiert. In Teilen erinnerten Herrn F.s Erzählungen so an Narrative bürgerlicher Bildungsromane.

Schnell wird aber auch deutlich, dass es sich bei diesen hoffnungsspendenden Objekten um idealisierte Bilder handelt. Bedingt durch den Verlust bedeutungsvoller Bindungen, Orte und sozialer Strukturen sowie massiver Kränkungen und Gewalterfahrungen, die mit der Flucht einhergingen, wird ein Teil des angeschlagenen Selbst dadurch zu retten versucht, dass es einem idealisierten bzw. narzisstisch besetzten Objekt zugeschrieben wird, welches die Funktion einer »Prothesensicherheit (Fromm 1936: 179) erfüllt. Ihre stabilisierende und mobilisierende Funktion droht jedoch in dem Moment brüchig zu werden, in dem die Konfrontation mit der Realität für Geflüchtete in Europa eine zu große Kluft zu den inneren Bildern offenbart. Eindrücklich tritt diese Dynamik in folgender Passage des Interviews mit Herrn F. hervor:

»Also, ich bin nach Italien gekommen, also in Lampedusa. Ich habe aber einen Schock bekommen. Ich hab nicht so erwartet. Europa habe ich nicht so erwartet. Die haben uns in ein Container-Haus gebracht und in so einen kleinen Raum, mit elf Personen mussten wir da schlafen und dieser Container hat auch viele Löcher gehabt, wenn es geregnet hat, auch haben wir Wassertropfen abbekommen. [...] Das war kein gutes Leben. Ich habe anderes erwartet. [...] Ich habe/meine Erwartung war anderes, aber was ich in Europa gesehen habe - vor allem in Italien was ich gesehen habe, das war eine Katastrophe. Ich habe so viele Probleme gesehen, aber so wie in Italien, ich habe keine Worte mehr, um das zu beschreiben. Und dann nach einem Jahr in Italien, bin ich nach Deutschland gekommen. Die Lebensqualität in Deutschland ist viel, viel, viel besser. Und meine Situation hat sich auch geändert. (Interview mit Herrn F.) 
Deutlich wird, wie sich mit der Ankunft in Italien eine eklatante Entzauberung der einst gehegten Wünsche und Phantasien abzeichnet, die als so niederschmetternd erfahren wird, dass Herr F. sogar auf betäubende Substanzen zurückgreift, um den schmerzlichen »Schock« ertragen zu können. Vermutlich steht dieser Versuch, die Erfahrungen in Italien zu »vergessen«, auch im Zusammenhang mit einem Gefühl des Scheiterns und daraus resultierenden kränkenden Schamgefühlen. In den einst wunderbaren Bildern über Europa scheinen für Herrn F. viele - auch intime - Wünsche eines besseren Lebens und der persönlichen Entwicklung aufgehoben zu sein und in Erfüllung gehen zu können. Die realen Erfahrungen jedoch stellen einen so immensen Bruch dar, dass sie Kränkungen und Scham hervorrufen. Denn was er sich so intensiv gewünscht hat, rückt in unerreichbare Ferne. Es ist ebendiese Situation des Ankommens, die seine Vorstellungen von einem Leben in Europa brüchig werden lässt und damit nachträglich, in der Ankunftsgesellschaft, die destruktive Potenz der vergangenen Verlust- und Gewalterfahrungen zu entfesseln droht. Die Angst, sein hoffnungsspendendes Objekt zu verlieren und dieser Situation ohnmächtig ausgesetzt zu sein, bleibt auch für die Lebenssituation von Herrn F. in Deutschland kennzeichnend:

»Aber nur diese Angst, nach Italien wieder zurückzu/, weil ich Fingerabdruck in Italien habe. [...] Diese Angst, dass ich wieder nach Italien zurückgehe und auf der Straße lande. Diese Angst macht mich ständig verrückt. Und das ist mein großes Problem. Diese Angst begleitet mich jeden Tag, Tag und Nacht, dass ich zurück nach Italien gehe und wieder dieses Leben, was ich gesehen habe, zu erleben. Und ich bin fünf Jahre hier, das ist/ich bin immer noch/. Ich kann in keine Schule gehen, ich kann nicht arbeiten, weil ich keine Aufenthaltserlaubnis oder Arbeitserlaubnis habe. [...] Das ist meine große Sorge und Problem, dass ich keinen Kontakt mit Leuten habe. Ich habe immer Angst, wenn ich mich mit Leuten treffe, vor allem mit deutschen Leuten und die fragen oft: >Was machst du, wo arbeitest du? \& Und so. Und damit diese Fragen nicht kommen, geh ich immer weg. Und ich habe nicht so viel Kontakt mit Leuten, unter Leuten.« (Ebd.)

Auch wenn das Leben in Deutschland von Herrn F. als "viel, viel, viel besser« beschrieben wird, bleiben seine Hoffnungen auch hier bedroht, da das Risiko einer Abschiebung ${ }^{4}$ weiter besteht und die eigenmächtige Gestaltung seines Lebens verunmöglicht wird. Physisch ist Herr F. zwar angekommen, doch scheinen die sozialen, politischen und rechtlichen Bedingungen in Deutschland ihn psychisch weiter auf der Flucht zu halten. Der Psychoanalytiker und Migrationsforscher Salman Akhtar formulierte: »Sich nützlich und effektiv zu fühlen, bedeutet Lebendig-Sein; Band. 
das Gefühl der beruflichen Ohnmächtigkeit hingegen führt zu psychischem Absterben « (Akhtar 2014: 48). Das Erleben der Ohnmacht, Passivität und des Feststeckens in Deutschland scheint für Herrn F. etwas zu reaktualisieren, was er psychisch früher - vielleicht an dem Ort, den er zu verlassen gezwungen war oder auf der Flucht - erfahren musste. Die reale Immobilisierung regt Erinnerungen von Hilflosigkeit und Überwältigtwerden an. Die einst mobilisierende Wirkung des hoffnungsspendenden Objekts verkehrt sich auf diese Weise in ihr Gegenteil. Wo sich früher noch der Ausweg der Flucht bot, herrscht heute nur noch Leere. Dieser Zusammenhang von Hoffnungslosigkeit und Immobilisierung wird in folgender Interviewsequenz deutlich:

»Als Kind habe ich immer gesagt bekommen: Europäer [...] sind gute Menschen. Die helfen armen Leuten, die aus Afrika kommen. Diese Vorstellung war mit so vielen Hoffnungen verbunden, ein besseres Leben zu bekommen. Mit so Hoffnungen bin ich nach Deutschland gekommen. Jetzt bin ich fünf Jahre lang wie behindert in einem Raum. Ich kann nicht arbeiten, obwohl ich gesund bin, Lust und Motivation zu arbeiten habe. Ich kann nicht lernen, obwohl ich den Willen habe und ich kann nicht an eine Zukunft denken. Ich existiere nur. Sonst bin ich nicht am Leben. Ich existiere nur, ich atme. Ich lebe, aber das ist kein Leben. Ein Mann, der gesund ist, der einen Arbeitswillen hat und arbeiten kann und nicht darf. Ich habe mein Leben überhaupt nicht so erwartet. Ich bin ein gesunder Kerl, ein junger Kerl. Ich habe den Willen zu arbeiten, ich habe gesunde Arme und Füße. Jeden Monat kriege ich Celd vom Amt. Ich kriege Cash auf die Hand und jeder Mensch freut sich, wenn er Geld bekommt, aber ich freue mich nicht, wenn ich von einem Amt Celd in meine Hand bekomme. Ich freue mich überhaupt nicht. Wie geht das, dass ich das selber verdienen kann [...]? Das ist für meine Moral, für meinen Kopf nicht gut und macht mich wie behindert. [...] Das ist die größte Strafe, die man bekommen kann: Einfach zuhause zu sitzen. Ohne nix zu machen, Zeit zu verlieren.«(Interview mit Herrn F.)

Und auf die Frage, ob es in seinem persönlichen Leben irgendetwas gebe, das ihm helfe und das für ihn schön sei, antwortete er:

»Im Moment, keiner, nichts macht mich glücklich. [...] Innerliche Ruhe hab ich nicht. Ich habe eine schöne Jacke, T-Shirt, Hose, Schuhe. Kann ich kaufen von dem, was das Amt mir gibt. Ich kann auch essen, warmes Essen. Ein Dach habe ich auch über dem Kopf, aber innere Zufriedenheit hab ich nicht. Ich bin durch die Sahara gekommen vom Sudan nach Libyen - und die Sahara ist der gefährlichste Ort aber ich habe diese Angst nicht gehabt. Ich habe die ganze Nacht geschlafen. Aber was ich hier an schlaflosen Nächten verbringe, diese Angst begleitet mich jeden Tag. Es gibt manche Nächte, in denen ich überhaupt meine Augen nicht zu mache, es gibt viele Nächte. Zu leben ist für einen Mensch mehr als Essen und anderes, 
sondern Hoffnung. Wenn man keine Hoffnung hat, ist der Mensch verloren. Ohne Hoffnung zu leben, ist kein Leben. Was ist meine Hoffnung? Bleibe ich in Deutschland? Bleibe ich nicht? Was ist meine Zukunft? Gehe ich zurück oder bleibe ich? Ich bin Luft. Auf dem Mittelmeer [...], da habe ich die Hoffnung gehabt, Europa zu sehen und Freude habe ich gehabt, trotz diesem gefährlichen Meer, da kann man auch sterben. Aber mit dieser Hoffnung bin ich nach Europa gekommen, aber jetzt ist Deutschland für mich schlimmer als dieses Mittelmeer geworden, weil ich ohne Hoffnung, ohne Sinn vor dem Auge, einfach nur existiere.« (Ebd.)

Deutlich wird, dass die scheinbar unverdiente finanzielle Sicherheit bei gleichzeitiger Verunmöglichung, diese selbst »redlich« verdient zu haben, eine Dynamik in Gang setzt, die um das Erleben von Abhängigkeit und Scham kreist. So sei es die "größte Strafe, die man bekommen kann: Einfach zuhause zu sitzen. Ohne nix zu machen, Zeit zu verlieren«. Anstatt sich in Europa ein gutes Leben selbst verdienen $\mathrm{zu}$ können, wird er mit den Alimenten in die Position eines handlungsunfähigen Bedürftigen manövriert, die in ihm intensive Gefühle von Immobilisierung auslösen, welche er thematisiert, wenn er sich selbst als »behindert « beschreibt. Eigentlich will Herr F. etwas in Deutschland zum Wachsen bringen - so schildert er in seinem Interview seinen Wunsch, in Deutschland aus eigener Kraft einen Baum pflanzen zu können- gleichzeitig wird er aber daran gehindert, diesen Wunsch zu verfolgen. Deutschland erweist sich nicht nur als Objekt seiner Hoffnung, sondern auch als eine Instanz, die ihn zwar duldet, die ihm aber auch zu verstehen gibt, dass er nicht gebraucht wird, die ihn nicht als Mitglied anerkennt, sondern als »Flüchtling « festschreibt: einer Identität, der er nicht entrinnen kann. Deutlich wird auch, dass Herr F. an Verhältnissen leidet, die er nicht einsehen und die er nicht in einen sinnstiftenden Zusammenhang bringen kann. Stehen seine Entbehrungen auf der Flucht noch im Rahmen der Hoffnung eines guten Lebens in Europa, wird sein Leiden in Deutschland buchstäblich sinnlos. Seine Hoffnung schwindet und mit ihr jegliche, auch psychische Mobilität. Die erfahrene Festgefahrenheit in Deutschland erzeugt verständlicherweise Aggression, die sich in der Passage ebenfalls andeutet, wenn Herr F. Begriffe wie »Strafe« oder »behindert« gebraucht, um seine Situation zu beschreiben. Diese Aggression richtet sich jedoch nur zum Teil gegen das Objekt (Deutschland), von dem die Repression ausgeht. Denn von diesem Objekt ist Herr F. im lebensentscheidenden Maße abhängig. Die immobilisierenden Verhältnisse wirken daher nicht nur von außen auf ihn ein, vielmehr scheinen diese zusätzlich verinnerlicht zu werden.

Vor dem Hintergrund des Abhängigkeitsverhältnisses, in dem er zu Deutschland steht, kehrt Herr F. einen Teil der Aggression, die sich gegen das Objekt richten sollte, das ihn in seiner Entwicklung unterdrückt, gegen sich selbst, was seine prekäre psychische Situation umso auswegloser werden lässt. Der deutsche Staat als Objekt, das ihn zur Passivität verdammt, lediglich duldet und weitgehend hand- 
lungsunfähig macht, ist gleichzeitig auch die Instanz, an der er psychisch nach wie vor seine ganzen Hoffnungen knüpft und die er braucht, um am Leben zu bleiben. Aus einer psychoanalytischen Perspektive lässt sich diese Verinnerlichung auch als eine Introjektion des Angreifers beschreiben (vgl. Ferenczi 1933). Demnach unternimmt das Subjekt den Versuch, die Bedrohung einer endgültigen Abwendung des Primärobjekts zu verhindern, indem es sich mit dem Angreifer identifiziert, der als einzig verfügbares Objekt psychisch mit dem Primärobjekt verwechselt wird (vgl. Ehlert-Balzer 1996: 299). Entscheidend ist, dass der äußere Aggressor erst durch die Introjektion unmittelbaren Anschluss an die unbewussten Phantasien und Wünsche des Opfers erhält, was dem Ich die Unterscheidung von Außen und Innen, von eigenen und fremden Anteilen erschwert oder gar verunmöglicht (vgl. ebd.). In dieser Situation lähmen Herr F. daher auch eigene Anteile, die ihn eigentlich zur Aktivität antreiben könnten, aber mit zu großer Angst besetzt sind, als dass er sie für sich nutzen könnte.

Der Fall von Herrn F. zeigt, wie komplex das Erleben von Immobilisierung mit eigenen Anteilen, Selbstbildern, (frühen) traumatischen Erfahrungen von Verlust und Zurückweisung, aber auch mit den strukturellen rechtlichen und politischen Bedingungen in der Ankunftsgesellschaft verschränkt ist. Dabei deuten die Schilderungen zur Forschungssituation bereits an, dass auch die Mitarbeitenden der Geflüchtetenhilfe unter Strukturen arbeiten, die die Versorgung von Geflüchteten erschweren. Die Frage, wie sich die Arbeit mit Menschen gestaltet, die derart von Immobilisierung betroffen sind und wie sich diese Situation auf die eigene Rolle und das Erleben der »Helfer*innen« auswirkt, soll im nächsten Abschnitt des Artikels beleuchtet werden.

\section{"Wenn das Existenzielle nicht geklärt ist ". Fokusgruppe mit Mitarbeiter*innen der Geflüchtetenhilfe}

Im Rahmen der Begleitforschung wurden mit den Belegschaften der psychosozialen Zentren u.a. Fokusgruppen (vgl. Lamnek 2005; Loos/Schäfer 2001) durchgeführt. In diesen wurden die Mitarbeitenden - hauptsächlich Sozialarbeiter*innen und Psycholog*innen, aber auch Verwaltungsangestellte und Dolmetscher*innen zunächst gebeten, zu einer Falldarstellung aus der Geflüchtetenhilfe als Diskussionsimpuls Stellung zu nehmen. Die Gruppen wurden von zwei Forschenden geleitet, deren Fragen und Interventionen darauf zielten, Narrationen anzuregen und einen offenen Austausch unter den Teilnehmer*innen zu ermöglichen. Die Diskussionen kreisten u.a. um ihre Beweggründe in der Geflüchtetenhilfe zu arbeiten, ihr Erleben des Arbeitsfeldes, ihre Handlungskonzepte sowie ihre Belastungen und Unterstützungsbedarfe. 
In der nachfolgenden Passage werden Ausschnitte aus einer eineinhalbstündigen Fokusgruppe mit zwei Sozialarbeiter*innen, zwei Psycholog*innen und einer Verwaltungskraft präsentiert. Die erste Passage setzt unmittelbar nach dem Diskussionsimpuls ein, der eine kurze Erzählung einer Mitarbeiterin aufnimmt, in der sie Schwierigkeiten ihrer Arbeit in einer Erstaufnahmeeinrichtung schildert. Ebenjene Schwierigkeiten greifen die Diskussionsteilnehmer*innen auf:

A: »]a, und auch dass viele Geflüchtete hier nicht so viel zu tun haben, auf ihren Zimmern sitzen und nicht so richtig was machen, das erleben wir ständig. [...] Wir haben auch viel mit Leuten zu tun, die Negativbescheide bekommen und dann Duldungen haben, die über einen kurzen Zeitraum verlängert werden, die keine Arbeitserlaubnis haben und dann über Jahre hinweg nicht arbeiten und nichts zu tun haben und in ein totales Loch fallen. [...]«

B: »]a, weil die Menschen in ihren Heimatländern Berufe hatten, versucht man das in den Erstaufnahmen eigentlich zu integrieren, aber da werden von gesetzlicher Seite ganz viele Hindernisse gelegt. Ich erinnere mich an einen Fall, wo sie einen Menschen hatten, der Friseur war und eigentlich wollten sie das gerne einrichten. Erst ging es wegen Hygienebestimmungen nicht, dann war der Sicherheitsaspekt da. Also dass es mit Scheren gefährlich wäre. Sie waren gewillt und wollten auch die eigene Handlungsautonomie fördern, aber es geht halt nicht, weil das Gesetz ganz viele Punkte findet, warum es eben nicht möglich ist. Und das löst einfach eine Frustration aus. [...]«

C: »Ich habe das Cefühl, dass viele sich auch wirklich beschäftigen wollen und dann ausgebremst werden und man muss irgendwie eine Lösung finden, wie die sich trotzdem beschäftigen. Aber dafür dann die Motivation finden. Wenn man denen sagt: 〉]a, gehen Sie doch spazieren. < Das klingt irgendwie schön, aber wie, wenn man an allen anderen Stellen so ausgebremst wird? Das ist ein unglaublich kleiner Spielraum, den man da hat."

A: »Und dann rüberzubringen, dass die Leute wieder Hoffnung haben, das finde ich gar nicht so leicht. Besonders, wenn sie einen Negativbescheid haben und gar nicht wissen, wie lang sie überhaupt hierbleiben können. Dann in ständiger Angst leben, dass sie wieder zurückmüssen und dazu nicht arbeiten können. Da ist es nicht einfach was zu finden, dass die wieder Hoffnung haben oder stabil werden, weil die Rahmenbedingungen dafür gar nicht gegeben sind."

B: »Da sind die Probleme von außen teils einfach so groß, dass die Person sich gar nicht fokussieren kann und sagen >Okay, ich kann mich jetzt hinsetzen, hab den Kopf wirklich auch FREI, beispielsweise eine andere Sprache zu lernen.« C: »Das sind existenzielle Fragen, worum es dann geht und ich kann das extrem gut nachvollziehen: Wenn das Existenzielle nicht geklärt ist, dann lerne ich keine Sprache.« (Fokusgruppe 1) 
Die Teilnehmer*innen beginnen ihre Diskussion mit reger Zustimmung. Sie schildern ihr Erleben, dass Geflüchtete häufig »nicht so richtig was machen« und führen dies allmählich auf strukturelle Bedingungen zurück: Negativbescheide, kurze Duldungen und das Fehlen einer Arbeitserlaubnis. Gleichzeitig wird diese Logik zunächst nicht hinterfragt. Sie akzeptieren die Begründung, es handele sich um feststehende gesetzliche Hindernisse, Hygienebestimmungen und Sicherheitsaspekte oder, wie eine Teilnehmerin es ausdrückt: »es geht halt nicht, weil das Gesetz dann ganz viele Punkte findet, warum es eben nicht möglich ist «. Dabei tritt eine deutliche Distanz zu den benannten strukturellen Bedingungen hervor, in der die Logik des Rechts als scheinbar unveränderliche, Zweite Natur erscheint. Die Geflüchteten nehmen sie dadurch wiederholt als "ausgebremst « wahr, verweilen aber auch hier in einer Distanz (»die«). Gleichzeitig beginnt das Nachdenken darüber, wie solche Bedingungen auch einschränkend auf die eigene helfende Praxis wirken. Es sei schwierig, unter diesen Bedingungen motivierend zu sein, eine Lösung zu finden, Hoffnung zu spenden oder die Geflüchteten »trotzdem [zu] beschäftigen«. Es sei ein »unglaublich kleiner Spielraum«, in dem »ganz einfache Sachen [...] nicht so richtig möglich «sind. Eine der Teilnehmerinnen resümiert in diesem Kontext die tragische Position der psychosozialen Betreuung angesichts der immobilen Situation der Geflüchteten: »)Ja, gehen Sie doch spazieren.< Das klingt irgendwie schön, aber wie, wenn man an allen anderen Stellen irgendwie so ausgebremst wird?« Die »Rahmenbedingungen « und Probleme »von außen« erschwerten, laut den Teilnehmer*innen, die Fähigkeit »wieder Hoffnung [zu] haben oder stabil [zu] werden«. Dies verhindere so mittelbar auch die Integration, denn: »Wenn das Existenzielle nicht geklärt ist, dann lerne ich keine Sprache.« In diesem letzten Abschnitt tritt der Wechsel in die Ich-Perspektive und damit eine erste Identifikation mit den Problemen der Geflüchteten eindrücklich hervor.

Im weiteren Verlauf der Diskussion kommen die Teilnehmer*innen auf ihren Umgang mit den Klient*innen zu sprechen sowie das Thema Abgrenzung und Frustrationen im Beratungsprozess. Ungefähr zehn Minuten später wendet eine Teilnehmerin das Gespräch in eine neue Richtung:

B: »Und man harkt halt auch an gesetzlichen Bestimmungen. [...] Einen Fall habe ich im Kopf von Dir, der vier Jahre in Deutschland ist und alle zwei Wochen seine Duldung verlängern muss. Wo man denkt, wie kann das sein, dass ein Land es nicht auf die Reihe bekommt, sich endlich zu entscheiden? Möchte ich diese Person hier halten oder muss sie halt gehen? Also das ist ein Umgang mit einem Menschen, der absolut unangebracht ist."

A: »Und der hat sich auch Jobangebote gesucht und das wurde abgelehnt, dass er die annehmen kann. Also ihm werden da auch wirklich aktiv-«

B: »Steine in den Weg gelegt. Ich meine, er kann sich nichts suchen. [...] Und dadurch schafft man natürlich von außen eine Grundlage. Wie soll es einem Men- 
schen da gut gehen? Wenn er alle zwei Wochen um seine Existenz bangen muss und nicht weiß, wie es weitergeht?«

$\mathrm{C}$ : $M \mathrm{Mmh}$, ja und wie ist dann meine Rolle als Helfer da? Also das ist eine unglaublich schwierige Rolle, finde ich.«

A: »Wir hatten da mal mit einem [Supervisor] gesprochen. Da fand ich das Bild ganz schön, dass wir uns als Begleiter sehen. Also dass man nicht die ganze Situation ändern kann, aber dass man die Geflüchteten ein Stück weit auf dem Weg begleiten kann. Und sei es jetzt irgendwie Sterbebegleitung im schlimmsten Fall. [...] Weil wir hatten auch schon Fälle, die wurden halt einfach nach Italien abgeschoben. [...] Und wir wissen, wie das ausgehen wird, wenn die nach Italien zurückmüssen. Aber das Bild, dass man begleitet, das entlastet mich auch. Also das finde ich ganz schön.«

C: »]a, das stimmt, das Begleiten, das beschreibt es echt ganz gut. Also, dass wir eben nichts an der Situation ändern können, sondern dass wir mit demjenigen irgendwie versuchen das durchzustehen. Dass wir dem einen Ort geben, wo er sich darüber auslassen kann, wo er darüber weinen kann und irgendwie seinen Schmerz ausdrücken kann, wo er aber ein Stück weit Würde zumindest zurückbekommt oder wir ihm zumindest zeigen können, dass wir ihn als Mensch wahrnehmen - nicht nur als Fall.« (Fokusgruppe 1)

Eine Diskussionsteilnehmerin beschreibt, wie schwer die psychosoziale Arbeit mit Geflüchteten unter den Bedingungen einer unsicheren Bleibeperspektive sei. Sie nimmt Bezug auf einen Fall ihrer anwesenden Kollegin, dem »Steine in den Weg gelegt « und dessen verzweifelte Versuche anzukommen und eine Arbeit zu finden, damit verunmöglicht wurden. Daraufhin kommt sie erneut auf das in der vorherigen Passage aufgerufene Bild jener Grundlage »von außen« zu sprechen und fragt sich: »Wie soll es einem Menschen da gut gehen? Wenn er alle zwei Wochen um seine Existenz bangen muss [...].« Eine dritte Teilnehmerin, die vorher nur kurz zustimmend interveniert hatte, ergreift daraufhin das Wort und bezieht die Frage auf ihre Rolle als Helfende, um gleich in einem Halbsatz hinterherzuschieben, dass sie diese auch »unglaublich schwierig« fände. Der Einwand löst wiederum eine Erinnerung an ein Gespräch mit einem Supervisor aus. Dabei hätten sie ein Bild für sich gefunden, das sie »schön« fände und ihre Rolle gut beschreibe: das des »Begleiters«. Die Teilnehmerin präzisiert daraufhin diese Rolle eben nicht als eine, die die »Situation ändern«, aber »ein Stück weit auf dem Weg« mitgehen könne und kommt unvermittelt zu dem Punkt, dass dies ja »irgendwie Sterbebegleitung« sei. Daraufhin erzählen sie in wechselnden Rollen von kurzfristigen Abschiebungen, den sich daraus ergebenden Beziehungsabbrüchen und eine Sprecherin mutmaßt: "wir wissen, wie das ausgehen wird«. In dieser Szene entsteht ein irritierendes Missverhältnis zwischen dem bedrückenden Bild der Sterbebegleitung, dessen Implikationen - dass man es bei Geflüchteten eigentlich mit hoffnungslosen Fällen 
zu tun habe - und der wiederholten Betonung der Schönheit des Bildes. Dabei kulminiert die Tragik der Unmöglichkeit psychosozialer Geflüchtetenhilfe unter den herrschenden gesellschaftlichen Bedingungen, in dem hilflosen Versuch dies in ein eigenes Rollenverständnis zu integrieren, der in seiner Resignation Bände spricht. Gleichzeitig wird dieses tiefe Tal von einer anderen Diskussionsteilnehmerin in einem weiteren Bild aufgehoben, indem sie eben die psychosoziale Praxis als einen »Ort« beschreibt. Einen Ort, der es trotz struktureller Immobilisierung erlaubt, sich psychisch ins Verhältnis zu setzen, die Klient*innen »als Mensch [...] - nicht nur als Fall« wahrzunehmen.

Das weitere Gespräch handelt auf der manifesten Ebene von Kostenübernahmen für Dolmetscher*innen, der Finanzierung von Therapien, den hohen Erwartungen an ihre Arbeit, dem öffentlichen Druck, Schwierigkeiten in der Therapiesituation, welche Entfernungen in der Arbeit zurückzulegen sind und mit welchen Belastungen sie hinsichtlich Kapazitäten und Zeitmanagement zu kämpfen haben. An dieser Stelle beginnt eine Diskussionsteilnehmerin diesen Rahmen mit ihrer eigenen Arbeits- und Vertragsbedingungen in Verbindung zu bringen und eröffnet damit eine Parallele zur Situation der Geflüchteten, die in der unsicheren Situation darüber besteht, »wie es überhaupt weitergeht « (Fokusgruppe 1). Die Sprecherin stellt sich die Frage $»[\ldots$... $]$ ringe ich mich jetzt wirklich voll rein oder ist das doch verschwendete Energie? (ebd.) und schließt damit gedanklich an die - eine halbe Stunde vorher über die Geflüchteten getätigte - Beschreibung an: »Wenn das Existenzielle nicht geklärt ist, dann lerne ich keine Sprache.« (Ebd.) Für die Diskutant*innen konstituiert sich die Unsicherheit aus dem Umstand, dass ihr ohnehin kurzer Vertrag bald auslaufe und sie bisher nicht wüssten, ob sie in wenigen Wochen überhaupt noch weiter angestellt seien. Die Immobilisierung der in der Geflüchtetenhilfe Tätigen vollzieht sich dabei mindestens auf doppeltem Wege: Einerseits müssen durch rechtliche Beschränkungen der Geflüchteten deutliche Einschränkungen der psychosozialen Beratungspraxis hingenommen werden, bis hin zur ständigen Bedrohung der therapeutischen oder beraterischen Beziehung durch Transfer oder Abschiebung. Gleichzeitig sind die Arbeits- und Vertragsbedingungen im Feld der Geflüchtetenhilfe derart prekär, dass eine Situation zu entstehen scheint, die im Erleben der Mitarbeitenden eine Ähnlichkeit zur existentiellen Bedrohung der Geflüchteten herstellt. Diese auf der Ebene des Erlebens rekonstruierbare Parallelität zwischen der Situation der Mitarbeitenden und der ihrer Klient"innen ist für die psychosoziale Arbeit mit Geflüchteten deswegen von hoher Bedeutung, weil sie die für projektive Mechanismen notwendige assoziative Ähnlichkeit beider Seiten konstituiert. So fällt es schwerer, zwischen eigenen Anteilen und den Bedürfnissen und Belastungen des Gegenübers zu unterscheiden sowie ein produktives Verhältnis von Nähe und Distanz gegenüber den Klient"innen aufzubauen, welches unabdingbar ist, um die Affekte in der gemeinsamen (Trauer-)Arbeit halten zu können. Um dennoch in dieser prekären Situation 
die psychosoziale Versorgung von Geflüchteten gewährleisten zu können, scheint ein reflektiertes berufliches Rollenverständnis unerlässlich, welches um die eigenen Belastungen und Grenzen weiß und diese in die eigene professionelle Rolle zu integrieren vermag. Die Auseinandersetzung mit psychoanalytischen Konzepten könnte hier einen wertvollen Beitrag leisten und die Erkenntnis der eigenen Position erleichtern. Es sind gerade diese Formen der Selbstreflexion und -erfahrung, die die Bedingung der Möglichkeit schaffen, individuelles Leid in allgemeines Unrecht zu verwandeln und damit auch die bescheidene Aufgabe umreißen, die Freud der Psychoanalyse zuwies (vgl. Freud 1985).

\section{Immobilisierung, Trauma, Warten, Hoffnung: einige weiterführende Gedanken}

In Kafkas Parabel Vor dem Gesetz (1915/1976) harrte der Mann, dem der Zutritt zum Gesetz untersagt wurde, in der Hoffnung, doch noch Einlass zu erhalten, im limbischen Vorraum aus. Kurz vor seinem Tod fragt er den Türhüter, warum niemand außer ihm jemals Einlass verlangt habe. Der Türhüter antwortet: »Hier konnte niemand sonst Einlaß erhalten, denn dieser Eingang war nur für dich bestimmt. Ich gehe jetzt und schließe ihn.« (ebd.: 121)

Mit diesem rätselhaften Ende der Erzählung beschreibt Kafka am Ende das Tor und den Türhüter als eine individuelle Wunde. Nicht umsonst verwies Theodor W. Adorno in seinen Aufzeichnungen zu Kafka (1953/1977) auf dessen tiefe Verwandtschaft mit Freud. Im Unterschied zu jenem, suche Kafka jedoch nicht die Neurose zu heilen, sondern ihr Erkenntnis abzuringen: »[D]ie Wunden, welche die Gesellschaft den Einzelnen einbrennt, werden von diesem [Franz Kafka] als Chiffren der gesellschaftlichen Unwahrheit, als Negativ der Wahrheit gelesen.« (Ebd.: 262)

Hier entspringt unser Fokus auf die individuellen psychischen Dynamiken, das Leid, die Gefühle von Stillstand, Feststecken im Limbus und Gefangensein sowie unser Interesse, in diesen Dynamiken die gesellschaftlichen Bedingungen und die Praktiken der Immobilisierung zu untersuchen.

Situationen, in denen - wie in Erstaufnahmeeinrichtungen - Immobilisierung erfahren wird, können auch deswegen psychisch so destruktiv wirksam werden, weil sie auf ontogenetisch, d.h. in der Entwicklung des Individuums, frühe Erfahrungen von Abhängigkeit und des Warten-Müssens rekurrieren. So beschreiben Geflüchtete nach dem Ankommen in Europa häufig »quälende zukunfts- und bewegungslose Stillstandsgefühle« (Gutwinski-Jeggle 1992: 191), die einerseits auf ihrer realen rechtlichen Lage beruhen, psychisch aber auch bei depressiven und Traumafolgeerkrankungen virulent werden können. Dieses Immobilisierungserleben wird häufig in einer raumzeitlichen Bildersprache des ewigen Wartens, des Stillstands, oder Festgehalten-Werdens gefasst. Das primäre Raum- und Zeiterle- 
ben wird nicht zufällig in frühen Phasen der menschlichen Entwicklung erlernt, nämlich dann, wenn der Säugling in absoluter Abhängigkeit zu seiner nächsten Bezugsperson steht (vgl. ebd.: 187f.). Die erste erlebte Zeit ist eine Dauer und ein Abstand, der gap zwischen Bedürfnis und Befriedigung (vgl. Chasseguet-Smirgel 1989), und durch die Immobilisierung des Säuglings bzw. seine Abhängigkeit zum Primärobjekt sowie das Unvermögen eigene Bedürfnisse selbsttätig befriedigen zu können bedingt. Ist die Erfahrung der Bedürfnisbefriedigung verlässlich, entsteht das sogenannte Urvertrauen. Dieses Urvertrauen bildet die Basis für die »Hoffnung auf eine neuerliche Befriedigung« (Gutwinski-Jeggle 1992: 188).

Nach schweren traumatischen Erfahrungen kommt es hingegen $\mathrm{zu}$ einem Verlust des »Weltvertrauens«, wie Jean Améry eindrücklich beschrieb (vgl. Améry 1977). ${ }^{5}$ Diese Formulierung trifft sehr genau, wie ein bestimmtes Verhältnis zur Welt zu Bruch geht, indem in einer Phase völliger Ohnmacht und Abhängigkeit das Gegenüber zum Folterer, Verfolger und Mörder wird und keine Hilfe erfolgt. Traumatische Erfahrungen rütteln an erlernten basalen Beziehungen, sie ziehen das Fundament des kindlichen Urvertrauens in Zweifel. Diese Wunden reichen teilweise so tief, dass sie das Raum- und Zeiterleben selbst beeinflussen. ${ }^{6}$ Dieser Zusammenhang wurde zunächst in Pionierarbeiten mit Überlebenden der Shoah beschrieben (vgl. bspw. Niederland 1968, 1961; Hoppe 1962; Niederland 1961). Schwer traumatisierte Patient*innen weisen häufig eine tiefgreifende Erosion der Raum-, Zeit- und Erinnerungsstruktur auf, berichten von einem eingefrorenen Zeitgefühl, dem Gefühl des ewigen Wartens, des Stillstands, dass ihre innere Uhr mit dem Datum der Traumatisierung stehen geblieben sei, dem Leben in einer anderen Zeit. Dieser Verlust betrifft das Gefühl für die individuelle Entwicklung und Lebenszeit, insbesondere die eigene Zukunft (vgl. Bohleber 2017; Grubrich-Simitis 1979). Erzählungen, die wir aus der Arbeit mit Geflüchteten und ihrer Situation nach der Ankunft in Europa und Deutschland kennen, offenbaren eine drastische Ähnlichkeit zu ebenjenen Erlebnisweisen mit Extremtraumatisierten.

Im vorliegenden Aufsatz wurden anhand von Erfahrungen aus einem Forschungsprojekt zur psychosozialen Betreuung von Geflüchteten die Praktiken der Immobilisierung und ihre psychischen Auswirkungen untersucht. Migration und Flucht sind psychosoziale Prozesse, die mit der Hoffnung auf ein besseres Leben verbunden sind. Gleichzeitig aber bedeutet Flucht die Erfahrung von Trennung, Verlust und Gewalt. Diese Erfahrungen enden nicht mit der Ankunft in der aufnehmenden Gesellschaft. Im Gegenteil, oftmals werden Hoffnungen wie bei Herrn F. - bitter enttäuscht, und der rastlosen Aktivität auf der Flucht

5 Für diesen lehrreichen Hinweis sind wir Kurt Grünberg zu Dank verpflichtet.

6 Gutwinski-Jeggle (1992) beschreibt wie sehr frühe Deprivationstraumata das Zeiterleben von Anfang an beeinflussen können und so zu sehr tiefen Störungen führen können. 
folgt eine Situation der Ohnmacht, des zeit- und sinnlosen Wartens, die zu schwerwiegenden psychischen Belastungen führen kann.

In einer Gruppendiskussion mit Sozialarbeiter*innen, Psycholog*innen und Therapeut"innen erhielten wir Einblicke in die Reflexions- und Identifikationsprozesse von in der Geflüchtetenhilfe Tätigen. Diese erfahren ähnliche (innere) Konflikte der Immobilisierung, wie ebenjene Klient*innen, die sie in ihrer Arbeit begleiten und beraten. Im Falle der psychosozialen Mitarbeiter*innen entfaltet sich dieser Immobilisierungskonflikt zwischen einer Logik des Rechts und einer Logik des Helfens, die sich gegenseitig auszuschließen scheinen. Darüber hinaus bieten die unsicheren Arbeitsbedingungen und der begrenzte Handlungsspielraum Anlass für teils problematische Identifikationsprozesse.

Zum Ende wollen wir auf die Metapher des Ortes aus der Fokusgruppe zurückkommen und damit auf die Kehrseite des Stillstands. Eine Mitarbeiterin in der Geflüchtetenhilfe beschrieb die psychosoziale Betreuung als einen Ort des Rückzugs, einen Ort sich zu öffnen und den eigenen Schmerz zuzulassen, um der Trauer und dadurch auch der Würde Raum zu geben. Dieser Ort der psychosozialen Arbeit ermöglicht das Innehalten und damit ein grundsätzlich anderes Element der Immobilisierung: Dieses temporäre Anhalten der ständigen Bewegung und des ständigen Weitergetrieben-Werdens findet in gelungener psychosozialer Betreuung statt. Damit schafft das sich widersetzende Moment der Ruhe einen Raum des Aufhorchens, des Zuhörens und bildet den möglichen Ausgangspunkt für Reflexion.

\section{Literaturverzeichnis}

Adorno, Theodor W. (1953/1977): »Aufzeichnungen zu Kafka«, in: Rolf Tiedemann (Hg.), Adorno: Gesammelte Schriften Band 10.1. Kulturkritik und Gesellschaft I. Prismen. Ohne Leitbild, Frankfurt: Suhrkamp, S. 254-287.

Akhtar, Salman (2014): Immigration und Identität. Psychosoziale Aspekte und kulturübergreifende Therapie, Gießen: Psychosozial-Verlag.

Améry, Jean (1977): Jenseits von Schuld und Sühne: Bewältigungsversuche eines Überwältigten, Stuttgart: Klett-Cotta.

Arnold, Simon/Jensen, Andreas/Kuhn, Magdalena/Zokai, Rana/Lohl, Jan (2020): »Affektive Anteile. Die Szene als psychoanalytischer Beitrag zu einer kritischen Migrationsforschung ", in: Psychologie \& Gesellschaftskritik 44(2), S. 5-32.

Becker, David (2006): Die Erfindung des Traumas - Verfochtene Geschichten, Gießen: Psychosozial-Verlag.

Bohleber, Werner (2017): »Die Entwicklung der Traumatheorie in der Psychoanalyse«, in: Marianne Leuzinger-Bohleber/Ulrich Bahrke/Tamara Fischmann/Simon Arnold/Stephan Hau (Hg.), Flucht, Migration und Trauma. Die Folgen für die nächste Generation, Göttingen: Vandenhoeck \& Ruprecht, S. 25-86. 
Chasseguet-Smirgel, Janine (1989): »Reflexions on some Thought Disorders in non-Psychotic Patients. Certain Disturbances of Thinking in Individuals and Groups «, in: The Scandinavian Psychoanalytical Review 12(1), S. 5-21.

Ehlert-Balzar, Martin (1996): Das Trauma als Objektbeziehung. Veränderung der inneren Objektwelt durch schwere Traumatisierung im Erwachsenenalter, in: Forum der Psychoanalyse 12, S. 291-314.

Ferenczi, Sandor (1933): »Sprachverwirrung zwischen den Erwachsenen und dem Kind. Die Sprache der Zärtlichkeit und der Leidenschaft«, in: Sandor Ferenczi (Hg.), Bausteine der Psychoanalyse Band 3, Frankfurt a.M.: Ullstein, S. 511-525. Freud, Sigmund (1985): »Zur Psychotherapie der Hysterie«, in: GW I, S. 75-312.

Fromm, Erich (1936): Studien über Autorität und Familie. Sozialpsychologischer Teil, in: Erich Fromm (Hg.), Gesamtausgabe Band 1, Stuttgart: Deutsche Verlagsanstalt, S. 139-187.

Foucault, Michel (1967/1984): »Des espaces autres«, in: Michel Foucault (Hg.), Dits et écrits II. 1976-1988, Paris: Gallimard, S. 1571-1581.

Grubrich-Simitis, Ilse (1979): »Extremtraumatisierung als kumulatives Trauma: Psychoanalytische Studien über seelische Nachwirkungen der Konzentrationslagerhaft bei Überlebenden und ihren Kindern«, in: Psyche 33(11), S. 991-1023.

Gutwinski-Jeggle, Jutta (1992): »Trauma und Zeiterleben«, in: Jahrbuch der Psychoanalyse 29 , S. 167-214.

Hoppe, Klaus D. (1962): »Verfolgung, Aggression und Depression«, in: Psyche 16(9), S. 521-537.

Kafka, Franz (1915/1976): »Vor dem Gesetz«, in: Max Brod (Hg.), Franz Kafka. Gesammelte Werke, Band IV Erzählungen, Frankfurt a.M.: Fischer, S. 120-121.

Keilson, Hans (1979): Sequentielle Traumatisierung bei Kindern. Deskriptiv-klinische und quantifizierend-statistische follow-up Untersuchung zum Schicksal der jüdischen Kriegswaisen in den Niederlanden, Stuttgart: Enke.

Lamnek, Siegfried (2005): Gruppendiskussion. Theorie und Praxis (2. Aufl.), Weinheim/Basel: Beltz.

Leuzinger-Bohleber, Marianne/Bahrke, Ulrich/Fischmann, Tamara/Arnold, Simon/Hau, Stephan (Hg.) (2017): Flucht, Migration und Trauma: Die Folgen für die nächste Generation, Göttingen: Vandenhoeck \& Ruprecht.

Leuzinger-Bohleber, Marianne/Hettich, Nora (Hg.) (2018): >Fremd bin ich eingezogen.... STEP-BY-STEP: Ein Pilotprojekt zur Unterstützung von Geflüchteten in einer Erstaufnahmeeinrichtung, Gießen: Psychosozial-Verlag.

Loos, Peter/Schäffer, Burkhard (2001): Das Gruppendiskussionsverfahren. Theoretische Grundlagen und empirische Anwendung, Opladen: Leske und Budrich.

Niederland, William G. (1961): »The Problem of the Survivor. Part I: Some Remarks on the Psychiatric Evaluation of Emotional Disorders in Survivors of Nazi Persecution«, in: Henry Krystal (Hg.), Massive Psychic Trauma, New York: International Universities Press, 1968, S. 8-22. 
Niederland, William G. (1968): „Clinical Observations on the 'Survivor Syndrome«", in: The International Journal of Psychoanalysis 49(2-3), S. 313-315.

Schmithüsen, Gerd (2004): ")Die Zeit steht still in rasender Eileく. Eine psychoanalytische Einzelfallstudie zu frühem Trauma und Zeiterleben«, in: Psyche 58, S. 293-320.

Witzel, Hauke (2020): »Neues zur saufsuchenden Psychoanalyseく mit Geflüchteten - Das Sigmund-Freud-Institut im Psychosozialen Verbund Rhein-Main«, in: Andreas Schulz/Tamara Schwertel (Hg.), Langer Sommer der Flucht. Fünf Jahre danach. Diskurse, Reflexionen, Perspektiven, Opladen: Barbara Budrich, S. 261-280.

Zimmermann, David (2012): Migration und Trauma. Pädagogisches Verstehen und Handeln in der Arbeit mit jungen Flüchtlingen, Gießen: Psychosozial-Verlag.

\section{Interviews}

Interview mit Herrn F. am 20.11.2018, Dauer: 00:49:06.

Fokusgruppe 1 mit Mitarbeiter*innen der Psychosozialen Zentren für Geflüchtete in Hessen am 05.11.2018, Dauer: 01:37:17. 



\title{
Perspektiven von Refugees auf Alltag und Widerständigkeit in Aufnahmeeinrichtungen Annäherungen an ein Dispositiv der Lager II
}

Simon Goebel

\begin{abstract}
Zusammenfassung
Dieser Beitrag stellt die Perspektiven von fünf Refugees ins Zentrum, die Erfahrungen mit dem Leben in Lagern gemacht haben. Im Versuch, ihre Stimmen hörbar zu machen, unterstützt er ihre Kämpfe für bessere Lebensbedingungen und gegen das repressive Asylregime. Die Auseinandersetzung erfolgt entlang der von den Refugees als besonders bedeutsam hervorgehobenen Alltagsbezüge wie Ernährung, Gesundheit, Rechte und Angst vor Abschiebungen. Die widerständigen Praktiken bzw. Agency der Refugees wurden analytisch in drei Ebenen unterteilt. So wurden Praktiken auf einer individuellen Ebene sichtbar, auf einer gemeinschaftlichen Ebene innerhalb der Lagergrenzen, sowie auf einer gemeinschaftlichen Ebene, die über die Lagergrenzen hinausweist. Im Kontext der letztgenannten Ebene werden u.a. öffentliche Artikulationen und Auseinandersetzungen mit Medienvertreter*innen diskutiert. Deutlich wurde, dass die durch das Lager intendierte Immobilität von Refugees in vielfältiger Weise durch Selbstmobilisierungen konterkariert wird. Das Lager wird zu einem Schauplatz der Kämpfe der Migration um Rechte, um Anerkennung, um Würde sowie gegen Rassismus und Entmenschlichung.
\end{abstract}

\section{Summary}

This article focuses on the perspectives of five refugees who have experienced life in camps. In an attempt to make their voices heard, it supports their struggles for better living conditions and against the repressive asylum regime. The debate takes place around the references to everyday life that have been highlighted by the refugees as being particularly significant, such as nutrition, health, rights and fear of deportation. The refugees' resistant practices or agency were analytically divided into three levels. This identified practices on an individual level, on a communal level within camp boundaries, and on a communal level going beyond camp boundaries. In the context of the latter, this article discusses public articulations 
and debates with media representatives. It became clear that the immobility of refugees, as intended by the camp, is counteracted in many ways by self-mobilisations. The camp turns into a setting for migration fights for rights, for recognition, for dignity and against racism and dehumanisation.

\title{
Refugee Voices als Teil eines Dispositivs der Lager
}

\begin{abstract}
»The fear of police and discharge has become the distinctive feature of our days in Europe, the spromised land. $<$ We live an illegal life, which we did not think before that we, as human beings could be illegal. We live in assembly camps, as we were in the chicken coop, the foxes of the enforced deportation hunt us one by one.« (Executive Committee of Sudanese Refugees 2019: 190f.)
\end{abstract}

Dieser Beitrag beleuchtet zum einen die Lebensrealitäten von Refugees ${ }^{1}$ in Lagern ${ }^{2}$, insbesondere in Ankerzentren, um zu untersuchen, wie sich die rechtlichen Regelungen und die medialen Diskurse im Alltag der Lagerinsassen materialisieren und zum anderen, welche Auseinandersetzungen in Form von widerständigen Praktiken von Seiten der Refugees sie zeitigen. Der Beitrag ist der zweite Teil meiner kulturanthropologischen Annäherung an ein Dispositiv der Lager. Er schließt an eine Untersuchung zum Zusammenhang zwischen Medienberichterstattung über Ankerzentren und einschlägigen asylrechtlichen Änderungen an (vgl. Goebel 2019). Diese Untersuchung legt nahe, dass Berichterstattung und Asylrechtsänderungen in einem sich gegenseitig bedingenden Verhältnis stehen: Die meist auf eine negative Kontextualisierung der Lagerinsassen ausgerichtete Berichterstattung kann der Legitimation von Asylrechtsverschärfungen bezüglich der Unterbringung in

1 Da dieser Beitrag nicht die Flucht, sondern das Schutzsuchen fokussiert, werden Personen, die in Aufnahmeeinrichtungen untergebracht sind oder wurden, als Refugees bezeichnet (vgl. Stefanowitsch 2012). Andere Bezeichnungen wie Asylbewerber*in oder Flüchtling verwende ich, wenn es um die rechtliche Kategorie des Aufenthaltsstatus geht.

2 René Kreichauf zeigt, dass die unterschiedliche Benennung von Lagern von unterschiedlichen diskursiven Kontexten und Interessen abhängt (vgl. Kreichauf 2018: 2f.). In Anlehnung an Kreichauf verwende ich den Begriff Lager (engl. [refugee] camp), wenn ich auf generelle Charakteristiken wie Exklusion insistiere. Wenn es aber um die formalen Spezifika eines Lager-Konzepts geht, dann orientiere ich mich am jeweiligen politischen oder rechtlichen Begriff wie beispielsweise Ankerzentrum oder Aufnahmeeinrichtung. 
Lagern dienen. Damit wurden zwei Elemente des Lagerdispositivs erforscht, die hier um zwei Elemente erweitert werden - um den imaginierten und materialisierten Lageralltag und um widerständige Praktiken.

Sowohl der Alltag, der in den Lagern weitgehend vorstrukturiert ist, als auch die Kämpfe der Migration ${ }^{3}$ (vgl. Ataç et al. 2015) sind von diversen und ambivalenten Praktiken und Wahrnehmungen unterschiedlicher Akteur*innen gekennzeichnet. Diese Praktiken theoretisiere ich in diesem Beitrag mit einem Mobilitätskonzept nach Holert und Terkessidis. Die Autoren grenzen ihr analytisches von einem normativen Mobilitätskonzept ab:

»Die Normativität der Mobilität schafft eigene Hierarchien, die von den Mobilitätseliten der hochqualifizierten und hochbezahlten Manager und Wissenschaftler bis zu den zwangsmobilisierten Bewohnerinnen und Bewohnern von Flüchtlingslagern reichen.« (Holert/Terkessidis 2005: 101)

Statt diese Hierarchien zu reproduzieren gehe es um die Sichtbarmachung der »Widersprüche von Mobilität und Immobilität« (ebd.) sowie darum »zu zeigen, wie die in diesen Räumen zirkulierenden Subjekte kriminalisiert, prekarisiert, marginalisiert oder einfach abgeschrieben werden; aber auch: welche Formen von Autonomie und Selbstorganisation sich hier beobachten lassen [...] (Holert/Terkessidis 2005: 101f.). Die Autoren konzeptualisieren Mobilität und Immobilität als Zustände, die über verschiedene Mobilisierungs- und Immobilisierungspraktiken hergestellt und verändert werden. Damit werden neben der Perspektive auf die jeweiligen Zustände, mit denen sich die Lagerinsassen konfrontiert sehen, auch die Ursachen und die Konsequenzen dieser Zustände analytisch einbezogen - beispielsweise immobilisierende Regierungspraktiken und mobilisierende widerständige Praktiken der Refugees. Der Beitrag fokussiert damit das Spannungsverhältnis zwischen erzwungener »Immobilisierung von Geflüchteten durch das Asylsystem« (Etzold 2019: 47; vgl. bspw. Jefferson/Turner/Jensen 2019; Kreichauf 2018; Christ/Meininghaus/Röing 2017) sowie selbstermächtigenden »widerständige[n] Praktiken und Mobilitätsstrategien « (Etzold 2019: 47; vgl. bspw. Borri/Fontanari 2015) von Refugees. Eine solche Perspektive, so Benjamin Etzold, könne dazu beitragen, die alltäglichen Erfahrungen und Vorstellungen von Refugees hörbarer zu machen (vgl. Etzold 2019: 51).

Mit diesem Beitrag involviere ich mich zudem in die Kämpfe der Migration (vgl. Riedner 2018: 60f.), indem ich bewusst jene Stimmen verstärke, die im öffentlichen Diskurs unterrepräsentiert und nur selten hörbar sind (vgl. Díez Bosch/Micó Sanz/Sabaté Gauxachs 2019: 131). Während in der medialen Berichterstattung über 
Ankerzentren Polizeiberichte, Repräsentant*innen von Behörden, Mitarbeiter*innen der zuständigen Institutionen und in manchen Fällen auch Mitarbeiter*innen von Wohlfahrtsverbänden oder Aktivist*innen von Flüchtlingsräten zitiert werden, sind Stimmen von Refugees die Ausnahme (vgl. Goebel 2019). Dieser Mangel an Einbezug der Perspektiven derer, über die gesprochen wird, reproduziert ein ungleiches Machtverhältnis in Form einer einseitigen Wissensproduktion. Der Einbezug von Refugee Voices kann ein Korrektiv dieser Wissensproduktion darstellen und dazu beitragen, emanzipatorische Prozesse zu unterstützen. Im Sinne gegenwärtiger Ansätze aus der kritischen Migrationsforschung - Autonomie der Migration (vgl. Bojadžijev/Karakayalı 2010), Migrantisierung der Gesellschaftsforschung (vgl. Bojadžijev/Römhild 2014) bzw. de-migranticization (Dahinden 2016), Postmigration (vgl. Foroutan 2019) - beteilige ich mich nicht an der Produktion vermeintlich objektiven Wissens über »die Anderen« und vermeide dadurch die Reproduktion einer essentialistischen Differenz zwischen den imaginierten "Anderen« und dem imaginierten »Eigenen «. Stattdessen verstehe ich Migration als konstitutiven Bestandteil von Gesellschaft. Dem stehen jedoch Migrations- und Asylregime gegenüber, die durch Hierarchisierung, Kategorisierung und Stereotypisierung »die Anderen « als zu steuernde Masse entsubjektivieren und diejenigen, denen keine ökonomische Verwertbarkeit zugeschrieben wird, zwischen restriktiven Sonderrechten zerreiben. Legitimationsgrundlage solcher Migrationsregime sind rassistisch grundierte Diskurse, die gerade dadurch funktionieren, dass sie diejenigen überhören und ignorieren, die den restriktiven und repressiven Praktiken des Migrationsregimes ausgeliefert sind. Diese »Anderen« bleiben dadurch eine anonyme, gesichtslose Projektionsfläche für Ängste, Sorgen oder Hass. Aktuelle deutschsprachige Studien zu Lagern, die zentrale Bestandteile von Asylregimen sind, sind unmissverständlich in ihrer Bewertung: Lager separieren, stigmatisieren, demütigen und exkludieren Menschen. Sie machen krank, depressiv und sie verursachen Konflikte (vgl. u.a. Christ/Meininghaus/Röing 2017; Pieper 2013, Täubig 2009). Von Seiten der Sozialarbeitswissenschaft wird daher eine »dezentrale Unterbringung (Initiative Hochschullehrender zu Sozialer Arbeit in Gemeinschaftsunterkünften 2016: 4) gefordert.

Die Etablierung des Lagersystems für Asylsuchende in Deutschland in den 1970er und 1980er Jahren war als Abschreckungsmaßnahme intendiert (vgl. Kapraun 2002) und so fungieren sie bis heute: Kreichauf schreibt, dass »[t]he concentration of large numbers of refugees in one place is a result of the increasing attempts of the EU and nation states to regulate and reduce the number of refugees arriving«. (Kreichauf 2018: 1)

Für diesen Beitrag wurden fünf qualitative problemzentrierte Interviews (vgl. Lamnek 2010: 332f.) mit Refugees durchgeführt, die in Lagern leben oder gelebt 
haben. ${ }^{4}$ Ihre Erfahrungen der Lagerunterbringung haben sie in vier Aufnahmeeinrichtungen in Bayern und in einer Aufnahmeeinrichtung in Baden-Württemberg gemacht. Die Auswahl der Interviewpartner*innen erfolgte explorativ und entlang heuristischer Überlegungen, wonach bevorzugt ein heterogenes Sample ausgewählt werden sollte. Dabei sollten weniger die gängigen Kategorien Herkunftsland, Geschlecht und Alter ausschlaggebend sein, sondern »inhaltliche Merkmale« (El-Mafaalani/Waleciak/Weitzel 2016: 87). Mit Blick auf die Forschungsfrage sollten die Interviewpartner*innen unterschiedliche Erfahrungen mit dem Lageralltag und mit widerständigen Praktiken gemacht haben.

Die transkribierten Interviews wurden induktiv codiert und problemzentriert ausgewertet, d.h. dass die Analyse (zum Schutz der Interviewpartner*innen) nicht die Fälle darstellt, sondern entlang der Erzählungen der Interviewpartner*innen die inhaltlichen Auseinandersetzungen diskutiert.

\section{Analysen}

Die Aussagen der Intervierpartner*innen ${ }^{5}$ werden thematisch systematisiert, beginnend mit einer Beschreibung des Alltags der Interviewpartner*innen während ihrer Unterbringung in Aufnahmeeinrichtungen. Ein zweiter Schwerpunkt liegt auf der Agency - also selbstbestimmten bzw. eigensinnigen Praktiken - der Interviewpartner*innen, da sich vier der fünf für ihre eigenen Belange und die ihrer befreundeten Mitinsassen einsetzten. Sie haben dabei auch Erfahrungen mit Journalist"innen und Berichterstattung über sie als Personen oder über Ereignisse und Strukturen, die sie betrafen oder betreffen, gemacht.

\section{Alltag in Aufnahmeeinrichtungen}

\section{Routinen}

Die alltäglichen Routinen in einer Aufnahmeeinrichtung beschreibt Tayo als sehr eintönig: „Sleep, wake up, go to the canteen, eat, go back, sleep, that is just it [...] for

Ich danke allen Interviewpartner*innen und Kontaktpersonen sehr für ihre Zeit und ihr Engagement. Die Interviewpartner*innen wurden über unterschiedliche Kontaktpersonen gewonnen. Zudem gilt mein Dank dem Zentrum für Forschungsförderung (ZFF) der Katholischen Universität Eichstätt-Ingolstadt, das das Forschungsprojekt über die proFOR+Förderung unterstützt hat.

5 Alle Interviewpartner*innen sind in westafrikanischen Ländern geboren. Die Namen der Interviewpartner*innen sind anonymisiert. Sämtliche Daten, wie das Jahr der Einreise nach Deutschland oder wann die Personen in Aufnahmeeinrichtungen leben oder gelebt haben, bleiben sicherheitshalber unerwähnt. Lediglich das Geschlecht der Interviewpartner*innen ist durch die verwendeten Pseudonyme erkennbar. 
years, and nothing more.« (Interview mit Tayo) Ähnlich beschreiben es alle Interviewpartner*innen. Diese Routinen, die besonders durch die Öffnungszeiten der Essensausgabe vorgegeben sind, zeichnen sich durch Leerstellen aus, die zu Langeweile und Frustration führen, sofern sie nicht sinngebend gefüllt werden können. Das Verbot, sich außerhalb der Stadt oder des Landkreises aufzuhalten (räumliche Beschränkung), Ausbildungs- und Arbeitsverbote und fehlender Zugang zu Deutschkursen schränken die Möglichkeiten, den Alltag selbstbestimmt zu gestalten, massiv ein. Gleichwohl fanden einige Interviewpartner*innen Möglichkeiten, etwas zu tun. Die meisten berichten von lagerinternen Arbeitsgelegenheiten, den sogenannten »Flüchtlingsintegrationsmaßnahmen«. Für das Sauberhalten des Lagers und das Putzen von Toiletten erhalten sie 80 Cent pro Stunde. Wer allerdings dazu verpflichtet wird und dem nicht nachkommt, dem drohen Kürzungen seiner Asylbewerberleistungen. Lamin organisierte zudem Sportaktivitäten mit anderen Bewohner*innen »just to make people not to be bored « (Interview mit Lamin).

\section{Ernährung}

Allgemeine Unzufriedenheit, wie sie aus Langeweile resultieren kann, ist ebenso eine Folge des bereitgestellten Essens als Teil der Sachleistungen, die die Bewohner*innen erhalten. William erzählt von verschimmeltem Brot, verschimmelten Orangen und saurer Milch. Er sagt, das Essen würde man »not even give someone that is a human being (Interview mit William) und Tayo bestätigt, dass "the food there is nothing to eat « (Interview mit Tayo). Daher, so Lamin, sei es gang und gäbe, dass die Leute - sofern sie es sich noch leisten könnten - außerhalb des Lagers Essen kaufen (vgl. Interview mit Lamin).

\section{Gesundheit und Hygiene}

Die Gesundheit der Geflüchteten in Aufnahmeeinrichtungen wird durch zahlreiche Faktoren gefährdet. Lamin macht auf diverse Hygienemängel aufmerksam und beschreibt die gesundheitsgefährdenden Konsequenzen der Unterbringung von acht Personen in einem Raum:

»We are living close to somebody, who is suffering from TB, tuberculosis and during that time, you know, we are diagnosed at the hospital [...], that we have to go for testing to find out if we are not affected. [...] Tuberculosis [...] can spread at any time and then you mix that person along with people who are very healthy and strong, then this is not conducive.« (Ebd.)

Massenunterkünfte wie Aufnahmeeinrichtungen (und auch Gemeinschaftsunterkünfte) sind für Asylbewerber*innen und Personen mit Duldung vorgesehen. Sie erhalten Leistungen nach dem Asylbewerberleistungsgesetz, das eine eingeschränkte medizinische Versorgung vorsieht. William beschreibt seine Erfahrung so: "In camp they don't give us proper treatment. When we are sick, the mes- 
sage they will tell you [is]: >Drink enough water.« (Interview mit William) Im Zuge der Corona-Pandemie wurden einmal mehr die gesundheitlichen Zustände in den Aufnahmeeinrichtungen kritisch in Augenschein genommen. In einem Dossier des Mediendienstes Integration werden die Gesundheitswissenschaftler Oliver Razum und Kayvan Bozorgmehr zitiert, die das Offensichtliche klarstellen: "Je mehr Asylbewerberinnen und Asylbewerber in großen Gemeinschaftsunterkünften und Anker-Zentren untergebracht werden, desto menschenunwürdiger und gesundheitsschädlicher werden die Lebensbedingungen." (Mediendienst Integration 2020)

\section{Beratungsangebote und Soziale Arbeit}

Besonders brisant ist die Darstellung der Beratungsangebote in den Lagern durch die Interviewpartner*innen. Die sozialarbeiterische Beratung wird von unterschiedlichen sozialen Trägern wie AWO, Caritas und Diakonie innerhalb der Aufnahmeeinrichtungen angeboten. ${ }^{6}$ Bukola, die insgesamt eher wenig Kenntnis von den Strukturen und Institutionen in der Aufnahmeeinrichtung zeigte, weiß nicht, welche Beratungsangebote von welchen Trägern mit welcher Intention vor Ort sind. Neben ihrem fehlenden Interesse dafür deutet dies auf eine unzureichende Abgrenzung der sozialarbeiterischen Beratung von den Beratungsangeboten der Behörden (Bundesamt für Migration und Flüchtlinge (BAMF), Ausländerbehörde, Agentur für Arbeit) hin. Dafür gibt es weitere Hinweise. Aleeke sieht die Unterstützungsmöglichkeiten der Sozialen Arbeit im Lager eingeschränkt:

»The social workers firstly were the ones given advice to people. Regarding the law, regarding their rights, from some points because they have also their limits. Even if they say they are the no-government workers, they were still working from the government. So the way they [were] taking their reports and giving you advice in law. So when you receive a letter, you go to the translation, they tell you, you have to do this and you have to do that. "(Interview mit Aleeke)

Darüber hinaus kritisiert Tayo die Zusammenarbeit eines sozialen Trägers mit dem BAMF und der Polizei im Zuge von Abschiebungen: »The Caritas secretly call the police« (Interview mit Tayo), was dazu führe, dass »the people don't go [to] them because they are scared, they are not safe [from] them « (ebd.). Einen anderen Träger in derselben Aufnahmeeinrichtung findet Tayo besser, weil er nicht mit dem BAMF zusammenarbeite, gleichwohl sei auch der nicht in der Lage »[to] change anything« (ebd.). Durch die Aussagen von William wird deutlich, worauf die Problematik der Sozialen Arbeit in den Lagern beruht: Integrationsberatung (FiB) und beruht auf der Beratungs- und Integrationsrichtlinie (BIR) vom 16.11.2017. 
»Every social workers in that camp obey, they don't break the rule [...] they will read the law that is guiding the camp for you. And that is what she will follow. [...] So all of them there work together, there is no office that works different, all offices in Ankerzentrum they work together. [...] they don't work with the refugee, they work on their own with the camp. (Interview mit William)

Die Rechtslage wird hier als zentrales Problem dargestellt, das die Lebensbedingungen im Lager bestimmt. Sollen die Lebensbedingungen verändert werden, bedürfe es demnach einer Abweichung von den rechtlichen Regelungen. Solange sich die Sozialarbeiter*innen an die rechtlichen Regelungen hielten, könnten sie an den Lebensbedingungen - insbesondere an der von Interviewpartner*innen häufig angeführten Angst vor Abschiebungen - nichts ändern. Von William werden die Wohlfahrtsverbände demnach als Teil des restriktiven Systems wahrgenommen. Damit wird exakt jenes Spannungsfeld offensichtlich, das in der Sozialen Arbeit unter dem Begriff »Tripelmandat« diskutiert wird. Sozialarbeiter*innen haben sich an verschiedenen Bezugsrahmen und Interessen $\mathrm{zu}$ orientieren (Politik/Recht/Geldgeber, Klientel, Profession), die - wie in diesem Fall - völlig konträr zueinander stehen (vgl. Staub-Bernasconi 2007). Die Mitwirkung an einer Abschiebung durch eine*n Sozialarbeiter*in, wie sie Tayo beschreibt, widerspricht der sozialarbeiterischen Berufsethik. Die Berufsethik der Sozialen Arbeit beinhaltet das Recht auf Selbstbestimmung und soll »die körperliche, psychische, emotionale und spirituelle Integrität und das Wohlergehen einer jeden Person wahren und verteidigen« (Deutscher Berufsverband für Soziale Arbeit e.V. 2017: 3). Damit »[verstoßen] Abschiebungen [...] von Natur aus gegen das Verständnis der Profession der Sozialen Arbeit « (ebd.: 4). ${ }^{7}$

\section{(Grund-)Rechte und Gesetze}

Wenn die Interviewpartner*innen von Rechten sprechen, geht es vor allem um Grundrechte und um Menschenrechte. Lamin kritisiert "a situation whereby all your basic rights have been seized « (Interview mit Lamin) und Tayo vergleicht das Ankerzentrum mit einem Gefängnis, weil »basic human rights« (Interview mit Tayo) fehlten. Denselben Vergleich zieht William, da sie ebenso wie Gefangene kein »right to request for their needs « (Interview mit William) hätten. Aleeke zitiert das Grundgesetz: »They say: >Die Würde der Menschen ist unantastbar« «, und er kritisiert, dass

»we refugees, our wish is sometimes violated, we have no dignity. And this is what we always ask: the respect of our right and the respect of people who we 
are, like a human being, even if our skin have some colours, we are still breathing and we are still having the same blood." (Interview mit Aleeke)

Die Einschränkung ihrer grundlegenden Rechte veranschaulichen die Interviewpartner*innen an zahlreichen Beispielen:

»Everything was restricted to you, you cannot go out more than 24 hours to visit a friend, you cannot leave your accommodation room to go and spend the night at another room. Then you were not given pocket allowances [...] that what you are allocated to.« (Interview mit Lamin)

Eingeschränkt seien »freedom of movement, [...] the right to travel« (Interview mit Tayo). William kritisiert die fehlende »freedom of expression [...]: In camp, we don't have the right to speak, when you speak, you will be punished. When you do anything, you'll be punished. No one have rights. " (Interview mit William) Ebenso würde das Recht auf Privatsphäre verletzt, beispielsweise als ein Mitarbeiter des Sicherheitspersonals »badged into their rooms and he stared the nakedness of a woman« (ebd.). Das Einfordern von Grundrechten auf dem Rechtsweg gestaltet sich schwierig, da das praktische Recht, also das deutsche Migrationsrecht mitsamt seiner länderspezifischen und kommunal unterschiedlichen Ausgestaltung, niemand kennt: »Nobody knows the law, you are in Germany (Interview mit Aleeke) und »we don't know the normal procedures of asylum seekers in Germany« (Interview mit Lamin). William hat im Laufe seiner Auseinandersetzung mit den Zuständen im Lager herausgefunden, dass »the laws [...] covering the asylum case are different in every part of Germany [...]. Every Ankerzentrum now they have different kind of law, the way they follow asylum process « (Interview mit William). Die föderalen Ungleichheiten in der Asylentscheidungspraxis des BAMF (vgl. Schneider/Segadlo/Leue 2020) werden von Refugees wahrgenommen und moniert. $\mathrm{Zu}$ dem ist hier anzumerken, dass die faktische Unmöglichkeit, dass die vom Migrationsrecht betroffenen Lagerinsassen das einschlägige Recht umfassend verstehen, vom Gesetzgeber mitunter intendiert ist. Horst Seehofer hat auf einer Konferenz im Juni 2019 als Bundesinnenminister sein zutiefst antidemokratisches Verständnis von Gesetzgebung dargelegt - ironischerweise auf dem 2. Berliner Kongress für wehrhafte Demokratie. Demnach habe er »die Erfahrung gemacht «, dass man »Gesetze kompliziert machen « und "ganz stillschweigend « einbringen muss, da Gesetze "ja oft unzulässig in Frage gestellt« würden (Seehofer, zitiert nach: Youtube 2019). Wer das Gesetz nicht versteht, hat es schwer, seine Rechte einzufordern. Und so erzählen die Interviewpartner*innen von offensichtlichen Rechtsverletzungen, die überhaupt nur dann möglich sind, wenn diejenigen, die die Rechte der Geflüchteten verletzen, sich sicher wähnen, dafür nicht zur Rechenschaft gezogen zu werden. Beispielsweise berichtete William von Erfahrungen während der Anhörung durch das BAMF: 
»When you say something in the interview, they will tell you, the translator will tell you that what you say is a lie, that this doesn't happen, that your story is scheiße, your story is nasty, this thing. They will start abusing you in the interview day. [...] Everything they write on many people's interview is nonsense, it's not what you said. [...] Then we don't understand how it goes. They will ask you to sign, you will sign. That means you have agreed what they wrote.« (Interview mit William)

Tayo erzählt, dass das BAMF Entscheidungen über Asylanträge im Copy-andPaste-Verfahren reproduziere und nicht auf die individuellen Fluchtgründe aus der Anhörung eingehe. Versuche, bei behördlichen Mitarbeiter*innen im Ankerzentrum Informationen über BAMF-Bescheide $\mathrm{zu}$ erhalten, führten $\mathrm{zu}$ ablehnenden und repressiven Reaktionen:

»In Anker centre they just tell you: 'Hey, we don't want to talk to you, you have to go now or we call the security for your, and the security comes and starts molesting the people. So that is what Anker centre is all about. They just try to frustrate the people.« (Interview mit Tayo)

\section{Rassismus}

So stellt er einen Zusammenhang her zwischen den rechtlichen Regelungen und Rassismus: "Bayern has the worst asylum law and racist way of treating the refugees." (Interview mit Tayo) Die Erfahrung einer rassistisch begründeten Hierarchie der Geflüchteten in den Lagern wird von mehreren Interviewpartner*innen geteilt. Beispielsweise sagt Aleeke, dass nicht nur Geflüchtete im Allgemeinen, sondern »especially [...] Africans are not welcome in many, many camps in Germany« (Interview mit Aleeke). Die Lager werden von William als »centre of hell« (Interview mit William) tituliert und von Aleeke als Ort, an dem »people [...] were oppressed and they will not [be] living anymore because surviving is not [...] living (Interview mit Aleeke). Ursächliche Erfahrungen für solch drastische Beurteilungen gibt es viele - u.a. die allgegenwärtige Angst vor Abschiebungen.

\section{Abschiebungen und Polizeieinsätze}

Abschiebungen drohen insbesondere nach rechtskräftig abgelehnten Asylanträgen oder wenn Asylbewerber*innen bereits in einem EU-Mitgliedsstaat gemäß der Dublin III-Verordnung als asylsuchend registriert wurden. Die Gefahr von DublinAbschiebungen wird von vier der befragten Interviewpartner*innen mehrfach als besondere Bedrohung und Belastung beschrieben. Versuche, Abschiebungen durchzusetzen, führten zu martialischen Polizeieinsätzen:

»They were in large numbers, [...] that was just like an invasion. A lot of cars and then the police presence was too huge and [...] there are helmets, there are 
shields, there are bludgeons, there are dogs. And then everybody was armed, highly armed with their guns. [...] So but then I wonder, what went wrong? [...] So I want to force myself out, then the police said: >No, nobody is allowed to go out or in. Like the camp is at lockdown. Said that this must be a serious case. And then I start hearing this information spreaded. [...] They said, they came for [name] and then the boys said: >[name] is not going anywhere, he's not going to be arrested or is not going to be deported. [...] I asked the police: >But what is going on, can you tell us? He said: >No.< They have the order to be here [...] and that's all. So that was the time, they [...] started entering by force in [one of the buildings in the Anker centre, Anm. d.Verf.]. I cannot know what exactly happened [...] and then people who we are passing by were caught, beaten and then handcuffed and then straight they take them to the cars and then this [is] how they keep arresting. They've keep arrested until they have a number of almost thirty-three, I don't know, thirty-two. [...] Still now the operation is on. [...] They are waiting there and then they were using this tear gas and then when they used this tear gas, then people have nowhere to inhale oxygen, they have to break the glasses and this is why a lot of glasses were broken on that day. Because of the police act, the way they act, they acted horribly bad.« (Interview mit Lamin)

Auch William berichtet von einer gewalttätigen Dublin-Abschiebung, bei der »they even arrest women, [...] they handcuffed [her], [...] they pressed her down, [...] they were pressing her on the floor. [...] Four police are pressing a woman on the floor « (Interview mit William).

William hält eine derartige Behandlung, wie man sie für Straftäter*innen erwarten würde, für nicht gerechtfertigt, denn: »It's just Dublin, but the way they treat us in the common arrest because of Dublin is even worse [...] than when they arrest criminals.« (Ebd.) Er problematisiert zudem, dass das Security-Personal als Handlanger der Polizei fungiere:

»Even security in camp, [...] they authorized them to be using handcuffs on us. When the police informed them that this person have Dublin, the security will start chasing after you or looking after you. When they see you, they will put handcuffs on your hand. They will be up to ten security that will press you down and handcuff you and put you in a single room. That is worse [...] than the prison.« (Ebd.)

Aus den kollektiven und individuellen Erfahrungen von Unrecht resultieren eine zentrale Motivation für Agency, Protest, Widerständigkeit und Versuche, sich öffentlich Gehör zu verschaffen. 


\section{Agency, Protest, Widerständigkeit und Öffentlichkeit/Medien}

Aus dem beschriebenen Mangel an Vertrauen in die vorhandenen Beratungsstrukturen hat Lamin mit einer Gruppe von Refugees im Lager eine eigene Beratungsstruktur etabliert:

»We want to sensitise our people about the asylum procedures and situations in Cermany. [...] Because the little we know, this are the little that we share with them. But if we don't know [...] we will ask people who know this better, then we will give you that information. We don't want to give any false information to any asylum seeker here.« (Interview mit Lamin)

Dass die Interviewpartner*innen teilweise ein hohes Maß an Agency mitbringen, liegt in der Auswahl des Samples begründet. Zunächst sei aber erwähnt, dass auch Resignation und Apathie zu den Lebenswirklichkeiten von Geflüchteten im Lager zählen. So äußert sich Bukola zu ihren Lebensumständen, dass »for six month, I think it's not so bad. It's just for a while« (Interview mit Bukola). Sie weiß, dass ihr Aufenthalt im Ankerzentrum laut Gesetz sechs Monate nicht überschreiten sollte, weil sie ein Kind hat, kennt aber auch Fälle, in denen der Transfer in eine Gemeinschaftsunterkunft länger gedauert hat. Den Transfer beschreibt sie als Ausweg aus den Lebensumständen im Ankerzentrum, in denen sie kaum etwas tun kann: "So life in the camp, we are no allowed to do nothing." (Ebd.) Und Lamin sagt, dass »what you can do is bear on the consequence that you are facing, and this is what everybody does in the Anker centre« (Interview mit Lamin). Allerdings stellen die Interviewpartner*innen verschiedene Strategien ihrer Agency dar - widerständige Praktiken gegen die Lebensumstände, die auf drei Ebenen angesiedelt sind:

\section{Individuelle Ebene}

Es werden Handlungen vollzogen, die einer akuten Bedrohung wie dem Zugriff durch die Polizei zum Zwecke der Abschiebung entgegenwirken. Die Befürchtung der eigenen Abschiebung ebenso wie die Zeugenschaft von Abschiebungen anderer Lagerinsassen werden von den meisten Interviewpartner*innen als brutal, psychisch belastend und angsteinflößend beschrieben: "And then when this Dublin is affected on you, people have this fear. It's like a mental torture on them.« (Interview mit Lamin) Viele könnten nicht schlafen, da die Polizei Abschiebungen häufig nachts durchführt. Einige Lagerinsassen, so Lamin, verbrächten ihre Nächte auf "plastic bags" in "the bushes [...] so when the police comes they will not find them in their room« (ebd.). Der dadurch verursachte Schlafentzug stellt eine enorme Belastung dar, weshalb William fordert: "As a refugee, even if you don't have a right to achieve anything at least as a human, we have a right to sleep.« (Interview mit William) 


\section{Gemeinschaftliche Ebene innerhalb der Lagergrenzen}

Durch die proaktive Gestaltung des Alltags wird das Lagerleben erträglicher gemacht. Die erzwungene Lähmung des Alltags wird durch selbstgemachte Strukturen und sinngebende Tätigkeiten kompensiert. Gegenseitige Unterstützungsangebote von Lagerinsass*innen für Lagerinsass"innen helfen in problematischen Alltagssituationen. Dabei bilden sich Gruppen heraus, die hier federführend sind. Die Bedeutung von Gruppen erklärt Aleeke:

"So after I reach in [city, in which the camp is, Anm. d.Verf.], we started to create an alliance, you know. [...] So we united with friends and started to build like a community. [...] When you reach somewhere, you have to create a community, you have to know your friends, come to them and know about their history, what they are facing in the camp, if they are facing the same thing like you.« (Interview mit Aleeke)

Auch Lamin berichtet von seiner Beteiligung an der Institutionalisierung einer lagerinternen Organisation, an der sich Lagerinsassen beteiligen konnten. Sie sahen ihre Aufgabe in der Aufrechterhaltung einer lagerinternen Ordnung, »we always tried to maintain peace and order (Interview mit Lamin), und in der gegenseitigen Unterstützung. Die Mitglieder der Gruppe waren angehalten, einen Euro pro Monat in eine Solidaritätskasse zu geben und »if someone is affected that particular time, then the money contributed will be used for that purpose or that person« (ebd.). So seien beispielsweise Medikamente für Kranke bezahlt worden, die sie aufgrund der unzureichenden Krankenversorgung andernfalls nicht bekommen hätten. Die Gruppe war allerdings begrenzt auf Lagerinsassen einer Nationalität. ${ }^{8}$ Aleeke beschreibt dagegen seine nationalitätenunabhängige, aber auf die Ausübung religiöser Praktiken fokussierte Agency. Er mobilisierte die muslimische Community im Lager und ihre »revendication to have a mosque war erfolgreich: »They prepared a special place for us and we were praying there every time. They made special food for us and we make a Ramadan's time together." (Interview mit Aleeke)

\section{Gemeinschaftliche Ebene über die Lagergrenzen hinaus}

Durch Aktivismus und Protest - dazu gehört auch die Herstellung von Artikulationsfähigkeit in Medien - werden Rechte und strukturelle Verbesserungen eingefordert. Ursächlich für aktivistische Praktiken sind die Erfahrungen mit Rechtlosigkeit, Zurückweisung, Diskriminierung, Rassismus und Gewalt.

Medien, die über Ereignisse in Ankerzentren berichten, stellen die Vorkommnisse häufig völlig konträr zu den Erfahrungen der Interviewpartner*innen dar. 
Dies knüpft an die Diskursanalyse zur Berichterstattung in der Augsburger Allgemeinen über den Kontext von Ankerzentren an (vgl. Goebel 2019). Darin wurde gezeigt, dass die Zeitung meist affirmativ jene Perspektiven expliziert oder impliziert, die die Unterbringung von Geflüchteten in Lagern befürworten und die restriktiven (rechtlichen) Maßnahmen gegen Geflüchtete legitimieren. Auch rassistische Stereotype werden reproduziert und Geflüchtete bzw. Lagerinsassen selbst wurden nicht gefragt. Diese Problematik beschreiben auch die Interviewpartner*innen: »[...] but what's coming in newspaper in the morning, wasn't what we were expected.«(Interview mit Aleeke) ${ }^{9}$

So entschieden sich einige, durch Gespräche mit Journalist*innen und Demonstrationen die Perspektiven der Geflüchteten in die Öffentlichkeit zu tragen. Aleeke wollte mit der Presse sprechen »because what the newspaper said is not what we live in the camp« (ebd.). Da ihm nicht egal sei, was die Öffentlichkeit über die Geflüchteten denkt, problematisiert er, dass »nobody were in our side to tell [...] true about us. We were like rejected from the society looking upon when we are going to the street, rejected by the people living in this city« (Ebd.). Ergänzend lässt sich die Aussage von William anschließen, wonach »it's very obviously that people doesn't know, what refugees are passing through in Ankerzentrum « (Interview mit William).

Manche der Interviewpartner*innen haben Medieninterviews gegeben. Für Aleeke kam es dabei $\mathrm{zu}$ besonders gravierenden Falschdarstellungen und $\mathrm{zu}$ Verleumdung. Mit Unterstützung von Freund*innen gelang es ihm, Klagen gegen die betreffenden Medienunternehmen auf den Weg $\mathrm{zu}$ bringen, von denen er bereits mehrere gewonnen hat: »We've fight about for more than one years now, about this reportage of media. [...] Specially the bourgeois media [...] are trying to criminalize refugees. [...] We are fighting with them now in the court.« (Interview mit Aleeke) ${ }^{10}$ Seine Gegenstrategie verlief ebenso medial und so findet sich auch Berichterstattung über seine Person, die ihn nicht diffamiert, sondern neutral berichtet und ihn unverfälscht zu Wort kommen lässt. Die Artikulation in der Öffentlichkeit ist mit hohen Risiken verbunden:

»[I was] trying to be hiding my heads not to be killed by any fascist people because my picture have been shown everywhere and my history have been told to

$9 \quad$ Zwar findet teilweise aufgrund von Sprachbarrieren, teilweise wegen fehlendem Zugang keine Rezeption lokaler Medien durch die Interviewpartner"innen statt, jedoch sind sie mit aktivistischen Cruppen vernetzt, über die sie die einschlägige Medienberichterstattung kennen. Zur Medienberichterstattung über Lager siehe den Beitrag von Tanja Evers in diesem Band.

10 Dies entspricht der Analyse von Kreichauf, wonach »(refugee) migration is deeply related to discourses on crime, terror and a general criminalization of migration« (Kreichauf 2018: 18). In Lagern materialisierten sich diese Diskurse, so Kreichauf (vgl. ebd.: 19). 
anyone. Everything about me have been exposed, even my dignity from journalists and social network. I was living like a hiding man trying to escape from the hand of population, trying to escape from the hand of police, trying to escape from anybody.«(Ebd.)

Auch Lamin hat schlechte Erfahrungen mit einer Journalistin gemacht, die ihn via Chatnachrichten interviewte: "And then she put this interview in the newspaper. But what I said in the interview and what she did was quite different. She was writing it in a negative way like putting all the blame of what happened in [city] on us, the immigrants." (Interview mit Lamin)

Manche Interviewpartner*innen berichten von einer mitunter hohen Nachfrage an geflüchteten Gesprächspartner*innen von Seiten der Presse, was sich allerdings nicht in der Berichterstattung widerspiegelt. Tayo berichtet, dass »maybe every month the media [...] come [...] with the bus [...]. They can interview one or two refugees, then they are going to give a wrong impression to the people« (Interview mit Tayo). Auch Tayo problematisiert die Kriminalisierung von Geflüchteten in der Berichterstattung und vermutet in solchen Fällen eine Nähe zwischen den Journalist*innen und dem BAMF. Möglicherweise manifestiert sich die Nähe zumindest darin, dass Journalist*innen dazu tendieren, Vertreter*innen von Behörden mehr Glaubwürdigkeit beizumessen als Refugees.

Wo die journalistische Praxis des Interviews bei Politiker*innen und anderen Personen des öffentlichen Lebens in der Regel die Möglichkeit einräumt, ein verschriftlichtes Interview gegenzulesen bzw. Zitate $\mathrm{zu}$ autorisieren, scheint diese Praxis bei den von mir befragten Interviewpartner*innen die Ausnahme zu sein. William, der einige Interviews mit Journalist*innen geführt hat, erinnert sich lediglich an drei Fälle, in denen »they sent it to me to go through [...] before they published it« (Interview mit William).

Trotz aller negativen Erfahrungen sehen einige Interviewpartner*innen in ihren Medienauftritten eine Möglichkeit, gegen die Zustände anzugehen, mit denen sie zu kämpfen haben. Dabei nehmen sie Gefahren in Kauf. Für William ist es der Ausbruch aus der »Hölle« des Lagerlebens: »I'm going to fight for the people, that is living, I'm going to dedicate myself and I will sacrifice that time for them because I [...] don't want to keep quiet and diked in silence.« (Ebd.) Diese Haltung vertrete er, selbst wenn es dazu führte, dass er abgeschoben wird. Die Hörbarkeit und Artikulationsfähigkeit verschaffte sich William durch das Organisieren und Teilnehmen an Demonstrationen und Konferenzen. Er will so die Interessen von Geflüchteten vertreten: »I always like to represent refugees.« (Ebd.) Außerdem versteht er sich als politischer Aktivist. Infolge seines Aktivismus sieht er sich zunehmend bedroht, $\mathrm{da}$ »the camp authority became against me, they began to fight against me and they began to fight that they deport me back to Italy« (ebd.). William hofft, dass »even if they don't change the 100 percent of the law, at least, if they can hear our voice, 
change at least 20 percent, so that's at least, we can grab some things as a human« (ebd.).

Auch Aleeke berichtet von der Organisation einer Demonstration mit dem Ziel, der Berichterstattung der Medien über einen Polizeieinsatz im Lager entgegenzuwirken:

»We decided to speak out, taking advise from some organisation, and we decided to do our own demonstration in the city to proof to people that what we are facing is not like making power with the government, it's not like trying to go upon the law, that it was like self-defence, we are trying to defend ourselves.« (Interview mit Aleeke)

In den Gesprächen mit den Interviewpartner*innen hat sich gezeigt, dass die aktivistischen Refugee-Gruppen innerhalb und außerhalb der Lager gut vernetzt sind mit anderen (Refugee-)Aktivist*innen. So wurden beispielsweise bei Demonstrationen Solidaritätsbekundungen von Lagerinsass*innen aus anderen Lagern übermittelt. Oftmals hängt das Lagergrenzen überschreitende widerständige Potenzial an mehreren Einzelpersonen, so dass deren Präsenz im Lager ausschlaggebend für öffentliche Artikulation und Protest ist.

\section{Fazit}

Der Versuch, in diesem Beitrag die Stimmen von Refugees hörbar zu machen, bleibt zwangsläufig unvollständig. Die Perspektiven der fünf Interviewpartner*innen können nicht die Heterogenität all derer repräsentieren, die in den letzten Jahren in deutschen Lagern untergebracht wurden. Im Kern zeigen die Interviews jedoch, dass Refugees nicht nur resignieren, sondern auch gestalten oder wie Ulrike Krause schreibt: »People determined as refugees (try to) create meaningful lives, despite the adversities they face.« (Krause 2018: 484) Und so sind Lager - wie René Kreichauf gezeigt hat - als prozessuale Orte zu verstehen, »where involved actors, producers, and users, constantly reproduce and transform socio-spatial configurations (Kreichauf 2018: 4). Sie sind ein umkämpfter Schauplatz, dessen Ambivalenz aus immobilisierenden und mobilisierenden Faktoren den Lageralltag prägt. Die Refugees gehen unterschiedlich damit um. Julia Sophia Schwarz kommt in ihrer methodologisch, theoretisch und thematisch ähnlich ausgerichteten Ethnographie des Lageralltags von Refugees in einer Münchner Aufnahmeeinrichtung zum dem Schluss, dass sich Selbstmobilisierungen von Refugees innerhalb der institutionalisierten Grenzen (Immobilisierung) abspielen (vgl. Schwarz 2016: 140f.).

Dies stimmt nur zum Teil mit den Erkenntnissen aus vorliegender Untersuchung überein. Zum einen sind verschiedene Alktivitäten - insbesondere der Protest - der von mir interviewten Refugees zwar nicht rechtswidrig, werden aber 
offenbar dennoch von den Behörden nicht gern gesehen. Dies führt dazu, dass neben den rechtlich materialisierten, institutionalisierten Grenzen des Lagers auch imaginativ-institutionalisierte Grenzen bzw. Machtverhältnisse evident werden. Die Refugees berichten beispielsweise davon, dass ihre widerständigen Praktiken dazu führen, dass man sie loswerden will - in einem Fall bedeutete das den Transfer in eine Gemeinschaftsunterkunft, in einem anderen Fall wurde auf die Dublin-Abschiebung insistiert. Gleichwohl sind imaginativ-institutionalisierte Grenzen durchlässiger und angreifbarer, so dass Rechte auch erkämpft werden können - wie im Fall von Aleeke die Möglichkeit religiösen Praktiken nachzugehen oder im Fall von Tayo die erfolgreiche Beschwerde bei einem Ombuds-Team. Allgemein gesprochen: Wo Macht ist, ist auch Widerstand (vgl. Moebius 2012: 19). Zum anderen werden in Einzelfällen auch rechtliche Grenzen mit dem Ziel überschritten, sich ein Ideal von Freiheit (vgl. Etzold 2019: 47) zu erkämpfen. Durch Selbstmobilisierung gelingt es also nicht, die Unsicherheit, die alle Lebensbereiche von Refugees bestimmt, $\mathrm{zu}$ überwinden. Wenn Selbstermächtigung rechtliche Grenzen überschreitet, kann die Konsequenz sowohl ein Mehr an Freiheitsgefühl als auch die totale Freiheitsbeschränkung im Gefängnis bedeuten - beispielsweise, wenn jemand wiederholt gegen Auflagen wie die räumliche Beschränkung verstößt oder wenn sich jemand gänzlich dem Asylregime entzieht und damit den Straftatbestand des unerlaubten Aufenthalts erfüllt. Solche rechtswidrigen Formen des Widerstandes scheinen für manche Refugees eine Option zu sein, wenn - wie manche Interviewpartner*innen berichteten - das Ankerzentrum ohnehin als Gefängnis erlebt wird. Der mögliche weitreichende Gewinn von Freiheit steht dann einem bloß marginalen Verlust von Freiheit gegenüber.

Die Analyse der Interviews mit Refugees hat gezeigt, dass widerständige Praktiken gegen die prekarisierende ${ }^{11}$ Unterbringung in Lagern auf unterschiedlichen Ebenen stattfinden. Individuelle, den Nahraum und Alltag betreffende Praktiken, sowie gemeinschaftliche Praktiken innerhalb des Lagers und über Lagergrenzen hinweg zielen allesamt auf Selbstbestimmung und Sinnstiftung. Sie sind damit ein essentieller Bestandteil der Aufrechterhaltung eines würdigen Lebens, das durch die restriktive Unterbringungspraxis bedroht ist.

\section{Literaturverzeichnis}

Ataç, Ilker/Kron, Stefanie/Schilliger, Sarah/Schwiertz, Helge/Stierl, Maurice (2015): »Kämpfe der Migration als Un-/Sichtbare Politiken. Einleitung zur zweiten Ausgabe«, in: movements. Journal für kritische Migrations- und Grenzregimeforschung $20151(2)$, S. 1-18. 
Bojadžijev, Manuela/Karakayalı, Serhat (2010): »Recuperating the Sideshows of Capitalism: The Autonomy of Migration Today«, in: e-flux 17, http://workero 1.e-flux.com/pdf/article_8888154.pdf, Abrufdatum: 16.05.2020.

Bojadžijev, Manuela/Römhild, Regina (2014): »Was kommt nach dem >transnational turn«? Perspektiven für eine kritische Migrationsforschung«, in: Labor Migration (Hg.), Vom Rand ins Zentrum. Perspektiven einer kritischen Migrationsforschung, Berlin: Panama Verlag, S. 10-24.

Borri, Giulia/Fontanari, Elena (2015): »Lampedusa in Berlin: (Im)Mobilität innerhalb des europäischen Grenzregimes«, in: Peripherie 35(138/139), S. 193211, www.zeitschrift-peripherie.de/138-139_05_Borri-u-Fontanari.pdf, Abrufdatum: 16.05.2020.

Christ, Simone/Meininghaus, Esther/Röing, Tim (2017): »All Day Waitingく. Konflikte in Unterkünften für Geflüchtete in NRW«, BICC Working Paper 3/2017, https://www.bicc.de/uploads/tx_bicctools/BICC_WP_3_2017_web_01.pdf, Abrufdatum: 16.05.2020.

Dahinden, Janine (2016): "A plea for the >de-migranticization of research on migration and integration «, in: Ethnic and Racial Studies 39(13), S. 2207-2225.

Deutscher Berufsverband für Soziale Arbeit e.V. (2017): Kann Soziale Arbeit im Rahmen von Abschiebungen stattfinden?, von 03/2017, https://www.dbsh .de/media/dbsh-www/downloads/Kann_Soziale_Arbeit_im_Rahmen_von_ Abschiebungen_stattfinden_3_2017_02.pdf, Abrufdatum: 14.07.2020.

Díez Bosch, Míriam/Micó Sanz, Josep Lluís/Sabaté Gauxachs, Alba (2019): »Letting Diasporic Voices Be Heard. Refugees and Migrants in European Media«, in: The Ecumenical Review 71(1-2), S. 110-132.

El-Mafaalani, Aladin/Waleciak, Julian/Weitzel, Gerrit (2016): »Methodische Grundlagen und Positionen der qualitativen Migrationsforschung«, in: Débora B. Maehler/Heinz Ulrich Brinkmann (Hg.), Methoden der Migrationsforschung. Ein interdisziplinärer Forschungsleitfaden, Wiesbaden: Springer VS, S. 60-95.

Etzold, Benjamin (2019): "Auf der Flucht - (Im)Mobilisierung und (Im)Mobilität von Schutzsuchenden«, State-of-Research Papier 04, Osnabrück: IMIS/Bonn: BICC, von 06/2019, https:/flucht-forschung-transfer.de/wp-content/uploads/ 2019/06/SoR-04-Benjamin-Etzold-WEB.pdf, Abrufdatum: 16.05.2020.

Executive committee of Sudanese Refugees (2019): "Speech at We'll Come United demonstration in Berlin 16.09.2017«, in: Natascha Süder Happelmann/Franciska Zólyom (Hg.), Ankersentrum, Berlin: Archive Books, S. 190-192.

Foroutan, Naika (2019): Die postmigrantische Gesellschaft. Ein Versprechen der pluralen Demokratie, Bielefeld: transcript.

Goebel, Simon (2019): »Medial (re)produzierte Narrative und Asylrechtsänderungen - Annäherungen an ein Dispositiv der Lager«, in: Reinhard Johler/Jan Lange (Hg.), Konfliktfeld Fluchtmigration. Historische und ethnographische Perspektiven, Bielefeld: transcript, S. 207-227. 
Holert, Tom/Terkessidis, Mark (2005): »Was bedeutet Migration?«, in: Aytaç Eryılmaz/Frank Frangenberg (Hg.), Projekt Migration, Köln: DuMont, S. 98-107.

Initiative Hochschullehrender zu Sozialer Arbeit in Gemeinschaftsunterkünften (2016): Positionspapier: Soziale Arbeit mit Geflüchteten in Gemeinschaftsunterkünften. Professionelle Standards und sozialpolitische Basis, o.D., www.fluechtlingssozialarbeit.de/Positionspapier_Soziale_Arbeit_mit_Geflüchteten.pdf, Abrufdatum: 16.05.2020.

Jefferson, Andrew/Turner, Simon/Jensen, Steffen (2019): »Introduction: On Stuckness and Sites of Confinement «, in: Ethnos 84(1), S. 1-13, https://doi.org/10.108 o/00141844.2018.1544917.

Kapraun, Inge (2002): Flüchtlingsunterbringung und der Schutz der Menschenwürde: Dimensionen eines politischen Konflikts. Hintergründe und Einflußfaktoren kommunaler Policy-Prozesse am Beispiel der Münchner Flüchtlingsunterbringungspolitik in den Jahren 1986-1944, Dissertation, München: Akademischer Verlag.

Krause, Ulrike (2018): »Protection | Victimisation | Agency? Gender-sensitive Perspectives on Present-day Refugee Camps«, in: zeitgeschichte 45(4), S. 483-505.

Kreichauf, René (2018): „From forced migration to forced arrival: the campization of refugee accommodation in European cities«, in: Comparative Migration Studies 2018 (6,7), S. 1-22, https://doi.org/10.1186/s40878-017-0069-8.

Lamnek, Siegfried (2010): Qualitative Sozialforschung, 5. Aufl., Weinheim: Beltz. Mediendienst Integration (2020): Corona-Pandemie und Migration, von 05/2020, https://mediendienst-integration.de/migration/corona-pandemie.html/, $\mathrm{Ab}$ rufdatum: 16.05.2020.

Moebius, Stephan (2012): „Cultural Studies«, in: Stephan Moebius (Hg.), Kultur. Von den Cultural Studies bis zu den Visual Studies. Eine Einführung, Bielefeld: transcript, S. 13-33.

Pieper, Tobias (2013): Die Gegenwart der Lager. Zur Mikrophysik der Herrschaft in der deutschen Flüchtlingspolitik, 2. Aufl., Münster: Westfälisches Dampfboot.

Riedner, Lisa (2018): Arbeit! Wohnen! Urbane Auseinandersetzungen um EUMigration. Eine Untersuchung zwischen Wissenschaft und Aktivismus, Münster: edition assamblage.

Schneider, Gerald/Segadlo, Nadine/Leue, Miriam (2020): "Das dreifache Asylroulette: Föderale Ungleichheiten in der deutschen Asylpraxis«, in: Fluchtforschungsblog vom 17.01.2020, https://blog.fluchtforschung.net/das-dreifache -asylroulette-foderale-ungleichheiten-in-der-deutschen-asylpraxis/, Abrufdatum: 16.05.2020.

Schwarz, Julia Sofia (2016): »Mobility in a Congealed Room? Asylum Seekers (in Munich) between Institutionalised Immobility and Self-Mobilisation«, in: Miriam Gutekunst/Andreas Hackl/Sabina Leoncini/Julia Sophia Schwarz/Irene Götz 
(Hg.), Bounded Mobilities. Ethnographic Perspectives on Social Hierarchies and Global Inequalities, Bielefeld: transcript, S. 129-144.

Staub-Bernasconi, Silvia (2007): »Vom beruflichen Doppel- zum professionellen Tripelmandat: Wissenschaft und Menschenrechte als Begründungsbasis der Profession Soziale Arbeit«, in: Sozialarbeit in Österreich 2007/2, S. 8-17.

Stefanowitsch, Anatol (2012): Flüchtlinge zu Geflüchteten? in: Sprachlog vom 12.12.2015, www.sprachlog.de/2015/12/12/fluechtlinge-zu-gefluechteten/, Abrufdatum: 16.05.2020.

Täubig, Vicki (2009): Totale Institution Asyl. Empirische Befunde zu alltäglichen Lebensführungen in der organisierten Desintegration, Weinheim/München: Juventa.

Youtube (2019): »Demokratie verstehen - Horst Seehofer CSU »Man muss Gesetze komplizierter machen«, hochgeladen von "grafbyte« am 08.06.2019, https://w ww.youtube.com/watch?v=wJAxwiUYJMA, Abrufdatum: 16.05.2020.

\section{Interviews}

Interview mit Bukola, geführt im Januar 2020, Länge: 0:26:51. Interview mit Lamin, geführt im Februar 2020, Länge: 1:45:41. Interview mit Aleeke, geführt im Februar 2020, Länge: 1:09:13. Interview mit Tayo, geführt im April 2020, Länge: 0:44:08. Interview mit William, geführt im April 2020, Länge: 1:20:06. 
Politische, soziale und rechtliche Aushandlungen 



\section{Lager - Prognosen - Labels Zur Rolle der »Bleibeperspektive« im bayerischen Unterbringungssystem}

Simon Sperling und Sebastian Muy

\section{Zusammenfassung}

Prognosewissen spielt bei Fragen der bayerischen Unterbringungspolitik eine große Rolle. So führte die Bayerische Landesregierung seit 2015 mit den Ankunfts- und Rückführungseinrichtungen (ARE), den Transitzentren und den Ankerzentren mehrere Unterbringungskonzepte ein, bei denen Asylsuchende nach unterschiedlichen Arten von »Bleibeperspektiven« kategorisiert und reguliert werden sollten. Zugleich werden derartige Aufenthaltsprognosen im Lagerkontext von verschiedenen Akteur"innen angezweifelt und revidiert. Ziel des Beitrags ist es, diesen Aushandlungsprozessen nachzugehen. Dabei zeigen wir, wie die bayerische Landesregierung Bleibeprognosen für Belegungsund Verteilungsfragen nutzt, und argumentieren, dass die Zuschreibung von schlechten oder unklaren »Bleibeperspektiven« als »selbsterfüllende Prophezeiung « faktisch Bleibechancen verschlechtern kann. Zudem machen wir deutlich, dass das Lagerarrangement auch auf subjektiver Ebene schlechte »Bleibeperspektiven« produzieren soll, um die Rückkehrwilligkeit zu fördern. Diese Regulationsversuche von Behördenseite bleiben allerdings nicht unhinterfragt. So greifen auch die Bewohner*innen selbst auf eigene Prognosen zurück, um ihre faktischen Aufenthaltschancen zu erhöhen. Prognostischen Zuschreibungen, so schlussfolgern wir, sind selbst Teil der Kämpfe um Aufenthaltschancen und haben faktisch Einfluss auf die Möglichkeiten, »Bleibeperspektiven«zu schaffen.

\section{Summary}

Prognosis of future residence plays a major role in Bavarian accommodation policies. Since 2015, the Bavarian state government has introduced several accommodation concepts: the »Ankunfts- und Rückführungseinrichtungen« (ARE), the »Transitzentren « and the »Ankerzentren«, in which asylum seekers were to be categorised and regulated according to different types of prospects to stay (»Bleibeperspektiven«). At the same time, such forecasts are questioned and 
revised by various players in camp-related contexts. The aim of this paper is to investigate these negotiation processes. We show how the Bavarian government uses prognoses of future residence for matters of accommodation and argue that the attribution of low prospects to stay worsens the actual likelihood to stay in the country, like a self-fulfilling prophecy. In addition, we point out that the configuration of the camp is also intended to produce poor "prospects to stay« on a subjective level, in order to incentivise the willingness to return. However, the government's attempts of regulation do not remain unquestioned, as the residents themselves rely on their own prognoses to increase their actual chances of staying. Prognostic ascriptions themselves, we conclude, are part of the struggles about residence and de facto influence the possibilities of creating »prospects to stay«.

\section{Einleitung}

Seit 2015 sind die bayerischen Sonderaufnahmeeinrichtungen für Geflüchtete in aller Munde. Von manchen Medien als »Balkanlager« (Donaukurier 2015) deklariert, sollten die Ankunfts- und Rückführungseinrichtungen (ARE) und ebenso die bayerischen Transitzentren dazu dienen, Asylsuchende aus bestimmten Herkunftsländern in Schnellverfahren zu prozessieren und abzuschieben. Kriterium für die $\mathrm{Zu}$ weisung in die Lager war die Zuschreibung einer geringen »Bleibeperspektive«, das heißt einer negativen Prognose über den künftigen Verbleib in Deutschland, die dann in veränderter Form auch in den ab 2018 entstandenen Ankerzentren genutzt wurde. Während einige wissenschaftliche Beiträge existieren, die die Situation in deutschen Flüchtlingslagern untersuchen (z.B. Pieper 2008; Deutsches Institut für Menschenrechte 2017) und dabei zum Teil auch die neueren Entwicklungen v.a. im Kontext der Ankerzentren in den Blick nehmen (vgl. z.B. Schmitt 2020; Hess et al. 2018; Schader/Rohmann/Münch 2018), gibt es keine Arbeiten, die sich explizit mit der Frage von Aufenthaltsprognosen im Rahmen von Unterbringungspolitiken beschäftigen. Dementsprechend wollen wir in diesem Beitrag herausarbeiten, welche Rolle prognostische Überlegungen bei der Umsetzung und Infragestellung der bayerischen Unterbringungspolitik spielen.

Theoretisch orientiert sich der Beitrag dabei an der Grenzregimeanalyse (vgl. Transit Migration Forschungsgruppe 2007), indem er Grenz- bzw. Migrationspolitiken als dynamische, multiskalare und häufig konfliktive Aushandlungsprozesse versteht, in denen Versuche von Regulation stets v.a. auch durch die eigensinnigen Praktiken der Migrierenden selbst herausgefordert werden. Analog zu anderen Arbeiten, die etwa auf das Konzept des »Geschlechterwissen[s] (Dölling 2005) zurückgreifen, um migrationspolitische Aushandlungsprozesse zu analysieren (vgl. Hess/Schwenken/Neuhauser 2017; Eberhardt/Schwenken 2010), nutzt der Beitrag 
das Konzept des >Prognosewissens $\triangleleft$, das wir aus der Forschungsliteratur zu sozialer Prognostik ableiten. Grundsätzliches Ziel von Prognosen ist es demnach, »die für die Praxis konstituierende Offenheit der Zukunft zu schließen« (Behrend 2005: 88). Sie konstruieren dabei Möglichkeitsräume, die Komplexität im Hinblick auf Entscheidungsfindungsprozesse reduzieren. Manche Handlungen erscheinen im Lichte der so entwickelten Zukunftsszenarien naheliegender, während andere stärker ins Abseits rücken oder gar verworfen werden können. Geht man nicht von einem abbildtheoretischen Zugang zur Welt aus, so ist klar, dass Prognosen zudem immer nur eine Beschreibung sozialer Wirklichkeiten unter mehreren sind. Sie sind damit eng mit vorhandenen Macht/Wissen-Komplexen (vgl. Foucault 2013: 39) verschränkt, in denen manche Prognosen hegemonial werden, während andere in den Hintergrund rücken. Analog zur Konzeptualisierung von Geschlechterwissen, lässt sich dabei auch Prognosewissen als »strategische Ressource« (Dölling 2005: 50) für »symbolische Kämpfe um die Legitimität bzw. Dominanz von Deutungen bzw. Klassifizierungen sozialer Wirklichkeit« (ebd.) beschreiben. Einerseits stellt das Prognosewissen dabei selbst den Verhandlungsgegenstand dar. Andererseits wird auf Prognosewissen zurückgegriffen, um mögliche künftige Ereignisse zu beeinflussen (vgl. Stagl 2016: 19). Prognosen haben insofern potenziell auch Auswirkungen auf das Prognostizierte selbst (vgl. Merton 1965). Sie können zur Selbsterfüllung aufrufen oder als Warnung dienen.

Dementsprechend wird es im Folgenden darum gehen, herauszuarbeiten, wie unterschiedliche Akteur*innen im Rahmen der Unterbringungspolitik auf Formen von Bleibeprognosen zurückgreifen, wie sie Prognosewissen untereinander aushandeln und welche Rolle dieses Wissen in der Praxis spielt, um reale Bleibechancen zu erhöhen bzw. zu verringern. Zunächst gehen wir der Frage nach, wie Aufenthaltsprognosen für Belegungs- und Verteilungsentscheidungen genutzt werden. Wir argumentieren, dass die Zuschreibung einer »schlechten Bleibeperspektive« in den neu erprobten bayerischen Lagertypen faktisch die Bleibechancen von Asylsuchenden verringert. Die Prognose »schlechte Bleibeperspektive« erfüllt sich dementsprechend in diesem Kontext tendenziell selbst. Danach zeigen wir, wie durch das Lagerarrangement und Beratungsprozesse vor Ort auch subjektiv »schlechte Bleibeperspektiven « vermittelt werden (sollen). Vor allem in den Abschnitten Identitätsklärung und Returnability wird deutlich, dass die Bewohner*innen im Lager diese Politiken aber selbst in Frage stellen, indem sie sich Rückführungsbestrebungen widersetzen und Weiterverlegungen einfordern. Auch sie nutzen dabei Formen von Bleibeprognosen, die allerdings andere Kriterien bzw. andere Referenzräume heranziehen. In einem kurzen letzten Teil ermitteln wir statistisch alternative Berechnungen von realen Bleibechancen und gehen darauf ein, welche Auswirkungen speziell die Sonderlager auf Mobilitätsentscheidungen haben.

Das empirische Material stammt aus Dokumenten sowie Interviewmaterial, das beide Autoren im Rahmen ihrer jeweiligen Promotionsprojekte in den Jahren 
2019/2020 erhoben haben, und bezieht sich auf zwei bayerische Ankerzentren. ${ }^{1}$ Sie setzen sich aus Interviews mit Geflüchteten (9 in Lager A/7 in Lager B), Sozialarbeiter*innen ( 2 in Lager $A / 4$ in Lager $B$ ) und mit dem Vertreter der für Lager $B$ zuständigen Bezirksregierung zusammen. ${ }^{2}$ Um die Perspektive der bayerischen Landesregierung zu rekonstruieren, greifen wir zudem auf Presseerklärungen zurück.

\section{Belegungspolitik und die Produktion von negativen Aufenthaltschancen}

\section{Prognosekriterien und Belegung}

Aufenthaltsprognostische Argumente spielten bei der Belegungspolitik der bayerischen Sonderlager eine große Rolle. So sollten seit 2015 in neu gegründeten Ankunfts- und Rückführungseinrichtungen (ARE) speziell Geflüchtete aus den Balkanstaaten wegen ihrer "geringen Bleibeperspektive« bzw. ihrer Herkunft aus sogenannten "sicheren Herkunftsstaaten« (BStMI 2015d) untergebracht werden. Die Regierung betonte dabei einerseits, dass die Anträge schlicht aussichtslos seien (vgl. BStMI 2016b, 2015c u.a.), andererseits wurde den Geflüchteten hierbei pauschal auch die Schutzbedürftigkeit abgesprochen, was zudem mit dem Vorwurf des »Asylmissbrauch[s] «(BStMI 2015b) einherging. Als die Antragszahlen von Asylsuchenden aus den Balkanländern zurückgingen (vgl. BStMI 2016a) erweiterte die bayerische Landesregierung den Begriff der "geringen Bleibeperspektive« und ab spätestens April 2016 wurden auch Geflüchtete aus der Ukraine in der Einrichtung untergebracht (vgl. BayLT 2016b). In der Antwort auf eine Landtagsanfrage wird die Gruppe der in den ARE untergebrachten Menschen nun als »Personen aus sicheren Herkunftsländern sowie mit geringer Bleibeperspektive« (ebd.) definiert. Mit der Einführung der Transitzentren ${ }^{3}$ am 21.03.2017 wurde die Kategorie "schlechte Bleibeperspektive« dann abermals ausgeweitet. Sie umfasste nun alle Gruppen von Asylsuchenden, deren Anerkennungsrate im Asylerstverfahren weniger als 50 Prozent betrug. Damit entsprach die bayerische Festlegung der Definition der Bundesregierung, die bereits seit 2015 den Zugang zu z.B. Sprachkursen oder Ausbildungsfördermaßnahmen auf die derart definierte Gruppe der

Da die beiden Promotionsprojekte unterschiedliche Fragestellungen verfolgen, wurden nicht in allen Interviews die gleichen Fragen gestellt, weshalb die Materialfülle bei verschiedenen Themen unterschiedlich dicht ist. wohner*innen), ASA 1-6 (Asylsozialarbeiter“innen), BezReg (Vertreter*innen Bezirksregierung). Um die Anonymisierung zu verstärken, wird nicht erkennbar sein, welchem der beiden Lager die jeweiligen Bewohner*innen und Sozialarbeiter*innen zugeordnet sind. 
Asylsuchenden mit "guter Bleibeperspektive« beschränkte. Die Landesregierung nutzte, wie auch die Bundesregierung, für ihre Begründung die Asylstatistik des BAMF. So heißt es z.B. bezüglich der ARE:

»Dort werden speziell Asylbewerber ohne Bleibeperspektive untergebracht, derzeit knapp 530. Fast alle aktuell dort untergebrachten Asylbewerber kommen aus den Westbalkanstaaten und haben in nahezu 100 Prozent der Fälle keine Chance auf Anerkennung.« (BStMI 2016b)

Die Statistik sollte insofern auch die fehlenden Bleibechancen belegen. Mit der Einführung der Ankerzentren am 1. August 2018 wurden schließlich alle ankommenden Asylsuchenden in Bayern zunächst in diesen Lagern untergebracht. Während einige der Zentren neu eröffnet wurden, führte die Regierung die Transitzentren unter neuem Namen weitestgehend unverändert weiter. Auch in den Ankerzentren werden bleibeprognostische Kategorien für Verteilungsfragen genutzt. Allerdings soll dadurch nun nicht mehr wie zuvor der Einzug, sondern der Auszug geregelt werden. So heißt es etwa im Koalitionsvertrag, in dem die Einrichtung der Ankerzentren zunächst beschlossen wurde:

»Wir streben an, nur diejenigen auf die Kommunen zu verteilen, bei denen eine positive Bleibeprognose besteht. Alle anderen sollen, wenn in angemessener Zeit möglich, aus diesen Einrichtungen in ihre Heimatländer zurückgeführt werden.« (CDU, CSU, SPD 2018: 107)

Und auf der Website der bayerischen Landesregierung heißt es: »Die Anschlussunterbringung dient insbesondere der Unterbringung von Asylsuchenden mit positiver Bleibeperspektive.«(BStMI o.J.). Während sich das Kriterium »Bleibeperspektive« aber zuvor an der herkunftslandspezifischen Schutzquote orientierte, gibt es nun sehr unterschiedliche Antworten darauf, was der Begriff in diesem Kontext bedeuten soll. Nach längeren Recherchen v.a. in einer der beiden untersuchten Einrichtungen und Kontaktaufnahme mit (sich diesbezüglich teils widersprechenden) Akteur*innen vor Ort (Landesregierung, Mittelregierung, Stadtverwaltung, Ausländerbehörde, Sozialdienst, Bewohner*innen) wurde deutlich, dass der Begriff in der Praxis zweierlei Gruppen bezeichnet. Eine positive »Bleibeperspektive« haben in dieser Einrichtung einerseits Geflüchtete, die eine positive Schutzzuerkennung haben und andererseits Asylsuchende, denen das BAMF individuell und nicht ausschließlich nach dem Kriterium des Herkunftslandes eine positive Bleibeprognose zuschreibt. Umgekehrt haben demnach nun alle anderen Asylsuchenden, die sich noch im Lager befinden, zumindest keine "positive Bleibeperspektive«. Hintergrund für die Benutzung der Prognosekategorie in diesem Ankerzentrum ist eine Vereinbarung zwischen Kommune und Landesregierung, wonach außerhalb des Ankerzentrums keine weiteren Asylsuchenden in die Stadt verlegt werden sollen. Nun können Asylsuchende nur im laufenden Verfahren bzw. bei Ablehnung 
des Asylantrags zur Wohnsitznahme in anderen staatlichen Gemeinschaftsunterkünften gezwungen werden, aber nicht mehr, nachdem ihnen ein Schutzstatus zuerkannt wurde. Um zu verhindern, dass Asylsuchende im Wohnungslosensystem der Kommune landen, in denen sich das Ankerzentrum befindet, werden sie bei positiver Prognose in Gemeinschaftsunterkünfte verteilt, die sich in der Regel in anderen Kommunen befinden (vgl. E-Mail ASA1). Wer nun im Einzelfall eine "positive Bleibeperspektive« besitzt und wie diese individualisierte Prognose genau vom BAMF berechnet wird, ist von außen kaum einsehbar. Die Interviews legen aber nahe, dass die Festlegung nicht zuletzt auch von Aushandlungsprozessen zwischen Asylsuchenden und Behörden abhängen.

\section{Isolationsstrategien}

Die bayerische Landesregierung schreibt den Einrichtungen ARE, Transitzentren und Ankerzentren das primäre Ziel zu, Verfahren und Abschiebungen zu beschleunigen. So definiert die Regierung das zentrale Ziel der ARE wie folgt: »Wir brauchen diese Einrichtung dringend, um zu einer schnelleren Bearbeitung und Abwicklung der Asylverfahren für Antragsteller ohne Bleibeperspektive zu kommen.« (BStMI 2015a) Bezüglich der Transitzentren heißt es: »Mit bayerischen Transitzentren für Asylbewerber mit geringer Bleibeperspektive wollen wir die Verfahren beschleunigen und zeitnahe Rückführungen ermöglichen.« (BReg 2017) Und auch der Bayerische Asylplan forderte bezüglich der Ankerzentren "schnellere und effektivere Verfahren - von der Einreise bis zur Rückführung « (BReg 2018). ${ }^{4} » B l e i b e p e r s p e k t i v e n «$, so legen diese Aussagen der Regierung nahe, werden durch die Landesregierung nicht beeinflusst. Die Aufenthaltschancen ergeben sich durch die Passung bzw. Nicht-Passung von Fallkonstellationen mit dem bundesrechtlichen Rahmen, während die Landesregierung den Prozess nur beschleunigt. Dementgegen lässt sich argumentieren, dass sich das Lagerarrangement faktisch auch selbst negativ auf die realen Bleibechancen von Asylsuchenden auswirkt. So hieß es bereits im Konzept für die bayerischen Transitzentren: »Neuankommende Asylbewerber mit geringer Bleibeperspektive sollen künftig nicht mehr bayernweit auf die Kommunen verteilt werden, um zu verhindern, dass sich der Aufenthalt verfestigt.«(BReg 2017) Explizit soll also die Verfestigung des Aufenthalts von Asylsuchenden verhindert werden, die zuvor als Personen mit "geringer Bleibeperspektive« gelabelt wurden. Die Argumentation ist damit spiralförmig: Die Zuschreibung einer "schlechten Bleibeperspektive« soll immer noch schlechtere Bleibeaussichten nach sich ziehen. Während die Regierung in der Praxis schon in der ARE Isolationsstrategien nutzte und etwa Schulunterricht

$4 \quad \mathrm{Zu}$ ähnlichen Narrativen über Ankerzentren im öffentlichen Diskurs siehe den Beitrag von Tanja Evers in diesem Band. 
(vgl. BKM 15.12.2017) und Freizeitgestaltung (vgl. BStMI 2015a) innerhalb der Einrichtung etablierte, wird nun explizit, dass es dabei auch um Fragen des Aufenthalts geht. Technisch sollte die Separierung nicht zuletzt durch die Einrichtung von Gemeinschaftsunterkünften auf und um das Gelände der Transitzentren perpetuiert werden (vgl. Bay. LT 2017a: 3), wodurch die bundesrechtlichen Fristen zum Verbleib in Erstaufnahmeeinrichtungen de facto umgangen wurden. Auch mit der Entstehung der Ankerzentren wurde das Prinzip, Asylsuchende erst nach Schutzzuerkennung bzw. positivem Prognoseentscheid auf die Kommunen zu verteilen, beibehalten. Dementsprechend schildert Bundesinnenminister Seehofer bezüglich der Ankerzentren im Interview:

»Die Schwierigkeit ist doch: Wenn Zuwanderer jahrelang hier sind, können sie immer schwerer zurückgeführt werden, weil sie Wurzeln geschlagen haben. Deshalb setze ich auf die neuen >AnkER-Zentren<, wo die Ankunft, die Verfahren und die Rückführung gebündelt und beschleunigt werden. Dort wird, noch bevor die Asylbewerber auf die Cemeinden verteilt werden, entschieden: Wer hat ein Recht auf Schutz und wer nicht.«(SPIEGEL 2018)

Auch hier ist es also das Ziel, eine >Verfestigung des Aufenthalts d durch den Kontakt zur umliegenden Bevölkerung zu verhindern. Was in den Transitzentren nur für Personen mit »schlechter Bleibeperspektive« galt, gilt nun zumindest zu Beginn für alle ohne "positive Bleibeperspektive« bzw. Schutzentscheid, wobei Personen mit positivem Prognoseentscheid ${ }^{5}$ das Lager ggf. vergleichsweise schnell wieder verlassen.

\section{Schutzzuerkennungsraten}

Von verschiedener Seite wurde zudem argumentiert, dass die Schutzzuerkennungschancen in den bayerischen Ankerzentren geringer seien als andernorts (vgl. Heinhold 2019). Aus der erweiterten Asylstatistik der Bundesregierung ergibt sich dementsprechend, dass sich von den neun BAMF-Außenstellen, bei denen die reale Schutzquote im Vergleich zu der zur Kontrolle errechneten Referenz-Schutzquote ${ }^{6}$

6 »Durch die Bildung der Referenzschutzquote soll die Möglichkeit geschaffen werden, Vergleichsmaßstäbe zu bilden, die die Schutzquoten nicht bieten. Die Referenzschutzquote wird je Organisationseinheit gebildet, um eine methodische Vergleichsbasis zur Entscheidungspraxis der Organisationseinheiten auf der Grundlage der jeweils entschiedenen Herkunftsländer zu erhalten. Die Anzahl an entschiedenen Verfahren je Herkunftsland und je Organisationseinheit wird mit der für das Herkunftsland üblichen Bundesschutzquote bewertet und so ein neuer Mittelwert gebildet. Die Referenzschutzquote vergleicht das je Orga- 
besonders niedrig ausfällt, vier in bayerischen Ankerzentren befinden (in Manching beträgt die Abweichung zur Referenz-Schutzquote $9 \%$, in Zirndorf $9 \%$, in Regensburg 8,6\%, in Schweinfurt 7,3\%) (vgl. BT 2019: 23). Während das BAMF argumentiert, dass die starke Negativabweichung bei der Schutzzuerkennung "von individuellen Merkmalen der Antragsteller, unterschiedlich hohem Aufkommen von Personengruppen oder Unterschieden in der regionalen Verteilung abhängen « können (ebd.: 24), werden von anderer Seite Aspekte betont, die unmittelbar mit den Einrichtungen zusammenhängen. So nennt Heinhold etwa folgende Gründe:

»1. die mangelnde Beratung der Asylsuchenden [...] und

2. das Klima in den >ANKER-Zentren<, das nicht nur die dort Untergebrachten demotiviert und aggressiv macht, sondern reflexiv auch Auswirkungen auf die Anhörungen und infolgedessen die Entscheidungen hat und

3. das Zusammenwirken zwischen den vorgenannten Punkten und der Schnelligkeit des Verfahrens.« (Heinhold 2019: 6)

Im Interview mit den Beratungsstellen (vgl. Interview mit ASA1 u. ASA2) wurde zudem darauf hingewiesen, dass es im Umfeld der Einrichtungen keine und nur unzureichend Fachanwält"innen für Asylrecht gibt. Außerdem wiesen Interviewpartner*innen auf weitere Schwierigkeiten hin, die sich aus den Schnellverfahren ergaben. So war es in der Regel nicht möglich, ggf. psychotherapeutische Atteste fristgerecht einzureichen, zumal die Möglichkeiten für Therapie und Behandlung wegen der eingeschränkten Gesundheitsversorgung nach dem Asylbewerberleistungsgesetz sowie der Lagerunterbringung prinzipiell stark begrenzt sind. Ebenso konnten die Sozialdienste Geflüchtete in der Praxis nicht auf die BAMF-Anhörung zu den Fluchtgründen vorbereiten, weil die Anhörung bereits wenige Tage nach der Ankunft der Schutzsuchenden stattfindet und die Zuständigkeit für die Durchführung der Asylverfahrensberatung im Zuge der »Anker-Werdung« 2018 zunehmend dem BAMF selbst übertragen wurde. ${ }^{7}$ Sie wiesen in den Interviews zudem auf starke Kapazitätsmängel hin, die sich ebenfalls auf die Beratungsmöglichkeiten niederschlagen. Während sich das Rätsel der relativ geringeren Anerkennungsquoten auch hier nicht vollständig auflösen lässt, zeigte die Untersuchung aber zumindest, dass Schutzgründe im Lageralltag zum Teil nicht oder nur ungenügend geltend gemacht werden können.

nisationseinheit entschiedene Mengenvolumen mit dem entsprechenden Bundesschnitt.« (BT 2018)

7 Behrens (2020) kritisiert, dass mit dem BAMF ausgerechnet die Behörde mit der Asylverfahrensberatung betraut wird, die über die Anträge entscheidet und im Falle eines Klageverfahrens Klagegegnerin ist. Eine unparteiische und bedarfsgerechte Beratung der Asylsuchenden durch die Behörde sei daher schon aus rechtlichen und strukturellen Gründen nicht zu erwarten, was sich negativ auf die Schutzzuerkennungschancen auswirken könne. Siehe dazu auch den Beitrag von Mathias Schmitt in diesem Band. 


\section{Produktion subjektiver "Bleibeperspektiven«}

\section{Returnability}

Neben den Auseinandersetzungen um den aufenthaltsrechtlichen Status und die praktische Abschiebbarkeit gibt es Konflikte um die subjektiven »Bleibeperspektiven« bzw. die Rückkehrwilligkeit der Geflüchteten. Wenngleich in den analysierten Regierungsdokumenten nicht explizit formuliert, lässt sich argumentieren, dass die widrigen Lebensbedingungen in den bayerischen Sonderlagern Geflüchtete faktisch zur Ausreise drängen (sollen) und darauf abzielen, die Einreise zum vermeintlichen "Asylmissbrauch « unattraktiv zu machen. Dementsprechend fasst einer der Bewohner das Ziel des Unterbringungsarrangements wie folgt zusammen: »Es ist alles gemacht, und diese schlechte Bedingungen dienen zuerst dafür, Leute abschrecken. " (Interview mit Bew5) Angesichts des historischen Hintergrundes, vor dem sich in Deutschland die Unterbringung von Geflüchteten in Lagern entwickelte, ist die Annahme durchaus plausibel. So wurden schon bei ihrer Etablierung in den 1980er Jahren Abschreckungsmotive explizit geäußert (vgl. Pieper 2008: 46ff.). Im Bayerischen Asylplan heißt es, mit einem »klaren Bekenntnis zum Sachleistungsprinzip « in den bayerischen Unterkünften mache man deutlich, dass das Asylrecht "nicht zur Einwanderung in unser Sozialsystem « diene (BReg 2018: 3). Bezüglich der Ankerzentren formulierte Horst Seehofer im April 2018 im SPIEGEL: »Am Ende werden die >AnkER-Zentren dazu beitragen, dass es deutlich weniger Zuwanderung nach Deutschland gibt.« (zit.n. SPIEGEL 2018) Gleichwohl ist davon auszugehen, dass die Ausreisewilligkeit der Geflüchteten faktisch durch das Zusammenwirken ganz verschiedener Akteur*innen (wie z.B. Mitarbeiter*innen der Ausländerbehörde, der Lagerorganisation, der Security und der Sozial- und Rückkehrberatung) beeinflusst wird, die im Rahmen ganz unterschiedlicher Logiken agieren und sich teilweise auch widersprechen (vgl. Bartels 2019: 344). Den Effekt solcher Praktiken fasst Bartels als returnability bzw. Rückführbarkeit, d.h. die »Erzeugung eines prekären Zustandes, der die Migrant*innen zur Mitwirkung an ihrer Rückkehr [bewegt bzw.] bewegen soll, die als freiwillig deklariert wird « (ebd.). Dementsprechend schilderten die interviewten Bewohner*innen durchgehend die besonderen Härten in den Einrichtungen. Sie problematisierten die Isolation, die sich für sie aus der Residenzpflicht, der Abgeschiedenheit der Unterkunft, stark eingeschränkten Besuchsmöglichkeiten, dem Ausschluss von regulärem Schulunterricht sowie von regulärer Kinderbetreuung ergaben. Als »prison«bzw. »Gefängnis« (Interview mit Bew1u.2, Bew3, Bew5, Bew9, Bew6 u.a.) verdichtet sich der Ort in einigen Interviews vor dem Hintergrund des umzäunten Geländes, den Zimmerdurchsuchungen, Einlasskontrollen und den damit verbundenen Leibesvisitationen, wozu auch noch die Allgegenwärtigkeit von Abschiebungen kommt. Darüber hinaus beklagten viele die fehlende Privatsphäre in den von mehreren 
Personen geteilten Zimmern sowie dadurch, dass weder Schlafzimmer noch Badezimmer noch Schränke abschließbar sind und Sicherheitsbedienstete und Polizist*innen ohne Einholung einer Erlaubnis die Zimmer betreten. Auch die eingeschränkte Gesundheitsversorgung, das Kantinenessen und andere Formen der Sachleistungsversorgung und Einschränkungen des täglichen Bedarfs wurden immer wieder problematisiert. Zudem beschrieben sie Gefühle von Entmündigung, Nutzlosigkeit und Langeweile, die sich aus der erzwungenen Untätigkeit ergaben. Sie kritisierten die ihnen auferlegten Arbeitsverbote, sowie die Regel, weder selbst kochen zu dürfen noch befugt zu sein, Essen von außerhalb in die Einrichtung zu bringen. »He just eats (C: sleep), sleep, (C: eat, sleep), wake up, eat, sleep, good two years (Interview mit Bew1u.2), fassen zwei Interviewparter*innen ihren Alltag zusammen. Darüber hinaus schilderten viele der Gesprächspartner*innen Konflikte mit anderen Bewohner*innen, die sich aus den äußeren Umständen ergeben, Schikane und Gewalt durch Securities und verschiedene Formen von Diskriminierung und Rassismus. ${ }^{8}$ Auf die Frage nach den eigenen Zukunftsplänen fasste einer der Interviewpartner zusammen:

»In, in that camp there is no future. (C: There is not any future in that camp) In that camp, no future. [...] Because they are killing our future. They are bringing us down. [...] No future! No ambition! No focus! No directives! Nothing, nothing! That is why we are crying.« (Interview mit Bew1u.2)

Dementsprechend verwiesen zwei Interviewpartner darauf, dass sie die Aussicht, noch über längere Zeit im Lager bleiben zu müssen, schlicht nicht mehr ertragen konnten und dies letztendlich den Grund oder einen der Gründe darstellte, den Asylantrag zurückzuziehen (vgl. Interview mit Bew5) bzw. keine weiteren Rechtsmittel einzulegen:

I: »Warum ist keiner zum Anwalt gegangen oder zum Verwaltungsgericht?«

B: »Weil das zum Beispiel, das war so dauert, das einfach zu bekommen vom Bundesamt. Das war ein Jahr oder eineinhalb Jahre bis zu zwei Jahre konnte man warten, um zu bis man diese Antwort kriegt und deswegen: [Name der Unterkunft], das ist zu schwer. Das macht Kopfschmerzen und das macht Kopf kaputt. Wenn jemand lebt ein, zwei Jahre hier. Deswegen die wollen, die wollen nicht mehr. Weil wenn, zum Beispiel jemand macht die Klage, dann ist/dann es kommt noch ein, zwei Jahre. Deswegen, wir gehen raus, wir verstehen, dass zum Beispiel, wir sind Flüchtlinge und sowas, aber das ist zu schlecht, was hier gibt [...].« (Interview mit Bew4) 
Beide Interviewpartner trafen ihren Entschluss, obwohl sie auch im Herkunftsland keine Perspektive für sich sahen. Einer der beiden Interviewpartner erklärte explizit, sich für die Ausreise entschieden zu haben, obwohl er die Gefahrenlage in seinem Heimatland weiterhin als gefährlich einstufte:

I: »Was sind jetzt Ihre Pläne für die Zukunft?«

B: »In die Ukraine zurück, und dann, was passiert, dann passiert. Ich will nur kurz leben. Zumindest ein Monat in normale Wohnung, wo ich alleine bin, mit Wanne, mit Küche, mit alles. Und dann, wenn ich sogar tot werde, dann wäre es nicht so schrecklich für mich. Zumindest sehe ich mein Heimatland und etwas Komfort, mit normalen menschlichen Bedingungen. Was passiert, passiert, was sollte passieren.« (Interview mit Bew5)

Die übrigen Interviewpartner*innen hatten sich nicht zur Ausreise entschieden, obwohl auch sie von der Erschöpfung durch die Lagerbedingungen berichteten. Vor dem Hintergrund der Perspektivlosigkeit im Lager stand für sie die Hoffnung auf Auszug im Vordergrund. Dementsprechend bezogen sich prognostische Überlegungen der Bewohner*innen nicht nur darauf, ob sie nun wohl in Deutschland bleiben würden oder nicht, sondern auch auf die Frage, wann sie wohl aus der Einrichtung ausziehen könnten. Angesichts der Unklarheit über das Kriterium »Bleibeperspektive«, das in vielen Fällen für die Auszüge maßgeblich war, sowie des Umstands, dass teilweise auch die eigentlich rechtlich geltenden Verlegungsfristen nicht eingehalten wurden (vgl. Interview mit Bew6, Bew1o, Interview mit ASA1, ASA2), stellte sich die Ungewissheit über den Auszugstermin als besondere Belastung dar. So fragte etwa eine Interviewpartnerin rhetorisch: We will remain here, for long, for how many years? Everybody (else?) is saying:Yes, we are suffering.« (Interview mit Bew3) Die Bewohner*innen machten dementsprechend auch bei Verlegungsfragen die weitgehende Fremdbestimmtheit zum Thema, wobei zumindest einige der Interviewpartner*innen versuchten, dem etwas entgegenzusetzen. So schilderten Bewohner*innen, an Demonstrationen teilgenommen zu haben (vgl. Interview mit Bew1u.2), die neben den Zuständen und den eingeschränkten Möglichkeiten vor Ort sowie den Abschiebungen auch die ausbleibenden Verlegungen kritisierten. Aus Sicht eines Interviewpartners ergaben sich hieraus auch zumindest für manche Bewohner"innen konkrete Verbesserungen: »Because most of the times, most of these things, we are benefitting now, maybe, the transfer and stuff like that, is because we came together, that period. (Interview mit Bew6) Folgt man dem Argument ${ }^{9}$, so ließ sich faktisch die »Bleibeperspektive« im Lager (zumindest auf das eigentlich gesetzlich vorgesehene Mindestmaß) verkürzen. Angesichts der war, ließ sich im Rahmen der Forschung nicht abschließend klären. 
beschriebenen Prozesse und Umstände im und um das Lager kann gefolgert werden, dass dies wiederum potentiell auch Auswirkungen auf den längerfristigen Verbleib in Deutschland haben kann.

\section{Beratungspolitiken}

Auch bei der Beratung der Bewohner*innen sind Bleibeprognosen relevant. So versuchen verschiedene Akteur*innen, der jeweils eigenen Abschätzung von »Bleibeperspektiven« Geltung zu verschaffen und ggf. Geflüchtete von ihrer fehlenden »Bleibeperspektive« zu überzeugen. Dementsprechend schilderte ein Interviewpartner:

"Yeah, they explain to you from the first/ from the first day that you met Bundesamt, you go to the interview and they say to you. They say: You come from a safe country, you/ you have very little possibilities to win this procedure. If you want to go back yourself, we have some procedures to sign in.« (Interview mit Bew11)

Dezidiert wird hierbei also bereits vor Asylverfahrensabschluss auf die (vermeintlich) geringen Chancen für eine Schutzzuerkennung verwiesen, um Geflüchtete zur Rückreise zu motivieren (vgl. auch Interview mit Bew4, Bew9, Bew1o, Bew11, anders: Interview mit Bew7u.8). Wie aus zwei Interviews zudem hervorgeht, erhalten Bewohner* innen diese >Information< letztlich auch ungefragt: »Sowas, wenn ich erzähle über Ausbildung oder sowas, dann die sagen: Nein, musst du nach Ukraine ausreisen. (Interview mit Bew4; ähnlich: Interview mit Bew1o). In der Praxis bekommen Geflüchtete im Ankerzentrum bei Asylantragstellung zudem ein »Rückkehrinformationspaket« (vgl. Interview mit Bew6, Bay. LT 2017b), wobei im Falle einer Ablehnung weitere Informationen zur >freiwilligen Rückkehr folgen (ebd.).

Neben diesen behördlichen Informationen bezogen Geflüchtete ihr Wissen über Aufenthaltschancen aber auch von anderen Stellen, die ggf. alternative Einschätzungsarten von »Bleibeperspektiven« relevant machen konnten. So schilderte etwa einer der Bewohner, dass er von anderen Geflüchteten sowie einer Dolmetscherin beim Behördenbesuch in der Raucherpause auf seine geringen Chancen hingewiesen worden sei (vgl. Interview mit Bew4). Andere Interviewpartner*innen verwiesen auf Informationen durch andere persönliche Kontakte oder Selbstinformation über das Internet, die sie zur Chanceneinschätzung nutzen (vgl. Interview mit Bew5). Dementsprechend wird teilweise auch von den Geflüchteten selbst eine realistische Einschätzung von geringen Aufenthaltschancen als positiv beurteilt, um eigene Mobilitätsstrategien daran auszurichten. So antwortete etwa eine der Interviewpartner*innen auf die Frage, ob sie nach Ankunft im Lager von den Behörden über Rückkehroptionen informiert worden sei: »No! (B: No!). That was/ that is even better. If I/ I wish I came to the first time, I came to Germany, 
they said: No, you can't stay to Germany. I will go back. But not after staying a year and six month, they are telling me to go back to (France?).« (Interview mit Bew7) Andererseits können Bleibeprognosen und deren kommunikative Vermittlung zugleich potentiell als Element von Strategien betrachtet werden, auf die Rückkehrwilligkeit der Geflüchteten einzuwirken. Die Ambivalenz zwischen der Vermittlung von Orientierungswissen und einer Wissenspolitik, die letztlich auf die Produktion von Ausreisewilligkeit zielt, lässt sich letztlich grundsätzlich kaum auflösen. Klar ist aber, dass es teils erhebliche Unterschiede dabei gibt, wie die Akteur*innen Bleibeprognosen abschätzen und vermitteln. Während etwa genannte Regierungsstellen vielen Asylsuchenden schon vor Abschluss des Asylverfahrens zur Rückkehr raten, geschieht dies bei der Sozialberatung in der Regel erst nach erfolglosem Ausschöpfen der Rechtsmittel. Dementsprechend kann auch die Beratung über »Bleibeperspektiven« als umkämpftes Terrain betrachtet werden, auf dem faktische Bleibeentscheidungen beeinflusst werden.

\section{Identitätsklärung und eigensinnige Praktiken}

Während die Einrichtung konzeptionell darauf zielt, reale Bleibechancen zu verringern und die Rückkehrwilligkeit zu fördern, beschrieben mehrere Interviewpartner*innen eigensinnige Praktiken, durch die sie oder andere Bewohner*innen versuchten, ihre Aufenthaltschancen zu erhöhen. So berichteten Interviewpartner* innen etwa davon, wie ein Abschiebeversuch wegen Mitwirkungsverweigerung abgebrochen werden musste (vgl. Interview mit Bew6), wie sich Bewohner*innen über längere Zeit vor der Abschiebung verstecken konnten (vgl. Interview mit Bew7u.8) oder wie sie sich der Aufforderung der Passbeschaffung verweigerten (vgl. Interview mit Bew6), um Abschiebungen zu erschweren. ${ }^{10}$ Dies hatte mitunter weitere Repressionen und äußerst prekäre Lebensumstände zur Folge, die sich aus den behördlichen Bemühungen, Personen »abschiebbar « zu machen und dem daraus resultierenden Zustand der Deportability (De Genova 2002: 438) ergeben. Gleichzeitig schafften die Interviewten es faktisch aber (gerade bei Dublin-Fällen, in denen es v.a. darum ging, die Überstellungsfristen verstreichen zu lassen) dadurch auch, real ihre eigenen »Bleibeperspektiven« zu verbessern. Die Einrichtung der Ankerzentren zielte genauso wie die Vorgängereinrichtungen darauf, diese »eigensinnigen« (Benz/Schwenken 2005) Versuche von Geflüchteten, sich selbst »Bleibeperspektiven « zu schaffen, einzuschränken. Wie schon in den Vorgängereinrichtungen legte die Regierung im Koalitionsvertrag einen besonderen Fokus auf die Fragen von »Identitätstäuschungen« (CDU, CSU, SPD 2018: 107) bzw. auf den Versuch, die Bewohner*innen dazu zu bringen, Ausweisdokumente vorzulegen, um

10 Zu widerständigen Praktiken der Lagerbewohner*innen siehe auch den Beitrag von Simon Coebel in diesem Band. 
so die Abschiebungen zu erleichtern. Diese Strategie ist auf Seiten der Geflüchteten bekannt. So schilderte etwa eine* $r$ der Bewohner*innen: "When you get your passports, that's the way, the only thing, they will take to deport you to Nigeria.« (Interview mit Bew6) Nach der Interpretation des interviewten Vertreters einer Bezirksregierung nutzen Geflüchtete dieses Wissen auch, um reale Bleibechancen zu berechnen und ggf. daran eigene Mobilitätsprojekte auszurichten:

»Es ist natürlich auch so, dass die Asylbewerber manchmal wissen, wie wahrscheinlich es ist, dass ne Abschiebung stattfinden kann. Und es gibt halt Länder, in die findet keine Abschiebung statt, weil die [...] nicht mitspielen. Beispiel Senegal, Senegal verweigert sich praktisch den Abschiebungen, indem er keine Pässe ausstellt, oder keine Passersatzpapiere für seine Bewohner. Da wissen die Bewohner durchaus, dass das keine, also, dass die Abschiebung nicht funktionieren kann, entsprechend [...] wählen sie nicht die freiwillige Ausreise. (Interview mit BezReg)

Folgt man dem Argument, so gibt es neben der rein asylrechtlichen Prognose für die Geflüchteten selbst auch alternative Prognoseformen, die etwa Fragen von Abschiebewahrscheinlichkeiten mitberücksichtigen. Die Attraktivität der >freiwilligen Ausreise`, die viele Geflüchtete letztlich nur wählen, um der Abschiebung als noch schlechterer Alternative zu entgehen (vgl. Dünnwald 2013: 233), rückt im Rahmen des entsprechenden Prognosewissens in den Hintergrund, wodurch sich selbst neue, wenn auch oft prekäre »Bleibeperspektiven« ergeben können.

\section{Prognosen und Kämpfe um »Bleibeperspektiven«}

Wie wir in diesem Beitrag gezeigt haben, sind Prognosen über >Bleibewahrscheinlichkeiten keineswegs objektive und neutrale Aussagen. Stattdessen stehen sie als soziale Tatbestände (Durkheim 1984: 114) im Raum und wirken auf den Einzelnen zurück. Im Rahmen der bayerischen Belegungspolitiken dienen sie als selbsterfüllende Prophezeiung, wobei die Zuschreibung von schlechten oder unklaren »Bleibeperspektiven« faktisch Aufenthaltsmöglichkeiten verringern kann. Dabei werden sie manchmal von anderen gestützt, die ihr Prognosewissen teilen, und manchmal von Betroffenen und anderen Akteur*innen herausgefordert, die vermeintlich gegebene "Bleibeperspektiven « nicht akzeptieren wollen. Dementsprechend gibt es praktisch sehr unterschiedliche Arten, »Bleibeperspektiven« abzuschätzen. Seit 2015 besonders dominant war jedoch die Ableitung der »Bleibeperspektive« für Asylbewerber*innen aus den Schutzzuerkennungsquoten der jeweiligen Herkunftsländer. Dadurch allerdings wird tendenziell ausgeblendet, »dass Bleibeperspektiven sich völlig unabhängig vom Ausgang des Asylverfahrens und vom Herkunftsland ergeben können: Aus den unterschiedlichsten Gründen 
wird es auch in Zukunft vorkommen, dass Menschen trotz der ihnen zugeschriebenen sgeringen Bleibeperspektive auf Dauer in Deutschland bleiben." (Voigt 2016: 251) Claudius Voigt zeigt anschaulich, dass die Flucht aus einem Land mit einer niedrigen Schutzquote und auch ein abgelehnter Asylantrag in der Realität keineswegs immer in eine "geringe Bleibeperspektive« münden müssen:

»Die Realität hält sich nicht an Statistiken. Menschen heiraten oder bekommen Kinder und damit ein familiäres Aufenthaltsrecht; Menschen können aus bestimmten Gründen langfristig nicht abgeschoben werden und sind hier irgendwann verwurzelt, was ihnen die Chance auf ein humanitäres Aufenthaltsrecht eröffnet. Der Cesetzgeber hat in den letzten Jahren mit der Einführung der sogenannten Bleiberechtsregelungen nach § 25a und 25b AufenthG für Personen, die sich nachhaltig integriert haben, diese Realität anerkannt und ausdrücklich für geduldete Personen neue Aufenthaltsrechte geschaffen, um sinnvollerweise das Recht der Realität anzupassen.«(Ebd.: 247)

Einer Datenanalyse von Sebastian Ludwig im April 2019 ist zu entnehmen, dass rund die Hälfte der zwischen 2014 und 2018 abgelehnten Asylsuchenden sich noch in Deutschland aufhält und dass wiederum etwa die Hälfte dieser Personen mittlerweile im Besitz eines Aufenthaltstitels ist (vgl. Ludwig 2019: 4). Konkret im Falle der bayerischen Transitzentren ${ }^{11}$ machen die Statistiken der bayerischen Landesregierung aus dem Jahr 2017 deutlich, dass faktisch nur ein vergleichsweise geringer Teil der sausgezogenen Bewohner*innen abgeschoben bzw. überstellt wurde (1.261 Personen), während ein wesentlich größerer Teil (2.535 Personen) in der Kategorie »Fortzüge ins Ausland/Fortzüge nach unbekannt " geführt wird (Bay. LT 2018a: 5f.). Da über kontrollierte, ,freiwillige Ausreisen keine Statistiken existieren, ist letztlich unbekannt, wie hoch deren Anteil an dieser Zahl ist. Aber sowohl in den Geflüchteteninterviews (vgl. Interview mit Bew4, Bew11, Bew14) als auch in der Literatur (Hess et al. 2018: 6) wird darauf verwiesen, dass sausgezogene ‘ Geflüchtete in anderen europäischen Ländern Asyl gesucht hätten, andere untergetaucht und wieder andere zurück in ihr Herkunftsland gezogen seien. ${ }^{12}$ Zudem sind Ausreiseentscheidungen nicht immer endgültig. So erklärte etwa einer der Gesprächspartner, nun sogar schon zum dritten Mal von Deutschland in die Ukraine hin und wieder zurück gereist zu sein und dies auch im Falle einer anstehenden Abschiebung

11 Gleiches legen die Statistiken zumindest für das Jahr 2015 auch für die ARE nahe (Bay. LT 2016a). Für die Ankerzentren werden entsprechende Zahlen dagegen nicht mehr erfasst (Bay. LT 2019a u. b). Abweichende Abschiebezahlen nennt die Regierung auf eine andere Anfrage (Bay. LT 2018b). Der Kern der Aussage verändert sich aber auch hierbei nicht. »nicht nur möglich, sondern Teil der konzeptionellen Zielrichtung« sei: »Das Abtauchen in die >lllegalität< ist aus Behördensicht ein Erfolg des Konzepts der Forcierung der >freiwilligen Ausreise.«(Pieper 2008: 250) 
wieder versuchen zu wollen (vgl. Interview mit Bew4). Darüber, wie viele Personen letztlich in Deutschland bleiben werden, lässt sich dementsprechend nur spekulieren. Wie wir mit diesem Beitrag zu zeigen versuchten, ist dies zum Teil auch Resultat von Kämpfen um Bleibeprognosen, deren weiterer Verlauf offen ist.

\section{Literaturverzeichnis}

Bartels, Inken (2019): »>Rückführbarkeit fördern<: Das Zusammenwirken von freiwilliger Rückkehr und Abschiebungen in Nordafrika«, in: PERIPHERIE - Politik • Ökonomie • Kultur 156, S. 343-368.

[Bay. LT] Bayerischer Landtag (2016a): Freiwillige Rückkehr aus Bayern 2015, Drs. 17/10797.

[Bay. LT] Bayerischer Landtag (2016b): Anfragen zum Plenum vom 11. April 2016, Drs. 17/10940.

[Bay. LT] Bayerischer Landtag (2017a): Ankunftszentren und Transitzentren, Drs. $17 / 17526$.

[Bay. LT] Bayerischer Landtag (2017b): Abschiebungen und freiwillige Rückkehr aus Bayern 2016/2017, Drs. 17/18067.

[Bay. LT] Bayerischer Landtag (2018a): Personal und Bewohner der Aufnahmeeinrichtung Oberfranken sowie der Transitzentren Manching, Deggendorf und Regensburg, Drs. 17/20725.

[Bay. LT] Bayerischer Landtag (2018b): Abschiebungen 2017 und 2018 aus Bayern, Drs. $17 / 23537$.

[Bay. LT] Bayerischer Landtag (2019a): ANKER-Einrichtungen in Bayern I, Drs. 18/1695.

[Bay. LT] Bayerischer Landtag (2019b): Abschiebungen in Bayern, Drs. 18/3672.

Behrend, Olaf (2005): »Forschen und Wetten - zum Verhältnis von Diagnose und Prognose«, in: Michael Pfadenhauer/Ronald Hitzler (Hg.), Gegenwärtige Zukünfte. Interpretative Beitrage zur sozialwissenschaftlichen Diagnose und Prognose, Wiesbaden: Springer VS, S. 81-94.

Behrens, Falko (2020): "Asylverfahrensberatung ohne Rechtsberatung? Diskussionsbeitrag zur Umsetzung von \$12a AsylG«, in: Asylmagazin, Zeitschrift für Flüchtlings- und Migrationsrecht 1-2, S. 5-11.

Benz, Martina/Schwenken, Helen (2005): »Jenseits von Autonomie und Kontrolle. Migration als eigensinnige Praxis«, in: PROKLA - Zeitschrift für kritische Sozialwissenschaft 3(35), S. 363-377.

[BKM] Bayerisches Staatsministerium für Unterricht und Kultus (2015): Bayerns Bildungsministerium unterbreitet Kindern in Ankunfts- und Rückführungseinrichtungen in Bamberg und Manching Unterricht, vom 15.12.2015, https:// www.km.bayern.de/pressemitteilung/9907/.html, Abrufdatum: 20.05.2020. 
[BReg] Bayerische Staatsregierung (2017): Bericht aus der Kabinettssitzung vom 21. März 2017, https://www.bayern.de/bericht-aus-der-kabinettssitzung-vom-21maerz-2017/, Abrufdatum: 02.12.2020.

[BReg] Bayerische Staatsregierung (2018): Bericht aus der Kabinettssitzung vom 5. Juni 2018, https://www.bayern.de/bericht-aus-der-kabinettssitzung-vom-5Juni-2018/, Abrufdatum: 02.12.2020.

[BStMI] Bayerisches Staatsministerium des Inneren, für Sport und Integration (2015a): Max-Immelmann-Kaserne Ankunfts- und Rückführungseinrichtung für Asylbewerber vom Balkan, vom 30.07.2015, https://www.stmi.baye rn.de/med/pressemitteilungen/pressearchiv/2015/271/index.php, Abrufdatum: 20.05.2020.

[BStMI] Bayerisches Staatsministerium des Inneren, für Sport und Integration (2015b): Taschengeldkürzung und Sammelabschiebung, vom 18.08.2015, http $\mathrm{s}: / /$ www.innenministerium.bayern.de/med/pressemitteilungen/pressearchiv/ 2015/292/index.php, Abrufdatum: 20.05.2020.

[BStMI] Bayerisches Staatsministerium des Inneren, für Sport und Integration (2015c): Erstmals Rückführung aus Aufnahmezentren Ingolstadt/Manching, vom 08.09.2015, https://www.stmi.bayern.de/med/pressemitteilungen/presse archiv/2015/310/index.php, Abrufdatum: 22.05.2020.

[BStMI] Bayerisches Staatsministerium des Inneren, für Sport und Integration (2015d): Herrmann besucht Ankunfts- und Rückführungseinrichtung in Bamberg, vom 13.11.2015, https://www.stmi.bayern.de/med/aktuell/archiv/2015/151 113besuchbamberg/index.php, Abrufdatum: 20.05.2020.

[BStMI] Bayerisches Staatsministerium des Inneren, für Sport und Integration (2016a): Herrmann: Nur noch wenige Anträge von Asylbewerbern aus dem Balkan - Bayerisches Staatsministerium des Innern, für Sport und Integration, vom 24.02.2016, https://www.stmi.bayern.de/med/pressemitteilungen/presse archiv/2016/53/index.php, Abrufdatum: 20.05.2020.

[BStMI] Bayerisches Staatsministerium des Inneren, für Sport und Integration (2016b): Unterbringung in Bamberger Ankunfts- und Rückführungseinrichtung angemessen, vom 20.05.2016, https://www.stmi.bayern.de/med/pressem itteilungen/pressearchiv/2016/173/index.php, Abrufdatum: 20.05.2020.

[BStMI] Bayerisches Staatsministerium des Inneren, für Sport und Integration (o.J.): Unterbringung und Versorgung, o.D., https://www.stmi.bayern .de/mui/asylsozialpolitik/unterbringung_versorgung/index.php, Abrufdatum: 19.05.2020.

[BT] Deutscher Bundestag (2018): Ergänzende Informationen zur Asylstatistik für das erste Quartal des Jahres 2018, Drs. 19/3148.

[BT] Deutscher Bundestag (2019): Ergänzende Informationen zur Asylstatistik für das Jahr 2018, Drs. 19/8701. 
CDU, CSU, SPD (2018): Ein neuer Aufbruch für Europa. Eine neue Dynamik für Deutschland. Ein neuer Zusammenhalt für unser Land, Koalitionsvertrag vom 12.03.2018, 19. Legislaturperiode.

De Genova, Nicholas P. (2002): »Migrant >Illegality and Deportability in Everyday Life, « in: Annual Review of Anthropology 31(1), S. 419-447.

Deutsches Institut für Menschenrechte (2017): »Menschenrechtskonforme Ausgestaltung des Alltags in Gemeinschaftsunterkünften«, in: Deutsches Institut für Menschenrechte (Hg.), Entwicklung der Menschenrechtssituation in Deutschland Juli 2016 - Juni 2017. Bericht an den Deutschen Bundestag gemäß $\$ 2$ Absatz 5 DIMRG, Berlin, S. 45-61.

Dölling, Irene (2005): »'Geschlechter-Wissen< - ein nützlicher Begriff für die `verstehende`Analyse von Vergeschlechtlichungsprozessen?«, in: Zeitschrift für Frauenforschung \& Geschlechterstudien 23(1+2), S. 44-62.

Donaukurier (2015): Manching: Geplatzte Träume im Balkanlager, vom 28.01.2015, https://www.donaukurier.de/lokales/ingolstadt/Manching-Geplatzte-Traeum e-im-Balkanlager;art599,3139060, Abrufdatum: 19.05.2020.

Dünnwald, Stephan (2013): »Voluntary Return«, in: Martin Geiger/Antoine Pécoud (Hg.), Disciplining the Transnational Mobility of People, International Political Economy Series, London: Palgrave Macmillan UK, S. 228-249.

Durkheim, Emil (1984): Die Regeln der soziologischen Methode, Frankfurt a.M.: Suhrkamp.

Eberhardt, Pia/Schwenken, Helen (2010): »Gender Knowledge in Migration Studies and in Practice«, in: Christoph Scherrer/Brigitte Young (Hg.), Gender Knowledge and Knowledge Networks in International Political Economy, BadenBaden: Nomos, S. 94-114.

Foucault, Michel (2013): Überwachen und Strafen. Die Geburt des Gefängnisses, Frankfurt a.M.: Suhrkamp.

Heinhold, Hubert (2019): ANKER-Einrichtungen in Bayern. Anhörung im Bayerischen Landtag am 26.09.2019, München.

Hess, Sabine/Pott, Andreas/Schammann, Hannes/Scherr, Albert/Schiffauer, Werner (2018): Welche Auswirkungen haben >Anker-Zentren«? Eine Kurzstudie für den Mediendienst Integration, Berlin: Mediendienst Integration.

Hess, Sabine/Schwenken, Helen/Neuhauser, Johanna (2017): »Wie lässt sich genderanalytisch auf Geschlecht und Flucht blicken? Skizze eines Forschungsprogramms«, in: Corinna Onnen/Susanne Rode-Breymann (Hg.), Zum Selbstverständnis der Gender Studies, Leverkusen-Opladen: Budrich, S. 71-87.

Ludwig, Sebastian (2019): Inwiefern verlassen ausreisepflichtige Personen Deutschland nicht? Eine Datenanalyse, https:/www.diakonie.de/fileadmin/ user_upload/Diakonie/PDFs/Stellungnahmen_PDF/Verlassen_ausreisepflichtige_Personen_Deutschland_nicht___Eine_Datenana....pdf, Abrufdatum: 26.05.2020. 
Merton, Robert K. (1965): »Die Eigendynamik gesellschaftlicher Voraussagen«, in: Ernst Topitsch (Hg.), Logik der Sozialwissenschaften, Köln/Berlin: Kiepenheuer \& Witsch, S. 144-161.

Pieper, Tobias (2008): Die Gegenwart der Lager: Zur Mikrophysik der Herrschaft in der deutschen Flüchtlingspolitik, Münster: Westfälisches Dampfboot.

Schader, Miriam/Rohmann, Tim/Münch, Sybille (2018): »Isolation im Gesetz verankern? $\mathrm{Zu}$ den Plänen der großen Koalition, zentrale Aufnahme-, Entscheidungs- und Rückführungseinrichtungen einzuführen«, in: Z’Flucht Zeitschrift für Flüchtlingsforschung 2(1), S. 91-107.

Schmitt, Caroline (2020): »Vermessen, Klassifizieren, Zuweisen. Das AnKERZentrum als machtvolle Organisation der Asylverwaltung«, in: Soziale Passagen 12, S. 135-154.

SPIEGEL (2018): Horst Seehofer will härter mit abgelehnten Asylbewerbern umgehen, vom 21.04.2018, https://www.spiegel.de/spiegel/horst-seehofer-will-hae rter-mit-abgelehnten-asylbewerbern-umgehen-a-1204059.html, Abrufdatum: 19.05.2020.

Stagl, Justin (2016): »Zur Prognostik und ihrer Geschichte«, in: Reinhard Bachleitner/Marin Weichbold/Markus Pausch (Hg.), Empirische Prognoseverfahren in den Sozialwissenschaften, Wiesbaden: Springer VS, S. 17-33.

Transit Migration Forschungsgruppe (2007): Turbulente Ränder. Neue Perspektiven auf Migration an den Grenzen Europas, Bielefeld: transcript.

Voigt, Claudius (2016): »DieBleibeperspektive. Wie ein Begriff das Aufenthaltsrecht verändert«, in: Asylmagazin 8, S. 245-251.

\section{Interviews}

E-Mail ASA1 von April 2020.

Interview mit ASA1 von März 2019, 2 Std 5 min 12 Sek.

Interview mit ASA2 von Februar 2019, 1 Std 10 min 21 Sek.

Interview mit Bew1 und Bew2 von Februar 2019, Länge 32 min 57 Sek.

Interview mit Bew3 von März 2019, Länge 14 min 8 Sek.

Interview mit Bew4 von Dezember 2019, Länge: 55 min 41 Sek.

Interview mit Bew5 von Februar 2020, Länge: 39 min 25 Sek.

Interview mit Bew6 von Februar 2020, Länge: 52 min 35 Sek.

Interview mit Bew7 und Bew 8 von Februar 2020, Länge: 28 min 45 Sek.

Interview mit Bew9 von Februar 2020, Länge: 1 Std 18 min 49 Sek.

Interview mit Bew1o von Januar 2020, Länge: 1 Std 19 min 4 Sek.

Interview mit Bew11 von Januar 2020, Länge: 1 Std 47 min 25 Sek.

Interview mit Bew14 von Juni 2020, Länge: 36 min 33 Sek.

Interview mit BezReg von Juni 2020, Länge: 1 Std 14 min 3 Sek. 



\section{Das Lager als Nicht-Ort Anmerkungen zum Bamberger Ankerzentrum}

Daniel Göler

\section{Zusammenfassung}

Die Migration von Flüchtlingen nach Europa und das politische Management der Asylzuwanderung um 2015 haben sowohl sozial-räumlich entwurzelte Individuen als auch identitäts- und geschichtslose Orte hervorgebracht. Das »Ankerzentrum« in Bamberg, eröffnet im Sommer 2015 als ARE II (Ankunfts- und Rückführungseinrichtung - nomen est omen), stellt gleichsam die räumliche Verortung dieser These dar. In der Zusammenschau sind das alles Phänomene, deren Merkmalszüge Marc Augé 1992 in seiner Skizze zur Übermoderne in die konzeptionelle Denkfigur der »Nicht-Orte« überführt hat. Im Nicht-Ort steht die Funktionalität des Lokalen im Vordergrund; das Individuum wird sukzessive auf den Zweck des Ortes reduziert. Flüchtlingscamps, respektive Ankerzentren, folgen insofern Heterotopien im Foucault'schen Sinn: Sie sind das räumliche Produkt politischer Entscheidungen, sie spiegeln gesellschaftliche Verhältnisse und funktionieren nach eigenen Regeln. Im lokalen Zusammenhang betrachtet ist eine Erstaufnahmeeinrichtung lediglich ein unpersönlicher, entfremdeter Ort des Transits. Abgeschiedenheit, Zugangsbeschränkungen und Eingangsrituale unterstreichen die nur partielle und inkohärente Wahrnehmung des Ortes, aus dem nur wenig Information nach außen dringt. Im Beitrag werden Logiken eines Lagers am Beispiel der Bamberger Aufnahmeeinrichtung aufgezeigt, aus raumwissenschaftlich-geographischer Perspektive analysiert und Assemblagen des CampScapes auf empirischer Basis diskutiert.

\section{Summary}

The migration of refugees to Europe and the political management of asylum migration around 2015 have led to both socially and spatially uprooted individuals and places without identity or history. The »Ankerzentrum« in Bamberg, which was opened in summer 2015 as ARE II (acronym for arrival and repatriation facility - nomen est omen), represents the spatial location of this thesis. In synopsis, these are all phenomena the characteristics of which were transferred into the conceptual figure of thought of »non-places« by Marc Augé in his 1992 
draft on the supermodernity. In the non-place, the functionality of the local is in the centre of attention; the individual is successively reduced to the purpose of the place. Refugee camps, or »Ankerzentren«, thus follow heterotopias in the sense of Foucault: They are the spatial product of political decisions, they reflect social conditions and function according to their own rules. Seen in a local context, a reception centre is merely an impersonal, alienated place of transit. Seclusion, access restrictions and entry rituals underline the only partial and incoherent perception of the place from which only little information leaks out. This article shows the logics of a camp using the example of the Bamberg reception centre, analyses them from a spatial-scientific and geographical perspective and discusses assemblages of the CampScapes on an empirical basis.

\section{Die Logik des Lagers: Forschungsproblem und Fragestellung}

Flüchtlingslager und ihre Problematik werden üblicherweise in den globalen Krisenregionen oder ihren Kontaktzonen verortet. So haben sich infolge des Bürgerkrieges in Syrien in Nachbarländern wie Jordanien oder Libanon Camps in mittlerweile urbanen Dimensionen formiert (vgl. Martin/Minca/Katz 2019: 14). Auch auf dem afrikanischen Kontinent gibt es solche oder ähnliche transitorischen Orte des temporären, aber unbestimmten Aufenthaltes in großer Zahl. In Europa finden sich spontan entstandene, informelle Flüchtlingslager beispielsweise im bosnischen Vučjak oder dem französischen Calais (vgl. Gueguen-Teil/Katz 2018). Provisorische und hochgradig prekäre Unterkünfte dieser Art stellen hier jedoch die Ausnahme dar.

Die Regel der Unterbringung von Geflüchteten in der Europäischen Union bzw. im Schengenraum sind institutionalisierte, meist staatlich organisierte Gemeinschaftsunterkünfte, so auch in Deutschland. Hier tradiert die Lagerunterbringung von geflüchteten Menschen die Aufnahmepraktiken aus Zeiten nach den Weltkriegen bis hin zur Asylzuwanderung der 1990er und der Gegenwart. "Ankerzentren« schließen daran nahtlos an. Prozesse wie »Encampment « (Bakewell 2014) oder »Campization « (Kreichauf 2018) und Kontexte wie »Campscapes« (Martin 2015) werden also zwar oft als abstrakte, ferne Phänomene wahrgenommen, tatsächlich aber ordnen sie sich auch bzw. gerade in Deutschland sowohl in das Agens der Zeitgeschichte »le siècle des camps« (Kotek/Rigoulot 2000) - als auch in die lokale Lebenswelt einer Mittelstadt wie Bamberg ein.

Die hier nur holzschnittartig skizzierten Zusammenhänge sollten eine tiefergehende Analyse der Lagerunterbringung im globalen wie v.a. im lokalen, mithin "glokalen« Zusammenhang somit lohnen. Die Überlegungen fokussieren sukzessive auf das konkrete Exempel der heutigen Ankereinrichtung Oberfranken (AEO) in Bamberg, eines von zwei Ankerzentren in Bayern, und folgen dazu Marc Au- 
gés Denkfigur der Nicht-Orte als Grundlage für einen geeigneten Analyserahmen. Besondere Berücksichtigung erfährt die Perspektive der Räumlichkeit eines institutionellen Lagers, mithin Aspekte der Geographizität von Migration, Flucht und Asyl (vgl. Göler 2020). Die Frage ist, wie im Spannungsfeld europäischer, nationaler und lokaler Politiken der räumliche Zusammenhang und der lokale Diskurs um eine solche institutionalisierte Einrichtung produziert wird, wie sich dadurch die Logik des Lagers als Nicht-Ort konstituiert und welchen Veränderungen sie unterworfen ist. Für die Struktur des Beitrages ergibt sich daraus eine Agenda mit drei Feldern der Fluchtforschung: die kontextuelle Rahmung, die Unterbringung und die Menschen. Ziel ist eine weiterführende Reflexion zu Raum und Ort von Flucht im lokalen Zusammenhang. Mit dem Konzept der Geographizität (vgl. Göler/Krišjāne 2017) wird hierbei das breite Spektrum raumrelevanter Phänomene von Migration und Flucht betont und mit einer relationalen Perspektive konnotiert. Die Betonung liegt auf den räumlichen Ordnungen von Akteur*innen und relevanten Institutionen unter Berücksichtigung der jeweiligen Rahmung und ihrer Variabilität. Zunächst also einige Anmerkungen zur räumlichen Analyseperspektive.

\section{Konzeptuelle Überlegungen zur Lagerunterbringung}

Die temporäre, transitorische Unterbringung Geflüchteter kennt zahllose Formen. Eine grundsätzliche Typisierung unterscheidet zwischen der freien Entscheidung der Migrierenden für einen Aufenthaltsort (self-settlement; Bakewell 2014) und der gesteuerten, zentralisierten Unterbringung (campization; Kreichauf 2018). Dazwischen spannt sich ein Bogen von spontan entstandenen, provisorischen Formen bis hin zur organisierten, institutionellen und manchmal sogar erzwungenen Niederlassung.

Die systematische Auseinandersetzung mit der Verortung von Flucht, Asyl und Aufnahmepraxis ist relativ jung (vgl. Ramadan 2012). Die Herausforderungen infolge der Ereignisse um 2015 rückten das Thema im europäischen Aufnahmekontext ins Interesse der Forschung, so auch in Deutschland. Zur hiesigen Aufnahmeperspektive fällt zunächst die Würdigung der Willkommens- und Helferkultur ins Auge, so z.B. bei Schiffauer/Eilert/Rudloff (2017), wo auch ein Beitrag zur Bamberger Initiative "Freund statt fremd e.V.« enthalten ist (vgl. Rauber 2017: 232). Daneben finden wir teilweise auch ideologisch aufgeladene Politikkritiken (Davies/Isakjee 2019) oder die Beiträge in Hess et al. (2017). Andere Studien befassten sich mit Spezifika wie dem Flughafenasylverfahren (Nieswand 2018) oder der Rolle von Grenzen bzw. Grenzziehungen ${ }^{1}$ (»b/ordering«; Hartmann 2017: 239). Nur wenige fokussieren

Siehe dazu auch den Beitrag von Lea Celardi in diesem Band. 
Probleme der Alltagsgegenwart und der lokalen Praxis der Unterbringung, wie Kublitz (2016) mit Beispielen aus Dänemark.

Nicht selten wird der Eindruck erweckt, als würden völlig neue Diskurse eröffnet. Dabei wird übersehen, dass Zuwanderung einschließlich Fluchtmigration tatsächlich immer wiederkehrende Themen sind. Ohne zu weit in die Historie gehen zu wollen, so sind in Deutschland aktuell deutliche Parallelen zur Asyldebatte $\mathrm{zu}$ Beginn der 1990er Jahre oder zur damaligen Aufnahme jugoslawischer Bürgerkriegsflüchtlinge erkennbar. In der Folge wurde der gesamte Komplex der Asylverfahren hinterfragt und novelliert sowie zugleich ein Paradigmenwechsel in der Integrationspraxis vollzogen (vgl. z.B. Isaakyan 2016: 169ff.; zum »Asylkompromiss« 1992 vgl. Heckmann 2015: 222).

Seitdem hat sich die Reichweite interdisziplinärer Refugee Studies massiv erweitert; allein die beiden Handbücher von Fiddian-Qasmiyeh et al. (2014) und Triandafyllidou (2016) mögen als Beleg der gestiegenen Evidenz gelten. Einschlägige Periodika wie das bereits 1988 gegründete »Journal of Refugee Studies« untermauern das: Das Themenheft zur anhaltenden europäischen Flüchtlingskrise aus 2019 beleuchtet die kritischen Zustände in den griechischen Lagern u.a. übrigens auch - noch vor Covid-19 - bezüglich des Umgangs mit Infektionskrankheiten in solchen Zusammenhängen (vgl. Piselli et al. 2019). Im selben Periodikum findet sich darüber hinaus ein Themenheft »What is Camp?« mit dem Beitrag von Kublitz (2016) zur europäischen Unterbringungspraxis, was uns direkt zur Frage der konkreten Aufnahmeroutine und mithin direkt zurück zum Spannungsfeld von »Encampment and Self-settlement « (Bakewell 2014) führt. Auf die bundesdeutsche Tagespolitik übertragen ist das der Diskurs um die dezentrale (private) Unterbringung versus zentralisierte (staatliche) Sammelunterkunft, der noch zu thematisieren sein wird.

Im globalen Maßstab ist die Selbstorganisation der Unterbringung der Regelfall. Geflohene sorgen für sich selbst und die Rolle des Staates fällt sehr unterschiedlich, meist eher zurückhaltend, aus (vgl. ebd.: 129). Diese Variante wird zumeist per se als zielführender angesehen, birgt sie doch für Migrierende beispielsweise aus Syrien in der Türkei oder solchen aus Venezuela in Ecuador potenziell mehr Freiheitsgrade und entbindet den Staat von faktisch kaum zu bewältigenden Aufgaben. ${ }^{2}$ Allerdings ist diese Option in einigen Kontexten aus humanitärer Sicht zuletzt kaum mehr vertretbar, setzt sie doch eine hochgradig vulnerable Gruppe mehr oder weniger schutzlos multiplen Bedrohungen aus. So werden beispielsweise Migrierende aus Subsahara-Afrika in Libyen Opfer krimineller Banden und selbst der Aufenthalt im selbstorganisierten Dschungel von Calais (vgl. Davies/Isakjee 2019) oder in Vučjak - mitten in Europa - bedeutet ein Dasein in kritischen Verhältnissen ohne Zugriff auf notwendige Infrastrukturen. Das wiederum 
legitimiert ein Stück weit die Variante des organisierten Encampments in Sammelunterkünften in den Herkunftskontexten bzw. deren Nachbarregionen, wie es z.Zt. v.a. in Sudan, Jordanien und dem Libanon gegeben ist (vgl. u.a.: Oesch 2017; Minca 2015; Ramadan 2012). Ganz ähnlich kann das auch auf sichere Aufnahmeländer wie Deutschland übertragen werden.

Hier, wo »self-settlement « definitiv keine Option darstellt und provisorische Camps nicht toleriert werden, ist die zentralisierte Sammelunterbringungen von Flüchtlingen prinzipiell nicht neu - man denke an die aus der direkten Nachkriegszeit stammenden "Grenzdurchgangslager « wie in Zirndorf oder Friedland (vgl. Oltmer 2016: 50), die später unter anderen Etiketten wie »Sammellager für Ausländer« und heute als "Zentrale Aufnahmeeinrichtung für Asylbewerber« in ganz vergleichbaren Formen existieren (vgl. Poutrus 2017). Dennoch, gerade in historisch und gegenwartsbezogen sensibilisierten Aufnahmekontexten wie in Deutschland ist die Lagerunterbringung politisch, gesellschaftlich, moralisch und auch wissenschaftlich höchst strittig (vgl. Hess et al. 2018; Pieper 2010). Gleichwohl, mit Überlegungen zur Exterritorialisierung des Grenzregimes der »Festung Europa« in Form von vorgelagerten »Hotspots« und »Transferzonen « zur Abwicklung von Asylverfahren vor Erreichen Europas - also "offshore processing" (Papagianni 2016: 326) der Flüchtlingsproblematik - hat in Wissenschaft und Politik die Diskussion über eine effiziente und zugleich humanitär vertretbare Verfahrenspraxis neue Nahrung erhalten (vgl. Pott/Schmiz 2018). Und die Implementierung von (im Sinne der Namensgebung) zweckbestimmten, funktionalen Ankunfts- und Rückführungseinrichtungen, wie sie 2015 in Bayern eingerichtet wurden, rückte die Frage der angemessenen Form der Unterbringung von Geflüchteten just auf dem Höhepunkt der »Flüchtlingskrise« auch in Deutschland ins Zentrum des Interesses. Praktiken der Unterbringung im Speziellen und die "geographies of forced migration" (Collyer 2014: 118ff.) im Allgemeinen, die nach wie vor üblicherweise aus der Perspektive des sogenannten Globalen Südens als potenzielle Herkunftsregionen gedacht werden, sind nun auch zu einem zentralen Thema von Machtdynamiken im Globalen Norden geworden (vgl. Rechitski 2016: 173).

Wie auch immer, die Zentralisierung der Entscheidungs- und Aufnahmeprozedur ist die politisch implementierte Normalität und ein integraler Bestandteil der Aufnahmepraxis in der Bundesrepublik Deutschland geworden. Das politische Fundament bildeten die sogenannten Asylpakete I und II von Oktober 2015 bzw. Februar/März 2016; eine der konkreten Maßnahmen darin sind die »besonderen Aufnahmeeinrichtungen « (vgl. Pelzer/Pichl 2016). Und schließlich sind die »AnKER-Zentren ${ }^{3}$ ein ganz wesentlicher Bestandteil der Geschäftsgrundlage der Rückführung (AnKER) stattfinden.« (Koalitionsvertrag 2018: 107, Herv. d.Verf.) 
seit März 2018 im Amt befindlichen Bundesregierung (vgl. Koalitionsvertrag 2018: 107). Mit der 2015 eröffneten Großunterkunft in Bamberg existierte die Kopiervorlage für die angestrebte Form des künftigen »onshore-processing« hier schon längst.

\section{Die Geographizität des Lagers. Das Beispiel der AEO}

Der »Lange Sommer der Migration« (Hess et al. 2017) und das politische Management der »Flüchtlingskrise« (Luft 2017), die mehr und mehr als Krise der europäischen Aufnahmepraxis interpretiert wird (vgl. Knipper 2016: 993), sind bis heute im medialen und öffentlichen Diskurs sehr präsent; zumindest war das vor Einsetzen der Covid-19-Pandemie so. Die Fluchtmigration hat, wie vergleichbare Ereignisse vorher auch, eine große Zahl sowohl räumlich als auch identifikativ entfremdeter Individuen im Sinne von Rosa hervorgebracht (Rosa 2014: 122ff.). Eine direkte räumliche Konsequenz sind Flüchtlingslager gleichsam als identitäts- und geschichtslose Orte. Dem Anthropologen Marc Augé folgend sind solche Nicht-Orte eines der zentralen Kennzeichen der »Situation der Übermoderne« (Augé 1994: 39) und im definitorischen Sinn dann Funktionsräume, »to which individuals are connected in a uniform manner and where no organic social life is possible«, mithin »something we perceive, but only in a partial and incoherent manner " (Augé 1992/1995, Klappentext).

Entlang dieser Grundthesen rücke ich nun den lokalen Wirkungszusammenhang von Flucht im Aufnahmekontext in den Vordergrund und argumentiere da$\mathrm{zu}$ einerseits aus einer sozialen und andererseits aus der räumlichen Perspektive. Entsprechende Strukturen, Praktiken und Diskurse lassen sich nicht zuletzt am Beispiel einer Aufnahmeeinrichtung in Deutschland thematisieren, wo es um die "geographischen Logiken sozialer Praktiken« (Werlen 2013: 84) gehen soll. Im Mittelpunkt des Interesses stehen, wie eingangs bereits betont, Aspekte der Geographizität, hier in Zusammenhang mit Fragen der Räumlichkeit von Migration, Flucht und Asyl.

\section{Daten zum Bamberger Ankerzentrum ...}

Die Bamberger AEO darf also, wie bereits angedeutet, zumindest zu Beginn als eine Art zeitweiliges Laboratorium für die Suche nach einer effizienten Form der Aufnahme- und Verfahrenspraxis für Flüchtlinge in Deutschland gelten. Die Einrichtung startete am 14.9.2015 als eines von zwei »Ankunfts- und Rückführungszentren « im Bundesland Bayern (abgek. ARE II; die ARE I ist jene in Manching/Oberbayern). Angesichts des sehr kurzen Vorlaufs war das nur möglich, weil in beiden Fällen militärische Konversionsflächen kurzfristig zur Verfügung standen. In Bamberg handelt es sich um einen Teil eines US-amerikanischen 
Kasernengeländes am östlichen Stadtrand, welches nach dem Abzug der Streitkräfte 2014 eigentlich in einen längerfristigen städtischen Konversionsprozess übergehen sollte (vgl. Göler 2019: 4). ${ }^{4}$ Angesichts der dramatischen Lage Mitte 2015 und der drängenden Frage der Unterbringung einer großen Personenzahl war die Umwandlung zur Flüchtlingsunterkunft naheliegend, zumal sich die Konversionsfläche im Eigentum der Bundesrepublik Deutschland (und nicht des Bundeslandes Bayern oder der Stadt Bamberg) befand. So konnte der Bund das Gelände dem Land zweckbestimmt zur Nutzung als Aufnahmeeinrichtung überlassen. Eine Zustimmung der kommunalen Ebene (Stadt Bamberg) war nicht nötig.

Zunächst ausschließlich als besondere Aufnahmeeinrichtung für Asylsuchende sowie Geduldete aus sicheren Herkunftsstaaten wie den Ländern des Westbalkans ${ }^{5}$ eröffnet, gehören seit Juli 2016 eine reguläre Erstaufnahmeeinrichtung sowie, als dritte Säule seit September 2017, auch die Funktion eines Ankunftszentrums zu der Anlage, die seitdem AEO (Aufnahmeeinrichtung Oberfranken) genannt wird. Dort sind die relevanten Behörden (insbes. BAMF, Ausländerbehörde, Jugendamt sowie eine Rechtsantragsstelle des Verwaltungsgerichts) präsent, sodass das den Asylsuchenden zustehende Verwaltungsverfahren vor Ort durchgeführt werden kann. Die Antragstellenden sollen schnellstmöglich Auskunft erhalten, ob sie in Deutschland bleiben können oder ob eine Rückführung - sei es durch freiwillige Rückkehr oder Abschiebung - ansteht. Die durchschnittliche Aufenthaltsdauer wird vom Betreiber der Unterkunft, der Regierung von Oberfranken, mit zwei Monaten angegeben

$4 \quad$ Nachdem neben der Flüchtlingsunterkunft ein weiterer Teil des 190 Hektar großen, ehemaligen Kasernengeländes seit 2016 von einem Ausbildungszentrum der Bundespolizei belegt wird, steht für die ursprüngliche Bamberger Konversionsidee nur noch ein kleiner Teil des Areals zur Verfügung.

5 Zentraler Bestandteil der Neuregelung der Asylgesetzgebung im Rahmen der Asylpakete I und II (Pelzer/Pichl 2016) war das Ausweisen sicherer Herkunftsstaaten (vgl. Luft 2017: 96). Dazu gehörten (neben den Mitgliedsstaaten der EU) bereits die Westbalkanstaaten sowie seit längerem Senegal und Chana; die Erweiterung der Liste wurde angestrebt. Asylsuchende aus solchen Ländern werden direkt nach Ankunft bzw. Antragstellung in zentrale Aufnahmeeinrichtungen wie jene in Bamberg gelenkt. So wird mit Blick auf die Verfahrenspraxis schon ex ante eine Cruppe mit geringer Bleibewahrscheinlichkeit konstruiert; letztere lag bei Asylbewerbern aus Albanien und dem Kosovo 2015 beispielsweise bei 0,2 \% bzw. 0,4\% (vgl. BAMF 2016: 50). Die Antragsteller sind bis zur Entscheidung verpflichtet, in der Sammelunterkunft zu wohnen; sie dürfen das in ihrer Aufenthaltsgestattung genannte Cebiet (Landkreis) nicht bzw. nur vorübergehend mit Erlaubnis des Bundesamtes verlassen und dürfen nicht arbeiten. Wird ihr Asylantrag als »offensichtlich unbegründet« oder »unzulässig « abgelehnt, gelten diese Regelungen bis zur Ausreise. Zudem wird dann der Leistungsbezug, v.a. was monetäre Zuwendungen angeht, erheblich eingeschränkt. Asylsuchende aus Ländern mit »guter Bleibeperspektive«, d.h. mit über $50 \%$-iger Schutzquote wie Eritrea und Syrien durchlaufen ein beschleunigtes Asylverfahren. 
(vgl. Regierung von Oberfranken 2018). Dieser Wert wird nicht selten unter-, in einigen Fällen jedoch auch erheblich überschritten (vgl. Kraft 2018: 353), was noch zu thematisieren sein wird.

Seit der Eröffnung 2015 wurde die Kapazität von anfänglich 1.500 Personen stetig erweitert. Im Juli 2017 hatte sie ihren (momentanen) Endausbau mit 3.400 Plätzen - seitens der Staatsregierung war auch schon die Rede von 4.500 (vgl. Fränkischer Tag 2015) - erreicht. Eine Belegung in diesen Dimensionen war allerdings nie gegeben. Üblicherweise wohnten dort zuletzt zwischen ca. 1.200 und 1.600 Menschen. Anfang März 2018 z.B. waren es knapp 1.300 Personen, davon 223 in der besonderen und 1.073 in der regulären Aufnahmeeinrichtung. Im Mai 2020 wurden wegen Pandemie-bedingt rückgängiger Zahlen nur noch 1.170 gezählt; im Juli waren es 741. ${ }^{6}$ Anfangs (2015/2016) waren überwiegend Personen aus Westbalkan-Staaten untergebracht. Deshalb wird die Einrichtung im Volksmund bis heute »Balkan-Zentrum " genannt, obwohl sich die Herkunft nun deutlich heterogener darstellt und von Nordafrika über Syrien, Irak und Iran bis zu ehemals sowjetischen Republiken wie Russland, Ukraine und Georgien (zeitweilig die größte Gruppe) reicht.

Spannend bleibt die Frage nach der Laufzeit der Großunterkunft, welche so die vertragliche Festlegung zwischen der Stadt Bamberg und dem Bundesland Bayern aus dem Jahr 2015 - auf zehn Jahre begrenzt bleiben soll. Da die Fluchtmigration nach Deutschland trotz Covid-19 anhalten wird, erscheint das höchst unwahrscheinlich: Warum sollte ein mit hohem Aufwand entwickelter, funktionierender und eingespielter Prototyp in Ruhestand gehen und anderswo ersatzweise Kapazitäten aufgebaut werden? Insofern steht 2025 in Bamberg nichts weniger als der Lackmustest bezüglich der Halbwertszeit von politischen Zusagen von Bund und Land gegenüber der Kommune an.

\section{... und der öffentlichen Diskurs ${ }^{7}$}

Das eine ist die Datenlage im gegebenen politischen und gesellschaftlichen $\mathrm{Zu}$ sammenhang um 2015, das andere der begleitende öffentliche Diskurs. Die Eröffnung der Bamberger Großunterkunft wurde in der Bürgerschaft kontrovers aufgenommen und entsprechend medial begleitet. Ein Rückblick auf 2015/2016 zeigt

6 Die Angaben zu Belegungszahlen und -strukturen sowie weitere Informationen zum Zentrum sind der Webseite der Regierung von Oberfranken (2018) entnommen.

7 Grundlage ist eine Auswertung des Online-Archivs »inFranken«. Dort sind die Artikel der von der Mediengruppe Oberfranken herausgegebenen Lokalpresse Nordbayerns (insbes. »Fränkischer Tag«) archiviert. Für die Jahre 2015 und 2016 wurden 312 Beiträge ausgewertet, von denen 189 einen direkten Bezug zur ARE/AEO aufwiesen. Diesen sachdienlichen empirischen Befund hat Jan Thelen M.A. im Rahmen seiner Masterarbeit dokumentiert (Thelen 2017). Dafür gebührt ihm großer Dank. 
die Komplexität der Debatten auf (vgl. Thelen 2017). Er verdeutlicht die anfänglichen Erwartungen hinsichtlich der Funktionalität des Nicht-Ortes, aber auch die Befürchtungen, Vorbehalte und Ängste gegenüber der Großunterkunft bzw. der Akzeptanz der dort Untergebrachten.

Die Standortentscheidung für das Armeegelände wurde zunächst als Vorteil bewertet. Anfänglich war sogar von »Rückenwind für die Konversion« (Thelen 2017: 42) die Rede. Davon spricht jedoch spätestens seit dem Einzug der Bundespolizei in einen weiteren großen Teil der Kaserne niemand mehr. Einerseits werden dem Wohnungsmarkt über den Konversionsprozess nun nur noch wenige Immobilien zugeführt und andererseits verschärft die Nachfrage von mehreren hundert Beschäftigten bei Polizei und AEO - und letztlich auch von Geflüchteten mit Aufenthaltstitel (vgl. Luft 2017: 117) - die ohnehin angespannte Situation. Immerhin ist der Konversionsprozess nicht zuletzt mit Kompensationsmitteln des Freistaates Bayern auf einem kleineren, stadteinwärts gelegenen Areal zwischenzeitlich tatsächlich angelaufen. Der in Bamberg oft zu hörende Ruf nach bezahlbarem Wohnraum konnte damit jedoch nicht erstickt werden.

Quantitäten bestimmten nicht nur die Frage nach der maximalen Kapazität der Einrichtung, sondern v.a. jene nach einer lokal akzeptablen Größenordnung, welche sich um etwa 1.500 Menschen einpendelte. Der Diskurs um Selbige bezog sich zunächst insbesondere auf deren Herkunft und die damit verbundene Frage der »Fremdheit«; diesbezüglich entwickelte sich nach der Kölner Silvesternacht Anfang 2016 eine kritische Stimmungslage. Schien gegen Jahresende 2015 die Belegung der ARE mit einer begrenzten (und rückläufigen) Anzahl an Asylsuchenden aus Westbalkanländern in der Bevölkerung weitgehend akzeptiert, so mehrten sich nun Berichte einer Umwandlung zur regulären Aufnahmeeinrichtung. Dort würden dann eben auch Personen aus (Nord-)Afrika untergebracht. Aus dem nach anfänglichen Problemen nun, nicht zuletzt wegen der Belegung mit »weißen Menschen aus Europa«, weitgehend akzeptierten »Balkanzentrum« würde dann eine Einrichtung mit Menschen aus kulturell ferneren Zusammenhängen werden. Das erinnert stark an die beispielsweise von dem britischen Demographen Coleman geführte Argumentation einer hierarchischen Fremdheit von Immigrierenden und der vermeintlichen Verdrängung der als autochthon empfundenen (ehemaligen) Mehrheitsbevölkerung (vgl. Coleman 2006). Das Argument, dass damit der Charakter der Aufnahmeeinrichtung als »Ort der Perspektivlosigkeit « (Thelen 2017: 48) überwunden würde, da er nun auch Geflüchtete mit Bleibeperspektive beherberge, blieb meist ungehört, zumal sich zeitgleich die Berichte zu steigender Kriminalität in Form von Ladendiebstählen, Pkw-Aufbrüchen, Sachbeschädigungen und Körperverletzungen in und um die Großunterkunft herum mehrten. Immer wieder rückten in der Folge einzelne Gruppen bzw. Nationalitäten aus unterschiedlichen Gründen - häufig eben Straftaten - in den Fokus. Das in den lokalen Medien pro- 
duzierte Bild der Menschen in der Unterkunft in Bamberg-Ost war und ist insofern einem steten Wandel ausgesetzt. ${ }^{8}$

Die Funktionalität des Ortes definiert sich über die geballte Präsenz der Behörden, die Nähe zu den Antragstellenden sowie dem Ziel der Beschleunigung der Verfahren inklusive Weiterverteilung bei positivem oder Rückführung bei negativem Bescheid. Schon die erste Namensgebung als ARE (für Ankunft und Rückführung) hatte darauf in bemerkenswerter Offenheit hingewiesen. AEO und Ankerzentrum klingen dagegen zumindest ergebnisoffener, wenngleich alleine die Dominanz der Funktion als »besondere Aufnahmeeinrichtung « auf Abschiebung als wahrscheinlichste Variante hindeutet. Dazu entwickelte sich im Verlauf des Jahres 2016 eine inflationäre Begriffsvielfalt mit Terminologien wie »Turboabschiebezentrum «, »Abschiebelager«, »Bamberger Abschiebeeinrichtung« oder »Abschiebelager ohne Integration« (Thelen 2017: 61, 68). Sehr kontrovers diskutiert wird die Durchführung von Abschiebungen in den frühen Morgenstunden, wobei den Betroffenen nur wenig Zeit zur Vorbereitung zugestanden wird. Die Rolle der nicht-abschließbaren Türen in den Wohneinheiten wird dabei distinkt eingeordnet. Sie erleichtern dem Vollzugspersonal die Arbeit im Falle, dass sich Menschen widersetzen sollten. Der Betreiber der Unterkunft dagegen führt das Argument der Sicherheit für die dort Untergebrachten z.B. im Brandfall ins Feld. Kritik entzündete sich zudem am äußeren Erscheinungsbild der Anlage. Mit der noch aus Zeiten der USArmee stammenden Umzäunung vermittelt deren Physiognomie tatsächlich den Eindruck der Kasernierung und Internierung der dort Lebenden, welche das Camp aber jederzeit verlassen und betreten dürfen. Die Betreiber weisen wiederum auf den Sicherheitsaspekt hin: Unbefugten, d.h. Personen ohne Passierschein, wird der Zugang verwehrt; das gilt im Übrigen auch für Presse, Forschende und andere Berichterstattende gleichermaßen. Entsprechende Eingangskontrollen unterstreichen, wenn man sie als Rituale interpretieren will, den bei Augé (1994) konstruierten Charakter eines Nicht-Ortes. Jener Nicht-Ort ist im vorliegenden Fall den bürgerlichen Wohngebieten im Stadtteil Bamberg-Ost zwar sehr nah, wegen der eingeschränkten Zugänglichkeit zugleich aber - ganz ähnlich den Verhältnissen zur Zeit der US-Kaserne - ganz fern.

Ebenfalls aus zwei Perspektiven dargestellt werden jeweils der medizinische Dienst, das Angebot der Beschulung oder beispielsweise die im März 2016 eingerichtete Stadtbuslinie, welche die AEO mit dem Bahnhof, Busbahnhof und Klinikum verbindet. Einerseits werden die inkrementellen Verbesserungen hinsichtlich der Funktionalität des Ortes gesehen. Andererseits entspinnt sich zugleich eine Kontroverse, weil die Angebote stets in Konkurrenz mit jenen für die restliche Bamberger Bevölkerung bewertet werden. So wurde der - kostenfreie - Shuttle schnell 
als Luxus eingestuft, gleichwohl im Rahmen des Sachleistungsprinzips den in der AEO Untergebrachten von ihrem »Taschengeld« vorab schon der Obolus dafür einbehalten worden ist.

Hinsichtlich der Funktionalität der Einrichtung entwickelte sich der Diskurs also stets um zwei gegensätzliche Perspektiven. In der einen, oft aus Helferkreisen geäußerten, ist die Einrichtung inhuman, Menschenrechte verachtend und alleine dem Ziel der Abschottung untergeordnet. In der anderen, speziell aus Kreisen der konservativen (bayerischen) Regierungspolitik gerne eingenommenen Sichtweise wird die Effizienz der Einrichtung, insbesondere mit Blick auf die konstruierte Gruppe der Personen mit "geringer Bleibewahrscheinlichkeit«, betont. Die Einschätzung eines ehemaligen Asylsozialberaters in der AEO allerdings relativiert die Argumente Effizienz und Kostenersparnis in Zusammenhang mit Ankerzentren deutlich (vgl. Kraft 2018: 356).

\section{Die Sicht der Geflüchteten in der $\mathrm{AEO}^{9}$}

Der Charakter der AEO als Ort des Transits mit ständig wechselnder Belegschaft macht einen kohärenten empirischen Befund zur Situation und Perspektive der Bewohner schwierig; angesichts der Heterogenität der individuellen Biographien und spezifischen Fallkonstellationen kann es einen solchen nicht geben. Die Interviews einer Erhebung im Juli und August 2016 wurden allein aufgrund des Zeitraumes der Durchführung mit Personen geführt, die überwiegend aus (sicheren) Westbalkanstaaten kamen. Gleichwohl ergaben sich daraus wertvolle Erkenntnisse zu organisationalen Praktiken der Großunterkunft.

Die Mehrzahl der damals dort Untergebrachten wurde aus anderen, dezentralen Unterkünften, in denen sie bisweilen schon längere Zeit gelebt hatten und sich schon auf einem guten Weg der Integration sahen, zwecks Beschleunigung der Verfahren in die ARE gebracht. Oft lag der Negativ-Bescheid schon vor, die Ausreise war aber wegen fehlender Dokumente oder aus anderen Gründen noch nicht vollzogen worden, was die teilweise unverhältnismäßig lange Aufenthaltsdauer in der Großunterkunft erklärt. Der Aufenthalt 2016 in Bamberg ist in den meisten Fällen also eine weitere Etappe in elusiven Migrationsbiographien, wie sie bei Menschen aus dem Kosovo und insbesondere aus Albanien häufig anzutreffen ist (vgl. Göler

9 Im Juli und August 2016 wurden insgesamt 20 Interviews in der damaligen ARE II/AEO geführt. Aufgrund der damaligen Belegungsstruktur handelte es sich v.a. um Personen aus Westbalkanstaaten, insbesondere aus Albanien und Kosovo. Die Ergebnisse sind an anderer Stelle ausführlich dargelegt (Göler 2020) und können hier nur im Überblick wiedergegeben werden. Aussagen aus Interviews sind durch ein Kürzel referenziert (I1 bis I20). Ich danke Mehdi Sejdiu M.A. für die muttersprachliche Durchführung der Interviews und der Regierung von Oberfranken für deren Einverständnis und Mithilfe. 
2017). Angesichts der Umstände drängt sich der Eindruck auf, dass die Bleibeperspektive der vor 2015 Zugewanderten aus Westbalkanstaaten (zumindest in Form einer Duldung) anfänglich relativ gut gewesen war und letztlich erst die Aufnahmekrise den individuellen Migrationsprojekten die entscheidende Wende gab. Jene, die erst 2015/16 gekommen waren, räumten bemerkenswert offen ein, dass man Fehlinformationen, die oft aus dem familiären Umfeld stammten, oder - für viel Geld allzu blauäugig - den Versprechungen von Schleusern aufgesessen war. Einige Aussagen belegen ein nach wie vor großes Informationsdefizit. Die Ansicht, dass »wenn man hier arbeitet, sich informiert und integriert, dann hat man das Recht hier zu leben« (I6), mag aus der individuellen Perspektive verständlich sein, ein Aufenthaltstitel erwächst daraus nicht. Einen völlig abstrusen Sinnzusammenhang bezüglich politischen Asyls wird mit dem Satz »Ich habe politisches Asyl beantragt, weil ich von der Politik im Kosovo enttäuscht bin« (I5) konstruiert. Ebenso erstaunt die Erwartung "Ich war mir sicher, dass ich Asyl bekomme, weil jetzt in Frankreich die nicht-weiße Rasse dominiert und ich gelesen habe, dass Deutschland das vermeiden will mit den weißen, albanischen Migranten« (I18), zeigt, wie hier offenbar durch Fehlinformationen bzw. krude Deutungen völlig falsche Erwartungshaltungen entstanden sind.

Doch zurück zur Lage der Menschen in der AEO. Die Abgeschlossenheit gegenüber der umgebenden Lebenswelt und v.a. der fehlende Zugang zum Arbeitsmarkt gereicht bisweilen zum Problem. Jene, die im Bewusstsein der Begrenztheit ihres Aufenthaltes nach Möglichkeit Ressourcen und Kapitalien für die Zeit nach ihrer voraussichtlichen Rückführung aufbauen wollen, haben dazu nur wenig Möglichkeiten. Die Umstellung auf das Sachleistungsprinzip schränkt das Generieren von Ersparnissen weiter ein. Mit der Überführung in die AEO wurden einigen Befragten die aufgebauten, für eine (ggf. auch informelle) Erwerbstätigkeit notwendigen Netzwerke entzogen. Einige wenige geben an, über Schwarzarbeit etwas Rücklagen - berichtet wird von 50 Euro pro Tag - zu verdienen. Darüber hinaus lässt sich allenfalls über (genehmigte) Hilfstätigkeiten innerhalb der AEO etwas dazuverdienen.

Höchst kritisch zur Situation der Bewohner der Unterkunft und insbesondere der Roma äußert sich eine Studie zur Gewährleistung von Kinderrechten in Aufnahme- und Rückführungseinrichtungen (Alexandropoulou/Leucht/Salimovska 2016) ${ }^{10}$. Es wird dezidiert auf Defizite z.B. im Bereich der Beschulung hingewiesen (vgl. ebd.: 19ff.). Der Besuch einer Regelschule im Stadtgebiet Bambergs ist in der Tat nicht vorgesehen, vielmehr wird auf dem Gelände ein Substitut in Form einer besonderen Bildungseinrichtung angeboten. ${ }^{11}$ Anwesenheit wird aber kaum

10 Die Studie wurde von der Hildegard Lagrenne Stiftung finanziert und fokussiert gemäß Stiftungszweck v.a. auf Bildung, Inklusion und Teilhabe von Sinti und Roma.

11 Vgl. dazu auch den Beitrag von Elisabeth Beck und Christine Heimerer in diesem Band. 
kontrolliert und Absenz nicht sanktioniert. Weiterhin wird mit Blick auf Ängste bei u.U. bereits traumatisierten Kindern die Tatsache nicht abschließbarer Wohnungen bzw. Türen als höchst problematisch eingeschätzt. Und letztlich würde der auf dem Balkan weitverbreitete Antiziganismus in der Unterkunft unverhohlen fortgeführt. Insgesamt werden in der Studie die Lebensbedingungen von Familien in der ARE II als »durchgehend negativ bewertet (ebd.: 27).

In unserem Survey hinsichtlich der Unterbringung in der ARE/AEO wurden neben zahlreichen negativen immer wieder auch positive Momente berichtet. Dazu zählen das gute Gesundheitssystem in Deutschland generell, die medizinische Versorgung in der Einrichtung speziell sowie der respektvolle Umgang seitens der Behörden, den man von Autoritäten im Herkunftsland so nicht gewohnt ist: »Ich habe hier mehr Rechte als im Kosovo, obwohl ich Asylbewerber bin« (Ii) lautete eine Stimme diesbezüglich. Gleichwohl, dramatisch ist die Situation der Roma als eine Volksgruppe, die in Südosteuropa zweifelsohne bedroht und deren Lage auch in der AEO prekär ist. Einerseits ist die Rückführung für sie wegen mannigfaltiger Unsicherheiten überhaupt keine Option, so dass Roma sich dem mit allen Mitteln widersetzen. Als grundsätzlich Ausreisepflichtige entfällt damit allerdings der Leistungsanspruch, so dass sie selbst in der Unterkunft jenseits der reinen Unterbringung keine Existenzgrundlage haben. Ein Rom gibt offen an, er sei aus diesem Grund gezwungen, für die Familie stehlen zu müssen.

Jenseits aller Bewertungen des Lebens in der Großunterkunft, die, wie gezeigt, stark von der Perspektive abhängen können, kann für alle dort Untergebrachten egal ob sie eine »hohe« oder "geringe Bleibewahrscheinlichkeit« haben - ein Leben mit permanenten Unsicherheiten angenommen werden. Unabhängig von der Dauer des Verfahrens und des Aufenthaltes oder der Perspektive des Bleibens bzw. Gehens ist die AEO per se gleichsam ein fluider Ort. Insofern soll im Weiteren der Frage nachgegangen werden, inwieweit sich der Aufenthalt in einer solchen heterotopen Parallelwelt in der Wahrnehmung des Nicht-Ortes und seiner Umgebung durch die dort untergebrachten Menschen spiegelt.

\section{Geflüchtete im lokalen Umfeld: Die Orientierung am Nicht-Ort}

Aufnahmeeinrichtungen sind transitorische Orte, an denen Menschen als Individuen temporär auf den Zweck der Institution reduziert werden. Ein Nicht-Ort wie das Bamberger Ankerzentrum folgt insofern der Vorstellung von Heterotopien im Sinne Foucaults (1992): Sie sind das räumliche Produkt politischen Handelns, sie spiegeln gesellschaftliche Verhältnisse und funktionieren dennoch nach eigenen Regeln. Zugangsbeschränkungen und Eingangsrituale beispielsweise - mithin Elemente einer "Liquid Surveillance nach Bauman/Lyon (2013) - unterstreichen die partielle und inkohärente Wahrnehmung eines an sich nahen Ortes, über den nur 
begrenzt Information nach außen dringt. Insofern stellt der Ort der Erstaufnahme in seinem lokalen Bezug für dessen Bürgerschaft wie für den Geflüchteten zunächst einen unpersönlichen, geschichts- und identitätsarmen Ort des Transits dar. Manche der Untergebrachten verlassen das Ankerzentrum selten oder gar nicht, andere zeigen große Aktionsräume im örtlichen Zusammenhang. Doch wie bewegen sich Menschen unter diesen Voraussetzungen im lokalen Umfeld und an was orientieren sie sich? Welche Raummuster werden erkennbar? Antworten auf solche und ähnliche Fragestellungen $\mathrm{zu}$ finden, war die zentrale Zielsetzung der Studie von Fritzler (2018).

Die räumliche Repräsentation ausgewählter Personen wurde dabei mit der klassischen Methode der »mental maps« (Downs/Stea 1974), d.h. gezeichneter Karten der räumlichen Umgebung, in der zweiten Jahreshälfte 2017 erhoben. Insgesamt 15 Personen (zehn Männer und fünf Frauen) dokumentierten in sog. »sketch maps « ihre Vorstellung von der räumlichen Umwelt, welche durch jeweils relevante Orte konstituiert wird. Zwei Aspekte sind dafür maßgeblich: Das sind zum einen die Marginalität und Isoliertheit des Standortes und zum anderen die individuelle, ggf. biographisch bedingte Ermöglichung durch entsprechende Handlungsmacht. Jene wiederum wird von der Differenziertheit der Bewohnerschaft beeinflusst. Im Vergleich $\mathrm{zu} 2016$ waren in der zweiten Jahreshälfte 2017 gänzlich andere Staatsbürgerschaften anzutreffen, darunter insbesondere Personen aus Syrien, Eritrea, Iran und Marokko. Die Aufenthaltsdauer betrug zwischen zwei Wochen und acht Monaten; jener Faktor hatte allerdings, ähnlich wie Sprachkenntnisse, kaum differenzierenden Einfluss auf Raumkenntnis und aktionsräumliches Verhalten. Ganz anders ist das bei Bildungsniveau und Alter.

Im Einzelnen repräsentieren insgesamt sechs der Probanden das Bild von lokal- bzw. quartiersbezogenen, höchst begrenzten Aktionsradien; konkret waren das junge, männliche und bildungsferne Migranten aus Eritrea. In deren Skizzen findet sich eine überschaubare Anzahl an Elementen (sechs bis 16 Nennungen), welche sich überwiegend in Nähe des Ankerzentrums finden. Ein wichtiger strategischer Punkt ist beispielsweise eine stark frequentierte Kreuzung an einer Ringstraße, an der zeitweilig freier Zugriff auf einen WiFi-Hotspot bestand, was allerdings die einzige Aufenthaltsqualität des Ortes darstellt. Haupt- (und zugleich einziger) Anlaufpunkt in der Innenstadt ist ein Internet-Cafe, welches Netzzugang und Pre-Paid-Karten zu günstigen Konditionen anbietet und zudem von einem nigerianischen Migranten betrieben wird. Daneben sind die Raumkenntnisse dieser Probanden eher dürftig; bei drei von ihnen genügte ein A4-Blatt zur Erhebung.

Das Raumbild von anderen Probanden mit, orientiert an bundesdeutschen Standards, mittlerem Bildungsniveau wird ebenfalls hauptsächlich aus der Perspektive der AEO wiedergegeben bzw. ist maßgeblich auf die Umgebung zentriert. Es werden deutlich mehr Raumelemente genannt. Auch wenn deren Bezeichnung, Lokalisierung und Lagerelation oft fehlerhaft wiedergegeben werden, so spiegeln 
sie eine erweiterte räumliche Orientierung und v.a. individuelle Interessenslagen und Bedürfnisse. Für eine christliche Iranerin beispielsweise spielen die Kirchen eine wichtige Rolle; daneben werden Einkaufsmöglichkeiten der zentralen Fußgängerzone genannt, deren Angebote zwar wahrgenommen, aber nicht genutzt werden können. Ein 35-jähriger Syrer zeichnet einen weiten Aktionsradius mit zahlreichen Einrichtungen, deren Bezeichnung und v.a. deren Funktion er aber kaum kennt. Er ist mit dem Fahrrad unterwegs und sammelt Leergut (Pfandflaschen), um sich etwas dazuzuverdienen. So erklärt sich beispielsweise auch, dass ihm die Bamberger Kneipenmeile wohlbekannt ist, er die Angebote dort gleichwohl nie in Anspruch nimmt bzw. nehmen kann.

Fünf weitere Personen mit hohem Bildungsrad aus Syrien und Iran verfügen über detaillierte Raumkenntnis - eine der sketch maps beinhaltet mehr als 120 Kartenelemente - und dokumentieren ein klar innenstadtzentriertes aktionsräumliches Verhalten. Die Informiertheit ist breit und umfasst Orte unterschiedlichster Funktionen (Sozialberatung, Anwalt, Rathaus, Zahnarzt, Apotheke, Einkaufsmöglichkeiten etc.). Auch Kultureinrichtungen wie ein Kino oder eine temporäre Kunstinstallation im öffentlichen Raum sowie symbolische Orte, wie der »Gabelmann", ein bekannter Brunnen und Treffpunkt in der Fußgängerzone, werden genannt. Bei zwei Karten ist das Ankerzentrum - d.h. der eigene Wohnort! - und dessen Umfeld gar nicht enthalten.

In Zusammenhang mit der Orientierung und mithin auch der Steuerung des räumlichen Verhaltens spielt der bereits erwähnte Shuttle-Bus, welcher seit März 2017 das Ankerzentrum mit dem Bahnhof, Innenstadt und dem Klinikum am anderen Ende der Stadt verbindet, eine wichtige Rolle. Oft ist das jeweilige Bewegungsprofil und in einem Falle sogar die gesamte Zeichnung entlang des detailliert wiedergegebenen Linienverlaufs kalibriert.

\section{Diskussion und Fazit}

Vorstehend wurde das Bamberger Ankerzentrum hinsichtlich der Spezifik des Ortes, der räumlichen Einbettung und der dort lebenden Menschen exemplarisch analysiert. Als empirische Evidenz verbleibt der zusammenfassende Hinweis auf mannigfaltige Differenzierungen, Dichotomien und Mehrdeutigkeiten; solche scheinen derartigen Orten immanent zu sein (vgl. Oesch 2017). Das Zusammenspiel von (Nicht-)Ort, Raum und Individuum lässt sich in Anlehnung an Martin (2015), dort allerdings in einem anderen Zusammenhang, als CampScape interpretieren.

$\mathrm{Zu}$ der sehr speziellen Assemblage eines solchen CampScapes gehört die temporäre Unbestimmtheit bei zugleich implizierter Begrenztheit des Aufenthaltes der dort Untergebrachten. Deren transitorische Episode endet, dem politisch formu- 
lierten Ziel des Ankerzentrums entsprechend, mit der Variante Bleiben oder Gehen. Diesbezüglich ist bereits die Frage der Herkunft nicht unerheblich, definiert sie doch über das politische Konstrukt sicherer (und unsicherer) Herkunftsstaaten die Perspektive einer hohen oder geringen Bleibewahrscheinlichkeit und legitimiert damit quasi schon ex ante die spätere Entscheidung über das Einräumen eines Aufenthaltsstatus oder die anstehende Rückführung. Gerahmt ist die Problematik durch die Erfordernisse der Umsetzung staatlicher Ordnungsstrukturen einerseits und der Wahrung von Humanität und Menschenrechten andererseits.

Mit Blick auf den Anspruch größtmöglicher Effizienz wird während des Aufenthaltes im Nicht-Ort Ankerzentrum bis zur Entscheidung über das Asylverfahren tatsächlich ein Durchschnitt im Sinne Augés (1992) hergestellt. Faktisch war und ist die Belegung weder strukturell noch im Zeitverlauf tatsächlich homogen, sondern von ständiger Veränderlichkeit gekennzeichnet. Eine solche behält sich der Staat als Betreiber der Aufnahmeeinrichtung angesichts der instabilen Realität internationaler Flüchtlingsbewegungen auch ausdrücklich vor.

Für die Dauer des Verfahrens ist der Aufenthalt in der Unterkunft obligatorisch und es besteht Residenzpflicht, d.h. der kommunale Bezugsrahmen darf nicht verlassen werden. Durch die Immobilisierung sollen ganz offensichtlich Ansätze zur Integration während des laufenden Verfahrens geringgehalten werden, nicht zuletzt um bei Ablehnung des Asylgesuchs Rückführungen zu vereinfachen. Selbst die örtliche Bewegungsfreiheit ist durch die Umzäunung des Areals eingeschränkt, was allerdings ein wesentlicher Teil der Sicherheitsgarantie auf dem Gelände ist. Sie scheint von den meisten dort Untergebrachten auch durchaus akzeptiert zu sein, schließlich werden damit Übergriffe jeglicher Art von außen definitiv erschwert. In der Konsequenz sind nicht zuletzt die räumliche Orientierung und Interessiertheit am Lokalen, einschließlich der individuellen Fähigkeit bzw. Interessen dazu, seitens der Geflüchteten meist begrenzt.

Die für das Exempel des Ankerzentrums in Bamberg vorgelegte Analyse zu raumbezogenen Auswirkungen von Migration und Flucht in lokalen Zusammenhängen hat sich Bausteine der Figur der Heterotopie und das Konstrukt des NichtOrtes zu eigen gemacht. Mit der Rahmung in der Übermoderne wird ein Vorschlag für ein analytisches Konzept für weitere empirische Annäherungen an den Forschungsgegenstand Migration und Flucht im lokalen Kontext unterbreitet.

\section{Literaturverzeichnis}

Alexandropoulou, Magdalini/Leucht, Christoph/Salimovska, Sabina (2016): Gewährleistung der Kinderrechte in den Aufnahme- und Rückführungseinrichtungen für Asylbewerber mit geringer Bleibeperspektive, Berlin: Hildegard Lagrenne Stiftung. 
Augé, Marc (1992): Non-lieux: Introduction a une anthropologie de la surmodernité, Paris: Seuil.

Augé, Marc (1994): Orte und Nicht-Orte. Vorüberlegungen zu einer Ethnologie der Einsamkeit, Frankfurt a.M.: Fischer Verlag.

Augé, Marc (1995): Non-Places. Introduction to an Anthropology of Supermodernity, London/New York: Verso.

Bakewell, Oliver (2014): „Encampment and Self-settlement«, in: Elena FiddianQasmiyeh/Gil Loescher/Katy Long/Nando Sigona (Hg.), The Oxford Handbook of Refugee and Forced Migration Studies: Oxford University Press, S. 127-138.

[BAMF] Bundesamt für Migration und Flüchtlinge (2016): Das Bundesamt in Zahlen 2015. Asyl, Migration und Integration, Nürnberg: BAMF.

Bauman, Zygmunt/Lyon, David (2013): Liquid surveillance: a conversation, Cambridge [u.a.]: Polity Press.

Coleman, David (2006): »Immigration and Ethnic Change in Low-Fertility Countries: A Third Demographic Transition«, in: Population and Development Review 32(3), S. 401-446.

Collyer, Michael (2014): »Geographies of Forced Migration«, in: Elena FiddianQasmiyeh/Gil Loescher/Katy Long/Nando Sigona (Hg.), The Oxford Handbook of Refugee and Forced Migration Studies: Oxford University Press, S. 112-123.

Davies, Thom/Isakjee, Arshad (2019): »Ruins of Empire: Refugees, race and the postcolonial geographies of European migrant camps«, in: Geoforum 102, S. 214217.

Downs, Roger M./Stea, David (1974): Image and Environment. Cognitive Mapping and Spatial Behavior, Chicago: Transaction Publishers.

Fiddian-Qasmiyeh, Elena/Loescher, Gil/Long, Katy/Sigona, Nando (Hg.) (2014): The Oxford Handbook of Refugee and Forced Migration Studies: Oxford University Press.

Foucault, Michel (1992): »Andere Räume«, in: Karlheinz Barck/Peter Gente/Heidi Paris/Stefan Richter (Hg.), Aisthesis. Wahrnehmung heute oder Perspektiven einer anderen Ästhetik, 4. Aufl., Leipzig: Reclam.

Fränkischer Tag (2015): Titelseite Ausgabe Bamberg, in: Fränkischer Tag vom 05.11.2015.

Fritzler, Bettina (2018): Aktionsräume von Asylbewerbern in Bamberg: Eine sketchmap-basierte Analyse. Unveröffentlichte Masterarbeit im Fach Sozialund Bevölkerungsgeographie an der Fakultät Geistes- und Kulturwissenschaften der Universität Bamberg.

Göler, Daniel/Krišjāne, Zaiga (2017): »Geographicities of Migration. Adding a New Direction«, in: Regions 305(1), S. 13-15.

Göler, Daniel (2017): »From an Isolated State to a Migration Society - Transnationalism and Multilocality as Social Practise in Contemporary Albania«, in: 
Peter Jordan (Hg.), 10 Years of EU Enlargement. The Geographical Balance of a Courageous Step (= ISR-Forschungsbericht, Heft 42), Vienna, S. 137-158.

Göler, Daniel (2019): »The invention of new territories. Spatial redistribution, agents of change and the question of power - an example from Bamberg/Germany «, in: Proceedings of the 45th International Conference on Regional Sciences: Tackling with societal, technological and climate changes in peripheral territories, University Jaume I, Castelló.

Göler, Daniel (2020): »Places and Spaces of the Others. A German Reception Center in Public Discourse and Individual Perception«, in: Birgit Glorius/Jeroen Doomernik (Hg.), Geographies of Asylum and the Role of European Localities (= IMISCOE Research Series), Cham: Springer, S. 69-91.

Gueguen-Teil, Cannelle/Katz, Irit (2018): »On the Meaning of Shelter: Living in Calais's Camps de la Lande«, in: Irit Katz/Diana Martin/Claudio Minca (Hg.), Camps Revisited. Multifaceted Spatialities of a Modern Political Technology, London/New York: Rowman \& Littlefield.

Hartmann, Melanie (2017): "Contested Boundaries: Refugee Centers as Spaces of the Political«, in: Zeitschrift für Flüchtlingsforschung 1(2), S. 218-243.

Heckmann, Friedrich (2015): Integration von Migranten. Einwanderung und neue Nationenbildung, Wiesbaden: Springer VS.

Hess, Sabine/Kasparek, Bernd/Kron, Stefanie/Rodatz, Mathias/Schwertl, Maria/Sontowski, Simon (Hg.) (2017): Der lange Sommer der Migration. Grenzregime III, Berlin: Assoziation A.

Hess, Sabine/Pott, Andreas/Schammann, Hannes/Scherr, Albert/Schiffauer, Werner (2018): Welche Auswirkungen haben »Anker-Zentren«? Eine Kurzstudie für den Mediendienst Integration, Berlin: Mediendienst Integration.

Isaakyan, Irina (2016): »Integration paradigms in Europe and North America«, in: Anna Triandafyllidou (Hg.), Routledge Handbook of Immigration and Refugee Studies, New York: Routledge, S. 169-179.

Knipper, Michael (2016): »Migration, public health and human rights «, in: International Journal of Public Health 61, S. 993-994, DOI 10.1007/s00038-016-0893-x. Koalitionsvertrag zwischen CDU, CSU, SPD (2018): Ein neuer Aufbruch für Europa. Eine neue Dynamik für Deutschland. Ein neuer Zusammenhalt für unser Land, Koalitionsvertrag vom 12.03.2018, 19. Legislaturperiode.

Kotek, Joël/Rigoulot, Pierre (2000): Le siècle des camps, Paris: JC Latt'es.

Kublitz, Anja (2016): »The Ongoing Catastrophe: Erosion of Life in the Danish Camps«, in: Journal of Refugee Studies 29(2), S. 229-249, https://doi.org/10.1 093/jrs/fevo19.

Kraft, Markus (2018): »ANKER-Einrichtung Oberfranken (AEO) - Grundlagen, Kritik und Alternative«, in: Asylmagazin. Zeitschrift für Flüchtlings- und Migrationsrecht 10-11, S. 351-358. 
Kreichauf, René (2018): „From forced migration to forced arrival: the campization of refugee accommodation in European cities «, in: Comparative Migration Studies 6(7), DOI 10.1186/s40878-017-0069-8.

Luft, Stefan (2017): Die Flüchtlingskrise. Ursachen, Konflikte, Folgen, München: C.H. Beck.

Martin, Diana (2015): »From spaces of exception to >campscapes`: Palestinian refugee camps and informal settlements in Beirut «, in: Political Geography 44, S. 9-18.

Martin, Diana/Minca, Claudio/Katz, Irit (2019): »Rethinking the camp: On spatial technologies of power and resistance«, in: Progress in Human Geography, DOI: 10.1177/0309132519856702.

Minca, Claudio (2015): »Geographies of the camp«, in: Political Geography 49, S. 7483.

Nieswand, Boris (2018): „Die Transitzone und die Fiktion der Nichteinreise. Das Flughafenasylverfahren im Zwielicht von Normalität und Ausnahme«, in: Jochen Oltmer (Hg.), Migrationsregime vor Ort und lokales Aushandeln von Migration, Wiesbaden: Springer VS, S. 345-376.

Oesch, Lucas (2017): "The refugee camp as a space of multiple ambiguities and subjectivities«, in: Political Geography 60, S. 110-120.

Oltmer, Jochen (2016): Migration vom 19. bis zum 21. Jahrhundert (= Enzyklopädie deutscher Geschichte, 86), Oldenburg: De Gruyter.

Papagianni, Georgia (2016): »Asylum in the twenty-first century: trends and challenges«, in: Anna Triandafyllidou (Hg.), Routledge Handbook of Immigration and Refugee Studies, New York: Routledge, S. 320-329.

Pelzer, Marei/Pichl, Maximilian (2016): » Die Asylpakete I und II: Verfassungs-, europa- und völkerrechtliche Probleme«, in: Kritische Justiz 49(2), S. 207-219.

Pieper, Tobias (2010): »Das Lager als variables Instrument der Migrationskontrolle«, in: Sabine Hess/Bernd Kasparek (Hg.), Grenzregime. Diskurse, Praktiken, Institutionen in Europa, Berlin/Hamburg: Assoziation A, S. 219-228.

Piselli, Pierluca/Samuilova, Mariya/Bozorgmehr, Kayvan/Ippolito, Giuseppe/Petrova-Benedict, Roumyana/Kentikelenis, Alexander/Girardi, Enrico (2019): »Infectious-disease Screening and Vaccination for Refugees and Asylum Seekers Entering Europe in 2015-16: A Scoping Study of Six European Union Countries«, in: Journal of Refugee Studies 32, Special Issue Dec. 2019, S. i92-i104, https://doi.org/10.1093/jrs/fezo42.

Pott, Andreas/Schmiz, Antonie (2018): "Migration und Flucht als Forschungsthemen der Geographie. Eine Standortbestimmung«, in: Standort 42, S. 3-9, http s://doi.org/10.1007/s00548-018-0517-1.

Poutrus, Patrice G. (2017): »Zirndorf und die Anfänge des Bundesamtes für Migration und Flüchtlinge«, in: Bundeszentrale für politische Bildung (Hg.), Kurz- 
dossiers Zuwanderung, Flucht und Asyl, https://www.bpb.de/gesellschaft/mig ration/kurzdossiers/246940/zirndorf, Abrufdatum: 20.04.2020.

Ramadan, Adam (2012): »Spatialising the refugee camp«, in: Transactions of the Institute of British Geographers 38(1), S.65-77, DOI: 10.1111/j.14755661.2012.00509.x.

Rauber, Mona (2017): »Freund statt fremd e.V.«, in: Werner Schiffauer/Anne Eilert/Marlene Rudloff (Hg.), So schaffen wir das - eine Zivilgesellschaft im Aufbruch: 90 wegweisende Projekte mit Geflüchteten, Bielefeld: transcript, S. 232234.

Rechitsky, Raphi (2016): »Global Migration and Extraterritorial Controls: The Case of International Refugee Policy in Ukraine«, in: International Journal of Sociology 46, S. 169-188, DOI: 10.1080/00207659.2016.1163990.

Regierung von Oberfranken (2018): Aufnahmeeinrichtung Oberfranken, https:// www.regierung.oberfranken.bayern.de/buerger_und_staat/migranten/ae_ oberfranken/, Abrufdatum: 05.03.2020.

Rosa, Hartmut (2014): Beschleunigung und Entfremdung, 4. Aufl., Berlin: Suhrkamp.

Schiffauer, Werner/Eilert, Anne/Rudloff, Marlene (Hg.) (2017): So schaffen wir das eine Zivilgesellschaft im Aufbruch: 90 wegweisende Projekte mit Geflüchteten, Bielefeld: transcript.

Thelen, Jan (2017): Der Ort der >Anderen $\lessdot$. Die Rolle lokaler Medien bei der Entstehung von Nicht-Orten. Unveröffentlichte Masterarbeit im Fach Sozial- und Bevölkerungsgeographie an der Fakultät Geistes- und Kulturwissenschaften der Universität Bamberg.

Triandafyllidou, Anna (2016) (Hg.): Routledge Handbook of Immigration and Refugee Studies, New York: Routledge.

Werlen, Benno (2013): »Praktiken der Welt-Bindung. Gesellschaftliche Raumverhältnisse als trans-disziplinäres Forschungsfeld«, in: Europa Regional 21, 2013 (2015) (1-2), S. 83-92.

\section{Interviews}

I1 (Juli 2020); männl., geb. 1993 im Kosovo, int. Erstmigration Feb. 2015. I5 (Juli 2020); männl., geb. 1993 im Kosovo, int. Erstmigration Juli 2014. I6 (Juli 2020); männl., geb. 1984 im Kosovo, int. Erstmigration April 2011. I18 (August 2020); männl., geb. 1980 im Kosovo, int. Erstmigration 1996. 


\section{Die Flüchtlings- und Integrationsberatung in den Ankerzentren im Spannungsfeld von politischer Beeinflussung und sozialarbeiterischer Einflussnahme}

Mathias Schmitt

\section{Zusammenfassung}

Cegenstand der hier vorgestellten explorativen Forschungsarbeit ist die Flüchtlings- und Integrationsberatung (FIB) in den 2018 entstandenen Ankerzentren. Die Arbeit fokussiert einerseits die politische Einflussnahme auf die FIB und untersucht anderseits Formen der politischen Einflussnahme von Seiten der Asylberater*innen auf die Politik. Zur Analyse der Einflussnahme von Seiten der Politik auf die Soziale Arbeit wird eine Policy-Analyse in Form einer »Problemanalyse als Programmanalyse« (Benz/Rieger 2015: 83) durchgeführt, mit deren Hilfe die konstitutiven Elemente der Ankerzentren herausgearbeitet werden und mit einer Bewertung des politischen Programms, welches die Errichtung der Ankerzentren beinhaltet, abschließt. Zur Erfassung dieser konstitutiven Elemente, welche das neue Arbeitsfeld der Asylberater*innen strukturieren, wird eine Inhaltsanalyse nach Kuckartz (2018) in Form einer Dokumentenanalyse durchgeführt. Bevor jedoch eine abschließende Bewertung des Programms im Rahmen der Programmanalyse vollzogen werden kann, müssen zuerst die Auswirkungen des politischen Programms auf die FIB als auch auf deren Adressat*innen aufgezeigt werden. Die Analyse der Auswirkungen erfolgt durch leitfadengestützte Interviews mit sieben Asylberater*innen in drei verschiedenen Ankerzentren in Bayern. Für die Auswertung der Interviews wird die qualitative Inhaltsanalyse nach Mayring (2015) angewendet. In den Interviews wird neben den Auswirkungen die politische Einflussnahme von Seiten der Asylberater*innen fokussiert. Die Sozialarbeitspolitik nach Rieger (2013) und der Ansatz von Policy Practice nach Burzlaff (2020) stellen den Fachkräften Methoden der politischen Einflussnahme zur Verfügung. Der qualitative Forschungsansatz setzt somit einen weiteren Schwerpunkt dieser Arbeit darauf, welche Methoden des politischen Handelns im Rahmen dieser Ansätze in der Praxis angewandt werden und ob darüber hinaus weitere Formen der Einflussnahme der Asylberater*innen im Sinne dieser Ansätze erkennbar sind. 


\section{Summary}

The subject of the explorative research project presented herein is the refugee and integration counselling (Flüchtlings- und Integrationsberatung, FIB) in the Anker centres that were established in 2018. On the one hand, the work focuses on political interference with FIB and, on the other hand, investigates forms of political influence on politics on the part of asylum counsellors. In order to analyse the influence of politics on social work, a policy analysis in the form of a »problem analysis as a program analysis« (Benz/Rieger 2015: 83) is conducted, with the help of which the constitutive elements of Anker centres are identified and which concludes with an evaluation of the political program that includes the establishment of Anker centres. In order to identify the constitutive elements that structure the new field of work of asylum counsellors, a content analysis according to Kuckartz (2018) is carried out in the form of a document analysis. However, before a final evaluation of the program can be carried out in the context of the program analysis, the effects of the political program on the FIB as well as on its addressees must be demonstrated in a first step. The analysis of the effects is based on structured interviews with seven asylum counsellors in three different Anker centres in Bavaria. The qualitative content analysis according to Mayring (2015) is used to evaluate the interviews. In addition to the effects, the interviews also focus on the political influence of the asylum counsellors. The social work policy according to Rieger (2013) and the approach of Policy Practice according to Burzlaff (2020) provide the professionals with methods of political interference. The qualitative research approach thus places a further focus of this work on which methods of political action are applied in practice within the framework of these approaches and whether other forms of influence on the part of asylum counsellors in the sense of these approaches can be identified.

\section{Einleitung}

Im März 2017 sorgte eine Ankündigung der damaligen bayerischen Sozialministerin, Emilia Müller, für große Aufregung. Sie drohte den Wohlfahrtsverbänden damit, die finanzielle Förderung zu streichen, wenn die Asylberater*innen den Geflüchteten Hinweise gäben, wie diese sich der Abschiebung durch fehlende Anwesenheit oder durch Einlegung weiterer Rechtsmittel entziehen könnten (vgl. Süddeutsche Zeitung 2017). An diesem Beispiel wird sichtbar, wie weitreichend sich politische Akteur*innen in die Praxis der Sozialen Arbeit einzumischen versuchen. In den letzten Jahren sind neue Einrichtungen zur Unterbringung von Geflüchteten in Bayern entstanden, die sogenannten Ankerzentren. Auch und gerade im Kontext 
der Ankerzentren stellt sich die Frage, wie ${ }^{1}$ diese Einrichtungen einen Einfluss auf die Asylsozialberatung ${ }^{2}$ nehmen, denn in Ankerzentren sollen neben sämtlichen für das Asylverfahren relevanten Behörden auch die Wohlfahrtsverbände vertreten sein um die Flüchtlings- und Integrationsberatung (FIB) vor Ort durchzuführen. Die hier vorgestellte explorative Forschungsarbeit ${ }^{3}$ fokussiert die politische Einflussnahme auf dieses Beratungsangebot und fragt - vice versa - nach Formen der Einflussnahme von Seiten der Sozialen Arbeit auf die Politik. Diese doppelte Fragestellung ist notwendig, da davon ausgegangen wird, dass sich die Beeinflussung nicht nur einseitig von der Politik auf die Soziale Arbeit vollzieht, sondern die Soziale Arbeit ebenso als Akteur im politischen Geschehen mitwirkt und selbst Politik macht (vgl. Rieger 2013: 55). Dabei bedienen sich die sozialarbeiterischen Fachkräfte bewusst oder unbewusst und in unterschiedlichem Maße der Methoden des politischen Handelns und nutzen so »Politik als Hilfe« (Rieger 2006).

\section{Die Ankerzentren im Kontext der politischen Programmanalyse}

Die angewandte »Problemanalyse als Programmanalyse« (Benz/Rieger 2015: 83) beschränkt die Analyse von Politik auf die politischen Inhalte (Policy) und das darauf bezogene politische Programm: »Unter einem politischen Programm sind alle Maßnahmen (Gesetze, Richtlinien, Förderpläne, Konzepte usw.) zu verstehen, welche die Politik ergreift, um ein als lösungsbedürftig erkanntes (soziales) Problem zu regeln bzw. zu bewältigen.« (Ebd.: 81) Das Ziel dieser Programmanalyse ist es, das politische Programm, welches als wesentlicher Bestandteil die Errichtung der Ankerzentren beinhaltet, aber auch weitere Politiken im Zusammenhang mit den Ankerzentren umfasst, $\mathrm{zu}$ analysieren und zu bewerten. Die Programmanalyse in der Politikwissenschaft für die Soziale Arbeit fragt insbesondere nach den Auswirkungen des politischen Programms auf ihre Adressat*innen und die Arbeitsweise der Sozialarbeiter*innen, um gegebenenfalls Einfluss auf das politische Programm zu nehmen. Mit Hilfe der inhaltlich strukturierenden Inhaltsanalyse nach Udo Kuckartz (2018) wird im Rahmen der Programmanalyse eine Dokumentenanalyse vorgenommen, welche die politikauslösenden Probleme, die daraufhin gesetzten Ziele

Die Einflussnahme der Politik auf die Soziale Arbeit gilt in den hier dargestellten Ansätzen der Sozialen Arbeit als unbestritten (vgl. Burzlaff 2020; Borstel/Fischer 2018) und erfordert eine qualitative Herangehensweise mit der Fragestellung wie diese Einflussnahme sich darstellt.

2 Seit 2018 heißt die Asylsozialberatung »Flüchtlings- und Integrationsberatung (FIB)«basierend auf der Richtlinie für die Förderung der sozialen Beratung, Betreuung und Integration von Menschen mit Migrationshintergrund (vgl. Bayerisches Staatsministerium 2017: 578).

3 Die hier vorliegende Arbeit stellt eine Zusammenfassung meiner Masterarbeit an der Dualen Hochschule Baden-Württemberg (DHBW) dar. 
und die Maßnahmen zur Zielerreichung in den Blick nimmt. Durch die Analyse der Dokumente werden die konstitutiven Elemente der Ankerzentren herausgearbeitet, welche das Arbeitsfeld der Sozialarbeiter*innen prägen. Die Auswahl der Dokumente für die Programmanalyse orientierte sich an der Architektur des Asylsystems und an den Abhängigkeiten der Asylpolitik als "Mehrebenenpolitik « (Schammann 2018: 77). Auf internationaler Ebene waren beispielsweise die Empfehlungen des UNHCR Deutschland (2018) zu den Ankerzentren und der Bericht des European Council on Refugees and Exiles (ECRE 2019) relevante Bestandteile der Dokumentenanalyse. Die Mehrzahl der Dokumente in der politischen Problemanalyse sind der Bundes- bzw. Landesebene zuzuordnen. Beispielhaft sei hier für die Bundesebene der Koalitionsvertrag, der Masterplan Migration, Veröffentlichungen des BAMF und schriftlichen Anfragen auf Bundesebenen aufgeführt, für die Landesebene Berichte aus den Kabinettssitzungen, das Parteiprogramm der CSU sowie Anfragen an den Landtag. Es werden nicht nur staatlich Dokumente und Quellen herangezogen, sondern auch Positionspapiere und Stellungnahmen der Wohlfahrtsverbände und der verschiedenen Nichtregierungsorganisationen, ebenso wie Presseberichte, Fachzeitschriftenartikel und Fachbücher aus den Sozialwissenschaften, insbesondere aus der Sozialen Arbeit.

Am 1. August 2018 wurden die ersten Ankerzentren in Bayern eröffnet und ersetzten die bestehenden Erstaufnahmeeinrichtungen in den jeweiligen Regierungsbezirken (vgl. StMI 2018). Diese Vorläufer-Einrichtungen der Ankerzentren waren die Ankunfts- und Rückführungseinrichtungen (ARE) in Bayern, welche später als Transitzentren fortgeführt wurden ${ }^{4}$. Die bayerische Landesregierung verfolgte mit der Einführung der ARE bzw. Transitzentren das Ziel, eine Verfahrensbeschleunigung im Asylverfahren zu erreichen, welche eine schnelle Rückführung von Asylbewerber*innen ohne Bleibeperspektive intendiert (vgl. Bayerischer Landtag 2017: 3). Zudem sollten die Kommunen in ihrer Aufgabe der Unterbringung der Geflüchteten entlastet werden (vgl. ebd.). Dass dies im Sinne der Kommunen passierte, bestätigt der Beschluss des Präsidiums des Deutschen Städtetages aus dem Jahr 2015, in dem der Ausbau der Landeserstaufnahmeeinrichtungen gefordert wurde (vgl. Deutscher Städtetag 2015).

Im Zuge der Programmanalyse wurden insgesamt acht politikauslösende Probleme identifiziert ${ }^{5}$. In den analysierten Dokumenten fanden sich Aussagen über die vermehrte Einreise von Geflüchteten, die Überlastung der Behörden im Asylverfahren, welche nicht allein auf die vermehrte Einreise bezogen werden konnten, sondern auf die bestehenden internen Problemlagen im BAMF hinwiesen (vgl. Thränhardt 2016: 2). Als weiteres politikauslösendes Problem wurden von Seiten

4 Siehe dazu auch den Beitrag von Lea Celardi in diesem Band.

5 Die Ergebnisse der Programmanalyse lassen sich nur ansatzweise und verkürzt darstellen. Für eine ausführliche Darstellung wird auf Schmitt (2019) verwiesen. 
des Staates auf den drohenden Kontrollverlust über die Einreise und den Aufenthalt hingewiesen, wie er beispielsweise aus Sicht des Staates durch die unkontrollierte Einreise der Geflüchteten im Jahr 2015 erfolgte. Die CSU gab daher das Versprechen an die Wähler, dass »sich der Zustand vom Herbst 2015 nicht wiederholen wird « (CSU 2017: 15) und kündigte einen »effektiven Maßnahmenplan« (ebd.) an. Als ein weiteres politikauslösendes Problem wurde die Angst vor dem Verlust von Wählerstimmen der etablierten Parteien an die AfD, welche der Kategorie des politischen Motivs zugeordnet wurde, identifiziert. Als weitere politikauslösende Probleme wurden in den verschiedenen Dokumenten die Überlastung von Kommunen bei der Unterbringung von Geflüchteten sowie die Dauer der Asylverfahren und Rückführungen aufgeführt. Als angestrebtes Ziel wurde von Seiten der Politik in den analysierten Dokumenten insbesondere die Beschleunigung der Asylverfahren angeführt. Des Weiteren wurde die Entlastung der Kommunen, die Rückerlangung der Kontrolle über das Migrationsgeschehen, die Ausweitung der Abschiebebemühungen und die Verminderung sogenannter Pull-Faktoren ${ }^{6}$ aufgeführt. Die Wohlfahrtsverbände und Organisationen der Flüchtlingshilfe betonten, dass sogenannte Abschreckungsmaßnahmen zur Verminderung der Pull-Faktoren aus menschenrechtlicher Sicht kritisch zu sehen sind und aus sozialwissenschaftlicher Sicht fraglich ist, ob »die Prekarisierung der Lebensbedingungen Einfluss auf die Asylantragszahlen [haben] (Hess et al. 2018: 9). Die einzelnen Maßnahmen, welche von der Politik ergriffen wurden, lassen sich den jeweiligen Kernelementen der Ankerzentren zuordnen, die als Ergebnis der Dokumentenanalyse festgehalten werden:

Die Ankerzentren sind mit der klaren Intention errichtet worden, die Asylverfahren zu beschleunigen und Abschiebungen leichter vollziehen zu können. Als entscheidende Elemente hierfür sind die Zentralisierung der Behörden und Geflüchteten aufgeführt worden, welche von Kontroll-und Abschreckungsmaßnahmen begleitet werden. Diese Kernelemente sind konstitutiv für die Ankerzentren und prägen das neue Arbeitsfeld der Asylberater*innen.

Im Folgenden wird die FIB mit ihren Zielen, Aufgabenfeldern, dem eigenen Selbstverständnis ihrer Arbeit sowie den Auswirkungen des aufgeführten politischen Programms auf die FIB und den damit verbundenen Herausforderungen näher beschrieben. Zur Darstellung der Auswirkungen werden einzelne Aussagen aus den Interviews mit den Fachkräften herangezogen. Die Auswahl der Ankerzentren erfolgte über das Kriterium der Anzahl der verschiedenen Träger der FIB in den jeweiligen Zentren und sollte sicherstellen, dass die Auswirkungen als auch nach Deutschland zu fliehen bzw. soll abschreckend auf Geflüchtete wirken und wird daher als Abschreckungsmaßnahme bezeichnet. 
Möglichkeiten der politischen Einflussnahme in ihrer Vielzahl und Vielfältigkeit erfasst werden. Die Auswahl der Interviewteilnehmer erfolgte durch die angefragten Wohlfahrtsverbände in Eigenregie. Aus Gründen der Anonymisierung werden keine weiteren Angaben zu Sozialdaten oder beruflichen Eckdaten aufgezeigt.

Der Einfluss der Politik auf die Soziale Arbeit wird bei der Aufgabenzuweisung deutlich sichtbar. In der Beratungs- und Integrationsrichtlinie (BIR) werden die Beratungsziele der FIB benannt (vgl. Bayerisches Staatsministerium 2017: 578f.). Dabei stehen die Befriedung des Umfelds durch die Förderung des gegenseitigen Verständnisses und die Konfliktbewältigung in den Unterkünften laut BIR an vorderster Stelle. Dies ist sicherlich ein wichtiger Aspekt, aber bei derartigen Vorgaben laufen die Fachkräfte der FIB Gefahr, zur Akzeptanz und zum Erhalt von Ankerzentren beizutragen und die bestehenden Rahmenbedingungen in diesen Zentren $\mathrm{zu}$ legitimieren. Dies würde im Widerspruch zu den Äußerungen über die Ankerzentren in den Stellungnahmen der Wohlfahrtsverbände stehen, bei denen die Fachkräfte angestellt sind. So ist in einer Stellungnahme der AWO zu lesen, dass diese »die geplanten Ankerzentren entschieden ab[lehnt] « (AWO Bundesverband 2018: 5). Nach Ansicht von Diakonie und Caritas widersprechen die Ankerzentren den »Grundsätzen einer menschenrechtskonformen Flüchtlingspolitik« (Diakonie Deutschland/Deutscher Caritasverband 2018: 4). Es besteht eine deutliche Diskrepanz über die Vorstellung einer geeigneten Unterbringungsform zwischen Staat und Wohlfahrtsverbänden.

Zudem ist auffällig, dass die unabhängige Asylverfahrensberatung durch die Wohlfahrtsverbände in der BIR nicht genannt wird. Dies ist bemerkenswert, da alle an dieser Studie beteiligten Träger der freien Wohlfahrtspflege auf ihren Internetauftritten die Asylverfahrensberatung als Beratungsangebot benennen, oftmals sogar an allererster Stelle. Die Unterschlagung der unabhängigen Asylverfahrensberatung wird von Akteur*innen der Sozialen Arbeit kritisch gesehen. In den Ankerzentren können beschleunigte Asylverfahren durchgeführt werden, was eine zeitnahe Anhörung nach der Ankunft bedeutet. Wenn die "Anhörung das Herzstück des Verfahrens« (BAMF 2019: 2) und »der zentrale und wichtigste Vorgang im Rahmen des behördlichen Asylverfahrens« (Heinhold 2015: 108) darstellt, dann muss in der Asylverfahrensberatung die Vorbereitung auf eben diese Anhörung einen entscheidenden Stellenwert einnehmen. Mit dem Zweiten Gesetz zur besseren Durchsetzung der Ausreisepflicht (seit dem 21. August 2019 in Kraft) wurde die Möglichkeit geschaffen, eine staatliche Asylverfahrensberatung durch Mitarbeiter*innen des BAMF einzuführen. Das BAMF vollzog bereits im Juli 2018 bei allen drei in die Studie aufgenommenen Ankerzentren die Asylverfahrensberatung. Die Unabhängigkeit einer Beratung durch Mitarbeiter*innen einer staatlichen Behörde wurde von verschiedenen Seiten angezweifelt, da einerseits die Mitarbeiter*innen als Personal des BAMF nicht unabhängig agieren können und anderseits die Geflüchteten kein wirkliches Vertrauen aufbauen können, wenn die Beratung als 
auch die Entscheidung von der gleichen Behörde durchgeführt wird (vgl. Wiebke 2019: 76). In den Interviews äußerte eine Fachkraft, dass die Beratung von FIB und BAMF nicht vergleichbar wäre, da die Beratung des BAMF eine Aufklärung und keine Beratung darstelle (vgl. Interview 2). Sowohl im ECRE-Bericht als auch in der Stellungnahme des UNHCR und in der Stellungnahme der Bundesrechtsanwaltskammer wurde darauf hingewiesen, dass die behördliche Beratungsmöglichkeit keine unabhängige, also nichtstaatliche Verfahrensberatung ersetzen kann (vgl. ECRE 2019: 10f.; UNHCR 2018: 7f.; Bundesrechtsanwaltskammer 2018: 6). Die Wohlfahrtsverbände bemängeln zudem, dass ihre unabhängigen Beratungsstrukturen dem Bedarf nicht gerecht werden können (vgl. Diakonie Deutschland/Deutscher Caritasverband 2018: 4) und fordern daher eine stabile Finanzierung ihrer Beratungsangebote in den Ankerzentren (vgl. BAGFW 2017: 2).

Aus dem Leitbild der Träger und aus dem Selbstverständnis der Profession und Disziplin der Sozialen Arbeit ergeben sich klare Aufgabengebiete und ethische Vorgaben für die Fachkräfte in der FIB. So bildet die internationale Definition der Sozialen Arbeit, welche von der International Federation of Social Workers (IFSW) im Jahr 2014 in Melbourne erarbeitet wurde, die gemeinsame Grundlage für die Disziplin und Profession der Sozialen Arbeit weltweit. Die Definition benennt die »Prinzipien sozialer Gerechtigkeit, die Menschenrechte, die gemeinsame Verantwortung und die Achtung der Vielfalt« (DBSH 2016) als Grundlage der Sozialen Arbeit. Gerade in der migrationsbezogenen Sozialen Arbeit sind die Menschenrechte und der Ansatz der Sozialen Arbeit als Menschenrechtsprofession nach Silvia Staub-Bernasconi (2003) ein wichtiger Bezugspunkt für die Ausarbeitung von Handlungsansätzen (vgl. Gögercin 2018: 552; Prasad 2018: 10f.).

Für diesen menschenrechtlichen Ansatz sprechen aus Sicht des Autors vor allem drei Gründe. Der erste Grund ist die Tatsache, dass sich die nationale Gesetzgebung an den nationalstaatlichen Interessen orientiert und dadurch im Widerspruch stehen kann zum globalen Phänomen der Migration als auch zu den menschenrechtlichen und europarechtlichen Vorgaben. Beispielhaft sei hier verwiesen auf die jahrelange Weigerung der deutschen Politik die Kinderrechtskonvention (KRK) im vollen Umfang anzuerkennen (vgl. Kauffmann 2010). Die nationale Gesetzgebung kann daher nicht mehr allein als Orientierungsrahmen für die Sozialarbeiter*innen dienen, denn nach Staub-Bernasconi können »Gesetze wohl legal, aber nicht unbedingt auch ethisch legitim sein «(Staub-Bernasconi 2018: 112). Ersichtlich wird dies beispielsweise auch beim Asylbewerberleistungsgesetz: "Die seit März 2015 geltende überarbeitete Fassung des Asylbewerberleistungsgesetzes entsprach in Teilen nicht den internationalen Menschenrechtsstandards, dies betraf insbesondere den Bereich der Gesundheitsfürsorge. (Amnesty International 2016: 142) Der zweite Grund ist das Selbstverständnis von Sozialer Arbeit als Menschenrechtsprofession, das auf der Grundlage des Tripelmandats Eingang in die Soziale Arbeit gefunden hat. 
»Das heißt, dass Sozialarbeiterlnnen auch dann aktiv werden können, wenn kein Mandat seitens der Cesellschaft oder eines Trägers des Sozialwesens vorliegt, wobei sie sich dieses in diesem Fall, wenn immer möglich von den Problembetroffenen geben lassen müssen.«(Staub-Bernasconi 2018: 118)

Wenn bestimmten Kindern der Zugang zu Bildung verhindert wird und somit internationale Menschenrechtsstandards wie die KRK verletzt werden, so wäre es hier im Sinne einer menschenrechtsorientierten Sozialen Arbeit Aufgabe, sich gegen diskriminierende Strukturen einzusetzen. Der dritte Grund ist die sozialarbeiterische Fokussierung auf menschliche Bedürfnisse, wie sie Silvia Staub-Bernasconi (2018) in ihrem systemischen Ansatz der Sozialen Arbeit vorschlägt. Demnach sind »Menschen aufgrund ihrer psychischen bzw. psychobiologischen Beschaffenheit zur Erhaltung ihrer Ausstattung lebenslänglich auf biologische, psychische, soziale und kulturelle Ressourcen angewiesen « (StaubBernasconi 2003: 27). Diese Angewiesenheit auf die Chancen und Möglichkeiten der Bedürfnisbefriedigung, welche einer Person in ihrer konkreten Umwelt zur Verfügung stehen, macht es für die Soziale Arbeit notwendig, sich nicht nur auf das Individuum zu konzentrieren, sondern die Bedingungen der Umwelt in ihre Arbeit miteinzubeziehen.

Das Arbeitsfeld der Sozialarbeiter*innen in den Ankerzentren ist wie aufgezeigt wurde durch die Zentralisierung der Geflüchteten, die bewusst hergestellten prekären Lebensbedingungen, die verstärkten Abschiebebemühungen oder die Kontrollmaßnahmen vorstrukturiert. Die Auswirkungen dieser Maßnahmen auf die FIB zeigen sich beispielhaft im eingeschränkten Handlungsspielraum der Fachkräfte. Da keine Integrationsleistungen angeboten werden können, findet auch keine Vermittlung in Arbeit oder Integrationskurse statt (vgl. Interview 3) und schränkt so die weiteren Unterstützungsmaßnahmen grundlegend ein. Die Lebensbedingungen der Adressat*innen in den Ankerzentren spiegeln sich auch in den Beratungsinhalten der FIB wieder. Die Fachkräfte bekommen so "ganz viel Aggression, Verzweiflung, Frustration, Depression, wie auch immer, alle Facetten des Menschseins wie man quasi mit schwierigen Lebenslagen umgeht« (Interview 6) mit. Die psychischen Belastungen der Adressat*innen (vgl. Interview 4) kommen erschwerend hinzu, genauso wie die eingeschränkten Gesundheitsleistungen (vgl. Interview 7), welche ein ständiges »rumdiskutieren« (ebd.) mit dem Sozialamt nach sich ziehen. Einen großen Anteil in den Beratungen nimmt auch das jeweilige Asylverfahren der Adressat*innen ein (vgl. Interview 3). Als Themen, welche durch die Asylpolitik die Beratungsinhalte bestimmen, wurden u.a. genannt: neue Gesetzesänderungen (vgl. Interview 1), drohende Rückführungen oder Dublin-Überstellungen (vgl. Interview 2) und die Negativ-Bescheide im Asylverfahren (vgl. Interview 4). Für eine unabhängige Asylverfahrensberatung bedeutet dies, dass die Adressat*innen über mögliche Rechtsmittel aufgeklärt werden müs- 
sen (vgl. Interview 6), Rechtsanwälte vermittelt werden (vgl. Interview 3) oder in Fällen mit hohem Zeitdruck den Geflüchteten bei der Formulierung von Rechtsmitteln geholfen wird (vgl. Interview 7). Da derartige Maßnahmen nicht von der staatlichen Asylverfahrensberatung und den Mitarbeitern vom BAMF angeboten werden, stellt die Asylverfahrensberatung eine der Haupttätigkeiten in der Beratung dar.

Die Zentrierung der Behörden hat Auswirkungen sowohl im positiven als auch im negativen Sinne. Einerseits zeigte sich in den Interviews, wie die FIB durch die Nähe zu den anderen Behörden an Vertrauen bei ihren Adressat*innen verliert und als »Teil des Systems« (Interview 4) gesehen wird. Was dazu führt, dass bei manchen Themen die Geflüchteten bei den umliegenden Bürgerinitiativen Hilfe suchen, was wiederum auf die Angewiesenheit von ehrenamtlichen Unterstützungsformen hindeutet. Andererseits führt die Nähe zu den Behörden und der Regierung zur Erleichterung der Kommunikation (vgl. Interview 3) und hat darüber hinaus Einfluss auf das politische Handeln der Sozialarbeiter*innen in den Ankerzentren. Bezug genommen wurde in den Interviews auch auf die erschwerte Vorbereitung auf die Anhörung. Da die fehlende oder stark eingeschränkte Vorbereitung insbesondere Auswirkungen auf die Geflüchteten und ihr Asylverfahren haben, werden diese im Folgenden näher beschrieben.

\section{Bewertung des politischen Programms}

Policy-Analysen können auf unterschiedlichste Weise evaluiert werden, beispielsweise hinsichtlich ihrer inhaltlichen Logik oder in Bezug auf Effektivität oder Effizienz (vgl. Popple/Leighninger/Leighninger 2019: 47). Für die Soziale Arbeit ist eine weitere Evaluationsform von Bedeutung: die »Legitimität einer Politik« (Benz/Rieger 2015: 93). "Soziale Arbeit muss Politik ethisch bewerten, denn sie ist handlungsorientiert und muss Ziele setzten [sic!].« (Ebd.) Für eine menschenrechtsorientierte Soziale Arbeit, möchte sie sich im Rahmen ihres Tripelmandats gegen diskriminierenden Strukturen einsetzen, ist die Legitimität der bestehenden Strukturen von entscheidender Bedeutung. Wenn Diskriminierung als eine »Ungleichbehandlung von sozial hergestellten Gruppen « (Melter 2015: 9) verstanden wird, dann stellt sich die Frage, warum eine Ungleichbehandlung der Geflüchteten gegenüber der restlichen Bevölkerung trotz bestehendem Gleichbehandlungsgesetz nicht als solche erkannt wird. »Bestimmte Diskriminierungspraxen werden durch das allgemeine Gleichbehandlungsgesetz verboten, staatsbürgerliche, aufenthalts- und asylrechtliche Diskriminierung jedoch nicht.« (Ebd.) Die Einschätzung der Legitimität eines politischen Programms stellt somit eine Grundvoraussetzung für jedes weitere Handeln der Fachkräfte dar. Des Weiteren führen die ergriffenen Maßnahmen aus Sicht der Fachkräfte zu mannigfaltigen Problemlagen bei den Geflüchte- 
ten. Für die Einschätzung der Legitimität sind die beabsichtigten oder unbeabsichtigten Auswirkungen auf die Adressat*innen von besonderem Interesse. Es werden daher die konstitutiven Elemente der Ankerzentren und deren Auswirkungen auf die Adressat*innen aufgezeigt.

Das politische Programm, das sich in den aufgezeigten Kernelementen der Ankerzentren wiederspiegelt, führt aus Sicht der Fachkräfte beispielsweise durch die interne Beschulung (vgl. Interview 1), fehlenden Bustickets (vgl. ebd.) und fehlenden Integrationsangebote (vgl. Interview 3) zur Isolation der Geflüchteten. Negative Auswirkungen haben diese auch auf Kinder, die in einer Umgebung aufwachsen, welche die Entwicklung eher hemmt als fördert (vgl. Interview 6) und von einer Fachkraft als »eine wahnsinnige schwierige Situation « (Interview 5) für Kinder beschrieben wird. Diese Aussagen werden auch durch eine Experten-Anhörung im Bayerischen Landtag bestätigt. Ein Facharzt der Organisation Ärzte der Welt machte dabei die Aussage, dass die vorherrschenden Lebensbedingungen in den Ankerzentren die Kinder krankmacht (vgl. Bayerischer Landtag 2019) und die Organisation kündet kurz darauf ihren Rückzug aus den Ankerzentren an. Wenn eine weltweit tätige Organisation, die teilweise in Konfliktregionen agiert, sich aus den Ankerzentren herauszieht, wirft dies erhebliche Fragen zur Legitimität dieser Einrichtungen auf, insbesondere wie dies mit der Kinderrechtskonvention vereinbar ist.

Als ein weiteres Kernelement der Ankerzentren wurden die Abschreckungsmaßnahmen im Rahmen der politischen Programmanalyse herausgearbeitet. In den Interviews ist hervorgehoben worden, dass die prekären Lebensbedingungen in den Ankerzentren bewusst zur Abschreckung hergestellt werden und dies auch so von den Behörden verkündet wird: "Was man tut, ist dafür gedacht, um die Leute abzuschrecken. Und das wird ja auch so kommuniziert. Also wir hören das auch von der Ausländerbehörde ganz oft. «(Interview 2) Die Zentralisierung der Geflüchteten erschwert einen Rückzug in die Privatsphäre und bietet keinerlei Möglichkeiten, sich dieser psychischen Belastung zu entziehen (vgl. Interview 2). Dadurch wird zu einer Verschärfung der Situation in Ankerzentren beigetragen. Ersichtlich wurde dies an der Kategorie Stimmung und psychische Belastung, welcher die meisten Textstellen zugewiesen wurden. Die ergriffene Maßnahme der Zentralisierung der Geflüchteten als auch die Abschreckungsmaßnahmen, welche als konstitutive Elemente der Ankerzentren bezeichnet wurden, führen zu mannigfaltigen Problemlagen, welche teilweise bewusst von der Politik erzeugt werden.

Gemäß Art. 19 Abs. 1 der Asylverfahrensrichtlinie der EU müssen die EUMitgliedsstaaten im Rahmen des erstinstanzlichen behördlichen Asylverfahrens »mindestens Auskünften [sic!] zum Verfahren unter Berücksichtigung der besonderen Umstände des Antragstellers« gewährleisten. Die Richtlinie impliziert also, dass eine allgemeine Aufklärung über das Asylverfahren nicht ausreichend erscheint, weshalb individuelle Auskünfte möglich sein müssten. In sechs von sieben Interviews wurde jedoch angeführt, dass die individuelle Vorbereitung auf 
die Anhörung durch die Wohlfahrtsverbände nur in sehr eingeschränktem Maße stattfindet. Dies hat aus Sicht der Fachkräfte mehrere Gründe: die Zeitspanne von der Ankunft in den Ankerzentren bis zur Anhörung ist sehr kurz, so dass kaum Zeit für eine Beratung bleibt (vgl. Interview 2). Zudem macht sich hier die ungenügende Finanzierung und die daraus folgende fehlende Kapazität bemerkbar (vgl. Interview 4). Insbesondere wird immer wieder auf die neu eingeführte Beratung durch Mitarbeiter*innen des BAMF verwiesen, obwohl diese von vielen Fachkräften sehr kritisch gesehen wird und es stellt sich die Frage, ob das aktuelle Beratungsangebot des BAMF der Asylverfahrensrichtlinie noch gerecht wird.

Als weitere konstitutive Maßnahmen des politischen Programms sind die verstärkten Abschiebebemühungen und die erweiterten Kontrollmaßnahmen in der Programmanalyse aufgeführt worden. Hier soll auf die drastischen Leistungskürzungen bei fehlender Mitwirkung oder Abwesenheit bei Dublin-Überstellungen hingewiesen werden. Diese Leistungskürzungen machen ein menschenwürdiges Leben und die Teilhabe an der Gesellschaft unmöglich (vgl. Interview 7). In welchem Umfang dies geschieht, macht folgende Aussage einer Fachkraft deutlich:

"Sobald aber jemand bei der Dublin-Abschiebung nicht mitwirkt, wird das komplett runtergekürzt. Das Sozialamt ist zuständig für die Barzahlungen, die zahlen dann nur noch 7 Euro [im Monat; Anmerkung M.S.] aus und die Regierung, der $<$ NAME $>$ ist zuständig für die Sachleistungen. Das heißt es gibt Essen, Trinken, Hygienepakete, aber keine Kleidergutscheine mehr und keine Bustickets mehr.« (Interview 7)

Aus Sicht einer weiteren Fachkraft »öffnet das Tür und Tor der Kriminalität« (Interview 6), wenn die Personen kein Geld zur Verfügung haben und hat des Weiteren zur Folge, dass sich die Geflüchteten keinen Rechtsbeistand mehr leisten können (vgl. ebd.). Zu den Kontrollmaßnahmen gehört beispielsweise der Einsatz von Chip-Karten. So werden die Geflüchteten »praktisch beim Rein und Rausgehen gescannt. Damit die Regierung quasi weiß, sind sie auf dem Gelände oder nicht« (Interview 5). Die Durchführung von Razzien, insbesondere bei Familien (vgl. Interview 7), erzeugt ein Klima der Angst. In den Interviews zeigte sich, dass immer wieder Familien auseinandergerissen werden, um eine Überstellung im Rahmen des Dublin-Verfahrens eines Elternteils zu ermöglichen (vgl. Interview 6). Das Grundgesetz stellt Familien unter einen besonderen Schutz und verweist darauf, dass die Familieneinheit nur in sehr schwerwiegenden Fällen gegen ihren Willen getrennt werden dürfen. Die ergriffenen Kontrollmaßnahmen und die Ausweitung der Abschiebebemühungen müssen sich am juristischen Grundsatz der Verhältnismäßigkeit orientieren und dessen Berücksichtigung ist mit Blick auf die Beispiele in Frage zu stellen. 


\section{Politisches Handeln in der FIB}

Was viele Theorien der Sozialen Arbeit, ebenso die Sozialarbeitspolitik und der Ansatz von Policy Practice, vereint, ist die Annahme des Grundtheorems von der Person in der Umwelt (Person-in-Environment) (vgl. Rieger 2013: 56). Daraus wird ersichtlich, wie die Umwelt in Interaktion mit der Person selbst steht und daher Einfluss auf die Entwicklung der Menschen nimmt und zwar im Positiven wie auch im Negativen (vgl. Cummins/Byers/Pedrick 2011: 7). Es lässt sich daraus ableiten, dass in der jeweiligen Fallbearbeitung die alleinige Arbeit mit dem Subjekt ohne Berücksichtigung der strukturellen Bedingungen, wie sie durch die Politik wesentlich mitgestaltet werden, nicht ausreichend sein kann und ergo politische Einflussnahme in die Tätigkeit der Sozialen Arbeit einfließen muss. ${ }^{7}$

Das aus den USA stammende Konzept von Policy Practice geht davon aus, dass Soziale Arbeit in vielfacher Weise mit (Sozial-)Politik verwoben ist (vgl. Burzlaff 2020: 27). Policy Practice wird nach Burzlaff in Anlehnung an Gal/Weiss-Gal (2014) wie folgt definiert:

»Policy Practice verweist auf Handlungen von Sozialarbeitenden, welche die Cestaltung und Implementierung neuer Politiken oder die Veränderung, ggf. Abschaffung bereits existierender Politiken zugunsten von Social Justice fokussieren. Entsprechende Handlungen, die einen integralen Bestandteil aller Felder Sozialer Arbeit ausmachen und nicht einzelnen Sozialarbeitenden vorbehalten sind, gehen über individuelle Unterstützung respektive Symptombekämpfung hinaus und zielen mittels Strukturveränderung auf langfristige Problemlösungen sowie Verbesserungen der Lebensbedingungen von Adressat_innen Sozialer Arbeit. Ausgangspunkt von Policy Practice ist eine Orientierung am Subjekt, und die Bedürfnisse, Fähigkeiten, Forderungen, Interessen, Wünsche etc. von denjenigen, die eine Intervention betrifft, sind in den Mittelpunkt gerückt. Um eine Verbindung zwischen einem spezifischen Einzelfall und Veränderungen auf struktureller Ebene sicherzustellen, basieren entsprechende Handlungen auf einem dialogisch-partizipativen Aushandlungsprozess. Policy Practice ist an Autonomie und Perspektivenvielfalt gebunden, der ethische Kodex Sozialer Arbeit dient als normativer Referenzrahmen.«(Burzlaff 2020: 36)

Ersichtlich wird dadurch, dass unter politischem Handeln in der hier vorliegenden Arbeit eine sehr spezifische Form der politischen Einflussnahme beschrieben wird. Das politische Handeln der Sozialarbeiter*innen muss daher unter den hier beschriebenen Voraussetzungen stattfinden. In der Auswertung der Interviews legte

7 Zur weiteren Ausführung des Begriffs der Sozialarbeitspolitik wird auf das Einführungswerk von Benz/Rieger verwiesen, insbesondere auf deren Darstellung der drei Dimensionen der Sozialarbeitspolitik (vgl. Benz/Rieger 2015: 44f.). 
die Kategoriendefinition fest, wann eine Handlung unter dem Begriff des politischen Handelns fällt. Zum besseren Verständnis wird hier die genaue Kategoriendefinition aufgeführt. Als politisches Handeln wird im Folgenden begriffen, wenn Interventionen von Sozialarbeiter*innen zur Gestaltung von Politiken und Praktiken stattfinden, die den Werten der Sozialen Arbeit entsprechen, mit dem Ziel, eine Verbesserung der Situation der Geflüchteten zu erreichen, welche über den Einzelfall hinausgeht und im Rahmen der professionellen Tätigkeit eingebettet ist. Dies schließt sowohl die Einflussnahme auf die Ausgestaltung der Ankerzentren, als auch auf kommunaler, sowie Landes- und Bundesebene mit ein. Das so erfasste politische Handeln der Fachkräfte wurde den Methoden des politischen Handelns der Sozialarbeitspolitik (vgl. Rieger 2013) und den Interventionen von Policy Practice, wie sie von Burzlaff (2020) und Cummins et al. (2011) aufgezeigt werden, zugeordnet. Aufgrund des explorativen Charakters der Studie wurde nach dem Prinzip der Offenheit die Möglichkeit geschaffen, auch bislang unbekannte Formen der politischen Einflussnahme zu erfassen.

Es zeigte sich, dass häufig die politische Einflussnahme der Sozialarbeiter*innen in Form von Mikropolitik erfolgte und zwar unabhängig vom jeweiligen Ankerzentrum und ebenso unabhängig vom jeweiligen Wohlfahrtsverband. Mit dem Begriff der Mikropolitik werden »jene elementaren Interaktionen und Kommunikationen aus denen sich politische Prozesse zusammensetzen« (Benz/Rieger 2015: 173) beschrieben. Die politische Einflussnahme in Form der Mikropolitik erfolgte häufig durch den direkten Kontakt mit der Leitung der Einrichtung um eine strukturelle Veränderung herbeizuführen. Beispielhaft sei hier auf die Aussage einer Fachkraft verwiesen, die sich für eine beschleunigte Verteilung von Familien aus den Ankerzentrum heraus einsetzte. Die Fachkraft schrieb in Zusammenarbeit mit den Familien Briefe an die Leitung der Einrichtung und erlangte dadurch die Zusicherung zur Unterstützung einer zeitnahen Umverteilung bei Familien (vgl. Interview 6). Darüber hinaus finden auch Treffen mit den Behörden statt, wenn beispielsweise vermehrt ähnliche Probleme bei den Geflüchteten vorzufinden sind (vgl. Interview 1). Aber auch im Rahmen der Organisationsentwicklung wirken die Fachkräfte mit und bringen beispielsweise ihre Erfahrungen bei der Etablierung eines Gewaltschutzkonzeptes mit ein (vgl. Interview 3). Das häufige Vorfinden der politischen Einflussnahme in Form der Mikropolitik lässt sich aus Sicht des Autors durch die Zentrierung der Behörden begründen, da durch die Nähe zur Regierung und den Behörden informelle Treffen und schnelle Absprachen und somit Einflussnahme im Sinne der Mikropolitik möglich sind. Eine Fachkraft drückte dies wie folgt aus: »Wir arbeiten auch hier politisch. Ich natürlich, wenn ich ein Missstand sehe, werde ich das nicht für mich behalten, sondern werde das mit unserer Leitung hier besprechen.« (Interview 4)

Eine weitere Form der politischen Einflussnahme erfolgt in Form der Rückmeldung und Informationsweitergabe an die Vorgesetzten bzw. Mitarbeiter*innen 
der Wohlfahrtsverbände. Durch die Anbindung der Fachkräfte an die jeweiligen Wohlfahrtsverbände erfolgt ein Großteil der politischen Einflussnahme über die Verbände, die sich u.a. mit Stellungnahmen und Positionspapieren in den politischen Prozess miteinbringen. Die Fachkräfte erleben sich so nicht als Einzelkämpfer*in, sondern als »Teil von einem großen Wohlfahrtsverband« (vgl. Interview 6). Die Wohlfahrtsverbände und die direkten Vorgesetzten sind auf diese Rückmeldungen von der Basis auch angewiesen und wollen mit Informationen "gefüttert « (Interview 2) werden. Denn »was ganz oben ankommt ist ja das Resultat von vielen Einzelwahrnehmungen « (Interview 6). Kritisch betrachtet könnte hier die Frage gestellt werden, ob hier von politischem Handeln gesprochen werden kann. Zunächst sei darauf verwiesen, dass auch in verschiedenen Fachbüchern auf diese Form der politischen Einflussnahme hingewiesen wird. Christiane Wahl zeigt auf, dass einzelne Mitarbeiter nur schwer strukturell gegen gesetzlich verankerte Marginalisierungen vorgehen können, aber durch Vernetzung, politische Lobbyarbeit der Wohlfahrtsverbände und zivilgesellschaftliche Gruppen gemeinsam politische Forderungen erhoben werden können (vgl. Wahl 2018: 313). Erkennbar wird dadurch, dass politisches Handeln zwar bei der Fachkraft beginnt, dies aber oftmals nicht von ihr allein vollzogen wird, sondern sich im Verbund mit anderen Akteur*innen vollzieht. Umso entscheidender ist daher, das vorherrschende politische Bewusstsein der Fachkräfte zu fördern, um politische Forderungen formulieren zu können.

Als problematisch wurde bei der Auswertung vom Autor gesehen, dass die politische Einflussnahme teilweise nicht bewusst als solche von den Fachkräften wahrgenommen und teilweise ein diffuses Verständnis von politischem Handeln vorgefunden wurde. Vereinzelt wurde das politische Handeln im privaten Bereich verortet oder die politische Einflussnahme überhaupt nicht als Aufgabe der Sozialarbeiter*innen gesehen. Dies führte dazu, dass zwar politisches Handeln festgestellt werden konnte, weniger jedoch methodisches Handeln, was stellenweise dazu führte, dass die Methoden der Sozialarbeitspolitik und Interventionen von Policy Practice nur vereinzelt in Erscheinung traten. Hier wurden von den interviewten Fachkräften Lobbying und Gremienarbeit, das Bilden von Koalitionen und die Reform mittels Gerichtsverfahren angeführt. Im Rahmen von Lobbying und Gremienarbeit wurde erkennbar, welche wichtige Rolle ein vorhandenes Ombudsteam bei der Ausgestaltung der Ankerzentren einnimmt. Es wurde als ein entscheidender Ort der politischen Einflussnahme benannt. So erwähnte eine Fachkraft, dass sich positive Veränderungen im Ankerzentrum durch den Einfluss des Ombudsteam ergeben haben und gerade in den Anfängen das Ombudsteam »unheimlich stark gebraucht « (Interview 4) wurde. Derartige Gremien können, so die Hypothese, eine wichtige Rolle für die politische Einflussnahme darstellen, insbesondere dann, wenn bei diesen Gremien die Selbstvertretung der Geflüchteten ermöglicht wird. Gerade dieser letzte Aspekt scheint aus Sicht des Autors eine entscheidende Rolle einzunehmen um den Personen selbst politisches Gehör zu verschaffen. 


\section{Schlussfolgerung und Fazit}

Die Auswirkungen der analysierten Intention der Ankerzentren auf die FIB als auch auf deren Adressat*innen zeigten, dass bis auf die Zentralisierung der Behörden alle ergriffenen Maßnahmen, welche als konstitutiv für die Zentren gelten, erhebliche Problemlagen mit sich bringen und ethische Bedenken aufwerfen. Die politische Einflussnahme der FIB auf die Politik erfolgte meist über mikropolitisches Handeln der Fachkräfte und in Zusammenarbeit mit den Wohlfahrtsverbänden. Als wichtiges Gremium wurde in den Interviews das Ombudsteam genannt. Durch die Nähe zu den Behörden und der Einrichtungsleitung in den Ankerzentren befindet sich die FIB in einer Situation, welche zum Handeln auffordert. Einerseits sollte klar das politische Bewusstsein der Fachkräfte gestärkt werden, um das methodische Handeln im Bereich der politischen Einflussnahme zu stärken, was wiederum auch den Wohlfahrtsverbänden selbst bei ihren politischen Forderungen zugutekommen würde. Andererseits müssen Wege und Möglichkeiten gefunden werden, wie die bestehende Unabhängigkeit der FIB klar in den Vordergrund gestellt werden kann, um so das Vertrauen der Geflüchteten in diese Beratungsangebote zu stärken. Deutlich wurde in dieser Arbeit auch, wie das politische Handeln zur Verbesserung der Lebenslagen der Adressat"innen beitragen kann. Daher sollte die bislang randständige Thematisierung politischen Handelns in Studium und Praxis der Sozialen Arbeit überwunden werden.

\section{Literaturverzeichnis}

Amnesty International (2016): Amnesty Report 2015/16. Zur weltweiten Lage der Menschenrechte, Frankfurt a.M.: S. Fischer.

AWO Bundesverband (2018): Stellungnahme des AWO Bundesverbandes zur geplanten Einrichtung von sogenannten AnkER - Zentren, vom 04.06.2018, https://www.awo.org/sites/default/files/2018-06/Stellungnahme \%20des$\% 20$ AWO \%20Bundesverbandes \%20zu \%20AnkER-Zentren.pdf, Abrufdatum: 30.04.2020.

[BAGFW] Bundesarbeitsgemeinschaft der freien Wohlfahrtspflege (2017): Unabhängige Asylverfahrensberatung - ein Beitrag zur Verbesserung von Fairness, Qualität und Effizienz des Asylverfahrens, vom 14.11.2017, https://www. bagfw.de/fileadmin/user_upload/Veroeffentlichungen/Stellungnahmen/ 2017/2017-11-14_Unabhaengige_Asylverfahrensberatung.pdf, Abrufdatum: 30.04.2020.

[BAMF] Bundesamt für Migration und Flüchtlinge (2019): Entscheiderbrief 5/2019. Informations-Schnelldienst, vom 31.05.2019, https://www.bamf.de/ 
SharedDocs/Anlagen/DE/Behoerde/Informationszentrum/Entscheiderbrief/ 2019/entscheiderbrief-05-2019.html, Abrufdatum: 30.04.2020.

Bayerischer Landtag (2017): Ankunftszentren und Transitzentren, Drs. 17/17526. Bayerischer Landtag (2019): Rechtsausschuss: Experten ziehen Zwischenbilanz $\mathrm{zu}$ Ankerzentren für Flüchtlinge, vom 26.09.2019, https://www.bayern. landtag.de/aktuelles/aus-den-ausschuessen/rechtsausschuss-experten-z iehen-zwischenbilanz-zu-ankerzentren-fuer-fluechtlinge, Abrufdatum: 30.04.2020.

Bayerisches Staatsministerium für Arbeit und Soziales, Familie und Integration (2017): Richtlinie für die Förderung der sozialen Beratung, Betreuung und Integration von Menschen mit Migrationshintergrund (Beratungs- und Integrationsrichtlinie - BIR), in: Allgemeines Ministerialblatt 30(12), S. 578584, https://www.verkuendung-bayern.de/files/allmbl/2017/12/allmbl-2017-12. pdf\#page=1, Abrufdatum: 22.09.2020.

Benz, Benjamin/Rieger, Günter (2015): Politikwissenschaft für die soziale Arbeit. Eine Einführung, Wiesbaden: Springer VS.

Borstel, Dierk/Fischer, Ute (2018): Politisches Grundwissen für die Soziale Arbeit, Stuttgart: Kohlhammer.

Bundesrechtsanwaltskammer (2018): Stellungnahme Nr. 33. Oktober 2018. Sicherstellung der Inanspruchnahme unabhängiger rechtlicher Beratung und Vertretung in AnkER-Zentren, https://www.brak.de/zur-rechtspolitik/ stellungnahmen-pdf/stellungnahmen-deutschland/2018/oktober/stellungnahme-der-brak-2018-33.pdf, Abrufdatum: 30.04.2020.

Burzlaff, Miriam (2020): »Policy Practice - Eine Einführung mit Fokus auf Curricula Sozialer Arbeit«, in: Günter Rieger/Jens Wurtzbacher (Hg.), Tatort Sozialarbeitspolitik. Fallbezogene Politiklehre für die Soziale Arbeit, Weinheim/Basel: Beltz Juventa, S. 27-51.

CSU (2017): Der Bayernplan. Klar für unser Land. Programm der CSU zur Bundestagswahl 2017, vom 17.07.2017, https://www.csu.de/common/csu/content/c su/hauptnavigation/politik/beschluesse/Beschluss_Bayernplan_BF.pdf, Abrufdatum: 30.04.2020.

Cummins, Linda K./Byers, Katharine V./Pedrick, Laura (2011): Policy practice for social workers. New strategies for a new era, Boston, MA: Allyn \& Bacon.

[DBSH] Deutscher Berufsverband für Soziale Arbeit (2016): Deutschsprachige Definition Sozialer Arbeit, vom 10.09.2016, https:/www.dbsh.de/media/dbshwww/redaktionell/bilder/Profession/20161114_Dt_Def_Sozialer_Arbeit_FBTS_ DBSH_01.pdf, Abrufdatum: 30.04.2020.

Deutscher Städtetag (2015): Aufnahme und Integration von Zuwanderern, Asylbewerbern und Flüchtlingen. Beschluss des Präsidiums des Deutschen Städtetages, www.staedtetag.de/presse/beschluesse/073198/index.html, Abrufdatum: 30.04.2020. 
Diakonie Deutschland/Deutscher Caritasverband (2018): Anschreiben zur 208. Sitzung der Ständigen Konferenz der Innenminister und -senatoren der Länder vom 06. bis 08. Juni 2018, https://www.fluechtlingskirche.de/images/Temp or \%C3\%A4r/Schreiben_an_IMK_AnKER-Zentren_DD_DCV_20180528.pdf, Abrufdatum: 30.04.2020.

ECRE (2019): The AnkER centres. Implications for asylum procedures, reception and return, vom 30.04.2019, www.asylumineurope.org/sites/default/files/anker_centres_report.pdf, Abrufdatum: 30.04.2020.

Gal, John/Weiss-Gal, Idit (2014): Social workers affecting social policy. An international perspective on policy practice, Bristol/Chicago: Policy Press.

Gögercin, Süleyman (2018): »Soziale Arbeit mit geflüchteten Menschen. Spannungsfelder und Herausforderungen«, in: Beate Blank/Süleyman Gögercin/Karin E. Sauer/Barbara Schramkowski (Hg.), Soziale Arbeit in der Migrationsgesellschaft. Grundlagen - Konzepte - Handlungsfelder, Wiesbaden: Springer VS, S. 551-561.

Heinhold, Hubert (2015): Recht für Flüchtlinge. Ein Leitfaden durch das Asyl- und Ausländerrecht für die Praxis, Karlsruhe: Von Loeper Literaturverlag.

Hess, Sabine/Pott, Andreas/Schammann, Hannes/Scherr, Albert/Schiffauer, Werner (2018): Welche Auswirkungen haben »Anker-Zentren«? Eine Kurzstudie für den Mediendienst Integration, in: Mediendienst Integration vom August 2018, https://mediendienst-integration.de/fileadmin/Dateien/Expertise_Anke r-Zentren_August_2018.pdf, Abrufdatum:30.04.2020.

Kauffmann, Heiko (2010): »Deutsche Vorbehalte gegen Flüchtlingskinder: Das Ende einer schier unendlichen Geschichte politischen Versagens? «, in: Heiko Kauffmann/Albert Riedelsheimer (Hg.), Flüchtlingskinder in Deutschland nach der Rücknahme der Vorbehalte. Kindeswohl oder Ausgrenzung?, Karlsruhe: Von Loeper Literaturverlag, S. 17-47.

Kuckartz, Udo (2018): Qualitative Inhaltsanalyse. Methoden, Praxis, Computerunterstützung (= Grundlagentexte Methoden), Weinheim/Basel: Beltz Juventa.

Mayring, Philipp (2015): Qualitative Inhaltsanalyse. Grundlagen und Techniken, Weinheim: Beltz Verlag.

Melter, Claus (2015): »Diskriminierungs- und rassismuskritische Soziale Arbeit und Bildung im postkolonialen und postnationalsozialistischen Deutschland?! Einleitende Überlegungen«, in: Claus Melter (Hg.), Diskriminierungs- und rassismuskritische soziale Arbeit und Bildung. Praktische Herausforderungen, Rahmungen und Reflexionen, Weinheim/Basel: Beltz Juventa, S. 7-19.

Popple, Philip R./Leighninger, Leslie/Leighninger, Robert D. (2019): The policybased profession. An introduction to social welfare policy analysis for social workers, New York: Pearson. 
Prasad, Nivedita (Hg.) (2018): Soziale Arbeit mit Geflüchteten. Rassismuskritisch, professionell, menschenrechtsorientiert, Opladen/Toronto: Verlag Barbara Budrich.

Richtlinie 2013/32/EU des Europäischen Parlaments und des Rates vom 26. Juni $2013 \mathrm{zu}$ gemeinsamen Verfahren für die Zuerkennung und Aberkennung des internationalen Schutzes (Neufassung).

Rieger, Günter (2006): „Weniger Staat, mehr Politik. Soziale Arbeit als politischer Unternehmer«, in: Blätter der Wohlfahrtspflege 153, S. 90-93.

Rieger, Günter (2013): „Das Politikfeld Sozialarbeitspolitik«, in: Benjamin Benz/Günter Rieger/Werner Schönig/Monika Többe-Schukalla (Hg.), Politik Sozialer Arbeit. Band 1: Grundlagen, theoretische Perspektiven und Diskurse, Weinheim: Beltz Juventa, S. 54-69.

Schammann, Hannes (2018): »Migrationspolitik«, in: Beate Blank/Süleyman Gögercin/Karin E. Sauer/Barbara Schramkowski (Hg.), Soziale Arbeit in der Migrationsgesellschaft. Grundlagen - Konzepte - Handlungsfelder, Wiesbaden: Springer VS, S. 67-85.

Schmitt, Mathias (2019): »Die Flüchtlings- und Integrationsberatung in den ANKER-Zentren - im Spannungsfeld von politischer Beeinflussung und sozialarbeiterischer Einflussnahme«, Unveröffentlichte Masterarbeit, Duale Hochschule Baden-Württemberg.

Staub-Bernasconi, Silvia (2003): »Soziale Arbeit als (eine) >Menschenrechtsprofession<, in: Richard Sorg (Hg.), Soziale Arbeit zwischen Politik und Wissenschaft. Ein Projekt des Fachbereichs Sozialpädagogik der Hochschule für Angewandte Wissenschaften Hamburg, Münster: Lit Verlag, S. 17-54.

Staub-Bernasconi, Silvia (2018): Soziale Arbeit als Handlungswissenschaft. Soziale Arbeit auf dem Weg zu kritischer Professionalität, Opladen/Toronto: Verlag Barbara Budrich; UTB.

[StMI] Bayerisches Staatsministerium des Innern, für Sport und Integration (2018): Startschuss für ANKER-Einrichtungen, vom 01.08.2018, www.stmi.bayern.de/med/aktuell/archiv/2018/180801anker/, Abrufdatum: 30.04.2020.

Süddeutsche Zeitung (2017): Empörung über Sozialministerium. Wohlfahrtsverbände warnen vor Eingriff in Flüchtlingsberatung, in: Süddeutsche Zeitung vom 08.03.2017, https:/www.sueddeutsche.de/bayern/asylpolitik-empoerung -ueber-sozialministerium-1.3410753, Abrufdatum: 30.04.2020.

Thränhardt, Dietrich (2016): Schnelligkeit und Qualität - Impulse aus der Schweiz für faire Asylverfahren in Deutschland, in: Bertelsmann Stiftung o.D., https:// www.bertelsmann-stiftung.de/fileadmin/files/BSt/Publikationen/GrauePubli kationen/Studie_IB_Impulse_fuer_das_Asylverfahren_2016.pdf, Abrufdatum: 30.04.2020. 
UNHCR Deutschland (2018): Empfehlungen zur Ausgestaltung der geplanten »AnkER«-Einrichtungen, Juni 2018, https://www.unhcr.org/dach/wp-content/uplo ads/sites/27/2018/06/20180606_Anker_UNHCR.pdf, Abrufdatum: 30.04.2020.

Wahl, Christiane (2018): »Möglichkeiten und Grenzen einer menschenrechtsorientierten Sozialen Arbeit in Unterkünften für Geflüchtete«, in: Nivedita Prasad (Hg.), Soziale Arbeit mit Geflüchteten. Rassismuskritisch, professionell, menschenrechtsorientiert, Opladen/Toronto: Verlag Barbara Budrich, S. 300-316.

Wiebke, Judith (2019): »Druck auf die Länder? Lex AnkER im >II. Hau-Ab-Gesetz . Neuregelungen zur Wohnpflicht in Aufnahmeeinrichtungen und zur Asylverfahrensberatung «, in: Asylmagazin. Beilage zum Asylmagazin - Das Migrationspaket o. Jg., S. 73-77.

Zweites Gesetz zur besseren Durchsetzung der Ausreisepflicht vom 15. August 2019, BGBI. I 2019 S. 1294.

\section{Interviews}

Interview 1 wurde geführt am 06.08.2019. Interview 2 wurde geführt am 06.08.2019. Interview 3 wurde geführt am 25.07.2019. Interview 4 wurde geführt am 25.07.2019. Interview 5 wurde geführt am 25.07.2019. Interview 6 wurde geführt am 23.07.2019. Interview 7 wurde geführt am 23.07.2019. 



\section{Bildung unter den Bedingungen von (Im-)Mobilität}

Elisabeth Beck und Christine Heimerer

\section{Zusammenfassung}

Der Zugang zu formaler Bildung ist für verschiedene Adressat"innengruppen im Kontext von Flucht und Migration unterschiedlich geregelt und gestaltet sich bisweilen herausfordernd. Besonders unter den Bedingungen von (Im-)Mobilität, hervorgebracht durch die zentrale Unterbringung von Geflüchteten in Anker-Einrichtungen, gestalten sich die Bildungs- und Lernsituationen von geflüchteten Kindern, Jugendlichen und Erwachsenen komplex. Die Frage, wie sich die Bildungssituation in Anker-Einrichtungen darstellt, wurde in der Forschung bisher wenig systematisch beantwortet. Diesem Desiderat widmet sich der Beitrag und möchte am Beispiel der bayerischen Anker-Einrichtung ManchingIngolstadt Erkenntnisse zur Gestaltung von Bildung und Bildungsangeboten in zentralen Unterkünften für Geflüchtete liefern und dabei Formen von Mobilität und Immobilität analysieren. Dabei wird zunächst die schulische Bildung von Kindern und Jugendlichen als einer vulnerablen Gruppe betrachtet. Weiter wird ein Einblick in die Angebote der Erwachsenenbildung für Geflüchtete in der Anker-Einrichtung gegeben. Aufbauend auf theoretische Annäherungen an Formen der (Im-)Mobilität sowie an das Konstrukt eines Lernorts werden mittels qualitativer Forschung (problemzentrierte Interviews in Anlehnung an Witzel) Erkenntnisse zur Cestaltung von Bildungsangeboten in der Anker-Einrichtung Manching-Ingolstadt und zur Konzeptionierung der Anker-Einrichtung als besonderer Lernort generiert. Es zeigen sich zahlreiche Bildungsanlässe und Bildungsmöglichkeiten mit einem deutlichen Schwerpunkt auf der Vermittlung und dem Ausbau von Deutschkenntnissen. Nicht selten wird Bildung normativ definiert und mit spezifischen Vorstellungen von Integration verbunden. Die Anker-Einrichtung lässt sich insgesamt als ein besonderer Lernort charakterisieren, dessen Besonderheit darin besteht, dass Bildungs- und Lernprozesse stets stattfinden, zugleich jedoch die (im-)mobilisierenden Rahmenbedingungen insgesamt ein nachhaltiges Lernen und Bildung erschweren. 


\begin{abstract}
Summary
Access to formal education is regulated differently for different target groups in the context of flight and migration and is sometimes challenging. Especially under the conditions of (im-)mobility, brought about by the central accommodation of refugees in Anker centres, the educational and learning situations of refugee children, adolescents and adults are complex. The question of how the educational situation in Anker centres presents itself has not been answered systematically in research to date. This article is dedicated to this desideratum and aims to use the example of the Bavarian Anker centre in Manching-Ingolstadt to provide insights into the design of education and educational opportunities in central accommodations for refugees and to analyse forms of mobility and immobility. First of all, the article will focus on school education of children and adolescents, which is considered a particularly vulnerable group. Furthermore, the article gives an insight into the adult education offers for refugees in the Anker centre. Based on theoretical approaches to the forms of (im-)mobility as well as to the construct of a learning location, qualitative research (problem-centred interviews based on Witzel) will give insights into the design of educational offers in the Anker centre Manching-Ingolstadt as well as the conceptualisation of this centre as a special learning location. Numerous educational offers and educational opportunities with a clear focus on the teaching and development of Cerman language skills are revealed. Education is often normatively defined and associated with specific ideas of integration. The Anker centre can be characterised as a special place of learning. Special is that educational and learning processes always take place, but at the same time, sustainable learning and education is made difficult due to the (im-)mobilising conditions.
\end{abstract}

\title{
Einleitung
}

Migration und Bildung gehören grundlegend zueinander. Bildung gedacht als die humanistische und aufklärerische Befreiung des Menschen aus der unreflektiert übernommenen Unmündigkeit und Ausbildung von Kritik- und Urteilsfähigkeit (vgl. Tippelt 2010) kommt eine zentrale Rolle in Migrationsprozessen zu. Migrationsbedingte krisenhafte Situationen, Umbrüche, Veränderungen und (temporäre) Orientierungslosigkeit bedürfen eines Lernens, Umlernens und auch Verlernens (vgl. Garnitschnig et al. 2017). Die untrennbare Verbindung von Migration und Bildung zeigt sich nicht nur in den stets vorhandenen Möglich- und Notwendigkeiten des informellen Lernens, sondern auch in den mannigfaltigen Angeboten formalen Lernens, welche die »Fragen der Lebensbewältigung und des Miteinanders in heterogenen Gesellschaften " (Kloubert 2020: 1) adressieren und verhandeln. Bildung wird in diesem Sinne umfassend gedacht und beschreibt alle bildenden Prozesse 
von der frühen Kindheit, über das Jugendalter bis hin zum späten Erwachsenenalter. Bei der Implementierung von Anker-Einrichtungen für Geflüchtete wurde Bildung nicht als Kernaufgabe formuliert (vgl. BAMF 2019). Allein »integrationsvorbereitende Maßnahmen « geben einen Hinweis darauf, dass Bildung zwar eine Rolle spielt, jedoch nicht in einem humanistischen Sinne als Selbstzweck, sondern im Sinne eines Prozesses, der zu Integration führen soll. So wird von Seiten der Bundesregierung gern die Weisung »Integration durch Bildung« (BMBF o.J.) proklamiert, doch wird letztere nicht als konkretes Ziel für Geflüchtete, die zentral untergebracht werden, genannt. Der Ausgestaltung von Bildungsangeboten in AnkerEinrichtungen liegt kein starres und standardisiertes Konzept zugrunde, sondern den involvierten Akteur*innen ist vielmehr ein gewisser Gestaltungsspielraum gegeben, der sowohl Schwerpunktsetzungen als auch Auslassungen erlaubt. Damit ist jede Anker-Einrichtung mit Blick auf Bildung ein Einzelfall; welche Angebote geschaffen werden, obliegt nicht selten dem individuellen Engagement einzelner Akteur*innen. Jedoch lassen sich auch Gemeinsamkeiten in der Gestaltung erkennen. Die Frage, wie sich die Bildungssituation in Anker-Einrichtungen darstellt, wurde in der Forschung bisher wenig systematisch beantwortet. Der vorliegende Beitrag möchte daher - am Beispiel der bayerischen Anker-Einrichtung ManchingIngolstadt - Erkenntnisse zur Gestaltung von Bildung und Bildungsangeboten in zentralen Unterkünften für Geflüchtete liefern und dabei Formen von (Im-)Mobilität analysieren. Bildung in bzw. im Kontext einer Anker-Einrichtung vollzieht sich oftmals in einem Spannungsverhältnis von Praktiken der Immobilisierung, im Sinne eines Lokalisierbarmachens an einem bestimmten geographischen Ort, und gleichzeitigen individuellen und kollektiven Formen der (Im-)Mobilität von Migrant*innen.

In einem ersten Schritt werden die vom Gesetzgeber vorgesehenen schulischen und nicht-schulischen ${ }^{1}$ Bildungsangebote in einer Anker-Einrichtung skizziert. Dabei soll die schulische Bildung von Kindern und Jugendlichen als besonders vulnerable Gruppe betrachtet sowie ein Einblick in die Angebote der Erwachsenenbildung für Geflüchtete in der Anker-Einrichtung gegeben werden. Daran anschließend erfolgt eine allgemeine theoretische Annäherung an Formen der (Im-)Mobilität sowie an das Konstrukt eines Lernorts, bevor das forschungsmethodische Vorgehen beschrieben wird. Mittels der Analyse des empirischen Materials werden die Fragen nach der Gestaltung von Bildungsangeboten in der Anker-Einrichtung Manching-Ingolstadt sowie der Konzeptionierung dieser als besonderer Lernort beantwortet. Zusammenfassend werden Chancen und Herausforderungen für die Bildungsarbeit unter den Bedingungen von (Im-)Mobilität sich nicht auf den formalen Schulunterricht beziehen und in der Regel Jugendliche und Erwachsene adressieren. 
identifiziert und deren praktische Implikationen für die Gestaltung von Angeboten in Anker-Einrichtungen reflektiert.

\section{Lernen und Bildung in einer Anker-Einrichtung: rechtliche Rahmenbedingungen und theoretische Zugänge}

\section{Schule, Schulpflicht und Deutschklassen in Bayern}

Die detaillierte Ausgestaltung und Umsetzung der Schulpflicht ist in Deutschland Ländersache und wird in Bayern durch das Bayerische Gesetz über das Erziehungsund Unterrichtswesen (BayEUG) geregelt. Dieses besagt, dass jede Person im schulpflichtigen Alter, die sich nicht in einem Ausbildungs- oder Beschäftigungsverhältnis befindet und ihren gewöhnlichen Aufenthaltsort in Bayern hat, der Schulpflicht unterliegt. Diese beträgt in Bayern insgesamt zwölf Jahre, wobei die Vollzeitschulpflicht nach neun Jahren endet. Sofern Schüler*innen nach Vollendung ihrer Vollzeitschulpflicht nicht weiterhin eine Schule nach Art. 36 BayEUG besuchen (z.B. Gymnasium, Berufsfachschule), wird die restliche Schulpflicht durch den Besuch einer Berufsschule erfüllt (vgl. Art. 35-39 BayEUG).

Die Berufsschule begleitet die Schüler*innen in der Regel im dualen System gemeinsam mit einem Ausbildungsbetrieb. Doch auch wenn noch kein Ausbildungsplatz gefunden ist, besteht die Schulpflicht weiter und z.B. die Möglichkeit zum Besuch des Berufsvorbereitungsjahrs oder zum Besuch eines Berufsgrundschuljahres. Letzteres steht auch Personen zu, die nicht mehr berufsschulpflichtig sind (vgl. StMUK o.J. c).

Diese gesetzlichen Regelungen betreffen - ungeachtet der Gründe für den Zuzug nach Bayern - auch Neuzugewanderte, z.B. Asyl- und Schutzsuchende (vgl. Art. 35 Abs. 1 Satz 2 BayEUG). Jedoch können sich in diesem Zusammenhang auch einige Sonderregelungen ergeben. Beispielsweise beginnt für Asylsuchende die Schulpflicht »drei Monate nach dem Zuzug aus dem Ausland« (ebd.). Eine weitere Ausnahmeregelung betrifft »Schulpflichtige, die nach dem Asylgesetz verpflichtet sind, in einer besonderen Aufnahmeeinrichtung im Sinn des $\$ 30$ asylG zu wohnen«. Sie »werden zur Erfüllung der Schulpflicht besonderen dort eingerichteten Klassen und Unterrichtsgruppen zugewiesen« (Art. 36 Abs. 3 Satz 6 BayEUG). Diese Regelungen betreffen u.a. auch die Bewohner*innen der Anker-Einrichtungen in Bayern.

Für Schulpflichtige ohne Deutschkenntnisse bzw. mit (sehr) geringen Deutschkenntnissen gibt es innerhalb des bayerischen Schulsystems verschiedene Fördermöglichkeiten im sprachlichen Bereich, darunter auch spezielle Unterrichtsformate, die sogenannten Deutschklassen. Alle Deutschklassen zeichnen sich durch eine inhaltliche Konzentration des Unterrichts auf den Erwerb der deutschen Sprache 
aus. $^{2}$ Der Besuch einer solchen Deutschklasse dauert in der Regel ein, maximal zwei Jahre (vgl. \$ 8 Abs. 1 und Anlage 2 GrSO bzw. $\$ 10$ Abs. 1 und Anlage 2 MSO) und soll die Schüler*innen auf den Unterricht in einer Regelklasse ihrer Jahrgangsstufe vorbereiten (vgl. StMUK o.J. b).

Auch an bayerischen Berufsschulen und beruflichen Schulzentren sind solche speziellen Formate installiert. Die »Deutschklassen an Berufsschulen« (DK-BS) bieten die Möglichkeit, zunächst niederschwellige Deutschkenntnisse zu erwerben und sich bei Bedarf zu alphabetisierten. Sobald das entsprechende sprachliche Niveau erreicht ist - spätestens nach einem Jahr - haben Schüler*innen die Möglichkeit, den einjährigen Vorkurs zum Berufsintegrationsjahr (BIK-V) zu besuchen. In diesen BIK-V-Klassen werden schon vorhandene Deutschkenntnisse weiter ausgebaut und es findet gleichzeitig bereits berufsvorbereitender Unterricht statt. In den anschließenden Berufsintegrationsklassen (BIK) werden die Schüler*innen dann intensiv auf die Berufsschule vorbereitet, wobei auch hier wieder ein Großteil der Gesamtstunden auf den Ausbau der Deutschkenntnisse fällt (vgl. ISB 2017; StMUK o.J. a).

\section{Nicht-schulische Bildung in der Anker-Einrichtung}

Nicht-schulische Bildungsangebote in Anker-Einrichtungen, die von Bund und Land zentral geregelt und eingerichtet sind, adressieren Erwachsene und stellen sich weniger stark reguliert dar als schulische Bildung. Für nicht-schulpflichtige Erwachsene ist von Seiten der Bundes- und Landesregierung ausschließlich eine sogenannte "Herkunftssprachliche Wertevermittlung und Erstorientierung« (BAMF 2018) vorgesehen. In diesem Rahmen werden Kurse angeboten, die dem Kurskonzept »Erstorientierung und Deutsch lernen für Asylbewerber « folgen. Diese Kurse »richten sich primär an Asylbewerberinnen und -bewerber, die weder aus einem Land mit hoher Anerkennungsquote (gute Bleibeperspektive) noch aus einem sicheren Herkunftsland stammen « (BAMF 2017). Diese Regelung führt $\mathrm{zu}$ der paradoxen Situation, dass die sogenannten `Erstorientierungskurse zunächst nur bestimmten Personengruppen zugänglich sind, so z.B. Asylbewerber*innen mit einer sogenannten sschlechten Bleibeperspektive nachrangigen Zugang zum Angebot (vgl. StMI 2019) und müssen bzw. dürfen - abhängig von den jeweiligen Aufenthaltsstatus - an Angeboten außerhalb der Anker-Einrichtung teilnehmen, z.B. an Integrationskursen. Darüberhinausgehende Angebote werden optional eingerichtet, so z.B. Deutschkurse von

2 Für die Grund- und Mittelschulen beinhalten diese Deutschklassen laut der Bayerischen Mittelschulverordnung (MSO) und der Grundschulverordnung (GrSO) jeweils zehn Wochenstunden Deutsch als Zweitsprache und fünf bis acht (Grundschule) bzw. vier bis sechs (Mittelschule) Schulstunden Sprach- und Lernpraxis und bilden damit einen deutlichen Schwerpunkt. 
bürgerschaftlich Engagierten, Konversationskurse, Vorträge und Workshops zu alltagsweltlichen und bedarfsorientierten Themen, und obliegen der Verantwortlichkeit meist zivilgesellschaftlicher Akteur*innen. Die generell weniger stark regulierte Bildungslandschaft im Bereich der Erwachsenen- und Weiterbildung und eine damit einhergehende größere Verantwortlichkeit, die eigenen Bildungsprozesse zu planen und zu gestalten, spiegelt sich auch in den wenigen zentral vorgesehenen Bildungsangeboten in Anker-Einrichtungen wider. Dies führt dazu, dass nur bestimmte Adressat*innengruppen sowohl einen gesicherten Zugang zu erwachsenenbildnerischen Kursen innerhalb der Anker-Einrichtungen erhalten als auch kostenfrei daran teilnehmen können. Im Gegensatz zur schulischen Bildung lässt sich im Zugang zu Kursen der Erwachsenenbildung eine Ungleichbehandlung der Bewohner*innen auf Basis ihrer Herkunftsländer festhalten. So müssen sich bestimmte Bewohner*innen selbstverantwortlich um anderweitige Bildungsangebote außerhalb der Einrichtungen oder jenseits der von Bund und Ländern vorgesehenen Kurse bemühen.

\section{(Im-)Mobilität und Bildungsteilhabe}

Kreichauf zeigt, dass trotz der Konstruktion der Anker-Einrichtungen als Lager diese nicht ausschließlich exkludierend, isolierend und abschottend wirken (vgl. Kreichauf 2018). ${ }^{3}$ Stellt sich die Anker-Einrichtung in der Regel als »waiting zone« (ebd.: 16) mit teils starken Restriktionen im Zugang zu Bildung ${ }^{4}$ und zum Arbeitsmarkt dar (vgl. dazu im Kontext der Unterbringung in Gemeinschaftsunterkünften Täubig 2009: 27), so lassen sich dennoch individuelle Handlungs- und Bildungsstrategien als Formen der (Im-)Mobilität identifizieren. So können Bewohner*innen die Einrichtung verlassen mit dem Ziel der Interaktion mit ihrem Umfeld, auf der Suche nach Anstellung, Lernmöglichkeiten und Teilhabe. Der Teilhabe am Arbeitsmarkt und dem Bildungssystem - und damit an selbstbestimmter Mobilität - stehen jedoch nicht selten rechtliche, soziale und individuelle Hürden und Barrieren entgegen (vgl. ebd.).

(Im-)Mobilität stellt - im Zuge des sog. new mobilities paradigm (vgl. z.B. Hannam/Sheller/Urry 2006) - eine Betrachtungsperspektive auf Flucht und Migration dar, die Bewegungsprozesse in ihrer engen Verwobenheit mit einem weitreichenden sozialen und gesellschaftlichen Wandel (vgl. de Haas 2014: 4) betrachtet und diese als einen konstitutiven Teil des menschlichen Daseins versteht. Modelle

3 Siehe hierzu auch den Beitrag von Lea Gelardi in diesem Band.

4 Die Restriktionen sind je nach Adressat*innengruppe der Bildungsangebote/-programme unterschiedlich stark ausgeprägt. 
von Gesellschaften und Raum als statische, homogene und abgeschlossene Entitäten (vgl. Wille 2009: 74) werden von vielfältigen sozialen, räumlichen und alltagsbezogenen Mobilitätspraktiken in Frage gestellt. Dabei wird räumliche Mobilität oftmals mit Migration gleichgesetzt. Im öffentlichen und medialen Diskurs wird Migration in der Regel im Kontext des Überwindens nationalstaatlich gefasster Grenzen thematisiert und als Krise und/oder konflikthaft dargestellt (vgl. z.B. Altmeppen 2020: 138; Goebel 2017). Postmigrantische Perspektiven beispielsweise distanzieren sich jedoch von einer solchen Darstellung von Migration und betonen einen »Perspektivwechsel« in der »Beschreibung der aktuellen gesellschaftlichen Situation « (Foroutan/Karakayali/Spielhaus 2018: 10), die in hohem Maße von Praktiken der »Wanderung« (ebd.) beeinflusst ist. Räumliche Mobilität nimmt erheblichen Einfluss auf die Ausgestaltung alltäglicher Mobilität, also die Veränderungsprozesse von Normen, Werten, Einstellungen und Handlungspraktiken, sowie sozialer Mobilität, also die Teilhabe-, Auf- und Abstiegsmöglichkeiten im sozialen Gefüge (vgl. Berger 2001). Soziale Mobilität ist nicht trennscharf von räumlicher Mobilität abzugrenzen, sondern beide zeigen sich häufig verwoben ${ }^{5}$. Besonders deutlich lässt sich dies am Beispiel von Bildung in Anker-Einrichtungen zeigen, die zum einen im Rahmen von oftmals unfreiwilliger geographischer Immobilität (sog. involuntary immobility nach Carling 2002) und zum anderen im Rahmen von teilweise stark regulierten Bildungszugängen, also auch eingeschränkter sozialer Mobilität, stattfinden. Staatliche, organisationale und individuelle Politiken ermöglichen, kontrollieren, regulieren und/oder verhindern räumliche und soziale Mobilitäten von Geflüchteten. Diese Prozesse können als Praktiken der (Im-)Mobilisierung bezeichnet werden und umfassen nicht nur das (Nicht-)Ausschöpfen individueller Handlungsmöglichkeiten, sondern auch strukturelle Barrieren, die rechtlicher, administrativer oder sozialer Natur sein können. Dennoch besitzen Migrant*innen stets agency, sie sind selbst Akteur*innen komplexer Bildungs- und Mobilitätsentscheidungen.

\section{Die Anker-Einrichtung als Lernort}

Lernen findet immer, überall, bewusst und unbewusst, gewollt und unintendiert statt. Wenngleich die Anker-Einrichtung keinen primären Bildungsauftrag hat (vgl. BAMF 2018), sie also keine Bildungsinstitution ist, findet Lernen statt. Denn Migration und Mobilität sind ein herausforderndes Ereignis, »a social stressful event« (Vinciguerra 2017: 354), durch welches grundlegende Bildungsprozesse angestoßen werden, welche die Lernenden dazu befähigen, als handelnde Subjekte unter neuen Rahmen- und Lebensbedingungen zu agieren. Unter den Bedingungen der (Im-) 
Mobilität kommt besonders informellen, selbstinitiierten und selbstorganisierten Lern- und Bildungsprozessen eine zentrale Rolle zu. Es stellt sich also die Frage, ob die Anker-Einrichtung als Lernort oder gar Bildungsraum verstanden wird, »wo sich Bildung im Sinne einer reflexiven Durchdringung von Welt entfalten kann« (Gruber/Schmid 2019: 2). Raum umfasst in diesem Verständnis mehr als nur einen geographischen Ort, sondern auch soziale und symbolische Beziehungen. Ein Ort wird dann zum Lernort, wenn ein bestimmtes soziales Setting vorhanden ist und die Lernenden ein Gegenüber haben, sei es ein anderes Individuum, ein Artefakt oder "geronnene« Gedanken anderer (z.B. Bücher) (vgl. ebd.). Lernräume sind auch dadurch gekennzeichnet, dass Bildung an gesellschaftlich relevanten Orten stattfindet, dass »[sie] dort etabliert [werden], wo es gesellschaftliche Veränderungsprozesse zu gestalten [gilt] «(Stang 2019:3). Unter den Bedingungen von (Im-)Mobilität in der Anker-Einrichtung stellt sich dabei die Frage, welche Lernformate, -orte und -zugänge für die einzelnen Adressat*innengruppen relevant und erreichbar sind, welche Formen des Lernens bestehen und von welchen Angeboten Migrant"innen in der Anker-Einrichtung Gebrauch machen. Die Prozesshaftigkeit, »die Vorläufigkeit, das Provisorium «(Bochmann 2017: 2) der Anker-Einrichtung, die Notwendigkeit der stetigen Anpassung an neue Verhältnisse innerhalb und außerhalb der Einrichtung durch die Bewohner*innen macht sie zu einem besonderen Lernort, denn auch dieser ist eine temporäre »Konstellation«, bei dem es darum geht, »festzustellen, unter welchen Bedingungen ein Ort (temporär) zu einem Lernort wird « (Kraus 2015: 49).

\section{Bildung in der Anker-Einrichtung - Bildung im Kontext von (Im-)Mobilität}

\section{Methodisches Vorgehen}

Am Beispiel der Anker-Einrichtung Manching-Ingolstadt nimmt das Forschungsprojekt formale und non-formale Bildung in Anker-Einrichtungen als Handlungsfeld verschiedener Akteur*innen in den Blick. Dazu wurden Einzel- und Gruppeninterviews durchgeführt, in deren Mittelpunkt das Repertoire, die Ausgestaltung und Implementierung von formalen und non-formalen Bildungsangeboten in der Einrichtung sowie die in den Prozess um die Entwicklung und Durchführung von Bildungsangeboten involvierten Akteur*innen standen. Ziel ist es auch, einen Überblick über unterschiedliche Adressat"innengruppen und die jeweiligen Zugänge zu gewinnen sowie über das Zusammenwirken unterschiedlicher professioneller Akteur*innen untereinander und mit bürgerschaftlich Engagierten. Dazu wurden Fragen (a) nach der Gestaltung von Bildung in der Anker-Einrichtung, den Angeboten und den involvierten Akteur*innen sowie (b) nach der Beschaffenheit der Anker-Einrichtung als Lernort gestellt. 
Da zur Beantwortung der Forschungsfragen spezielles Wissen vonnöten ist, wurde als Erhebungsinstrument ein leitfadengestütztes problemzentriertes Expert*inneneninterview in Anlehnung an Witzel (2000) gewählt. Für das Experten*inneninterview wurden Leitfragen entwickelt, die auch Raum lassen sollten für offene Redeanteile. Der halbstrukturierte Interviewleitfaden erlaubte so Interviewer*innen wie Interviewten mehr Offenheit in der Gestaltung des Gesprächs (vgl. dazu Helfferich 2019: 670ff.).

Im Rahmen des Forschungsprojekts wurden insgesamt neun Personen als Expert $^{*}$ innen $^{6}$ aus dem Bereich Bildung und Migration identifiziert und interviewt, die auf professioneller Ebene Berührungspunkte zur Anker-Einrichtung Manching-Ingolstadt haben. Teils wurden die Experteninterviews in Gruppen mit mehreren Expert*innen geführt, um ihnen die Möglichkeit zu geben, unterschiedliche Standpunkte in diskursiver Weise argumentativ entwickeln und vertreten zu können. ${ }^{7}$ Die Auswertung der Ergebnisse erfolgte mittels der qualitativen Inhaltsanalyse (vgl. dazu Kuckartz 2016), wobei sowohl induktive als auch deduktive Kategorien gebildet wurden (vgl. dazu Mayring/Fenzl 2019: 637f.).

\section{Bildungsarbeit zwischen variablen Institutionen, Akteur*innen und Kompetenzen}

Im Rahmen des Forschungsprojektes wurde deutlich, dass den Bewohner*innen der Anker-Einrichtung Manching-Ingolstadt unterschiedliche formale und non-formale Bildungsangebote zur Verfügung stehen, die von verschiedenen Akteur*innen entwickelt, implementiert und bespielt werden.

Zunächst ist an dieser Stelle der Schulunterricht als formales Bildungsangebot zu nennen. Dabei wird unterschieden zwischen dem Unterricht der Berufsschule und dem Unterricht der Grund- und Mittelschule. Er findet jeweils auf dem Gelände der Anker-Einrichtung in eigens eingerichteten Klassen und Unterrichtsräumen statt. Diese Klassen sind offiziell »Außenstellen« öffentlicher Schulen in Ingolstadt (vgl. I4_91 ${ }^{8}$ ). Der Unterricht erfolgt jeweils in altersgemischten Klassen

Die gewählte Anonymisierungsstrategie lässt keine weitere Systematisierung der Interviewpartner*innen zu. Aufgrund des eng eingegrenzten Forschungsfeldes wären sonst Rückschlüsse auf Personen möglich.

7 Die Transkription der Interviews erfolgte wörtlich, wobei eine leichte sprachliche Glättung (z.B. Vermeidung sprachlicher Varietäten - etwa dialektale Abweichungen von der Standardsprache) vorgenommen wurde. Ferner wurden längere Pausen der Interviewten durch Klammern z.B. (...) markiert, ebenso wie laute, besonders deutliche Äußerungen durch Croßbuchstaben. Nonverbale Lautäußerungen, z.B. Lachen, sind ebenfalls in Klammern im Transkript kenntlich gemacht.

8 Die angegebene Signatur verweist auf das jeweilige Interview »/4 « und die entsprechende Position in der Transkription des Interviews »91«. Alle weiteren Zitate sind in derselben Weise kenntlich gemacht. 
und entspricht - so die Rückmeldung der Interviewten - den bereits erwähnten Deutschklassen. Die große - auch sprachliche - Heterogenität der Schüler*innen und die hohe Fluktuation in den Klassen gestalten den Unterricht bisweilen herausfordernd. Um auf diese Umstände zu reagieren, findet der Deutschunterricht modularisiert nach Kompetenzstufen statt. Weiter wurde darauf verwiesen, dass die Schüler*innen dann die Möglichkeit hätten, eine Schule außerhalb der AnkerEinrichtung zu besuchen, sobald ihre Deutschkenntnisse dem Niveau entsprächen, das nötig wäre, um dem Regelunterricht folgen zu können (vgl. I4_97; I4_104f.).

Dass die Schulpflicht erst nach drei Monaten beginnt, empfinden einige Interviewpartner*innen als zu spät, da die Kinder und jungen Erwachsenen so zu viel Zeit verlieren würden. Daher wird bisweilen die Praxis verfolgt, bei Bedarf und freien Kapazitäten und in Abstimmung mit den Verantwortlichen, die Berufsschüler*innen bereits vor Ablauf der Frist zum Unterricht zuzulassen (vgl. I1_24; I4_144ff.).

Neben dem staatlich organisierten und verantworteten Unterricht für Schulpflichtige existieren aber noch weitere Bildungsangebote in der Anker-Einrichtung: So werden durch externe Bildungsträger sowohl ein Alphabetisierungskurs angeboten als auch ein Kurs auf Grundlage des Kurskonzepts »Erstorientierung und Deutsch lernen für Asylbewerber«.

Des Weiteren gibt es auch non-formale Bildungsangebote in der AnkerEinrichtung Manching-Ingolstadt. So wurden von den Gesprächspartner*innen unter anderem Formate aufgeführt wie gesonderter Deutschunterricht oder Hausaufgabenbetreuung durch bürgerschaftlich Engagierte oder das Angebot eines Konversationsraums zum gemeinsamen Austausch auf Deutsch. Ferner wurde auf Informationsveranstaltungen, z.B. zum Asylverfahren, verwiesen. Darüber hinaus werden auch immer wieder (Freizeit-)Angebote zur Tagesgestaltung aufgeführt, darunter z.B. ein Frauencafé, gemeinsames Nähen oder Aktionstage innerhalb und außerhalb der Anker-Einrichtung wie Bastelaktionen für Kinder oder ein gemeinsamer Koch-Tag (vgl. u.a. I1_91; I1_98; I5_19). Oftmals werden auf Nachfrage hin neben Bildungs- auch Freizeitangebote, die informelle Bildungsprozesse anstoßen können, genannt. Zum einen kann dies auf einen breiten Bildungsbegriff der Interviewpartner*innen verweisen, zum anderen kann dies auf eine fehlende klare Distinktion von formaler Bildung und informellen Freizeitangeboten zurückzuführen sein.

Was alle Befragten immer wieder betonten, ist die Spezifität der genannten (Bildungs-)Angebote für die Anker-Einrichtung Manching-Ingolstadt, die sich - etwa hinsichtlich des Repertoires an Bildungsangeboten - durchaus von Angeboten in anderen Einrichtungen unterscheiden könnten. Ein einheitliches Vorgehen für die Gestaltung von (Bildungs-)Angeboten ist demzufolge nicht gegeben. Dies hängt auch vom Leistungsspektrum der jeweiligen Betreiberfirma und den in der jeweiligen Anker-Einrichtung tätigen Akteur*innen ab. Eine Ausnahme bildet in diesem 
Zusammenhang der staatlich verantwortete Schulunterricht. Aber auch hier ist zumindest die operative Umsetzung nicht einheitlich geregelt. Während die Kinder und jungen Erwachsenen der Anker-Einrichtung Manching-Ingolstadt innerhalb der Einrichtung unterrichtet werden, besuchen beispielsweise die Schulpflichtigen der Unterkunfts-Dependancen in Garmisch oder Fürstenfeldbruck die an den jeweiligen Sprengelschulen eingerichteten Deutschklassen, was einer »Integration von Anfang an« (I1_154) gleichkomme (vgl. I1_152f.). Ein ähnliches Vorgehen sei, so einige Interviewpartner*innen, jedoch für die Anker-Einrichtung ManchingIngolstadt bislang nicht umsetzbar. Als Grund dafür wurde die deutlich höhere Anzahl der Schulpflichtigen genannt (vgl. I4_75f.).

Während der formale Schulunterricht von staatlicher Seite organisiert, verantwortet und von staatlichen Lehrkräften bestritten wird, spielen im Bereich der nonformalen Bildung unterschiedliche Akteur*innen, teils in öffentlicher oder privater Trägerschaft, eine Rolle. Neben den institutionell verorteten Hauptamtlichen, sind in der Anker-Einrichtung Manching-Ingolstadt auch bürgerschaftlich Engagierte tätig und teilweise auch in Bildungsprozesse involviert. ${ }^{9}$ Von dieser Seite wurde, wie oben bereits erwähnt, ein bedarfsorientiertes zusätzliches Angebot zum Deutschunterricht bzw. zur Hausaufgabenbetreuung als Ergänzung zum Schulunterricht installiert (vgl. I5_2f.).

\section{Entwicklung von Bildungsangeboten - zwischen Institution und Intuition}

Was die Entwicklung der einzelnen Bildungsangebote anbelangt, werden teils unterschiedliche Prozesse beschrieben: Während z.B. der Schulunterricht ohnehin von staatlicher Seite aus inhaltlich ausgestaltet und organisiert wird - ein formalisierter Prozess also bereits vorgelagert ist - gestaltet sich das Entstehen nonformaler Bildungsangebote variantenreicher. Zwei der Interviewten nannten ihre »Erfahrung« (I5_62) als Parameter dafür, welche (Bildungs-)Angebote "gut « oder »nicht gut « seien (ebd.: 60) bzw. benötigt oder nicht »funktionieren« würden (ebd.).

Ähnlich scheint sich auch das Repertoire der Leistungsübersicht für Betreiberfirmen der Anker-Einrichtungen entwickelt zu haben. Auch in diesem Zusammenhang wird auf Strukturen verwiesen, die aus den gemachten Erfahrungen mit Bildungs- und Freizeitangeboten oder einmal identifizierten Bedarfen gewachsen seien (vgl. 14_61). Allgemein scheint die Entwicklung mancher Angebote mit der Genese der Anker-Einrichtung einhergegangen zu sein, durch die ebenfalls Strukturen im Freizeit- und Bildungsbereich gewachsen sind, welche sich verstetigt haben. Andere Angebote hingegen seien aus einem von verschiedenen Akteur"innen 
beobachteten Bedarf heraus entwickelt worden. In diesem Zusammenhang wurde z.B. ein Säuglingspflegekurs genannt, der installiert wurde, als besonders viele Eltern mit Säuglingen und Kleinkindern in der Anker-Einrichtung untergebracht waren (vgl. I2_21).

Sehr deutlich wird, dass der Erwerb von Deutschkenntnissen einen Schwerpunkt im Repertoire formaler wie non-formaler Bildungsangebote bildet. Nahezu alle Befragten empfanden das Erlernen der deutschen Sprache als (sehr) wichtig für die Bewohner*innen, denn »ohne Sprache komme [man] nicht weiter« (I4_141). Allgemein ist zu beobachten, dass die Perspektive der Adressat*innen bzw. ihre Teilhabe am Entwicklungs- oder Installationsprozess von - auch non-formalen Bildungsangeboten nicht systematisch miteinfließt.

\section{Herausforderung Kommunikation - miteinander, füreinander, durcheinander?}

Die Kommunikation der einzelnen Bildungsangebote verläuft über verschiedene Wege. Zum einen informieren manche Akteur*innen, die für die Entwicklung und/oder Organisation des Angebots verantwortlich sind, über schriftliche Aushänge in der Anker-Einrichtung. Das mache - zumal in der Fremdsprache Deutsch - einigen Interviewpartner*innen zufolge wenig Sinn, da das Aufmerksammachen auf Bildungsangebote lediglich über den persönlichen Kontakt funktioniere und »viel Beziehungs- und Motivationsarbeit« benötige (I1_88). Einige Akteur*innen weisen daher (zusätzlich) mündlich auf Angebote hin (vgl. I1_9of.).

Die Information über den staatlichen Schulunterricht und auch über die Schulpflicht in Bayern erfolgt hingegen über einen Informationsbrief in deutscher Sprache an die künftigen Schüler*innen oder deren Erziehungsberechtigte. Laut einiger Interviewpartner*innen stelle diese Art der Kommunikation kein Problem dar, da die Adressat" innen »hervorragend vernetzt «(I4_131) seien, und im Hinblick auf die Informationsbriefe wüssten, "was da draufsteht« (I4 _130). Dennoch auftretende sprachliche Schwierigkeiten - so zumindest die Einschätzung dieser Interviewpartner*innen - würden durch zur Verfügung stehende Dolmetscher*innen ausgeglichen (vgl. I4_131).

Durch die Anker-Einrichtung als gemeinsames Betätigungs- und Handlungsfeld und das Involviertsein in die Gestaltung von adäquaten Bildungs- und Freizeitangeboten ergeben sich unweigerlich Berührungspunkte zwischen den einzelnen Akteur*innen. Diese münden allerdings nicht notwendigerweise in eine Zusammenarbeit. Manche Akteur*innen unterstützen sich gegenseitig, indem sie beispielsweise auf die Angebote anderer aufmerksam machen. Andere versuchen, ergänzende Angebote zu entwickeln. Manchmal scheint der genaue Umfang der Tätigkeiten und Zuständigkeiten untereinander jedoch nicht ganz transparent zu sein, weshalb sich bisweilen auch Unsicherheiten in der Einschätzung zum Aufga- 
benbereich und Angebots- bzw. Leistungsrepertoire verschiedener Akteur*innen ergeben. Bei unklaren Zuständigkeiten erwächst in der Praxis dann mitunter die Frage »Ja wer macht [das] dann? [...]«, die letztlich dazu führt, dass Akteur*innen sich gegenseitig auch Grenzen des eigenen Aufgabenbereichs und Leistbaren aufzeigen: »Wo man sagt [...] Leute, wir sind hier nicht für die Gesamtversorgung zuständig.«(I1_11) Tatsächlich scheint die Frage der Zuständigkeit, die vordergründig wohl geregelt ist, in der realen Alltagspraxis nicht immer eindeutig erkennbar zu sein. Dies spiegelt sich auch im Wunsch mancher Befragten nach einer übergeordneten Instanz bzw. einer/einem übergeordneten gemeinsamen Ansprechpartner*in wider (vgl. I1_6f.).

\section{Zwischen (Bildungs-)Angebot und Nachfrage}

Leider, so die häufige Rückmeldung aus den geführten Interviews, würden viele der Angebote nicht angenommen bzw. erfreuten sich keiner großen Nachfrage. Die Gründe dafür können in unterschiedlichen Umständen gesehen werden. Zum einen ist es möglich, dass die Information über die an sich erwünschten und nachgefragten Angebote die Bewohner*innen nicht erreicht, zum anderen auch, dass das Wissen um entsprechende Bildungsangebote zwar besteht, diese aber - erschwert durch äußere Umstände - nicht wahrgenommen werden können. Es wird z.B. darauf hingewiesen, dass viele Berufsschulpflichtige - insbesondere junge Mütter kaum Gelegenheit hätten, überhaupt am Unterricht teilzunehmen, da keine geregelte Betreuung ihrer Kinder angeboten würde, was eine "große Lücke« und einigen Interviewpartner*innen zufolge einen echten Bedarf darstelle (vgl. I1_73). Dieser Umstand mache einen geregelten Schulbesuch und auch den Besuch anderer Bildungsformate für viele nahezu unmöglich (vgl. I1_71). An dieser Stelle zeigt sich die enge Verwobenheit von strukturellen Barrieren und Bildungszugängen.

Eine weitere Erklärung für die geringe Nachfrage nach Bildungsangeboten besteht darin, dass zwar alle äußeren Faktoren positiv zusammentreffen, die Adressat*innen jedoch kein Interesse an den jeweiligen Angeboten haben. Das kann damit zusammenhängen, dass manche Angebote schlicht nicht dem Bedarf entsprechen. Die geringe Nachfrage muss aber nicht unbedingt mit der Attraktivität des Bildungsangebots zu tun haben. Zwar misst, so der Eindruck der Interviewpartner*innen, ein Großteil der Adressat*innen der Bildung im Allgemeinen einen großen Stellenwert bei. Tatsächlich scheint es, als fänden genau diejenigen Angebote den meisten Anklang, die sich mit den momentanen Bedürfnissen und Bedarfen der Menschen in der Anker-Einrichtung befassen, z.B. der bereits erwähnte Säuglingspflegekurs oder manche Deutschlernangebote. Jedoch sei es vielen Bewohner*innen der Anker-Einrichtungen aufgrund ihrer momentanen ungewissen Lebenssituation mehrheitlich schlicht nicht möglich, Bildungsangebote wahrzunehmen. Im Zustand grundlegender Lebenskrisen rücke die Bildung in den Hin- 
tergrund. Und da die Bewohner*innen der Anker-Einrichtung »[...] mit [...] existentiellen Dingen zu kämpfen haben [...], da gehts halt irgendwie um ganz viel ganz andere Dinge. Da gehts irgendwie um Abschiebung, um Familientrennung, um medizinische Behandlungen, [...] um Psychiatrie-Notfalleinweisung [...]« (I2_39). Dies würde nicht nur die geringe Nachfrage an manchen Bildungsangeboten erklären, sondern auch das geringe Interesse an der Gestaltung von Bildungsprozessen bzw. das fehlende Nachfragen bestimmter Angebote. Dieser Umstand wie auch die oben genannten Vermutungen werfen unweigerlich die Frage nach der Beschaffenheit der Anker-Einrichtung als Lernort auf.

\section{Der besondere Lernort Anker-Einrichtung: Formen sozialer (Im-)Mobilität und immobilisierende Praktiken}

In den oben beschriebenen schulischen und nicht-schulischen Bildungsangeboten, im Zugang zu und in der Wahrnehmung von diesen, lassen sich Formen der (Im-)Mobilität identifizieren. Sie zeigen sich einerseits aufgrund - wenn möglich - selbstbestimmter und freiwilliger Entscheidungen von Migrant*innen, andererseits aufgrund von Praktiken der Immobilisierung. In den Interviews beschreiben die Gesprächspartner*innen einheitlich, dass die Bewohner*innen der AnkerEinrichtung eher an Angeboten teilnehmen würden, wenn diese innerhalb der Einrichtung stattfinden (vgl. I1_103). Der Grund hierfür läge zum einen darin, dass die Bewohner*innen direkt und unmittelbar von den (Bildungs-)Akteur*innen angesprochen werden können (vgl. I1_91). Zum anderen erschwerten es die organisatorischen Bedingungen den Bewohner*innen der Anker-Einrichtung oft, Veranstaltungen außerhalb der Einrichtung zu besuchen. Dazu gehört unter anderem die häufig schwierige Verkehrsanbindung bestimmter Teile der Anker-Einrichtung (vgl. I1_157). Gleichwohl zeigt sich sowohl inner- als auch außerhalb der Einrichtung, dass es auch herausfordernd für die bürgerschaftlich und hauptamtlich Tätigen sein kann, Teilnehmer*innen für nicht-schulische Angeboten zu gewinnen. Hier zeigen sich Tendenzen einer freiwilligen Nicht-Teilnahme und damit Formen von teils freiwilliger - sozialer - Immobilität ${ }^{10}$. Im Bereich der schulischen Bildung lassen sich räumliche Immobilität und soziale Mobilität in ihrer Verschränkung beschreiben: Der Besuch einer Deutschklasse in der Sprengelschule ist nicht vorgesehen, sollen die Kinder und Jugendlichen doch am Unterricht der in der Einrichtung und ihren Dependancen eingerichteten Deutschklassen teilnehmen.

10 Selbstverständlich kann die Ursache einer Nicht-Teilnahme, die hier als freiwillige Immobilität beschrieben wird, auch in den später zu beschreibenden Praktiken der Immobilisierung liegen. Um die tatsächlichen Motive einer Teilnahme oder Nicht-Teilnahme von Bewohner*innen zu analysieren, böte es sich anschließende Interviews mit Adressat*innen an. An dieser Stelle können also nur vorläufige Schlüsse gezogen werden. 
Dies soll den Zugang zu schulischer Bildung ermöglichen und auch sicherstellen. Gleichzeitig wird jedoch der Kontakt zum Außen, zu Kindern und Jugendlichen außerhalb der Einrichtung, und damit die Chance auf weitergehende informelle Lernprozesse im Austausch mit Gleichaltrigen behindert. Es zeigt sich also die enge Verknüpfung von räumlicher Immobilität bei gleichzeitiger sozialer Mobilität, dabei wird erstere beschränkt, während letztere ermöglicht wird.

Im Zugang zu Angeboten der Erwachsenen- und Weiterbildung, die außerhalb der Anker-Einrichtung stattfinden, zeigen sich Praktiken der Immobilisierung in besonderem Maße. Die Teilnahme von Bewohner*innen z.B. an Sprachkursen wird zum einen aufgrund fehlender finanzieller Mittel ${ }^{11}$ erschwert (vgl. I1_106). Zum anderen wird berichtet, dass der Besuch bestimmter Angebote von Seiten der kommunalen Verwaltung nicht gewollt sei: »Weil eben von der Stadtspitze des so gewünscht war: >Unsere städtischen Angebote sind nicht für Ankerleute geöffnet«.« (I1_67) Hier lässt sich sowohl ein räumliches als auch soziales Festsetzen der Geflüchteten identifizieren, um eine selbstgewählte Mobilität oder gar integrative Bestrebungen zu stören (vgl. I5_57). Gleichwohl werden Formen des widerständigen (Wieder-)Aneignens der Selbstbestimmung mittels der Unterstützung durch ein Netzwerk deutlich: Bewohner*innen wird der Zugang zu versagten Angeboten dennoch »unter der Hand« (I1_95) gewährt. Solche individuellen und kollektiven Praktiken unterlaufen Bestrebungen einer Immobilisierung von staatlicher und kommunaler Seite.

Besonders deutlich werden Ungleichbehandlungen von Bewohner*innen von Anker-Einrichtungen in Bezug auf Bildung und deren Zugänge im Bereich der Erwachsenenbildung. Bildung läuft den Einschätzungen einer Interviewpartnerin zufolge »außerhalb des Systems« (I1_85), was »Verlierer« produziere (ebd.: 154). Dies überrascht nicht, scheint doch die Orientierung im Gemenge unübersichtlicher (Bildungs-)Möglichkeiten, Pflichten, Aufgaben und Restriktionen schwer und die selbstbestimmte Gestaltung der eigenen (Bildungs-)Biographie beeinträchtigt. Einerseits würden nahezu alle Belange des täglichen Lebens zentral geregelt, z.B. die Wohnsituation und Verpflegung, völlig konträr dazu seien andererseits andere Angelegenheiten, wie beispielsweise die eigene gesundheitliche Versorgung oder eben der Zugang zu Bildungsangeboten, der Selbstorganisation der Bewohner*innen überlassen. Dies führe zu einer Lebenssituation, in der "man den Leuten die Selbstständigkeit nimmt, aber alle Verantwortung übergibt« (I1_11). bestehen, so bleibt ausschließlich die Möglichkeit bzw. Notwendigkeit bestehen, einen formalen Sprachkurs bei einem der zahlreichen Anbieter selbst zu finanzieren. Dies ist jedoch für Bewohner*innen der Anker-Einrichtung nahezu unmöglich, da mit dem sogenannten »persönlichen Bedarf zur Sicherstellung des sog. soziokulturellen Existenzminimums « (StMI o.J.) kaum ein kommerzieller Sprachkurs zu finanzieren ist. 


\section{Lernen und Lehren am besonderen Lernort}

»Du darfst nichts lernen« (I1_11), so schätzt eine Interviewpartnerin die Bildungssituation in der Anker-Einrichtung ein. Gleichwohl berichten die Gesprächspartner*innen immer von Lern- und Bildungsprozessen, machen aber zugleich deutlich, dass die Lernbedingungen in der Anker-Einrichtung nicht optimal seien. Die dort herrschenden Lebensumstände seien nicht dazu geeignet, ein förderliches Lernklima zu schaffen und so Bildungsprozesse zu unterstützen: viele »Menschen auf engstem Raum« (I2_27), kaum Rückzugsmöglichkeiten oder ein »ruhiges Plätzchen« (I1_88). Besonders die unklare Situation, in der sich die Bewohner*innen befänden, die Unsicherheit über das eigene Asylverfahren sowie aktuelle und künftige Lebensumstände (vgl. I2_39), werden als belastend geschildert. Der Wunsch nach zielgerichteter und formaler (Weiter-)Bildung würde häufig keine Priorität genießen. Andere »existenzielle Themen« (ebd.) spielten im Alltag der Migrant*innen eine zentralere Rolle. Vor diesem Hintergrund stellt sich die Frage, ob die AnkerEinrichtung »denn per se die Aufgabe hätte, für Bildung zu sorgen« (I2_25).

Die Gleichzeitigkeit von strukturellen sowie individuellen Bildungsbarrieren und mannigfaltigen Lernanlässen und -möglichkeiten erlauben es, die AnkerEinrichtung als einen besonderen Lernort $\mathrm{zu}$ beschreiben. Dennoch verstehen sich die Akteur*innen, die zwar allesamt Berührungspunkte mit dem Thema herstellen, nicht alle primär als Bildungsakteur*innen. Oftmals wird eher »erklären, erklären, erklären« (I1_120) als die zutreffendere Beschreibung der Tätigkeit genannt. So sprechen einige Interviewpartner*innen eher von Beratung als von Bildung. Deutlich wird hier, dass Beratung abgekoppelt von Bildung verstanden wird, obschon Beratung als eine »durch und durch pädagogische Handlungsform« (Giesecke/Nittel 2016: 21) klassifiziert werden kann. Es zeigt sich, dass alle Interviewten zwar im Bildungsbereich tätig werden, jedoch nicht alle Bildung als Kernthema ihres Arbeitens identifizieren. Trotz diesen teils zu konstatierenden Rollendiffusionen betonen alle die Relevanz und hohe Bedeutung von Bildung. Diese Relevanzsetzung von Bildung erfolgt meist gekoppelt an eine bestimmte Integrationsvorstellung:

»[A]lso aus unserer Sicht gesprochen, hat Bildung einen sehr hohen Stellenwert [...] und Bildung ist der Schlüssel [...] zur Integration, zur Einbindung in die Cesellschaft, auch der Schlüssel, um dann sich selber hier selbständig orientieren zu können. Also und ganz besonders ist es natürlich die Sprache.« (I4_141)

Die enge Verknüpfung von Integration und Bildung, die oftmals mit sprachlichem Kompetenzerwerb assoziiert wird, zeigt sich in allen Gesprächen. Festzuhalten ist andererseits auch ein deutliches Spannungsverhältnis: Integration kann laut den Gesprächspartner*innen nur durch Bildung erfolgen, jedoch ist die gewählte Form der Unterbringung wenig geeignet, um nachhaltiges Lernen und Bildung zu er- 
möglichen. Obschon stets Lern- und Bildungsprozesse stattfinden und diese auch institutionell gefördert und gefordert werden, kann die Anker-Einrichtung vor dem Hintergrund der beschriebenen Formen von (Im-)Mobilität und Praktiken der (Im)Mobilisierung nicht vorbehaltslos als ein Ort der Bildung beschrieben werden. Noch weniger kann sie als Ort einer Integration gelten, die in den Interviews in mannigfaltigen und oftmals normativ aufgeladenen Definitionen skizziert wurde. "Integration durch Bildung« ist den Worten einer Interviewpartnerin folgend besonders in der untersuchten Anker-Einrichtung ein »mühsames Geschäft [...], [bei welchem] man unterwegs die Leute verliert«(I1_115).

\section{Schlussbetrachtung}

Obwohl Anker-Einrichtungen nicht primär als Bildungseinrichtungen fungieren, sind sie dennoch besondere Lernorte. Wie gezeigt wurde, finden in der AnkerEinrichtung Manching-Ingolstadt sowohl schulische wie auch nicht-schulische Bildungsangebote statt. Ein Schwerpunkt bei beiden liegt dabei auf der Vermittlung und dem Ausbau von Deutschkenntnissen. Die Besonderheit besteht darin, dass die Anker-Einrichtungen der Definition eines Lernorts folgend zwar als ein solcher gelten kann, die Rahmenbedingungen insgesamt, Lernen und Bildung sich jedoch stets herausfordernd gestalten.

Der Zugang zu den einzelnen Angeboten ist teilweise gesetzlich geregelt und bestimmten Adressat"innengruppen vorbehalten. Dabei können sich aber auch Ausnahmen »unter der Hand« ergeben. Andere Angebote hingegen stehen allen Interessierten offen. Dennoch werden diese nicht immer wahrgenommen. Die durch die Umgebung bedingten ungünstigen Lernbedingungen tragen dazu bei, die Anker-Einrichtung nicht als geeigneten Lernort wahrzunehmen und charakterisieren sie daher als besonderen Lernort.

Viele Akteur*innen sind in die Gestaltung der Bildungs- und Freizeitangebote involviert, darunter vor allem Wohlfahrtsverbände, kommunale und staatliche Stellen, die Betreiberfirma der Einrichtung und bürgerschaftlich Engagierte, jedoch selten die Adressat"innen der Angebote selbst.

Der besondere Lernort Anker-Einrichtung zeigt sich also in mehrerlei Hinsicht in einem ambivalenten Zusammenspiel von fremd- und selbstbestimmter (Im-)Mobilisierung und lässt im Hinblick auf die Gestaltung von Bildungsangeboten variable Herausforderungen erkennen. Dazu gehört unter anderem die sinnvolle Zusammenarbeit aller beteiligten Akteur*innen. Zwar wird häufig auf das große Engagement aller unmittelbar Beteiligten hingewiesen. Gleichzeitig scheinen bestimmte Zuständigkeiten und Verantwortlichkeiten in der Alltagspraxis oft nicht klar für andere erkennbar zu sein. Aus dieser Situation ergibt sich - auch über den Bildungsbereich hinaus - ein Geflecht aus Akteur*innen, Angeboten und Zuständigkeiten, 
das bisweilen für Involvierte wie Außenstehende schwer zu überblicken wirkt. Eine übergeordnete Instanz und damit ein*e gemeinsame* $r$ Ansprechpartner*in für alle würde hier nach Meinung vieler Interviewpartner*innen Abhilfe schaffen.

Als weitere Herausforderung wird die Anker-Einrichtung als solche gesehen, also als ein von der Regierung zur Unterbringung von Asylsuchenden und zur Durchführung des Asylverfahrens zentral eingerichteter Ort. Zwar fungiert sie de facto als Lernort, wird aber von vielen Interviewpartner*innen nicht als Ort gesehen, der dem Lernen zuträglich ist. Diese Diskrepanz kann lediglich dann ein Stück weit ausgeglichen werden, wenn die Anker-Einrichtung auch formal als Lern- und Bildungsort definiert und geformt wird. So sei zum Zeitpunkt der Interviews geplant, in naher Zukunft Verbesserungen im Hinblick auf den schulischen Unterricht vor Ort umzusetzen. Demzufolge soll ein Schulhaus auf dem zentralen Gelände eingerichtet werden, das - ausgestattet mit allen üblichen Standards - den Ansprüchen modernen Unterrichts genügen soll (vgl. I4_73).

Dennoch wünschen sich viele Interviewpartner*innen weniger Sonderregelungen für Geflüchtete (vgl. I1_5), besonders für Schüler*innen. Durch die Etablierung der Deutschklassen an den jeweiligen Sprengelschulen statt in der AnkerEinrichtung würden Kinder und jungen Erwachsene eine gewisse Normalität erfahren und könnten unter denselben Bedingungen lernen wie andere Schüler*innen.

Eine weitere Verbesserungsmöglichkeit wird von einigen Interviewten im schnelleren Zugang zu Bildungsangeboten gesehen. Im Moment setzt die Schulpflicht für Kinder und junge Erwachsene in einer Anker-Einrichtung erst drei Monate nach ihrer Ankunft ein, was teilweise als zu lang empfunden wird. Weiter muss nicht nur der formelle Zugang, sondern auch das praktische Wahrnehmen von Bildungsangeboten ermöglicht werden. Für viele junge Eltern könnte dies durch eine institutionell geregelte Kinderbetreuung erreicht werden. Eine solche Kinderbetreuung könnte dabei gleichzeitig der frühpädagogischen Bildung Vorschub leisten, welche derzeit nicht stattfindet.

Abgesehen von den äußeren Rahmenbedingungen sind auch inhaltliche Anregungen und Anliegen zu nennen: So wird auf den Bedarf nach mehr sportlichen und musischen Angeboten sowie nach handwerklicher Aus- und Weiterbildung hingewiesen.

Die Ausführungen zur Bildung in der Anker-Einrichtung Manching-Ingolstadt als besonderen Lernort zeigen, welche Maßnahmen bereits ergriffen wurden und wo noch Verbesserungspotential besteht. Die geäußerten Wünsche und Prognosen der Interviewpartner"innen lassen den Eindruck gewinnen, dass sich die Einrichtung auch weiterhin in einem steten Veränderungsprozess befindet und auch Neuerungen hinsichtlich der Gestaltung von Bildung- und Freizeitangeboten durchaus möglich sind. Grundsätzlich ist eine Unterbringung in dezentralen 
Unterkünften einer Anker-Einrichtung stets vorzuziehen. ${ }^{12}$ Chancen aber, die Bildungssituation in Anker-Einrichtungen zu verbessern, wären denkbar, z.B. indem ein Ausbau der Bildungsangebote hinsichtlich festgestellter Bedarfe (z.B. Kinderbetreuung, frühpädagogische Bildung) und grundsätzlich eine weitere Öffnung der Anker-Einrichtung und mehr Normalität (z.B. durch Verlegung der Deutschklassen in Sprengelschulen) im Hinblick auf Bildungsbelange umgesetzt würden.

Abschließend ist das Engagement aller an der Bildung in Anker-Einrichtungen Beteiligten hervorzuheben und auch alle geschilderten geplanten und bereits erfolgten Optimierungen als gut und wünschenswert $\mathrm{zu}$ betrachten. Dennoch lässt sich festhalten, dass Bildung unter den Bedingungen von (Im-)Mobilität sich für alle Involvierten herausfordernd gestaltet. So befinden sich nicht nur Hauptamtliche und bürgerschaftlich Engagierte, sondern vor allem die Bewohner*innen selbst in einem Spannungsverhältnis zwischen Freiheit und Notwendigkeit zur Bildung. Dies zeigt sich einerseits darin, dass Bildung stets ein individueller und autonomer Prozess ist. Bildung als Selbstbildung bedarf einer "freien Entscheidung« (vgl. Nuissl 1996) zur Bildung. Diese Freiheit haben Bewohner*innen von AnkerEinrichtungen grundsätzlich, denn sie ist gegeben, jedoch die Möglichkeiten zur Realisierung nicht immer. Gleichzeitig lassen sich deutliche - normativ aufgeladene - Verknüpfungen von Bildung und »Integrationserwartungen« bzw. »Integrationsanforderungen « identifizieren, welche als eine Notwenigkeit zur Bildung im Sinne einer Anpassung interpretiert werden können. Die Relevanz von Bildung und Lernen wird von allen Seiten betont. Zugleich kann problematisiert werden, dass die derzeitige Ermöglichung und Ausgestaltung von Bildung in der Einrichtung Manching-Ingolstadt nicht uneingeschränkt als die humanistische und aufklärerische Befreiung des Menschen aus Unmündigkeit (vgl. Tippelt 2010) im Sinne eines Empowerments gelten kann. Bildung gestaltet sich besonders, unter den Bedingungen von (Im-)Mobiltät. Die vorliegende Arbeit stellt also einen ersten Versuch dar, Einblicke in die komplexe Bildungssituation von Bewohner*innen einer bayerischen Anker-Einrichtung zu liefern. Gleichzeitig bleibt die Untersuchung folgender Fragen Aufgabe weiterer Forschung: Welche Bewertung der Relevanz von Bildung nehmen Bewohner*innen von Anker-Einrichtungen vor? Welche Formen der individuellen Gestaltung der eigenen Bildungsbiographien eignen sie sich an? Wie kann sich eine Bildung zur vollumfänglichen Teilhabe, die einer sozialen Mobilisierung und einem Empowerment verpflichtet ist und gleichzeitig dennoch in immobilisierende Strukturen eingebettet ist, individuell und strukturell gestalten?

12 Dies ist nicht zuletzt wünschenswert mit Blick auf die durch eine zentrale Unterbringung zu erwartenden Problematiken einer »nachholende[n] Integrationspolitik«, also einer nachgelagerten, verspäteten und daher kostenintensiven Sprachförderung sowie Integration in Schule und Ausbildung (vgl. Bade 2007: 71ff.). 


\section{Literaturverzeichnis}

Altmeppen, Klaus-Dieter (2020): »Medien und digitale Plattformen in der Migrationsgesellschaft. Zu den Strukturen öffentlicher Kommunikation über Flucht und Migration«, in: Tetyana Kloubert (Hg.), Erwachsenenbildung und Migration, Wiesbaden: Springer VS, S. 133-151.

Bade, Klaus J. (2007): »Versäumte Integrationschancen und nachholende Integrationspolitik«, in: Klaus J. Bade/Hans-Georg Hiesserich (Hg.), Nachholende Integrationspolitik und Gestaltungsperspektiven der Integrationspraxis, Beiträge der Akademie für Migration und Integration, Heft 11, Göttingen: V\&R unipress, S. 21-95.

[BAMF] Bundesamt für Migration und Flüchtlinge (2017): Erstorientierungskurse für Asylbewerber mit unklarer Bleibeperspektive, vom 22.12.2017, https:// www.bamf.de/DE/Themen/Integration/ZugewanderteTeilnehmende/Erst eOrientierung/Erstorientierungskurse/erstorientierungskurse-node.html, Abrufdatum: 01.09.2020.

[BAMF] Bundesamt für Migration und Flüchtlinge (2018): AnkER-Einrichtung - Ein Überblick, vom 01.08.2018, https:/www.bamf.de/SharedDocs/An lagen/DE/Behoerde/Aufbau/anker-einrichtungen-ueberblick.pdf?_blob= publicationFile\&v=5, Abrufdatum: 01.09.2020.

[BAMF] Bundesamt für Migration und Flüchtlinge (2019): Ankunftszentren und AnkER-Einrichtungen, vom 14.11.2019, https:/www.bamf.de/DE/Themen/A sylFluechtlingsschutz/Ankunftszentren/ankunftszentren-node.html, Abrufdatum: 01.09.2020.

[BayEUG] Bayerisches Gesetz über das Erziehungs- und Unterrichtswesen in der Fassung der Bekanntmachung vom 31. Mai 2000, https:/www.gesetze-bayern .de/Content/Document/BayEUG, Abrufdatum: 01.09.2020.

[BMBF] Bundesministerium für Bildung und Forschung (o.J.): Integration durch Bildung, https:/www.bmbf.de/de/integration-durch-bildung-1092.html, Abrufdatum: 01.09.2020.

Berger, Peter A. (2001): »Soziale Mobilität«, in: Bernhard Schäfers/Wolfgang Zapf (Hg.), Handwörterbuch zur Gesellschaft Deutschlands. 2., erweiterte und aktualisierte Auflage, Opladen: Leske + Budrich, S. 595-604.

Bochmann, Annett (2017): »Soziale Institution Lager. Theoretische Grundlagen, Flüchtlingslager und die Macht lokaler Mikrostrukturen«, in: Stephan Lessenich (Hg.), Geschlossene Gesellschaften. Verhandlungen des 38. Kongresses der Deutschen Gesellschaft für Soziologie in Bamberg 2016, http://publikationen.s oziologie.de/index.php/kongressband_2016/article/download/480/pdf_111,Abrufdatum: 01.09.2020. 
Carling, Jørgen (2002): »Migration in the age of involuntary immobility: theoretical reflections and Cape Verdean experiences«, in: Journal of Ethnic and Migration Studies 28(1), S. 5-42.

De Haas, Hein (2014): »Migration Theory. Quo vadis?«, in: IMI Working Papers Working Paper 100, Oxford: International Migration Institute, University of Oxford.

Foroutan, Naika/Karakayali, Juliane/Spielhaus, Riem (2018): »Einleitung: Kritische Wissensproduktion zur postmigrantischen Gesellschaft «, in: Naika Foroutan/Juliane Karakayali/Riem Spielhaus (Hg.), Postmigrantische Perspektiven. Ordnungssysteme, Repräsentationen, Kritik, Frankfurt a.M.: Campus Verlag, S. 9-16.

Garnitschnig, Ines/Hollwart, Renate/Smodics, Elke/Sternfeld, Nora (Hg.) (2017): Strategien für Zwischenräume. Ver_Lernen in der Migrationsgesellschaft, schulheft 165, Innsbruck: Studien Verlag.

Giesecke, Wiltrud/Nittel, Dieter (Hg.) (2016): Handbuch Pädagogische Beratung über die Lebensspanne, Weinheim und Basel: Beltz Juventa.

Goebel, Simon (2017): Politische Talkshows über Flucht. Wirklichkeitskonstruktionen und Diskurse. Eine kritische Analyse, Bielefeld: transcript.

[GrSO] Grundschulordnung vom 11. September 2008 (GVBl. S. 684, BayRS 2232-2K), die zuletzt durch $\$ 3$ der Verordnung vom 9. Juli 2019 (GVBl. S. 420) geändert worden ist, https:/www.gesetze-bayern.de/Content/Document/BayVsO, Abrufdatum 01.09.2020.

Gruber, Elke/Schmid, Kurt (2019): »Editorial«, in: Magazin erwachsenenbildung.at. Das Fachmedium für Forschung, Praxis und Diskurs, Ausgabe 35/36, Wien, S. 01-1-01-8.

Hannam, Kevin/Sheller, Mimi/Urry, John (2006): »Editorial: Mobilities, Immobilities and Moorings«, in: Mobilities, 1(1), S. 1-22.

Helfferich, Cornelia (2019): "Leitfaden- und Experteninterviews«, in: Nina Baur/Jörg Blasius (Hg.), Handbuch Methoden der empirischen Sozialforschung. 2., vollständig überarbeitete und erweiterte Auflage, Wiesbaden: Springer Verlag.

[ISB] Staatsinstitut für Schulqualität und Bildungsforschung (2017): Lehrplan für die Berufsintegrations- und Sprachintensivklassen, Juli 2017, https://www.isb .bayern.de/download/19736/lp_berufsintegrationsklassen_07_2017.pdf, Abrufdatum: 01.09.2020.

Kloubert, Tetyana (2020): »Einleitung der Herausgeberin«, in: Tetyana Kloubert (Hg.), Erwachsenenbildung und Migration, Wiesbaden: Springer VS, S. 1-10.

Kraus, Katrin (2015): „Ortes des Lernens als temporäre Konstellationen. Ein Beitrag zur Diskussion des Lernortkonzepts«, in: Christian Bernhard/Katrin Kraus/Silke Schreiber-Barsch/Richard Stang (Hg.), Erwachsenenbildung und Raum. 
Theoretische Perspektiven - professionelles Handeln - Rahmungen des Lernens, Bielefeld: W. Bertelsmann, S. 41-54.

Kreichauf, René (2018): „From forced migration to forced arrival: the campization of refugee accommodation in European cities«, in: Comparative Migration Studies 6(7), S. 1-22.

Kuckartz, Udo (2016): Qualitative Inhaltsanalyse: Methoden, Praxis, Computerunterstützung. 3., überarbeitete Auflage, Weinheim und Basel: Beltz Juventa.

Mayring, Philipp/Fenzl, Thomas (2019): »Qualitative Inhaltsanalyse«, in: Nina Baur/Jörg Blasius (Hg.), Handbuch Methoden der empirischen Sozialforschung. 2., vollständig überarbeitete und erweiterte Auflage, Wiesbaden: Springer Verlag.

[MSO] Mittelschulordnung vom 4. März 2013 (GVBl. S. 116, BayRS 2232-3-K), die zuletzt durch $\$ 3$ der Verordnung vom 22. Juni 2020 (GVBl. S. 335) geändert worden ist, https://www.gesetze-bayern.de/Content/Document/BayMSO, Abrufdatum 01.09.2020.

Nuissl von Rein, Ekkehard (Hg.) (1996): »Ende der Freiwilligkeit?!«, in: DIE Zeitschrift für Erwachsenenbildung 4, Bonn: DIE.

Stang, Richard (2019): "Auf der Suche nach der »atmenden Raumstruktur«. Historische Betrachtungen zu Diskursen über Lern- und Bildungsräume«, in: Magazin erwachsenenbildung.at. Das Fachmedium für Forschung, Praxis und Diskurs 35/36, Wien, S. 02-1-02-8.

[StMI] Bayerisches Staatsministerium des Innern, für Sport und Integration (o.J.): Leistungen für Asylbewerber, https://www.stmi.bayern.de/mui/asylsozialpolit ik/leistungen/index.php, Abrufdatum: 01.09.2020.

[StMI] Bayerisches Staatsministerium des Innern, für Sport und Integration (2019): Ihr Besuch in der ANKER-Einrichtung Manching/Ingolstadt am 01.04.2019. [E-Mail an Jost Herrmann], www.fluechtlingshelfer-traunstein.de/downloads/besuch-anker-einrichtung_fragen_reinschrift.pdf, Abrufdatum: 01.09.2020.

[StMUK] Bayerisches Staatsministerium für Unterricht und Kultus (o.J. a): Berufsintegrationsklassen in Bayern, https://www.km.bayern.de/allgemein/m eldung/3755/junge-asylbewerber-und-fluechtlinge-koennen-in-ganz-bayernberufsintegrationsklassen-besuchen.html, Abrufdatum: 01.09.2020.

[StMUK] Bayerisches Staatsministerium für Unterricht und Kultus (o.J. b): Deutschförderung an bayerischen Grund- und Mittelschulen, https:// www.km.bayern.de/ministerium/schule-und-ausbildung/foerderung/sprachfoerderung.html, Abrufdatum: 01.09.2020.

[StMUK] Bayerisches Staatsministerium für Unterricht und Kultus (o.J. c): Die Berufsschule in Bayern, https://www.km.bayern.de/eltern/schularten/berufssch ule.html, Abrufdatum: 01.09.2020. 
Täubig, Vicki (2009): Totale Institution Asyl. Empirische Befunde zu alltäglichen Lebensführungen in der organisierten Desintegration, Weinheim und München: Juventa.

Tippelt, Rudolf (2010): »Bildung in der Demokratie< als Thema der Erziehungswissenschaft «, in: Stefan Aufenanger/Franz Hamburger/Luise Ludwig/Rudolf Tippelt (Hg.), Bildung in der Demokratie. Beiträge zum 22. Kongress der Deutschen Gesellschaft für Erziehungswissenschaft, Opladen: Barbara Budrich, S. 17-25.

Vinciguerra, Maria (2017): »Narrating Migration. The Result of Transformative Learning«, in: Anna Laros/Thomas Fuhr/Edward E. Taylor (Hg.), Transformative Learning Meets Bildung. An International Exchange, Rotterdam: Sense Publisher, S. 353-362.

Wille, Christian (2009): »Zum Modell des transnationalen sozialen Raums im Kontext von Grenzregionen: theoretisch-konzeptionelle Überlegungen am Beispiel des Grenzgängerwesens«, in: Europa Regional 16.2008(2), S. 74-84.

Witzel, Andreas (2000): »Das problemzentrierte Interview«, in: Forum Qualitative Sozialforschung 1(1), https://www.qualitative-research.net/index.php/fqs/artic le/view/1132/2519. \%5D, Abrufdatum: 01.09.2020.

\section{Interviews}

Interview 1, geführt im Januar 2020, Dauer: 01:12 h. Interview 2, geführt im Januar 2020, Dauer: $00: 28 \mathrm{~h}$. Interview 3, geführt im Februar 2020, Dauer: $00: 34 \mathrm{~h}$. Interview 4, geführt im Februar 2020, Dauer: 01:41 h. Interview 5, geführt im Februar 2020, Dauer: 00:57 h. 



\section{Zwischen räumlicher Mobilität und struktureller Immobilität \\ Venezolanische Geflüchtete in Kolumbien}

Alina Löffler

\section{Zusammenfassung}

Rund fünf Millionen Venezolaner*innen haben in den letzten Jahren ihr Heimatland verlassen und sind in umliegende Staaten geflohen. Diese stehen angesichts dieser neuen Form der Mobilität auf dem Kontinent vor institutionellen, sozialen und wirtschaftlichen Herausforderungen. Besonders betroffen ist dabei Kolumbien, welches mit mehr als 1,8 Millionen am meisten Venezolaner*innen aufgenommen hat. Dabei hat Kolumbien in der Vergangenheit bereits die Mobilisierung eigener Bevölkerungsteile, vor allem in Form von interner Vertreibung während des bewaffneten Konflikts, erlebt. Der Beitrag widmet sich zunächst der Frage, welche Erfahrungen in Kolumbien in der Vergangenheit mit Mobilität gemacht wurden und wie die kolumbianische Regierung vor diesem Hintergrund mit venezolanischen Geflüchteten umgeht. Ein besonderes Augenmerk wird auf die Einführung von speziellen Aufenthaltstiteln für Venezolaner*innen und die mit diesen verbundenen Rechte und Einschränkungen gelegt. Hierbei fällt auf, dass die nur wenig konsolidierte kolumbianische Migrationspolitik nicht auf die massive Einreise ausländischer Staatsbürger*innen vorbereitet war und somit nur kurzfristig Maßnahmen ergreifen konnte, ohne die längerfristige Integration der Venezolaner*innen ins Auge zu fassen. Schließlich fokussiert der Beitrag die Arten der Unterbringung venezolanischer Geflüchteter in Kolumbien. Diese leben zumeist in prekären Wohnverhältnissen im kolumbianisch-venezolanischen Grenzbereich oder in der Peripherie der großen Städte. In diesem Zusammenhang wird argumentiert, dass die Geflüchteten in Kolumbien keinerlei Wohnsitzauflagen oder Bewegungsbeschränkungen unterworfen sind und folglich über eine hohe räumliche Mobilität verfügen. Dennoch sind sie durch strukturelle Umstände wie den mangelnden Zugang zu einer formellen Beschäftigung, zum Gesundheits- und Bildungssystem in ihrer Selbstbestimmtheit eingeschränkt und werden aufgrund fehlender Handlungsmöglichkeiten immobilisiert. 


\begin{abstract}
Summary
About five million Venezuelans have left their home country in recent years and fled to surrounding states. These countries face institutional, social and economic challenges in view of this new form of mobility on the continent. Colombia is particularly affected by this development, being one of the countries that took in most Venezuelans with the number exceeding 1.8 million. In the past, Colombia had already experienced the mobilisation of its own population, especially in the form of internal displacement during the armed conflict. This article first addresses the question of what experiences have been made with mobility in Colombia in the past and how the Colombian government deals with Venezuelan refugees against this backdrop. Special attention will be paid to the introduction of special residence permits for Venezuelans and the rights and restrictions associated with them. In this context, it is striking that Colombia's migration policy which is only consolidated to a limited degree - was not prepared for the massive entry of foreign citizens and could therefore only take short-term measures without considering the longer-term integration of Venezuelans. Finally, this article focuses on the types of accommodation for Venezuelan refugees in Colombia. Most of them live in precarious housing conditions in the Colombian-Venezuelan border area or on the outskirts of large cities. In this context, it is argued that the refugees in Colombia are not subject to any residence or movement restrictions and therefore have a high degree of spatial mobility. Nevertheless, they are limited in their self-determination by structural circumstances such as a lack of access to formal employment, to the health care and education system and are immobilised due to a lack of opportunities for action.
\end{abstract}

\title{
Einleitung
}

Bis März 2020 haben infolge der Zuspitzung der sozialen, politischen und wirtschaftlichen Situation im Land rund fünf Millionen Menschen die Bolivarische Republik Venezuela verlassen (vgl. IOM 2020). Damit stellt diese Migrationsbewegung eine der derzeit größten weltweit dar. Für den lateinamerikanischen Kontinent handelt es sich sowohl zahlenmäßig als auch hinsichtlich des regionalen Fokus der Flucht um eine neue Form und Dimension der Mobilität. Die umliegenden Aufnahme- und Transitländer stehen aus diesem Grund vor nie dagewesenen Herausforderungen an Staat und Gesellschaft, denn sie sind es, die sowohl die grundlegenden Voraussetzungen zur Einhaltung der Rechte venezolanischer Geflüchteter schaffen als auch Bedingungen und Regelungen in Bezug auf ihre Einreise und Aufnahme festlegen. 
Staaten versuchen, Einfluss auf die Mobilität von Menschen innerhalb und außerhalb ihres Territoriums zu nehmen. Dies betrifft insbesondere Menschen, die zwanghaft aus ihrer Heimat vertrieben wurden. Dabei kann der Staat, wie Cornelius und Rosenblum (2005: 112) anführen, zwar oftmals nicht über die genaue Anzahl der einreisenden Personen bestimmen, dennoch legt er die Bedingungen von Migration fest. Zudem bestimmt er über grundlegende Kategorisierungen von Personen als »Flüchtling« oder »Migrant*in« und legt mit ihnen verbundene Rechte und Pflichten fest. Auf diese Weise wird über die Aufenthaltserlaubnis oder -beschränkung erheblicher Einfluss auf die Mobilität von betroffenen Personen ausgeübt (vgl. FitzGerald/Arar 2018: 394; Glick Schiller/Salazar 2012: 14).

In Bezug auf venezolanische Geflüchtete zeichnen sich die lateinamerikanischen Staaten grundsätzlich durch eine große Solidarität und Aufnahmebereitschaft aus (vgl. Freier/Parent 2019: 57). Viele der Venezolaner*innen sind nach Peru, Brasilien oder Ecuador geflohen. Die Mehrheit jedoch begab sich in das direkte Nachbarland Kolumbien, dessen Regierung sich den venezolanischen Staatsbürger*innen gegenüber zumeist offen präsentierte - wie aus einem Statement des Präsidenten Iván Duque Márquez am 25. September 2018 hervorgeht:

»Aber wir werden sie [die Venezolaner*innen, Anm. d.Verf.] immer mit offenen Armen und offenen Türen empfangen, weil es nicht unsere moralische Pflicht ist, die Grenzen zu schließen, sondern es ihnen zu ermöglichen, dieser Tragödie zu entfliehen. «" (Presidencia de la República 2018)

Dabei befindet sich Kolumbien derzeit selbst in einer Phase der Transition, welche sich an die Unterzeichnung des historischen Friedensvertrags mit der größten Guerillagruppe FARC-EP im September 2016 anschließt. ${ }^{2}$ Durch den Friedensvertrag wurde der mehr als 60 Jahre andauernde bewaffnete Konflikt offiziell beendet, der vor allem die Zivilgesellschaft andauernder Formen von Gewalt und interner Vertreibung ausgesetzt hatte. Die Geschichte Kolumbiens beinhaltet also verschiedene Erfahrungen mit Mobilität.

Vor diesem Hintergrund stellt der vorliegende Beitrag in einem ersten Schritt die Frage, welche Regelungen die kolumbianische Regierung auf Basis bereits gesammelter Erfahrungen mit Mobilität für venezolanische Geflüchtete getroffen hat und welche politischen Maßnahmen sie zur Aufnahme und Unterbringung dieser ergriffen hat. In einem zweiten Schritt soll beantwortet werden, wie sich diese Regelungen und Maßnahmen auf die Mobilität venezolanischer Geflüchteter in

Diese und alle folgenden Übersetzungen sind von der Verfasserin. Der Originaltext lautet: »Pero nosotros siempre vamos a estar con los brazos abiertos, con las puertas abiertas para acogerlos, porque nuestro deber moral no es cerrar las fronteras sino permitirles a ellos salir de esa tragedia."

2 Siehe dazu auch den Beitrag von Anna-Lena Dießelmann und Andreas Hetzer in diesem Band. 
Kolumbien auswirkt. Ziel ist es aufzuzeigen, in welchem Umfang der kolumbianische Staat venezolanische Geflüchtete in ihrer Mobilität bestärkt oder einschränkt. Diesbezüglich wird argumentiert, dass in Kolumbien zwar keine restriktiven Politiken in Bezug auf Unterbringung und Wohnort von Venezolaner*innen vorliegen, dass diese jedoch durch strukturelle Gegebenheiten in ihrer Selbstbestimmung eingeschränkt werden. Diese These wird anhand von Interviews diskutiert, die im Januar 2020 mit Venezolaner*innen in Bogotá geführt wurden. ${ }^{3}$

\section{Erfahrungen mit Mobilität in Kolumbien: Die Desplazados und die Fokussierung der Migrationspolitik auf eigene Bevölkerungsgruppen}

Die zeitlich wohl am weitesten zurückreichende und zahlenmäßig größte Erfahrung mit Mobilität stellt im kolumbianischen Kontext die der internen Vertriebenen, der sogenannten Desplazados dar. So mussten bereits während der Gran Violencia der 1940er und 1950er Jahre zahlreiche Kolumbianer*innen in andere Regionen des Landes fliehen (vgl. Juliao 2011: 5). Heute zählt Kolumbien mit mehr als sieben Millionen Binnenvertriebenen als das Land, in welchem noch vor Syrien die meisten Menschen ihren Heimatort verlassen und innerhalb der Landesgrenzen ein neues Zuhause finden mussten (vgl. UNHCR 2019b: 35). Am stärksten betroffen sind nach wie vor die ländlichen Regionen, in denen in der Vergangenheit schon ganze Dörfer zur Umsiedlung gezwungen wurden. Insbesondere auch indigene und afrokolumbianische Bevölkerungsgruppen leiden unter dieser Form von Gewalt (vgl. Curcio et al. 2019: 61). Viele der Binnenvertriebenen ziehen in umliegende Gebiete oder in die größeren Städte, in welchen in den letzten Jahren Formen der innerstädtischen Vertreibung eine immer größere Rolle spielen (vgl. CNMH 2015: 229f.; Ocampo et al. 2015: 161).

Die Gründe für diese massive Form der Mobilisierung von Menschen liegen im bewaffneten Konflikt zwischen staatlichen Kräften, Guerillas und Paramilitärs, welcher das Land seit den 1960er Jahren überschattete. Die aus dem Konflikt resultierende Gewalt, beispielsweise in Form von Landraub, Massakern, Entführungen und Zwangsrekrutierungen, richtete sich überwiegend gegen die Zivilgesellschaft. In den 1980er und 1990er Jahren stieg die Anzahl der Vertriebenen aufgrund des wachsenden Drogenhandels und der Formierung des Paramilitarismus stark an (vgl. CNMH 2015: 62ff.).

3 Der Feldzugang erfolgte über eine Anfrage in der Facebook-Gruppe »Venezolanos en Bogotá« mit mehr als 15.000 Mitgliedern. Aus den zahlreichen Interessenten wurden Personen mit möglichst unterschiedlichen Charakteristika in Bezug auf Alter, Geschlecht, Familienverhältnisse und Aufenthaltsstatus ausgewählt. Vier Interviews kamen zustande, von denen drei für den Beitrag ausgewählt wurden. Die Interviews wurden auf Spanisch geführt und transkribiert, ausgewählte Zitate wurden für diesen Beitrag ins Deutsche übersetzt. 
Obwohl ein großer Teil der Bevölkerung während des bewaffneten Konflikts von Zwangsmigration betroffen war, wurde diese Form der Gewalt von der Politik lange Zeit ignoriert. Louis (2018: 63) argumentiert, dass interne Vertriebene lange nicht als Opfer des Konflikts wahrgenommen wurden, sondern vielmehr als Teil der allgemeinen Binnenmigration. Aus diesem Grund wurde erst im Jahr 1997 die Existenz der Desplazados im Kontext des bewaffneten Konflikts gesetzlich anerkannt und Institutionen zum Schutz dieses Teils der Bevölkerung geschaffen - zum Beispiel das Nationale System zur Betreuung intern Vertriebener (Sistema Nacional de Atención Integral a la Población Desplazada por la Violencia, SNAIPD) (vgl. Juliao 2011: 7). Dennoch führten die neuen Gesetze der 1990er Jahre nicht zu einer generellen Entspannung der Situation. Im Gegenteil erreichte die Zahl der Betroffenen erst zur Jahrtausendwende ihren Höhepunkt. So wurden allein im Jahr 2002 mehr als 680.000 Personen intern vertrieben (vgl. CNMH 2015: 94, 101; Ibañez/Moya 2007: 10). Zum Wendepunkt kam es erst im Jahr 2005, als mit dem Gesetz für Gerechtigkeit und Frieden (Ley de Justicia y Paz, Nr. 975) das Recht der Opfer des Konflikts auf Wahrheit, Gerechtigkeit und Wiedergutmachung durch den Staat festgeschrieben wurde. Weiter gestärkt wurden diese Rechte durch das im Jahr 2011 verabschiedete Gesetz für Opfer und Landrückgabe (Ley de Víctimas y Restitución de Tierras, Nr. 1448) (vgl. Louis 2018: 66). Trotz des Friedensabkommens im Jahr 2016 hält die interne Vertreibung in ländlichen Regionen, wenngleich die Zahlen rückläufig sind, weiter an (vgl. Hernández 2017: 17).

Aufgrund des bewaffneten Konflikts und der daraus resultierenden wirtschaftlichen und politischen Instabilität flohen neben den Vertriebenen innerhalb Kolumbiens auch zahlreiche Kolumbianer*innen ins Ausland, insbesondere in das Nachbarland Venezuela. In den 1950er und 1960er Jahren war Venezuela aufgrund der steigenden Erdölpreise und der daraus resultierenden Nachfrage nach Arbeitskräften vielfach Ziel kolumbianischer Migrant*innen. Mit der Zuspitzung des internen Konflikts in Kolumbien wandelte sich die wirtschaftlich motivierte Migration in der zweiten Hälfte des 20. Jahrhunderts zunehmend in eine Fluchtmigration (vgl. Álvarez de Flores 2009: 51; 2004: 192).

Der kolumbianische Staat und die Zivilgesellschaft verfügen also über Erfahrungen mit Auswanderung und Binnenmigration, kaum jedoch über Erfahrungen mit Einwanderung. Dies spiegelt sich auch in den Migrationspolitiken des Landes wider. Obwohl sich bereits in den 1990er Jahren erste Initiativen mit der Steuerung von Immigration beschäftigten, lag hier der Fokus auf der wirtschaftlichen Entwicklung, indem vor allem Hochqualifizierten die Einwanderung ermöglicht wurde (vgl. Castro 2016: 3ff.). Erst 2009 wurde durch ein Dokument des Nationalen Rates für Wirtschafts- und Sozialpolitik (Consejo Nacional de Política Económica y Social, CONPES, Nr. 3603) die sogenannte »umfassende Migrationspolitik« (Política Migratoria Integral, PIM) entworfen, welche vorherige politische und rechtliche Bemühungen bündelte und in einen gemeinsamen Rahmen überführte (vgl. Bonil 
2019; Palacios et al. 2019). Zudem wurde im Jahr 2011 mit dem Nationalen System für Migration (Sistema Nacional de Migraciones, Gesetz Nr. 1465) eine Plattform zur Koordinierung, Umsetzung und Evaluation der Migrationspolitik geschaffen und im Jahr 2012 die kolumbianische Immigrationsbehörde (Migración Colombia) gegründet (vgl. Ramos et al. 2019: 14f.).

Trotz jüngerer Bemühungen, die kolumbianische Migrationspolitik einheitlicher und umfassender zu gestalten, fokussiert diese weiterhin die selektive Immigration von Fachkräften und stellt nur wenige Regelungen zum Umgang mit Fluchtbewegungen bereit. Zudem legt sie einen starken Fokus auf die Betreuung von Kolumbianer*innen im Ausland und vernachlässigt ausländische Migrant*innen im Inland. Insbesondere der Schutz von Rechten und die Befriedigung der Bedürfnisse von Migrant*innen in Bezug auf Versorgung und gesellschaftliche Teilhabe werden vom kolumbianischen Staat nach wie vor außer Acht gelassen (vgl. Bonil 2019: 94ff.). Die kolumbianische Migrationspolitik ist folglich noch immer als lückenhaft und wenig kohärent einzustufen. Durch ihre reaktive Ausrichtung hat sie sich lange Zeit nur an bestehende Phänomene angepasst, ohne Instrumente $\mathrm{zu}$ entwickeln, die das Potential hätten, mit größeren Immigrationsbewegungen unter Beachtung der Menschenrechte von Migrant*innen umzugehen (vgl. ebd.: 102).

\section{Gründe für die Flucht und Charakteristika venezolanischer Geflüchteter in Kolumbien}

Mobilitäten haben sich in Kolumbien in den letzten Jahren grundlegend verändert. Zum einen sehen weniger Kolumbianer*innen aufgrund des Friedensabkommens die Notwendigkeit, ihre Heimat zu verlassen. Zum anderen begeben sich immer mehr venezolanische Staatsbürger*innen nach Kolumbien; bis Ende Februar 2020 waren es mehr als 1.8 Millionen (vgl. R4V 2020).

Die Gründe für die große Anzahl venezolanischer Geflüchteter in Kolumbien liegen zum einen in der durch den ehemaligen Präsidenten Hugo Chávez gegen Ende der 1990er Jahre eingeleiteten sozialistischen Umstrukturierung Venezuelas nach der Idee der bolivarischen Revolution. In diesem Zusammenhang verließen nach der Jahrtausendwende zunächst wohlhabende Venezolaner*innen das Land und migrierten in die USA und nach Europa. Nach massiven Entlassungen von Mitarbeiter*innen des staatlichen Erdölkonzerns und der Wiederwahl von Chávez im Jahr 2006 kam es zudem zur Auswanderung von Fachkräften und Akademiker*innen ins lateinamerikanische Ausland (vgl. FIP 2018: 4-6; Ramos et al. 2018: 10; Mijares 2014: 2). Zuletzt hat sich die politische, soziale und wirtschaftliche Situation im Land nach dem Tod von Chávez im März 2013 und der Ernennung von Nicolás Maduro zum Präsidenten weiter drastisch verschlechtert. Das Land fiel in 
eine tiefe politische Krise, die ihren Höhepunkt am 23. Januar 2019 erreichte, als sich der Vorsitzende der von der Opposition dominierten Nationalversammlung Juan Guaidó als Interimspräsident deklarierte (vgl. Zilla 2019: 1, 5; Mijares/Rojas 2018).

Aufgrund der zunehmenden Autokratisierung des politischen Systems und der Verschlechterung der wirtschaftlichen Situation im Land gingen immer wieder Teile der Bevölkerung auf die Straße. Die Regierung ging dabei höchst repressiv gegen die Demonstrierenden vor. Nicht zuletzt die grassierende Korruption im politischen System Venezuelas und die mangelnde Strafverfolgung gegen kriminelle Organisationen führten außerdem dazu, dass Venezuela heute als eines der gewaltsamsten Länder der Welt gilt (vgl. Huang/Gough 2018; IACHR 2017: 21). Auch wirtschaftlich ist Venezuela seit dem Absturz des Erdölpreises im Jahr 2014 stark angeschlagen, was auch auf die geringe Diversifizierung der venezolanischen Wirtschaft und die Konzentration der Produktion auf die Erdölförderung zurückgeführt werden kann. Im Jahr 2018 verzeichnete das Land eine Inflationsrate von 1.000.000 Prozent (vgl. Ramos et al. 2019: 10; Otero 2014: 7). Infolge dessen ist die Armutsrate innerhalb der Bevölkerung stark angestiegen. Viele Menschen können sich die ohnehin schon knappen Lebensmittel nicht mehr leisten und auch die medizinische Versorgung ist nicht gewährleistet (vgl. Rendon/Schneider 2018: 2; Ramsey/Sánchez 2018: 4). Diese Entwicklungen haben seit 2014 insbesondere die noch im Land verbliebenen ärmeren Bevölkerungsteile getroffen. Als Konsequenz haben tausende Venezolaner*innen ihr Eigentum verkauft und sind über den Landweg in die umliegenden Staaten geflohen (vgl. Freier/Parent 2019: 56).

Die Migration von Venezolaner*innen nach Kolumbien ist von unterschiedlichen Formen und Motiven gekennzeichnet (vgl. Mazuera et al. 2019: 17ff.). Neben Personen, die dauerhaft in Kolumbien bleiben möchten, überqueren zahlreiche Venezolaner*innen nur kurzfristig die Grenze. Einige beschaffen sich im Nachbarland Lebensmittel und andere Güter und kehren umgehend nach Venezuela zurück, andere nutzen Kolumbien als Transitland auf dem Weg in andere lateinamerikanische Staaten. Eine weitere Gruppe sind sogenannte Rückkehrer*innen, d.h. Kolumbianer*innen, die nach Venezuela ausgewandert waren und nun zurückkehren (vgl. CODHES 2018: 6; CONPES 2018: 31ff.).

Die meisten Venezolaner*innen reisen über die nördlichen Grenzregionen, etwa Norte de Santander, Arauca oder La Guajira ein. Dabei erlangte vor allem die Grenzstadt Cúcuta besondere Relevanz, weil sich dort die Auseinandersetzung um den Zugang von Hilfsgütern nach Venezuela im Jahr 2019 zuspitzte (vgl. Ramos et al. 2019: 10; Zilla 2019: 5). Nach Übertritt verbleiben die Geflüchteten mehrheitlich in den Grenzregionen oder begeben sich in die großen Städte. So befinden sich rund 40 Prozent aller venezolanischen Migrant*innen in Bogotá, Cúcuta, Barranquilla, Medellín und Cali (vgl. Migración Colombia 2020). 


\section{Regelungen zur Aufnahme venezolanischer Geflüchteter: Eine Notlösung?}

Als Reaktion auf die große Zahl venezolanischer Geflüchteter hat sich zwar der grundlegende Fokus der kolumbianischen Migrationspolitik auf eigene Bevölkerungsgruppen im Ausland nicht verändert, jedoch musste die kolumbianische Regierung neue Instrumente zur Bewältigung der gestiegenen Anforderungen an die kolumbianischen Institutionen entwickeln (vgl. Bonil 2019: 101ff.). Bestimmend für den Umgang mit den venezolanischen Geflüchteten waren dabei immer wieder die Beziehungen zur venezolanischen Regierung. Juan Manuel Santos, in dessen Staatspräsidentschaft (2010-2018) die ersten massiven Einreisebewegungen fielen, hatte sich zunächst aufgrund des Beobachterstatus von Venezuela während der Friedensverhandlungen an die venezolanische Regierung angenähert. Erst nach Unterzeichnung des Friedensabkommens und der Zuspitzung der politischen Situation im Nachbarland positionierte sich Santos kritisch gegenüber Maduro. Diese Position wurde von seinem Nachfolger Iván Duque Márquez, seit August 2018 im Amt, übernommen und intensiviert (vgl. Márquez 2019: 494-498).

Erste Maßnahmen ergriff die kolumbianische Regierung im August 2016, als sich ein starker Anstieg der venezolanischen Migration an der Grenze abzeichnete. Dabei wurden Venezolaner*innen von der Regierung von Beginn an grundsätzlich nicht als Flüchtlinge nach der Genfer Flüchtlingskonvention eingestuft, sondern als Migrant*innen. Auch die weiter gefasste Definition der Erklärung von Cartagena aus dem Jahr 1984, welche auch humanitäre Fluchtgründe beinhaltet, findet in Kolumbien trotz der Überführung dieser Definition in nationales Recht keine Anwendung (vgl. HRW 2018: 3, 9). Dementsprechend wurde in den letzten Jahren nur sehr wenigen Venezolaner*innen der Asylstatus zugesprochen und die kolumbianische Regierung entwickelte andere Maßnahmen, um den Geflüchteten einen legalen Aufenthalt zu ermöglichen (vgl. CNR 2019: 14). So führte sie die Grenzmobilitätskarte (Tarjeta de Movilidad Fronteriza, TMF) ein, welche sich an die im unmittelbaren Grenzbereich lebenden Pendler*innen richtet und einen regulären Aufenthalt im Staatsgebiet für sieben Tage ermöglicht. Im Februar 2018 wurde die Vergabe der Karte jedoch frühzeitig wieder eingestellt (vgl. Bonil 2019: 105).

Das wohl wichtigste Instrument zur Regularisierung venezolanischer Staatsbürger*innen schuf die Regierung im Juli 2017 mit der Einführung der Speziellen Erlaubnis zum Aufenthalt (Permiso Especial de Permanencia, PEP). Zugang zu dieser Aufenthaltserlaubnis erhalten Venezolaner*innen, die mit einem Pass regulär in das Land eingereist sind und über keine Vorstrafen oder eine Abschiebeanordnung verfügen. Die PEP besitzt eine Gültigkeit von zwei Jahren und befähigt dazu, in Kolumbien einer Beschäftigung nachzugehen und Leistungen des Gesundheitsund Bildungssystems in Anspruch zu nehmen (vgl. FIP 2018: 27; Weltbank 2018: 18). Dabei war die Vergabe der Erlaubnis bisher an bestimmte Zeiträume in verschie- 
denen Monaten in den Jahren 2017 bis 2020 gebunden $^{4}$ (vgl. El Espectador 2020; Rodríguez/Ramos 2019: 569).

Weitere Maßnahmen umfassten zudem die Etablierung der Speziellen Gruppe für Migration (Grupo Especial Migratorio, GEM), welche verschiedene mit Migration befasste Institutionen, wie die Immigrationsbehörde, die nationale Polizei oder den Zoll, zur Verbesserung der staatlichen Koordination zusammenschließt (vgl. FIP 2018: 27). Zudem wurde mit dem Verwaltugsregister der venezolanischen Migrant*innen in Kolumbien (Registro Administrativo de Venezolanos en Colombia, RAMV) ein Instrument geschaffen, welches mehr Informationen über Umfang und Charakteristika der venezolanischen Migration erheben soll. Auch ein Strategiepapier (CONPES, Nr. 3950), welches die wichtigsten Bedürfnisse von Venezolaner*innen zusammenfasst und Handlungsempfehlungen formuliert, wurde als Basis für zukünftige Maßnahmen entwickelt (vgl. Palacios et al. 2019; Ramos et al. 2019: 10; CONPES 2018).

Trotz der Initiativen zur Regularisierung venezolanischer Geflüchteter und zur staatlichen Koordination ist der gesetzliche Rahmen zur Aufnahme der Geflüchteten vergleichsweise gering ausgeprägt. So konnten zwar zahlreiche Menschen mit Hilfe von PEP und TMF in die Legalität überführt werden, dennoch befinden sich von den mehr als 1.8 Millionen Venezolaner*innen rund eine Millionen Menschen noch immer irregulär, d.h. ohne gültigen Aufenthaltstitel im Land (vgl. R4V 2020). Dies liegt daran, dass viele Venezolaner*innen über keinen gültigen Pass verfügen, was in vielen Fällen darauf zurückzuführen ist, dass dieser nur schwer zu beschaffen ist. Ohne Pass ist der legale Zugang nach Kolumbien und somit der Erhalt eines Aufenthaltstitels erheblich erschwert (vgl. Ramos et al. 2019: 11; FIP 2018: 28). Zudem haben je nach Zeitpunkt der Vergabe verschiedene Aufenthaltstitel unterschiedliche Berechtigungen der Betroffenen in Bezug auf den Zugang zum Arbeitsmarkt und Sozialsystem zur Folge. In ihrer komplexen Unübersichtlichkeit haben die bislang geschaffenen Möglichkeiten der Regularisierung eher den Charakter von »Notpflastern«, die zumeist in Reaktion auf spontan aufkommende Herausforderungen entstanden sind. Die Etablierung eines gesetzlichen Rahmens, welcher auf die dauerhafte Integration venezolanischer Geflüchteter ausgerichtet ist, können sie nicht ersetzen (vgl. Bonil 2019: 102). 


\section{Die Unterbringung venezolanischer Geflüchteter: Leben in prekären Verhältnissen}

Viele venezolanische Geflüchtete sind mittellos und nach ihrer Ankunft im Aufnahmeland auf Unterstützungsleistungen - insbesondere Nahrungsmittel und medizinische Versorgung - angewiesen. Ebenso zentral ist die Frage der Unterbringung der Geflüchteten, die für ihre Gesundheit und Sicherheit essentiell ist (vgl. Maldonado et al. 2018: 94).

Eine Untersuchung der Weltbank (2018) hat festgestellt, dass zwar die Nachfrage nach temporären und dauerhaften Unterkünften in Kolumbien aufgrund venezolanischer Geflüchteter gestiegen ist, jedoch in den Gemeinden keine Pläne zur Erhöhung des Wohnraums vorliegen. Der Staat stellt grundsätzlich keine Wohnmöglichkeiten zur Verfügung: »In Bezug auf die Unterbringung erhalten weder kolumbianische Rückkehrer noch venezolanische Migranten finanzielle Unterstützung oder Hilfe in Form einer temporären Unterkunft durch die Regierung « (Weltbank 2018: 109). Gleichzeitig herrscht in Kolumbien ohnehin eine Wohnungsknappheit, die dazu führt, dass sich informelle Wohnsiedlungen bilden. Dies trifft auch auf die strukturschwachen Grenzregionen rund um Cúcuta, Maicao oder Puerto Santander zu, die nur über wenige Kapazitäten für die Aufnahme venezolanischer Geflüchteter verfügen (vgl. ebd.; CONPES 2018: 61).

Eine Studie des Norwegian Refugee Council, in welcher 1.473 Venezolaner*innen, davon 919 in Kolumbien, befragt wurden, fand heraus, dass 81 Prozent der Familien in einer selbstgemieteten Wohnung in urbanen Räumen untergebracht sind (vgl. CNR 2019: 19-23). Gerade in den großen Städten gibt es zwar mehr Aufnahmekapazitäten und Chancen auf eine Beschäftigung, jedoch siedeln sich hier viele Geflüchtete mangels Alternativen unter prekären Verhältnissen in öffentlichen Räumen oder in den Armutsgürteln der Stadt an (vgl. Weltbank 2018: 65, 109). Dies bestätigte sich auch in den eigens durchgeführten Interviews mit Venezolaner*innen in Bogotá. Paola ${ }^{6}, 18$ Jahre, reiste Anfang 2019 als Minderjährige allein nach Kolumbien und folgte damit ihrem Freund, der kolumbianische Wurzeln hat. Während sie zunächst eine TMF besaß, verfügte sie zum Zeitpunkt des Interviews über keine Aufenthaltserlaubnis: »Als wir in Medellín waren, lebten wir in Santo Domingo. Das ist ein Stadtteil weit oben, weit oben, weit oben. $\aleph^{7}$ (Interview mit Paola) Die Ansiedlung in informellen Wohngegenden ist auf die hohe Nachfrage an Wohnraum, mangelnde Einkünfte sowie auf Diskriminierung im

5 »Ni los ciudadanos colombianos retornados ni los migrantes venezolanos están recibiendo ayuda económica o de albergue temporal en materia de vivienda de parte del gobierno.«

6 Alle Namen wurden anonymisiert.

7 »Estando allá en Medellín, estuvimos en Santo Domingo. Esto es un barrio para arriba, para arriba, para arriba.« 
regulären Wohnungsmarkt zurückzuführen. Daher sehen sich venezolanische Geflüchtete teilweise dazu gezwungen, tageweise Zimmer in illegalen Unterkünften, etwa in Hotels, die von Privatpersonen ohne Genehmigung betrieben werden oder in Wohnungen in Mehrfamilienhäusern, anzumieten. Diese sind sowohl in sanitärer Hinsicht als auch in Bezug auf Sicherheit und Privatsphäre oftmals nicht auf eine große Anzahl von Bewohner*innen und ihren dauerhaften Verbleib ausgelegt (vgl. CNR 2019: 19; CONPES 2018: 59):

»Weil wir dort, wo wir derzeit untergekommen sind in einem, in einem Zimmer leben, verstehst $d u$, weil es verschiedene Arten von Räumen gibt. Aber da wir ein Paar sind, ist das nicht schlimm, verstehst du. Wofür bräuchten wir etwas größeres? Aber dann hat er seinen Sohn hergebracht. Deshalb sind wir zu dritt in einem Zimmer [...] er braucht seine Privatsphäre, verstehst du, wir auch. ${ }^{8}$ (Interview mit Paola)

Häufig sind weder staatliche Akteur*innen noch zivilgesellschaftliche Organisationen die erste Anlaufstelle nach der Einreise, sondern Freunde, Familie oder sogar zufällige Bekanntschaften. Dies sind oftmals nur temporäre Lösungen, so auch bei Victor und Ana. Während sich Victor, 42 Jahre, seit Oktober 2019 in Kolumbien befindet und mit Hilfe des UNHCR einen Asylantrag gestellt hat, verfügt Ana, 50 Jahre und 2018 eigereist, über den PEP:

»Zu dieser Zeit, ich erinnere mich, dass es ein Freitag war, kaufte ich mein Ticket für mittags und kam her. Zufälligerweise traf ich einen jungen Mann, einen kolumbianisch-venezolanischen Jungen, seine Eltern sind Kolumbianer, hier in Bogotá geboren, aber sie sind nach Venezuela ausgewandert bis sie zurückkehrten. Sie kamen über Puerto Ordaz, Venezuela, seine Ceschwister waren schon hier. Und [...] bei ihnen sind wir geblieben, als wir nach Bogotá gekommen sind. Ich bin bei ihnen geblieben, da ich keinen anderen Ort hatte, an den ich gehen konnte. «" (Interview mit Victor)

»Porque ahí donde estamos, nos estamos viviendo en un, en un cuarto, me entiendes, porque hay diferentes tipos de habitaciones. Pero como somos una pareja, ósea que tanto, me entiendes. ¿Total, para qué necesitamos vainas así más grandes? Pero pues se trajo el hijo. Entonces los tres en una habitación [...] él necesita su privacidad, me entiendes, nosotros también.«

9 „En ese momento, un día viernes me recuerdo, compré pasaje para mediodía y me vine. Casualmente me conseguí a un joven, un muchacho colombo-venezolano, de los papas son colombianos nacidos aquí en Bogotá, pero se migraron a Venezuela hasta el momento que venía. Venía desde, ósea por Puerto Ordaz, Venezuela y los hermanos estaban aquí. Y [...] con ellos fue que cuando llegue acá a Bogotá nos quedamos. Me quedé con ellos porque no tenía que a donde llegar.« 
»Nein, die Hilfe, die ich erhalten habe, habe ich erhalten, weil meine Tochter schon hier war. Also blieb ich bei ihr und so. Und sie half mir die ersten Tage, aber jetzt nicht mehr [...]. $\ll^{10}$ (Interview mit Ana)

Viele der Venezolaner*innen in Kolumbien leben in prekären Wohnverhältnissen. Oftmals leben mehrere Familien auf wenig Wohnraum zusammen, nach den Daten des Norwegian Refugee Council durchschnittlich acht Personen in einer Wohnung (vgl. CNR 2019: 23). Die generellen Wohnverhältnisse und die Lokalisierung in den ärmeren Stadtvierteln führen dazu, dass viele venezolanische Geflüchtete multiplen Sicherheitsrisiken ausgesetzt sind:

»Das Schwierigste, was passiert ist, war, dass sie dort, wo ich wohne, einen Jungen getötet haben. Sie haben einen Jungen getötet, einen kolumbianischen Jungen. Ein Venezolaner hat ihn getötet. [...] der Junge, den sie töteten, war der Sohn eines harten Mannes, ein harter Mann bedeutet jemand mit Macht, der in den Drogenhandel verwickelt ist und er, alle Venezolaner die in der Gegend waren, wurden verfolgt. Sie folgten uns. [...] ich weiß nicht mal, wer wen getötet hat oder wer das war, ich weiß es nicht. Ich weiß nicht, wer der eine ist, noch wer der andere ist. Aber sie haben angewiesen, alle, die in der Zone leben, zu verfolgen. « ${ }^{11}$ (Interview mit Ana)

In Bezug auf ihre Wohnsituation in der Peripherie der Städte weisen die venezolanischen Geflüchteten eine große Ähnlichkeit mit den kolumbianischen Desplazados auf. Auch sie werden vor allem in die großen Städte vertrieben, siedeln sich insbesondere in den äußeren Stadtbezirken an und sind extremer Armut und Marginalisierung ausgesetzt. Aus diesem Grund haben sich in den betroffenen Zonen durch den Zuzug venezolanischer Geflüchteter neue Problematiken des Zusammenlebens und eine Konkurrenz um staatliche und nicht-staatliche Hilfen, Arbeit und Wohnraum entwickelt (vgl. Beltrán 2018; Pérez 2018: 153-158; Weltbank 2018: 89).

Doch nicht alle Venezolaner*innen sind in der Lage, eine bezahlbare Unterkunft zu finden. Ein erheblicher Teil - nach Angaben der Weltbank (2018: 60) rund 32 Prozent - lebt daher in öffentlichen Räumen wie Parks oder an großen Straßen und ist auf die Hilfe anderer Personen angewiesen:

10 »No, la ayuda que recibió, la ayuda que yo recibí, porque mi hija ya estaba aquí. Entonces me quedaba ahí y eso. Y me ayudaba pues los primeros días, pero ya no ya [...].«

11 »Lo más difícil que pasó fue que por donde yo vivo mataron un muchacho. Mataron un muchacho, como es, mataron un muchacho colombiano. Lo mató un venezolano. [...] el muchacho que mataron era hijo de un duro, un duro quiere decir un, alguien de poder que anda metido en el narco y él sí, a todos los venezolanos que estábamos por ahí nos perseguían. Nos seguían. [...] no sé ni quién lo mató ni quién lo fue, ni sé. Ni sé quién es uno, ni sé quién es el otro. Pero todos los que vivíamos ahí en la zona nos mandaron a seguir.« 
»Als ich den Essensstand hatte, ein Junge [...] ich half ihm finanziell mit dem Wenigen, das ich verdiente [...]. Er musste, er hatte nicht genug, um seine Miete zu bezahlen, bis er seine Unterkunft räumen musste, da die Frau ihm sagte, dass er ausziehen muss. Und es hat ihn sehr hart getroffen. Dieses Kind hat es hart getroffen. [...]. Und ich musste seine Kleidung bei mir zuhause aufbewahren, dort wo ich zur Miete lebte, und ich musste [...] ihm helfen, finanziell. In dem Sinne, nicht so sehr finanziell, sondern mit Essen, er musste auf der Straße schlafen. ${ }^{12}$ (Interview mit Ana)

Zudem haben sich in einigen Städten informelle Lager venezolanischer Geflüchteter gebildet. $\mathrm{Zu}$ diesen gehören zum Beispiel temporär angelegte Ansiedlungen auf einem Sportplatz in Cúcuta oder ein Zeltlager auf dem Plaza de Bolívar in Bucaramanga, aber auch längerfristige Unterkunftsformen wie eine Blechhaussiedlung, genannt »Villa Caracas«, in Barranquilla. Auch in Bogotá formierte sich im Jahr 2017 ein informelles Lager rund um den Busbahnhof, welches jedoch im November 2018 durch die staatlichen Autoritäten aufgelöst und in einen anderen Stadtteil verlegt wurde (vgl. Bonil 2019: 109; Deutsche Welle 2018). Neben diesen informellen Lagern bemühen sich verschiedene nationale und internationale Akteur*innen wie die katholische Kirche, das Rote Kreuz oder der UNHCR um den Aufbau temporärer Aufnahmemöglichkeiten in den Grenzgebieten. Solche sogenannten Assistenzzentren gibt es beispielsweise in Maicao und in Cúcuta, diese sind jedoch nur auf die Aufnahme von Geflüchteten für wenige Tage ausgelegt (vgl. UNHCR 2019a; El Tiempo 2018).

\section{Zwischen Mobilität und Immobilität: Räumliche Bewegungsfreiheit und strukturelle Einschränkung}

Der kolumbianische Staat war in der Vergangenheit durch die hohe Anzahl intern vertriebener Desplazados und die zahlreichen Kolumbianer*innen, welche ins Ausland abwanderten, dazu gezwungen, sich mit diesen Formen von Mobilität zu beschäftigen. Die genannten Personengruppen weisen jedoch als kolumbianische Staatsbürger*innen eine andere rechtliche Basis als ausländische Migrant*innen auf. Somit beinhalten die als Reaktion auf die beschriebenen Phänomene entstandenen Migrationspolitiken des Landes nur wenige Regulierungen für den Fall einer

12 »Cuando yo tenía el puesto de comida rápida, un muchacho [...], yo le ayudaba económicamente con lo poco que yo hacía [...]. Tuvo que, no le quedaba para pagarle arriendo hasta que tuvo que desalojar el arriendo porque la señora le dijo que se desocupaba pues porque no. Y le tocó muy duro. Ese niño le tocó duro. [...] Y yo le tuve que guardar la ropa en mi casa, donde yo vivía arredrando en ese tiempo y tuve que [...] ayudarlo pues, económicamente. En el sentido, no tanto económicamente, sino con la comida, le tocó dormir en la calle.« 
massiven Zuwanderung aus dem Ausland. Dies trifft auch auf die Bedingungen von Aufnahme und Unterkunft venezolanischer Geflüchteter zu. In Bezug auf ihre Wohnsituation hat dies zur Folge, dass venezolanische Geflüchtete - sowohl mit regulärem als auch mit irregulärem Aufenthalt - selbst für die Art und Weise ihrer Unterbringung verantwortlich sind, was ihnen eine große Freiheit in Bezug auf die Wahl des Aufenthaltsortes einräumt:

»Nun, als ich den Meta [Verwaltungsbezirk im Zentrum Kolumbiens, Anm. d.Verf.] verließ, ging mein Freund nach Bogotá und ich ging nach Bucaramanga, verstehst du. Weil wir dort im Meta schlecht verdienten, verstehst du, uns ging es schlecht und ich musste einige schlechte Arbeiten machen, Saft, Empanadas und solche Dinge verkaufen. Aber es lief nicht gut für uns, was soll ich sagen, das dort ist auf dem Land und sie brauchen nicht viele Menschen dort, wo wir waren. Und er ist hierhergekommen und fand danach eine Arbeit. Ich war dort und habe keine Arbeit gefunden. Dort in Bucaramanga ist es sehr schwer mit der Arbeit, vor allem mit den Venezolanern. Also brachte er mich her und ich kam wieder hierher. Weil wir dort hingingen, wo der erste von uns Arbeit findet, verstehst du. $\ll^{13}$ (Interview mit Paola)

Venezolanischen Geflüchteten wird durch das Erlangen eines Aufenthaltstitels wie der PEP eine Arbeitserlaubnis erteilt, was sie dazu befähigen soll, selbst für ihren Unterhalt aufzukommen. Wie auch in der Aussage von Paola deutlich wird, wird das Problem jedoch grundsätzlich nur verlagert: Während die venezolanischen Geflüchteten zwar nicht gesetzlich darin eingeschränkt sind, wo sie sich aufhalten und wie sie leben, wird die Arbeit und ihre Entlohnung zum bestimmenden Faktor. Gerade die Suche nach einer formellen Beschäftigung stellt sich häufig als äußerst schwierig dar:

»]a, aber hier gibt es, hier einen sicheren Arbeitsplatz zu finden mit allen Vorzügen ist ziemlich schwierig. Es ist nicht leicht. Es ist nicht leicht, weil, erinnere dich, weil schon die Kolumbianer diese Art von Arbeit nicht bekommen, wenn sie nicht eine bestimmte Anzahl von Erfahrungen haben, bestimmte Jahre, Anzahl

13 »Bueno, primero cuando yo salí del Meta, mi marido cogió para ir para Bogotá, y yo cogí para ir para Bucaramanga, entiendes. Porque ahí en el Meta estábamos ganando mal, entiendes, estábamos mal que me tocaban unos trabajos malos, vendiendo jugo, empanadas, y cosas así. Pero no nos iba muy bien, que se diga entonces, como te digo esto allá es campo y no necesitaban mucha gente por donde nosotros estábamos. Y él se vino por acá y después encontró un trabajo. Yo estaba allá y no encontré ningún trabajo. Allá en Bucaramanga la cosa es demasiado pesado con los trabajos, más con los venezolanos pues. Entonces él me trajo para acá y vine para acá otra vez. Porque era donde el que encontraba primero trabajo pues, me entiendes.« 
von Jahren an Erfahrung. Hier gibt es viel Arbeit, aber viel informelle Arbeit. $\ll^{14}$ (Interview mit Victor)

»Nein, eine würdevolle Arbeit, bei der du alle Vorzüge genießen kannst, nein. Nein, es ist sehr schwer, sehr schwer. Ich habe nur Schichten in Restaurants gearbeitet, welche mich heute oder morgen anrufen, was weiß ich. Abgesehen davon, ich habe zumindest eine Schicht in einem Restaurant gearbeitet, ich habe das für eine Woche gemacht und sie haben mir einen Teil nicht bezahlt. « ${ }^{15}$ (Interview mit Ana)

Die mehrheitlich irregulär eingereisten Venezolaner*innen, aber auch jene, die mit regulären Aufenthaltstiteln in Kolumbien sind, gehen mangels Alternativen häufig informellen Beschäftigungen nach. In diesen sind sie schlechten Arbeitsbedingungen und Ausbeutung ausgesetzt. So verdienen mehr als 70 Prozent der Haushalte von Migrant*innen, die sich in den letzten zwei Jahren in Kolumbien niedergelassen haben, weniger als den Mindestlohn. Gleichzeitig erhalten Venezolaner*innen, die informellen Tätigkeiten nachgehen, nur einen stark eingeschränkten oder gar keinen Zugang zum Gesundheits- und Sozialsystem (vgl. CNR 2019: 33; CONPES 2018: 62).

Die genannten Faktoren führen dazu, dass venezolanische Geflüchtete in Kolumbien nur über einen beschränkten Zugang zu grundlegenden Rechten wie Wohnraum, Gesundheit oder Bildung verfügen. Dies ist in großen Teilen auf die mangelnde Überführung der Geflüchteten in reguläre Aufenthaltsformen, die fehlende Bereitstellung von Hilfen in Bezug auf angemessenen Wohnraum und formelle Arbeit sowie fehlende Initiativen zur Unterstützung bei der Integration in die kolumbianische Gesellschaft zurückzuführen. Hierdurch werden Arbeitslosigkeit, Informalität, Ausbeutung und die Diskriminierung und Stigmatisierung der Geflüchteten gefördert (vgl. Ramos et al. 2019: 14). Wenngleich es also keine Regulierungen des kolumbianischen Staates in Bezug auf die Einschränkung des Aufenthaltsortes venezolanischer Geflüchteter oder ihre Unterbringung in Lagerstrukturen, wie dies in vielen europäischen Ländern der Fall ist (vgl. z.B.

14 "Sí, pero, aquí, hay como, aquí conseguir un trabajo estable con todos los beneficios es bastante difícil. No es fácil. No es fácil porque recuérdate que, ya es porque los colombianos no, no obtienen ese tipo de empleos si no tienen cierta cantidad de experiencias, ciertos años, cantidad de años de experiencia. Aquí hay empleo. Aquí hay mucho empleo, pero mucho empleo informal.«

15 »No, trabajo digno que donde tú goces de todos los beneficios no. No, es muy difícil, muy difícil. Yo solo he trabajado por turnos en restaurantes, que me llaman hoy, me llaman mañana, que sé yo. Entonces aparte de eso, por lo menos yo hice un turno en un restaurante, ya lo hice por una semana y quedaron de pagarme una cosa y me salieron con otra.« 
Kreichauf 2018), gibt, so nehmen viele Venezolaner*innen ihre Situation dennoch als alternativlos wahr:

»]a, ja, [Hilfe von] Freunden und Familie. Aber vom Staat, von der Regierung als solche nicht. Und es gibt viel Fremdenfeindlichkeit, weißt du. Zu viel. Zu viel. [...] Ich bekomme nicht mal Arbeit, weil ich nichts mehr bekomme, weil sie keine Venezolaner nehmen. Ich habe sogar darüber nachgedacht zurückzugehen. Ich habe daran gedacht zurückzugehen, weil wenn es mir hier schlecht geht, dann geht es mir doch besser in meinem eigenen Land schlecht. Ich sage [...], man ist wie zwischen zwei Wänden. Weil wenn ich gehe, ist es schlimmer, wenn ich bleibe, naja, dann muss ich es aushalten. ${ }^{16}$ (Interview mit Ana)

Die häufig unerfüllten Erwartungen der Geflüchteten an die Lebensumstände in Kolumbien und die Rolle des kolumbianischen Staates werden zudem durch das vom sozialistischen System geprägte Leben in Venezuela beeinflusst:

»Ich sagte: >Nein, ich muss arbeiten, ich muss Geld verdienen<. Und ich sagte: >Etwas Geld und in ungefähr drei Monaten gehe ich<. Aber nein, es ist nicht so einfach. Es ist nicht einfach zu sparen. Man hat nicht so viel Geld, weil man die Miete bezahlen muss. Man muss verstehen, dass es nicht so ist wie in Venezuela. ${ }^{17}$ (Interview mit Paola)

Auch in Kolumbien befinden sich Geflüchtete daher in einer, wie Turner (2015: 142) in Bezug auf das Lager beschreibt, paradoxen Situation zwischen dem UnterwegsSein und der Unmöglichkeit unterwegs zu sein. Wenngleich die venezolanischen Geflüchteten nicht durch Wohnsitzauflagen oder andere Aufenthaltsbeschränkungen in ihrer Mobilität innerhalb Kolumbiens eingeschränkt werden, so wirkt sich die kolumbianische Migrationspolitik in ähnlicher Weise auf die Selbstbestimmtheit der Geflüchteten aus. Diese sieht zwar den Zugang von venezolanischen Geflüchteten zum kolumbianischen Staatsgebiet vor, ermöglicht gleichzeitig jedoch nur wenige Möglichkeiten zur Integration in die Gesellschaft und bestärkt indirekte Einschränkungen.

16 „Sí, sí, [ayuda de] amigos y familiares. Pero así del Estado, del gobierno como tal no. Y hay mucha xenofobia, sabes. Demasiada. Demasiada. [...] Ya ni consigo trabajo, porque ya no consigo nada porque no aceptan los venezolanos. He pensado hasta regresarme. He pensado hasta regresarme porque si la estoy pasando mal aquí, mejor la paso mal en mi país. Digo yo. [...] ósea uno está como que entre la pared y la pared. Porque si me voy es peor, si me quedo, bueno, tengo que aguantar.«

17 „Bueno, lo que, como viste, la idea con la que me vine fue trabajar. Yo dije: ^No, tengo que trabajar. Hacer la plata<. Y yo dije: >Trabajo, hago la plata y en unos tres meses me voy<. Pero no, no es fácil. No es fácil ahorrar. Uno no tiene tanta plata porque uno tiene que pagar el arriendo. Uno tiene que entender que no es como Venezuela.» 


\section{Schlussbetrachtung}

Menschen, die aus ihren Heimatländern vertrieben werden, sind auf die Aufnahmebereitschaft anderer Staaten angewiesen. Dabei sind es die Migrations- und Asylpolitiken dieser Staaten, die darüber bestimmen, wie die Aufnahme und Unterbringung konkret aussieht. So werden die Geflüchteten bei der Unterbringung in Lagern in einigen Teilen der Welt erheblich in ihrer Mobilität begrenzt. Dabei kann das Beispiel geflüchteter Venezolaner*innen in Kolumbien wichtige Hinweise darauf geben, dass eine Einschränkung von Mobilität nicht immer in Form von Lagerstrukturen oder Wohnsitzauflagen vorliegen muss, sondern durch andere Gegebenheiten, die nicht direkt mit dem Themenbereich der Unterbringung verbunden sind, verursacht werden kann. Hierzu zählt in Kolumbien vor allem der mangelnde Zugang zu einer formellen Beschäftigung, welcher aufgrund fehlender finanzieller Unterstützung entscheidend für die Sicherung des Lebensunterhalts und somit einer der wichtigsten Faktoren für den Aufenthaltsort und die Wohnsituation ist. Dabei ist der Zugang zu Arbeit sowohl für Venezolaner*innen mit regulärem Aufenthaltsstatus als auch für jene ohne Aufenthaltstitel eingeschränkt. Erschwerend wirkt, dass Venezolaner*innen trotz der nicht vorhandenen Sprachbarriere gerade in den Bereichen Arbeit und Unterbringung häufig Diskriminierung und Stigmatisierungen ausgesetzt sind.

Zurückzuführen sind diese Hindernisse zum einen auf strukturelle Gegebenheiten in Kolumbien, wie zum Beispiel die ungleiche Ressourcenverteilung, der unterschiedliche Zugang zu Bildung, Arbeit und Gesundheit und die mangelnde politische Teilhabe, wobei diese Einschränkungen Armut, Ungleichheit und die Marginalisierung einiger Bevölkerungsteile zur Folge haben. Zum anderen war die kolumbianische Migrationspolitik kaum auf die hohe Anzahl venezolanischer Geflüchteter vorbereitet und die Regierung erwies sich - insbesondere vor dem Hintergrund der komplexen Situation im Land nach dem Friedensabkommen als überfordert. Denn trotz des Friedensschlusses sind auch zahlreiche Kolumbianer*innen noch immer Gewalt und Armut ausgesetzt. Zwar hat das Land bereits Erfahrungen mit der großflächigen Mobilisierung eigener Bevölkerungsteile im Rahmen des bewaffneten Konflikts gemacht, jedoch wurde mit Blick auf die migrationspolitischen Entscheidungen der jüngsten Vergangenheit offenbar kaum aus vergangenen Erfahrungen gelernt, sodass sich viele Venezolaner*innen in einer ähnlich prekären Situation wie die Desplazados befinden. Getroffene Maßnahmen zur Aufnahme und Unterbringung, wie beispielsweise die Einführung von PEP und TMF, ermöglichten den Geflüchteten teilweise einen regulären Aufenthalt, waren allerdings nicht darauf ausgerichtet, bestehenden strukturellen Einschränkungen dauerhaft bzw. nachhaltig entgegenzuwirken. Somit sind venezolanische Geflüchtete nach ihrer Ankunft in Kolumbien weitestgehend auf sich selbst gestellt. Sie sind durch den verwehrten Zugang zu regulärer Arbeit und die fehlen- 
de Grundsicherung in sozialer Hinsicht immobilisiert, wenngleich sie sich räumlich frei bewegen können. Dies wird insbesondere auch in der derzeitigen CoronaPandemie deutlich: Zahlreiche Venezolaner*innen begeben sich aufgrund der drastischen Verschlechterung ihrer Lebenssituation in Kolumbien zu Fuß auf den Rückweg nach Venezuela (vgl. Reith 2020: 3).

\section{Literaturverzeichnis}

Álvarez de Flores, Raquel (2004): »La dinámica migratoria colombo-venezolana: Evolución y perspectiva actual«, in: Geoenseñanza 9(2), S. 191-202.

Álvarez de Flores, Raquel (2009): »Refugiados entre fronteras: La nueva realidad migratoria colombo-venezolana«, in: Observatorio Laboral Revista Venezolana 2(4), S. 49-65.

Beltrán, Rodolfo (2018): La vivienda y la migración venezolana, un tema pendiente, in: Semana vom 30.07.2018, https://www.semana.com/contenidoseditoriales/la-vida-se-construye/la-vivienda-y-la-migracion-venezolana-untema-pendiente/577195, Abrufdatum: 20.04.2020.

Bonil, Alejandro (2019): »Análisis de política pública de recepción de venezolanos en Colombia«, in: Alexandra Castro Franco (Hg.), Venezuela migra: aspectos sensibles del éxodo hacia Colombia (=Temas de Derecho Internacional Público Nr. 1), Bogotá: Universidad Externado de Colombia, S. 87-122.

Castro Franco, Alexandra (2016): Inmigración en Colombia: Hacia una gestión migratoria coherente, https://www.academia.edu/27633030/INMIGRACION_ EN_COLOMBIA_HACIA_UNA_GESTION_MIGRATORIA_COHERENTE_1, Abrufdatum: 20.04.2020.

[CNMH] Centro Nacional de Memoria Histórica (2015): Una nación desplazada. Informe nacional del desplazamiento forzado en Colombia, Bogotá: $\mathrm{CNMH}-$ UARIV.

[CNR] Consejo Noruego para Refugiados (2019): Identificación de necesidades de protección de la población venezolana en el territorio colombiano y otros países de acogida, von 04/2019, https://www.refworld.org.es/docid/5e5450b4a.html, Abrufdatum: 20.04.2020.

[CONPES] Consejo Nacional de Política Económica y Social (2018): Documento CONPES 3950. Estrategia para la atención de la migración desde Venezuela, Bogotá: CONPES.

[CODHES] Consultoría para los Derechos Humanos y Desplazamiento (2018): $\mathrm{Ne}$ cesidades de protección de las personas venezolanas forzadas a migrar, refugiadas y en riesgo de apatridia en Colombia, Informe país como aporte a la audiencia temática 168 período de sesiones de la Comisión Interamericana de derechos humanos (CIDH) en república dominicana, Bogotá: CODHES. 
Cornelius, Wayne/Rosenblum, Marc (2005): »Immigration and Politics«, in: Annual Review of Political Science 8, S. 99-119.

Curcio, Carmen-Lucía/Hoover Vanegas, José/Palacio, María/Corchuelo Ojeda, Jairo (2019): »Elderly and forced displacement in Colombia«, in: Colombia Médica $50(2)$, S. 52-66.

Deutsche Welle (2018): Campamento humanitario de venezolanos en Bogotá, vom 21.11.2018, https://www.dw.com/es/campamento-humanitario-de-venezolano s-en-bogotá/g-46391531, Abrufdatum: 20.04.2020.

El Espectador (2020): Atención venezolanos: estos son los nuevos términos del Permiso Especial de Permanencia (PEP), vom 30.01.2020, https://www. elespectador.com/noticias/el-mundo/atencion-venezolanos-este-son-losnuevos-terminos-del-permiso-especial-de-permanencia-pep-articulo-902277, Abrufdatum: 20.04.2020.

El Tiempo (2018): Así se vive en el primer hogar de paso para venezolanos en la frontera, 04.02.2018, https://www.eltiempo.com/colombia/otras-ciudades/asi-fun ciona-el-primer-hogar-de-paso-en-la-frontera-con-venezuela-178770, Abrufdatum: 20.04.2020).

[FIP] Fundación Ideas para la Paz (2018): Seguridad ciudadana y migración venezolana. Análisis exploratorio, Bogotá: FIP.

Freier, Luisa/Parent, Nicolas (2019): »The regional response to the Venezuelan Exodus«, in: Current History 118, S. 56-61.

FitzGerald, David Scott/Arar, Rawan (2018): »The sociology of refugee migration«, in: Annual Review of Sociology 44, S. 387-406.

Glick Schiller, Nina/Salazar, Noel (2012): »Regimes of Mobility across the globe«, in: Journal of Ethnic and Migration Studies 39, S. 1-18.

Hernández Sabogal, Myriam (2017): »Gewaltsame Vertreibung in Kolumbien - eine Geschichte der Ausgrenzung«, in: Perspectivas. Politische Analysen und Kommentare 3, Kommen, Gehen, Bleiben, Weiterziehen. Facetten der Migration in Lateinamerika, Berlin: Heinrich Böll Stiftung, S. 16-20.

[HRW] Human Rights Watch (2018): The Venezuelan exodus. The need for international protection and the region's response to an unprecedented migration crisis, USA: Human Rights Watch.

Huang, Cindy/Gough, Kate (2018): The Venezuelan Migrant Crisis: Forging a Model for Regional Response, CGD Note 08/2018, Center for Global Development.

Ibañez, Ana/Moya, Andrés (2007): La población desplazada en Colombia: Examen de sus condiciones socioeconómicas y análisis de las políticas actuales, Bogotá: Departamento Nacional de Planeación.

[IACHR] Inter-American Commission on Human Rights (2017): Democratic Institutions, the Rule of Law and Human Rights in Venezuela. Country Report 2017, Washington: IACHR. 
[IOM] International Organization for Migration (2020): Profile of Venezuelan Refguees and Migrants in Latin America \& the Caribbean Reveals Country-to-Country Variations in their Characteristics and Experiences, vom 27.08.2020, https:/www.iom.int/news/profile-venezuelan-refugees-an d-migrants-latin-america-caribbean-reveals-country-country, Aubrufdatum: 09.09.2020.

Juliao Vargas, Clara (2011): »Los desplazados en Bogotá y Soacha: características y protección«, in: Revista Paz y Conflictos 4, S. 1-19.

Kreichauf, René (2018): »From forced migration to forced arrival: the campization of refugee accommodation in European cities «, in: Comparative Migration Studies 6(7), https://doi.org/10.1186/s40878-017-0069-8.

Louis, Tatjana (2018): " Wir sind vertrieben, ohne es zu wissen . Narrative Konstruktionen zu Binnenmigration und Binnenvertreibung in Kolumbien«, in: Simon Goebel/Thomas Fischer/Friedrich Kießling/Angela Treiber (Hg.), FluchtMigration und gesellschaftliche Transformationsprozesse. Transdisziplinäre Perspektiven, Wiesbaden: Springer VS, S. 61-84.

Maldonado Valera, Carlos/Martínez Pizarro, Jorge/Martínez, Rodrigo (2018): Protección social y migración. Una mirada desde las vulnerabilidades a lo largo del ciclo de la migración y de la vida de las personas, Santiago de Chile: CEPAL.

Márquez Restrepo, Martha (2019): »Relaciones bilaterales entre Colombia y Venezuela ante la crisis y el posacuerdo.«, in: Eduardo Pastrana Buelvas/Hubert Gehring (Hg.), La crisis venezolana: impactos y desafíos, Bogotá: Fundación Konrad Andenauer, S. 493-512.

Mazuera-Arias, Rina/Albornoz-Arias, Neida/Morffe Peraza, Miguel/RamírezMartínez, Carolina/Carreño-Paredes, Myrian-Teresa (2019): Informe sobre la movilidad humana venezolana II. Realidades y perspectivas de quienes emigran (8 de abril al 5 de mayo de 2019), San Cristobal: SJR.

Migración Colombia (2020): Más de un millón 825 mil venezolanos estarían radicados en Colombia, vom 03.04.2020, https:/www.migracioncolombia.go $\mathrm{v} . \mathrm{co} /$ noticias/265-abril-2020/mas-de-1-millon-825-mil-venezolanos-estarianradicados-en-colombia, Abrufdatum: 20.04.2020.

Mijares, Victor (2014): »Proteste in Venezuela und die Krise des Chavismus«, in: Giga Fokus Latin America 2, German Institute of Global and Area Studies.

Mijares, Victor/Rojas Silva, Nastassja (2018): »Venezuelan Migration Crisis puts the region's democratic governability at risk«, in: Giga Fokus Latin America 6, German Institute of Global and Area Studies.

Ocampo Prado, Myriam/Martínez Carpeta, Mábel/Zuluaga Tapia, Sandra (2015): "Del campo a la periferia de la ciudad, la omnipresente sombra de la violencia. Campesinos desplazados forzados en Colombia caminan de la mano del eterno retorno a la violencia: vulneración y potencia de vida«, in: Psicología USP 26(2), S. 161-168. 
Otero Prada, Diego (2014): Situación social, económica y política de Venezuela. Documentos de investigación, Bucaramanga: Centro de Estudios Latinoamericanos, Cooperación Universitaria de Ciencia y Desarrollo.

Palacios Sanabria, María/Lodoño Toro, Beatriz/Lozano Amaya, Alejandra (2019): »Nuevas realidades de los flujos migratorios hacia Colombia«, in: María Palacios Sanabria/Beatriz Lodoño Toro (Hg.), Migración y derechos humanos: El caso colombiano. 2014-2018, Bogotá: Editorial Universidad del Rosario, S. 11-53.

Presidencia de la República (2018): »Palabras del Presidente Iván Duque en la reunión de alto nivel >Refugiados y migrantes de Venezuela: Hacia una respuesta regional« vom 25.09.2018, https://id.presidencia.gov.co/Paginas/ prensa/2018/180925-Palabras-Presidente-Ivan-Duque-reunion-alto-nivelRefugiados-y-migrantes-de-Venezuela-Hacia-una-respuesta-regional.aspx, Abrufdatum: 20.04.2020.

Pérez Fonseca, Andrea (2018): »Las periferias en disputa. Procesos de poblamiento urbano popular en Medellín«, in: Estudios Políticos 54, S. 148-170.

Ramos, Francesca/Rodríguez, Ronal/Robayo, María (2018): Retos y oportunidades de la movilidad humana venezolana en la construcción de una política migratoria venezolana, Bogotá: Konrad Adenauer Stiftung/Universidad del Rosario.

Ramos, Francesca/Rodríguez, Ronal/Robayo, María (2019): Las migraciones en el contexto colombo-venezolano, Bogotá: Fundación Konrad Adenauer/Universidad del Rosario.

Ramsey, Geoff/Sánchez-Garzoli, Gimena (2018): Responding to an exodus. Venezuela's migration and refugee crisis as seen from the Colombian and Brazilian borders, Research Report, WOLA Advocacy for Human Rights in the Americas.

Reith, Stefan (2020): Krisencocktail in Kolumbien. Covid-19 stürzt venezolanische Migranten in ausweglose Lage, Länderbericht vom 11.06.2020, KonradAdenauer-Stiftung.

Rendon, Moises/Schneider, Mark (2018): Venezuela's crisis is now a regional humanitarian disaster. A comprehensive framework for the United States, regional countries and the international community to address Venezuela's growing humanitarian crisis, CSIS Briefs, Washington: Center for Strategic and International Studies.

Rodríguez, Ronal/Ramos, Francesca (2019): „Colombia de cara a los desafíos y oportunidades que representa la migración venezolana«, in: Eduardo Pastrana Buelvas/Hubert Gehring (Hg.), La crisis venezolana: impactos y desafíos, Bogotá: Konrad Adenauer Stiftung, S. 547-577.

[R4V] Respuesta a los Venezolanos (2020): Reporte Situacional Febrero 2020 Colombia, https://reliefweb.int/report/colombia/colombia-situation-report-fe bruary-2020, Abrufdatum: 20.04.2020. 
Turner, Simon (2015): What is a refugee camp? Explorations of the limits and effects of the camp«, in: Journal of Refguee Studies 29(2), S. 139-148.

[UNHCR] United Nations High Commissioner for Refugees (2019a): ACNUR abre un centro de recepción cerca de la frontera de Colombia para ayudar a los venezolanos vulnerables, vom 08.03.2019, https:/www.acnur.org/noticias/ briefing/2019/3/5c82b8b84/acnur-ab...un-centro-de-recepcion-cerca-de-lafrontera-de-colombia-para.html, Abrufdatum 20.04.2020.

[UNHCR] United Nations High Commissioner for Refugees (2019b): Global Trends Forced Displacement 2018, Genf: UNHCR.

Weltbank (2018): Migración desde Venezuela a Colombia. Impactos y estrategia de respuesta en el corto y mediano plazo, Washington: Banco Mundial.

Zilla, Claudia (2019): Venezuela, die Region und die Welt: Stationen für einen möglichen Ausweg aus der Krise, SWP-Aktuell 14, Stiftung Politik und Wissenschaft.

\section{Interviews}

Interview mit Ana, geführt am 22.01.2020 in Bogotá.

Interview mit Paola, geführt am 19.01.2020 in Bogotá.

Interview mit Victor, geführt am 09.02.2020 in Bogotá. 
Medien und Öffentlichkeit 



\section{Komplizen des Asylregimes? \\ Historische Medieninfrastrukturen in Flüchtlingslagern und Asylunterkünften}

Philipp Seuferling

\section{Zusammenfassung}

Medientechnologien sind essentielle Bestandteile von Flucht- und Lagererfahrungen. Medien bilden infrastrukturelle Umgebungen, in denen Geflüchtete sowie Verwaltungen das Asylregime realisieren und ihm gleichzeitig ausgeliefert sind. Der vorliegende Beitrag geht der Frage nach, welche Rolle solche Medieninfrastrukturen in Lagern und Asylunterkünften historisch gespielt haben. Digitalisierte Verfahren in Asylregimen und Lagerverwaltung sowie die Bedeutung von WLAN für Geflüchtete haben historische Vorgänger. Diesen Spuren geht dieser Beitrag aus der Perspektive eines kritischen Infrastruktur-Ansatzes nach und erfragt, wie Medientechnologien die Kommunikation im Raum des Lagers formen und beeinträchtigen. Die Analyse von historischem Archivmaterial aus Lagern und Asylunterkünften in Deutschland zwischen 1945 und den 1990er Jahren historisiert diese Fragestellung und zeigt Cenealogien von Medieninfrastrukturen in vordigitalen Lagerkontexten auf. Archivdokumente geben Einblick in die materielle und soziale Konstruktion von Lagerräumen durch Medien. Die Analyse beleuchtet drei Dimensionen von Medieninfrastrukturen: (1) Architektur und materielle Raumkonstruktion als Grundlage für Kommunikationsräume, in die Medien eingebettet sind; (2) medientechnologische Ausstattung im Lager und die Kontrolle über deren Nutzung; und (3) Medientechnologien, die zur Umsetzung und Verwaltung des Asylregimes im Lager eingesetzt wurden. Dieser Querschnitt durch Medieninfrastrukturen in historischen Lagern zeigt auf, wie Vorstellungen, Diskurse und Praktiken von »Fluchtmanagement «sowie Mediennutzung durch Lagerbewohner*innen zu einer Verflechtung von Medien mit dem Asylregime geführt haben. Medieninfrastrukturen sind eingebettet und ermöglichen Migrationsinfrastrukturen und werden zu Komplizen der Immobilisierung und des Asylregimes. Die historisierende Perspektive macht so deutlich, wie heutige Medien- und Migrationsinfrastrukturen ältere Praktiken der Kontrolle, Überwachung, Registrierung und Kategorisierung gleichzeitig ersetzen und fortsetzen. 


\section{Summary}

Media technologies are essential components of refugee and camp experiences. Media forms infrastructural environments, in which forced migrants as well as authorities simultaneously realise the refugee regime while being dependent on it. This chapter investigates the historical role of such media infrastructures in camps and asylum-seeker shelters. Digitised processes of refugee and camp administration, as well as the meaning of Wi-Fi for forced migrants have historical predecessors. This chapter traces these roots from a critical approach to infrastructures, questioning how media technologies have shaped and affected communication in camp spaces. The analysis of archive material from camps and shelters in Cermany between 1945 and the 1990 s historicises this inquiry and outlines genealogies of media infrastructures in pre-digital camp contexts. Archival records provide insight into the material and social construction of camp spaces through media. The analysis approaches three dimensions of media infrastructures: (1) architecture and material construction of camp space, forming a basis for communication spaces and media to be embedded in; (2) hardware of media technologies in camps and control of provided media and their uses; and (3) media technologies used for the implementation and administration of refugee regimes in the camp. This cross section of media infrastructures in historical camps demonstrates how the imaginaries, discourses and practices of managing refugees, as well as the media practices of camp inhabitants have led to an interrelationship of media with the asylum regime. Media infrastructures are integrated and enable migration infrastructures. They become accomplices of immobilisation processes and of the refugee regime. The historicising perspective ultimately emphasises how contemporary media and migration infrastructures both replace and pursue older practices of control, surveillance, registration and categorisation.

\section{Medien im Lager}

Die Digitalisierung hat für die Gestaltung und Umsetzung von Asylregimen neue Medientechnologien hervorgebracht, die Infrastrukturen in Lagern und die Erfahrungen der Bewohner*innen entscheidend mitformen. Ob Iris-Scans oder Fingerabdrücke zur Bezahlung, Bitcoins als Lagerwährungen oder algorithmisierte und KI-basierte Verfahren von Asylmanagement und Grenztechnologien (vgl. Macias 2020; Metcalfe/Dencik 2019): Bewohner*innen von riesigen Lagern im globalen Süden, sowie in Asyleinrichtungen im globalen Norden, sind abhängig von dieser Vielfalt an Medientechnologien. Abhängigkeit entsteht einerseits dadurch, dass die Medien des Lagers und die Technologien des Asylregimes unumgänglich und nicht 
optional sind; andererseits sind Geflüchtete auch bei ihren eigenen Kommunikationsbedürfnissen und -praktiken den vorhandenen Medientechnologien ausgeliefert. Erfahrungen von »information precarity« (Wall/Campbell/Janbek 2017: 240) prägen das Lagerleben und Geflüchtete sind durch mangelnden Zugang zu Informationsmedien und Kommunikationsmöglichkeiten oft sozial blockiert. Aktivistische Eingriffe wie freies WLAN in deutschen Asylunterkünften als »humanitarian media interventions" (Kubitschko/Schütz 2016: 1) achten und fordern diese grundlegende, infrastrukturelle Bedeutung von Medien und Kommunikation für Geflüchtete.

Doch die infrastrukturellen Medienpraktiken des Asylregimes - Disziplinierung, Einordnung, Kategorisierung und Kontrolle mithilfe von Medientechnologien -, genauso wie die Mediennutzung der Lagerbewohner*innen sind weder neu noch an Digitalisierung gebunden. Vorstellungen, Diskurse und Praktiken von Fluchtmanagement sowie Mediennutzung von Geflüchteten lassen sich zurückverfolgen und verweisen auf Verflechtungen der Genealogien von Medientechnologien und Asylregimen. Medien sind tief eingebettet in Geschichten und Erfahrungen von Immobilisierung, Lagerunterbringung und Migrationsverwaltung. Diesen Spuren geht dieser Beitrag nach. Er wirft die Frage auf, welche Rolle Medien als Infrastrukturen, als sozial geformte Technologien und Kommunikationspraktiken, im Kontext von Lagern und deren Funktionsweisen historisch gespielt haben.

Lager sind als sozial und materiell konstruierte Räume Werkzeuge und Institutionen des modernen Asylregimes. Entstanden und formalisiert im 20. Jahrhundert, vor allem nach dem Zweiten Weltkrieg, hat das Asylregime je nach Kontext Dutzende Begriffe für diese Räume geprägt (siehe Bispinck/Hochmuth 2014; Gatrell 2013: 2). Da in diesem Beitrag der Raum des Lagers und nicht spezielle Gruppen im Fokus stehen, werden hier unter den Begriffsfamilien "Lager« und »Geflüchtete«sämtliche verschiedene Gruppen, Labelings, und Institutionsformen zur organisierten Unterbringung von Zwangsmigrant*innen in Deutschland nach 1945 verstanden. Sie alle eint die räumliche und institutionelle Verbindung von humanitärer Hilfe und sozialer Kontrolle und Ausschluss (siehe Agier 2011; Agamben 2000).

In der Konstruktion solcher Räume sind Medien zentrale Bestandteile. Als Technologien zur Speicherung, Austausch und Zirkulation von Informationen und Bedeutungen nehmen Medien infrastrukturelle Bedeutung für die Erfahrungsumgebung der Lagerbewohner*innen an. Ziel dieses Beitrags ist es, solche Medieninfrastrukturen im Raum des Lagers $\mathrm{zu}$ beschreiben, $\mathrm{zu}$ verstehen und $\mathrm{zu}$ historisieren - aus Sicht der Bewohner*innen sowie aus Sicht der Akteur*innen, die Lager verwalten, strukturieren und das Asylregime in ihnen umsetzen. Der Begriff Infrastruktur bietet hier ein Prisma, das die Schnittstelle von materiell und sozial konstruierten Umgebungen analytisch greifbar macht. Klassische Beispiele sind Straßen, Kanalisationen, oder Kabel - materielle Anordnungen, 
fast unsichtbare Substrate der Gesellschaft, die Sozialitäten möglich machen. In diesem Sinne fassen Medieninfrastrukturen als "situated sociotechnical systems« (Parks/Starosielski 2015: 4) die materiellen Grundlagen für Kommunikation für die Verteilung von Information in Zeit und Raum. Die Entwicklung von infrastrukturellen Technologien folgt oft historischen Pfadabhängigkeiten: Genauso wie Internet- und Telefonkabel oft entlang älterer Zuggleise verlaufen, ersetzen digitale Asyl- und Grenztechnologien Praktiken von Fluchtmanagement durch Papier und Druck (Karteiakten, Laufscheine oder Ausweise). Medien entwickeln sich in historischen Schichten, Genealogien und Remediationen fort: Technologien und Praktiken werden nicht (nur) ersetzt, sondern immer auch fortgesetzt auf älteren Unterlagen (vgl. Bolter/Grusin 2000; Bowker/Star 1999).

Der vorliegende Beitrag nimmt diese theoretischen Überlegungen zum Ausgangspunkt, um historische Medieninfrastrukturen in Lagern und Asylsammelunterkünften zu beschreiben. Die Analyse fußt auf Archivmaterial aus Deutschlands Nachkriegszeit bis zur Jahrtausendwende. ${ }^{1}$ Dieser Zeitraum ist vom globalen Asylregime nach dem Zweiten Weltkrieg geprägt, welches sich in vordigitalen Medienumgebungen weiterentwickelt hat. Ziel einer (medien-)infrastrukturalistischen Perspektive (vgl. Peters 2015) ist es, das »Unsichtbare« sichtbar zu machen, und die Konstruktionsprozesse von unterliegenden Strukturen freizulegen und $\mathrm{zu}$ politisieren. Im Sinne der »infrastructural inversion« (Bowker/Star 1999: 34) werden daher vignettenartig verschiedene Beispiele von Medieninfrastrukturen beleuchtet, sowie Bedeutungslinien und Funktionen aufgezeigt, die Medien in Flüchtlingsunterkünften haben und hatten. Nach einer weiteren theoretischen Erläuterung werden diese in einem analytischen Abschnitt auf drei Dimensionen heruntergebrochen: Architektur und Aufbau des Lagers ${ }^{2}$, medientechnologische Ausstattung dieser Räume, und Nutzung von Medien zur Umsetzung des Asylregimes. Anhand dieser Ebenen zeigen sich historische Verflechtungen von Lagern, Asylregimen und Medieninfrastrukturen: eine Komplizenschaft von Medien- und Migrationsinfrastrukturen, die im abschließenden Abschnitt diskutiert werden.

\section{Medieninfrastrukturen als theoretische Perspektive}

Als Instrument des Asylregimes ist das Lager eine infrastrukturelle Assemblage, ein Arrangement von Technologien und Dingen mit unterliegenden Rationalitäten, nämlich der Behausung und Kontrolle von Menschen in Zeit und Raum. Der

\footnotetext{
1 Das Material stammt aus meinem laufenden Dissertationsprojekt über Medienpraktiken in Lagern und Unterkünften für Geflüchtete zwischen 1945 und 2000. 
Begriff Infrastruktur, entwickelt in ethnographischer und anthropologischer Forschung im Bereich der Science and Technology Studies, aber auch in den Medienund Kommunikationswissenschaften, umfasst grundlegend "matter that enable the movement of other matter « (Larkin 2013: 329). Unabhängig davon, ob es sich um Dinge, Ideen, kommunizierte Inhalte oder Personen handelt, sind Infrastrukturen Netzwerke und Systeme, gleichzeitig Gegenstände und soziale Relationen, die sich in situ durch Praktiken realisieren (vgl. Star/Ruhleder 1996: 112). Straßen ermöglichen Verkehr und Mobilität, Kabel oder Papier ermöglichen Kommunikation und Zirkulation von Wissen - beide Beispiele sind grundlegend für Sozialitäten in Gesellschaften. Dadurch sind Infrastrukturen Substrate, die unsere Wahrnehmungen und Einbettung in soziale Umwelten definieren und formen - ein zutiefst politischer Vorgang. Technopolitiken beeinflussen, wie Materialität Dinge und Personen in Relationen bringen (oder nicht), sowie mobilisieren und immobilisieren. Wie Ressourcen verteilt werden und unsere Welt geformt wird, übt daher Macht aus (vgl. Larkin 2013). Als Schnittstelle zwischen Struktur und Agency konditionieren somit Infrastrukturen Gouvernementalität und biopolitische Macht, und verhandeln Zugehörigkeiten: kulturelle, soziale und administrative Praktiken siedeln genau an dieser Verflechtung von Materiellem und Sozialem an (vgl. von Schnitzler 2008).

Auch Medien können als elementare Umgebungen begriffen werden, die unsere Wahrnehmung der Welt strukturieren (vgl. Peters 2015). Ein solcher infrastrukturalistischer Blick auf Medien rückt unterliegende materielle Strukturen ins Zentrum, die soziale Praktiken von medienvermittelter Kommunikation ermöglichen, formen und bedingen. Dieser theoretische Ansatz wurzelt sowohl in deutschsprachiger als auch in kanadischer Medientheorie ${ }^{3}$ und stützt empirische Studien zu Medieninfrastrukturen und deren Erfahrungen in verschiedenen Räumen, wie Städten, Dörfern oder Klassenzimmern (vgl. Forsler 2020; Mattern 2017; Parks/Starosielski 2015). Parks und Starosielski bieten eine umfassende Definition für den Begriff und sehen

»sites such as data centers, mobile-telephone towers, and undersea cables as media infrastructures - situated sociotechnical systems that are designed and configured to support the distribution of audio visual signal traffic. Media infrastructures are concentrated in particular locations and spread across vast distances. They are highly automated, relying on sensors and remote control, and require human labor for their design, installation, maintenance, and operation [...] Media infrastructures are material forms as well as discursive constructions. hard Siegert oder Cornelia Vismann. In McLuhans berühmtem Satz »The medium is the message. verbirgt sich die Annahme, dass technische Formen von Medientechnologien deren Nutzungsmöglichkeiten und kulturelle Einflussnahmen bedingen. 
They are owned by public entities and private companies and are the products of design schemes, regulatory policies, collective imaginaries, and repetitive use. Interwoven within political-economic agendas, media infrastructures have historically been used in efforts to claim and reorganize territories and temporal relations.«(Parks/Starosielski 2015: 4f.)

Diese Perspektive greift oben genannte Charakteristiken eines InfrastrukturAnsatzes auf und stellt Technopolitiken von Medientechnologien unter Einbezug verschiedener Akteur*innen und Ebenen ins Zentrum. Dadurch sind für eine Analyse sowohl Prozesse und Materialitäten von Verteilung, Planung, Herstellung und Arbeit mit Medien als auch Beziehungen von technologischen Kompetenzen und öffentlicher Teilhabe in Regulierung, Entwicklung und Nutzung von Interesse. Mattern weist hierbei auf die tiefen Historizitäten von Medieninfrastrukturen hin, die sich als Schichten, Überbleibsel und Pfadabhängigkeiten historisch bedingen, ersetzen und fortsetzen: als "modes and ideologies and aesthetics of operation « (Mattern 2015: 96). Historisierende Erforschung von Medieninfrastrukturen deckt so Zusammenhänge von Praktiken und Infrastrukturen auf und geht der Frage nach, wie Medientechnologien über Zeiträume hinweg bestimmte Kommunikationsformen ermöglicht oder verhindert haben. Medieninfrastukturen bilden hier »Konstellationen« von Institutionen und Praktiken von Nutzer*innen:

»It is important to recognize the codependency, the intertwining of these various entities and systems - the telegraph and the telephone, the railroad and the telegraph, transportation infrastructures and the postal system, print and writing infrastructures, writing and oral address, architecture and inscription, and various social and regulatory systems - and perhaps write their histories together.« (Ebd.: 104)

In diesem Sinne erfassen Medieninfrastrukturen in Lagern verschiedene Ebenen: sie entstehen in den Kommunikationsumgebungen, geschaffen durch den architektonischen Aufbau von Lagern, sowie in der Zusammensetzung von vorhandenen Medientechnologien und den alltäglichen Praktiken von Verwaltung, Bewohner*innen und anderen involvierten Personen (z.B. Aktivist*innen oder freiwillige Helfer*innen). Mithilfe eines solchen kritischen infrastrukturellen Blicks auf Medien sowie Lager entsteht nun ein hilfreiches Vokabular, um die Rolle von Medieninfrastrukturen in Unterkünften historisch zu analysieren. Welche Materialitäten und Technologien form(t)en Medieninfrastrukturen in Lagern? Welche Technopolitiken werden durch Medieninfrastrukturen im Lager realisiert? Wie sind Medientechnologien infrastrukturell mit dem Asylregime und Praktiken von Immobilisierung verflochten?

Im folgenden Abschnitt werden diese Ausgangsfragen entlang dreier Dimensionen von Medieninfrastrukturen im Lager diskutiert. Die Analyse setzt erstens 
auf der Ebene von Architektur an, die Medien- und Kommunikationsräume konstruiert. Darauf folgen zweitens die Dimensionen der Hardware von Medieninfrastrukturen, der Materialitäten von medientechnologischen Ausstattungen im Lager, und deren entsprechende Nutzung. Drittens führt die Analyse zu solchen Medieninfrastrukturen im Lager, die im Zusammenhang mit dem Asylregime und dessen mobilitätsregulierenden Praktiken stehen: medienbasierte Verwaltung und Management von Lagerbewohner*innen und Asylprozessen.

\section{Spuren von Medieninfrastrukturen in Lagern und Unterkünften}

Die Beispiele für eine solche Analyse, die im Rahmen dieses Beitrags möglich ist, stammen aus Archivfunden zu Lagerkontexten zwischen 1945 und 2000 in Deutschland. Die Dokumente ${ }^{4}$ sind als Spuren und Überbleibsel von Praktiken zu verstehen, und bilden durch Quellenkritik und situierte Interpretation eine empirische Grundlage in verschiedenen historischen Kontexten. Solche Kontexte formieren sich sowohl in Medienumgebungen, die sich durch technologische Veränderungen wandeln, als auch in sich wandelnden Asylregimen, die verschiedene Fälle von Zwangsmigration beeinflussten und steuerten. Das Lager bildet hier eine historisch konstante Institution des deutschen Asylregimes zur Unterbringung und zum Management von Geflüchteten, Verschleppten, Vertriebenen und Asylbewerber*innen (vgl. Schießl 2019; Bispinck/Hochmuth 2014) ${ }^{5}$. Medientechnologien waren immer Bestandteil dieser Räume und wurden von Bewohner*innen, Verwaltungsangestellten ${ }^{6}$ oder Aktivist*innen für verschiedene Zwecke und aus verschiedenen Machtpositionen heraus genutzt. Präsent waren neben klassischen Massenmedien wie Radio (oft UKW-Radios für grenzüberschreitenden Empfang), Zeitungen (auch »Lagerzeitungen«), Lagerkinos oder Fernseher in dafür vorgesehenen Räumen auch Telefone/Telegrafen, papierbasierte Registrierungs- und Kontrollsysteme, Anschlagstafeln und eigene Poststellen (vgl. Seuferling 2019). $\mathrm{Ob}$ und inwieweit diese Technologien überhaupt vorhanden waren, wer exakt

Die verwendeten Archivdokumente stammen aus verschiedenen Archiven (Landesarchiv Niedersachsen, Staatsarchiv Nürnberg, Staatsarchiv Hamburg, UN Archives New York), sowie aktivistischen Community-Archiven (Archive für Soziale Bewegungen Hamburg, Freiburg und Bremen). Durch Schlagwortsuche in den jeweiligen Katalogen wurden Dokumente ausgewählt, die Bezüge zu sowohl Lagern und Asylunterkünften sowie Medien (im weitesten Sinne) aufweisen.

$5 \quad$ Siehe hierzu auch den Beitrag von Julia Devlin in diesem Band.

6 Lagerleitungen und -verwaltungen bestanden meist aus deutschem, behördlichem Personal. In der direkten Nachkriegszeit gab es hier auch personelle Kontinuitäten in die NSVerwaltung. In den von den Alliierten betriebenen DP-Lagern kam das UNRRA-Personal zumeist aus Großbritannien und den USA. Für bestimmte praktische Aufgaben wurden auch Lagerbewohner*innen in die Verwaltung integriert. 
Zugang hatte, wie lange sie von wem genutzt werden durften oder hergestellt werden konnten (z.B. Lagerzeitungen), offenbart bereits die erste Dimension von Technopolitik und Macht in diesen Medieninfrastrukturen. Als Institutionen regulieren und kontrollieren Lager Medieninfrastrukturen anders und stärker, als dies in anderen Räumen der Fall ist. Doch ein kritischer Infrastruktur-Ansatz muss tiefer ansetzen und unterliegende Schichten freilegen.

\section{Architektur und Raumkonstruktion}

Die Konstruktion von materiellen und sozialen Räumen ist - im Sinne von Stadtgestaltung, Architektur und öffentlichem Design - eine der Grundlagen von Infrastrukturen und bildet historisch gewachsene Umgebungen für medienvermittelte Kommunikation (vgl. Mattern 2015). Lager ähneln kleinen Städten, sind jedoch geplant und installiert unter extremer Kontrolle und Aufsicht. Archivierte Karten, Bau- und Lagepläne sind Quellen für Raumaufteilungen, Anordnungen von Gebäuden und Funktionen von Raumgestaltung. Sie zeigen aber auch in ihrer Eigenschaft als Dokumente, wie Politik, Ämter und machthabende Akteur*innen diese Planungen vorgenommen und beeinflusst haben: Sie dokumentieren den Raumkonstruktionsprozess selbst.

Abbildung 1: Karte des Lagers Finkenwerder, 1962

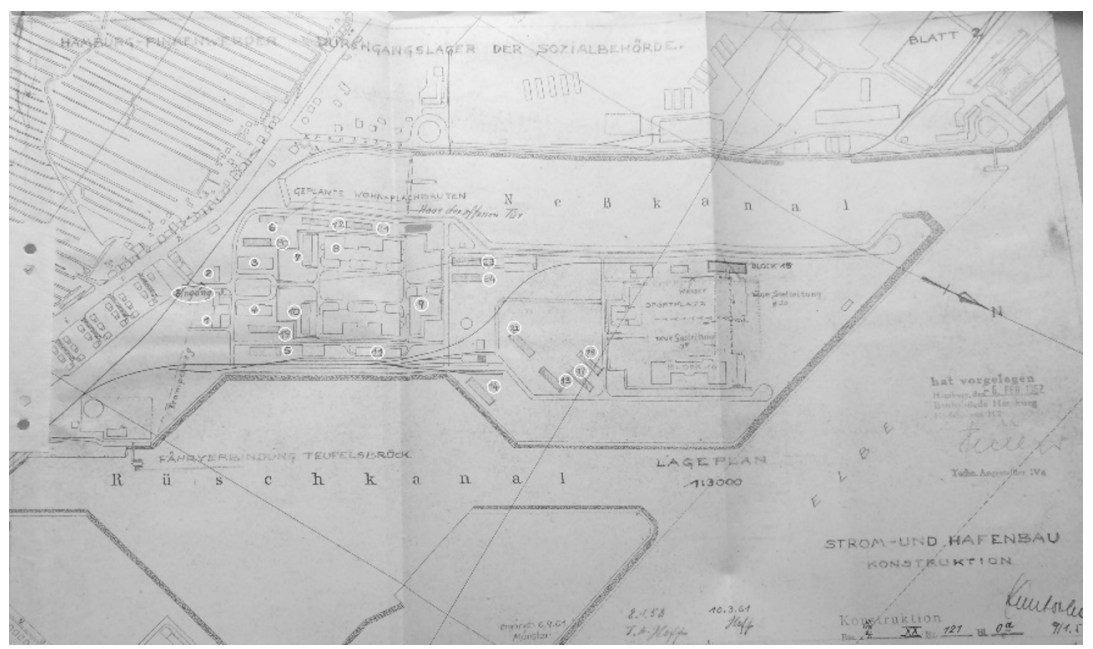

Quelle: Staatsarchiv Hamburg, 321-3 I_239. Eingezeichnet sind der (einzige) Eingang links, die Nummern der Häuser und deren räumliche Anordnung im Kreis, "geplante Wohnflachbauten«, sowie ein Sportplatz und neue Gas- und Wasserleitungen (Herv. d.Verf.). 
Abbildung 1 zeigt einen Lageplan des Lagers Finkenwerder im Hamburger Hafen. Der Plan zeigt das abgeschlossene Gebiet des Lagers auf der Rüschhalbinsel, das vor allem in den 1950er Jahren für Geflüchtete aus Ungarn genutzt wurde. Nummerierte Wohnbaracken, Gemeinschaftsräume, Verwaltungsbaracken, und Räume für Hygiene, Essensversorgung, Unterricht oder Kinos strukturieren physisch und sozial den Raum: es werden Grenzen von Mobilität und Sozialität gesetzt, die Machtverhältnisse zwischen Bewohner*innen und Verwaltungspersonal prägen. Das Lager ist abgeschlossen von seiner Umgebung, es gibt nur einen Eingang, und Grenzen zwischen gemeinschaftlicher Öffentlichkeit und Privatsphäre verschwimmen im kontrolliert geplanten Barackendorf. Somit entstehen in Architektur soziomaterielle Umgebungen für Kommunikation: wo sie möglich war, wo nicht, und wie reguliert.

Gerade im Nachkriegsdeutschland zeigen sich hier auch deutliche Kontinuitäten der physischen Räume, denn oft wurden ehemalige Konzentrationslager (KZ), deren Satellitenlager oder Wehrmachtsunterkünfte als Lager für Geflüchtete umfunktioniert (wie Finkenwerder, das vor 1945 an das KZ Neuengamme angeschlossen war). Das sind historische Pfadkontinuitäten, in denen sich Lagerinfrastrukturen fortsetzen und aufeinander aufbauen. Architektonisch war ein Standardmodell für Lagerbaracken die sogenannte Reichsarbeitsdienst-Baracke (kurz: RADBaracke), entwickelt für den mobilen Autobahnbau in den 1930er Jahren. Auch die Nissenhütte diente lange Zeit als Unterkunft für Geflüchtete: Die runde Wellblechhütte nach kanadischem Modell (charakteristisch für das Lager Friedland) bot ursprünglich Soldaten im Ersten Weltkrieg ein mobiles Heim. In den 1980er und 1990er Jahren wurden diese Modelle weitestgehend durch den Euro-Container ersetzt, ein neues, größenstandardisiertes mobiles Zuhause für Geflüchtete. Hier werden historische Kontinuitäten von mobilen Raumkonstruktionen deutlich: Baracken, Container, oder auch Zelte, repräsentieren einen losen, vorübergehenden Zustand für ihre Bewohner*innen. Diese provisorischen Lösungen der Unterbringung sowie die räumliche Abtrennung von ihrer Umgebung verhindern dadurch Beständigkeit und auch Ankommen im neuen Land.

Was Mattern (2017) für antike und moderne Städte gezeigt hat, trifft auch im Lager zu: Infrastrukturelles, architektonisches Design prägt medienvermittelte Kommunikation, und ermöglicht oder verhindert Oralität, Sprache und Schrift, Klang und Ton sowie Treffen, Austausch und Öffentlichkeit. Beengte Räume ohne Privatsphäre und geteilte Gemeinschaftsräume formen, wie und welche Form von Kommunikation möglich ist. Über die Ermöglichung und Regulierung von Kommunikation im Raum des Lagers geben Ausstattungslisten, Lagerregelwerke sowie Berichte und Beschwerden der Bewohner*innen Aufschluss. Spezielle Räume für Mediennutzung waren üblicherweise vorhanden: Zeitungsräume, Fernseh- oder Radioräume, Kino- oder Theaterbaracken - vergleichbar mit Computerräumen in heutigen Unterkünften (vgl. Witteborn 2014). Üblicherweise wurden diese Arten 
von (Massen-)Medien verwaltungsmäßig unter der Rubrik »Unterhaltung«, »Freizeit«, oder »Wohlfahrt« gefasst und verstanden; zwar als grundlegende Bestandteile des Lagerbetriebs, aber auch als Extra-Aktivität, die kontrolliert und verwaltet war. Dass dies essentielle Grundbedürfnisse waren, zeigen überlieferte Fotos und Berichte von eigenen UKW-Radios in den Zimmern, Anfragen zur Anschaffung von Zeitungen in verschiedenen Sprachen und nach Einrichtung von Kommunikationsräumen. Darüber hinaus sind auch eigene Initiativen dokumentiert, wie die Umfunktionierung von Wänden zu Anschlagstafeln für lagerinterne Kommunikation und zum Informationsaustausch. Diese Fälle zeigen: Kommunikationsinfrastrukturen entstanden durch relationale Praktiken verschiedener Akteur*innen. Oft wurden sie von Bewohner*innen erkämpft ${ }^{7}$, z.B. in Lagerversammlungen, Anträgen, offenen Briefen, oder durch gewählte Vertretungen der Bewohner*innen $^{8}$. Letztendlich waren sie jedoch abhängig und reguliert von den Lagerleitungen, denn es galt, die Kontrolle über den Informationsfluss zu behalten und z.B. Rebellionen zu verhindern.

Doch auch Medieninfrastrukturen waren von wiederum unterliegenden Infrastrukturen abhängig. Beispielsweise war die Stromversorgung reguliert, wie Hamburger Verwaltungsberichte aus den 1990er und 2000er Jahren zeigen: $\mathrm{Zu}$ bestimmten Uhrzeiten wurde der Strom wegen schwacher Sicherungen abgeschaltet, was besonders während des Ramadans unter den muslimischen Bewohner"innen $\mathrm{zu}$ Unmut führte, da sie nachts kein Essen zubereiten konnten. ${ }^{9}$ Dies lässt weiter darauf schließen, dass auch bestimmte Medien durch Regulierung der Elektrizität nicht mehr genutzt werden konnten: Radios oder Fernseher funktionierten dann schlichtweg nicht. Auch unmittelbar nach dem Zweiten Weltkrieg im Nürnberger »Valka-Lager « für ausländische Geflüchtete berichtet ein Verwaltungsdokument von häufigen Streitigkeiten über die Begleichung der Stromrechnungen für Kinovorführungen, die die externen Wanderkinos nicht übernehmen wollten. ${ }^{10}$

7 Siehe zu Refugee Voices und widerständigen Praktiken auch Simon Coebels Beitrag in diesem Band.

8 Beispiele von solchen aktivistischen Aktionen z.B. in: Landesarchiv Niedersachsen, NDS380 Acc. 32/97 Nr. 8 »Beschwerden über das Durchgangslager Friedland«, 1955-1956; Staatsarchiv Hamburg, 442-7_219, »Finkenwerder Ungarnflüchtlinge«, 1956-1960; Archiv für Soziale Bewegungen Hamburg, 04.500.

9 Staatsarchiv Hamburg, "Schaffung und Ausstattung von Wohnunterkünften und Cemeinschaftsunterkünften für Asylbewerber«, 442-11_273.

10 Staatsarchiv Nürnberg, »Flüchtlingslager Langwasser Il«, 1951-1958 (Reg. v. Mfr. Abg. 1978 Nr. 19805). 


\section{Medientechnologien: Lager-Hardware}

Wie der Lagerraum also rein physisch aufgebaut, verkabelt und strukturiert war, hatte und hat erhebliche Auswirkungen auf Medien- und Kommunikationspraktiken. Konkrete Medientechnologien sind in diese Räume eingebettet und ko-konstituieren sie. Hier belegen Inventarlisten, welche Medientechnologien (theoretisch) zur Verfügung gestellt werden sollten. Zugehörige »Heimordnungen« regulierten ihre Nutzung. Amtliche Regeln definierten nicht nur die absolute Kontrolle des Raumes (Quadratmeter pro Person, exaktes Mobiliar etc.), sondern übten auch infrastrukturelle Kontrolle über Medien und Kommunikationsmöglichkeiten aus. In vordigitalen Medienumgebungen gehörten dazu Tageszeitungen und Printmagazine, Fernseher, Radios (auch Lagerradiostationen) und Lagerkinos, aber auch interpersonale Kommunikationsmedien wie Telefone, Telegrafie oder Lagerpoststellen. Letztere standen jedoch oft nur dem Lagerpersonal für ihre Arbeit zur Verfügung; in manchen Fällen gab es jedoch Münztelefone, von denen aus Bewohner*innen zu immensen Preisen Anrufe tätigen konnten, wie Interviews mit Geflüchteten in aktivistischen Protestmagazinen berichten. ${ }^{11}$

Ein näherer Blick auf die Materialität, die Hardware, dieser diversen Medientechnologien zeigt, wie Mediennutzung durch Installation und Verfügbarkeit kontrolliert wurde. Dies umschließt neben der Gestaltung entsprechender Räumlichkeiten (wie Kinobaracken oder Gemeinschaftsräume) auch die Verkabelung oder Medienproduktionsmöglichkeiten. Verwaltungsdokumente zeigen detailliert, wie Infrastrukturen angeschafft, instandgehalten und reguliert wurden. Der Betrieb von Lagerkinos ist hier beispielhaft. Eine Kinobaracke musste den Brandschutzvorkehrungen genügen, da Schmalfilmprojektoren feueranfällig waren und in einem Raum aus Stein stehen mussten. Der mobile Wanderkinodienst mit Filmen und Projektoren musste gebucht werden - ein Moment der Kontrolle über Zugang und Medieninhalt, welcher zu Konflikten führte, wenn Bewohner*innen und Lagerleitung verschiedener Meinung waren, wie oft und welche Filme gezeigt werden sollten. Bei den Geflüchteten waren Unterhaltungsfilme beliebter als die von der Lagerleitung favorisierten Erziehungs- und Dokumentarfilme. ${ }^{12}$

Als zweites Beispiel zeigt ein Bericht über ein Lautsprechersystem im Displaced Persons (DP)-Lager ${ }^{13}$ Wentorf die Ausmaße medieninfrastruktureller Kontrol-

11 Archiv der Sozialen Bewegungen, Hamburg, »04. Antirassismus, Asyl- und Immigrationspolitik«.

12 Staatsarchiv Nürnberg, »Flüchtlingslager Langwasser Il«, 1951-1958 (Reg. v. Mfr. Abg. 1978 Nr. 19805).

13 DP-Lager unterlagen der Verwaltung der Alliierten, organisiert durch die UNRRA. Sie beherbergten zwischen ca. 1945 und 1948 acht Millionen Displaced Persons, befreite Zwangsarbeitende und ehemalige KZ-Insassen. 
le. Eine von der UNRRA (United Nations Relief and Rehabilitation Administration) verfasste Lagerchronik berichtet:

»Entertainment. Broadcasting System.

1. The $2^{\text {nd }}$ of July saw the inauguration of a camp broadcasting system which by means of 200 loudspeakers, carefully placed to cover the whole camp, allowed the benefits of outside as well as internal news and entertainment program. As this department grew older so it gradually depended less for entertainment on the retransmission of external broadcasting elements and so improved its own home-made entertainment value that it was able to satisfy all sections of the community. ${ }^{14}$

Hier wurde ein Kommunikationssystem errichtet, das die Beschallung des gesamten Lagers mit Radioprogrammen und Durchsagen ermöglichte. Den Nutzer*innen blieb wohl kaum eine Wahl: Man musste zuhören, ob man wollte oder nicht.

Abbildung 2: Radiostudio, DP-Lager Berchtesgaden

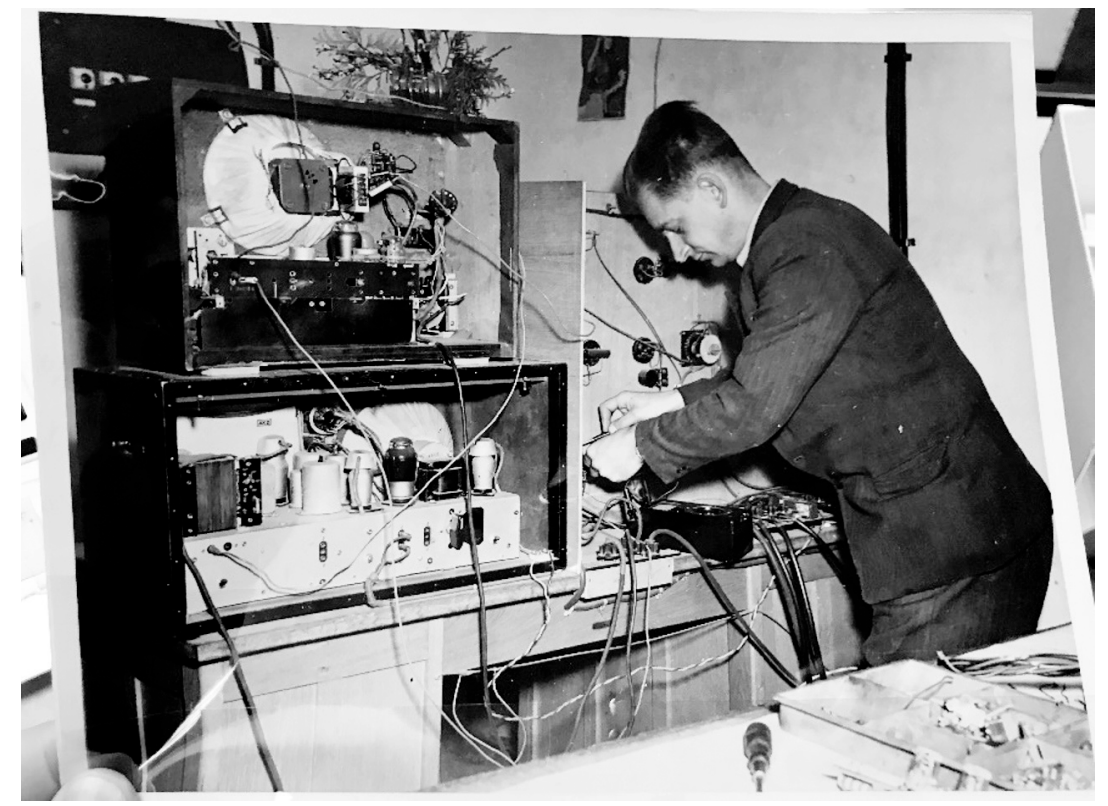

Quelle: UN Archives, S-1058-0001-01, »Germany Mission - Photographs«, 1943-1948. 
Das Foto in Abbildung 2 zeigt ein weiteres Beispiel für Medientechnologie in Lagern: »Richards Harjess, head of the camp communication section [...] checking the broadcast apparatus in the camp's midget radio studio «. ${ }^{15}$ Diese Überlieferung aus einem Berchtesgadener DP-Lager zeigt die Involvierung von Lagerbewohner*innen in die Aufrechterhaltung von Medieninfrastrukturen, in diesem Fall koordiniert durch eine »camp communication section«. Zwar fehlen leider Quellen zum gesendeten Radioprogramm, doch waren vor allem in DP-Camps neben solchen Lagerradiostationen auch Lagerzeitungen üblich, deren Inhalte gut überliefert sind. Diese wurden auch von Lagerbewohner*innen selbst verlegt. Zuvor musste eine Lizenz von der Lagerleitung eingeholt werden, da von 1945 bis 1949 alliierte Zensur in Deutschland galt. Gedruckt wurden sie in Druckereien in der Umgebung der Lager. Papier war generell knapp in der unmittelbaren Nachkriegszeit, sodass Lagerzeitungen oft improvisiert zusammengeheftete Stapel engbeschriebener Schreibmaschinenseiten waren. Auch Briefpapier für die Bewohner*innen wurde rationiert und von der Lagerleitung ausgehändigt. Papierbasierte Kommunikation beschränkte sich jedoch nicht nur auf Lagerzeitungen: Andere Quellen berichten von Anschlagstafeln an Barackenwänden ${ }^{16}$, mittels derer Bewohner*innen oft nach ihren verlorenen Angehörigen suchten.

Letztendlich sind solche Zeitungen, Radios und Schwarze Bretter auch symbolische Mobilisierungen der Bewohner*innen, Möglichkeiten zur Teilhabe und Kommunikation über die Lagergrenzen hinaus. Improvisierte Infrastrukturen, geboren aus einem Mangel an Medientechnologien, zeigen die Verflechtung von Nutzer*innen, ihrer Kommunikationsbedürfnisse und der Medienmaterialität. Infrastrukturelle Arbeit und Entwicklung von Medien wurde von Lagerbewohner*innen ausgeführt und übernommen. Gleichzeitig sind Infrastrukturen der Kontrolle der Lagerleitung ausgesetzt und in Machtverhandlungsprozesse eingebettet. Letztere sind besonders kontextabhängig. Die DP-Lager der Alliierten hatten mehr Mittel $\mathrm{zu}$ Verfügung und »kulturelle Angebote« wurden von der Lagerleitung zwar reguliert, aber auch ermutigt. Diese Wertschätzung von Medien nahm über die Jahre hin stark ab. In den 1980er und 1990er Jahren hatten Medien einen deutlich geringeren Stellenwert in der Lagerausstattung, wie Ausstattungslisten zeigen. Damals herrschten in den Asylunterkünften harsche, von Rassismus und aktiver Verhinderung von Integration gezeichnete Bedingungen ${ }^{17}$, nachdem in Reaktion auf steigende Asylzahlen Gesetze zur Aufnahme und Unterbrinung mehrfach verschärft wurden, Leistungen gekürzt und Rechte beschränkt. Viele Quellen zeigen, wie Geflüchtete und Aktivist*innen durch Anträge, offene Briefe oder andere Initiativen

15 UN Archives, S-1058-0001-01, »Cermany Mission - Photographs«, 1943-1948.

16 Zu sehen im Museum Friedland, siehe Seuferling 2019: 212.

17 Siehe z.B. den sogenannte »Toscani-Bericht « des UNHCR von 1983 über Zustände in westdeutschen Asylunterkünften (Refugee Survey Quarterly 2008: 163). 
Zugang und Beschaffung von Medien forderten. Denn selbst wenn Technologien vorhanden waren, war dies keine Garantie für deren Nutzbarkeit, wie eine iranische Bewohnerin einem aktivistischen Magazin im Jahr 1996 berichtete: Das Fernsehgerät sei seit langem kaputt und der entsprechende Raum abgeschlossen. ${ }^{18} \mathrm{Me}$ dieninfrastrukturelle Kontrolle und Verhinderung von Kommunikation geschieht auch durch Nicht-Instandhaltung oder Nicht-Vorhandensein.

\section{Medien für das Asylregime}

Ein dritter Baustein von Lagermedieninfrastrukturen sind Medien, die in direktem Zusammenhang mit dem Asylregime stehen. Lager sind nicht nur Orte temporärer Unterkunft, sondern beherbergen auch institutionelle Verwaltungsvorgänge: Sie manifestieren Grenzen und führen Vorgänge wie Registrierung, Kategorisierung, Anhörung und Entscheidung über Asylstatus oder Gesundheitsprüfung durch all diese Vorgänge gehören zum Management des Asylprozesses und fanden historisch auch im Lager selbst statt. Diese Prozesse basieren auf Medieninfrastrukturen zur Speicherung und Zirkulation von asylregimerelevanten Informationen. Hier zeigen sich besonders deutlich historische Genealogien zu modernen, digitalisierten Verfahren des Lager- und Migrationsmanagements. Historische Vorgängertechnologien zeigen, wie das Asylregime Vorstellungen und Praktiken rund um Medien entwickelte und umsetzte.

Quellen aus Durchgangslagern wie Uelzen-Bohldamm, Berlin-Marienfelde oder Friedland zeigen die medienbasierte Koordination und Kontrolle der Asylsuchenden und Geflüchteten. Ein komplexes System aus Bescheinigungen und »Laufzetteln« dokumentierte die Verwaltungsvorgänge, kontrollierte Zugang zu rationierten Leistungen wie Essen, Kleidung oder Spielzeug und managte den Asylprozess. Im West-Berlin der 1950er Jahre erwartete die »Ostzonen-Flüchtlinge« folgendes Verfahren: "Alle in Westberlin ankommenden Flüchtlinge melden sich bei der Senatsstelle in Berlin-Marienfelde. Dort erhalten alle Flüchtlinge den Laufzettel für das Notaufnahmeverfahren, welcher den Flüchtling durch alle Instanzen - bis nach Westdeutschland - begleitet. « ${ }^{19}$

Diese Stationen umfassten eine ärztliche Untersuchung und Zuständigkeitsprüfung: »Dort werden alle den Flüchtling betreffenden Angaben auf einer Karteikarte erfasst, insbesondere die Fluchtgründe. ${ }^{20}$ Die kontinuierliche Dokumentation durch Karteisysteme, Laufzettel (Abbildung 3), Lagerausweise, Essenskarten und Spendenaushändigungsbescheide diente der Überwachung jeglicher Aktivitäten im Lagerkomplex - eine Infrastruktur, die auf Trab hält:

\footnotetext{
18 Archiv für Soziale Bewegungen Hamburg, 04.210, »Flüchtlingsleben, Beispiel Lübeck«, 1996.

19 Rotes Kreuz Archiv, DRK 530.

20 Ebd.
} 
Abbildung 3: »Laufzettel für das Notaufnahmeverfahren«

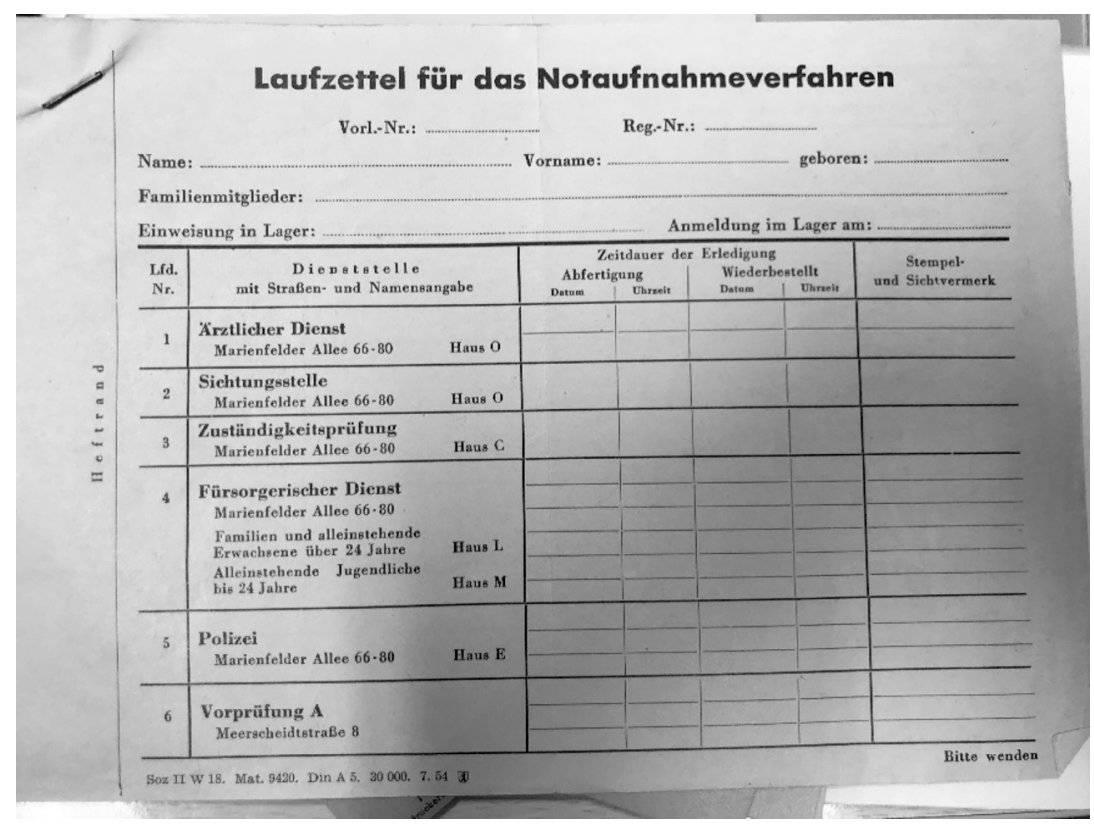

Quelle: Rotes Kreuz Archiv, DRK 4750.

»Der Flüchtling hat in den ersten Tagen die Gänge zu erledigen, die ihm der Laufbogen vorschreibt. Dieser Pflichtunterziehung wird im Lager Rechnung getragen. Da er oft von morgens bis abends unterwegs sein muss, wird abends nochmals warmes Mittagessen ausgegeben. ${ }^{21}$

Mobilität, Tagesabläufe und Verhalten im Allgemeinen wurden mithilfe von Medieninfrastrukturen dokumentiert und überwacht. Papier als Technologie von Dokumenten ermöglichte dadurch gleichzeitig Praktiken von »knowing « und »showing« (»Wissen « und »Beweisen/Zeigen«) (Gitelman 2014: 1f.). In der epistemischen Funktion des Mediengenres Dokument, Realitäten zu schaffen, bedingen sich Form und Inhalt des Mediums gegenseitig (vgl. Gitelman 2014 und Vismann 2000). Ausweise, Belege und andere Dokumente können gleichzeitig Zustände speichern, schaffen und vorzeigen und dadurch Steuerung und Kontrolle von Lagerleben und Asylprozessen ausüben. Ein Beispiel berichtet sogar von einem dokumentierten Punktesystem beim Spielzeugverleih: Je nach Zustand des Spielzeugs bei Rückgabe notierte die Verwaltung ein Plus oder Minus in ihren Dokumenten. So wurde jeder Schritt 
in Medien überführt: Von der Ankunft über Aufenthalte in Durchgangslagern und Ausreiselagern, Anhörungen, Essens- und Spendenausgaben und so weiter. ${ }^{22}$

Abbildung 4: International Tracing Service in DP-Lagern, UN Archives, S-1058-0001-01, »Germany Mission-Photographs«, 1943-1948

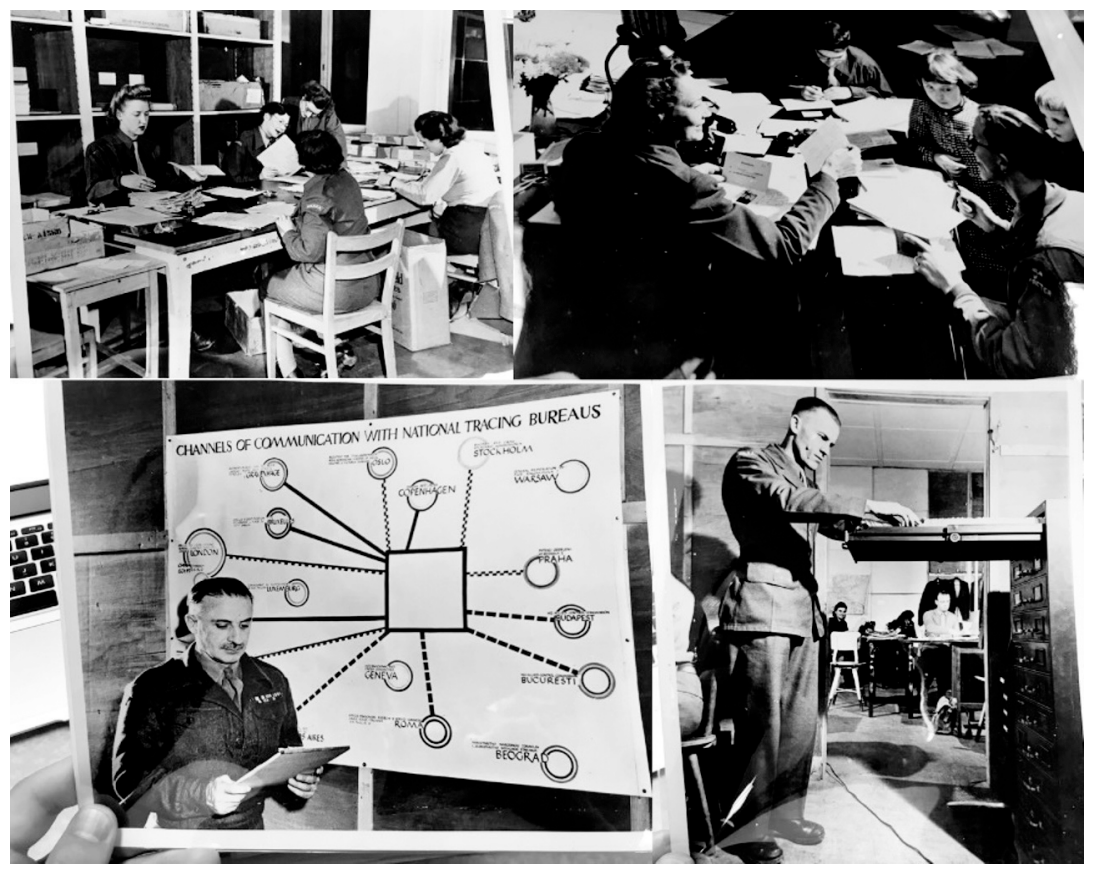

Quelle: Rotes Kreuz Archiv, DRK 530.

Die karteibasierte Registrierung von Fluchtschicksalen wurde nicht nur zur Beurteilung über Asylansprüche verwendet, sondern machte auch Familienzusammenführungen möglich. Gegen Ende des Zweiten Weltkriegs errichteten die Alliierten einen Suchdienst für Verfolgte des NS-Regimes und Geflüchtete, der unter Einbezug von UNRRA, IRO und dem Roten Kreuz ab 1948 zum International Tracing Service (ITS) wurde: eine europäische Kommunikationsinfrastruktur mit Zentrale in Bad Arolsen, die millionenfache Kontaktaufnahmen, Rückführungen und Wiedervereinigungen ermöglichte, und somit auch symbolische und physische Remobilisierungen. Quellen aus DP-Lagern zeigen, wie die zugehörigen Medieninfrastrukturen - Karteien, Registrierung von Fluchtgeschichten, Telegrafennetzwerke 
- in den Lagern angesiedelt waren. Abbildung 4 zeigt vier Fotografien aus dem PRFotobestand von UNRRA, sie illustrieren ITS-Medieninfrastrukturen im DP-Lager Hoechst.

Die Mitarbeiter*innen (eine Mischung aus meist britischem oder amerikanischem UNRRA-Personal und Lagerbewohner"innen) errichteten eine Karteiregistratur, um Einzelfälle europaweit zuordnen zu können (unten rechts). Das Bild oben links zeigt die Eingangspoststelle: »[M]ail from all over the world is sorted according to language and country, in preparation for the search for the missing person.« Unten links ist das Telegrafie- und Postsystem der Tracing Bureaus zu sehen, mit Bad Arolsen als Hauptquartier in der Mitte. Eine aufwendige Medieninfrastruktur institutionalisierte hier eines der wichtigsten Kommunikationsbedürfnisse von Verschleppten und Geflüchteten: den Kontakt zu verlorenen Angehörigen herzustellen. Gleichzeitig verhalf sie den Behörden, Millionen Schicksale zu registrieren, was als Grundlage zum Management von Migration diente. Dokumentierte Anhörungen und die Bezeugung des eigenen Schicksals sind bis heute Grundlage von Asylprozessen, und damit eine Konstante des modernen Asylregimes. Auch diese Anhörungen fanden lange in den Lagern selbst statt, in Verwaltungsräumen mit der entsprechenden Medienausstattung (wie Schreibmaschinen und Aufnahmegeräte).

\section{Medieninfrastrukturen: Komplizen der Immobilisierung und des Asylregimes?}

Medieninfrastrukturen in Lagern sind eng verflochten mit Infrastrukturen, die Vorgänge des Asylregimes und der Fluchtverwaltung ermöglichen. Wie die Analyse zeigt, können somit Medien im Lager infrastrukturell als Komplizen des Asylregimes verstanden werden, als Infrastrukturen, in die Prozesse und Vorstellungen von Migrationsverwaltung eingebettet sind. Dieses abschließende Kapitel diskutiert diese historische Verflechtung von Medien- und Migrationsinfrastrukturen.

\section{Medienbasierte Migrationsinfrastrukturen}

Technologische Lösungen für die Etablierung von globalen Migrationsregimen können ebenfalls als Infrastrukturen verstanden werden - als Migrationsinfrastrukturen, ein Begriff, den Leurs versteht als "tech-driven interventions developed to disrupt forced-migration crisis situations « (Leurs 2020: 91). Neben Grenzanlagen, Pässen und behördlichen Asylverfahren sind auch Lager und Asylunterkünfte solche Infrastrukturen, auf deren Basis Migrationskontrolle verwirklicht wird. Leurs (2020) sowie Dijstelbloem (2020) skizzieren hier Ansätze, um diese Infrastrukturen kritisch zu verstehen. Besonders Migrationskrisen sind »infrastructural events" 
(Dijstelbloem 2020: 311), bei denen sich technopolitische Prozesse abspielen und Migrationsinfrastrukturen Gewalt ausüben:

»[M]echanisms for observing, registering and monitoring international mobility - varying from large databases to satellites and drones and from iris-scans and fingerprints to algorithmic profiling and pre-emption - have turned border control into a technopolitical affair.« (Ebd.)

Praktiken von Migrationsinfrastrukturen haben historische Genealogien, die tief in koloniale und faschistische Historien hineinreichen. »[E]xperimental advanced technology-based infrastructuring initiatives « (Leurs 2020: 94) ermöglichen problematische technopolitische Projekte von Kontrolle, Observation, Überwachung, Registrierung und Kategorisierung. Gerade im Raumkonzept »Lager« begegnen sich auf problematische Weise die Historien von Konzentrations- und Flüchtlingslagern (vgl. Agamben 2000: 21). Im Falle von Flucht und Migration unterliegen Lager jedoch der diskursiven Logik des Humanitarismus. Infrastrukturelle Überschneidungen von humanitären Lösungsansätzen mit (medien-)technologischen Innovationen zur vermeintlichen Verbesserung der Umstände kreieren jedoch oft neue Abhängigkeiten (vgl. Macias: 2020) - ein Prozess, den Madianou »Technokolonialismus« (Madianou 2019: 2) nennt.

Infrastrukturen werden immer erst in koordinierten, standardisierten Praktiken realisiert, die jedoch wechselseitig durch selbige erst ermöglicht und bedingt werden (Star/Ruhleder 1996: 113). Bringt man nun Medieninfrastrukturen im Lager in Verbindung mit Migrationsinfrastrukturen werden diese Praktiken und Verflechtungen deutlich: Medien sind Substrate für die Umsetzung von Migrationsinfrastrukturen und machen sie aktiv möglich. Praktiken rund um Medieninfrastrukturen verhandeln und bedingen also technopolitisch die Gestaltung von Asylregimen - durch Ausgestaltung von Architektur und Räumen, medientechnologische Hardware sowie Medien zur Fluchtverwaltung. Migrationsinfrastrukturen bedienen sich solcher Technologien der Speicherung und Zirkulation von Informationen, um Kontrolle, Registrierung, Koordination in Zeit und Raum, Grenzverwaltung und Asylverfahren zu ermöglichen. Die Vorstellungen des Asylregimes und seiner Funktionsweisen werden in Medientechnologien »infrastrukturalisiert«, also standardisiert und umgesetzt, auch vor dem digitalen Zeitalter. Die Nutzung von Karteien und Papier zur Kontrolle, Kategorisierung und Registrierung führt direkt zu heutigen Innovationen wie Algorithmen, KI, und Gesichtserkennung und Ähnlichem zur Steuerung und Verwaltung von Asylprozessen und Lagern. Die Technologien haben sich verändert, doch Motive der Anwendung und entsprechende Ausgestaltung setzen sich fort. Die Beispiele zeigen aber auch, wie die Erfahrungen und Praktiken der Lagerbewohner*innen die Verflechtung von Medien- und Migrationsinfrastrukturen mitformen. Wie Leurs betont, zeigt aktives »infrastructuring « hier »how top-down forms of governmentality and control 
are mutually shaped through bottom-up lived experiences of forced migrants and acts of contestation « (Leurs 2020: 92). Lagerverwaltungen, Politik und Asylregime, NGOs, Aktivist*innen und Freiwillige, und natürlich die geflüchteten Lagerbewohner*innen selbst sind involvierte Akteur*innen, die Medien- und Migrationsinfrastrukturen aufrechterhalten und ihnen unterliegen.

\section{Medien als Komplizen der Immobilisierung?}

Wie kann also die Rolle von historischen Medieninfrastrukturen im Lager abschließend betrachtet werden? In ihrer Studie zur Bedeutung von Smartphones für Flüchtende auf der »digitalen Passage« nach Europa betonen Gillespie, Osseiran und Cheesman die Relevanz von Infrastrukturen für notwendige Medienpraktiken auf der Flucht:

»For our refugee respondents, smartphone infrastructures are precarious and contingent: They depend on but have limited access to charging docks, SIM cards, WiFi, or, for example, water-proof plastic bags to keep their devices dry at sea.« (Gillespie/Osseiran/Cheesman 2018: 2)

Wie dieser Beitrag gezeigt hat, lassen sich Abhängigkeit und Mangel von materiellen Medieninfrastrukturen in der Erfahrung von Flucht historisch zurückverfolgen: ähnliche Bedürfnisse, aber andere Technologien. Weiterhin weisen die Autorinnen darauf hin, dass Infrastrukturen »dialectical tensions between threat and resource, invisibility and exposure, and mobility and immobility « (ebd.: 10) entfalten. Digitale Medien bieten in ihrer Analyse also Möglichkeiten der Emanzipation und Agency, aber auch Gefahren der Überwachung und Kontrolle.

Auch diese Spannung zwischen Mobilisierung und Immobilisierung, Disziplinierung einerseits und Ermöglichung von Kommunikation andererseits ist in Medien- und Migrationsinfrastrukturen in Lagern historisch angelegt. Kommunikationsfreiheiten wurden erstritten und durch improvisierte Medieninfrastrukturen ermöglicht, und gleichzeitig jedoch reguliert und überwacht durch Lagerleitung und Behörden. Räume und Architektur sowie Vorhandensein und Betrieb von Medientechnologien infrastrukturalisieren die kommunikativen und physischen Im-/mobilitäten der Bewohner*innen. Die Verflechtung von Medien- und Migrationsinfrastrukturen bietet die Grundlage für Kontrolle und Disziplinierung von Lagerbewohner*innen in Zeit und Raum und ist dadurch technisches Substrat für Bewegung und Freiheit von Kommunikation. Medien wie Laufzettel, Ausweise oder Gruppenräume strukturieren Mobilität ganz offensichtlich. Doch auch Medieninfrastrukturen für Informationsnutzung oder zum Austausch von Informationen (Zeitungen, Radios, Anschlagstafeln oder Tagebücher) können als Mobilisierung verstanden werden, nämlich von Kommunikation und Inhalten über die Grenzen des Lagers und des Geflüchteten-Daseins hinaus. Wenn diese fehlen, werden La- 
gerbewohner*innen weiter immobilisiert, festgesetzt und sozial abgeschnitten. In einem Machtverhandlungsprozess von Akteur*innen - Geflüchtete, Lagerleitung und andere Involvierte (wie beispielsweise Aktivist*innen) - werden also die Möglichkeiten und Unmöglichkeiten von Kommunikation im Lager ausgehandelt. Bewohner*innen erbitten, erstellen und erhalten Medien aufrecht, Lagerleitungen stellen sie zur Verfügung - oder nicht.

Letztendlich stehen Medieninfrastrukturen in ihrer Nutzung für Praktiken der Kontrolle durch das Asylregime stets in einem Spannungsverhältnis zu den Möglichkeiten, die sie für Lagerbewohner*innen schaffen. Zahlreiche Quellen berichten von den positiven Erfahrungen mit Medien und den Erleichterungen für die Geflüchteten durch deren Nutzung. Diese Perspektive »von unten« sollte schlussendlich auch den kritischen Blick auf Medien und Infrastrukturen lenken: Welche Bedürfnisse, kreative Praktiken und Erfahrungen stehen für Geflüchtete selbst im Mittelpunkt, und welche Beziehungen haben solche Erfahrungen zu Medientechnologien? Denn diese Frage und der konsequente Blick aus der Perspektive der Betroffenen von Medien- und Migrationsinfrastrukturen nuanciert und korrigiert unsere Sicht auf Medien und Technologien, die in Asylkontexten angewandt werden.

\section{Literaturverzeichnis}

Agamben, Giorgio (2000): Means without End: Notes on Politics, Minneapolis: University of Minnesota Press.

Agier, Michel (2011): Managing the Undesirables: Refugee Camps and Humanitarian Government, Cambridge: Polity.

Bispinck, Henrik/Hochmuth, Katharina (2014): Flüchtlingslager im Nachkriegsdeutschland. Migration, Politik, Erinnerung, Berlin: Christoph Links Verlag.

Bolter, Jay David/Grusin, Richard (2000): Remediation: Understanding New Media, Cambridge: MIT Press.

Bowker, Geoffrey C./Star, Susan L. (1999): Sorting Things Out. Classification and Its Consequences, Cambridge: MIT Press.

Dijstelbloem, Huub (2020): "Borders and the Contagious Nature of Mediation«, in: Kevin Smets/Koen Leurs/Myria Georgiou/Saskia Witteborn/Radhika Gajjala (Hg.), The SAGE Handbook of Media and Migration, London: SAGE, S. 311-320.

Forsler, Ingrid (2020): Enabling Media: Infrastructures, Imaginaries and Cultural Techniques in Swedish and Estonian Visual Arts Education, Huddinge: Södertörns högskola.

Gatrell, Peter (2013): The Making of the Modern Refugee, Oxford: Oxford University Press. 
Gillespie, Marie/Osseiran, Souad/Cheesman, Margie (2018): »Syrian Refugees and the Digital Passage to Europe: Smartphone Infrastructures and Affordances«, in: Social Media + Society 4(1), S. 1-12.

Gitelman, Lisa (2014): Paper Knowledge. Toward a Media History of Documents, Durham \& London: Duke University Press.

Kubitschko, Sebastian/Schütz, Tim (2016): „Humanitarian Media Intervention: Infrastructuring in Times of Forced Migration«, in: Spheres Journal for Digital Cultures 3, S. 1-14.

Larkin, Brian (2013): »The Politics and Poetics of Infrastructure«, in: Annu. Rev. Anthropol. 42, S. 327-343.

Leurs, Koen (2020): »Migration Infrastructures«, in: Kevin Smets/Koen Leurs/Myria Georgiou/Saskia Witteborn/Radhika Gajjala (Hg.), The SAGE Handbook of Media and Migration, London: SAGE, S. 91-102.

Macias, Léa (2020): »Digital Humanitarianism in a Refugee Camp«, in: Kevin Smets/Koen Leurs/Myria Georgiou/Saskia Witteborn/Radhika Gajjala (Hg.), The SAGE Handbook of Media and Migration, London: SAGE, S. 334-345.

Madianou, Mirca (2019): »Technocolonialism: Digital Innovation and Data Practices in the Humanitarian Response to Refugee Crises«, in: Social Media and Society 5(3), S. 1-13.

Mattern, Shannon (2015): »Deep Time of Mediatization«, in: Lisa Parks/Nicole Starosielski (Hg.), Signal Traffic: Critical Studies of Media Infrastructures, Illinois: University of Illinois Press, S. 94-112.

Mattern, Shannon (2017): Code and Clay, Data and Dirt. Five Thousand Years of Urban Media, Minneapolis: University of Minnesota Press.

Metcalfe, Philippa/Dencik, Lina (2019): »The Politics of Big Borders: Data (In)justice and the Governance of Refugees", in: First Monday 24(4), S. 1-15.

Parks, Lisa/Starosielski, Nicole (Hg.) (2015): Signal Traffic: Critical Studies of Media Infrastructures, Illinois: University of Illinois Press.

Peters, John Durham (2015): The Marvelous Clouds. Towards a Philosophy of Elemental Media, Chicago: The University of Chicago Press.

Refugee Survey Quarterly (2008): „Selection of documents from UNHCR archives«, in: Refugee Survey Quarterly 27(1), S. 121-184.

Schießl, Sascha (2019): Das Tor zur Freiheit. Kriegsfolgen, Erinnerungspolitik und humanitärer Anspruch im Lager Friedland (1945-1970), Göttingen: Wallstein.

Schnitzler, Antina von (2008): "Citizenship prepaid: water, calculability, and techno-politics«, in: South Africa. J. South. Afr. Stud. 34(4), S. 899-917.

Seuferling, Philipp (2019): »We Demand Better Ways to Communicate: Pre-Digital Media Practices in Refugee Camps«, in: Media and Communication 7(2), S. 207217. 
Star, Susan L./Ruhleder, Karen (1996): »Steps toward an ecology of infrastructure: Design and access for large information spaces«, in: Information Systems Research 7(1), S. 111-135.

Vismann, Cornelia (2000). Akten. Medientechnik und Recht, Frankfurt a.M.: Fischer.

Wall, Melissa/Campbell, Madeline O./Janbek, Dana (2017): "Syrian refugees and information precarity“, in: New Media and Society 19(2), S. 240-254.

Witteborn, Saskia (2014): »Forced migrants, emotive practice and digital heterotopia«, in: Crossings: Journal of Migration \& Culture 5(1), S. 73-85. 


\section{Sichtweisen der bayerischen Bevölkerung auf das Unterbringungskonzept Ankerzentrum}

Ramona Kay und Nadine Segadlo

\section{Zusammenfassung}

Die Unterbringung geflüchteter Menschen in Lagern ist weltweit eine seit langem durchgeführte Praxis. Die bayerische Staatsregierung hat als Reaktion auf die sogenannte »Flüchtlingskrise« (2015) die Einführung von Ankerzentren (Ankunfts-, Entscheidungs- und Rückführungszentren) beschlossen. Hier findet an einem Ort sowohl die Unterbringung Geflüchteter als auch die Bearbeitung ihrer Asylanträge statt. Diese neue Organisationsform hat das Ziel, Asylanträge in kürzeren Zeiträumen zu bearbeiten und Menschen mit schlechter Bleibeperspektive zu einer schnelleren Ausreise zu bewegen sowie Menschen mit guter Bleibeperspektive entsprechend schnell in die Cesellschaft aufzunehmen. Diese Unterbringungsform segregiert und unterbindet den Kontakt zwischen Geflüchteten und bayerischer Bevölkerung. Vor diesem Hintergrund widmet sich dieser Beitrag daher der Frage, welche Sichtweise die bayerische Bevölkerung auf die zentrale Unterbringung Ceflüchteter in Ankerzentren einnimmt, wie die erzwungene Immobilität und Isolation der dort untergebrachten Ceflüchteten von der ansässigen Bevölkerung sowie die Unterbringungsdauer bewertet wird. Mithilfe einer für die bayerische Bevölkerung repräsentativen Online-Befragung im Frühjahr 2020 konnte gezeigt werden, dass deutliche Unterschiede in der bayerischen Bevölkerung zutage treten, was die Befürwortung der zentralen Unterbringung und der damit verbundenen Abgrenzung von Geflüchteten sowie ihrer Wahrnehmung als Fremde angeht sowie der Forderung nach einer dezentralen Unterbringung und der somit verbesserten Integrationsmöglichkeiten durch eine erleichterte Kontaktaufnahme mit der Außenwelt. Die Ergebnisse zeigen, dass Kontakt mit Ceflüchteten mehrheitlich zur Ablehnung der zentralen Unterbringungsform führt. Herrschen bei den Befragten hingegen negative Einstellungen gegenüber Ausländer*innen vor, nehmen diese eine vermehrte Norm- und auch Orientierungslosigkeit im gesellschaftlichen Miteinander wahr und sorgen sich um Recht und Ordnung in ihrer Umgebung, wird die zentrale Unterbringung in Form von Ankerzentren stärker befürwortet. 


\section{Summary}

The placement of refugees in camps is a long-established practice worldwide. In response to the so-called »refugee crisis« (2015), the Bavarian state government has decided to introduce Anker centres (arrival, decision and repatriation centres). Here, refugees are accommodated and their asylum applications are processed in the same place. This new form of organisation has the aim of being able to process asylum applications faster and to encourage people with poor prospects of staying to leave the country more quickly, as well as to integrate people with good prospects of staying into society as quickly as possible. This form of accommodation segregates refugees and the Bavarian population and prevents contact between these two groups. Against this background, this article is therefore dedicated to the question of how the Bavarian population perceives the centralised housing of refugees in Anker centres, how the forced immobility and isolation of the refugees there, and the length of their stay, are evaluated by the local population. An online survey conducted in spring 2020 that is representative of the Bavarian population revealed that there are clear differences within the Bavarian population with regard to their support for centralised accommodation and the associated demarcation of refugees and their perception as strangers, as well as the demand for decentralised accommodation and the resulting improved integration possibilities through easier contact with the outside world. The results show that contact with refugees leads to a majority of people rejecting the centralised form of accommodation. On the other hand, if the participants in the survey have negative attitudes towards foreigners, they perceive an increased lack of norms and orientation in social interaction and are concerned about law and order in their surroundings; consequently centralised accommodation in the form of Anker centres is more strongly advocated.

\section{Einleitung}

»The diversification in the forms of camp, the widening of frontier zones, the increased control of wandering populations - all this today adds up to consolidating a partition between two great world categories that are increasingly reified: on the one hand, a clean, healthy and visible world; on the other, the world's residual >remnants`, dark, diseased and invisible. (Agier 2011: 4)

Lager gelten weithin als präferierte Unterbringungsform geflüchteter Menschen. Sie gewährleisten Aufnahme, Schutz und Basisversorgung von Menschen nach ihrer Flucht. Gleichzeitig ermöglichen sie Kontrolle und Machtausübung über Geflüchtete durch staatliche Handlungsträger und Hilfsorganisationen. Sie stellen von der Gesellschaft abgegrenzte Räume für Menschen in Aufnahmekontexten 
dar, deren Status als Asylbewerber*innen oder Schutzsuchende noch zu klären ist oder bereits determiniert wurde. Lager nehmen weltweit unterschiedliche Gestalt an, weisen aber strukturelle Ähnlichkeiten wie klare Binnenstrukturen, geregelte Verbindungen nach außen, hierarchische Verhältnisse zur Lagerverwaltung und Selbstorganisation auf (vgl. Krause 2019; Kreichauf 2018; Thiel/Jahr 2017; Agier 2011). Sie sind nicht auf den Globalen Süden begrenzt, sondern umfassen beispielsweise auch das Konzept der Hotspots an den europäischen Außengrenzen in Griechenland und Italien (vgl. Europäischer Rechnungshof 2017; Markard/Heuser 2016) und Erstaufnahmelager sowie sogenannte Gemeinschaftsunterkünfte in Deutschland (vgl. Hofmann/Scherr 2017; Wendel 2014; Müller 2013: 22f.).

Hier haben politische Entscheidungsträger seit der »Flüchtlingskrise« 2015 zunehmend verschiedene Steuerungsmaßnahmen und Unterbringungskonzepte entwickelt, um auf den vermehrten Zuzug von Geflüchteten zu reagieren. Diese variieren von Bundesland $\mathrm{zu}$ Bundesland. In Bayern hat die Landesregierung im Jahr 2018 sogenannte »AnkER-Zentren« (Ankunfts-, Entscheidungs- und Rückführungszentren) ${ }^{1}$ eingeführt. Hierbei handelt es sich um ein Lagerkonzept, in dem Geflüchtete im Sinne einer Aufnahmeeinrichtung zentral untergebracht werden mit dem Ziel, ihre Asylanträge in kürzeren Zeiträumen vor Ort zu bearbeiten und Menschen mit schlechter Bleibeperspektive zu einer schnelleren Ausreise zu bewegen. Da es sich bei Lagern in der Regel um geografisch separierte, temporär angelegte Räume handelt, werden vorzugsweise leerstehende Armeequartiere oder bereits bestehende Sammelunterkünfte, welche aufgrund ihrer Vornutzung räumlich abgegrenzt sind, in Ankerzentren umgewandelt. ${ }^{2}$ So werden die Untergebrachten von ihrem Umfeld weitgehend abgeschottet und auch sozial isoliert. Diese Praxis hat erhebliche öffentliche Kritik hervorgerufen (vgl. u.a. Bayerischer Flüchtlingsrat 2019; BAfF 2018; Der Paritätische Gesamtverband 2018; Flüchtlingsrat Niedersachsen 2018) und Wissenschaftler*innen beschreiben die Folgen für die Kommunen, in denen solche Zentren entstanden sind, als auch für die Geflüchteten selbst, weitgehend als negativ:

»Die Zentren werden als Fremdkörper in oder neben der Kommune wahrgenommen. Es steht zu erwarten, dass sie wie andere segregierte Gemeinschaftsunter-

Obwohl die Einrichtung von AnkER-Zentren in den Bundesländern im »Masterplan Migration « von Bundesinnenminister Horst Seehofer vorgesehen ist und auch im Koalitionsvertrag 2018 zwischen CDU und SPD festgeschrieben wurde, haben bislang nur Bayern (7) sowie Sachsen und das Saarland (jeweils 1) AnkER-Zentren etabliert (vgl. Reiter/Töller 2019: 210f.). Die Autorinnen beziehen sich in diesem Beitrag auf das politische Konzept des AnkERZentrums. Aufgrund der Einheitlichkeit der Darstellung in diesem Sammelband wird jedoch die Schreibweise »Ankerzentrum« verwendet. 
künfte zudem Zielscheibe gewaltsamer, oft rechtsextremer Mobilisierung werden. Isolation und nicht Integration wird die Folge sein.« (Hess et al. 2018: 8)

Diese räumliche Abgrenzung einer Gruppe von Menschen und die damit verbundenen Folgen, wie beispielsweise unterbundene Kontaktmöglichkeiten, untermauert die Separation der Geflüchteten im Lager und der lokalen Bevölkerung draußen (vgl. Agier 2011: 4) und begünstigt ein Denken in den Kategorien »Wir« und »die Anderen«. Damit forciert es die Wahrnehmung des »Anderen« als fremd und nichtzugehörig, da denjenigen im Lager durch räumliche und soziale Ausgrenzungspraktiken, Überwachung und eingeschränkte Rechte begegnet wird. »Die Anderen « können somit scheinbar nicht ohne weiteres in die bestehende Ordnung eingefügt werden (vgl. Bauman 1995). Diese Behandlung trägt zur Bildung und Verfestigung von Vorurteilen bei (vgl. Hess et al. 2018: 9; Allport 1954), indem der separierten Gruppe ein Bedrohungspotenzial gegenüber der bestehenden Gesellschaft und ihres Zusammenhalts, kurz ihrer Ordnung, zugeschrieben wird.

$\mathrm{Zu}$ Lagern weltweit und den Auswirkungen dieser Unterbringungsform auf die darin lebenden Menschen wurden umfassende empirische Analysen angefertigt (vgl. u.a. Turner 2016; Missbach 2013; Jaji 2012; Agier 2011; Inhetveen 2010; Pieper 2008; Panagiotidis/Tsianos 2007). Das spezielle Konzept der Ankerzentren wurde bisher vornehmlich durch zivilgesellschaftliche und humanitäre Akteur*innen sowie politischen Parteien durch Positionspapiere und Stellungnahmen kommentiert (vgl. u.a. ANKER-WATCH.de 2020; Bayerischer Flüchtlingsrat 2019; Die Fraktion der Grünen in Bayern 2019; UNHCR 2018) und von Wissenschaftler*innen diskutiert (vgl. u.a. Hess et al. 2018). Vor allem hat sich bislang keine Studie auf die bayerische Bevölkerung und ihre Einstellungen zu Ankerzentren fokussiert.

Daher widmet sich dieser Beitrag, vor dem Hintergrund der Abgrenzung Geflüchteter von der Gesellschaft durch die zentrale Unterbringung in Ankerzentren, der Frage, wie die bayerische Bevölkerung die resultierende Immobilisierung und Isolation der untergebrachten Geflüchteten wahrnimmt und von welchen Faktoren die Befürwortung einer zentralen Unterbringung beeinflusst wird. Diesen Fragen wurde durch eine repräsentative Online-Befragung der bayerischen Bevölkerung von Februar bis März 2020 nachgegangen. ${ }^{3}$

Im Folgenden gibt der Beitrag zunächst einen Überblick über den Stand der Literatur zur Unterbringung Geflüchteter in Lagern und der Forschung zu Einstellungen hierzu. Anschließend wird die forcierte Trennung zwischen einem »Wir« und »den Anderen«, die in Lagern isoliert werden, theoretisch in die Überlegungen des Soziologen Zygmunt Baumans und seine Arbeit zu Abgrenzung und Fremdheit

3 Die Befragung wurde ermöglicht durch die proFOR+-Förderung des Zentrums für Forschungsförderung (ZFF) der Katholischen Universität Eichstätt-Ingolstadt. 
eingebettet. Daran schließt sich die Vorstellung der Befragung und ihrer Entstehung an, ehe die empirischen Ergebnisse der Online-Umfrage bezüglich der Bewertung des Unterbringungskonzepts Ankerzentrum dargestellt werden und das Fazit die zentralen Erkenntnisse der Studie zusammenfasst sowie einen Ausblick auf weitere Forschung gibt.

\section{Einstellungen zu Geflüchteten und ihrer Unterbringung in der Literatur}

Geflüchtete werden seit den 1980er Jahren in Deutschland in Lagern untergebracht. Die Bundesrepublik führte diese Praxis als eine politische Maßnahme ein, um die Anzahl neuer Asylbewerber*innen zu reduzieren. Von der Lagerunterbringung versprach man sich zunächst Abschreckung und eine Senkung der Antragszahlen, in dem man Lebensbedingungen für Ankommende verschlechterte (vgl. Pieper 2008: 45ff.). Für Pieper stellt die Lagerunterbringung die "materielle Struktur« (ebd.:342) einer Strategie der Verhinderung von Migrationsbewegungen nach Deutschland sowie der Überwachung Asylsuchender dar, die auf institutionellem Rassismus basiert. Ankerzentren lassen sich als eine Fortführung eines solchen Systems begreifen. Da es sich bei ihnen allerdings um ein relativ neues Konzept handelt, beginnen Forschende erst jetzt mit der Analyse des Phänomens (vgl. u.a. Göler 2020; Rohmann 2019). Studien, die nach 2015 entstanden sind, beleuchten die Unterbringung Geflüchteter in Gemeinschaftsunterkünften und die kommunale Unterbringungspraxis, die von Bundesland zu Bundesland variiert (vgl. Elle/Hess 2017; Hofmann/Scherr 2017). Ein Thema ist hierbei die Erforschung von Konflikten in der Unterbringung Geflüchteter. Bauer (2017) sowie Christ et al. (2017) argumentieren, dass es vor allem die strukturellen Faktoren im Zusammenhang mit dieser Unterbringungsform sind, die Konflikte entstehen lassen: Menschen unterschiedlicher Herkunft leben mit wenig bis keiner Privatsphäre auf engstem Raum zusammen, haben kaum Beschäftigungsmöglichkeiten und sind von der übrigen Gesellschaft abgeschnitten. Der dadurch entstehende Autonomieverlust und die Folgen für das eigene Selbstwertgefühl bieten einen Nährboden für Konflikte (vgl. Christ et al. 2017: 5).

Quantitative Erhebungen mit speziellem Fokus auf die Unterbringung Geflüchteter im deutschen Kontext sowie zur Einstellung der Bevölkerung dazu fehlen bislang. Vorhandene Umfragen haben einen Schwerpunkt auf sozialpsychologischen Konzepten, häufig mit Bezug zur Gruppenbezogenen Menschenfeindlichkeit (GMF). Hier sind vor allem die »Mitte-Studien« sowie die »ZuGleich-Studien« von Andreas Zick und Kolleg*innen zu nennen. Erstere untersuchen unter dem Konzept der GMF auch rechtsextreme Einstellungen, Gewalteinstellungen, kollektive Wut sowie ideologische und politische Meinungen (vgl. Zick/Küpper/Berghan 2019; Zick et al. 2016; Zick/Klein 2014; Decker/Kiess/Brähler 2012). Die Mitte-Studie 
2016 beschäftigt sich unter anderem auch mit den Themen Flucht und Geflüchtete, geht aber nicht auf Unterbringungspraktiken, Immobilität oder Isolation ein. So wird deutlich, dass die Hälfte der Befragten (56\%) die Aufnahme von Flüchtlingen gut findet (vgl. Zick et al. 2016: 86) und mehr als zwei Drittel (76\%) eher oder sehr hoffnungsvoll ist, dass es der Gesellschaft gelingt, die aktuelle Situation zu bewältigen (vgl. ebd.: 98).

Aufgrund der Entwicklungen im Jahr 2015 wurden Umfragen erstellt, um die Meinung der deutschen Bevölkerung zur aktuellen Situation widerzuspiegeln. Das Sozialwissenschaftliche Institut der Evangelischen Kirche in Deutschland (EKD) führte eine solche durch und kam darin u.a. zu dem Ergebnis, dass die dezentrale Unterbringung den direkten Kontakt zwischen Geflüchteten und lokaler Bevölkerung fördert und somit zu erhöhter Akzeptanz und Integration beiträgt (vgl. Ahrens 2017: 36, 63). In einer etwas älteren Befragung zur Haltung der deutschen Bevölkerung zu Asyl und Asylbewerber*innen zeigte die Robert Bosch Stiftung auf, dass der Anteil der Menschen, die die Errichtung einer Unterkunft für Asylbewerber*innen in ihrem Ort ablehnen von 37 Prozent (1992) auf 24 Prozent (2014) gesunken ist, während die Unterstützung für die Einrichtung im gleichen Zeitraum gestiegen ist ${ }^{4}$ (vgl. Robert Bosch Stiftung 2014: 28-31). Weitere quantitative Befragungen in Deutschland zeichnen sich dahingehend eher durch einen Fokus auf Integration, Aufnahmebereitschaft der Bevölkerung und Zuwanderungsfragen aus (vgl. Kober/Kösemen 2019; Zick/Preuß 2019).

Keine Erhebung im deutschen Kontext geht explizit auf die Einschätzung der Bevölkerung zu Unterbringungssituationen Geflüchteter ein. Auch Ankerzentren wurden aus dieser Perspektive noch nicht betrachtet. Bisher durchgeführte quantitative Befragungen beziehen sich in ihrem Forschungsdesign ausschließlich auf Gesamtdeutschland und lassen im besten Fall Ost-West- bzw. Bundesländervergleiche, jedoch keine kleinräumigeren Analysen zu. Allein das Integrationsbarometer ermöglicht durch eine Sonderauswertung 2018 eine detailliertere Betrachtung Bayerns. Allerdings beschränkt sich diese auch auf das Thema Integration und dessen Bewertung durch Menschen mit und ohne sogenannten Migrationshintergrund (vgl. SVR-Forschungsbereich 2018).

Die bislang geringe wissenschaftliche Auseinandersetzung mit dem Phänomen Ankerzentrum und besonders die mangelnden Einblicke in die Rezeption der Gesellschaft diesbezüglich bilden den Ausgangspunkt für erste Analysen zur Wahrnehmung dieser Unterbringungsform durch die bayerische Bevölkerung. gegen eine Bürgerinitiative geben würde, die Unterschriften gegen dieses Wohnheim sammelt, würden Sie dann auch unterschreiben, oder würden Sie das nicht tun?« (Robert Bosch Stiftung 2014: 31). 


\section{Theoretische Überlegungen zum (Lager-)Konzept der Ankerzentren}

Gerade die Praxis der Ankerzentren als ein Lagerkonzept verstärkt eine Teilung in »Wir« und »die Anderen«. So betont es auch das Konzept der Fremdheit, mit dem sich bereits Anfang des 20. Jahrhunderts Soziologen wie Alfred Schütz und Georg Simmel auseinandersetzten (vgl. Schütz [1944] 1972; Simmel [1908] 1958). Fremdheit zeichnet sich durch die drei zentralen Aspekte Nichtzugehörigkeit, Unvertrautheit und Ferne aus. Es ist kein festes Konstrukt, sondern eine subjektive Zuschreibung, die auf der eigenen Positionierung und dem eigenen Selbstbild basiert, und so eine Einteilung in »Wir« und »die Anderen« ermöglicht (vgl. Kleinert 2004). Die Unterscheidung zwischen »Wir« und »den Anderen« beruht auf einer »kognitive[n] Struktur, die unser Wissen, unsere Überzeugungen und Erwartungen über eine soziale Gruppe von Menschen enthält« (Pendry 2014: 111). Jede Gruppe kann demzufolge Ziel von Fremdheitsstereotypen und Vorurteilen werden (vgl. Reuter/Warrach 2015: 175).

Dass das Fremde auch als Bedrohung der bestehenden Ordnung wahrgenommen wird, ist ein Grundgedanke des Soziologen Zygmunt Bauman. In seinen Analysen der Moderne beschäftigt sich Bauman mit Globalisierung und Migration, da Einwandernde die Prozesse und Dynamiken einer Gesellschaft und somit deren Ordnung aufwühlen (vgl. Bauman 2016, 1996). Bauman argumentiert, dass aufgrund vielfältiger Veränderungsprozesse auf allen Ebenen der Gesellschaft, einer zunehmenden Individualisierung, steigender Lebenserwartung, technologischen Veränderungen und Migrationsbewegungen, Menschen heute Angst vor der $\mathrm{Zu}$ kunft und einer Verschlechterung ihrer Lebensverhältnisse haben (vgl. Bauman 2017: 77). Gerade Einwanderung bringt Komplexität und Unbehaglichkeit für bestehende gesellschaftliche Ordnungen mit sich. Daher werden Einwandernde bzw. Fremde oftmals von der Gesellschaft abgewertet und ausgegrenzt, um ein vermeintlich homogenes Konzept von gemeinschaftsbildender Nationalstaatlichkeit aufrecht zu erhalten (vgl. Messerschmidt 2015: 221).

Die Anwesenheit bzw. Sichtbarkeit Geflüchteter im eigenen Lebensumfeld steigert das Angstgefühl der Machtlosigkeit gegenüber Veränderungsprozessen noch einmal. Diese gesellschaftlichen Dynamiken gehen einher mit politischen Entscheidungen zum Umgang mit geflüchteten Menschen, welche die Fremdheit von Geflüchteten forcieren. Sie unterstreichen deren Bedrohung einer bestehenden Ordnung. Daher wird ihnen mit Aus- und Abgrenzungspraktiken, wie zum Beispiel durch die Unterbringung in Ankerzentren, begegnet, um eine Vorstellung von Ordnung und Sicherheit zu etablieren, indem Kontrolle über die Separierten ausgeübt wird. Vor diesem Hintergrund zielt diese Untersuchung darauf ab, wie Ankerzentren von der bayerischen Bevölkerung für die Unterbringung Geflüchte- 
ter wahrgenommen werden und wie die damit einhergehende Immobilität und Isolation Geflüchteter bewertet wird.

\section{Forschungsdesign}

Die Studie widmet sich der Einstellung der bayerischen Bevölkerungen gegenüber den 2018 eingeführten Ankerzentren.

\section{Fragebogenkonstruktion und Operationalisierung}

Die Befragten gaben ihre Wahrnehmung der Ankerzentren anhand verschiedener Dimensionen an, welche vorab anhand einer Dokumentenanalyse ${ }^{5}$ ermittelt wurden. Für diesen Beitrag wurde der Schwerpunkt insbesondere auf die Bewertung der zentralen Unterbringungsform, der damit verbundenen Isolation und Immobilität der Bewohner*innen sowie die Unterbringungsdauer gesetzt.

Aufgrund des neuartigen Themas wurden die jeweiligen Items zur Erfassung der oben genannten Bereiche eigens konstruiert ${ }^{6}$. Für weitere Konzepte (wie z.B. Autoritarismus oder Law-and-Order-Einstellungen) wurde auf bereits bestehende und getestete Items und Skalen zurückgegriffen.

\section{Datenerhebung und Beschreibung der Stichprobe}

Die Datenerhebung erfolgte mittels einer Onlinebefragung über ein Online Access Panel im Zeitraum vom 13. Februar bis 02. März 2020. Aufgrund des speziellen Schwerpunktes auf Ankerzentren wurde eine für Bayern repräsentative Umfrage durchgeführt, welche anhand von Alter (ab 18 Jahren, vier Altersgruppen nach der tatsächlichen Verteilung innerhalb der bayerischen Bevölkerung, Mittelwert

Hierbei handelt es sich um die Herausarbeitung der verschiedenen Positionen bezüglich Ankerzentren durch die in der Einleitung aufgeführten Positionspapiere und Stellungnahmen sowie Einblicke aus der Sachverständigenanhörung des Ausschusses für Verfassung, Recht, Parlamentsfragen und Integration zum Thema »Anker-Einrichtungen in Bayern« am 26.09.2019 im Bayerischen Landtag, die daraus hervorgehenden interfraktionellen Anträge sowie die daraus resultierenden Presseberichte (vgl. u.a. Guyton 2019; Mittelbayerische 2019; Süddeutsche Zeitung 2019; Bayerischer Rundfunk 2019).

6 Der entwickelte Fragebogen wurde mittels EFS/Unipark zweimal einem Pretest unterzogen. Der erste Pretest wurde an insgesamt zehn Expert“innen mit Erfahrung in der Fragebogenkonstruktion versandt (Zeitraum: 28.11. bis 10.12.2019). Nach der Einarbeitung dieser Kommentare wurde der Fragebogen an eine Personengruppe $(n=34)$ geschickt, die möglichst hohe Ähnlichkeit mit der tatsächlichen Zielgruppe hatte (Zeitraum: 19.12.2019 bis 31.01.2020). Der zweite Pretest diente vor allem dazu, die Bearbeitungszeit zu ermitteln sowie Probleme beim Verständnis der Fragen aufzudecken. 
46,81 Jahre), Geschlecht (50\% Männer, 50 \% Frauen), Regierungsbezirk (gleichverteilt über alle sieben Bezirke) und Bildungsniveau ${ }^{7}$ (niedrig, mittel, hoch) quotiert wurde. Angestrebt wurde eine möglichst hohe Teilnehmendenzahl, um in den Analysen Gruppengrößen zu erreichen, die Vergleiche erlauben. Die realisierte Stichprobengröße beträgt insgesamt 890 Personen $^{8}$ (siehe Tabelle 1).

Tabelle 1: Deskriptive Beschreibung der genutzten Variablen und Skalen

\begin{tabular}{|l|r|r|r|}
\hline Variable & \multicolumn{1}{|l|}{ Fallzahl } & \multicolumn{1}{l|}{$\begin{array}{l}\text { gültige } \\
\text { Prozent }\end{array}$} & \multicolumn{1}{l|}{ Prozent } \\
\hline Geschlecht & 890 & & 50,00 \\
\hline weiblich & 445 & 50,00 & 99,89 \\
\hline männlich & 444 & 49,89 & 100,00 \\
\hline divers & 1 & 0,11 & 19,89 \\
\hline Alter & 890 & & 45,84 \\
\hline 18-30 Jahre (20,4\%) & 177 & 19,89 & 77,87 \\
\hline 31-45 Jahre (26,1\%) & 231 & 25,96 & 100,00 \\
\hline $46-60$ Jahre (31,8\%) & 285 & 32,02 & \\
\hline $61-75$ Jahre (21,7\%) & 197 & 22,13 & 33,93 \\
\hline Bildungsniveau & 890 & & 67,08 \\
\hline niedrig & 302 & 33,93 & 100,00 \\
\hline mittel & 295 & 33,15 & \\
\hline hoch & 293 & 32,92 & 43,03 \\
\hline Kontakt zu Ceflüchteten & 890 & & 100,00 \\
\hline nein & 383 & 43,03 & \\
\hline ja & 507 & 56,97 & \\
\hline
\end{tabular}

7 Die Bildungsniveaus wurden wie folgt eingeteilt: niedrig (kein Schulabschluss, Hauptoder Volkshochschulabschluss, POS 8./9. Klasse, noch in der Schule), mittel (Realschulabschluss/Mittlere Reife, POS 10. Klasse oder gleichwertiger Abschluss, sonstiger Abschluss) und hoch (Abitur oder (Fach-)Hochschulreife, FOS, BOS).

8 Da die Anzahl der Antworten konstant bei 890 Personen bleibt, wird diese im weiteren Verlauf nicht extra ausgewiesen. Für Unterschiede zwischen den Geschlechtern wird die Antwort »divers « ausgeschlossen, weshalb in diesem Fall nur 889 Antworten für die Analyse zur Verfügung stehen und ebenfalls nicht mehr gesondert ausgewiesen werden. Die Fallzahl für die Lebenszufriedenheit liegt aufgrund fehlender Antworten bei $n=844$. 


\begin{tabular}{|c|c|c|c|c|c|}
\hline Verwendete Skalen & Fallzahl & Mittelwert & $\begin{array}{l}\text { Standard- } \\
\text { abweichung }\end{array}$ & Min. & Max. \\
\hline Immobilität & 890 & 2,92 & 1,02 & 1 & 5 \\
\hline Isolation & 890 & 2,71 & 0,97 & 1 & 5 \\
\hline Law-and-Order & 890 & 3,54 & 1,08 & 1 & 5 \\
\hline Autoritarismus & 890 & 3,15 & 0,79 & 1 & 5 \\
\hline neg. Einstellungen ggü. Juden & 890 & 2,82 & 1,46 & 1 & 7 \\
\hline neg. Einstellungen ggü. Islam & 890 & 4,44 & 1,66 & 1 & 7 \\
\hline $\begin{array}{l}\text { neg. Einstellungen ggü. Auslän- } \\
\text { der*innen }\end{array}$ & 890 & 4,25 & 1,38 & 1 & 7 \\
\hline Anomie & 890 & 3,37 & 0,73 & 1 & 5 \\
\hline Entfremdung & 890 & 3,83 & 0,87 & 1 & 5 \\
\hline Lebenszufriedenheit & 844 & 67,21 & 21,88 & 0 & 100 \\
\hline $\begin{array}{l}\text { eigene wirtschaftliche Lage in } 1 \\
\text { Jahr }\end{array}$ & 890 & 2,99 & 0,74 & 1 & 5 \\
\hline
\end{tabular}

Anmerkung: tatsächliche Altersverteilung in der bayerischen Bevölkerung in Klammern (Bayerisches Landesamt für Statistik 2019: 244).

\section{Unterbringung in Ankerzentren? - Eine Frage spaltet den Freistaat}

Die Frage nach der Unterbringungsform - ob zentral in einem Ankerzentrum, dem bestimmte ausgrenzende und einschränkende Merkmale zugeschrieben werden, oder dezentral in einzelnen Wohnungen in verschiedenen Kommunen, welche den Kontakt mit der Bevölkerung vor Ort fördert, spaltet die Befragten. Doch wie zeigt sich die Spaltung in der Unterbringungsfrage bezogen auf die erzwungene Immobilität und Isolation der Bewohner*innen und was beeinflusst die Befürwortung bzw. Ablehnung der jeweiligen Unterbringungsart? Diese Fragen werden in den folgenden Auswertungskapiteln beantwortet.

\section{Einschätzungen zur Unterbringungsform Geflüchteter}

»Wenn Sie entscheiden könnten, wie Geflüchtete untergebracht werden sollten, welche Form würden Sie wählen? 1) zentrale Unterbringung in einem Ankerzentrum oder 2) dezentrale Unterbringung in einzelnen Wohnungen in den Kommunen« (Frage 58). 
Zwei Drittel der Befragten $(66,40 \%, \mathrm{n}=591)$ befürworten die zentrale Unterbringungsform. Nur ein Drittel $(33,60 \%, n=299)$ spricht sich für eine dezentrale Unterbringung aus. Es zeigt sich, dass das Geschlecht keine Rolle bei der Entscheidung für eine Unterbringungsform spielt. Interessant ist hierbei jedoch, dass sich junge Erwachsene (18 bis 30 Jahre) signifikant von den restlichen drei Altersgruppen unterscheiden. Nur 55,37 Prozent dieser Altersgruppe sieht die Notwendigkeit einer zentralen Unterbringung, während es in den restlichen Altersgruppen zwischen 68,83 Prozent und 69,74 Prozent sind. Auffallend ist auch, dass vor allem Personen mit einem hohen Bildungsniveau eine dezentrale Form der Unterbringung $(45,39 \%)$ fordern. Personen mit einem geringen $(25,17 \%)$ oder mittleren $(30,51 \%)$ Bildungshintergrund tun dies signifikant seltener.

Diese Spaltung, vor allem bezogen auf das Bildungsniveau und das Alter, zeigt sich einerseits bei näherer Betrachtung einzelner Analysekategorien der Unterbringungsform Ankerzentrum, wie die Bewertung der erzwungenen Immobilität der Bewohner*innen, welche diese von ihrem Umfeld isoliert, und der Aufenthaltsdauer in dieser Unterbringungsform andererseits.

\section{Immobilität und Isolation der Bewohner*innen von Ankerzentren}

Durch die Unterbringung in Ankerzentren wird nicht nur die Bewegungsfreiheit Geflüchteter massiv eingeschränkt, diese erzwungene Immobilität, also der Zwang an einem Ort bleiben zu müssen (vgl. Etzold 2019: 8), fördert auch gleichzeitig ihre Isolation, worunter die räumliche und soziale $\mathrm{Ab}$ - und Ausgrenzung der Bewohner*innen verstanden wird.

Das Konzept der Immobilität wurde mit insgesamt vier Items ${ }^{9}$ abgefragt: kein Verlassen, da alle Einrichtungen vor Ort, keine Bewegungsfreiheit über Stadtbzw. Landkreisgrenzen, Verbot der Arbeitsaufnahme und Verlassen nur für Arztoder Schulbesuche (siehe Tabelle 2). Es zeigt sich, dass die Teilnehmenden an der Online-Befragung mehrheitlich gegen Bewegungsfreiheit der Asylbewerber"innen über Stadt- bzw. Landkreisgrenzen hinweg sind $(3,46)$. Allerdings findet sich beim Verbot einer Arbeitsaufnahme die geringste Zustimmung im Bereich der Immobilität $(2,47)$. Personen, die dem Konzept der Unterbringung im Ankerzentrum positiv gegenüberstehen, befürworten signifikant häufiger das Verbot, die Einrichtung verlassen zu dürfen, da alle Einrichtungen des täglichen Bedarfs vor Ort sind $(3,43$ vs. 2,05$)$ sowie die Ausnahme davon lediglich für Schul- oder Arztbesuche zu genehmigen (3,12 vs. 2,16). Dementsprechend häufiger sprechen sie sich gegen die Bewegungsfreiheit über Stadt- bzw. Landkreisgrenzen hinweg aus $(2,16$ vs. 3,29). Ein geringerer Teil der Befürworter"innen der zentralen Unterbringung spricht sich hingegen für ein Arbeitsverbot aus (2,81 vs. 1,81). 
Für den Faktor Immobilität ${ }^{10}$ zeigt sich die Spaltung der Befragten weiterhin deutlich. Während die Unterstützer*innen der zentralen Unterbringung die erzwungene Immobilität der Bewohner*innen mehrheitlich als hinnehmbar akzeptieren (56,35\%), lehnen die Gegner*innen diese mehrheitlich ab (79,60\%). Frauen befürworten die Immobilität der Geflüchteten signifikant weniger $(2,76)$ als Männer $(3,09)$. Ebenso sehen jüngere Personen (18 bis 30 Jahre) die erzwungene Immobilität kritischer $(2,57)$ als ältere Personengruppen. Signifikant geringere Zustimmungswerte für die Immobilität von Asylbewerber*innen gehen auch mit einem hohen Bildungsniveau einher.

Durch die hohe Korrelation $(r=.7592)$ zwischen Immobilität und Isolation zeigen sich ähnliche Ergebnisse auch im Bereich der Einstellungen zur Isolation der Bewohner*innen in abgeschotteten Ankerzentren. Personen, die Geflüchtete bevorzugt in Ankerzentren unterbringen wollen, befürworten die Praxis der Isolation $^{11}$ signifikant höher $(3,09)$ als Personen, die eine dezentrale Unterbringung fordern (1,96). Männer befürworten die erzwungene Isolation der Asylbewerber*innen auch signifikant stärker $(2,80)$ als Frauen $(2,62)$, obwohl die Zustimmung hier insgesamt eher gering ist. 18- bis 30-Jährige weisen hier auch signifikant geringere Zustimmungswerte zur Isolation von Geflüchteten $(2,47)$ auf als 31- bis 45 -Jährige $(2,76)$ und 46 - bis 60 -Jährige $(2,86)$. Personen mit einem niedrigen $(2,73)$ oder mittlerem $(2,90)$ Bildungsniveau sehen die gewollte Isolation ebenfalls weniger kritisch als Personen mit einem hohen Bildungsniveau $(2,49)$.

So zeigen sich bei den Einstellungen gegenüber der erzwungenen Immobilität der Bewohner*innen der Ankerzentren sowie der damit verbundenen Isolation von der Gesellschaft große Ähnlichkeiten, da sie vor allem von Frauen, Hochgebildeten, jungen Personen sowie denjenigen, die eine dezentrale Unterbringung fordern, abgelehnt und kritisiert werden.

\section{Kurze Unterbringungsdauer für Integration und Rückführung}

Zentral ist die Frage, wie die Befragten die propagierte kurze Unterbringungsdauer von maximal drei Monaten bewerten. Diese soll sowohl eine schnelle Integration

10 Eine Faktorenanalyse zeigte auf, dass alle vier Variablen auf einem gemeinsamen Faktor »lmmobilität« laden (Ladungswerte zwischen 0,64 bis 0,86; Eigenwert 2,02). Der Mittelwert der Skala »Immobilität« beträgt 2,92 (Std. Dev. 1,02, Minimum =1, Maximum = 5; Cronbachs Alpha $=0,797)$.

11 Eine Faktorenanalyse bestätigte den gemeinsamen Faktor »Isolation«, auf dem alle sechs Items (Lage am Stadtrand; Isolation von der Gesellschaft; Zugang für Ehrenamtliche; Förderung des Austauschs mit der ansässigen Bevölkerung; Teilhabe am gesellschaftlichen Leben außerhalb; Besuch einer Regelschule) laden (Ladungswerte zwischen 0,58 bis 0,92; Eigenwert 3,64). Der Mittelwert der Skala »lsolation« beträgt 2,71 (Std. Dev. 0,97, Minimum = 1, Maximum = 5; Cronbachs Alpha =0,897). 


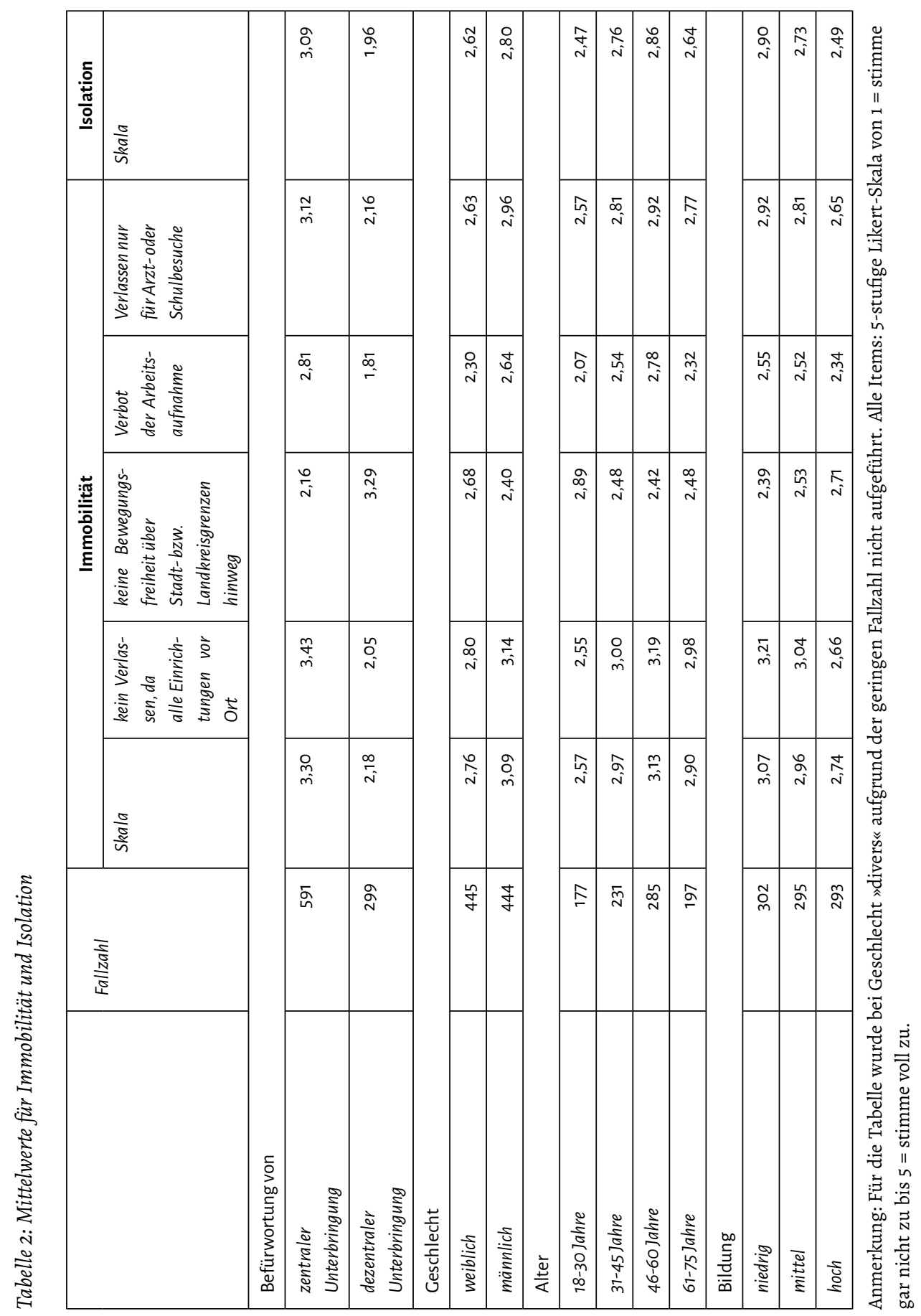


nach der Erteilung der Aufenthaltserlaubnis sowie die schnellstmögliche Rückführung von abgelehnten Asylbewerber*innen ermöglichen. Unabhängig davon ist eine möglichst kurze Verweildauer für Familien mit Kindern vorgesehen.

Entsprechend ihrer Einstellung gegenüber der Unterbringungsform zeigt sich auch hier eine gewisse Konsistenz (siehe Tabelle 3). Befürworter*innen der dezentralen Form stimmen einer maximalen Aufenthaltsdauer von drei Monaten für Familien mit Kindern (4,40 vs. 3,92) stärker zu. Des Weiteren stimmen sie einer möglichst kurzen Aufenthaltsdauer gefolgt von einer schnellen Integration in die Gesellschaft $(4,35$ vs. 3,40) signifikant häufiger zu. Auch die Unterstützer*innen der zentralen Unterbringung weisen eine signifikant höhere Zustimmung zu einer möglichst kurzen Aufenthaltsdauer auf. Allerdings liegt dieser die Erwartung einer schnellstmöglichen Rückführung zugrunde (4,30 vs. 3,70).

Auffällig ist, dass vor allem die Befragten zwischen 61 und 75 Jahren eine kurze Aufenthaltsdauer von Familien mit Kindern befürworten $(4,29)$, im Gegensatz $\mathrm{zu}$ den 31- bis 45 -Jährigen $(4,00)$ und den 46 - bis 60-Jährigen $(4,03)$. Eine schnelle Integration der Geflüchteten wird ebenfalls von den 61- bis 75 -Jährigen $(3,91)$ sowie von den 18- bis 30-Jährigen $(3,97)$ häufiger gefordert als von den 31- bis 45-Jährigen $(3,58)$ und den 46 - bis 60-Jährigen $(3,54)$. Dass Personen mit einem hohen Bildungsniveau signifikant öfter kurzen Aufenthaltsdauern für Familien mit Kindern $(4,26)$ sowie der Förderung einer schnellen Integration $(3,97)$ zustimmen, zeigt sich auch in der Bewertung der Unterbringungsdauer im Vergleich zu Befragten mit mittlerem $(4,05$ und 3,70) sowie geringem $(3,93$ und 3,49) Bildungsgrad. Bei der Frage nach der kurzen Aufenthaltsdauer für eine schnellstmögliche Rückführung kehrt sich dieses Bild um, und Hochqualifizierte $(3,93)$ haben hier signifikant geringere Zustimmungswerte als diejenigen mit mittlerem $(4,18)$ und geringem $(4,18)$ Bildungsniveau.

Demzufolge setzt sich die Spaltung zwischen Befürworter*innen und Gegner*innen der Ankerzentren auch beim Aspekt der Unterbringungsdauer fort und beide Gruppen bleiben konstant in ihren Einschätzungen. 
Tabelle 3: Mittelwerte für die Items zur Unterbringungsdauer

\begin{tabular}{|c|c|c|c|c|}
\hline & \multirow{2}{*}{ Fallzahl } & \multicolumn{3}{|c|}{ Unterbringungsdauer } \\
\hline & & $\begin{array}{l}\text { max. } 3 \text { Monate } \\
\text { für Familien } \\
\text { mit Kindern }\end{array}$ & $\begin{array}{l}\text { max. } 3 \text { Monate } \\
\text { gefolgt von einer } \\
\text { schnellen } \\
\text { Integration }\end{array}$ & $\begin{array}{l}\text { max. } 3 \text { Monate } \\
\text { gefolgt von einer } \\
\text { schnellen } \\
\text { Rückführung }\end{array}$ \\
\hline \multicolumn{5}{|c|}{ Befürwortung von } \\
\hline $\begin{array}{l}\text { zentraler } \\
\text { Unterbringung }\end{array}$ & 591 & 3,92 & 3,40 & 4,30 \\
\hline $\begin{array}{l}\text { dezentraler } \\
\text { Unterbringung }\end{array}$ & 299 & 4,40 & 4,35 & 3,70 \\
\hline \multicolumn{5}{|l|}{ Geschlecht } \\
\hline weiblich & 445 & 4,05 & 3,78 & 4,09 \\
\hline männlich & 444 & 4,10 & 3,66 & 4,10 \\
\hline \multicolumn{5}{|l|}{ Alter } \\
\hline 18-30 Jahre & 177 & 4,02 & 3,97 & 3,79 \\
\hline 31-45 Jahre & 231 & 4,00 & 3,58 & 4,07 \\
\hline 46-60 Jahre & 285 & 4,03 & 3,54 & 4,21 \\
\hline 61-75 Jahre & 197 & 4,29 & 3,91 & 4,22 \\
\hline \multicolumn{5}{|l|}{ Bildung } \\
\hline niedrig & 302 & 3,93 & 3,49 & 4,18 \\
\hline mittel & 295 & 4,05 & 3,70 & 4,18 \\
\hline hoch & 293 & 4,26 & 3,97 & 3,93 \\
\hline
\end{tabular}

Anmerkung: Für die Tabelle wurde bei Geschlecht »divers« aufgrund der geringen Fallzahl nicht aufgeführt. Alle Items: 5 -stufige Likert-Skala von $1=$ stimme gar nicht $\mathrm{zu}$ bis $5=$ stimme voll zu.

\section{Was beeinflusst die Befürwortung einer zentralen oder dezentralen Unterbringungsform?}

Die oben dargestellten Ergebnisse zeigen, dass der Bruch zwischen den Befürworter*innen der jeweiligen Unterbringungsform auch über die einzelnen Teil- bzw. Unteraspekte besteht, was auf eine verfestigte Einstellung der Befragten hindeutet. Es bleibt die Frage, was die Entscheidung für eine zentrale Unterbringung in Ankerzentren oder eine dezentrale Unterbringung in einzelnen Wohnungen in verschiedenen Gemeinden beeinflusst. 
Die theoretischen Überlegungen zu Fremdheit und der forcierten Teilung in ein »Wir« und »die Anderen«, wie es das Konzept der Ankerzentren hervorruft, werden hier als einige mögliche Erklärungsansätze zur Präferenz der Unterbringungsform herangezogen und mit den empirischen Daten der Studie getestet. Fremdheit, die sich in Nichtzugehörigkeit, Unvertrautheit und Ferne widerspiegelt, wird über die Frage, ob Befragte Kontakt zu Geflüchteten ${ }^{12}$ hatten, operationalisiert. Die wahrgenommene Bedrohung der bestehenden Gesellschaft und ihrer Ordnung durch Fremde (Bauman 2016) wird über eine autoritäre Einstellung ${ }^{13}$ (Beierlein et al. 2014) und die Befürwortung von Recht und Ordnung ${ }^{14}$ (Law-andOrder-Positionen, Ulbrich-Herrmann 2014) in das Modell aufgenommen. Negative Vorurteile gegenüber als fremd markierten Gruppen wie Personen muslimischen Glaubens (Einstellung zum Islam, Breyer/Danner 2015), Personen jüdischen Glaubens (Einstellung zu Juden, ZA/ZUMA 2014) und Ausländer*innen (Gesis 2017b) allgemein können ebenfalls einen Einfluss auf die Sichtweise der Unterbringungsform haben. Anomie und politische Entfremdung ${ }^{15}$ (Fischer/Kohr 2014) dienen als Erklärung für die Reaktion auf kontinuierliche Veränderungen unserer Umwelt. Die Angst vor einer Verschlechterung der Lebensverhältnisse (Bauman 2017) wird über die aktuelle Lebenszufriedenheit (Beierlein et al. 2015) sowie über die Einschätzung der eigenen wirtschaftlichen Lage in einem Jahr (Gesis 2017a) dargestellt.

Aufgrund der dichotomen abhängigen Variablen (dezentrale vs. zentrale Unterbringung) wird eine logistische Regression genutzt, bei der die Ergebnisse für die bessere Interpretierbarkeit als sogenannte Odds Ratios (Wahrscheinlichkeiten) dargestellt werden. Als Kontrollvariablen werden das Geschlecht, das Alter sowie das Bildungsniveau in das Modell aufgenommen.

12 Hierbei handelt es sich um ein für diese Studie entwickeltes Item, welches gemeinsam mit Kontakterfahrungen mit Ceflüchteten abgefragt wurde.

13 Unter Autoritarismus werden menschenfeindliche Einstellungen verstanden, welche Vorurteile, Diskriminierung, Konservatismus und Intergruppenkonflikte erklären sollen (vgl. u.a. Oesterreich 2005; Stellmacher/Petzel 2005; Altemeyer 1996; Adorno et al. 1950).

14 Hierbei handelt es sich um die tendenziell allgemeine Abwehr von allem, was als fremd oder bedrohlich wahrgenommen wird, und damit verbunden der Forderung staatliche Mittel einzusetzen (vgl. Ulbrich-Herrmann 2014; Fend 1994).

15 Personen, die sich von der Politik entfremden, haben das Cefühl, dass die Politik sich nicht für ihre Bedürfnisse interessiert, sondern Politiker*innen nur ihre eigenen Interessen vertreten. Anomie hingegen beschreibt das allgemeine Gefühl von vorherrschender Orientierungslosigkeit, Unsicherheit und das Fehlen von Normen, wobei vor allem das Fehlen von deutlichen verbindlichen Handlungsalternativen wahrgenommen wird (vgl. Fischer/Kohr 2014). 
Tabelle 4: Ergebnisse der logistischen Regression

\begin{tabular}{|c|c|c|}
\hline \multicolumn{3}{|l|}{ Unterbringungsform } \\
\hline$(0=$ dezentral $; 1=$ zentral $)$ & Odds Ratio & Std. Error \\
\hline \multicolumn{3}{|l|}{ Geschlecht } \\
\hline Weiblich (Basis: männlich) & 1,268 & 0,250 \\
\hline \multicolumn{3}{|l|}{ Altersgruppen } \\
\hline \multicolumn{3}{|l|}{ Basis: 18-30 Jahre } \\
\hline 30-45 Jahre & 1,002 & 2,670 \\
\hline 46-60 Jahre & 0,731 & 0,206 \\
\hline 61-75 Jahre & 0,863 & 0,268 \\
\hline \multicolumn{3}{|l|}{ Bildungsgruppen } \\
\hline \multicolumn{3}{|l|}{ Basis: niedrig } \\
\hline mittel & 1,054 & 0,500 \\
\hline hoch & 0,867 & 0,214 \\
\hline \multicolumn{3}{|l|}{ Kontakt zu Geflüchteten } \\
\hline \multicolumn{3}{|l|}{ Basis: kein Kontakt } \\
\hline Kontakt & $0,682^{*}$ & 0,128 \\
\hline Law-and-Order & $1,762^{* * * *}$ & 0,272 \\
\hline Autoritarismus & 1,020 & 0,192 \\
\hline neg. Einstellungen ggü. Juden & 1,116 & 0,940 \\
\hline neg. Einstellungen ggü. Islam & 1,123 & 0,100 \\
\hline neg. Einstellungen ggü. Ausländer*innen & $2,083^{* * * *}$ & 0,241 \\
\hline Anomie & $0,579^{* * *}$ & 0,138 \\
\hline Entfremdung & 0,944 & 0,135 \\
\hline Lebenszufriedenheit & 0,997 & 0,005 \\
\hline eigene wirtschaftliche Lage in 1 Jahr & 1,173 & 0,160 \\
\hline
\end{tabular}

Anmerkung: Pseudo $\mathrm{R}^{2}=0,2839, \mathrm{n}=843,{ }^{*}<0,05 ;{ }^{* * *}<0,01 ;{ }^{* * * *}<0,001$

Die Ergebnisse der logistischen Regression ${ }^{16}$ (Tabelle 4) zeigen, dass die Kontrollvariablen (Geschlecht, Alter, Bildungsniveau) keine signifikanten Effekte auf

16 Zur Interpretation der Odds Ratios: Eine Odds Ratio von z.B. 1,2 sagt, dass die Wahrscheinlichkeit, dass ein Ereignis eintritt um den Faktor 1,2 bzw. $20 \%$ steigt. Eine Odds Ratio von z.B. 0,7 sagt, dass die Wahrscheinlichkeit, dass ein Ereignis eintritt, um den Faktor 0,7 bzw. 30\% sinkt. Odds Ratios mit dem Wert 1 zeigen, dass die Wahrscheinlichkeit, dass eines der beiden Ereignisse eintritt, gleich groß ist (gleiches Quotenverhältnis). 
die bevorzugte Unterbringungsform für Geflüchtete haben. Wenn die Befragten jedoch angaben, dass sie mindestens einmal Kontakt zu Geflüchteten hatten (z.B. in der eigenen Familie oder Verwandtschaft, an ihrem Arbeitsplatz, in ihrer Nachbarschaft oder in ihrem sonstigen Freundes- und Bekanntenkreis) sinkt die Wahrscheinlichkeit um 31,8 Prozent, dass sie eine zentrale Unterbringung in einem Ankerzentrum fordern. Steigt die Befürwortung von Law-and-Order-Einstellungen um eine Einheit, wächst auch die Wahrscheinlichkeit um 76,2 Prozent, dass die an der Umfrage Teilnehmenden zentrale Einrichtungen wie das Ankerzentrum als Unterkunft für Asylbewerber*innen befürworten. Interessanterweise sinkt die Wahrscheinlichkeit um 42,1 Prozent, dass die Befragten eine zentrale Wohnform präferieren mit zunehmender Wahrnehmung von Anomie (also einem stärker werdenden Gefühl von Unsicherheit, Normlosigkeit und Orientierungslosigkeit). Dieses Ergebnis erscheint kontraintuitiv. Über den näheren Zusammenhang geben die Daten keine Auskunft. Wie Anomie auf die Wahl der präferierten Unterbringungsform wirkt, bedarf daher weitergehender Forschung. Den stärksten Effekt auf die Entscheidung der Unterbringungsform haben jedoch negative Einstellungen gegenüber Ausländer*innen. Steigen die negativen Einstellungen gegenüber Ausländer*innen um eine Einheit, dann erhöht sich auch die Wahrscheinlichkeit die zentrale Unterbringung wie in einem Ankerzentrum zu befürworten um den Faktor 2,083 bzw. um 108,3 Prozent. Im Rahmen dieser Studie ist es nicht möglich, diese Zusammenhänge tiefgehend aufzuschlüsseln. Es darf jedoch angenommen werden, dass es sich hierbei um eine generelle Ablehnung von Ausländer*innen, bezogen auf die Auswirkungen ihrer Anwesenheit auf das Sozialsystem, den Wohnungsmarkt und Arbeitsplätze, handelt. Die Vorurteile beruhen somit nicht allein auf der Religionszugehörigkeit (zum Islam oder zum Judentum) der Ausländer*innen.

Entgegen der Erwartungen und der Annahmen von Zygmunt Bauman haben Autoritarismus, negative Einstellungen gegenüber Juden und dem Islam sowie eine zunehmende politische Entfremdung keinen Effekt auf die Wahl der Unterbringungsform.

\section{Fazit}

Der zentralen Unterbringung Geflüchteter in sogenannten Ankerzentren in Bayern wird nachgesagt, Abgrenzung und Isolation geflüchteter Menschen hervorzurufen (vgl. Hess et al. 2018) und somit Geflüchteten das Bild »des Anderen«, der nichtzugehörigen Person, zuzuschreiben. Diese Ausgrenzungspraktiken vermitteln den Eindruck einer Bedrohung durch die fremden Geflüchteten. Wie die bayerische Bevölkerung die Unterbringung geflüchteter Menschen in Ankerzentren wahrnimmt, war Gegenstand der vorliegenden Untersuchung. Hierbei treten deutliche Unter- 
schiede zutage zwischen der Befürwortung der zentralen Unterbringung, welche Geflüchtete abgrenzt und dadurch ihre Wahrnehmung als Fremde begünstigt, sowie der Präferenz einer dezentralen Unterbringung, beispielsweise in Wohnungen in den Gemeinden vor Ort, was die Möglichkeiten der gegenseitigen Kontaktaufnahme erleichtert.

In diesem Zusammenhang konnte diese Studie zeigen, dass sich vor allem jüngere Personen, Frauen und Personen mit einem hohen Bildungsabschluss für eine dezentrale Unterbringungsform und gegen Immobilität, Isolierung und lange Aufenthaltsdauern aussprechen. Männer, ältere Personen sowie diejenigen mit einem geringen bis mittleren Bildungsniveau bevorzugen die Unterbringung in Ankerzentren und sehen die erzwungene Immobilität und Isolierung als vertretbar an.

Die Ergebnisse verdeutlichen, dass die Entscheidung für eine zentrale oder dezentrale Unterbringung von Asylbewerber*innen von vier Faktoren abhängt. Zunächst führt Kontakt mit geflüchteten Personen zur Befürwortung einer dezentralen Unterbringung. Weiterhin zeigt sich, dass Personen, die sich um Recht und Ordnung sorgen, die Unterbringung in Ankerzentren bevorzugen. Befragte mit negativen Einstellungen gegenüber Ausländer*innen im Allgemeinen (ohne besondere Berücksichtigung ihrer Religionszugehörigkeit) sehen ebenfalls Ankerzentren als geeignete Unterbringungsform an. Darüber hinaus befürworten Personen, welche im gesellschaftlichen Miteinander wenig bis gar keine Normlosigkeit, Unsicherheit und Orientierungslosigkeit empfinden, eine dezentrale Unterbringung.

Der vorliegende Beitrag zeigt erste Ergebnisse der bislang einzigen repräsentativen Studie zur Einstellung der bayerischen Bevölkerung gegenüber Ankerzentren und Geflüchteten. Ziel war es zum einen, bereits vermutete und in anderen Studien aufgezeigte Ergebnisse zu bestätigen bzw. zu reproduzieren. Hierzu gehört beispielsweise, dass ältere Personen sowie Personen mit geringerem Bildungsniveau und Männer allgemein fremdenfeindlicher eingestellt sind als jüngere Personen, Personen mit einem höheren Bildungsniveau und Frauen allgemein (vgl. Zick/Küpper/Berghan 2019: 87, 89, 92; Zick et al. 2016: 57, 59, 62). Zum anderen ging es darum, Items und Skalen zu entwickeln, um speziell die Bewertung von Ankerzentren zu messen.

Für die Vertiefung einzelner aufgezeigter Aspekte, wie beispielsweise die auffällig hohe Ablehnung des Arbeitsverbots von in Ankerzentren Untergebrachten können im nächsten Schritt ggf. qualitative Befragungen weitere Erklärungsansätze liefern. Um Entwicklungen in den Einstellungen aufzuzeigen, ist darüber hinaus eine Weiterführung in Form einer Trend- oder gar Panelstudie notwendig. Paneldaten, also die wiederholte Befragung der gleichen Personen, würden es erlauben eine Veränderung oder Stabilisierung der Einstellungen zu Ankerzentren und Wahrnehmungen von Geflüchteten nachzuzeichnen. Das Design ist zudem so angelegt, dass Elemente ausgetauscht werden können, um die Aufnahme weite- 
rer Fragen oder Frageblöcke zu aktuellen Themen (z.B. im Bereich der Integration oder der Rückführung) zu ermöglichen.

\section{Literaturverzeichnis}

Adorno, Theodor. W./Frenkel-Brunswik, Else/Levinson, Daniel/Sanford, Nevitt (1950): The authoritarian personality, New York: Harper.

Agier, Michel (2011): Managing the undesirables. Refugee camps and humanitarian government, Cambridge: Polity Press.

Ahrens, Petra-Angela (2017): Skepsis und Zuversicht. Wie blickt Deutschland auf Flüchtlinge? Hannover, Sozialwissenschaftliches Institut der EKD (SI), https:// www.siekd.de/wp-content/uploads/2018/06/Skepsis_und_Zuversicht.pdf, Abrufdatum: 27.03.2020.

Allport, Gordon W. (1954): The Nature of Prejudice, Cambridge, Mass: AddisonWesley.

Altemeyer, Bob (1996): The authoritarian spectre, Cambridge, Mass: Harvard University Press.

ANKER-WATCH.de (2020): Kritisches Monitoring der bayerischen ANKERZentren, https://www.anker-watch.de/, Abrufdatum: 29.04.2020.

[BAfF] Bundesweite Arbeitsgemeinschaft der psychosozialen Zentren für Flüchtlinge und Folteropfer (2018): Abschottung um jeden Preis? Wie sich die geplanten Ankerzentren auf Geflüchtete, Traumatisierte und die Gesellschaft auswirken, vom 18.06.2018, www.baff-zentren.org/wp-content/uploads/2018/06/Stellungnahme_BAfF_Ankerzentren_2018.06.18.pdf, Abrufdatum: 29.04.2020.

Bauer, Isabella (2017): Unterbringung von Flüchtlingen in deutschen Kommunen: Konfliktmediation und lokale Beteiligung. Flucht: Forschung und Transfer, State-of-Research Paper 10, https://flucht-forschung-transfer.de/wp-conte nt/uploads/2017/05/IB-SoR-10-BAUER_Konfliktmediation-1.pdf, Abrufdatum: 26.03.2020.

Bauman, Zygmunt (1995): »Making and unmaking of strangers«, in: Thesis Eleven 43(1), S. 1-16.

Bauman, Zygmunt (1996): »Glokalisierung oder: Was für die einen Globalisierung, ist für die anderen Lokalisierung«, in: Das Argument 38(5/6), S. 653-664.

Bauman, Zygmunt (2016): Die Angst vor den anderen: Ein Essay über Migration und Panikmache, Berlin: Suhrkamp.

Bauman, Zygmunt (2017): Retrotopia, Berlin: Suhrkamp.

Bayerischer Flüchtlingsrat (2019): Positionspapier AnkER-Zentren, https://www. fluechtlingsrat-bayern.de/tl_files/2019/Positionspapiere/Positionspapier_ ANKER.pdf, Abrufdatum: 29.04.2020. 
Bayerisches Landesamt für Statistik (2019): Altersstruktur der Bevölkerung Bayerns. Statistische Berichte, Stand: 31.12.2019, https:/www.statistik.bayern.de/ $\mathrm{mam} /$ produkte/veroffentlichungen/statistische_berichte/a1300c_201800.pdf, Abrufdatum: 18.03.2020.

Bayerischer Rundfunk (2019): Ankerzentren: Experten warnen vor Folgen für Kinder, vom 26.09.2019, https://www.br.de/nachrichten/bayern/ankerzentren-ex perten-warnen-vor-folgen-fuer-kinder,RdB8604, Abrufdatum: 31.10.2020.

Beierlein, Constanze/Asbrock, Frank/Kauff, Mathias/Schmidt, Peter (2014): Die Kurzskala Autoritarismus (KSA-3): Ein ökonomisches Messinstrument zur Erfassung dreier Subdimensionen autoritärer Einstellungen, https://doi.org/10. 6102/zis228, Abrufdatum: 07.12.2019.

Beierlein, Constanze/Kovaleva, Anastassiya/László, Zsuzsa/Kemper, Christoph J./Rammstedt, Beatrice (2015): Kurzskala zur Erfassung der Allgemeinen Lebenszufriedenheit (L-1), https://doi.org/10.6102/zis229, Abrufdatum: 07.12.2019.

Breyer, Bianka/Danner, Daniel (2015): Einstellung zum Islam (ALLBUS), https://doi. org/10.6102/zis231, Abrufdatum: 07.12.2019.

Christ, Simone/Meininghaus, Esther/Röing, Tim (2017): »All Day Waiting«: Konflikte in Unterkünften für Geflüchtete in NRW. Bonn. bicc Working Paper 3/2017, https:/www.bicc.de/publications/publicationpage/publication/all-day -waiting-konflikte-in-unterkuenften-fuer-gefluechtete-in-nrw-697/, Abrufdatum: 28.03.2020.

Decker, Oliver/Kiess, Johannes/Brähler, Elmar (2012): Die Mitte im Umbruch: Rechtsextreme Einstellungen in Deutschland 2012, Friedrich Ebert Stiftung, Bonn: Dietz.

Der Paritätische Gesamtverband (2018): Positionspapier des Paritätischen Gesamtverbandes zu den geplanten AnKER-Zentren, vom 15.06.2018, http://infothek. paritaet.org/pid/fachinfos.nsf/o/b351ce200051aebbc12582b100461164/\$FILE/Positionspapier \%20AnKER_150618_final.pdf, Abrufdatum: 29.04.2020.

Die Fraktion der Grünen in Bayern (2019): Dokumentation AnkER-Zentren Tour, https://www.gruene-fraktion-bayern.de/fileadmin/bayern/user_upload/download_dateien_2018/Anfragen_Antraege_Gutachten/2019/190801_Dokumentation_Ankerzentrentour_Variante.pdf, Abrufdatum: 29.04.2020.

Elle, Johanna/Hess, Sabine (2017): Leben jenseits von Mindeststandards. Dokumentation zur Situation in Gemeinschaftsunterkünften in Niedersachsen, https://www.gender-flucht.uni-osnabrueck.de/fileadmin/MWK-Projek-

t/Publikationen/Jenseits_von_Mindeststandards_Final.pdf, Abrufdatum: 24.03.2020.

Etzold, Benjamin (2019): Auf der Flucht - (Im)Mobilisierung und (Im)Mobilität von Schutzsuchenden, Bonn/Osnabrück, Flucht: Forschung und Transfer, State-ofResearch Paper 04. 
Europäischer Rechnungshof (2017): Reaktion der EU auf die Flüchtlingskrise: das »Hotspot-Konzept«. Luxemburg. Sonderbericht Nr. 06/2017, https://www.eca. europa.eu/de/Pages/DocItem.aspx?did=41222, Abrufdatum: 23.04.2020.

Fend, Helmut (1994): "Ausländerfeindlich-nationalistische politische Weltbilder und Aggressionsbereitschaft bei Jugendlichen in Deutschland und der Schweiz - kontextuelle und personale Antecedenzbedingungen«, in: Zeitschrift für Sozialisationsforschung und Erziehungssoziologie 14(2), S. 131-162.

Fischer, Arthur/Kohr, Heinz-Urlich (2014): Sozio-Politische Einstellungen, https:// doi.org/10.6102/zis6, Abrufdatum: 07.12.2019.

Flüchtlingsrat Niedersachsen (2018): Etablierung von Ankerzentren und die Rechte der Kinder. Stellungnahme von 24 Verbänden und Organisationen: Ankerzentren für Kinder und Jugendliche ungeeignet, vom 28.05.2018, https:// www.nds-fluerat.org/wp-content/uploads/2018/05/AnschreibenAnKERKomm unen_24052018-ALLE-LOGOS.pdf, Abrufdatum: 29.04.2020.

Gesis (2017a): ALLBUS. Allgemeine Bevölkerungsumfrage der Sozialwissenschaften. ALLBUS 2016. Fragebogendokumentation. Fo04, https://www.gesis.org/ allbus/inhalte-suche/frageboegen/, Abrufdatum: 07.12.2019.

Gesis (2017b): ALLBUS. Allgemeine Bevölkerungsumfrage der Sozialwissenschaften. ALLBUS 2016. Fragebogendokumentation. Fo35, https:/www.gesis.org/al lbus/inhalte-suche/frageboegen/, Abrufdatum: 07.12.2019.

Göler, Daniel (2020): »Places and Spaces of the Others. A German Reception Centre in Public Discourse and Individual Perception«, in: Birgit Glorius/Jeroen Doomernik (Hg.), Geographies of asylum in Europe and the role for European localities (= IMISCOE Research Series), Cham: Springer, S. 69-91.

Guyton, Patrick (2019): Anhörung in München »Entrechtung und Gewalt«, in: taz vom 26.09.2019, https://taz.de/Anhoerung-in-Muenchen/!5630403/, Abrufdatum: 31.10 .2020 .

Hess, Sabine/Pott, Andreas/Schammann, Hannes/Scherr, Albert/Schiffauer, Werner (2018): Welche Auswirkungen haben Anker-Zentren? Eine Kurzsstudie für den Mediendienst Integration, vom August 2018, https://mediendienst-integ ration.de/fileadmin/Dateien/Expertise_Anker-Zentren_August_2018.pdf, Abrufdatum: 28.04.2020.

Hofmann, Rebecca/Scherr, Albert (2017): Verwahrung in Aufnahmelagern oder Willkommenskultur? Eine Fallstudie zur Erstaufnahme von Geflüchteten, https://ratfuermigration.files.wordpress.com/2018/08/vorstudie_hofman n_scherr_2017.pdf, Abrufdatum: 27.03.2020.

Inhetveen, Katharina (2010): Die politische Ordnung des Flüchtlingslagers: Akteure - Macht - Organisation. Eine Ethnographie im südlichen Afrika, Bielefeld: transcript.

Jaji, Rose (2012): »Social Technology and Refugee Encampment in Kenya«, in: Journal of Refugee Studies 25(2), S. 221-238. 
Kleinert, Corinna (2004): FremdenFeindlichkeit: Einstellungen junger Deutscher zu Migranten, Wiesbaden: VS Verlag für Sozialwissenschaften.

Kober, Ulrich/Kösemen, Orkan (2019): Willkommenskultur zwischen Skepsis und Pragmatik: Deutschland nach der »Fluchtkrise«, Bertelsmann Stiftung, Gütersloh.

Krause, Ulrike (2019): »Flüchtlingslager: Im Spannungsverhältnis zwischen Schutz, Macht und Agency«, in: Agnes Bresselau von Bressendorf (Hg.), Über Grenzen, Migration und Flucht in globaler Perspektive seit 1945, Göttingen: Vandenhoeck \& Ruprecht, S. 87-103.

Kreichauf, René (2018): »From forced migration to forced arrival: the campization of refugee accommodation in European cities«, in: Comparative Migration Studies 6(7), S. 1-22.

Markard, Nora/Heuser, Helene (2016): Möglichkeiten und Grenzen einer menschenrechtskonformen Ausgestaltung von sogenannten »Hotspots« an den europäischen Außengrenzen. Gutachten von Prof. Dr. Nora Markard, MA und Ass. iur. Helene Heuser, MA, Refugee Law Clinic Hamburg. Hamburg, https://www.jura.uni-hamburg.de/media/ueber-die-fakultaet/personen /markard-nora/markard-heuser-hotspots-2016.pdf, Abrufdatum: 27.03.2020.

Messerschmidt, Astrid (2015): »Fremd machen. Zygmunt Baumans Retrospektionen moderner nationaler Zugehörigkeitsordnungen«, in: Julia Reuter/Paul Mecheril (Hg.), Schlüsselwerke der Migrationsforschung: Pionierstudien und Referenztheorien, Wiesbaden: Springer VS, S. 215-230.

Missbach, Antje (2013): »Waiting on the islands of >stuckedness $\triangleleft$ : managing asylum seekers in island detention camps in Indonesia; from the late 1970s to the early 2000s«, in: ASEAS - Austrian Journal of South-East Asian Studies 6(2), S. 281306.

Mittelbayerische (2019): Experten kritisieren Ankerzentren, vom 26.09.2019, https://www.mittelbayerische.de/bayern-nachrichten/experten-kritisierenankerzentren-21705-art1831241.html, Abrufdatum: 31.10.2020.

Müller, Andreas (2013): Die Organisation der Aufnahme und Unterbringung von Asylbewerbern in Deutschland. Fokus-Studie der deutschen nationalen Kontaktstelle für das Europäische Migrationsnetzwerk (EMN), Working Paper 55.

Oesterreich, Detlef (2005): »Flight into Security: A New Approach and Meassure of the Authoritarian Personality«, in: Political Psychology 26, S. 275-298.

Panagiotidis, Efthimia/Tsianos, Vassilis (2007): »Denaturalizing »Camps«: Überwachen und Entschleunigen in der Schengener Ägäis-Zone«, in: TRANSIT MIGRATION Forschungsgruppe (Hg.), Turbulente Ränder. Neue Perspektiven auf Migration an den Grenzen Europas, Bielefeld: transcript, S. 57-86.

Pendry, Louise (2014): „Soziale Kognition«, in: Klaus Jonas/Wolfgang Stroebe/Miles Hewstone (Hg.), Sozialpsycholgie, Berlin/Heidelberg: Springer, S. 107-140. 
Pieper, Tobias (2008): Die Gegenwart der Lager. Zur Mikrophysik der Herrschaft in der deutschen Flüchtlingspolitik, Münster: Verlag Westfälisches Dampfboot.

Reiter, Renate/Töller, Annette E. (2019): »Permissive und restriktive Muster in den Asylpolitiken der Bundesländer«, in: der moderne staat - Zeitschrift für Public Policy, Recht und Management 12(1), S. 194-220.

Reuter, Julia/Warrach, Nora (2015): "Die Fremdheit der Migrant_innen. Migrationssoziologische Perspektiven im Anschluss an Georg Simmels und Alfred Schütz' Analysen des Fremdseins«, in: Julia Reuter/Paul Mecheril (Hg.), Schlüsselwerke der Migrationsforschung: Pionierstudien und Referenztheorien, Wiesbaden: Springer VS, S. 169-189.

Robert Bosch Stiftung (2014): Asyl und Asylbewerber: Wahrnehmungen und Haltungen der Bevölkerung 2014. Ergebnisse einer repräsentativen Umfrage durchgeführt vom Institut für Demoskopie Allensbach im Auftrag der Robert Bosch Stiftung, Stuttgart, https://www.bosch-stiftung.de/sites/default/files/p ublications/pdf_import/RBS_Asyl_Studie_FINAL_RZ_einzel.pdf, Abrufdatum: 27.03.2020.

Rohmann, Tim (2019): »Mindeststandards verAnkERn - AnkER-Zentren und die Beschleunigung von Asylverfahren«, in: Im Dialog. Beiträge aus der Akademie der Diözese Rottenburg-Stuttgart 2, S. 117-160.

Schütz, Alfred ([1944] 1972): »Der Fremde. Ein sozialpsychologischer Versuch«, in: Alfred Schütz (Hg.), Gesammelte Aufsätze II. Studien zur Soziologischen Theorie, Den Haag: Nijhoff, S. 43-69.

Simmel, Georg ([1908] 1958): »Exkurs über den Fremden«, in: Georg Simmel (Hg.), Soziologie, Berlin: Duncker \& Humboldt.

Stellmacher, Jost/Petzel, Thomas (2005): "Authoritarianism as a group phenomenon«, in: Political Psychology 26, S. 245-274.

Süddeutsche Zeitung (2019): Heftige Debatten über »Ankerzentren«, vom 26.09.2019, https://www.sueddeutsche.de/bayern/bayern-ankerzentren-landt ag-debatte-1.4617424, Abrufdatum: 31.10.2020.

SVR-Forschungsbereich (2018): Integration in Bayern. Sonderauswertung des SVRIntegrationsbarometers 2018.

Thiel, Jens/Jahr, Christoph (2017): Begriff und Geschichte des Lagers, https://www. bpb.de/gesellschaft/migration/kurzdossiers/246175/begriff-und-geschichtedes-lagers? $\mathrm{p}=$ all, Abrufdatum: 08.08.2020.

Turner, Simon (2016): »What is a refugee camp? Explorations of the limits and effects of of the camp«, in: Journal of Refugee Studies 29(2), S. 139-148.

Ulbrich-Herrmann, M. (2014): Law-and-Order-Positionen, https://doi.org/10.6102/ zis75, Abrufdatum: 07.12.2019.

UNHCR (2018): Empfehlungen zur Ausgestaltung der geplanten »AnkER«Einrichtungen. Berlin, https://www.unhcr.org/dach/wp-content/uploads/sites /27/2019/07/20180606_Anker_UNHCR.pdf, Abrufdatum: 29.04.2020. 
Wendel, Kay (2014): Unterbringung von Flüchtlingen in Deutschland Regelungen und Praxis der Bundesländer im Vergleich, Stand: August 2014, Frankfurt a.M.. ZA/ZUMA (2014): Einstellungen zu Juden (ALLBUS), https://doi.org/10.6102/zis198, Abrufdatum: 07.12.2019.

Zick, Andreas/Küpper, Beate/Krause, Daniela (2016): Gespaltene Mitte - feindselige Zustände. Rechtsextreme Einstellungen in Deutschland 2016, Bonn: Dietz.

Zick, Andreas/Klein, Anna (2014): Fragile Mitte - Feindselige Zustände: Rechtsextreme Einstellungen in Deutschland 2014, Bonn: Dietz.

Zick, Andreas/Küpper, Beate/Berghan, Wilhelm (2019): Verlorene Mitte - Feindselige Zustände: Rechtsextreme Einstellungen in Deutschland 2018/19, Bonn: Dietz.

Zick, Andreas/Preuß, Madlen (2019): Einstellungen zur Integration in der deutschen Bevölkerung - dritte Erhebung im Projekt »Zugleich - Zugehörigkeit und Gleichwertigkeit«, Stiftung Mercator, Essen. 



\section{Medial verAnkERt \\ Die Darstellung bayerischer Erstaufnahmeeinrichtungen für Geflüchtete in der regionalen Berichterstattung}

Tanja Evers

\section{Zusammenfassung}

Medieninhaltsanalysen zur Darstellung von Flucht(Migration) haben in der Kommunikationswissenschaft eine lange Tradition. Eher selten stehen dabei jedoch Konzepte der Unterbringung von Geflüchteten und die zugehörigen Diskurse in lokalen Öffentlichkeiten im Mittelpunkt der Analyse. Der Beitrag begegnet diesem Forschungsdesiderat, indem er im Rahmen einer quantitativen Inhaltsanalyse von Regionalzeitungen die Themen, Akteur*innen, Bewertungen und Forderungen im massenmedialen Diskurs über Ankereinrichtungen in Bayern und Sachsen untersucht. In einer theoretischen Auseinandersetzung wird zudem der Versuch unternommen, journalistische Berichterstattung selbst als Faktor der (Im-)Mobilisierung und öffentliche Kommunikation als eigene Dimension der Mobilität zu konzeptualisieren. Mit Blick auf eine solche kommunikative Mobilität sollten journalistische Medien im Sinne ihres gesellschaftlichen Auftrags als Forum und integrative Plattform möglichst vieler unterschiedlicher Stimmen dienen und gesellschaftliche Aushandlungsprozesse moderieren. In der Folge entwickelt diese medial konstruierte politische Öffentlichkeit wiederum ein eigenes Mobilisierungspotential, das sowohl die Meinungsbildungsprozesse der Bürger innen als auch politisches Handeln beeinflussen kann. Der Diskurs zu Ankereinrichtungen in massenmedialen lokalen Öffentlichkeiten bewertet die Unterbringungssituation zwar insgesamt durchaus kritisch, jedoch weniger differenziert denn polarisiert. So bedienen die analysierten Artikel in der Regel einen engen Kanon von Narrativen, die zudem überwiegend einen problemzentrierten Blickwinkel einnehmen und den Geflüchteten kaum die Möglichkeit einräumen, sich aktiv an der Gestaltung der Öffentlichkeit zu Ankerzentren zu beteiligen.

\section{Summary}

Media content analyses used to depict (forced) migration have a long tradition in communication science. However, the analysis rarely focuses on accommoda- 
tion concepts for refugees and the associated discourses in local public spheres. This article seeks to counteract this research desideratum by investigating the topics, actors, evaluations and demands in the mass media discourse on Anker centres in Bavaria and Saxony within the framework of a quantitative content analysis of regional newspapers. In a theoretical discussion, it also attempts to conceptualise journalistic reporting itself as a factor of (im-)mobilisation and public communication as an own, separate dimension of mobility. With regard to such communicative mobility, journalistic media should serve as a forum and integrative platform for as many different voices as possible and moderate social negotiation processes in line with their social mission. As a result, this political public sphere constructed by the media in turn develops its own potential for mobilisation, which can influence both the opinion-forming processes of citizens and political action. The discourse on Anker centres in local public spheres within the mass media is critical overall, but still less differentiated than polarised. Thus, the articles that were analysed in the project generally serve a narrow canon of narratives, which also predominantly take a problem-oriented perspective, and hardly give refugees the opportunity to actively participate in shaping the public opinion with regard to Anker centres.

\section{Flucht(migration) als Thema einer umkämpften Öffentlichkeit}

»Es bleiben die richtigen, es gehen die richtigen « - Mit diesen Worten beschreibt der bayerische Ministerpräsident Markus Söder in einem ausführlichen Interview mit der Nürnberger Zeitung (14. September 2018) die vermeintlichen Vorzüge der Erstaufnahme in Ankereinrichtungen, welche im Frühjahr 2018 auf Basis des Asylplans nach bayerischem Modell eingeführt wurden (vgl. StMI 2018). Verdichtet in nur einem Satz finden sich hier Erzählstrukturen, an deren Beispiel sich grundlegende Tendenzen im politischen und massenmedialen Tenor zu Fluchtmigration als Thema veranschaulichen lassen: Geflüchtete Menschen werden hierarchisch kategorisiert in "richtig« und "falsch« und nach ihrem Nutzen - zumeist für die deutsche Volkswirtschaft oder ihrem Bedrohungspotential, wahlweise für die innere Sicherheit oder den Wohlfahrtsstaat - bewertet.

Kriminalität und der Wert migrantischer Arbeitskraft gelten als zentrale Assoziationen, die sich über die Jahrzehnte in der massenmedialen Berichterstattung als persistent erwiesen (vgl. Jung/Niehr/Böke 2000; Wengeler 2006). Insbesondere die Kontinuität negativer Narrative, die Migration und Flucht als Problem deuten (vgl. u.a. Geißler/Pöttker 2009; Bonfadelli/Moser 2007) begründen anhaltende Diskussionen um die Existenz und Verfestigung stereotyper oder gar rassistischer Diskursstrukturen in medialer Öffentlichkeit (vgl. Abadi 2017; Ter Wal 2002; van Dijk 1991). Während es an Erkenntnissen zur medialen Repräsentation 
von Geflüchteten und Migrant*innen nicht mangelt, hat die dezidierte öffentliche Aushandlung $\mathrm{zu}$ asylpolitischen Unterbringungskonzepten durchaus einen Neuigkeitswert. So verfügt die Fluchtforschung zwar über einen Kanon an Studien zu Lagern und Sammelunterkünften und auch aus aktivistischer Sicht wurde die Bundesrepublik mit Blick auf die Kontinuität dieser Unterbringungsform als »Lagergesellschaft « bezeichnet (vgl. Dünnwald 2002: 27). Forscher*innen beschäftigen sich bislang aber international (vgl. Inhetveen 2010) wie national (vgl. Bauer 2017; Christ/Meininghaus/Röing 2017; Täubig 2009; Pieper 2008) weniger mit der medialen Auseinandersetzung, sondern vorwiegend mit den Machtdynamiken, Konfliktkonstellationen, Organisationsformen und (Des-)Integrationsprozessen von und in Flüchtlingslagern als Teil des Asylregimes.

Aus der öffentlichen Aufmerksamkeit schien das Thema lange Zeit nahezu verschwunden, nicht zuletzt, weil es aufgrund moderater Zahlen von Asylanträgen zwischen 1994 und 2014 (vgl. BAMF 2020: 9) keinen Bedarf an innenpolitischen Legitimationsdiskursen gab (vgl. Pieper 2008: 22). Mit der signifikant gestiegenen Zuwanderung von Schutzsuchenden in den Jahren 2015 und 2016 rückte die Unterbringungssituation erneut auf die politische und mediale Agenda. Nach Angaben des bayerischen Innenministeriums leben aktuell (Stand 29.02.2020) rund 6.600 Personen in bayerischen Ankereinrichtungen ${ }^{1}$ inklusive der angeschlossenen Dependancen, was einer Auslastung von 60 Prozent entspricht (vgl. Bay. LT 2020: 3-5). Die Einführung der Ankereinrichtungen wurden von der politischen Opposition, Nichtregierungsorganisationen, Wohlfahrtsverbänden und der Flucht- und Migrationsforschung kritisch begleitet (vgl. u.a. Mouzourakis/Pollet/Ott 2019), indem unter anderem auf die »weitgehende Isolation « und »hohen Belastungen« bei den Geflüchteten verwiesen wird. Außerdem ignorieren Ankerzentren die »Bedeutung lokaler Unterstützungsstrukturen« und bilden einen »Nährboden für Vorurteile« (Hess et al. 2018: 2). Im Gegensatz dazu werden die Regierungsparteien, insbesondere die CSU, nicht müde, öffentlich ihr Gegennarrativ der Ankereinrichtungen als Erfolgskonzept zu bedienen. Zum einjährigen Bestehen begrüßte der bayerische Innenminister Joachim Herrmann erneut die Beschleunigung der Verfahren durch die Bündelung aller relevanten Behörden (vgl. FAZ 2019), und Ministerpräsident Markus Söder verkündete, die bayerische Flüchtlingspolitik habe eine "gelungene Balance zwischen Humanität und Ordnung« erreicht (Guyton 2019).

Mehrere teilweise widerstreitende Positionen, eingespeist in verschiedene öffentliche Arenen von unterschiedlichen Akteur*innen, zeigen: Digitale und analoge

Aktuell verweist eine Kurzanalyse des Bundesamtes für Migration und Flüchtlinge auf einen positiven Trend in der Wohnsituation Geflüchteter. Im Jahr 2018 wohnen bereits drei Viertel der Geflüchteten, die zwischen 2013 und 2016 als solche in Deutschland erfasst wurden, nicht mehr in Sammelunterkünften, sondern in Privatwohnungen (vgl. Tanis 2020). Zur Wohn- und Lebenssituation »nach dem Lager« siehe den Beitrag von Birgit Glorius in diesem Band. 
Medien spielen eine bedeutende Rolle in den öffentlichen Aushandlungsprozessen zu Ankereinrichtungen. Denn wer sich wie ausführlich, zu welchen Themenaspekten und in welcher Rolle öffentlich sichtbar an der Formulierung der zentralen Narrative beteiligen kann, darüber entscheiden in einer medialisierten Migrationsgesellschaft in nicht unerheblichem Maße nach wie vor (journalistische) Massenmedien. Die Platzierung und Bewertung von (migrations- und asylpolitischen) Themen in der Öffentlichkeit ist eng an die Forschung zu den Agenda-SettingEffekten zwischen Massenkommunikation und Politik (vgl. McCombs/Shaw 1972) gekoppelt. Die Kommunikationswissenschaft betont hier die besondere Relevanz politischer Öffentlichkeit, die einerseits das »Lebenselement der Politik« (Gerhardt 2012: 349) und gleichzeitig das zentrale Element ihrer Kontrolle ist.

Ziel des vorliegenden Beitrags ist es, zunächst einen Vorschlag dazu zu machen, wie der Begriff der Mobilität kommunikationswissenschaftlich nutzbar und an Konzepte von Öffentlichkeit gekoppelt werden kann. Im Anschluss an die theoretische Auseinandersetzung mit den Faktoren, die bei der kommunikativen Mobilisierung des Themas Flucht(migration) durch den Journalismus zu beachten sind, führt ein kurzer Überblick zum Forschungsstand zur Frage, in welcher Weise nun spezifisch Ankereinrichtungen in der medialen Berichterstattung dargestellt werden. Auf Basis der Daten einer quantitativen Inhaltsanalyse lokaler Printmedien zur Berichterstattung über die Ankerzentren in Bayern und Sachsen (Untersuchungszeitraum 1. Januar 2018 bis 1 . August 2019) sollen im Anschluss die zentralen Narrative zur asylpolitischen Frage der Unterbringung von Geflüchteten ermittelt werden. Neben der Nennung und Beschreibung der thematischen Aspekte, den Akteur*innen und formulierten Forderungen in den Artikeln liegt der Fokus der empirischen Analyse auf der konkreten Nennung von (im-)mobilisierenden Praktiken in der Berichterstattung. Dies geschieht auf zwei Ebenen: Zum einen gilt es, in den untersuchten Beiträgen manifeste Verweise auf die räumliche und soziale (Im-)Mobilität der Bewohner*innen zu identifizieren. Zum anderen liefert die inhaltsanalytische Auswertung Anhaltspunkte, wie aktiv bzw. passiv Geflüchtete in lokalen Öffentlichkeiten repräsentiert sind und inwieweit sie selbst an einer mobilisierenden Öffentlichkeit teilhaben (können), wenn Sichtbarkeit als Voraussetzung sozialer Mobilität konzipiert wird.

\section{Medien als Faktor der (Im-)Mobilisierung - Theoretische Einordnung des Konzepts Mobilität in der Kommunikationswissenschaft}

Die begriffliche Verknüpfung von Medien und Mobilisierung einerseits hat traditionell in der Kommunikationswissenschaft zwei zentrale Bezugspunkte: die politische Kommunikation, insbesondere die Wahlkampf- und Kampagnenforschung (vgl. u.a. Evers 2019; Holtz-Bacha 2019), und die Medienwirkungsforschung (vgl. 
zum Überblick Bonfadelli/Friemel 2017). Öffentlichkeitstheoretisch sind es in jüngerer Vergangenheit vor allem Studien zum Mobilisierungspotential digitaler Gemeinschaften, die sich vermehrt mit gesellschaftlicher Teilhabe durch soziale Medien beschäftigen (vgl. u.a. Scholz 2013; Wagner/Gerlicher/Brüggen 2011). Sie untersuchen, welche Formen der In- und Exklusion sich demokratietheoretisch aus der Option ergeben, dass Bürger"innen im Social Web verstärkt selbst als aktive Teilnehmer*innen den medialen gesellschaftlichen Diskurs mitgestalten können.

Die Auseinandersetzung mit dem Begriff der Mobilität ist andererseits für die Kommunikationswissenschaft bislang in der Regel mit Fragen des technischen Fortschritts und dem Bedeutungsgewinn mobiler Onlinemedien verbunden. Einen Versuch, diesen "technologischen Zentrismus « $\mathrm{zu}$ überwinden, beschreibt die Forschungsperspektive der »kommunikativen Mobilität« (Hepp 2006: 15; auch Berg 2017). Diese zielt darauf, die Nutzung und Aneignung mobiler Endgeräte im Medienalltag mit den daraus resultierenden Veränderungen soziokultureller Praktiken zu verbinden. An dieser Stelle zeigt sich die theoretische Auseinandersetzung anschlussfähig an Konzepte wie die des »mobilitiy turn«, nach dem alles Soziale als etwas Mobiles zu verstehen sei (Urry 2007).

Um ein solch erweitertes Verständnis von kommunikativer Mobilität anschlussfähig für die Fluchtmigrationsforschung zu machen, sollte es sich jedoch noch deutlicher von einem technologiegetriebenen Medienbegriff lösen und stattdessen stärker die soziale Dimension von Medien als gesellschaftliche Institutionen in den Mittelpunkt rücken (vgl. Altmeppen/Greck/Kössler 2013). Dieser Beitrag schlägt daher vor, öffentliche Kommunikation selbst als eine Dimension der Mobilität zu verstehen. Journalist*innen werden in einem solchen Verständnis zu Verantwortungsträger*innen, die Mobilität öffentlicher Kommunikation sicherzustellen. Mit dem Konzept einer »Mobilitätsgesellschaft" (Tully/Baier 2006) gilt es dann neben der räumlichen und sozialen mit der informationellen Mobilität noch eine dritte wesentliche Art zu beachten, die den Mobilitätsraum virtuell erweitert. Es wird die Frage aufgeworfen, inwiefern Kommunikation als Austausch von Information räumliche Mobilität substituieren oder akzelerieren kann (vgl. ebd.: 33f.). Massenmedien übernehmen nach dieser theoretischen Rahmung stärker eine dienende Funktion in der Bereitstellung und Verbreitung von Informationen. Journalistische Berichterstattung sorgt also für die Zirkulation von Themen und Bedeutungen in unterschiedlichen öffentlichen Sphären, welche wiederum vielgestaltig miteinander gekoppelt und zusätzlich mit den weiteren Mobilitätsformen verwoben sind (vgl. Wimmer/Hartmann 2014: 11ff.). Journalistische Medien fungieren dabei auf Basis ihres gesellschaftlichen Auftrags als Forum und integrative Plattform möglichst vieler unterschiedlicher Stimmen, sie moderieren gewissermaßen den Diskurs und fungieren als Katalysatoren gesellschaftlicher Aushandlungsprozesse. 
Kommunikative Mobilität meint vor diesem Hintergrund sowohl die Möglichkeit und Freiheit zur informationellen Selbstbestimmung als auch die Mobilität - das heißt die Durchlässigkeit und Wandelbarkeit - öffentlicher Kommunikationsarenen und die in ihnen verhandelten Themen. Der Journalismus besitzt so per se Mobilisierungspotential - nicht nur mit Blick auf die Meinungsbildung der Bürger*innen, sondern auch als Impulsgeber für politische Entscheidungen. Allerdings führen journalistische Selektionsmechanismen im Allgemeinen und zunehmend ökonomisch überformte Arbeitsroutinen im Speziellen dazu, dass medial konstruierte Wirklichkeiten an einem ausgewogenen und gerechten Abbild gesellschaftlicher Realitäten scheitern (müssen). Viele Themen, Akteur*innengruppen und deren Einschätzungen überwinden die journalistischen oder medialen Auswahlprozesse nicht und stellen somit eine Leerstelle in der massenmedialen Öffentlichkeit dar. Berg weist zurecht darauf hin, dass »bei der Untersuchung von mediatisierten Mobilitäten immer auch Machtverhältnisse sowie Momente von Inklusion und Exklusion zu berücksichtigen« sind (Berg 2014: 63).

Der vorliegende Beitrag nähert sich diesen vielfältig verschränkten kommunikativen Mobilitäten und (Im-)Mobilisierungspraktiken mit Zuschnitt auf eine massenmediale Öffentlichkeit. Das ist vor allem dadurch begründet, dass politische Öffentlichkeit »in der Topographie der Gesellschaft an zentraler Stelle im Vorhof zur Macht platziert «(Gerhards/Neidhardt 1990: 11) und deswegen gleichzeitig stark umkämpft ist. Für politische Akteur*innen sichern demnach Massenmedien letztendlich die Möglichkeit, die eigene (asyl-)politische Agenda öffentlich zu verhandeln, und in derselben ihre befristeten Herrschaftschancen zu sichern (vgl. ebd.: 8f.).

Durch die Auswahl politischer Themen rücken Massenmedien eine bestimmte Agenda in die öffentliche Aufmerksamkeit und geben so gleichzeitig den Nutzer*innen eine Rangfolge der Bedeutsamkeit der Themen vor. Der mediale Erfolg rechtspopulistischer Agitation ist daher nicht zuletzt auch darauf zurückzuführen, dass Journalismus wie neue Rechte dieselben auf der menschlichen Aufmerksamkeitslogik basierenden Nachrichtenfaktoren nutzen, um Nutzer*innen zu gewinnen (vgl. Evers/Altmeppen i.E.; Krämer/Schindler 2018). Obwohl die Stärke dieser Effekte unter anderem themenabhängig variiert, finden sich doch zahlreiche empirische Belege für eine Beeinflussung der Publikumsagenda durch die Medien (vgl. Wanta/Ghanem 2007). Das gilt für Untersuchungen zu Flucht in besonderer Weise, da Medien in diesem Kontext häufig die zentrale »Kontaktinstanz« zu einem Thema darstellen, das sich für die meisten Menschen in einer "Distanzrealität« (Hafez 2019: 493) befindet. Deshalb kann ein erhöhtes Einflusspotential auf die Einstellungen der Bürger*innen unterstellt werden (vgl. Arlt/Wolling 2018; Jacobs/Hooghe/de Vroome 2017). Noch wirkmächtiger als die einfache Priorisierung von Themen im Rahmen des Agenda-Settings ist hinsichtlich der Mobilisierungskraft medialer Diskurse ihre Bewertung und Einbettung in eine bestimmte Erzählstruktur, 
was in der kommunikationswissenschaftlichen Forschung unter dem Begriff des Framing firmiert (vgl. Entman 1993). Journalistische Berichterstattung beeinflusst also nicht nur, über was Nutzer*innen nachdenken, sondern auch wie sie das tun. Medien setzen »thematische und diskursive Schlüsselreize« (Hafez 2019: 494), die in der Folge latente Grundeinstellungen zu politischen Meinungen aktivieren oder transformieren können.

So ist die Mobilisierungskraft der Öffentlichkeit eben nicht nur medial getrieben, sondern Zeugnis der komplexen Abhängigkeitsverhältnisse zwischen Medien-, Politik- und Publikumsagenda. Der öffentliche Diskurs spiegelt zudem die parallel verlaufenden Wechselspiele in der Ausrichtung der Asylpolitik (vgl. Goebel 2019; Hafez 2019) und orientiert sich gleichzeitig rekursiv an den heterogenen Erkenntnissen der Einstellungsforschung zu Flucht und Migration (vgl. u.a. Zick/Küpper/Berghan 2019; Stavenhagen/Kossatz 2017).

Die Analyse medialer Narrative ist daher für die weitere theoretische Arbeit an einem Konzept kommunikativer Mobilität des Themas Flucht(migration) und der Mobilisierung öffentlicher Meinung gewinnbringend. Sie betont ein prozessuales Verständnis von Kommunikation und zeigt das Zusammenspiel und permanente Ringen unterschiedlicher gesellschaftlicher Kräfte mit dem Ziel, das jeweils eigene Deutungsangebot zu einem Thema besonders prominent massenmedial zu platzieren. Wie diese konfliktiven Aushandlungsprozesse die Gestalt der Berichterstattung über Flucht(migration) prägen, führt der folgende Abschnitt näher aus.

\section{Die Darstellung von Flucht(migration) in den Medien: von dominanten Diskursen und fehlender Forschung}

Neben Untersuchungen zum Mediennutzungsverhalten (vgl. Emmer/Richter/Kunst 2016) dominieren in der Kommunikationswissenschaft in der Auseinandersetzung mit Flucht und Migration nach wie vor Medieninhaltsanalysen. Der Kanon der Untersuchungen zur Darstellung von Einwander*innen, Migrant*innen und Geflüchteten in der medialen Berichterstattung ist demnach breit aufgestellt (vgl. u.a. Bucher/Piga 2009; Trebbe 2009).

Eine genauere Betrachtung des öffentlichen Diskurses im Zuge der zunehmenden Flucht(migration) im Jahr 2015 bringt zunächst zwei zentrale Erkenntnisse zum Vorschein: Erstens rückt das Thema stark in den öffentlichen Fokus und dominiert lange Zeit die mediale und politische Agenda (vgl. Krüger/Zapf-Schramm 2019), wobei sich zweitens der deutsche Journalismus nach einer kurzen Phase der engagierten Berichterstattung rund um das Deutungsmuster der »Willkommenskultur « bereits nach wenigen Wochen wieder deutlich inkonsistenter und auch polarisierter präsentiert (vgl. Maurer et al. 2019; Jäger/Wamper 2017). 
Unter dem Dach eines allgemeinen Krisendiskurses ist die mediale Berichterstattung auch hierzulande vermehrt geprägt von der Diagnose eines Normalitäts- und Kontrollverlustes (vgl. Link 2016: 7). Dies führt zu kulturalisierenden und hierarchisierenden Diskursen. Unter dem Narrativ der bedrohten Sicherheit wird also einerseits eine kulturell bedingte reduzierte Integrationsfähigkeit bestimmter Gruppen von Geflüchteten betont, während andererseits eine Ökonomisierung der Fluchtmigration festzustellen ist (vgl. Engel et al. 2019: 280-287). Diese Kategorisierung bestätigt eine Untersuchung der überregionalen Presse, die Geflüchtete am häufigsten als »Kriminelle« attribuiert, gefolgt von den Kategorisierungen »Nützliche«, »Integrationswillige«, »Kostenintensive« und »Willkommene« (vgl. Goedeke et al. 2016: 508f.). Ähnliche Befunde gehen aus einer Studie hervor, deren Stichprobe außer der überregionalen Presse auch Fernsehnachrichten und Boulevardmagazine umfasste. Bezeichnend ist zudem, dass Geflüchtete nur als Randfiguren auftauchen und selbst kaum zu Wort kommen (vgl. Hestermann 2020: 4-10). In diesem Punkt unterscheidet sich der bundesdeutsche Mediendiskurs kaum von dem in den europäischen Nachbarländern: Eine vergleichende Studie zwischen 17 Nationen ermittelt über alle europäischen Medien hinweg, dass Migrant*innen in nur zehn Prozent der Artikel selbst zu Sprecher*innen in eigener Sache werden und ansonsten als Teil einer anonymen Masse lediglich Gegenstand der Berichterstattung sind (vgl. Fengler/Kreutler 2020: 49f., 57f.).

In der Zusammenschau des breiten Forschungsstandes zur medialen Darstellung von Flucht(migration) lassen sich dennoch zwei relative Leerstellen identifizieren: Erstens bilden nur sehr wenige Untersuchungsdesigns bislang die öffentlichen Aushandlungsprozesse zur Unterbringung von Geflüchteten ab. Das erstaunt aus zwei Gründen: Zum einen ist dieser Themenfacette eine hohe Relevanz zu unterstellen, da sie die regionale Sichtbarkeit des abstrakten Phänomens Flucht erhöht. Zum anderen können die wenigen Diskursanalysen, die diesen Aspekt anreißen, zeigen, dass das Thema Unterkunft in deutschen Medien eine vergleichsweise wichtige Rolle spielt (vgl. Heidenreich et al. 2019: 178; Greck 2018: 371; Goebel 2017: 233-244). Zweitens bleiben Regional- oder gar Lokalzeitungen in Untersuchungen $\mathrm{zu}$ Medien und Migration überwiegend unberücksichtigt. Die wenigen Ausnahmen bestätigen zwar eine gewisse Konsistenz in deren Berichterstattung zur bundesweiten Presse - vor allem in der Betonung problemzentrierter Narrative -, allerdings finden sich auch positive Signale. So halten sich beispielweise bei Greck integrationsbetonte und problemzentrierte Narrative die Waage (vgl. Greck 2018: 376f.). Ebenso kommt Fick zu dem Ergebnis, dass der Lokal- im Unterschied zum Mantelteil über Menschen mit Migrationsgeschichte deutlich häufiger als Teil der Gesellschaft berichtet und dadurch die untersuchte regionale Presse zur »aktiven Akzeptanz ethnischer Minderheiten« beiträgt (Fick 2009: 265f.). 
Insbesondere für die Untersuchung der medialen Auseinandersetzung mit der Unterbringung geflüchteter Menschen in Ankerzentren kann daher die Relevanz lokaler Öffentlichkeiten kaum unterschätzt werden. Das gilt nicht nur, weil sich in der Betrachtung des öffentlichen Diskurses zu Ankereinrichtungen ein verkleinertes Strukturabbild des aktuellen Asylregimes manifestiert - so die These dieses Beitrags -, sondern auch weil das Interesse an lokalen Ereignissen ungebrochen ist (vgl. Oehmichen/Schröter 2011: 183). Die Besinnung auf die Lebenswelten vor Ort im Zuge der Globalisierung liefert auch dem Lokaljournalismus eine Strategie für die Zukunft (vgl. Friedrichsen 2010).

Das Forschungsprojekt nimmt deshalb das Thema Unterbringung innerhalb des lokalen bzw. regionalen medialen Diskurses um Flucht(migration) in den Blick. Dabei richtet das Untersuchungsdesign der Inhaltsanalyse sein Interesse auf die als Ankerzentren geführten Aufnahmeeinrichtungen. Die Entscheidung für einen quantitativen Zugang fiel bewusst, um die überwiegend in qualitativen Forschungsarbeiten generierten Erkenntnisse zur Lebenssituation Geflüchteter in Sammelunterkünften ${ }^{2}$ um eine vergleichende Außenperspektive zu ergänzen. Eine solche Perspektive überprüft, welche Aspekte dieses Alltagserlebens - und insbesondere der Praktiken der (Im-)Mobilisierung - es in die Aufmerksamkeit der unmittelbar umgebenden lokalen Öffentlichkeit schaffen, welche Akteur*innen dabei zu Wort kommen und welche Bewertungen und politischen Forderungen dabei formuliert werden.

Dieser Zielsetzung entsprechend fanden diejenigen Lokal- und Regionalzeitungen in die Stichprobe Eingang, deren Verbreitungsgebiet mit den Standorten der bayerischen Ankerzentren zusammenfällt. Aus forschungsökonomischen Gründen konnten dazu für Bayern nur vier der sieben Regierungsbezirke in die Analyse mit einbezogen werden, wobei auf eine möglichst großräumige geographische Verteilung geachtet wurde. Zusätzlich erweitert wurde die Datengrundlage, indem die Datenerhebung mit dem Ankerzentrum in Dresden einen nicht-bayerischer Standort und mit der Bildzeitung auch ein Boulevardmedium umfasste (vgl. Tabelle 1). Die Selektion der Artikel ${ }^{3}$ ( $\left.n=501\right)$ erfolgte mithilfe verschiedener digitaler Datenbanken oder in den Online-Archiven der jeweiligen Titel. Ausgewählt wurden relevante Artikel im Zeitraum vom 1. Januar 2018 bis zum ersten Jahrestag der Ankerzentren am 1. August 2019, um sowohl den Diskurs zur Einführung der Ankerzentren als auch die Themensetzung im ersten Jahr ihrer Laufzeit zu dokumentieren.

2 Siehe unter anderem die Beiträge von Simon Goebel, Daniel Göler und Elisabeth Beck \& Christine Heimerer in diesem Band.

3 In den jeweiligen Datenbanken beinhaltete jede Suchanfrage neben dem Untersuchungszeitraum stets auch folgende Schlagwortkombination: »Anker or AnkER or Ankerzentrum or Ankerzentren«. Die Stichprobe wurde weiter über die Länge der Artikel (>300 Wörter) eingegrenzt. 
Tabelle 1: Ausgewählte Lokal- und Regionalzeitung

\begin{tabular}{|l|l|}
\hline Titel des Mediums & Zugeordnete Ankereinrichtung \\
\hline Augsburger Allgemeine & Donauwörth \\
\cline { 1 - 2 } Deggendorfer Zeitung & \multirow{2}{*}{ Deggendorf } \\
\cline { 1 - 2 } Straubinger Tagblatt & Manching \\
\cline { 1 - 2 } Donaukurier & \multirow{2}{*}{ Zirndorf } \\
\cline { 1 - 2 } Nürnberger Nachrichten & Dresden \\
\hline Nürnberger Zeitung & Bundesausgabe \\
\hline Sächsische Zeitung &
\end{tabular}

Die inhaltsanalytische Erhebung, die auf einem 42 Variablen umfassenden Kategoriensystem basiert, wurde von zwei Codiererinnen ${ }^{4}$ durchgeführt. Sie untersucht zunächst deskriptiv erste Aspekte der medialen Darstellung der Ankerzentren und verknüpft diese mit dem theoretischen Konstrukt der Mobilität.

\section{Ankerzentren im Spiegel lokaler Medienöffentlichkeiten: Ergebnisse der Inhaltsanalyse}

Die regionale Berichterstattung zu den ausgewählten bayerischen und sächsischen Ankerzentren folgt im Zeitverlauf der bekannten ereigniszentrierten Aufmerksamkeitslogik journalistischer Auswahl (vgl. Abbildung 1). Während zu Beginn des Jahres noch kaum ein Artikel zu den geplanten Ankereinrichtungen erscheint, steigt die Zahl der Veröffentlichungen ab Mai extensiv an und erreicht im Juni 2018 ihren Höhepunkt mit 65 Artikeln pro Monat. Auf relativ hohem Niveau begleitet das Thema den öffentlichen Diskurs über den Sommer, bevor im Anschluss die mediale Aufmerksamkeit über den Jahreswechsel deutlich nachlässt, um jedoch $a b$ März 2019 erneut Fahrt aufzunehmen und zum ersten Jahrestag der Implementierung der Einrichtungen auf einem neuen Berichterstattungshoch zu landen. In-

4 Die Überprüfung der Zuverlässigkeit der Codierung der beiden involvierten Personen (Forscherin mit Unterstützung einer studentischen Hilfskraft) stützt sich auf die Inter-CoderReliabilität nach Krippendorff (Hayes/Krippendorff 2007) und basiert auf den Codierungen zu fünf prototypisch ausgewählten Artikeln in der Main Post, die im Untersuchungszeitraum veröffentlicht wurden, nicht aber Teil des Samples waren. Auch wenn es keine allgemeingültigen Grenzwerte gibt, gelten in der Regel Ergebnisse zwischen .61 und .80 als ausreichend (vgl. Landis/Koch 1977). Aufgrund der teils anspruchsvollen Kategorien u.a. zur Erfassung kombinierter Frame-Elemente und der Tatsache, dass es sich um ein sehr konservatives Reliabilitätsmaß handelt, halte ich ein Overall-Krippendorff's Alpha von 0.65 für ausreichend. 
teressanterweise lässt sich feststellen, dass die Beiträge zum Thema Ankerzentren immer dann an durchschnittlicher Länge und demnach wohl auch Hintergrundinformationen gewinnen, wenn die Menge der Berichterstattung eher abflaut - der Journalismus scheint also tendenziell die Atempausen in der politischen Debatte $\mathrm{zu}$ nutzen, um weniger ereignisbezogen $\mathrm{zu}$ berichten und stattdessen vertiefter $\mathrm{zu}$ recherchieren.

\section{Abbildung 1: Berichterstattung zu Ankerzentren im Zeitverlauf}

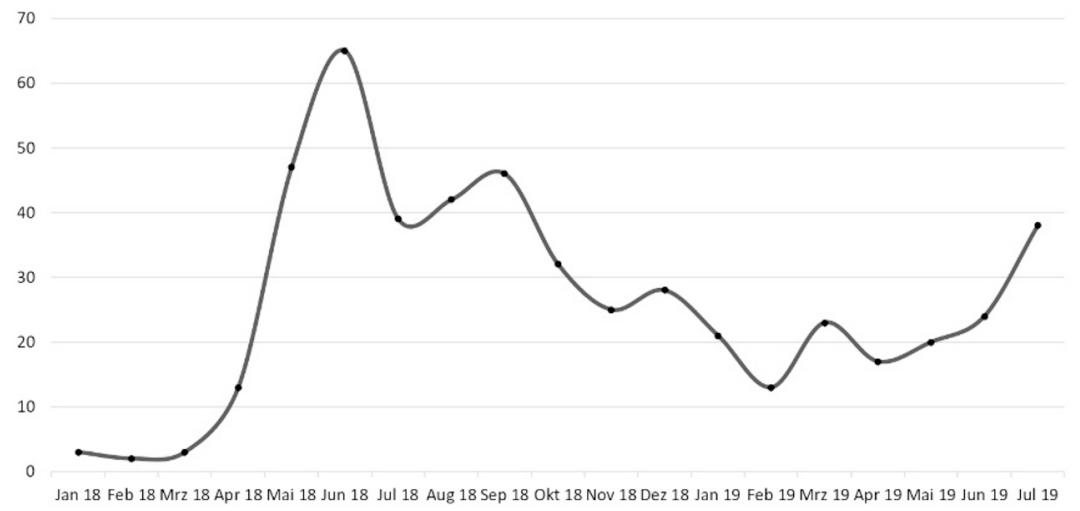

Quelle: Eigene Abbildung.

Ebenfalls bezeichnend ist, dass sich die Mehrheit der Artikel (42 \%) auf das Unterbringungskonzept Ankerzentrum allgemein bezieht und sich damit dem Metadiskurs der überregionalen Presse anschließt. Ihre Chance, den Faktor Lokalität in ihrer Berichterstattung zu betonen und die Asylpolitik auf die Lebenswelt vor Ort herunter zu brechen, bleibt so in vielen Fällen ungenutzt.

Bevor im Folgenden die thematische Einbettung und die wichtigsten Handlungsträger*innen im medialen Diskurs zu den Ankerzentren vorgestellt werden, folgen zunächst einige allgemeine Hinweise zur Relevanz der Unterbringung in den ausgewählten Artikeln. In 40,1 Prozent aller Beiträge stellt das Lagerleben von Geflüchteten das Hauptthema der Analyseeinheit dar. In etwa gleich vielen Artikeln konnte der Diskurs zu Ankerzentren immerhin als Nebenthema identifiziert werden, während sich die Nennung des Phänomens »Anker« in knapp einem Fünftel der Fälle lediglich auf einen Randaspekt bezog ${ }^{5}$. Gerade einmal 14,4 Prozent der Berichte liefern eine ausführlichere Erläuterung der Hintergründe, wohingegen fast darstellte, wurden für die vertiefte Analyse der Akteur schlossen. 
zwei Drittel der Artikel (62,1 \%) auf jede Form der Einordnung ihres Berichterstattungsgegenstandes Ankerzentrum verzichten.

Pro Artikel konnten bis zu zwei thematische Aspekte vercodet werden ( $\mathrm{n}=596)$. Knapp die Hälfte der analysierten Beiträge (47,7\%) rücken die Auseinandersetzung mit der Unterbringung von Geflüchteten in den Mittelpunkt ihrer Berichterstattung (vgl. Abbildung 2). In dieser Kategorie beschäftigen sich Artikel mit der konkreten Lebenssituation und Ereignissen direkt vor Ort in den Ankerzentren. Neben einer Vielzahl von Beiträgen, die dabei das Konzept als Ganzes thematisieren und keinen bestimmten Kontext des Lagerlebens ansprechen, verweisen knapp 30 Prozent der hier verorteten Themennennungen auf Polizeieinsätze oder Konflikte in den Einrichtungen. Zumeist handelt es sich um teils auch gewaltsame Auseinandersetzungen zwischen den Bewohner*innen und anwesenden Sicherheitskräften bzw. alarmierten Polizeibeamt*innen. In der Regel treten dabei die Geflüchteten als Unruhestifter*innen in Erscheinung. Im Gegensatz dazu betont jeder fünfte thematische Zugang entweder die schwierige Wohnsituation (z.B. fehlende Privatsphäre) und Perspektivlosigkeit oder die Verletzung von Menschenrechten, die unmittelbar aus der Unterbringungsform resultiert.

Abbildung 2: Überblick über die Themenfelder in der regionalen Berichterstattung zu Ankerzentren (in Prozent; $n=545$, ohne Sonstiges)

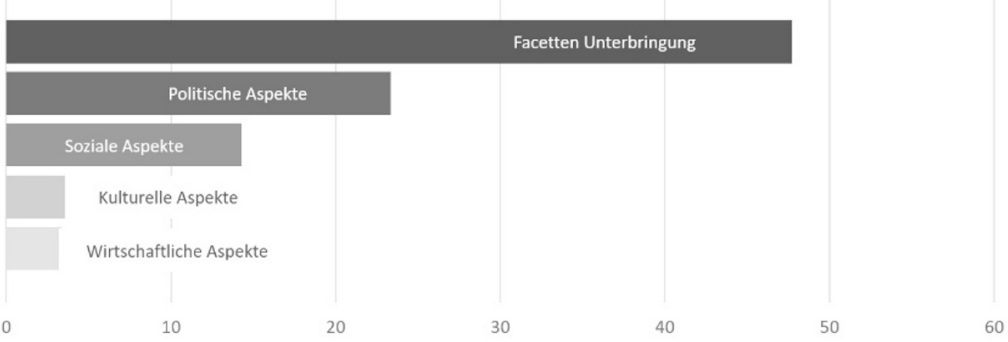

Quelle: Eigene Abbildung.

Neben spezifischen Fragen der Unterbringung prägen vor allem sozialpolitische Herausforderungen den lokalen Diskurs, wodurch sich die regionale Berichterstattung anschlussfähig an den nationalen migrationspolitischen Diskurs zeigt. Das Feld Politik hat in der Einzelanalyse hier einen klaren Fokus auf das Thema Abschiebung. Knapp ein Drittel der gefundenen politischen Facetten diskutieren diese asylpolitische Maßnahme. Heterogener fallen die Ergebnisse zu den Artikeln aus, die ihren Blick auf soziale Aspekte richten, denn außer um das negativ aufgeladene Narrativ der Kriminalität von Migrant"innen geht es hier vermehrt auch um Integrationskonzepte und bürgerschaftliches Engagement. 
Die Diversität eines Diskurses lässt sich neben den Themen auch an der Vielfalt der Handlungsträger*innen bemessen, die in ihm zu Wort kommen. Die Ergebnisse zu den hauptsächlich genannten Akteur*innen (vgl. Abbildung 3) vermitteln allerdings ein einseitiges Bild: Jedes zweite gefundenen Narrativ rückt Politiker*innen in den Mittelpunkt (schwarz hinterlegt), davon wiederum sind etwa die Hälfte Parteipolitiker*innen, und zwar besonders häufig von der CSU. Die gesamte parteipolitische Opposition, hauptsächlich vertreten durch die SPD und die Grünen, kommen gemeinsam auf gerade einmal genauso viele mediale Auftritte im Untersuchungszeitraum. Ein weiteres Viertel aller Handlungsträger*innen ist Regierungsmitglied. Weitere 40 Prozent aller genannten Hauptakteur*innen stammen aus der Zivilgesellschaft. Neben der Kirche (6,1\%) und Nichtregierungsorganisationen $(3,7 \%)$ sind es hier aber vor allem Bürger*innen $(12,4 \%)$ und Geflüchtete $(12,9 \%)$, die in den Mittelpunkt der thematischen Erzählung rücken.

Abbildung 3: Handlungsträger"innen in der regionalen Berichterstattung zu Ankerzentren (in Prozent; $n=593$; ohne Sonstiges)

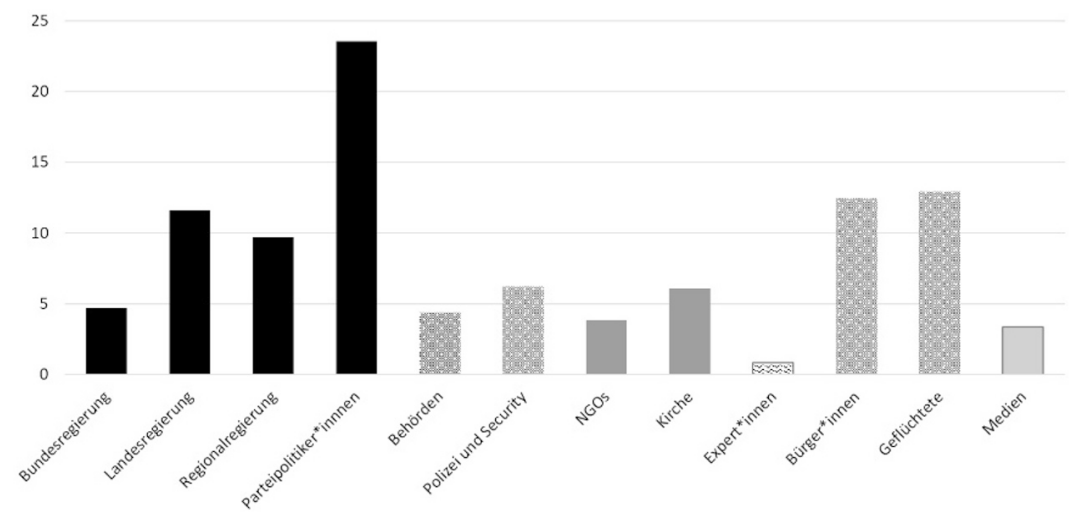

Quelle: Eigene Abbildung.

In mehr als zwei Dritteln der Fälle $(68,9 \%)$, in denen Geflüchtete als Hauptakteur*innen vorkommen, steht ihr medialer Auftritt in Zusammenhang mit den Themenfacetten »Gewalt im Ankerzentrum« (50,7\%) oder »Kriminalität« $(18,2 \%)$. Problematisch erscheint zudem der Umgang mit der Nennung von nationaler Herkunft der geflüchteten Handlungsträger*innen. Lediglich ein knappes Fünftel $(17,1 \%)$ der untersuchten Narrative macht keine Angabe zur Nationalität der geflüchteten Person(en), über die berichtet wird. Wenn eine ethnische Kategorisierung erfolgt, dann werden die Akteur*innen fast ausschließlich als Afrikaner*innen (63,2\%) identifiziert, am häufigsten handelt es sich um 
Nigerianer*innen $(22,4 \%)$. Bewohner*innen erscheinen also nicht nur wenig individualisiert und stimmlos, sondern es wird zudem eine ethnisch imaginierte Bedrohungshierarchie konstruiert. Eine solche Berichterstattung zwingt so Geflüchtete in die mediale Immobilität, während sie gleichzeitig durch die Überrepräsentation problemzentrierter Themenfacetten die öffentliche Debatte lediglich einseitig mobilisiert. Einen weiteren Indikator für eine einseitige Aufbereitung des Themenkomplexes Ankerzentren liefert die Analyse der Argumentationsstruktur in den Artikeln. Über alle untersuchten Zeitungstitel hinweg nennen etwas mehr als die Hälfte aller Artikel mindestens ein Pro- und ein Contra-Argument (37,9\%), 13,2 Prozent davon vereinen sogar eine hohe Dichte verschiedener Perspektiven. Mit Blick auf die einzelnen Zeitungstitel präsentieren sich mehr als zwei Drittel der Beiträge in der Bildzeitung (69,2\%) als einseitig, gefolgt von der Deggendorfer Zeitung (66,7\%). Als Positivbeispiele sind hingegen die Sächsische Zeitung und die Augsburger Allgemeine zu nennen, die in einer deutlichen Mehrheit der Artikel auf Ausgewogenheit setzen.

Abbildung 4: Ausgewogenheit der Argumentation in den Artikeln nach Gesamtbewertung des Unterbringungskonzept Ankerzentrum ( $n=372)$

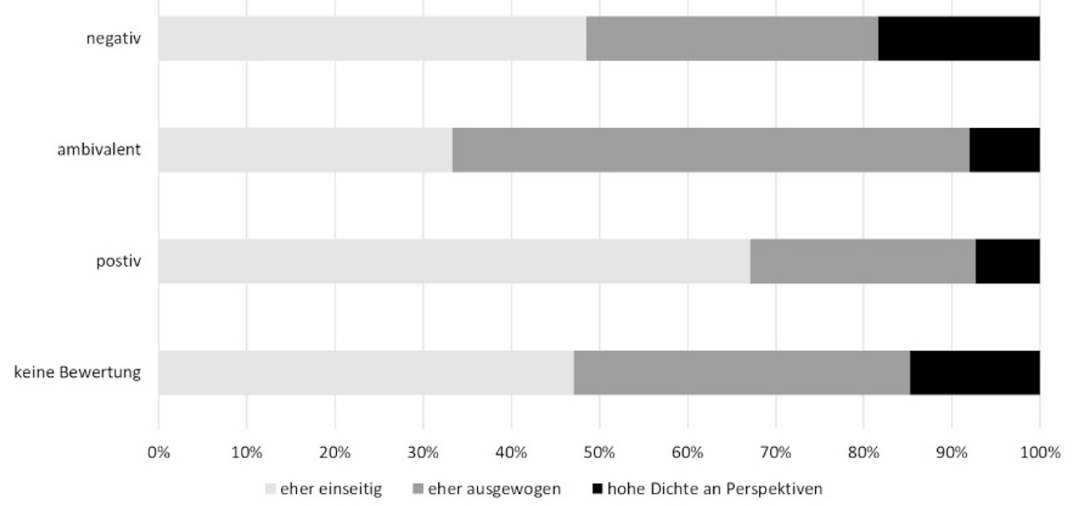

Quelle: Eigene Abbildung.

Interessant erscheint in diesem Zusammenhang, dass eine besonders einseitige Berichterstattung durchaus mit einer bestimmten Bewertungstendenz gegenüber den Ankerzentren einhergeht. Artikel mit einem positiven Gesamttenor gegenüber den Ankereinrichtungen sind signifikant häufiger $\left(\chi^{2}(6)=23.74, p=.001\right)$ einseitig aufbereitet als dies für Berichte mit ambivalentem oder negativem Urteil gilt. Doch selbst wenn kritische Berichterstattung in der Tendenz ausgewogener argumentiert, verzichtet auch hier nahezu jeder zweite Text $(48,4 \%)$ auf eine 
zweite, abweichende Position. Innerhalb eines Artikels begegnen in der Folge die Leser*innen selten einer kontrastreichen und abwägenden Berichterstattung, was zu einer Polarisierung der öffentlichen Meinung beitragen kann.

Die potentielle Mobilisierung durch die thematische und argumentative Verkürzung des Diskurses verstärkt sich auf der sprachlichen Ebene der Artikel: In einem guten Drittel der Beiträge, in denen Ankereinrichtungen ein Haupt- oder Nebenthema darstellen ( $\mathrm{n}=412$ ), sind zumindest wahrnehmbare, in der Hälfte sogar intensive Meinungsäußerungen vorhanden. Obwohl die Journalist"innen also stark darauf setzen, Einschätzungen zu diesem Thema zu sammeln und sich nicht auf eine rein faktenbasierte Aufbereitung beschränken, überwiegt in den Beiträgen dennoch eine sachliche Darstellungsweise der Argumente (51,5 \%). Im Umkehrschluss lässt sich jedoch auch knapp die Hälfte der Artikel als emotional beschreiben. So sagt beispielsweise der Chef der Deutschen Polizeigewerkschaft in einem Interview mit dem Straubinger Tagblatt, die Zahl der Abschiebungen sei »ein Witz« (4. April 2018) und der Autor eines Kommentars in der Augsburger Allgemeinen hält es für bedenklich, »dass sich viele Bürger mit durchaus ernst zu nehmenden Sorgen nach wie vor übergangen oder gar als Schmuddelkinder gebrandmarkt fühlen« (16. April 2018). Die allermeisten der formulierten Gefühle lassen sich der Kategorie »vorwurfsvoll« $(20,4 \%)$ zuordnen, allerdings steht in jedem zehnten Artikel auch Empathie im Vordergrund. Dies ist meist dann der Fall, wenn die Berichterstattung persönliche Schicksale thematisiert (vgl. Donaukurier 13. Juli 2018) oder von demütigenden Kontrollen und Gängelungen erzählt (vgl. Donaukurier 25. Juli 2019).

\section{Das Thema (Im-)Mobilität und Forderungen als Faktor der Mobilisierung}

Dieser Abschnitt widmet sich explizit der (Im-)Mobilität von Geflüchteten in Ankerzentren und den damit einhergehenden medialen (Im-)Mobilisierungsprozessen. Darüber können zwei Dimensionen des Codebuchs der Inhaltsanalyse genauere Informationen liefern, denn einerseits wurde offen kategorisiert, in welchen $\mathrm{Zu}$ sammenhängen (Im-)Mobilität als manifester thematischer Kontext (1) in der Berichterstattung auftaucht, und andererseits liefert die Erhebung von geäußerten Forderungen in den Artikeln (2) weitere Erkenntnisse. Unabhängig davon, ob eine solche Forderung von den Journalist*innen selbst verfasst wurde oder über die Meinungsäußerung einer direkt oder indirekt zitierten Person Eingang in den Beitrag fand, liefern sie weitere Anhaltspunkte für das Mobilisierungspotential lokaler Öffentlichkeiten.

Deutlich mehr Artikel illustrieren Praktiken der Immobilität (40,1\%), als dass in ihnen Verweise auf Mobilitätsprozesse $(28,2 \%)$ vorkommen. In beiden Fällen stehen Aspekte einer räumlichen (Im-)Mobilität im Vordergrund, die Förderung bzw. Verhinderung von sozialer Teilhabe als Form der Mobilität spielt eine unter- 
geordnete Rolle. Die Textstellen, welche Ankereinrichtungen als Institutionen der Immobilität rahmen, betonen in dieser Hinsicht vor allem zwei Faktoren: Zum einen die materialisierte Gegenständlichkeit von Exklusionsmechanismen, was sich in Metaphern ausdrückt, welche das Ankerzentrum mit einem Gefängnis gleichsetzen. Eine »abgeriegelte« Anlage, umgeben von »hohen Zäunen«, deren Funktion wahlweise der »Schutz« der Mehrheitsbevölkerung oder der Geflüchteten ist. Die Bewohner*innen werden in dieser Lagerarchitektur »festgehalten«, müssen »kaserniert«, »eingepfercht « und »zusammengesperrt« »auf engstem Raum« leben. Neben der Abschottung und Isolation als Ergebnis der Wohnsituation ist es vor allem die Erfahrung sozialer Kontrollmechanismen und die damit verbundene Symbolik der Überwachung und Entrechtung, die sich in der Berichterstattung in besonderer Häufigkeit antreffen lässt. Im Mittelpunkt stehen hier Erzählungen von langwierigen und teils willkürlich anmutenden Einlasskontrollen des Sicherheitspersonals sowie das Erleben eines Alltags mit vorgeschriebenen Essenszeiten und ohne Schlüssel für die eigenen Zimmer. Eine Institution, in der laut Bayerischem Flüchtlingsrat »Menschen abgefertigt [werden] wie Pakete« (Deggendorfer Zeitung, 6. Juni 2019).

Dieses Bild der Fremdbestimmung lässt sich auch auf die Artikel anwenden, in denen es um die Forcierung von Mobilität geht. Denn es handelt sich hierbei weniger um Berichte, in denen die Freiheit zur selbstbestimmten räumlichen oder sozialen Mobilität im Vordergrund steht, sondern vor allem um Beiträge, die die Mobilisierung der Geflüchteten im Zusammenhang mit ihrer potentiellen Abschiebung oder der Beschleunigung der Asylverfahren verhandeln. Mobilität stellt in diesen Fällen also weniger einen Möglichkeitsraum denn eine unfreiwillige Bewegung dar. Nur in Ausnahmefällen finden sich Bezüge zu Aspekten der Teilhabe wie beispielweise der Zugang zu Sprachkursen, die Regelbeschulung von Kindern, die möglichst zügige dezentrale Unterbringung anerkannter Geflüchteter oder auch Chancen auf einen Ausbildungsplatz.

Das Mobilisierungspotential lokaler Öffentlichkeiten hingegen lässt sich jedoch nicht aus der bloßen Nennung verschiedener Facetten von (Im-)Mobilität in der Berichterstattung ableiten. Vielmehr braucht es die Formulierung konkreter Forderungen, um die reine Beschreibung des Status Quo zu überwinden und Rückschlüsse auf politischen oder zivilgesellschaftlichen Willen zu ziehen. Forderungen in der Berichterstattung können also als ein Signal potentieller öffentlicher Mobilisierung dienen. Die Narrative zu Ankerzentren in den untersuchten Regionalzeitungen äußern solche Aufforderungen im Untersuchungszeitraum explizit und implizit in 56,5 Prozent der Fälle (vgl. Abbildung 5).

Knapp ein Viertel aller Themenbeiträge (24,2\%) fordert eine Verbesserung der Unterbringungssituation, womit zum einen die Infrastruktur, aber auch die Freizeitangebote sowie in den meisten Fällen der Wunsch nach Verteilung der Geflüchteten in dezentrale Unterkunftsstrukturen gemeint sein kann. In rund einem wei- 
Abbildung 5: Forderungen in der regionalen Berichterstattung zu Ankerzentren (in Prozent; $n=355$ )

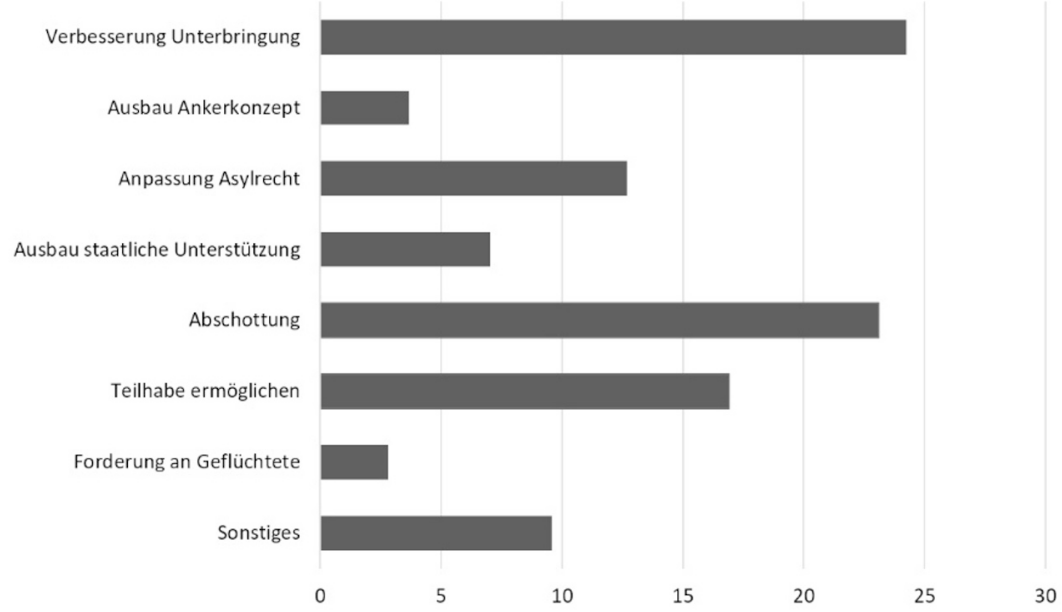

Quelle: Eigene Abbildung.

teren Fünftel des medialen Diskurses stehen eher abstrakte Forderungen nach politischen Lösungen in Form von Reformen des Asylrechtes (12,7 \%) und dem Ausbau staatlicher Unterstützungsleistung (7\%) im Mittelpunkt. Besonders dominant sind darüber hinaus vor allem die Stimmen in der Berichterstattung, die klare Abschottungspraktiken (23,1\%), z.B. durch einen Einwanderungsstopp bzw. die Sicherung der europäischen Außengrenzen verlangen oder eine schnelle Abschiebung - vor allem straffälliger Geflüchteter - begrüßen würden. Etwa jedes sechste Narrativ $(16,9 \%)$ betont hingegen den Wunsch nach Maßnahmen, die Geflüchtete schützen und Integrationsprozesse anstoßen sollen. Dass das Mobilisierungspotential des öffentlichen Diskurses dabei insgesamt eher die Positionen der Flüchtlingsgegner*innen stärkt, zeigt ein abschließender Blick auf die Intensität der Forderungen. Besonders prägnant fallen diese nämlich immer dann aus, wenn nach $\mathrm{Ab}$ schottung und/oder Abschiebung verlangt wird. Zwar gilt das auch für die Aufrufe zur Verbesserung der Unterbringungssituation, indem der mediale Diskurs aber mehr Freizügigkeit innerhalb der Lager oder auch bei der Wahl des Wohnortes fordert, konserviert er dennoch im Prinzip den bestehenden Zustand der »Verwahrung« von Geflüchteten, anstatt für mehr Teilhabechancen mobil zu machen. 


\section{Die lokalöffentliche Darstellung der Ankerzentren: Katalysator migrantischer (Im-)Mobilitäten?}

Die Analyse der medialen Darstellung des Unterbringungskonzepts »Ankerzentrum« in den Öffentlichkeiten bayerischer, einer sächsischen Regionalzeitung(en) und der Bildzeitung macht auf Chancen, aber auch Risiken einer öffentlichen Auseinandersetzung aufmerksam: So liefert der Diskurs einerseits Anlass für die aufnehmende Gesellschaft, sich mit den Lebensrealitäten geflüchteter Menschen zu beschäftigen, und eröffnet Anknüpfungspunkte, um asylpolitische Themen zu verhandeln, die über die Frage der Unterbringung hinausgehen. Andererseits - und so lassen sich die Ergebnisse der durchgeführten Inhaltsanalyse auch zusammenfassen - präsentiert sich die lokale massenmediale Öffentlichkeit zu diesem Thema in hohem Maße anschlussfähig an den gesamtgesellschaftlichen Diskurs zu Flucht(migration). Das wiederum geht mit der Diagnose einher, dass in der Tendenz auch Lokalmedien tradierte Narrative reproduzieren und in diesem Zuge Ankerzentren als »Problemorte « identifizieren und so erst recht zu einer Stigmatisierung der Orte beitragen (vgl. Hess et al. 2018). Dabei spiegelt die Berichterstattung drei bzw. vier Jahre nach 2015 den Eindruck, dass die Massenunterkünfte, die damals in einem als krisenhaft titulierten Ausnahmezustand unumgänglich erschienen (vgl. auch Jäger/Wamper 2017), nach wie vor eine vernünftige Entscheidung seien, um »die richtige Balance zwischen Humanität und Ordnung« (Nürnberger Zeitung 14. September 2018) zu erhalten bzw. wiederherzustellen. Die überwiegend problemzentrierten Konnotationen der Berichterstattung sind dabei bei weitem nicht immer ursächlich mit den Geflüchteten verknüpft, als Teilhabende mit eigener Agency werden sie jedoch ebenso wenig betrachtet. In der Regel werden sie als Gruppe entpersonalisiert und vor allem ohne die Möglichkeit dargestellt, sich mit ihrer eigenen Stimme und Meinung in den Diskurs einzubringen. Die (Im-)Mobilisierungspraktiken des deutschen Asylregimes finden ihren Ausdruck demnach nicht nur in der räumlichen und sozialen Isolation geflüchteter Menschen in Ankereinrichtungen, sondern auch in ihrer medialen Immobilität. Reduziert auf die Rolle eines Berichterstattungsgegenstandes gibt es für sie kaum Gelegenheiten, am gesellschaftlichen Aushandlungsprozess teilzuhaben.

Der regionale Mediendiskurs zu Ankerzentren wird damit seiner Integrationsfunktion nicht gerecht und trägt stattdessen dazu bei, "symbolische Ordnungen und [...] bestehende Herrschaftsstrukturen« zu reproduzieren (Engel et al. 2019: 291). Die Abschottungstendenzen in der Migrationspolitik, die laut Boswell in Wohlfahrtsstaaten auf »protektionistische Motive« zur Bewahrung "gesellschaftlicher Stabilität und Kohärenz« (Boswell 2007: 80) zurückzuführen sind, determinieren den öffentlichen Diskurs. So schafft beispielsweise der teils erschwerte Zugang von Journalist*innen zu Ankerzentren keine idealen Möglichkeiten, um $\mathrm{zu}$ recherchieren und vielfältig $\mathrm{zu}$ berichten. Im Umkehrschluss trägt jedoch 
eine eindimensionale mediale Öffentlichkeit zur Legitimation asylpolitischer Restriktionen bei.

Die Mobilisierungskraft des öffentlichen Diskurses kann und darf vor diesem Hintergrund nicht gleichgesetzt werden mit einer absichtsvollen Agitation der Journalist"innen. Denn die Debatte um Flucht und Migration zeigt deutlich wie nie zuvor, wie eng heutzutage »massenmediale, gruppeninterne und interpersonale Kommunikation miteinander verwoben sind « (Vowe 2016: 436). Netzwerkund massenmediale Öffentlichkeiten befinden sich in einer digitalen Gesellschaft nicht in Dualität zueinander, stattdessen entstehen in virtuellen Räumen eine Vielzahl von Sphären der Beteiligung, multiagorale Öffentlichkeiten (vgl. Meyer-Lucht 2008) mit hoher Bindungskraft für die jeweils dort interagierenden Gemeinschaften. Die unterschiedlichen Narrative zu Flucht(migration), die in diesen Communities kursieren, zeichnen sich durch eine große Heterogenität aus, allerdings driften die Positionen teils weit auseinander, was nicht etwa $\mathrm{zu}$ einer vielerorts erhofften Deliberation des Diskurses geführt, sondern vielmehr die Klüfte zwischen andersdenkenden politischen Lagern vertieft hat (vgl. Vowe 2016: 437f.). Zukünftige kommunikationswissenschaftliche Forschung zum Thema Flucht(migration) sollte diesem veränderten Kommunikationsumfeld daher noch stärker als bisher Rechnung tragen und versuchen, die pluralen und hybriden Diskurse mithilfe eines angepassten empirischen Vorgehens online wie offline einzufangen und zueinander in Verbindung zu setzen. Die Widersprüchlichkeiten und Mobilisierungskräfte medialer Diskurse zum Thema Flucht und Migration wirken demnach nicht nur auf politisches Handeln. Vielmehr lassen sich die "politischen Verwerfungen« nicht abschließend erklären, wenn der »strukturelle Wandel der Kommunikation« (ebd.: 439) als Faktor der Veränderung nicht miteinbezogen wird.

\section{Literaturverzeichnis}

Abadi, David (2017): Negotiating Group Identities in Multicultural Germany: The Role of Mainstream Media, Discourse Relations, and Political Alliances, Lanham/Boulder/New York/London: Lexington Books.

Altmeppen, Klaus-Dieter/Greck, Regina/Kössler, Tanja (2013): »Journalismus und Medien - organisationstheoretisch betrachtet «, in: Klaus Meier/Christoph Neuberger (Hg.), Journalismusforschung: Stand und Perspektiven, BadenBaden: Nomos, S. 37-51.

Arlt, Dorothee/Wolling, Jens (2018): »Bias wanted! Examining people's information exposure, quality expecta-tionsand bias perceptions in the context of the refugees debate among different segments of the German population «, in: Communications 43, S. 75-99. 
[BAMF] Bundesamt für Migration und Flüchtlinge (2020): Das Bundesamt in Zahlen 2019. Asyl. Nürnberg, https://www.bamf.de/SharedDocs/Anlagen/DE/Sta tistik/BundesamtinZahlen/bundesamt-in-zahlen-2019-asyl.pdf., Abrufdatum: 17.06.2020.

Bauer, Isabella (2017): Unterbringung von Flüchtlingen in deutschen Kommunen: Konfliktmediation und lokale Beteiligung. State-of-Research Papier 10, Osnabrück.

[Bay. LT] Bayerischer Landtag (2020): Status der Asylbewerberinnen und Asylbewerberzahlen und ANKER-Einrichtungen in Bayern, Drs. 18/7339.

Berg, Matthias (2014): »Mediatisierung, Mobilisierung und Individualisierung als Theorieansätze kommunikativer Mobilität«, in: Jeffrey Wimmer/Maren Hartmann (Hg.), Medienkommunikation in Bewegung. Mobilisierung - Mobile Medien - Kommunikative Mobilität, Wiesbaden: Springer VS, S. 47-68.

Berg, Matthias (2017): Kommunikative Mobilität. Die mediale Vernetzung beruflich mobiler Menschen, Wiesbaden: Springer VS.

Bonfadelli, Heinz/Friemel, Thomas (2017): Medienwirkungsforschung, 6. überarbeitete Auflage, Konstanz: UVK Verlagsgesellschaft.

Bonfadelli, Heinz/Moser, Heinz (2007): Medien und Migration. Europa als multikultureller Raum?, Wiesbaden: Springer VS.

Boswell, Christina (2007): »Theorizing migration policy: Is there a third way?«, in: International Migration Review 41(1), S. 75-100.

Bucher, Priska/Piga, Andrea (2009): »Medien und Migration - ein Überblick«, in: Urs Dahinden/Daniel Süss (Hg.), Medienrealitäten, Konstanz: UVK, S. 33-49.

Christ, Simone/Meininghaus, Esther/Röing, Tim (2017): »All Day Waiting«: Konflikte in Unterkünften für Geflüchtete in NRW (BICC Working Paper No. 3/2017), Bonn, https://www.bicc.de/uploads/tx_bicctools/BICC_WP_3_2017_w eb_01.pdf, Abrufdatum: 17.05.2020.

Dijk, Teun van (1991): Racism and the press, London: Routledge.

Dünnwald, Stephan (2002): Die BRD als Lagergesellschaft. Infodienst des Bayerischen Flüchtlingsrates 2, S. 27-38.

Emmer, Martin/Richter, Carola/Kunst, Marlene (2016): Flucht 2.0: Mediennutzung durch Flüchtlinge vor, während und nach der Flucht, Berlin: Freie Universität Berlin.

Engel, Susen/Deuter, Marie-Sophie/Mantel, Anna/Noack, Michael/Wohlert, Jale/Raspel, Julia (2019): »Die (Re)Produktion symbolischer Ordnung - Narrative in der deutschen Medienberichterstattung über Flucht und Geflüchtete«, in: Emre Arslan/Kemal Bozay (Hg.), Symbolische Ordnung und Flüchtlingsbewegungen in der Einwanderungsgesellschaft, Wiesbaden: Springer VS, S. 273-298.

Entman, Robert M. (1993): "Framing: Toward Clarification of a Fractured Paradigm«, in: Journal of Communication 4, S. 51-58. 
Evers, Tanja/Altmeppen, Klaus-Dieter (i.E.): »Kritischer Journalismus als Korrektiv im gesellschaftlichen Diskurs? Journalistische Berichterstattung als intervenierender Faktor in der Meinungsbildung in Zeiten von Rechtspopulismus und Lügenpresse«, in: Migrations- und Fluchtdiskurse im Zeichen des erstarkenden Rechtspopulismus.

Evers, Tanja (2019): Ich poste, also wähk mich! Parteien auf Facebook im Bundestagswahlkampf, Baden-Baden: Nomos.

FAZ (2019): Herrmann lobt Ankerzentren, vom 26.07.2019, https://www.faz.net/a ktuell/politik/inland/anker-zentren-hermann-zieht-positive-bilanz-16303462. html, Abrufdatum: 20.07.2020.

Fengler, Susanne/Kreutler, Marcus (2020): Stumme Migranten, laute Politik, gespaltene Medien. Die Berichterstattung über Flucht und Migration in 17 Ländern. Otto-Brenner-Stiftung, Frankfurt a.M.

Fick, Patrick (2009): »Der Wandel der Darstellung von Migranten am Beispiel Siegener Lokalmedien in den Jahren 1996 und 2006«, in: Rainer Geißler/Horst Pöttker (Hg.), Massenmedien und die Integration ethnischer Minderheiten in Deutschland. Bd. 2: Forschungsbefunde, Bielefeld: transcript, S. 235-270.

Friedrichsen, Mike (Hg.) (2010): Medienzukunft und regionale Zeitungen. Der lokale Raum in der digitalen und mobilen Medienwelt, Baden-Baden: Nomos.

Geißler, Rainer/Pöttker, Horst (2009): Mass media-integration. Media and migration: a comparative perspective, Bielefeld: transcript.

Gerhards, Jürgen/Neidhardt, Friedhelm (1990): Strukturen und Funktionen moderner Öffentlichkeit, Berlin: WZB.

Gerhardt, Volker (2012): Öffentlichkeit. Die politische Form des Bewusstseins, München: C.H. Beck.

Goebel, Simon (2019): »Medial (re)produzierte Narrative und Asylrechtsänderungen - Annäherungen an ein Dispositiv der Lager«, in: Reinhard Johler/Jan Lange (Hg.), Konfliktfeld Fluchtmigration. Historische und ethnographische Perspektiven, Bielefeld: transcript, S. 207-227.

Goebel, Simon (2017): Politische Talkshows über Flucht. Wirklichkeitskonstruktionen und Diskurse. Eine kritische Analyse, Bielefeld: transcript.

Goedeke Tort/Maheba Nuria/Guenther, Lars/Ruhrmann, Georg (2016): „Von kriminell bis willkommen. Wie die Herkunft über das mediale Framing von Einwanderern entscheidet «, in: M\&K Medien \& Kommunikationswissenschaft 64(4), S. 497-517.

Greck, Regina (2018): »Schaffen wir das? Frames im medialen Diskurs zur Flüchtlingskrise in der deutschen Regionalpresse des Jahres 2015 und ihre Lösungsorientierung«, in: Publizistik 3, S. 359-382.

Guyton, Patrick (2019): Ein Jahr Ankerzentren: Wo der Wachmann nicht mal klopft, in: taz vom 31.07.2019, https://taz.de/Ein-Jahr-Ankerzentren/!5613882/, Abrufdatum: 27.07.2020. 
Hafez, Kai (2019): » 'Die verhängnisvolle Neigung der Medien..... Plädoyer für einen Humanitären Journalismus«, in: Communicatio Socialis 4, S. 490-502.

Hayes, Andrew/Krippendorff, Klaus (2007): »Answering the Call for a Standard reliability Measure for Coding data«, in: Communication Methods and Measures 1(1), S. 77-89.

Heidenreich, Tobias/Lind, Fabienne/Eberl, Jakob-Moritz/Boomgaarden, Hajo G. (2019): »Media Framing Dynamics of the >EuropeanRefugee Crisis $\triangleleft$ : A Comparative Topic Modelling Approach«, in: Journal of Refugee Studies 32(1), S. 172-182.

Hepp, Andreas (2006): »Kommunikative Mobilität als Forschungsperspektive: Anmerkungen zur Aneignung mobiler Medien-und Kommunikationstechnologie«, in: Ästhetik \& Kommunikation 37(135), S. 15-22.

Hess, Sabine/Pott, Andreas/Schammann, Hannes/Scherr, Albert/Schiffauer, Werner (2018): Welche Auswirkungen haben »Anker-Zentren«? Eine Kurzstudie für den Mediendienst Integration, Berlin.

Hestermann, Thomas (2020): Berichterstattung über Eingewanderte und Geflüchtete. Die Unsichtbaren. Eine Expertise für den Mediendienst Integration.

Holtz-Bacha, Christina (2019): Die (Massen-)Medien im Wahlkampf. Die Bundestagswahl 2017, Wiesbaden: Springer VS.

Inhetveen, Katharina (2010): Die politische Ordnung des Flüchtlingslagers. Akteure - Macht - Organisation. Eine Ethnographie im Südlichen Afrika, Bielefeld: transcript.

Jäger, Margarete/Wamper, Regina (2017): Von der Willkommenskultur zur Notstandsstimmung. Der Fluchtdiskurs in deutschen Medien 2015 und 2016. Duisburg: DISS - Duisburger Institut für Sprach- und Sozialforschung, www.diss-duisburg.de/wp-content/uploads/2017/02/DISS-2017-Von-der-

Willkommenskultur-zur-Notstandsstimmung.pdf, Abrufdatum: 04.08.2020.

Jacobs, Laura/Hooghe, Marc/de Vroome, Thomas (2017): »Television and anti-immigrant sentiments: the mediating role of fear of crime and perceived ethnic diversity«, in: European Societies, S. 1-25.

Jung, Matthias/Niehr, Thomas/Böke, Karin (2000): Ausländer und Migranten im Spiegel der Presse. Ein diskurshistorisches Wörterbuch zur Einwanderung seit 1945, Wiesbaden: Westdeutscher Verlag.

Krämer, Benjamin/Schindler, Johanna (2018): »Zum Umgang der Medien mit dem Rechtspopulismus. Hintergründe, Herausforderungen und Handlungsempfehlungen«, in: Communicatio Socialis 2, S. 131-142.

Krüger, Udo Michael/Zapf-Schramm, Thomas (2019): »Info Monitor 2018. Grokound Migrationsdebatte prägten die Fernsehnachrichten«, in: Media Perspektiven 2, S. 44-73.

Landis, Richard/Koch, Gary (1977): »The measurement of observer agreement for categorical data«, in: Biometrics 33(1), S. 159-174. 
Link, Jürgen (2016): »Die Massenflucht zwischen Denormalisierung, Normalisierung und transnormalistischen Alternativen«, in: DISS-Journal. Zeitschrift des Duisburger Instituts für Sprach- und Sozialforschung 31, S. 7-8, https:/www.d iss-duisburg.de/download/dissjournal-dl/DISS-Journal-31-2016.pdf, Abrufdatum: 01.08.2020.

Maurer, Marcus/Jost, Pablo/Haßler, Joerg/Kruschinski, Simon (2019): »Auf den Spuren der Lügenpresse. Zur Richtigkeit und Ausgewogenheit der Medienberichterstattung in der >Flüchtlingskrise« «, in: Publizistik 64(1), S. 15-35.

McCombs, Maxwell/Shaw, Donald (1972): »The Agenda-Setting-Function of Mass Media«, in: Public Opinion Quarterly 36(2), S. 167-187.

Meyer-Lucht, Robin (2008): Virtualienmarkt. Habermas, die Medien, das Internet, in: perlentaucher. Das Kulturmagazin vom 04.06.2008, https://www.perlenta ucher.de/virtualienmarkt/habermas-die-medien-das-internet.html?highlight, Abrufdatum: 03.06.2020.

Mouzourakis, Minos/Pollet, Kris/Ott, Jean-David (2019): The AnkER centres. Implications for asylum procedures, reception and return. European Council on Refugees and Exiles, Brüssel.

Oehmichen, Ekkehardt/Schröter, Christian (2011): »Internet zwischen Globalität und Regionalität«, in: Media Perspektiven 4, S. 182-194.

Pieper, Tobias (2008): Die Gegenwart der Lager: Zur Mikrophysik der Herrschaft in der deutschen Flüchtlingspolitik, Münster: Westfälisches Dampfboot.

Scholz, Sophie (2013): Soziale Medien schaffen Möglichkeitsräume für das »BürgerSein«, in: bpb vom 12.12.2013, https://www.bpb.de/dialog/netzdebatte/175151/ soziale-medien-schaffen-moeglichkeitsraeume-fuer-das-buerger-sein, Abrufdatum: 25.08.2020.

Stavenhagen, Liane/Kossatz, Daniela (2017): »Einstellungen und Meinungen zur Migration. Eine vergleichende Europa-Studie«, in: Ipsos vom März 2017, https://www.ipsos.com/sites/default/files/2017-05/WP_Migration_RGBRZ_final.pdf, Abrufdatum: 05.05.2020.

[StMI] Bayerisches Staatsministerium des Innern und für Integration (2018): Der Bayerische Asylplan. Maßnahmen im Überblick, München, https://www.lfar. bayern.de/mam/header/lfar_im_ueberblick/ueber_das_lfar/der_bayerische_ asylplan_stand_juli_2018.pdf, Abrufdatum: 16.07.2020.

Täubig, Vicki (2009): Totale Institution Asyl. Empirische Befunde zu alltäglichen Lebensführungen in der organisierten Desintegration, Weinheim/München: Juventa.

Ter Wal, Jessica (2002): Racism and Cultural Diversity in the Mass media. An Overview over Research and Examples of Good Practice in the EU Member States, 1995-2000, Wien.

Tanis, Kerstin (2020): Entwicklungen in der Wohnsituation Geflüchteter, Ausgabe 05/2020 der Kurzanalysen des Forschungszentrums Migration, Integration 
und Asyl des Bundesamtes für Migration und Flüchtlinge, Nürnberg: Bundesamt für Migration und Flüchtlinge.

Trebbe, Joachim (2009): Ethnische Minderheiten, Massenmedien und Integration. Eine Untersuchung zu massenmedialer Repräsentation und Medienwirkungen, Wiesbaden: VS Verlag für Sozialwissenschaften.

Tully, Claus/Baier, Dirk (2006): Mobiler Alltag: Mobilität zwischen Option und Zwang - Vom Zusammenspiel biographischer Motive und sozialer Vorgaben, Wiesbaden: VS Verlag für Sozialwissenschaften.

Urry, John (2007): Mobilities, Cambridge: Polity Press.

Vowe, Gerd (2016): »Politische Kommunikation in der Migrationskrise. Der strukturelle Wandel der Kommunikation als Herausforderung für Politik und Wissenschaft «, in: Publizistik 61, S. 431-440.

Wagner, Ulrike/Gerlicher, Peter/Brüggen, Niels (2011): Partizipation im und mit dem Social Web - Herausforderungen für die politische Bildung. Eine Expertise für die Bundeszentrale für politische Bildung, München: JFF -Institut für Medienpädagogik in Forschung und Praxis.

Wanta, Wayne/Ghanem, Salma (2007): »Effects of Agenda-Setting «, in: Raymond W. Preiss/Barbara Mae Gayle/Nancy Burrell/Mike Allen/Jennings Bryant (Hg.), Mass Media Effects Research. Advances through Media-Analysis, Mahwah: Erlbaum, S. 37-51.

Wengeler, Martin (2006): »Zur historischen Kontinuität von Argumentationsmustern im Migrationsdiskurs«, in: Christoph Butterwegge/Gudrun Hentges (Hg.), Massenmedien, Migration und Integration. Herausforderungen für Journalismus und politischer Bildung, Wiesbaden: VS Verlag, S. 13-36.

Wimmer, Jeffrey/Hartmann, Maren (2014): »Mobilisierung, mobile Medien und kommunikative Mobilität aus kommunikations- und mediensoziologischer Perspektive«, in: Jeffrey Wimmer/Maren Hartmann (Hg.), Medienkommunikation in Bewegung. Mobilisierung - Mobile Medien - Kommunikative Mobilität, Wiesbaden: Springer VS, S. 11-30.

Zick, Andreas/Küpper, B./Berghan, W. (2019): Verlorene Mitte. Feindselige Zustände. Rechtsextreme Einstellungen in Deutschland 2018/19, Bonn: FriedrichEbert-Stiftung. 
Ausblick 



\section{Nach dem Lager \\ Begegnung, Inklusions- und Exklusionsmechanismen an ländlichen Wohnstandorten in Deutschland}

Birgit Glorius

\section{Zusammenfassung}

Dieser Beitrag setzt sich aus einer sozialgeographischen Perspektive mit (Im-) Mobilitäten geflüchteter Menschen im lokalen Kontext auseinander Dabei wird argumentiert, dass sich Mobilisierungen bzw. Immobilisierungen nicht nur an Orten zeigen, die durch physische Einhegungen geprägt sind, sondern sich auch in den vorherrschenden gesellschaftlichen Positionierungen, Praktiken und Diskursen zur Inklusion bzw. Exklusion widerspiegeln. Der Beitrag konzentriert sich auf den gesellschaftlichen Aufnahmekontext in ländlichen Räumen, denen spezifische Attribute zugesprochen werden, die eine soziale Inklusion von Zugewanderten fördern bzw. hemmen können. Zur Konzeptualisierung dieser Faktoren wird der Begriff der Rezeptivität sowie die Theorie sozialen Kapitals genutzt. Die empirischen Ergebnisse zeigen, dass ländliche Gesellschaften eine Vielzahl von potenziellen Ressourcen aufweisen, die die soziale Inklusion von Geflüchteten erleichtern können. Diese Ressourcen sind jedoch nicht automatisch für Neuankommende verfügbar, bzw. nicht automatisch inklusionsfördernd: so basiert die soziale Einbindung von Neuankommenden in die Nachbarschaft auf der funktionalen Reziprozität sowie dem Grundsatz, abweichendes und damit potenziell störendes Verhalten zu verhindern. Auch die Einbindung in lokale Institutionen vor Ort ist geprägt von impliziten Assimilationserwartungen an die Neuankommenden. Intensivere Bindungen im Sinne von »bonding social capital« sind zwar möglich, scheinen sich jedoch erst entwickeln zu können, nachdem eine Übernahme von sozialen Normen erfolgt ist. Um die Frage zu beantworten, warum dies so ist, zeigt sich die intensive Wahrnehmung von Gruppenzugehörigkeit und die enge Crenzziehung zwischen dem Eigenen und dem Anderen als entscheidend. Als Spezifik ländlicher Gemeinschaften für soziale Inklusion schält sich somit die erhebliche Wirkmächtigkeit von einmal hergestellten sozialen und räumlichen Ordnungen heraus. 


\section{Summary}

This article deals with the (im-)mobility of refugees in a local context from a socio-geographical perspective. It argues that processes of (im-)mobilization are not only relevant regarding physical enclosures, but are also reflected in terms of inclusionary or exclusionary societal attitudes, practices and discourses. The article focuses on rural areas as context for processes of (im-)mobilization, which are characterized by specific societal attributes that can promote or inhibit the social inclusion of immigrants. The concept of receptivity and social capital theory are used to conceptualize these factors. The empirical results show that rural societies have a multitude of potential resources that can facilitate the social inclusion of refugees. However, these resources are not automatically available for newcomers, and they don't automatically promote inclusion: for example, social inclusion of newcomers into the neighborhood and in societal institutions was found to be rather based on functional reciprocity and assimilative expectations. The intensification of social relations in the sense of »bonding social capital« is possible, but newcomers need to adopt local social norms first. The empirical results suggest that those assimilative expectations and the stress on social norms is due to a strong perception of group membership, thus creating insiders and outsiders. Thus, with regards to the specifics of social inclusion into rural societies, once established social and spatial orders show considerable persistence.

\section{Einleitung}

Asylsuchende sind während und nach ihrer Flucht lange mit Lagern und Gruppenunterkünften konfrontiert. Während des Lebens im Lager ist eine Annäherung an den Alltag »draußen« vielfach nur eingeschränkt möglich. Das Leben im Lager ist oft geprägt durch räumliche Enge und sozialräumliche Isolation, was Intergruppenkonflikte befördert und Integration ${ }^{1}$ hemmt (vgl. Täubig 2009). Die eigene Wohnung hingegen verleiht den Geflüchteten Autonomie über die eigene Lebensführung, Schutz und Geborgenheit und auch Selbstidentifikation (vgl. Aumüller/Daphi/Biesenkamp 2015: 38). Zudem erleichtert das Wohnen in der Nachbarschaft von Einheimischen die Herstellung von alltäglichen sozialen Kontakten und fördert somit den Integrationsprozess (vgl. Bensch 2017: 24; Aumüller/Daphi/Biesenkamp 2015: 62). Über die Wohnung hinaus und in Bezug auf einen größeren So-

1 Unter »Integration«soll im Rahmen dieses Beitrags der Prozess der gegenseitigen Annäherung von Geflüchteten und Aufnahmegesellschaft verstanden werden, mit dem Ziel der vollständigen Teilhabe an allen Lebensbereichen der Aufnahmegesellschaft, unter Beibehaltung der eigenen Kultur und Identität. Eine kritische Würdigung des Integrationsbegriffs und seiner vielen Lesarten findet sich bspw. in Schinkel 2017 sowie in Glorius/Schondelmayer 2019. 
zialraum werden häufig ländliche Gemeinden als besonders geeignet für Integrationsprozesse beschrieben. Zum einen bestehe hier weniger Druck auf den lokalen Wohnungsmärkten, so dass Geflüchtete seltener als in städtischen Siedlungen in segregierten und sozial stigmatisierten Quartieren leben müssen (vgl. Braun/Simons 2015). Zum anderen wird der Sozialraum als integrationsförderlich angesehen, da er sich durch geringere Anonymität auszeichnet, was bessere Chancen der Annäherung, Begegnung und schließlich der Integration und sozialen Teilhabe verspricht (vgl. Gruber 2013; Boos-Krüger 2005).

In diesem Beitrag soll diesen Vorannahmen über Integrationsmöglichkeiten dezentral lebender Geflüchteter in ländlichen Gemeinden nachgegangen werden. Dabei liegt die Konzentration auf den Wahrnehmungen und Einstellungsmustern der lokalen Bevölkerung in Bezug auf die Anwesenheit Geflüchteter in der Nachbarschaft und am Ort. Gestützt auf umfangreiches Befragungsmaterial untersucht dieser Beitrag die Bedeutung und Ausgestaltung von Nachbarschaftsbeziehungen im ländlichen Raum, die Konstruktion von sozialer Identität und Erfahrungen mit der Partizipation Geflüchteter am sozialen Leben vor Ort. Dabei wird die Frage, wie in den überschaubaren Sozialräumen ländlicher Gemeinden Zugehörigkeit und Fremdheit verhandelt werden, eine wichtige Rolle spielen. Der Beitrag hat nicht zum Ziel, diese Phänomene vollumfänglich und in statistischer Repräsentativität abzuhandeln. Vielmehr wird durch die Befassung mit Annäherungsprozessen im Sozialraum außerhalb des Lagers aufgezeigt, welche Mechanismen von sozialer Inklusion und Exklusion auch jenseits von physischen Einhegungen in der sozialen Welt wirksam sind.

Der Beitrag ist folgendermaßen gegliedert: Auf die Einleitung folgt eine Einführung in die wesentlichen konzeptionellen Begrifflichkeiten für die anschließende Analyse, ein Überblick über die Spezifik ländlicher Gemeinden als sozialer Ort für Geflüchtete, sowie Erläuterungen zur Methodik (Abschnitt 2). Der dritte Teil dieses Beitrags stellt ausgewählte Aspekte der Daten eines laufenden Forschungsprojekts zur Aufnahme von Geflüchteten und deren Bleibeorientierung in ländlichen Gemeinden Deutschlands vor. Der vierte Abschnitt fasst die Ergebnisse zusammen und zieht ein Fazit.

\section{Konzeptionelle und methodische Überlegungen}

Dieser Beitrag setzt sich aus einer sozialgeographischen Perspektive mit (Im-)Mobilitäten geflüchteter Menschen im lokalen Kontext auseinander. Dabei wird argumentiert, dass sich Mobilisierungen bzw. Immobilisierungen nicht nur an physischen Orten wie Sammelunterkünften zeigen, sondern sich auch in den vorherrschenden gesellschaftlichen Positionierungen, (Exklusions-)Praktiken und Diskursen widerspiegeln. Beispiele hierfür sind etwa die Reaktionen der Bevölkerung auf 
Geflüchtete, die Art der Unterbringung oder der Umgang vor Ort mit gesetzlich festgelegten rechtlichen Kategorien im Asylsystem, etwa beim Zugang zu Integrationsangeboten.

\section{Räumliche Differenzierung von In- und Exklusionsprozessen}

Die meisten wissenschaftlichen Studien und Integrationsmonitorings konzentrieren sich empirisch auf das Verhalten der Zugewanderten und ihre Schritte in die Ankunftsgesellschaft (vgl. Hersi 2014; Bowskill/Lyons/Coyle 2007), was je nach Epoche, Sprachverwendung und Intention als Prozess der Akkulturation, Integration, Assimilation oder Inklusion bezeichnet wird (vgl. Schinkel 2017; Sam 2006). Nimmt man die Konzeption des Integrationsbegriffs ernst, muss man jedoch auch die Ankunftsgesellschaft in die Forschung einbeziehen, denn ihre kollektiven Einstellungen und Erwartungen beeinflussen die Integrationsmöglichkeiten der Neuankommenden und bilden spezifische (Un-)Möglichkeitsräume aus. Ihre Aufnahme- und Integrationsfähigkeit ist von verschiedenen Faktoren abhängig, die in dem hier vorgestellten Forschungsprojekt unter dem Begriff der Rezeptivität (engl. receptivity) zusammengefasst werden (vgl. Glorius/Bürer/Schneider 2019). Wörtlich kann receptivity mit Offenheit oder Aufnahmefähigkeit übersetzt werden. Der Begriff ist vor allem im US-amerikanischen Kontext verwendet worden, um Einwanderungs- und Integrationsprozesse aus der Perspektive der aufnehmenden Gesellschaft zu konzeptualisieren (vgl. McDaniel 2013; Jensen 2006; De Jong/Tran 2001; Fetzer 2000). Meist werden die politische, die ökonomische und die kulturelle Dimension unterschieden, wobei Forschungsergebnisse zu politischen und ökonomischen Faktoren zahlreicher sind, als jene, die kulturelle und gesellschaftliche Faktoren in den Blick nehmen (vgl. McDaniel 2013: 19). Untersuchungen in US-amerikanischen Städten konnten Unterschiede in der Rezeptivität in Bezug zur ökonomischen Prosperität setzen, aber auch ethnische Zuschreibungen waren bedeutend. So wurden stärkere Marginalisierungsprozesse von Zuwander*innen dort nachgewiesen, wo die vermeintliche ethnische Andersartigkeit im Vergleich zur aufnehmenden Bevölkerung besonders groß war, oder wo auf einen Schlag besonders viel Zuwanderung stattfand (vgl. Fetzer 2000). Ökonomische Krisensituationen verstärkten dabei den »Nativismus«, d.h. die Überhöhung des »Eigenen«, verbunden mit der Deklaration von EtabliertenVorrechten (ebd.). Vor allem in Bezug auf »new immigrant gateways«, also neue Zuwanderungsorte jenseits der großen städtischen »Schmelztiegel«, konnten Arbeiten in den USA ähnliche Effekte nachweisen, wie die Studien zu Einwanderung in ländliche Regionen Deutschlands: Dort wird die größere Überschaubarkeit des Sozialraums hervorgehoben, was die Orientierung und Eingliederung erleichtert und eine hohe Zahl unmittelbarer Kontakte ermöglicht (vgl. Gruber 2013; Schader Stiftung 2011; Boos-Krüger 2005; Micksch/Schwier 2000). Andererseits sind 
ländliche Gesellschaften von geringerer Diversität geprägt; dies und das hohe Ausmaß sozialer Kontrolle kann die Integration von als fremd wahrgenommenen Personen erschweren. Es existiert eine höhere Sensibilität gegenüber Fremdheit und Unterschiedlichkeit, die häufiger als problematisch angenommen und wahrgenommen wird, aber auch ein höheres Potenzial an Gemeinschaft und sozialer Geborgenheit. Mehrere Studien betonen die positive Rolle von Vereinen für die soziale Teilhabe von Migrant*innen in ländlichen Gemeinden, da sie einen wichtigen Teil der sozialen Infrastruktur im ländlichen Raum darstellen (z.B. Roos 2016; Nadler/Kriszan/Nienaber 2010). Weiterhin sind auch die jeweils spezifischen Rahmenbedingungen zu berücksichtigen, etwa Lage, Infrastruktur oder ökonomische Situation vor Ort, aber auch historische Erfahrungen mit Zuwanderung. All diese Elemente prägen eine spezifische Hintergrundfolie für Prozesse der sozialen Inklusion oder Exklusion, die nicht per se unkomplizierter verlaufen als in städtischen Agglomerationen. Zudem weisen empirische Befunde zur Eigenwahrnehmung von Geflüchteten in unterschiedlichen Formen der Unterbringung darauf hin, dass der Grad der Rezeptivität direkte Effekte auf die räumliche und soziale Mobilität im Sinne einer Mobilisierung bzw. Immobilisierung haben kann (vgl. Glorius/Gasch i.E.).

\section{Konzeptualisierung von Rezeptivität in ländlichen Gesellschaften}

Der vorliegende Beitrag konzentriert sich auf die soziale und kulturelle Komponente von Rezeptivität und nimmt die gesellschaftlich-sozialen Ressourcen der aufnehmenden Gesellschaft in den Blick. Diese können sich bedingt durch die demographische, soziale und ökonomische Lage der Gesellschaft unterscheiden, aber auch in Bezug auf Einstellungen und Erfahrungen gegenüber Geflüchteten (bzw. Zugewanderten oder/und Ausländer*innen). Daraus leiten sich unterschiedliche Fähigkeiten zur Entwicklung zivilgesellschaftlicher Aufnahmestrukturen ab, die als Brücken zwischen Geflüchteten und der Residenzbevölkerung fungieren können. Zudem gehen wir davon aus, dass eine unterschiedliche Bereitschaft besteht, die vorhandenen Ressourcen zur Förderung der sozialen Inklusion von Geflüchteten einzusetzen (vgl. Glorius/Bürer/Schneider, i.E.).

Auf der Basis der Literaturschau lassen sich besondere gesellschaftlich-soziale Ressourcen in ländlichen Gemeinden in Bezug auf die Quantität und Ausgestaltung sozialer Kontakte im Alltag vermuten. Anders als in der Großstadt sind in der durch Überschaubarkeit und sozialräumliche Nähe geprägten ländlichen Umgebung alltägliche Handlungen und Sinnherstellungspraktiken wie z.B. das Grüßen auf der Straße von großer Bedeutung. Als typisch ländliche Ressource gilt die Intensität von Nachbarschaftsbeziehungen sowie die Vielfalt und Dichte von sozialen Netzwerken und institutionalisierten sozialen Strukturen, die einen Rahmen für Integrationsprozesse bieten können (vgl. Gruber 2013; Schader Stiftung 2011; 
Boos-Krüger 2005; Micksch/Schwier 2000). Auf der anderen Seite steht die Frage nach der Bereitschaft, diese Ressourcen auch zum Wohle der Neuankommenden einzusetzen, die sich empirisch auf explizite und implizite Weise zeigen dürfte; explizit etwa durch die Entwicklung von Diversitätskonzepten oder entsprechenden Leitlinien, durch die sich alle gesellschaftlichen Akteur*innen zur Diversitätsorientierung verpflichten; implizit im Sinne der grundsätzlichen Offenheit und Toleranz gegenüber dem Unbekannten, Neuen, oder Fremden. Daran ist wiederum die Frage geknüpft, wie die kollektive soziale Identität der ländlichen Gesellschaft konstituiert ist, d.h. wie das Eigene in Abgrenzung zum fremden Anderen definiert ist.

Zur Untersuchung dieser Komponenten von Rezeptivität kommen verschiedene Theorieansätze infrage: Zum einen knüpfen die Überlegungen zur sozialen Verfasstheit der ländlichen Gesellschaft an Putnams Theorie sozialen Kapitals an (vgl. Putnam 2000). Vor allem die Differenzierung von brückenbauendem (bridging) und soziale (lokale) Bindungen stärkendem (bonding) sozialen Kapital in sozialen Netzwerken ist hier relevant. Während bonding social capital die Blickrichtung der Gemeinschaft eher nach innen richtet und die Gruppenhomogenität unterstreicht, ist bridging social capital nach außen gewandt und überbrückt soziale Gegensätze. Putnam betont, dass beide Dimensionen in jedwedem sozialen Netzwerk in unterschiedlicher Stärke vorhanden sein können (vgl. ebd.: 22). Hinsichtlich der Integrationskraft sozialer Netzwerke im Kontext ethnischer Diversität stellt er die Frage der sozialen Identität in den Mittelpunkt: Das Konstrukt sozialer Identität, so Putnam, beeinflusst die soziale Distanz zwischen dem Eigenen und dem Anderen: Geringe soziale Distanz korreliert mit einer geteilten sozialen Identität, basierend auf Nähe und gemeinsamen Erfahrungen, während eine große soziale Distanz dazu führt, die Andersartigkeit oder Abweichungen von Neuankommenden stärker wahrzunehmen und dementsprechend zu handeln (vgl. Putnam 2007: 159, angelehnt an Alba/Nee 2003: 32).

\section{Untersuchungsmethodik}

Die hier präsentierten Daten sind einem größeren, laufenden Forschungsprojekt entnommen, das die langfristigen Bleibepotenziale von Geflüchteten in ländlichen Gemeinden untersucht. ${ }^{2}$ Dabei wurden in den Jahren 2018-2020 empirische Untersuchungen in ländlichen Gemeinden in insgesamt acht Landkreisen der Bundesländer Bayern, Hessen, Niedersachsen und Sachsen durchgeführt. Unter den

2 Die Förderung des Vorhabens erfolgte aus Mitteln des Bundesministeriums für Ernährung und Landwirtschaft (BMEL) aufgrund eines Beschlusses des deutschen Bundestages. Die Projektträgerschaft erfolgte über die Bundesanstalt für Landwirtschaft und Ernährung (BLE) im Rahmen des Bundesprogramms Ländliche Entwicklung. 
32 ausgewählten Fallstudiengemeinden sind Dörfer, kleine und Mittelstädte unter 20.000 Einwohner*innen, in denen Geflüchtete leben. Im Projektverlauf wurden Strukturdaten erhoben, Leitfadeninterviews mit politischen, administrativen und zivilgesellschaftlichen Akteur*innen, partizipative Interviews mit Geflüchteten sowie eine postalische Bewohner*innenbefragung durchgeführt. Im Folgenden wird ein Ausschnitt aus dem umfangreichen Datenmaterial präsentiert, der sich auf Einstellungen, Wahrnehmungsmuster und Erfahrungen der aufnehmenden Bevölkerung konzentriert. ${ }^{3}$

Der erste Datensatz stammt aus einer schriftlichen Erhebung in den ländlichen Untersuchungsregionen und thematisierte die Wohnzufriedenheit in der ländlichen Gemeinde, soziale Beziehungen vor Ort und die Haltung gegenüber Neuankommenden unterschiedlicher Herkunft. Die Daten wurden im März 2019 erhoben; die 904 komplettierten Fragebögen stellen den Rücklauf aus einer Zufallsstichprobe von 4.000 Haushalten dar (Rücklaufquote: $23 \%$ ). Der zweite Datensatz umfasst eine Serie von Leitfadeninterviews mit Akteur*innen der Zivilgesellschaft in den Untersuchungsregionen, wie z.B. Vereinsvorsitzende, Pfarrer*innen, ehrenamtlich Tätige, Lehrer*innen und Sozialarbeiter*innen. Im Mittelpunkt der bis dato 81 qualitativen Interviews standen die Erfahrungen der Befragten mit der Integration vor Ort, eine Reflexion von Integrationsstrategien, -verläufen und Schlüsselereignissen sowie eine Einschätzung zur Nachhaltigkeit des Aufenthalts der Geflüchteten in der Gemeinde und langfristigen Integrationsfolgen. Die weitere Auswertung wird auf Grundlage der dokumentarischen Methode durchgeführt. Diese beinhaltet zunächst eine thematische Sequenzierung und formulierende Interpretation zur »Entschlüsselung der thematischen Struktur» (Bohnsack 2014: 325) der transkribierten Texte. Darauf aufbauend wird eine reflektierende Interpretation durchgeführt, in der herausgearbeitet werden soll, in welchem Orientierungsrahmen die vorgefundenen Themen behandelt werden.

\section{Ergebnisse}

\section{Die Bedeutung von Nachbarschaft im ländlichen Raum für die Integration Geflüchteter}

Inwieweit Geflüchtete nach ihrer Verteilung auf die Unterbringungsgemeinden Zugang zum sozialen Leben erhalten, wird vielfach in Abhängigkeit von der Unterbringungsform gesehen. Lager bzw. Gruppenunterkünfte hemmen nach allgemeiner Auffassung Integrationsprozesse (vgl. Minca 2015; Darling 2009). Dies ist 
einerseits lagebedingt, denn Wohngebäude, die sich zur Gruppenunterbringung eignen, sind häufig an den Peripherien der Orte gelegen und haben teils auch Einhegungen oder Zugangsbeschränkungen. Zudem treten durch die räumliche Enge, die Monotonie des Alltags und die fehlende Privatsphäre häufiger Konflikte in der Einrichtung auf, was wiederum den Ruf der Einrichtung und ihrer Bewohner*innen nach außen hin verschlechtert (vgl. Christ/Meininghaus/Röing 2017a, b; Täubig 2009).

Als Vorteile einer dezentralen Unterbringung von Geflüchteten wird die Häufigkeit alltäglicher Kontakte, das Anschieben natürlicher Nachbarschaftsprozesse und die Verhinderung von Selbstisolation und Ghettoisierungseffekten gesehen (vgl. Aumüller/Daphi/Biesenkamp 2015: 38; Cremer 2014: 8). Da in ländlichen Gemeinden meist weniger Bevölkerungsdruck herrscht als in städtischen Agglomerationen, wird die dezentrale Unterbringung gerade im ländlichen Raum als gut umsetzbare und integrationsfördernde Maßnahme betrachtet (vgl. Braun/Simons 2015).

Historisch gesehen haben Nachbarschaftsbeziehungen in ländlichen Regionen eine große Bedeutung. In den ursprünglich von Landwirtschaft geprägten ländlichen Gemeinden leitete sich dies aus der räumlich dichten Wohnlage und Persistenz der familiären Verflechtungen $a b$. So mündete die traditionelle ländliche Nachbarschaftsbeziehung - verstärkt durch die landwirtschaftliche Wirtschaftsform und die Notwendigkeit der Selbstorganisation - in regelrechten Unterstützungspflichten (vgl. Henkel 2015: 143f.). In einigen der von uns untersuchten Gemeinden lassen sich diese traditionellen Nachbarschaften noch nachspüren. So berichtet ein Gesprächspartner, der selbst von außerhalb in den Ort zugezogen ist, von stark segmentierten Nachbarschaftsverhältnissen: »Das hatte früher eine größere Rolle gespielt, weil, wenn Hochzeiten, Todesfälle, dann hatte der erste Nachbar zu schaffen [...] zu organisieren.« (Interview mit D_II_9). ${ }^{4}$ Der »erste« Nachbar sei jedoch nicht zwangsläufig der geographisch nächste, sondern wohne »möglicherweise ganz woanders«. Er als Neuzuzügler konnte in dem persistenten Nachbarschaftssystem keinen Platz mehr finden:

»Und das hat JAHRE gedauert, bis wir das überhaupt begriffen haben. Wir sind ja hier zugezogen. Und so haben wir eigentlich keinen offiziellen Nachbarn hier. schreibung von Worten bedeutet Betonung. Aussagen in eckigen Klammern sind sprachliche Glättungen oder Ergänzungen der Autorin zum besseren Verständnis. Punkte in eckigen Klammern sind Aussparungen im Zitat. Punkte in runden Klammern kennzeichnen Sprechpausen, jeder Punkt entspricht dabei einer Sekunde. 
Und das kriegen die Syrer auch nicht hin, weil die Leute sagen, nein, wir haben unsere Nachbarschaften schon voll, wir wollen keinen mehr.« (Interview mit D_II_9)

Diese Aussage zeigt den Unterschied zwischen existierenden sozialen Ressourcen und dem Ressourceneinsatz: Neuankommende können nicht automatisch von einem bereits existierenden, über die Zeit dicht gewebten sozialen Netzwerk profitieren, wenn sich dieses Netzwerk als abgeschlossene soziale Gruppe erweist.

Auch die quantitativen Befragungsergebnisse weisen auf eher statische Sozialräume in den untersuchten ländlichen Gemeinden hin: 44,5 Prozent geben an, "schon immer« am Ort zu wohnen, bei weiteren 30,9 Prozent sind es mehr als zwanzig Jahre. Kürzer als fünf Jahre leben nur 7,2 Prozent am derzeitigen Wohnort. Drei Viertel der Befragten bewohnen zudem ein Eigenheim, was den Eindruck von statischen Sozialräumen noch verstärkt. Soziale Normen dürften hier also eine große Persistenz besitzen, und die Bereitschaft, Neues zuzulassen, entsprechend gering sein. Dies zeigen auch die Ergebnisse in Hinblick auf die Erwartungen gegenüber Neuankommenden in der Nachbarschaft. So erwartet die überwiegende Mehrheit (79,4\%) der Befragten, dass die Neuankommenden sie auf der Straße grüßen. Zudem sollten die Neuen offen für nachbarschaftliche Aktivitäten sein $(62,1 \%)$, sich an die (ungeschriebenen) Regeln halten (50,0\%) und sich selbst aktiv in der Nachbarschaft bekannt machen (40,2\%). Weitere Vorstellungen weisen auf die geringe Veränderungsbereitschaft der Befragten hin, etwa wenn der Wunsch zum Ausdruck gebracht wird, dass sich durch die Neuankommende nichts ändere $(21,3 \%)$ und man durch sie nicht gestört werden möchte $(33,4 \%)$.

Hinsichtlich der emotionalen Tiefe der Nachbarschaftsbeziehung deuten unsere Befragungsergebnisse auf das Vorherrschen funktionaler Beziehungen hin. So dominieren bei der Kontakthäufigkeit zu den Nachbar*innen die sporadischen Kontakte (»manchmal«), z.B. bei gegenseitigen Besuchen (46,5\%) oder dem Verleihen von Gegenständen (45,0\%). Auf der anderen Seite gibt es aber nur einen kleinen Teil, der gar keinen oder fast keinen derartigen Kontakt pflegt, und eine Mehrheit der Befragten bietet manchmal oder oft seine Hilfe in der Nachbarschaft an $(92,4 \%)$. Dies weist auf eine große Verbreitung und Stabilität von funktionalen Nachbarschaftsbeziehungen hin, die für den Alltagsvollzug der Betroffenen eine große Bedeutung haben. Dies kommt auch in folgendem Interviewzitat zum Ausdruck:

»Nachbarn müssen nicht unbedingt BEFREUNDET sein, aber es ist wichtig, gute Nachbarschaft zu haben. MEINE Erfahrung ist die, wenn ich nicht da bin oder Hilfe brauche, sind Menschen DA. Ich bin für ihn da, wenn er nicht da ist, angenommen er ist im Urlaub und dann kann ich auch für seine Blumen, für seine Post, für die Mülltonne auf die Straße bringen etc., das ist etwas, das auch das Zusammenleben oder das Leben überhaupt erleichtert.« (Interview mit C_I_8) 
Diese empirischen Ergebnisse bestätigen zunächst die große Bedeutung von Nachbarschaftsbeziehungen im ländlichen Raum, die als eine Form sozialer Netzwerke betrachtet werden können. Andererseits ist die Herstellung sozialer Beziehungen auch kein Selbstläufer, wie es das Überwiegen von funktionalen Nachbarschaftsbeziehungen nahelegt. Zudem weisen die Ergebnisse auf einen beträchtlichen Anpassungsdruck hinsichtlich der Erfüllung sozialer Normen als Voraussetzung der Integration in existierende soziale Netzwerke hin.

\section{Soziale Identifikation, Normen und Erwartungen}

Weiten wir unsere Beobachtungen von der unmittelbaren Nachbarschaft auf den Gesamtraum der ländlichen Siedlung aus. Forschungsergebnisse zu Integrationsprozessen in ländlichen Räumen heben vielfach die Vorzüge der größeren sozialräumlichen Nähe hervor (vgl. Gruber 2013). Zufällige Begegnungen, aus denen engere Kontakte resultieren, sind damit wahrscheinlicher als in der Großstadt. Die gegenseitige Identifikation als Dorfbewohner*in fällt durch die Überschaubarkeit des Sozialraums leichter. Neuankommende können somit bereits durch kleine Gesten der Identifikation als zugehörig markiert werden.

»Und wir sind ja hier in der Größenordnung, da ist ein Unterschied, sehe ich hier schon, zur nächsten Größenordnung in [Ortsname] oder [Ortsname], wo man sich WIRKLICH eigentlich noch selber KENNT auf der Straße, sage ich mal so, ja? Und ich glaube, das hat eine Menge Spannung rausgenommen, weil [...] Leute sich eben begegnet sind und wenn man sich dann bei Aldi über alle Regale hinweg lauthals begrüßt oder weniger lauthals, aber auf jeden Fall begrüßt, dann wird das auch wahrgenommen.«(Interview mit D_II_10)

Aus dieser Sequenz geht sehr deutlich der Verstärkungseffekt hervor, den ein - zumindest im ländlichen Sozialraum ritualisierter - Akt des persönlichen Grüßens haben kann: Der Akt der gegenseitigen Identifikation verbindet den Neuankommenden mit der Dorfgemeinschaft. Er ist einer der ihren, und hat daher das Recht darauf, erkannt und bekannt zu werden. Durch das performative Moment der individuellen Identifikation (»wenn man sich dann bei Aldi über alle Regale hinweg lauthals begrüßt«) wird diese auch für Dritte nachvollziehbar (»dann wird das auch wahrgenommen«) und stellt damit öffentlich eine Gruppenzugehörigkeit her.

Generell wird in Bezug auf ländliche Gemeinden die größere soziale Verbindlichkeit hervorgehoben, die sich unter anderem in der Alltagsnorm des Grüßens auf der Straße äußert. Auch wenn sich soziale Beziehungen im Dorf der Moderne offener gestalten, sind dennoch bestimmte soziale Alltagsnormen weiterhin stark ausgeprägt. Neuankommende müssen sich demnach an diese (oft unbekannten) Alltagsnormen anpassen, um als Teil der Gemeinschaft wahrgenommen zu werden. 
In vielen unserer Untersuchungsgemeinden wurde dabei das Kennenlernen der Alltagsnormen nicht dem Zufall überlassen. So zeigt es das Beispiel ehrenamtlicher Flüchtlingshelferinnen in einem ländlichen Kurort, die nach dem Einzug der Geflüchteten in dezentrale Wohnungen gegen äußere Veränderungen einschritten, welche nicht so recht zum Erscheinungsbild eines Kurortes passen wollten: Die Geflüchteten hatten mangels Gardinen einfach Zeitungspapier als Sichtschutz auf die Fensterscheiben geklebt. Die Frauen fingen an, von Wohnung zu Wohnung zu gehen, um darüber aufzuklären, »dass wir keine Zeitungen an Fenster kleben, denn wir sind ein [...] Bad - und die Kurgäste, die sollen hier nicht wissen, dass sonst wer hier wohnt. Das sind ganz normale Menschen, die vom Ausland kommen und wir machen Gardinen dran«. (Interview mit A_II_3) Diese Sequenz zeigt die klare Vorstellung des sozialen Gefüges und räumlichen Erscheinungsbildes einer Kleinstadt, die in diesem Fall durch die Antizipation der Außenwahrnehmung und das Image als Kurort noch verstärkt wird. Die Anpassung an die äußeren Normen (Gardinen an den Fenstern) geht in dieser Darstellung einher mit der Normalisierung des Status (»das sind ganz normale Menschen, die aus dem Ausland kommen«), die zwar als Ausländer*innen im Straßenbild nicht verheimlicht werden können, aber die durch eine Anpassung an die äußeren Normen zumindest nicht anecken. Die Frauen beließen es nicht bei einer Belehrung, sondern sorgten gleich selbst für Abhilfe:

»Und so sind wir dann von Wohnung zu Wohnung gegangen. Frau F. hat noch einen Bohrhammer gehabt und dann haben wir uns mit Gardinenstangen versorgt. Die [Einwohner*innen] sind großzügig im Spenden, die haben VIEL gespendet. Jeder brachte denen Gardinenstangen und Gardinen. Wir haben das erstmal als Grundlage genommen.«(Interview mit A_II_3)

Auch das Grüßen auf der Straße wird als wichtige Alltagsnorm erkannt und vermittelt, gerade um die kulturelle Andersartigkeit der Geflüchteten, die sich z.B. im Tragen des Kopftuchs zeigt, zu überbrücken und damit die Akzeptanz bei der lokalen Bevölkerung zu erhöhen:

»Wir haben unsre Bürger [hier sind die Geflüchteten gemeint, Anm. d.Verf.] aufgeklärt, dass sie einmal mehr >Cuten Morgen`sag[en], einmal mehr >guten Tagく sag[en] und, und, und. Weil ja auch viele mit den dunkleren Bekleidungen kamen und so. Kopftuch - war ja alles neu in [Ortsname].« (Interview mit A_II_3)

Anhand dieser Narrationen zeigen sich die Spezifika ländlicher Gesellschaften als Ankunftsgesellschaften recht deutlich: Im Vergleich zur Stadt ist hier eine größere soziale Nähe möglich und kann durch die Überschaubarkeit des Sozialraums auch leichter entstehen. Andererseits besteht gerade aufgrund dieser Konstellation auch die Gefahr der Ausgrenzung, sozialen Kontrolle und Sanktionierung abweichender Verhaltensweisen. Dabei ist die Definition dessen, wer dazugehört und wer nicht, 
oder welche äußeren und Verhaltensmerkmale »abweichen«, stark von den kollektiven Normen und Werteorientierungen geprägt, die überdies durch die geringe Mobilität der lokalen Gemeinschaft wenig Wandel erfahren. Selbst wenn also das gegenseitige Grüßen bereits ein Akt des Herstellens von Zugehörigkeit ist, entsteht daraus noch keine echte Zugehörigkeit, im Sinne einer vollständigen sozialen Teilhabe und der Abwesenheit von Ausgrenzung.

\section{Die Konstruktion von Fremdheit und Zugehörigkeit}

Während in städtischen Kontexten bedingt durch die hohe Bevölkerungsfluktuation ein kontinuierlicher Aushandlungsprozess von Zugehörigkeit stattfinden kann, scheinen in den ländlichen Gemeinden die Grenzen der Zugehörigkeit enger gezogen zu sein. Dabei ist es nicht etwa so, dass in den ländlichen Siedlungen gar keine Migrationserfahrungen existieren. Alle von uns untersuchten Gemeinden haben eine »Migrationsbiographie«, die von den meisten Gesprächspartner*innen auch dezidiert als Vorerfahrung für Integrationsprozesse angesprochen wird. Meist beginnt diese Narration mit der Aufnahme von Flüchtlingen und Vertriebenen nach dem Zweiten Weltkrieg und setzt sich fort mit der Anwerbung von Gastarbeiter*innen in den westdeutschen bzw. Vertragsarbeiter*innen in den ostdeutschen Untersuchungsgemeinden. In den 1990er Jahren wurden dann in vielen Gemeinden Spätaussiedler*innen aus Osteuropa angesiedelt, gefolgt von der Niederlassung von Arbeitsmigrant*innen aus Ostmitteleuropa, die vielfach in prekären Wohnund Arbeitsverhältnissen (Stichwort Fleischindustrie) temporär oder dauerhaft in den ländlichen Gemeinden leben.

In der Reflexion der kollektiven Erfahrungen mit diesen Gruppen wird oftmals die Fähigkeit, sich in den Arbeitsmarkt zu integrieren, als normalisierendes Attribut hervorgehoben. Die Arbeitsmarktintegration wird dabei nicht nur als positive Zielsetzung für die betroffenen Migrant"innen betont, sondern aus der Perspektive der ländlichen Gesellschaft als eine gesellschaftlich anerkannte Verhaltensform markiert. So berichten zwei sächsische Gesprächspartnerinnen von vietnamesischen Vertragsarbeiter*innen, die durch die starke zeitliche Einbindung am Arbeitsplatz öffentlich unauffällig waren und nicht als störend wahrgenommen wurden: »Vietnamesen hatten wir hier noch. Die waren sehr fleißig. Die haben in der ehemaligen Werkzeugmaschinenfabrik [gearbeitet]. Die waren aber unauffällig. Die waren da fleißig, die haben da gearbeitet.« (Interview mit A_II_5) Auch eine bayerische Gesprächspartnerin hebt die Arbeitsmarktaktivität der »Gastarbeiter« hervor und stellt damit einen Differenzbezug zu den Geflüchteten der 2010er Jahre her, die durch ihre fehlende unmittelbare »Nützlichkeit« schwierigere Integrationswege aufweisen: »Das war bei den Gastarbeitern anders. Die sind ja gekommen, um hier zu arbeiten, die haben hier gearbeitet, die haben hier ganz viel gestemmt 
und da war die Integration LEICHTER, als mit den anderen finde ich.« (Interview mit B_I_I)

In beiden Zitaten sind die Vokabeln der "Selbstmobilisierung « hervorzuheben, durch die die Arbeitsmigrant"innen charakterisiert werden: die Vietnames"innen haben "fleißig gearbeitet«, die »Gastarbeiter"innen« haben »hier gearbeitet« und "viel gestemmt«. Ihre Nützlichkeit ist vor der ganzen lokalen Bevölkerung sichtbar. Bei anderen Gruppen hingegen, denen der unmittelbare Arbeitsmarktzugang verwehrt ist, fällt auch im öffentlichen Raum des Ortes die »Nutzlosigkeit« auf, die sich in »Herumhängen im öffentlichen Raum« bis hin zu störenden und devianten Verhaltensweisen äußerte. So hätten die Spätaussiedler*innen »bis früh um vier [...] draußen gesessen und gesoffen und gesungen und getan und gemacht" (Interview mit A_II_3).

Damit ist - wie schon bei der Untersuchung von Nachbarschaftsbeziehungen und des sozialen Umgangs im öffentlichen Raum - der utilitaristische Ansatz deutlich, der lediglich einen Aktionsraum zwischen »sich für die Gemeinschaft als Nützlich erweisen« und »nicht stören« eröffnet. Demzufolge wurde auf die Frage, was denn »Integration « für die Gesprächspartner*innen bedeutet, neben assimilativen Vorstellungen vielfach auch das Argument der »Nützlichkeit« im Sinne der eigenen Erhaltungsfähigkeit oder des Sich-Einbringens in die Gemeinschaft hervorgehoben. Allerdings verbleibt auch bei Erfüllung dieser Verhaltensnormen die Definitionsmacht von »Zugehörigkeit« bei der alteingesessenen Bevölkerung. Dass hier die Grenzen sehr eng gezogen werden, zeigen Beispiele von deutschen Zuzügler*innen in die ländlichen Gemeinden, die trotz fehlender ethnisch-kultureller Fremdheitsattribute nicht als vollwertiger Teil der Gemeinschaft anerkannt sind. Dies betrifft in unserem Datenkorpus deutsche Binnenmigrant"innen, die durch ihren »exotischen« Dialekt auffielen (»Aber ich bin hierhergekommen als Kind mit zwölf Jahren, und ich war der Exot, weil ich ja Hochdeutsch gesprochen habe. Und das war SEHR SCHWER, A von der Sprache, und B auch von dieses PREUSSIN, PREUSSIN, also eine Preußin, das ist diese ABGRENZUNG, DU GEHÖRST NICHT ZU UNS.« (Interview mit B_II_I)), Personen, die im Kindesalter einige Jahre außerhalb des Ortes gelebt und dann zurückgekehrt waren (»Ich sage, ,Wie seid Ihr denn drauf? Ich bin in [Ortsname] aufgewachsen, ich bin hier zur Schule gegangen, ich bin hier konfirmiert worden und alles, und jetzt sagt ihr mir, ich bin kein [Ortsname]er? Meine ganze Familie kommt aus [Ortsname]. Seid ihr bedeppert?« (Interview mit D_II_7)), oder Menschen, die zum Zweck des Eigenheimbaus in ländliche Regionen umzogen und selbst nach einer Wohndauer von 20 Jahren nicht als Teil der dörflichen Gemeinschaft anerkannt werden. Eine Gesprächspartnerin sieht die Ursache in der mangelnden Zugehörigkeit in den persistenten Verwandtschaftsbeziehungen, über die sich im ländlichen Raum Beziehungsgefüge und gesellschaftlicher Status definierten: 
»Im ländlichen Raum muss man natürlich diese, darum sage ich ja, diese Prägung beachten, das was so diese Familientradition und Familie ist da bedeutsamer [...] Ich merke da die Tradition, die Werte und so über Generationen auf unerklärliche Wiese weitergegeben, obwohl andere Informationen da sind und anderer Input da ist. Diese Wertekonformität, dieser Wertefundamentalismus ist bedeutsam. Das muss berücksichtigt werden in jedem Fall.« (Interview mit A_II_1)

Ein anderer Gesprächspartner sieht im Fehlen einer raum-zeitlich geteilten kollektiven Biographie einen Grund für die andauernde Zuschreibung von Fremdheit auch gegenüber deutschen Binnenmigrant"innen an den ländlichen Wohnorten und hinterfragt in diesem Zusammenhang auch das Verständnis von Integration:

»Das ist auch für uns Deutsche so ein Moment, wo wir kurz mal innehalten sollten, was bedeutet denn für uns eigentlich jemanden mit in die Gemeinschaft zu lassen und was ist überhaupt Cemeinschaft für uns? Wo fängt das an? Im Kopf? Muss ich mit den Leuten zur Schule gegangen sein, um mit ihnen in einer Stadt leben zu dürfen?« (Interview mit A_II_5)

Der hier aufgeworfenen Frage, »Was ist überhaupt Gemeinschaft für uns? «lohnt sich, in Bezug auf ländliche Lebensweisen nachzuspüren. Mit dem Fokus auf der aufnehmenden Gesellschaft stellt sich die Frage, ob die bestehenden sozialen Strukturen und die Akteur*innen, die diese Strukturen herstellen, die Bereitschaft und Fähigkeit zur Öffnung und Integration besitzen.

\section{Integration durch Vereinsmitgliedschaft}

Der soziale Kitt der ländlichen Gemeinschaft sind nach einhelliger Meinung die sozialen Vereinigungen vor Ort, wie z.B. Kirche, Sportverein oder Feuerwehr. Der Organisationsgrad der ländlichen Bevölkerung ist deutlich stärker ausgeprägt als in Großstädten (vgl. Priemer/Krimmer/Labigne 2017; Simonson/Vogel/Tesch-Römer 2017) und die wichtigsten Personen am Ort sind vielfach auch jene, die in den genannten Institutionen Verantwortung tragen (vgl. Gruber 2013). Integration im Sinne sozialer Teilhabe kann über Vereine gelingen, insbesondere über Sportvereine (vgl. Burrmann/Mutz/Zender 2015; Braun/Nobis 2011). Häufig leiden Sportvereine im ländlichen Raum unter Nachwuchsmangel und die Beteiligung von Geflüchteten hat vielerorts neuen Schwung in die Strukturen gebracht und dem Wettkampfsport zu ungeahnten Erfolgen verholfen: »Also in [Ortsname], in der Nachbarstadt, in der Kreisstadt weiß ich, dass ein Verein vor dem Abstieg gerettet worden ist durch die vielen jungen Flüchtlinge, die er aufgenommen hat [lacht], die die Tore geschossen haben.«(Interview mit C_II_14)

Während viele Interviewpartner*innen von sehr positiven Integrationserfolgen durch die Aufnahme von Geflüchteten in den Verein berichten, thematisieren eini- 
ge jedoch auch die Diskrepanz zwischen der Erwartung an die Neuankommenden, sich in die bestehenden sozialen Strukturen zu integrieren, und den vereinseigenen, mehr oder weniger subtil exkludierenden Praktiken. So wird z.B. von mehreren Gesprächspartner*innen das soziale Leben im Verein thematisiert, das meist mit einem "geselligen Beisammensein « nach dem Trainingsabend endet. Diese Abende haben für die Herstellung von Gemeinschaft eine große Bedeutung, wie der folgende Gesprächspartner am Beispiel der Freiwilligen Feuerwehr berichtet:

»[...] dienstags ist Dienst, Feuerwehrdienst. ALSO, ich habe hier schon teilweise bis zwei, [...] bis drei Uhr gesessen, und da haben wir Bier getrunken, im Grunde genommen; und geschnackt. Und man schnackt dann ja über alles. Klar, Hauptthema ist meistens immer irgendwie Feuerwehr, aber man spricht dann ja auch allgemeine Themen. Was in der Cemeinde los ist, und der weiß dies, und der weiß das.« (Interview mit D_II_7)

Sich diesen geselligen Zusammenkünften zu entziehen, scheint fast noch schwerer zu wiegen, als die Übungen zu verpassen. Dabei kann es vielfältige Gründe geben, nicht teilzunehmen, etwa ein früher Arbeitsbeginn am nächsten Tag, oder das allgemeine Unwohlsein, sich als Abstinenzler*in in einer mehr und mehr angeheiterten Runde wiederzufinden. Dies wird in folgendem Zitat am Beispiel von Geflüchteten in Sportvereinen thematisiert:

»Vor allen Dingen, weil hier im [Regionsbezeichnung, Anm. d.Verf.] der Alkohol eine ganz große Rolle spielt. Und M. [ein junger, muslimischer Geflüchteter, Anm. d.Verf.], er trinkt keinen Alkohol, und da braucht man mit 22 hier in der Gegend - 99 Prozent der Begegnungen finden mit Alkohol statt. Da ist er bei seinen Altersgenossen KOMPLETT außen vor. Und selbst beim Fußball in den höheren Altersklassen haben wir Leute gehabt, die deswegen aufgehört haben Fußball zu spielen, weil sie eben jeden Monat 20 Euro für das Bier bezahlen sollten, das Geld hatten sie nicht, und Bier trinken sie sowieso nicht, haben sie gesagt: >Was soll das, ich will Fußball spielen.« (Interview mit D_II_11)

Die Zitate machen deutlich, dass in der Tradition der Vereine über die Kneipenabende Gemeinschaft hergestellt wird. Wer hier nicht mithält oder die sozialen Rituale hinterfragt, gehört trotz guter Leistungen im Kerngeschäft des Vereins (z.B. Fußball) doch nicht so richtig dazu. Zugleich nehmen neue Mitglieder gerade während der Kneipenabende auch ihre eigene Fremdheit am Verhalten der Anderen besonders deutlich wahr. Das geht nicht nur den Geflüchteten so, sondern auch Deutschen, wie unser Gesprächspartner berichtet:

»Du hast dann auch Deine Grüppchen hier. (.) Das ist dann schon schwierig. [...] Also, der ]. [deutsches Neumitglied, Anm. d.Verf.] sagte das damals auch. [leise] 
ICH PASSE HIER NICHT HER. Ich habe mich hier echt unwohl gefühlt auf dem Abend.«(Interview mit D_II_7)

Seitens der Alteingesessenen fehlt die Bereitschaft, die Ursache für die NichtTeilhabe der neuen Mitglieder anhand des eigenen Verhaltens zu reflektieren bzw. Verhaltensänderungen anzustoßen. Unser Gesprächspartner berichtet von einem jungen Geflüchteten, H., der nach anfangs sehr aktiver Beteiligung in der Freiwilligen Feuerwehr wieder ausgetreten ist. Auslöser war wohl ein rassistischer Videoclip, der von einem Kameraden in der Chatgruppe der Freiwilligen Feuerwehr geteilt wurde. Doch dies scheint nur der Endpunkt einer Serie von subtilen Praktiken der Ausgrenzung gewesen zu sein, die nicht allein auf einem fehlenden Verständnis für H.s Lebensumstände basieren. Der Gesprächspartner führt die mangelnde Integrationsbereitschaft auf die fehlende kollektive Sozialisierung vor Ort zurück:

»Klar, der ist nicht so integriert wie die Alteingesessenen. [...] Es ist ja eine gefestigte Struktur. Feuerwehr ist immer eine gefestigte Struktur, teilweise auch familiär. Die jungen Leute hängen auch außerhalb alle miteinander rum. Und die kennen sich ganz anders.«(Interview mit D_II_7)

In diesem Zitat wird die große Bedeutung des inneren Gruppenzusammenhalts deutlich, der eine geringe soziale Distanz und gegenseitiges Vertrauen erfordert. Dies wird im weiteren Verlauf des Interviews auch mit der verantwortungsvollen Tätigkeit der Freiwilligen Feuerwehr verbunden, wo man bei teils gefährlichen Einsätzen dem Zusammenspiel unter den Kameraden vertrauen muss. Der Aufbau dieses Vertrauens ist nicht nur an die regelmäßige Teilnahme an den Übungen geknüpft, sondern bedarf aus Sicht des Gesprächspartners einer kompletten Anpassung an die Gruppe mit ihren sozialen Ritualen.

»Aber bei uns [ist es] im Grunde genommen egal, ob ich Flüchtling bin oder Einheimischer, ich muss mich, um wieder auf die INTEGRATION zurückzukommen, ich muss mich integrieren. Also, ich muss mich darauf einlassen wollen, und die Leute müssen sich auf mich einlassen wollen. Sonst funktioniert das bei uns nicht.« (Interview mit D_II_7)

Die aufgezeigten Beispiele bestätigen einerseits die Hypothese von der großen Bedeutung der Vereine als »sozialer Kitt « in ländlichen Gemeinden, hinterfragen aber auch ihre "natürliche« Integrationskraft. In der Kategorisierung von Putnams Sozialkapitaltheorie bündeln Vereine soziales Kapital und verstärken es damit zum Wohle der Gemeinschaft. Diese Bündelung basiert auf einer starken Gruppenidentität, die vorwiegend durch soziale Nähe, soziale Rituale und gemeinsame Erfahrungen hergestellt wird. Diese Elemente des »bonding social capital« gehören eher zum impliziten Wissensbestand der sozialen Gruppe und werden - zumindest in 
unseren Beispielen - daher kaum offengelegt und in ihrer Wirkweise auf die Integration neuer Gruppenmitglieder hinterfragt.

\section{Fazit}

Der vorliegende Beitrag thematisierte die Möglichkeiten der Integration Geflüchteter in eine ländliche Gesellschaft aus der Perspektive der ansässigen Bevölkerung. Die Bedeutung dieses Themas wurde gleichsam als Kontrapunkt zum zentralen Thema dieses Bandes gesetzt, der sich mit den Effekten des Lebens in Flüchtlingslagern befasst. Der Fokus auf ländliche Gesellschaften verstärkt die Grundannahmen des selbständigen Lebens außerhalb von Lagern hinsichtlich der Integrationsmöglichkeiten von Geflüchteten: Häufigere Alltagskontakte, Überschaubarkeit der (sozial-)räumlichen Umgebung sowie die Bündelung von sozialem Kapital in einer Vielzahl von sozialen Netzwerken werden als Fundament für Integrationsprozesse angenommen. Basierend auf den Überlegungen zur Rezeptivität wurde konstatiert, dass es nicht nur auf die Existenz von sozialen Ressourcen ankommt, sondern auf den Willen und die Fähigkeit, diese Ressourcen auch zur Integration von Neuankommenden einzusetzen.

Die empirischen Erörterungen zu Nachbarschaftsbeziehungen, Alltagsnormen, der Wahrnehmung von Fremdheit und des in Vereinen gebundenen sozialen Kapitals hatten zum Ziel, einerseits einen differenzierten Blick auf die integrativen Ressourcen in ländlichen Gesellschaften $\mathrm{zu}$ werfen und andererseits die Passung zwischen Ressourcenausstattung und Ressourceneinsatz zu beleuchten. Die Ergebnisse haben exemplarisch aufgezeigt, dass ländliche Gesellschaften eine Vielzahl von potenziellen Integrationsressourcen aufweisen, wie z.B. Überschaubarkeit des Sozialraums, große Bedeutung von Alltagsnormen als Orientierungshilfe, ausdefinierte Nachbarschaftsbeziehungen und institutionalisierte Begegnungsräume in Form von Vereinen. Integrationsprozesse werden vielfach auf einer funktionalen oder normativen Ebene platziert: So basiert die Integration von Neuankommenden in die Nachbarschaft auf der funktionalen Reziprozität sowie dem Grundsatz, abweichendes und damit potenziell störendes Verhalten zu verhindern. Das bewusste Einbeziehen der Neuankommenden in Alltagsrituale wie dem Grüßen auf der Straße kann als Übertragen sozialer Normen interpretiert werden, die für die Erlangung von Gruppenzugehörigkeit fundamental sind. Auch die Aufnahme von Geflüchteten in Vereine basiert auf der Grundüberzeugung, dass soziale Normen und Rituale von den Neumitgliedern übernommen werden müssen, um als vollständiges Gruppenmitglied wahrgenommen zu werden. Für die langfristige Realisierung von sozialen Inklusions- (oder Exklusions-)prozessen scheint die implizite Dimension von Rezeptivität wesentlich: Hier zeigte sich eine 
sehr eng gefasste Definition von sozialer Identität und damit zusammenhängend eine starke Assimilationserwartung an die Neuankommenden.

Aus Perspektive der Sozialkapitaltheorie (vgl. Putnam 2000, 2007) gesprochen zeigt sich ein starker Zusammenhang zwischen »bonding social capital« und sozialer Distanz. Unsere empirischen Befunde weisen darauf hin, dass diese Distanz nur abgebaut werden kann, indem eine Übernahme von sozialen Normen, ein Anpassungsprozess im Sinne der Assimilation, erfolgt. »Bridging social capital«, also die Öffnung nach außen, ist hingegen weniger ausgeprägt. Um die Frage zu beantworten, warum dies so ist, zeigt sich die intensive Wahrnehmung von Gruppenzugehörigkeit und die enge Grenzziehung zwischen dem Eigenen und dem Anderen als entscheidend. Als Begründung kann die starke soziale Persistenz ländlicher Gemeinschaften herangezogen werden, die sich in den vorliegenden Daten einerseits durch die überwiegend lange Wohndauer begründet, andererseits durch die Generationen überspannenden Besitzverhältnisse und darauf aufbauende soziale Hierarchien im Ort, während parallel dazu auch Öffnungsprozesse durch Pendelbewegungen und Binnen- sowie internationale Migrant*innen stattfinden. Dieser Befund relativiert Forschungen, die eine Auflösung tradierter ländlicher Sozialstrukturen in der Moderne postulieren (vgl. Linke 2016; Oehme 2015; Hainz 1999), welche aber den Faktor ethnischer Diversität in ihren empirischen Beobachtungen eher ausklammern. Unsere ersten Ergebnisse weisen vielmehr auf die erhebliche Wirkmächtigkeit von einmal hergestellten sozialen und räumlichen Ordnungen hin. Weitere - insbesondere regional vergleichende - Analysen werden im weiteren Fortgang unseres Forschungsprojekts vertiefenden Aufschluss über den regional differenzierten Umgang mit Fremdheit und Integration geben. Damit wollen wir für das Beispiel Deutschlands zur Schließung der Forschungslücke zu den »new immigrant gateways« beitragen.

\section{Literaturverzeichnis}

Alba, Richard/Nee, Victor (2003): Remaking the American Mainstream: Assimilation and Contemporary Immigration, Cambridge, MA: Harvard University Press.

Aumüller, Jutta/Daphi, Priska/Biesenkamp, Celine (2015): Die Aufnahme von Flüchtlingen in den Bundesländern und Kommunen. Behördliche Praxis und zivilgesellschaftliches Engagement, Stuttgart: Robert Bosch Stiftung GmbH.

Bensch, Franziska (2017): »Ankommen auf dem Wohnungsmarkt«, in: Informationen zur Raumentwicklung 2, S. 22-31.

Bohnsack, Ralf (2014): Rekonstruktive Sozialforschung. Einführung in Methodologie und Praxis qualitativer Forschung, Opladen \& Farmington Hills: Barbara Budrich. 
Boos-Krüger, Annegret (2005): »Sozialräumliche Integration von Zuwanderern in Klein- und Mittelstädten des ländlichen Raumes. Annäherung an ein neues Forschungsgebiet«, in Schader-Stiftung, Deutscher Städtetag, GdW Bundesverband deutscher Wohnungs- und Immobilienunternehmen, Deutsches Institut für Urbanistik, Institut für Wohnungswesen, Immobilienwirtschaft und Stadtund Regionalentwicklung an der Ruhr-Universität Bochum (Hg.), Zuwanderer in der Stadt. Expertisen zum Projekt, Darmstadt: Schader-Stiftung, S. 407-444 Bowskill, Matt/Lyons, Evanthia/Coyle, Adrian (2007), »The Rhetoric of Acculturation: When Integration Means Assimilation«, in: British Journal of Social Psychology 46(4), S. 793-813.

Braun, Sebastian/Nobis, Tina (Hg.) (2011): Migration, Integration und Sport. Zivilgesellschaft vor Ort, Wiesbaden: VS Verlag für Sozialwissenschaften.

Braun, R./Simons, H. (2015): Familien aufs Land! Warum wir die Flüchtlinge im Leerstand unterbringen sollten und wie das funktionieren könnte, empirica paper Nr. 228, Bonn/Berlin: empirica Institut.

Burrmann, Ulrike/Mutz, Michael/Zender, Ursula (Hg.) (2015): Jugend, Migration und Sport. Kulturelle Unterschiede und die Sozialisation zum Vereinssport, Wiesbaden: Springer VS.

Christ, Simone/Meininghaus, Esther/Röing, Tim (2017a): »All Day Waiting«, Konflikte in Unterkünften für Geflüchtete in NRW, BICC Working Paper 3/2017, Bonn: BICC.

Christ, Simone/Meininghaus, Esther/Röing, Tim (2017b): Konfliktprävention in Unterkünften - Selbstverantwortung geflüchteter Menschen stärken, BICC Policy Brief 3/2017, Bonn: BICC.

Cremer, Hendrick (2014): Menschenrechtliche Verpflichtungen bei der Unterbringung von Flüchtlingen, Policy Paper Nr. 26, Berlin: Deutsches Institut für Menschenrechte.

Darling, J. (2009): »Becoming bare life: Asylum, hospitality, and the politics of encampment «, in: Environment and planning D: Society and space 27(4), S. 649665.

De Jong, Gordon F./Quynh-Giang, Tran (2001): »Warm Welcome, Cool Welcome: Mapping Receptivity toward Immigrants in the U.S.«, in: Population Today 29(8), o.S.

Dresing, Thorsten/Pehl, Thorsten (2015): Praxisbuch Interview, Transkription \& Analyse. Anleitungen und Regelsysteme für qualitative Forschende, Marburg: Dr. Dresing und Pehl.

Fetzer, Joel S. (2000): Public Attitudes Toward Immigration in the United States, France, and Germany, Cambridge, UK: Cambridge University Press.

Hainz, Michael (1999): Dörfliches Sozialleben im Spannungsfeld der Individualisierung, Bonn: VS. 
Henkel, Gerhard (2015): Das Dorf. Landleben in Deutschland - Gestern und Heute, Darmstadt: Wissenschaftliche Buchgesellschaft.

Hersi, Abidi M. (2014): »Discourses Concerning Immigrant Integration: A Critical Review«, in: European Scientific Journal, S. 590-604.

Glorius, Birgit/Gasch, Simone (i.E.): »Social demarcations and the creation of insiders and outsiders - the example of forced migrants' access to the German labor market«, in: Journal of Borderlands Studies.

Glorius, Birgit/Bürer, Miriam/Schneider, Hanne (i.E.): »Integration of Refugees in Rural Areas and the Role of the Receiving Society: Conceptual Review and Research Agenda«, in: Erdkunde.

Glorius, Birgit/Bürer, Miriam/Schneider, Hanne (2019): Integration von Geflüchteten und die Rolle der Aufnahmegesellschaft: Konzeptionelle Überlegungen und ihre Anwendung auf ländliche Räume, Thünen Working Paper 120, Braunschweig: Johann Heinrich von Thünen-Institut.

Glorius, Birgit/Schondelmayer, Anne-Christin (2019): »Perspektiven und Handlungslogiken der Integration von Geflüchteten an beruflichen Schulen: Einblicke aus Sachsen/Deutschland«, in: Zeitschrift für Flucht- und Flüchtlingsforschung 3(2), S. 219-253.

Gruber, Maria (2013): Integration im ländlichen Raum. Ein Praxishandbuch, Innsbruck: Studien Verlag.

Jensen, Leif (2006): New Immigrant Settlements in Rural America: Problems, Prospects, and Policies, Durham, NH: Carsey Institute, University of New Hampshire.

Linke, Simone (2016): »Sozialräumliche Segregation in ländlich bezeichneten Räumen«, in: Olaf Kühne/Florian Weber (Hg.), Fraktale Metropolen. Stadtentwicklung zwischen Devianz, Polarisierung und Hybridisierung, Wiesbaden: Springer VS, S. 245-270.

McDaniel, Paul N. (2013): Receptivity in a new immigrant gateway: immigrant settlement geography, public education and immigration integration in Charlotte/North Carolina, Dissertation, Charlotte: The University of North Carolina. Micksch, Jürgen and Schwier, Anja (Hg.) (2000): Fremde auf dem Lande (=Interkulturelle Beiträge 19), Frankfurt a.M.: LembeckVerlag.

Minca, Claudio (2015): »Geographies of the camp«, in: Political Geography 49, S. 7483.

Nadler, Robert/Kriszan, Michael/Nienaber, Birte/Frys, Wioletta (2010): »Zuwanderung internationaler Migranten in schrumpfende ländliche Regionen: die Fallbeispiele Ostsachsen und Saarland«, in: Europa Regional 18(2-3), S. 107-121.

Oehme, Ulrike (2015): Diversity im ländlichen Raum. Eine ethnographische Untersuchung zur Konstruktion von Unterschieden in der Regionalentwicklung, Dissertation, Hildesheim: Universität Hildesheim. 
Priemer, Jana/Krimmer, Holger/Labigne, Anaël (2017): ZiviZ Survey 2017. Vielfalt verstehen. Zusammenhalt stärken, Berlin: Edition Stifterverband.

Putnam, Robert D. (2000): Bowling alone. The collapse and revival of American community, New York: Simon and Schuster.

Putnam, Robert D. (2007): »E Pluribus Unum: Diversity and Community in the Twenty-first Century. The 2006 Johan Skytte Prize Lecture«, in: Scandinavian Political Studies 30(2), S. 137-174.

Roos, Ursula M. (2016): Migration und Integration in ländlichen Räumen am Beispiel der saarländischen Kreisstadt Merzig: eine empirische Untersuchung unter besonderer Berücksichtigung der Erfahrungen und Sichtweisen von Personen mit Migrationshintergrund, Dissertation, Saarbrücken: Universität des Saarlandes.

Sam, David L. (2006): "Acculturation: conceptual background and core components«, in: David L. Sam/John W. Berry (Hg.), The Cambridge Handbook of Acculturation Psychology, Cambridge: Cambridge University Press, S. 11-26.

Schader Stiftung (2011): Integrationspotenziale in kleinen Städten und Landkreisen. Ergebnisse des Forschungs-Praxis-Projekts, Darmstadt: Schader-Stiftung.

Schinkel, Willem (2017): Imagined Societies. A Critique of Immigrant Integration in Eastern Europe, Cambridge: Cambridge University Press.

Simonson, Julia/Vogel, Claudia/Tesch-Römer, Clemens (Hg.) (2017): Freiwilliges Engagement in Deutschland: Der Deutsche Freiwilligensurvey 2014, Wiesbaden: Springer VS.

Täubig, Vicki (2009): Totale Institution Asyl. Empirische Befunde zu alltäglichen Lebensführungen in der organisierten Desintegration, Weinheim/München: Juventa Verlag.

\section{Interviews}

A_II_1: Verein am 4.12.2019, $90 \mathrm{~min}$.

A_II_3: Verein am 11.12.2019, $81 \mathrm{~min}$.

A_II_5: Wohlfahrt/Kirche am 19.12.2019, $57 \mathrm{~min}$.

B_I_1: Politik/Verwaltung am 11.6.2019, $61 \mathrm{~min}$.

B_II_1: Wohlfahrt/Kirche am 13.11.2019, $85 \mathrm{~min}$.

C_I_8: Ehrenamt am 13.3.2020, $67 \mathrm{~min}$.

C_II_14: Ehrenamt am 23.3.2020, $84 \mathrm{~min}$.

D_II_7: Verein am 13.11.2019, $96 \mathrm{~min}$.

D_II_9: Wohlfahrt/Kirche am 12.11.2019, $103 \mathrm{~min}$.

D_II_10: Wohlfahrt/Kirche am 15.11.2019, $90 \mathrm{~min}$.

D_II_11: Ehrenamt am 14.11.2019, $100 \mathrm{~min}$. 



\section{Autor*innenverzeichnis}

Samia Aden, M.A. Soziale Arbeit, wissenschaftliche Mitarbeiterin am Fachgebiet Sozialisation mit dem Schwerpunkt Migration und interkulturelle Bildung und Promovendin an der Universität Kassel, Mitglied im Bildungslab* Berlin und assoziiert im Graduiertenkolleg »Vernachlässigte Themen der Flüchtlingsforschung«. Forschungsschwerpunkte: Transnationalität, Jugend/Adoleszenz und Familien, multilokale Forschung und kritische Wissensproduktion im Flucht- und Asylkontext.

Samira Aden, M.Sc. Architektur Design Research (DR), Architektin am HelmholtzZentrum Berlin für Materialien und Energie GmbH | PVcomB - Kompetenzzentrum für Photovoltaik, Assoziiertes Mitglied der Forschungsplattform Bau Kunst Erfinden der Universität Kassel und dem ARC Australian Center of Excellence in Exciton Science (Melbourne, Australia).

Simon E. Arnold, Dipl.-Psych., hat Psychologie und Literatur-Kunst-Medien in Konstanz, Paris und Beer Sheva studiert. Aktuell ist er wissenschaftlicher Mitarbeiter am Sigmund-Freud-Institut und absolviert eine Ausbildung in psychoanalytischer Beratung an der Universität Kassel in Kooperation mit dem Alexander-Mitscherlich-Institut. Forschungsinteressen: Psychoanalytische Theorie des Traumas, insbesondere hinsichtlich Flucht und Migration sowie transgenerationale Tradierung von Verfolgungserfahrungen im NS und deren Zusammenhang mit heutigem Antisemitismus.

Elisabeth Beck, M.A., Erziehungswissenschaft, wissenschaftliche Mitarbeiterin am Zentrum Flucht und Migration der Katholischen Universität EichstättIngolstadt. Forschungsschwerpunkte: Erwachsenenbildung, Bildung in der postmigrantischen Gesellschaft, Holocaust Education, Civic Education, Diversity Education. 
Janka Böhm, M.A., Interkulturelle Psychologie und Pädagogik, Kultur- und Literaturwissenschaft an der Loránd Eötvös Universität in Budapest, Ungarn und Erwachsenenbildung an der Katholischen Universität Eichstätt-Ingolstadt.

Tobias Breuckmann, Stadt- und Bevölkerungsgeographie, Wissenschaftlicher Mitarbeiter an der Christian-Albrechts-Universität zu Kiel. Forschungsschwerpunkte: Politische Geographie der Geflüchtetenlager, Macht und Raum, Theorien der geographischen Gouvernementalitätsforschung, Geographische Migrationsforschung.

Julia Devlin, Dr. phil., ist Historikerin mit Schwerpunkt auf Migrationsforschung. $\mathrm{Zu}$ ihren Forschungsschwerpunkten gehören die Migrationsgeschichte Ost- und Ostmitteleuropas, Gewaltmigration im Zweiten Weltkrieg und Kriegsfolgewanderungen, Biographieforschung und Erinnerungskultur in der Diaspora. Sie studierte Geschichte Ost- und Südosteuropas, Neuere und Neueste Geschichte, Kunstgeschichte und Slavistik an der Ludwig-Maximilians-Universität München, an der School of Slavonic and East European Studies London und an der Moskovskij Linguističeskij Universitet Moskau. Nach Lehre und Forschung am Ost-EuropaInstitut und der LMU München ist sie seit 2017 Geschäftsführerin des Zentrums Flucht und Migration an der Katholischen Universität Eichstätt-Ingolstadt.

Anna-Lena Dießelmann, Dr. phil., Philosophin und Linguistin mit Schwerpunkt Ethik, Rechts- und politische Philosophie, kritische Diskursanalyse. Promotion in Linguistik, Universität Siegen, und Magister in Philosophie, Universität Düsseldorf. Spezialisierung in Psychosoziale Intervention in Gewalt- und Katastrophensituationen, Universidad Complutense de Madrid. Derzeit Postdoc an der Universität Bayreuth und Mitarbeiterin in einem Wiedereingliederungsprogramm für Intensivtäter in Cali.

Anne-Marlen Engler, ref. iur, promoviert zum Thema »Flüchtlingslager als Orte des Ausnahmezustands? Eine rechtssoziologische Untersuchung« an der HumboldtUniversität zu Berlin, wissenschaftliche Mitarbeiterin an der Friedrich-SchillerUniversität Jena, Forschungsschwerpunkte: Rechtstheorie, Rechtssoziologie, Migrationsrecht.

Tanja Evers, Dr. phil, Dipl. Journ., studierte Journalistik, Politikwissenschaft und Kultur- und Wirtschaftsgeographie und promovierte im Bereich politische Kommunikation in digitalen Öffentlichkeiten. Seit 2019 ist sie wissenschaftliche Mitarbeiterin und Forschungskoordinatorin am Zentrum Flucht und Migration der Katholischen Universität Eichstätt-Ingolstadt. Forschungsschwerpunkte: Mediale 
Narrative, Zusammenhalt und bürgerschaftliches Engagement in einer Migrationsgesellschaft.

Lea Gelardi, M.A., Soziologie, wissenschaftliche Mitarbeiterin am Zentrum Flucht und Migration der Katholischen Universität Eichstätt-Ingolstadt. Forschungsschwerpunkte: Lager, Unterbringungen für Geflüchtete, Grenzen, Grenz- und Migrationsregime.

Birgit Glorius, Prof. Dr., Diplom-Geographin, Professorin für Humangeographie mit dem Schwerpunkt Europäische Migrationsforschung an der TU Chemnitz. Forschungsschwerpunkte: Geographische Migrationsforschung, Demographischer Wandel, Transnationalismus, Bildungs- und Hochqualifiziertenmigration, Flucht und Asyl in Europa, Sozialgeographien der Transformation.

Simon Goebel, Dr. phil., Europäische Ethnologie, wissenschaftlicher Mitarbeiter am Zentrum Flucht und Migration der Katholischen Universität EichstättIngolstadt. Forschungsschwerpunkte: Repräsentation von Migration in Medien, Asyl- und Migrationsrecht, Kontrollregime (Lager und Teilhabe am Arbeitsmarkt), Kultur und Diversität.

Daniel Göler, Prof. Dr., Professur für Geographische Migrations- und Transformationsforschung im Institut für Geographie an der Otto-Friedrich-Universität Bamberg. Forschungsschwerpunkte: interdisziplinäre Migrationsstudien und post-sozialistische Transformationskontexte mit einem besonderen Interesse an ökonomischen, sozialen, städtischen und ländlichen Geographien in Russland und Südosteuropa.

Christine Heimerer, M.A., Sprachwissenschaft, wissenschaftliche Mitarbeiterin am Zentrum Flucht und Migration der Katholischen Universität EichstättIngolstadt. Forschungsschwerpunkte: Sprachbildung und (Zweit-)Sprachdidaktik, innere und äußere Mehrsprachigkeit, Barrierefreie Sprache, Bildung im Kontext von Migration.

Andreas Hetzer, Dr. phil., Politikwissenschaftler mit Schwerpunkt in Internationalen Beziehungen, visuellen Methoden und politischer Kommunikation. Promotion in Politikwissenschaft und Diplom in Medienwissenschaften, Universität Siegen. Arbeitet im Moment in einem Projekt zur Sichtbarmachung und Verbesserung der Lebensbedingungen von afrokolumbianischen Gemeinden in Cali.

Andreas Jensen, M.A. Soziologie, hat Soziologie an der Eberhard Karls Universität Tübingen und der Goethe-Universität Frankfurt a.M. studiert. Aktuell ist er wis- 
senschaftlicher Mitarbeiter am Sigmund-Freud-Institut. Forschungsschwerpunkte: Flucht und Migration, sozialpsychologische Forschung zu Rechtsextremismus und islamistisch begründetem Extremismus sowie Methoden der qualitativen Sozialforschung.

Ramona Kay, Diplom-Soziologin und M.A. Internationale Kriminologie, ehemalige wissenschaftliche Mitarbeiterin im Forschungsbereich des Zentrums Flucht und Migration der Katholischen Universität Eichstätt-Ingolstadt bis Mai 2020. Forschungsschwerpunkte: Einstellungs-, Migrations- und Evaluationsforschung sowie Methoden der empirischen Sozialforschung.

Magdalena Kuhn, Dipl.-Psych., hat Psychologie an der Goethe-Universität Frankfurt und an der New School for Social Research New York studiert. Aktuell ist sie wissenschaftliche Mitarbeiterin am Sigmund-Freud-Institut und promoviert im Fachbereich Soziologie zum Thema »Elterliche Einflüsse in adoleszenten Identitätskonstruktionen«. Forschungsschwerpunkte: Adoleszenz- und Familienforschung, Psychoanalyse der Sozialisation, Identitätsentwicklung und transgenerative Weitergabe, Migration und Flucht.

Alina Löffler, M.A., Internationale Beziehungen und Conflict, Memory and Peace an der Katholischen Universität Eichstätt-Ingolstadt, Andrássy Universität Budapest und Universidad del Rosario in Bogotá. Forschungsschwerpunkte: Flucht und Migration in Lateinamerika, organisierte Kriminalität, regionale Integration und regionale Organisation.

Jan Lohl, Dr., Dipl. Sozialwiss. und Supervisor (DGSv), hat eine Professur für Erwachsenenbildung an der KH Mainz inne und leitet dort das Institut für Fort- und Weiterbildung.

Sebastian Muy, Dipl. Sozialarbeiter/Sozialpädagoge, Master of Social Work (Soziale Arbeit als Menschenrechtsprofession), Doktorand an der Pädagogischen Hochschule Freiburg, Mitglied im Netzwerk Kritische Migrations- und Grenzregimeforschung (kritnet). Forschungsschwerpunkte: Soziale Arbeit und Asylpolitik.

Ria Prilutski, Soziologin, promoviert zur sozialen (Im-)Mobilität in der deutschen Migrationsgesellschaft an der Universität Jena. Forschungsschwerpunkte: Kritische Migrationsforschung, Rassismus, Klassismus und Intersektionalität. Als Mitglied von Medinetz Jena e.V. beschäftigt sie sich mit rassismuskritischer politischer Bildungsarbeit und kämpft für den gleichen Zugang zur Gesundheitsversorgung. 
Caterina Rohde-Abuba, Dr. phil., promovierte 2013 an der Universität Bielefeld zur Au-pair-Migration russischer Frauen in Deutschland. Sie ist mit dem Zentrum für Deutschland- und Europastudien an der Universität Bielefeld und mit der Staatlichen Universität Sankt Petersburg assoziiert. Gegenwärtig arbeitet sie als Head of Research beim internationalen Kinderhilfswerk World Vision Deutschland e.V. Zuvor war sie in der Forschung und Lehre an der Universität Bielefeld, der Fachhochschule Bielefeld und der Hochschule Rhein-Waal angestellt. Sie hat Soziologie mit einem Fokus auf Europastudien und Migration an der Otto-Friedrich-Universität Bamberg, der Universität Lettlands in Riga, der Universität Wien und der Universität Bremen studiert.

Mathias Schmitt, M.A., Soziale Arbeit, Lehrkraft für besondere Aufgaben an der Katholischen Universität Eichstätt-Ingolstadt, aktives Mitglied von Amnesty International. Forschungsschwerpunkte: Fluchtmigration, Soziale Arbeit, Menschenrechte, Abschiebehaft, Asylberatung.

Nadine Segadlo, M.A., MSc, Politik- und Verwaltungswissenschaften, wissenschaftliche Mitarbeiterin am Institut für Migrationsforschung und Interkulturelle Studien (IMIS) und Institut für Sozialwissenschaften der Universität Osnabrück, Fachgebiet Flucht- und Flüchtlingsforschung. Forschungsschwerpunkte: Flucht und Migration im internationalen Kontext, Migrationsgovernance, Entwicklungs(-politik), Friedens- und Konfliktforschung, postkoloniale Theorien, regionaler Fokus auf Sub-Sahara Afrika.

Philipp Seuferling, M.Sc. in Medien- und Kommunikationswissenschaften, Doktorand am Institut für Medien- und Kommunikationswissenschaften an der Södertörn University, Stockholm, Schweden. Forschungsinteressen: Medien und Migration, Mediengeschichte, Medien und Erinnerung.

Simon Sperling, Dipl. Sc. Pol, Politikwissenschaften, Institut für Migrationsforschung und Interkulturelle Studien (IMIS) an der Universität Osnabrück, Stipendiat des Promotionsprogramms >Migrationsgesellschaftliche Grenzformationen<, Mitglied des Netzwerks Kritische Migrationsforschung. Forschungsschwerpunkte: Soziale Prognosen, Asylpolitik, Grenzregime, Politische Soziologie, Politische Theorie.

Rana Zokai, B.Sc. Psych., studiert derzeit Psychologie im Master an der Johannes Gutenberg-Universität Mainz. Im Sigmund-Freud-Institut arbeitete sie als wissenschaftliche Hilfskraft in den Projekten VTI und BioRex. Außerdem schrieb sie ihre Bachelorthesis im Projekt ERSTE SCHRITTE über den Zusammenhang zwischen depressiven Symptomen und mütterlicher Feinfühligkeit. 


\section{Soziologie}

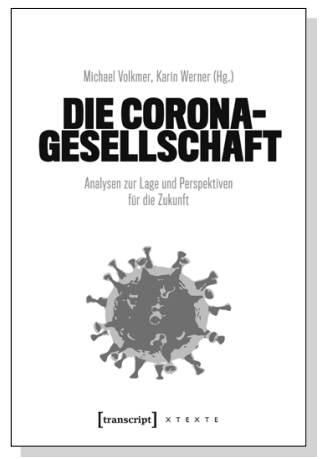

Michael Volkmer, Karin Werner (Hg.)

Die Corona-Gesellschaft

Analysen zur Lage und Perspektiven für die Zukunft

Juli 2020, 432 S., kart., 2 SW-Abbildungen

24,50€ (DE), 978-3-8376-5432-5

E-Book:

PDF: $21,99 €$ (DE), ISBN 978-3-8394-5432-9

EPUB: $21,99 €$ (DE), ISBN 978-3-7328-5432-5

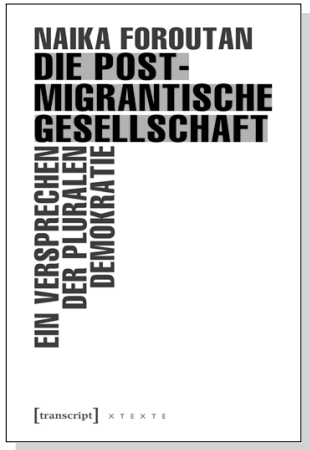

Naika Foroutan

Die postmigrantische Gesellschaft

Ein Versprechen der pluralen Demokratie

2019, 280 S., kart., 18 SW-Abbildungen

19,99€ (DE), 978-3-8376-4263-6

E-Book:

PDF: $17,99 €$ (DE), ISBN 978-3-8394-4263-0

EPUB: $17,99 €$ (DE), ISBN 978-3-7328-4263-6

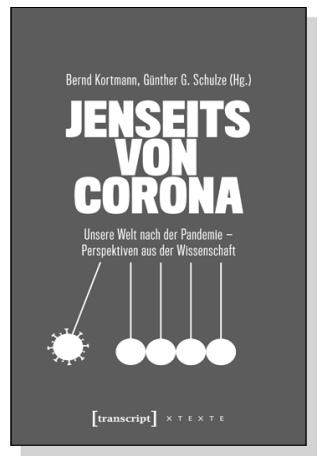

Bernd Kortmann, Günther G. Schulze (Hg.)

\section{Jenseits von Corona}

Unsere Welt nach der Pandemie -

Perspektiven aus der Wissenschaft

September 2020, 320 S., 1 SW-Abbildung

22,50€ (DE), 978-3-8376-5517-9

E-Book:

PDF: $19,99 €$ (DE), ISBN 978-3-8394-5517-3

EPUB: $19,99 €(D E)$, ISBN 978-3-7328-5517-9 


\section{Soziologie}

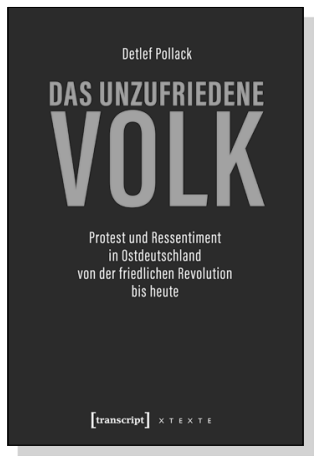

Detlef Pollack

\section{Das unzufriedene Volk}

Protest und Ressentiment in 0stdeutschland von der friedlichen Revolution bis heute

September 2020, 232 S., 6 SW-Abbildungen

20,00€ (DE), 978-3-8376-5238-3

E-Book:

PDF: $17,99 €(D E)$, ISBN 978-3-8394-5238-7

EPUB: $17,99 €(D E)$, ISBN 978-3-7328-5238-3

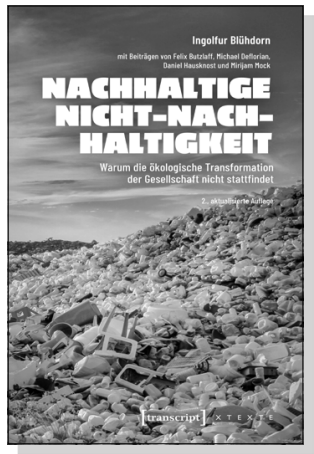

Ingolfur Blühdorn, Felix Butzlaff,

Michael Deflorian, Daniel Hausknost, Mirijam Mock

\section{Nachhaltige Nicht-Nachhaltigkeit}

Warum die ökologische Transformation der Gesellschaft nicht stattfindet

Juni 2020, 350 S., kart.

20,00€ (DE), 978-3-8376-5442-4

E-Book:

PDF: 17,99 € (DE), ISBN 978-3-8394-5442-8

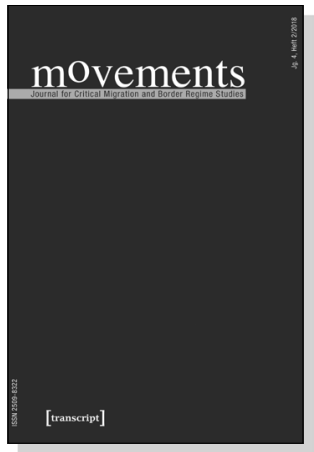

Juliane Karakayali, Bernd Kasparek (Hg.)

movements.

Journal for Critical Migration and Border Regime Studies

Jg. 4, Heft 2/2018

2019,246 S., kart.

$24,99 €(D E), 978-3-8376-4474-6$ 
